\title{
TRANSFERÊNCIA DE CALOR E PERDA DE PRESSÃO DE HIDROCARBONETOS DURANTE A EBULIÇÃO CONVECTIVA EM UM DISSIPADOR DE CALOR BASEADO EM MULTI-MICROCANAIS
}

Tese apresentada à Escola de Engenharia de São Carlos da Universidade de São Paulo para a obtenção do título de Doutor em Engenharia Mecânica.

Área de concentração: Térmica e Fluidos Orientador: Prof. Dr. Gherhardt Ribatski

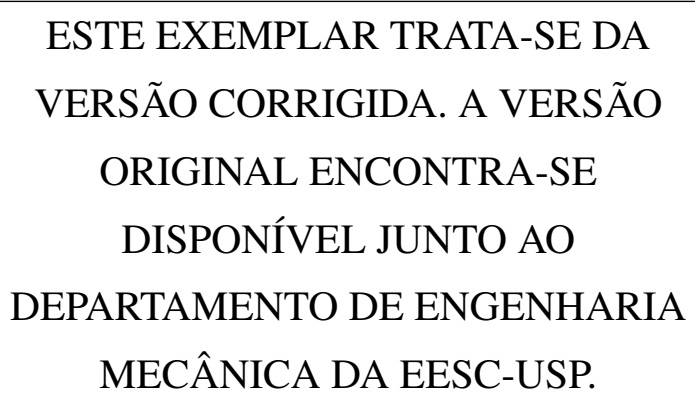


AUTORIZO A REPRODUÇÃO TOTAL OU PARCIAL DESTE TRABALHO, POR QUALQUER MEIO CONVENCIONAL OU ELETRÔNICO, PARA FINS DE ESTUDO E PESQUISA, DESDE QUE CITADA A FONTE.

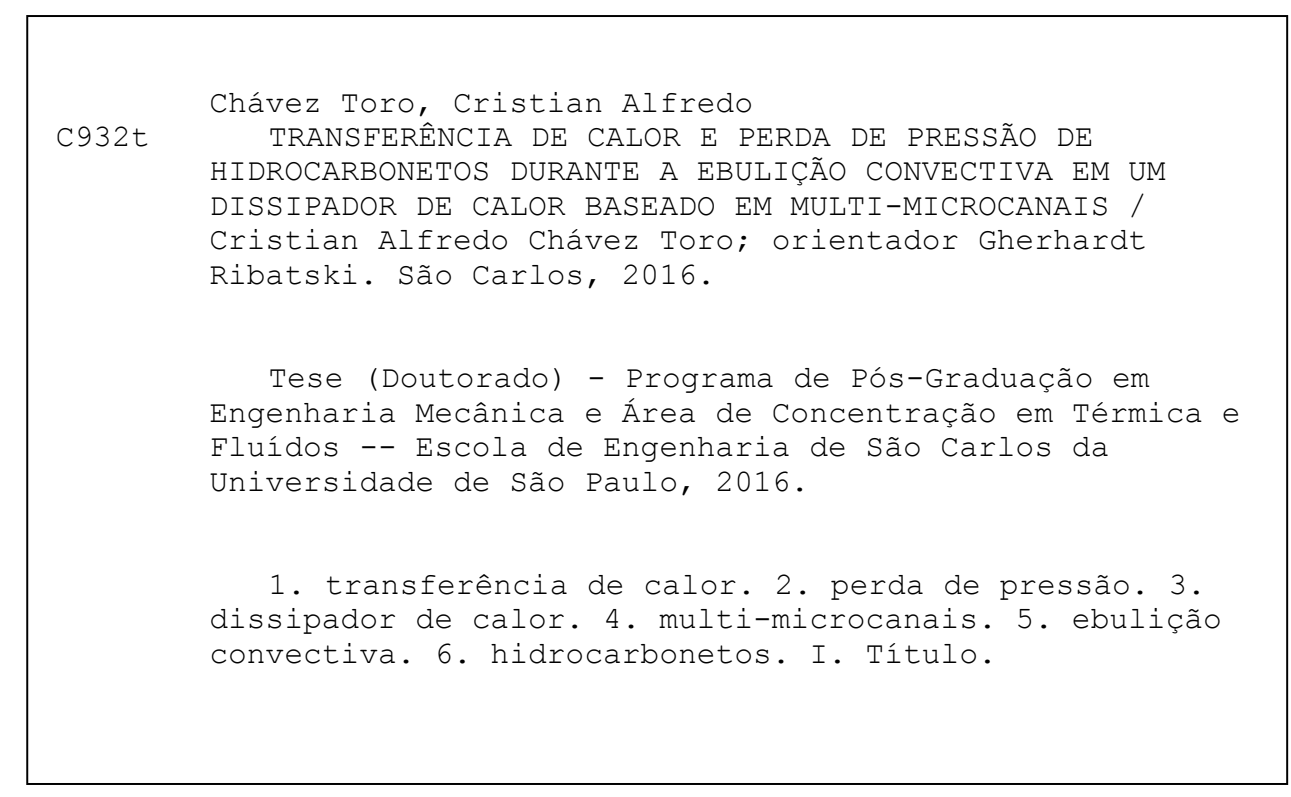




\section{FOLHA DE JULGAMENTO}

\section{Candidato: CRISTIAN ALFREDO CHÁVEZ TORO}

Título da tese: "Transferência de calor e perda de pressão durante a ebulição convectiva de hidrocarbonetos em um dissipador de calor baseado em multimicrocanais"

Data da defesa: 08.09.2016

\section{Comissão Julgadora:}

Prof. Associado Gherhardt Ribatski (Orientador)

(Escola de Engenharia de São Carlos/EESC)

$\operatorname{Prof}^{\mathrm{a}} \mathrm{Dr}^{\mathrm{a}}$. Elaine Maria Cardoso

(Universidade Estadual Paulista "Júlio de Mesquita Filho"/UNESP - Ilha Solteira)

Prof. Dr. Enio Pedone Bandarra Filho

(Universidade Federal de Uberlândia/UFU)

Prof. Dr. Cristiano Bigonha Tibiriçá

(Escola de Engenharia de São Carlos/EESC)

Prof. Dr. Fernando Guimarães Aguiar

(Universidade Federal de São Carlos/UFSCar)
Resultado:

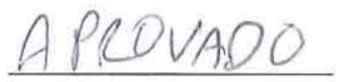

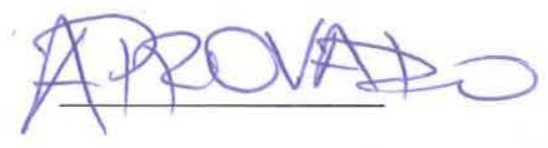
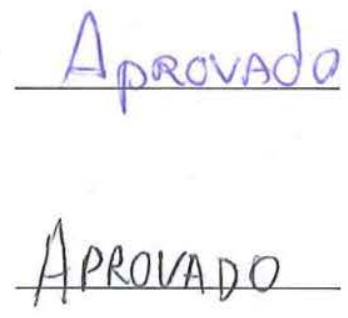

Coordenador do Programa de Pós-Graduação em Engenheira Mecânica: Prof. Associado Gherhardt Ribatski

Presidente da Comissão de Pós-Graduação:

Prof. Associado Luís Fernando Costa Alberto 


\section{Dedicatória}

Após o Mestrado, eu queria esquecer a vida acadêmica, mas você me incentivou a vir para o Brasil na busca deste sonho. Portanto, esta obra é dedicada a ti minha querida e amada esposa Viviana... 


\section{AGRADECIMENTOS}

Agradeço ao Prof. Gherhardt Ribatski, pela oportunidade concedida para realizar o doutorado. Quero valorizar sua orientação e dedicação para o desenvolvimento deste trabalho.

Aos Técnicos José, o Jorge e o Hélio pela ajuda na montagem e manutenções da bancada experimental.

Ao Prof. Carlos Hernán Salinas Lira pela indicação deste doutorado e recomendar como um programa de pós-graduação de qualidade.

Aos professores Antônio Moreira, Cristiano Tibiriçá e Oscar Hernández da Área Térmica e Fluidos do departamento de Engenharia Mecânica, os quais sempre que procurei, contribuíram com discussões que ajudaram para o desenvolvimento deste trabalho.

Ao pessoal do laboratório de refrigeração: Chicão, Daiane, Daniel, Débora, Erivelto, Fabio, Francisco, Gustavo, Hugo, Jaqueline, Karime, Livia, Nourjane e Tiago pela ajuda e companheirismo.

À Universidade de São Paulo, USP, e a Escola de Engenharia de São Carlos, EESC, pela oportunidade de realização do doutorado.

À Coordenação de Aperfeiçoamento de Pessoal de Nível Superior, CAPES, pela bolsa de estudos concedida para a realização deste doutorado.

Ao Senhor, por me permitir conhecer pessoas muito valiosas neste laboratório.

Finalmente quero agradecer de forma especial aos meus queridos pais, Luis e Mirta, pela dedicação, ajuda e o grande amor brindado cada dia. 


\section{RESUMO}

CHÁVEZ TORO, C. A. (2016). TRANSFERÊNCIA DE CALOR E PERDA DE PRESSÃO DE HIDROCARBONETOS DURANTE A EBULIÇÃO CONVECTIVA EM UM DISSIPADOR DE CALOR BASEADO EM MULTI-MICROCANAIS. 217p. Tese (Doutorado) - Escola de Engenharia de São Carlos, Universidade de São Paulo, São Carlos.

A presente tese envolve um estudo experimental da ebulição convectiva no interior de um dissipador de calor baseado em multi-microcanais. Resultados experimentais para perda de pressão e coeficiente de transferência de calor foram levantados para os hidrocarbonetos R600a (isobutano), R290 (propano) e R1270 (propileno), fluidos com reduzido GWP (Global Warming Potential) e ODP (Ozone Depletion Potential) nulo. O desempenho termo-hidráulico destes fluidos foi avaliado em um dissipador de calor de cobre, contendo cinquenta canais paralelos com seção transversal retangular de $123 \times 494 \mu \mathrm{m}^{2}, 15 \mathrm{~mm}$ de comprimento e área de base de $15 \times 15 \mathrm{~mm}^{2}$. Os experimentos foram realizados para fluxos de calor de até $400 \mathrm{~kW} / \mathrm{m}^{2}$, velocidade mássica variando entre 165 e $823 \mathrm{~kg} / \mathrm{m}^{2} \mathrm{~s}$, graus de sub-resfriamento do líquido na entrada da seção de testes de 5,10 e $15{ }^{\circ} \mathrm{C}$ e temperaturas de saturação de 21 e $25{ }^{\circ} \mathrm{C}$. Os dados experimentais foram amplamente analisados e discutidos, focando o efeito do fluido refrigerante. Oscilações dos sinais de temperatura e pressão foram analisadas parametricamente visando caracterizar efeitos de instabilidades térmicas. Adicionalmente, realizou-se análise comparativa de desempenho dos refrigerantes baseada na $2 \circ$ Lei da Termodinâmica. Os dados para hidrocarbonetos foram comparados com resultados de trabalhos prévios para o refrigerante R134a levantados na mesma seção de testes e utilizando a mesma bancada experimental. A partir destes dados, conclui-se que os hidrocarbonetos proporcionam coeficientes de transferência de calor superiores ao R134a. Em geral, o coeficiente de transferência de calor apresenta a seguinte ordem decrescente: R290, R1270, R600a e R134a. No entanto, o R290 necessitou superaquecimentos da parede superiores ao R1270 para iniciar o processo de ebulição. O refrigerante R1270 proporcionou perdas de pressão totais inferiores aos demais fluidos segundo a seguinte ordem decrescente: R600a, R134a, R290 e R1270. O refrigerante R1270 apresentou frequências de oscilação inferiores na temperatura da câmara de saída. Baseado na análise de desempenho da $2 \circ$ Lei da Termodinâmica, conclui-se que, as irreversibilidades devido ao processo de transferência de calor foram predominantes quando comparadas àquelas devido à perda de pressão. Através desta análise também constatou-se o melhor desempenho para o refrigerante R290.

Palavras-chave: ebulição convectiva, refrigerantes naturais, dissipador de calor, microcanais, hidrocarbonetos. 


\section{AbSTraCT}

CHÁVEZ TORO, C. A. (2016). HEAT TRANSFER AND PRESSURE DROP OF HYDROCARBON REFRIGERANTS DURING FLOW BOILING IN A MICROCHANNEL ARRAY HEAT SINK. 217p. Thesis (Doctoral) - School of Engineering of São Carlos, University of São Paulo, São Carlos-SP, Brazil.

The present thesis concerns an experimental study on flow boiling inside a microchannel array. Experimental results for two-phase pressure drop and heat transfer coefficient were acquired for the hydrocarbons R600a (isobutane), R290 (propane) and R1270 (propylene). These fluids present low Global Warming Potential (GWP) and null Ozone Depletion Potential (ODP). The cooling performance of these hydrocarbons were evaluated for a copper heat sink containing fifty parallel microchannels. The microchannels are rectangular with cross section of $123 \times 494 \mu^{2}, 15 \mathrm{~mm}$ length and a footprint area of $15 \times 15 \mathrm{~mm}^{2}$. The experimental evaluation was performed in a test facility located at the Laboratory of Thermal and Fluid Engineering of School of Engineering of São Carlos, University of Sao Paulo. The experiments were performed for heat fluxes up to $400 \mathrm{~kW} / \mathrm{m}^{2}$, mass velocities from 165 to $823 \mathrm{~kg} / \mathrm{m}^{2} \mathrm{~s}$, degrees of liquid subcooling at the test section inlet of 5,10 and $15{ }^{\circ} \mathrm{C}$ and saturation temperatures of 21 and $25{ }^{\circ} \mathrm{C}$. The experimental data were carefully analyzed and discussed focusing on the effects of the fluid on the heat sink thermal hydraulic performance. Fluctuations in the temperature and pressure were analyzed parametrically in order to evaluate thermal instability effects. Additionally, an exergy analysis was performed to evaluate the refrigerant efficiency during convective evaporation. Subsequently, the parametric effects and performance of hydrocarbons were compared with previous results for refrigerant R134a obtained in the same test facility and under the same experimental conditions. The refrigerant R290 provided heat transfer coefficients higher than R600a and R1270. However, R290 needed a degree of wall superheating for the onset of nucleate boiling higher than R1270. Based on the exergy analysis it was concluded that, the irreversibility associated to the heat transfer process are predominant compared with the irreversibility due to the pressure drop. According to the Second Law analyses it was also concluded R290 as the fluid providing the best performance.

Keywords: flow boiling, natural fluid, heat sink, microchannel, hydrocarbons. 


\section{LISTA DE FIGURAS}

Figura 1.1 Elevação do fluxo de calor dissipado por microprocessadores da Intel. . 29

Figura 2.1 Ilustração esquemática dos padrões de escoamento e da evolução das temperaturas da superfície e do fluido com o incremento do título de

\begin{tabular}{|ll}
\hline & vapor. $\ldots \ldots \ldots \ldots \ldots \ldots$ \\
\hline Figura 2.2 & Padrões de escoamento horizontais em microcanais, Tibiriçá e Ribatski \\
\hline
\end{tabular}

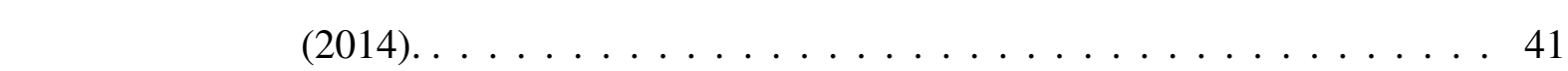

Figura 2.3 Comparação de dados experimentais para padrões de escoamento horizontal de Sempértegui-Tapia et al. (2013) com métodos de previsão da literatura. . . . . . . . . . . . . . . . . . . . 43

Figura 2.4 Comparação de dados experimentais com método k-means para padrões de escoamento horizontal para $\mathrm{D}=2,32 \mathrm{~mm}$, Sempértegui-Tapia et al. (2013). . . . . . . . . . . . . . . . . . . 44

Figura 2.5 Vista superior do padrão de escoamento jato em canal de $0,3 \times 10 \mathrm{~mm}^{2}$

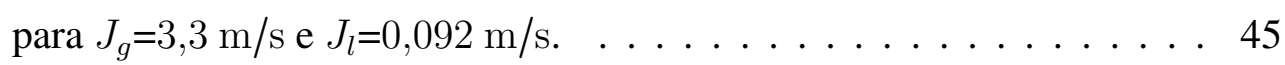

Figura 2.6 Mapa de padrões de escoamento para um canal de seção transversal de $0,42 \times 9 \mathrm{~mm}^{2}$, Chinnov et al. [2016). . . . . . . . . . . . . . . . 45

Figura 2.7 Mapa de padrões de escoamento para um canal de seção transversal de $0,3 \times 9 \mathrm{~mm}^{2}$, Chinnov et al. [2016). . . . . . . . . . . . . 45

Figura 2.8 Comparação entre os métodos empíricos para previsão da perda de pressão para R290, $T_{\text {sat }}=25^{\circ} \mathrm{C}, G=400 \mathrm{~kg} / \mathrm{m}^{2} \mathrm{~s} . \ldots \ldots \ldots \ldots$

Figura 2.9 Ilustração esquemática dos comportamentos indicados na literatura para o coeficiente de transferência de calor durante a ebulição convectiva em canais de diâmetro reduzido. . . . . . . . . . . . . 58

Figura 2.10 Diagrama esquemático do modelo de 3-zonas proposto por Thome et al. (2004). . . . . . . . . . . . . . . . . . . . . . 68

Figura 2.11 Configurações de multi-microcanais paralelos. . . . . . . . . . . 72

Figura 2.12 Multi-microcanais com seção transversal divergente. . . . . . . . . 72

Figura 2.13 Configurações de multi-microcanais modificados. . . . . . . . . . . 73

Figura 2.14 Mapas probabilísticos de padrão de escoamento para R134a segundo Niño et al.[2003] . . . . . . . . . . . . . . . . . . 80 
Figura 2.15 $\quad$ Visualizações de padrões de escoamento horizontal para R134 em multi-microcanais levantados por Niño et al. [2003). . . . . . . . . . . . 81

Figura 2.16 Padrões de escoamento observados por Chen e Garimella[2006) para multi-microcanais e fluxos de calor reduzido. . . . . . . . . . . . . . 82

Figura 2.17 Padrões de escoamento para configuração de multi-microcanais com escoamento cruzado, Koşar e Peles (2007b). . . . . . . . . . . . . . . . . 83

Figura 2.18 Mapa de padrões de escoamento para configurações de multi-microcanais proposto por Harirchian e Garimella(2009). . . . . . . . . . . . . . . . . 84

Figura 2.19 Efeito do ângulo de inclinação nos padrões de escoamento para configuração de multi-microcanais, Wang et al.[(2012). . . . . . . . . . . . . 85

Figura 2.20 $\quad$ Ilustração esquemática do fenômeno de crescimento "explosivo" de bolhas em condições confinadas. . . . . . . . . . . . . . . . . . 100

Figura 2.21 Oscilações da diferença de pressão e temperatura na saída segundo Hetsroni et al. (2002). . . . . . . . . . . . . . . . . . . . . . 102

Figura 2.22 Ilustração da distribuição de fases durante a ebulição convectiva em microcanais paralelos, Hetsroni et al. (2003). . . . . . . . . . . . . . 102

Figura 2.23 Ilustração esquemática de fluxo reverso de vapor na câmara de entrada, Qu e Mudawar[(2004). . . . . . . . . . . . . . . . . . . . . . . . . 103

Figura 2.24 Imagens da ebulição e escoamento reverso na câmara de entrada, Bogojevic et al. [2009). . . . . . . . . . . . . . . . . . . . 103

Figura 2.25 Configurações de entrada e saída de fluido avaliadas por Wang et al. (2008). . . . . . . . . . . . . . . . . 105

Figura 2.26 Geometria de dissipadores de calor avaliadas por Cho et al.[(2010). . . . 106

Figura 2.27 Dissipadores de calor com distribuição de canais segundo fractais. . . . 107

Figura 2.28 Dissipador com restrições na entrada dos microcanais. . . . . . . . . . . 107

Figura 2.29 Configuração de dissipador segundo Szczukiewicz et al. [2013a e 2013b). 108

Figura 2.30 Sequência de imagens ilustrando o crescimento de uma bolha em um microcanal, intervalo de tempo de 1,17 ms, Kandlikar et al. (2005). . . 109

Figura 2.31 Esquema de forças atuando durante o crescimento da bolha, Lee et al. (2010). . . . . . . . . . . . . . . . . . 110

Figura 2.32 Parâmetro R. a) R134a, b) R245fa . . . . . . . . . . . . . . . . . . . 111

Figura 2.33 Perda de pressão para o R245fa. . . . . . . . . . . . . . . . . 111

Figura 2.34 a) Efeito do fluxo de calor no parâmetro de instabilidade. G=600 $\mathrm{kg} / \mathrm{m}^{2} s$; fluido: R245fa. b) desenhos para restrição e coeficientes de perda de pressão locais, Blevins [1984). . . . . . . . . . . . . . . 112

Figura 3.1 Registro fotográfico do aparato experimental. . . . . . . . . . . . . 115

Figura 3.2 Diagrama do circuito principal. . . . . . . . . . . . . . . . . 117 
Figura 3.3 Diagrama p-i ilustrando os processos termodinâmicos do fluido de testes ao longo do circuito principal. . . . . . . . . . . . . . 118

Figura $3.4 \quad$ Esquema de circuitos auxiliar e de rejeição de calor. . . . . . . . . . . 120

Figura 3.5 Esquema do sistema para detecção de vazamento e acionamento do sistema de exaustão. . . . . . . . . . . . . . . . . . . . . . . 121

Figura 3.6 Registro fotográfico da seção de testes montada na bancada. . . . . . . . 122

Figura 3.7 Vista explodida dos componentes da seção de testes. . . . . . . . . . . 122

Figura $3.8 \quad$ Ilustração de corte da seção de testes. . . . . . . . . . . . . . . . . 123

Figura 3.9 Registro fotográfico da peça de vidro contendo termopar para medir a

temperatura do fluido. . . . . . . . . . . . . . . . . 124

Figura 3.10 Propriedades de alguns materiais. . . . . . . . . . . . . . . 125

Figura 3.11 Detalhes do dissipador de calor. . . . . . . . . . . . . . . . . 125

Figura 3.12 Ilustração dos termopares fixados na superfície inferior do dissipador

․ de calor. . . . . . . . . . . . . . . . . 126

Figura 3.13 Micro-perfil óptico da superfície de um microcanal. . . . . . . . . . . . 127

Figura 3.14 Modelo geométrico bidimensional do bloco de cobre indicando condi-

çc̃es de contorno para simulação. . . . . . . . . . . . . . . 127

Figura 3.15 Distribuição de temperaturas no bloco de cobre. . . . . . . . . . . . . . 128

Figura 3.16 Modelo geométrico bidimensional do trocador de calor indicando condições de contorno para simulação. . . . . . . . . . . . . . . . . . . 129

Figura 3.17 Distribuição de temperaturas no dissipador de calor para condições de escoamento monofásico. . . . . . . . . . . . . . . . 130

Figura 3.18 Distribuição de temperaturas no dissipador de calor para condições de ebulição convectiva. . . . . . . . . . . . . . . . . . . . . . 131

Figura 3.19 Ilustração dos volumes de controle adotado para calcular calor transferido para as câmaras. . . . . . . . . . . . . . . . 131

Figura 3.20 $\quad$ Modelo geométrico para simulação de condução de calor 3D. . . . . . . 132

Figura 3.21 Distribuição de temperatura na base do dissipador de calor. . . . . . . . 133

Figura 3.22 Ilustração esquemática da geometria para avaliar a condução de calor ao longo do microcanal 3D. . . . . . . . . . . . . . . . . . . . 134

Figura 3.23 Temperatura da parede ao longo do microcanal na presença de ebulição convectiva. . . . . . . . . . . . . . . . . . 135

Figura 3.24 Comparação entre os dados experimentais e a curva ajustada no presente estudo para previsão da perda de calor por convecção natural. . . . 138

Figura 3.25 Vista em corte do dissipador de calor ilustrando as condições de contorno adotadas para a avaliação das perdas de calor nas regiões das câmaras. . 
Figura 3.26 Temperaturas indicadas pelos termopares localizados na base do dissipador para R290. . . . . . . . . . . . . . . . . . . . . . . . . . . . . 140

Figura 3.27 $\quad$ Temperaturas indicadas pelos termopares localizados na base do dissipador para R600a. . . . . . . . . . . . . . . . . . . 140

Figura 3.28 Temperaturas indicadas pelos termopares localizados na base do dissipador para R1270. . . . . . . . . . . . . . . . . . . 141

Figura 3.29 Distribuição de juntas quentes dos termopares. . . . . . . . . . . . . . . 141

Figura 3.30 Efeito da resistência térmica de contato sobre a temperatura medida por um termopar . . . . . . . . . . . . . . . . . . . . . . . 142

Figura 4.1 Comparação dos resultados experimentais para o fator de atrito do Darcy com o método de previsão de Shah e London[1978). . . . . . . . 155

Figura 4.2 Comparação dos resultados experimentais para o Número de Nusselt médio com o método de previsão de Stephan e Preuber[(1979). . . . . . 155

Figura 4.3 Efeito do sub-resfriamento do líquido nas curvas de ebulição para o R600a. . . . . . . . . . . . . . . . . . 156

Figura 4.4 Efeito do sub-resfriamento do líquido nas curvas de ebulição para o R290. . . . . . . . . . . . . . . . . 157

Figura 4.5 Efeito do sub-resfriamento do líquido nas curvas de ebulição para o R1270. . . . . . . . . . . . . . . . . . . . 157

Figura 4.6 Efeito do fluido refrigerante sobre as curvas de ebulição. . . . . . . . . . 158

Figura 4.7 Efeito da velocidade mássica nas curvas de ebulição para o R290. . . . 159

Figura $4.8 \quad$ Efeito da velocidade mássica nas curvas de ebulição para o R1270. . . . 160

Figura 4.9 Início da nucleação de bolhas na região terminal dos microcanais para - o R600a. . . . . . . . . . . . . . . . . . . . 161

Figura 4.10 Efeito da velocidade mássica sobre o comportamento do coeficiente de transferência de calor médio com a variação do fluxo de calor para R600a. . . . . . . . . . . . . . . . . . . . . . . . . 161

Figura 4.11 Efeito da velocidade mássica sobre o comportamento do coeficiente de transferência de calor médio com a variação do fluxo de calor para R290.162

Figura 4.12 Efeito da velocidade mássica sobre o comportamento do coeficiente de transferência de calor médio com a variação do fluxo de calor para

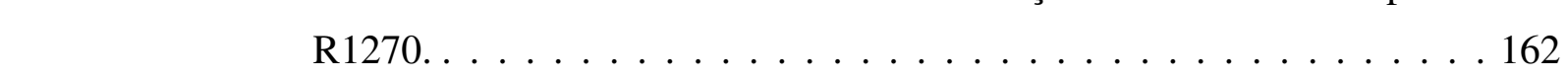

Figura 4.13 Efeito do fluido sobre o comportamento do coeficiente de transferência de calor médio com a variação do fluxo de calor para $\mathrm{G}=330 \mathrm{~kg} / \mathrm{m}^{2} \mathrm{~s}$. 163

Figura 4.14 Efeito do fluido sobre o comportamento do coeficiente de transferência de calor médio com a variação do fluxo de calor para $\mathrm{G}=494 \mathrm{~kg} / \mathrm{m}^{2} \mathrm{~s}$. .163 
Figura 4.15 Coeficiente de transferência de calor para ebulição nucleada em piscina estimado através do método de Cooper [1984).

Figura 4.16 Efeito do grau de sub-resfriamento do fluido na entrada da seção de

testes sobre o comportamento do coeficiente de transferência de calor
médio com a variação do fluxo de calor para R290. . . . . . . . . . . . . 165

Figura 4.17 Efeito do grau de sub-resfriamento do fluido na entrada da seção de

\begin{tabular}{|c|}
\hline testes sobre o comportamento do coeficiente de transferência de calor \\
\hline
\end{tabular}
médio com a variação do fluxo de calor para R1270. . . . . . . . . . 165

Figura 4.18 Ilustração do efeito de $T_{\text {sat }}$ no comportamento do CTC com o fluxo de calor para R290. . . . . . . . . . . . . . . . . . 166

Figura 4.19 Ilustração do efeito de $T_{\text {sat }}$ no comportamento do CTC com o fluxo de calor para R1270. . . . . . . . . . . . . . . . . . . . . . . 166

Figura 4.20 Comparação entre o coeficiente de transferência de calor experimental \begin{tabular}{|c|c|}
\hline e resultados determinados através do método de previsão de $\mathrm{Li}$ e $\mathrm{Wu}$ \\
\hline
\end{tabular} (2010). . . . . . . . . . . . . . . . . 168

Figura 4.21 Comparação entre o coeficiente de transferência de calor experimental e resultados determinados através do método de previsão de Kanizawa

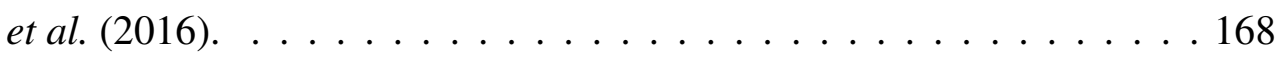

Figura 4.22 Comparação das tendências do CTC com a variação do título de vapor médio, segundo os resultados experimentais levantados neste estudo e métodos de previsão da literatura. . . . . . . . . . . . . . . . 170

Figura 4.23 Ilustração do efeito do sub-resfriamento do líquido sobre o comportamento da perda de pressão com a variação do fluxo de calor. . . . . . . . 172

Figura 4.24 Ilustração do efeito da velocidade mássica sobre o comportamento da perda de pressão com a variação do fluxo de calor. . . . . . . . . . . 173

Figura 4.25 Ilustração do efeito do fluido refrigerante sobre o comportamento da perda de pressão total com o decréscimo do fluxo de calor. . . . . . . . . 174

Figura 4.26 $\quad$ Ilustração do efeito do fluido refrigerante sobre o comportamento da perda de pressão total com a variação do título de vapor médio. . . . . . . 175

Figura 4.27 Comparação dos resultados experimentais com método de predição \begin{tabular}{|c|}
\hline Homogêneo + Beattie e Whalley[(1982) para perda de pressão por \\
\hline
\end{tabular}

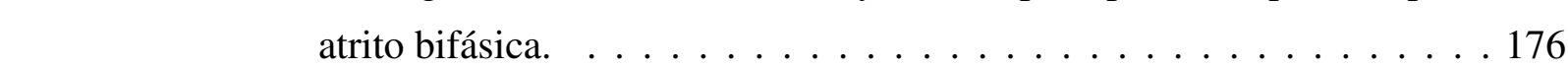

Figura 4.28 $\quad$ Ilustração do efeito do fluido refrigerante sobre a taxa de geração de entropia com a variação do fluxo de calor. . . . . . . . . . . . . . 178

Figura 4.29 Ilustração do efeito do fluido refrigerante sobre a taxa de geração de entropia com a variação do fluxo de calor. . . . . . . . . . . . . . . . 179 


\section{LISTA DE TABELAS}

Tabela 1.1 Análise comparativa de características e propriedades dos refrigerantes

para temperatura de saturação de $25^{\circ} \mathrm{C} . \ldots \ldots \ldots \ldots \ldots \ldots$

Tabela 2.1 Métodos para a estimativa da viscosidade da mistura bifásica no Modelo

Homogêneo. . . . . . . . . . . . . . . . . . . . . 47

Tabela 2.2 Métodos empíricos para perda de pressão por atrito durante escoamento bifásico. . . . . . . . . . . . . . . . . . . . . . 49

Tabela 2.3 Parâmetros e equações para previsão de perda de pressão por atrito segundo o método de Cioncolini et al. (2009). . . . . . . . . . . . . . 51

Tabela 2.4 Parâmetros para estimar a fração de líquido dispersa no vapor segundo Oliemans et al. $[(1986)$. . . . . . . . . . . . . . . . . . . 51

Tabela 2.5 Valores para a constante $\mathrm{C}$ de Chisholm[1967). . . . . . . . . . . . . . 52

Tabela 2.6 Métodos de perda de pressão por atrito baseados em multiplicadores

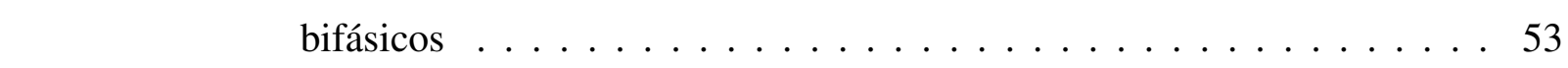

Tabela 2.7 Métodos empíricos para previsão do coeficiente de transferência de

calor em ebulição convectiva. . . . . . . . . . . . . . 60

Tabela 2.8 Valores das constantes para o método de Yan e Lin [1998). . . . . . . . . 63

Tabela 2.9 Métodos baseados na superposição de efeitos de ebulição nucleada e

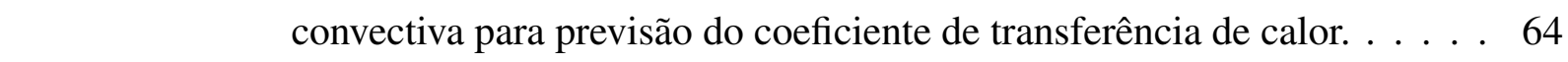

Tabela 2.10 Métodos fenomenológicos para previsão do coeficiente de transferência

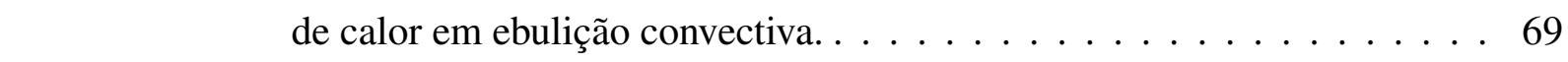

Tabela 2.11 Estudos experimentais sobre dissipadores de calor baseados em multimicrocanais . . . . . . . . . . . . . . . . 73

Tabela 2.12 Dados experimentais disponíveis na literatura para expansões abruptas durante escoamento bifásico, Wang et al.[2010)] . . . . . . . . . . . 88

Tabela 2.13 Resultados de comparações entre dados experimentais de perda de pres-

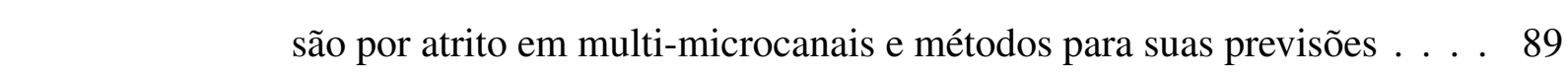

Tabela 2.14 Métodos de aquecimento para dissipadores de calor baseados em multimicrocanais verificados na literatura. . . . . . . . . . . . . . 91 
Tabela 2.15 Resultados de comparações entre dados experimentais para o coeficiente de transferência de calor em multi-microcanais e métodos para suas previsões. . . . . . . . . . . . . . . . . . 95

Tabela 2.16 Estudos experimentais sobre ebulição convectiva de HCs em microcanais 99

Tabela 3.1 Componentes do circuito principal $\ldots \ldots \ldots \ldots \ldots$

Tabela 3.2 $\quad$ Resumo das condições simuladas para verificar o efeito das câmaras. . . 130

Tabela 3.3 Resultados numéricos de calor axial transferido para as câmaras. . . . . . 131

Tabela 3.4 Condições de contorno simuladas para o microcanal 3D. . . . . . . . . . 135

Tabela 3.5 Incertezas dos parâmetros medidos. . . . . . . . . . . . . . . . . . 150

Tabela 3.6 Incertezas dos parâmetros calculados. . . . . . . . . . . . . . . . . 151

Tabela 4.1 Condições experimentais ensaiadas para escoamento monofásico. . . . . 153

Tabela 4.2 Condições experimentais ensaiadas com a presença do mecanismo de ebulição convectiva. . . . . . . . . . . . . . . . . . . . . . . 154

Tabela 4.3 Parâmetros estatísticos resultantes da comparação entre os dados experimentais e métodos de previsão para escoamento monofásico. . . . . . . 155

Tabela 4.4 Comparação entre resultados experimentais e estimados através do mé-

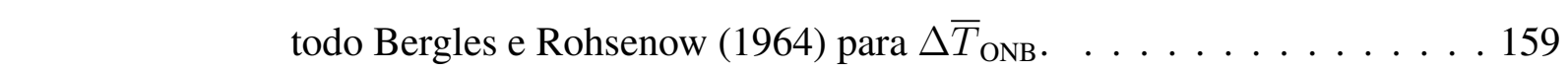

Tabela 4.5 Parâmetros estatísticos de comparação para coeficiente de transferência de calor bifásico . . . . . . . . . . . . . . . . . . . . . . . 167

Tabela 4.6 Parâmetros estatísticos de comparação para perda de pressão bifásica . . 176

Tabela 4.7 Resultados do efeito do fluxo de calor sobre forças associadas ao cresci-

mento de bolhas e o parâmetro de instabilidade para R290, G = $494 \mathrm{~kg} / \mathrm{m}^{2} \mathrm{~s}$,
$T_{s a t}=25^{\circ} \mathrm{C} \mathrm{e} \Delta T_{s u b}=5{ }^{\circ} \mathrm{C}$. . . . . . . . . . . . . . . 186

Tabela 4.8 $\quad$ Resultados do efeito da velocidade mássica sobre forças associadas ao crescimento de bolhas e o parâmetro de instabilidade para R1270, $q_{\text {base }}^{\prime \prime}=280 \mathrm{~kW} / \mathrm{m}^{2}, T_{\text {sat }}=25^{\circ} \mathrm{C} \mathrm{e} \Delta T_{\text {sub }}=5^{\circ} \mathrm{C} . \ldots \ldots \ldots 7 . \ldots \ldots$

Tabela 4.9 Resultados do efeito do grau de sub-resfriamento do líquido sobre forças associadas ao crescimento de bolhas e o parâmetro de instabilidade para R290, $q^{\prime \prime}$ base $=320 \mathrm{~kW} / \mathrm{m}^{2}, T_{\text {sat }}=25^{\circ} \mathrm{C} \mathrm{e} \mathrm{G}=330 \mathrm{~kg} / \mathrm{m}^{2} \mathrm{~s} . \ldots . . . .188$

Tabela 4.10 Resultados do efeito do fluido refrigerante sobre forças associadas ao crescimento de bolhas e o parâmetro de instabilidade para $q^{\prime \prime}$ base $=280$ $k W / m^{2}, T_{\text {sat }}=25^{\circ} \mathrm{C}, \mathrm{G}=494 \mathrm{~kg} / \mathrm{m}^{2}$ s e $\Delta T_{\text {sub }}=5^{\circ} \mathrm{C} . \ldots \ldots$. . . . . . 189

Tabela 4.11 Resultados do efeito da temperatura de saturação sobre forças associadas ao crescimento de bolhas e o parâmetro de instabilidade para $q_{\text {base }}=320 \mathrm{~kW} / \mathrm{m}^{2}, \mathrm{G}=494 \mathrm{~kg} / \mathrm{m}^{2} \mathrm{~s}$ e $\Delta T_{\text {sub }}=10^{\circ} \mathrm{C}$. . . . . . . . . 190 


\section{LISTA DE SÍMBOLOS}

\section{Letras Latinas}

\section{Maiúsculas}

$\begin{array}{ll}A & \text { Área }\left[\mathrm{m}^{2}\right] \\ C & \text { Constante de Martinelli } \\ D & \text { Diâmetro }[\mathrm{mm}] \\ \dot{E} & \text { Taxa de exergia }[\mathrm{W}] \\ E & \text { Entranhamento }[-] \\ F & \text { Fator de intensificação de efeitos convectivos }[-] \\ G & \text { Velocidade mássica }\left[\mathrm{kg} / \mathrm{m}^{2} \mathrm{~s}\right] \\ H & \text { Altura }[\mathrm{m}] \\ J & \text { Velocidade superficial }[\mathrm{m} / \mathrm{s}] \\ K & \text { Fator de perda de pressão localizada }[-] \\ L & \text { Comprimento }[\mathrm{m}] \\ M & \text { Peso molar }[\mathrm{kg} / \mathrm{mol}] \\ P & \text { Perímetro }[\mathrm{m}] \\ \dot{Q} & \text { Taxa de energia }[\mathrm{W}] \\ Q & \text { Fluxo volumétrico }\left[\mathrm{m}^{3} / \mathrm{s}\right] \\ R & \text { Parâmetro de instabilidade }[-] \\ \dot{S} & \text { Taxa de entropia }\left[\mathrm{W} /{ }^{\circ} \mathrm{C}\right] \\ S & \text { Fator de supressão de efeitos de ebulição nucleada }[-] \\ T & \text { Temperatura }\left[{ }^{\circ} \mathrm{C}\right] \text { ou }[\mathrm{K}] \\ V & \text { Velocidade }[\mathrm{m} / \mathrm{s}] \\ W & \text { Largura }[\mathrm{m}] \\ X & \text { Parâmetro de Martinelli }[-]\end{array}$

\section{Minúsculas}

e

$c$

$f$

$g$

$h$

$i$
Espessura $[m]$

Constante de ajuste [-]

Fator de atrito [-]

Aceleração da gravidade $\left[\mathrm{m} / \mathrm{s}^{2}\right]$

Coeficiente transferência de calor $\left[\mathrm{kW} / \mathrm{m}^{2} \mathrm{~K}\right]$

Entalpia $[k J / k g]$

Condutividade térmica $[\mathrm{kW} / \mathrm{mK}]$

Pressão $[k P a]$

Fluxo de calor $\left[\mathrm{kW} / \mathrm{m}^{2}\right]$

Razão de aspecto [-]

Entropia $[k J / k g K]$

Volume específico $\left[\mathrm{m}^{3} / \mathrm{kg}\right]$

Título de vapor [-] 


\section{Letras gregas}

$\begin{array}{ll}\alpha & \text { Fração de vazio superficial }[-] \\ \beta & \text { Fração de vazio volumétrica }[-] \\ \delta & \text { Espessura do filme líquido }[\mathrm{m}] \\ \Delta & \text { Diferença [-] } \\ \eta & \text { Eficiência [-] } \\ \mu & \text { Viscosidade dinâmica }[\mathrm{N} / \mathrm{m}] \\ \nu & \text { Viscosidade cinemática }\left[\mathrm{m}^{2} / \mathrm{s}\right] \\ \rho & \text { Densidade }\left[\mathrm{kg} / \mathrm{m}^{3}\right] \\ \theta & \text { Ângulo [] } \\ \phi & \text { Fase }[-] \\ \sigma & \text { Tesão superficial }[\mathrm{N} / \mathrm{m}] \\ \psi & \text { Exergia }[\mathrm{kJ} / \mathrm{kg}] \\ \varsigma & \text { Razão de aspecto }[-]\end{array}$

\section{Subscritos}

$\begin{array}{ll}a & \text { Aceleração } \\ e x p & \text { Experimental } \\ e q & \text { Equivalente } \\ e n & \text { Ebulição nucleada } \\ f & \text { Atrito } \\ g & \text { Gravitacional } \\ g e r & \text { Gerado, geração } \\ I I & \text { Segunda Lei da Termodinâmica } \\ l & \text { Líquido saturado } \\ l o & \text { Mistura bifásica como líquido } \\ g & \text { Gás saturado } \\ g o & \text { Mistura bifásica como gás } \\ l g & \text { Diferença de propriedades líquido-gás, latente de vaporização } \\ h & \text { Hidráulico } \\ m o & \text { Momento } \\ \text { orif } & \text { Orifício, restrição } \\ p & \text { Parede } \\ \text { pred } & \text { Preditivo } \\ \text { sat } & \text { Saturação } \\ 1 \phi & \text { Monofásico } \\ 2 \phi & \text { Bifásico } \\ 1 & \text { Entrada ao pré-aquecedor } \\ 2 & \text { Entrada ao dissipador de calor } \\ 3 & \text { Saída ao dissipador de calor }\end{array}$




\section{Siglas}

CTC Coeficiente de transferência de calor

$M A E \quad$ Mean absolute error, (Erro absoluto médio)

GWP Global Warming Potential, (Potencial de aquecimento global)

HFC Hidrofluorocarbonetos

$\mathrm{HFO} \quad$ Hidrofluorolefina

HC Hidrocarbonetos

LEL Lower Explosive Limit, (Limite inferior de explosividade)

$O D P \quad$ Ozone Depletion Potential, (Potencial de destruição da camada de ozônio)

$O N B \quad$ Onset of Nucleate Boiling, (Inicio da ebulição nucleada)

UEL Upper Explosive Limit, (Limite superior de explosividade)

\section{Números adimensionais}

$$
\begin{aligned}
& B e=\frac{1}{1+N_{i}} \quad \text { Número de Bejan } \\
& B O=\frac{q}{G \cdot i_{l g}} \quad \text { Número de Ebulição } \\
& B o=\frac{g \cdot\left(\rho_{l}-\rho_{g}\right) \cdot D^{2}}{\sigma} \quad \text { Número de Bond } \\
& C o=\frac{1}{\sqrt{E o}}=\frac{1}{D} \sqrt{\frac{\sigma}{g \cdot\left(\rho_{l}-\rho_{g}\right)}} \quad \text { Número de Confinamento } \\
& E O=\frac{g \cdot\left(\rho_{l}-\rho_{g}\right) \cdot D^{2}}{\sigma} \quad \text { Número de Eötvös (similar a Bo) } \\
& F r=\frac{G^{2}}{\rho \cdot g \cdot D} \quad \text { Número de Froude } \\
& N_{i}=\frac{\dot{S}_{g e r ; \Delta p}}{\dot{S}_{g e r ; \Delta T}} \quad \text { Número de intensificação } \\
& N u=\frac{h \cdot L}{k} \quad \text { Número de Nusselt } \\
& \operatorname{Pr}=\frac{\nu}{\alpha}=\frac{C p \cdot \mu}{k} \quad \text { Número de Prandl } \\
& p_{r}=\frac{p_{\text {sat }}}{p_{\text {critica }}} \quad \text { Pressão reduzida } \\
& R e=\frac{V \cdot D}{\nu}=\frac{G \cdot D}{\mu} \quad \text { Número de Reynolds } \\
& R=\sqrt{\frac{F_{\text {ebulição }}}{F_{\text {inercial }}+F_{\text {orif }}+F_{\text {expansão }}} \quad \text { Parâmetro de instabilidade }} \\
& S u=L a=\frac{\sigma \cdot \rho \cdot D}{\mu^{2}}=\frac{R e^{2}}{W e} \quad \text { Número de Suratman ou Número de Laplace } \\
& W e=\frac{\rho \cdot V \cdot D}{\sigma}=\frac{G^{2} \cdot D}{\sigma \cdot \rho} \quad \text { Número de Weber }
\end{aligned}
$$


xxiv

Números adimensionais (continuação)

$\begin{array}{ll}F r_{l}=\frac{G^{2}}{\rho_{l} \cdot g \cdot D} & \text { Número de Froude da fase líquida } \\ R e_{l}=\frac{G \cdot(1-x) \cdot D}{\mu_{l}} & \text { Número de Reynolds da fase líquida } \\ R e_{g}=\frac{G \cdot x \cdot D}{\mu_{g}} & \text { Número de Reynolds da fase vapor } \\ R e_{l 0}=\frac{G \cdot D}{\mu_{l}} & \text { Número de Reynolds da mistura escoando como líquido } \\ R e_{g 0}=\frac{G \cdot D}{\mu_{g}} & \text { Número de Reynolds da mistura escoando como vapor } \\ W e_{l 0}=\frac{G^{2} \cdot(1-x) \cdot D}{\sigma \cdot \rho_{l}} & \text { Número de Weber da fase vapor } \\ W e_{g 0}=\frac{G^{2} \cdot x \cdot D}{\sigma \cdot \rho_{g}} & \text { Número de Weber da mistura escoando como líquido } \\ W e_{l}=\frac{G^{2} \cdot D}{\sigma \cdot \rho_{l}} & \text { Número de Weber da mistura escoando como vapor } \\ W e_{g}=\frac{G^{2} \cdot D}{\sigma \cdot \rho_{g}} & \end{array}$




\section{SUMÁRIO}

RESUMO $\quad x$

ABSTRACT

LISTA DE FIGURAS xiii

LISTA DE TABELAS

LISTA DE SÍMBOLOS xxi

\begin{tabular}{|l|l|l|l|l|}
\hline CAPÍTULO|1 INTRODUÇÃO E OBJETIVOS & 27
\end{tabular}

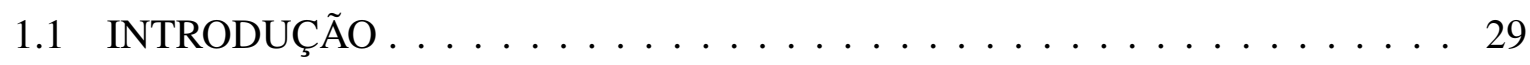

1.2 OBJETIVOS $\ldots \ldots \ldots \ldots \ldots \ldots \ldots \ldots \ldots \ldots \ldots \ldots \ldots \ldots$

1.3 ESTRUTURA DO TEXTO . . . . . . . . . . . . . . . . . . . 34

CAPÍTULO|2: REVISÃO BIBLIOGRÁFICA

$2.1 \quad$ INTRODUÇÃO . . . . . . . . . . . . . . . . . . . . . 37

2.1.1 Parâmetros característicos do escoamento bifásico . . . . . . . . . . 37

2.1 .2 Ebulição convectiva em canais convencionais . . . . . . . . . . . . . . 39

2.2 EBULIÇÃO CONVECTIVA EM MICROCANAIS ÚNICOS $\ldots \ldots \ldots \ldots .41$

2.2 .1 Padrões de escoamento em microcanais únicos . . . . . . . . . . . 41

$2.2 .2 \quad$ Perda de pressão em microcanais únicos $\ldots \ldots \ldots \ldots \ldots \ldots$. . . . 46

2.2 .3 Transferência de calor em microcanais únicos . . . . . . . . . . . . 57

2.3 EBULIÇÃO CONVECTIVA EM MULTI-MICROCANAIS . . . . . . . . . 70

2.3.1 Literatura sobre dissipadores de calor baseados em multi-microcanais . . 70

2.3 .2 Padrões de escoamento em multi-microcanais . . . . . . . . . . . 80

2.3 .3 Perda de pressão em multi-microcanais. . . . . . . . . . . . . 86

2.3.3.1 Avaliação da perda de pressão em multi-microcanais . . . . . . 86

2.3.3.2 Comparação dos bancos de dados para $\Delta p_{\text {atrito }}$ para multimicrocanais e métodos de previsão $\ldots \ldots \ldots$. . . . . . 88

2.3 .4 Transferência de calor em multi-microcanais . . . . . . . . . . . 91 
2.3.5 Avaliação do coeficiente de transferência de calor em multi-microcanais 91

2.3.6 Comparação dos bancos de dados para CTC médio para multi-microcanais e métodos de previsão . . . . . . . . . . . . . . . . . . . . . . 93

2.4 EBULIÇÃO CONVECTIVA DE HIDROCARBONETOS EM MICROCANAIS 97

2.4.1 Estudos sobre efeito do fluido na ebulição convectiva em multi-microcanais 97

2.4 .2 Estudos sobre hidrocarbonetos em microcanais . . . . . . . . . . . . . . . 98

2.5 INSTABILIDADES TÉRMICAS EM MULTI-MICROCANAIS. . . . . . . . . . 100

2.5 .1 Introdução $\ldots \ldots \ldots \ldots$. . . . . . . . . . . . . . 100

2.5.2 Visualizações do escoamento em condições de instabilidades térmicas. . 101

2.5 .3 Geometrias para reduzir efeitos de instabilidades . . . . . . . . . . . . 104

2.5.4 Conclusões da análise de instabilidades térmicas em multi-microcanais . 112

CAPÍTULO|3: BANCADA E PROCEDIMENTO EXPERIMENTAL

3.1 DESCRIÇÃO DO APARATO EXPERIMENTAL . . . . . . . . . . . . . . . 115

3.1 .1 Circuito principal $\ldots \ldots \ldots \ldots \ldots \ldots \ldots \ldots \ldots$

3.1.1.1 Descrição funcional . . . . . . . . . . . . . . . . . 116

3.1.1.2 Especificação dos componentes . . . . . . . . . . . . 118

3.1 .2 Circuitos auxiliar, compressão e rejeição de calor . . . . . . . . . . . . . 120

3.1 .3 Sistema de segurança $\ldots \ldots \ldots \ldots$. . . . . . . . . . . . . 121

3.1 .4 Seção de testes . . . . . . . . . . . . . . . . . . . . . . . . 121

3.1.4.1 Descrição da seção de testes . . . . . . . . . . . . . . 122

3.1.4.2 Avaliação de efeitos de condução na distribuição de temperaturas da seção de testes . . . . . . . . . . . . . . . . . 127

3.2 PROCEDIMENTO EXPERIMENTAL . . . . . . . . . . . . . . . . . 136

3.3 PROCEDIMENTO DE TRATAMENTO DE DADOS . . . . . . . . . . . . . . . 137

3.4 DETERMINAÇÃO DE INCERTEZAS $\ldots \ldots \ldots$. . . . . . . . . . . . 150

CAPÍTULO 4: ANÁLISE DE RESULTADOS EXPERIMENTAIS 152

4.1 DESCRIÇÃO DO BANCO DE DADOS EXPERIMENTAIS. . . . . . . . . . . . 153

4.2 VALIDAÇÃO DO PROCEDIMENTO EXPERIMENTAL E DO MÉTODO DE REGRESSÃO DE DADOS . . . . . . . . . . . . . . . . . . . . . . . . 154

4.3 RESULTADOS SEGUNDO CURVAS DE EBULIÇÃO . . . . . . . . . . . . . . . 156

4.4 RESULTADOS PARA O COEFICIENTE DE TRANSFERÊNCIA DE CALOR 160

4.4.1 Análise paramétrica do efeito dos parâmetros experimentais no CTC . . 160

4.4 .2 Comparação com métodos de previsão do CTC . . . . . . . . . . . . . . . 167

4.5 PERDA DE PRESSÃO . . . . . . . . . . . . . . . . . . . 171

4.5.1 Análise paramétrica dos efeitos dos parâmetros experimentais na perda

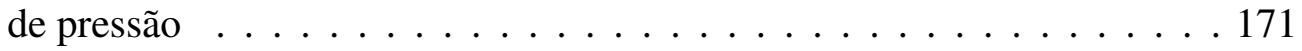


4.5.2 Comparação entre os resultados experimentais e métodos de previsão para perda de pressão por atrito bifásica ～. . . . . . . . . . . . . 175

4.6 ANÁLISE COMPARATIVA DO DESEMPENHO DOS REFRIGERANTES

BASEADA NA $2^{\circ}$ LEI DA TERMODINÂMICA . . . . . . . . . . . . . . 177

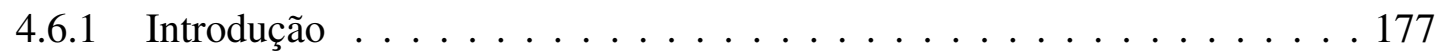

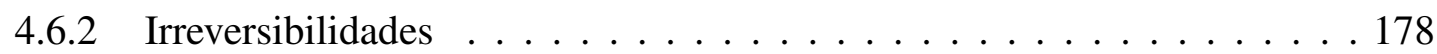

4.6 .3 Eficiência de acordo com a $2^{\circ}$ Lei da Termodinâmica . . . . . . . . . . 179

4.7 ANÁLISE DAS INSTABILIDADES TÉRMICAS DURANTE A EBULIÇÃO

CONVECTIVA . . . . . . . . . . . . . . . . . . . . . . . 181

CAPÍTULO 5 : CONCLUSÕES E RECOMENDAÇÕES 191

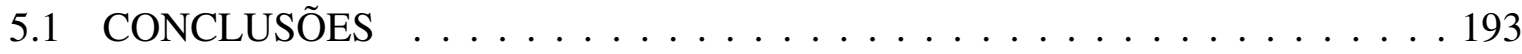

5.2 RECOMENDAÇÕES PARA TRABALHOS FUTUROS . . . . . . . . . . . . 196

REFER̂̂NCIAS BIBLIOGRÁFICAS 


\section{INTRODUÇÃO E OBJETIVOS}

\subsection{INTRODUÇÃO}

O desenvolvimento dos circuitos integrados (CIs) se deu através da elevação exponencial no número de transistores acompanhada da redução do tamanho destes componentes. Este fato implicou no incremento do calor dissipado por processadores conforme ilustrado na Fig. 1.1. a qual apresenta a evolução do fluxo de calor gerado por processadores Intel a partir de 1980. Sistemas microeletromecânicos (MEMs), os quais combinam processadores, sensores e atuadores com dimensões micrométricas, também se caracterizam pela dissipação de elevadas taxas de calor podendo alcançar, segundo Darabi et al. (2001), valores superiores a $10000 \mathrm{~kW} / \mathrm{m}^{2}$.

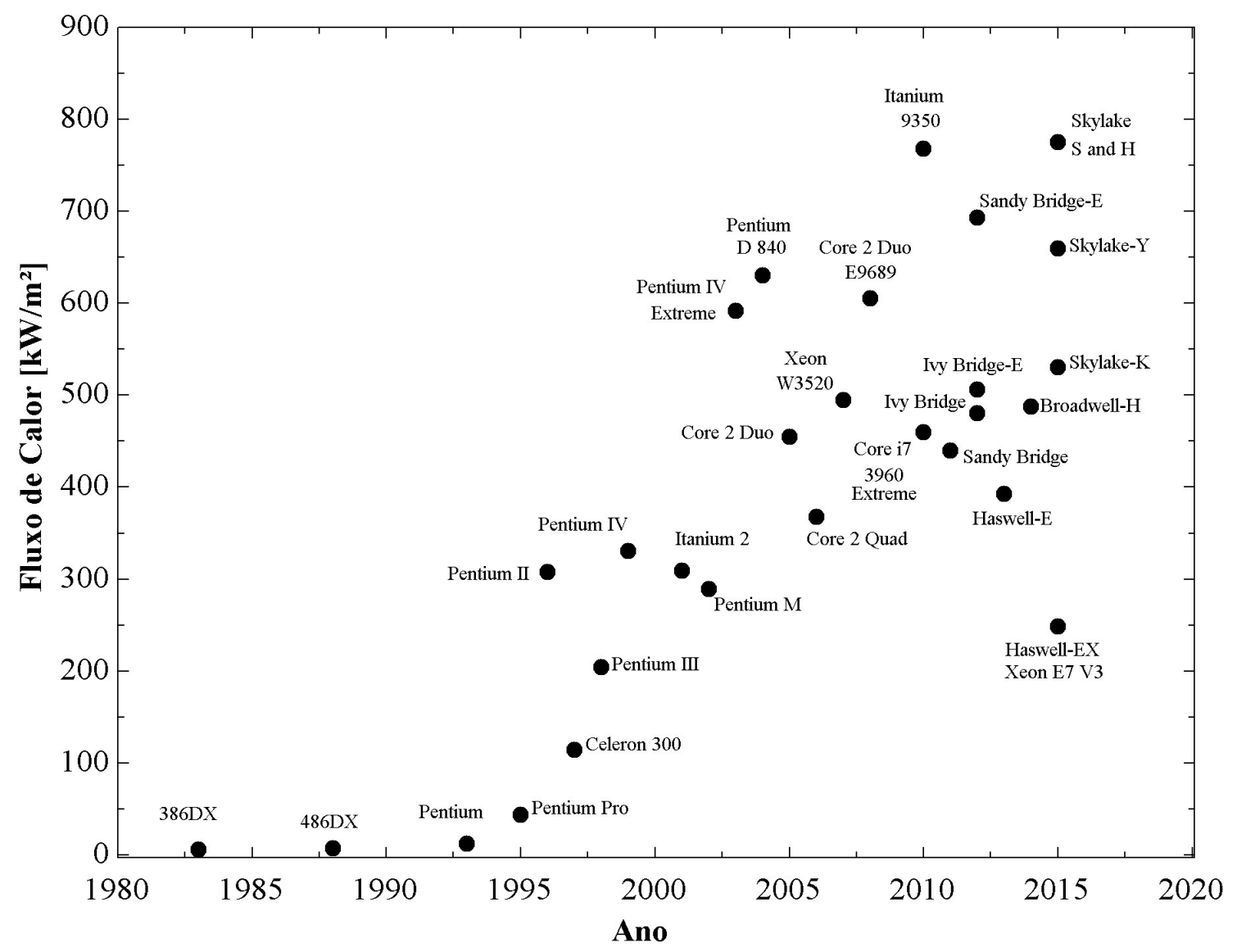

Figura 1.1 - Elevação do fluxo de calor dissipado por microprocessadores da Intel. Intel (2016). 
Neste contexto, vale destacar que se encontram em desenvolvimento processadores 3D os quais buscam reduzir o calor dissipado através das trilhas dos circuítos impressos e proporcionar o aumento da velocidade de processamento pela redução das distâncias entre os componentes. Nestes processadores propõe-se a fabricação dos canais para circulação do fluido refrigerante e resfriamento destes dispositivos em suas próprias estruturas. Atualmente, os processadores são fabricados considerando áreas da base (footprint) próximas a $82 \mathrm{~mm}^{2}$ apresentando a necessidade de dissipação de fluxos de calor de até $800 \mathrm{~kW} / \mathrm{m}^{2}$ (Intel, 2016). Este cenário resultou nas últimas décadas na intensificação das pesquisas visando o desenvolvimento de dispositivos que permitam transferir elevadas taxas de calor em condições confinadas. Cogitase para as próximas gerações de microprocessadores, a necessidade de dissipação de fluxos de calor de até $3000 \mathrm{~kW} / \mathrm{m}^{2}$, segundo Silvério et al. (2015) e Leão et al. (2015).

Dissipadores de calor baseados no escoamento de um fluido através de microcanais foram propostos como solução para o resfriamento de componentes eletrônicos no trabalho pioneiro de Tuckerman e Pease (1981), conduzido para escoamento monofásico. Desde então, vários autores têm realizado estudos sobre o escoamento monofásico e ebulição convectiva em microcanais com o objetivo de dissipar fluxos de calor extremamente elevados. Atualmente, os microcanais são encontrados em diversos setores industriais tais como eletrônico, satélites, equipamentos espaciais, biorreatores, células combustíveis, indústria de petróleo, refrigeração e nuclear. Em geral, estudos sobre este tema envolvem avaliações experimentais focadas no levantamento de resultados para perda de pressão, coeficiente de transferência de calor, padrões de escoamento, fração de vazio e instabilidades termo-hidráulicas durante a ebulição convectiva em dissipadores de calor baseados em multi-microcanais.

De acordo com Ribatski (2013), os dissipadores baseados em microcanais apresentam vantagens sobre as demais tecnologias, pois permitem inventário reduzido de refrigerante, compacidade, operação com pressões elevadas, processo de transferência de calor quase-isotérmico e coeficientes de transferência de calor elevados. Estas características são responsáveis pelas seguintes vantagens: (i) melhoria da eficiência termo-hidráulica do sistema de refrigeração; (ii) adequação do sistema à condições caracterizadas por restrições a líquidos tóxicos e inflamáveis, permitindo o uso de refrigerantes com baixo custo e insignificante GWP (Global Warming Potential) e ODP (Ozone Depletion Potential); (iii) a minimização do impacto ambiental através da redução de refrigerante contido no sistema e o material utilizado para a fabricação dos trocadores de calor; (iv) possibilidade de dissipação de elevadas taxas de calor sob condições confinadas. No entanto, apesar do reconhecimento das vantagens da implementação da ebulição convectiva em dissipadores de calor baseados em microcanais para a gestão térmica dos dispositivos eletrônicos, o fluido refrigerante adequado para estes sistemas ainda é uma questão em aberto na literatura.

A maioria dos estudos disponíveis sobre ebulição convectiva em dissipadores de calor 
baseados em microcanais foram realizadas para HFCs (hidrofluorocarbonos), principalmente o R134a. Investigações experimentais envolvendo HFOs (hidrofluorolefinas) também foram desenvolvidas por Costa-Patry et al. (2012) e Szczukiewicz et al. (2013a, 2013b, 2013c). Resultados para HFE7100, FC77, FC72, metanol, acetona e água também estão disponíveis na literatura. Entretanto, a maioria destes estudos foram realizados para dissipadores de calor com diferentes geometrias e configurações de distribuições de microcanais, o que torna difícil a comparação de dados para refrigerantes distintos, obtidos em laboratórios independentes. Assim, uma análise comparativa e ampla do desempenho de refrigerantes para ebulição convectiva considerando uma configuração única de dissipador de calor baseado em microcanais é algo raro na literatura aberta.

A partir dos Protocolos de Montreal, Kyoto e, recentemente, do Protocolo de Paris, a academia e a indústria de refrigeração intensificaram o foco de suas pesquisas em refrigerantes com propriedades e características menos prejudiciais ao ambiente visando substituir parcela dos fluidos atualmente utilizados.

Recentemente, como destacado por Mota-Babiloni et al. (2015), existe a tendência de substituição dos HFCs, devido à estes apresentarem elevado GWP, por refrigerantes menos prejudiciais ao ambiente. A busca destes novos refrigerantes se norteia pelos seguintes critérios principais: (i) nulo ou reduzido ODP; (ii) reduzido GWP; (iii) proporcionar sistemas com elevada eficiência. Neste contexto, refrigerantes naturais, como amônia (R717), $\mathrm{CO}_{2}$ (R744) e hidrocarbonetos, embora utilizados a mais de um século, emergem como alternativa razoável para diversas aplicações, pois atendem a tais critérios.

Thome et al. (2008) destacam os hidrocarbonetos como fluidos refrigerantes por atenderem tanto a critérios de eficiência energética como ambientais. No entanto, eles também ressaltam a elevada inflamabilidade destes fluidos implicando em restrições quanto a seu uso relacionadas a aspectos de segurança em caso de vazamentos. No entanto, este aspecto torna-se menos relevante quando se opera em dissipadores de calor baseados em microcanais, uma vez que a quantidade de refrigerante necessária é reduzida.

A Tabela 1.1 compara as características de três hidrocarbonetos (R600a, R290 e R1270) com o refrigerante R134a. De acordo com esta tabela, os hidrocarbonetos respondem às exigências ambientais, pois apresentam ODPs nulos e GWPs insignificantes. Além disso, suas propriedades de transporte como maior condutividade térmica e viscosidades inferiores favorecem coeficientes de transferência de calor superiores sob condições em que predominam efeitos convectivos. Destaca-se ainda, o calor latente de vaporização superior dos hidrocarbonetos em relação ao R134a implicando em velocidades mássicas inferiores para se dissipar fluxos de calor similares. 
Tabela 1.1 - Análise comparativa de características e propriedades dos refrigerantes para temperatura de saturação de $25^{\circ} \mathrm{C}$.

\begin{tabular}{|c|c|c|c|c|}
\hline \multirow[b]{2}{*}{ Propriedade } & \multicolumn{4}{|c|}{ Refrigerantes } \\
\hline & R600a & R290 & R1270 & $\mathrm{R} 134 \mathrm{a}$ \\
\hline Massa molar, $[\mathrm{kg} / \mathrm{kmol}]^{\text {iv) }}$ & 58,12 & 44,10 & 42,02 & 102,03 \\
\hline Densidade do líquido, $\left[\mathrm{kg} / \mathrm{m}^{3}\right]^{\text {iv })}$ & 549,9 & 492,1 & 504,5 & 1207 \\
\hline Densidade do vapor, $\left[\mathrm{kg} / \mathrm{m}^{3}\right]^{\text {iv) }}$ & 9,12 & 20,64 & 24,40 & 32,37 \\
\hline Pressão crítica, $[k P a]^{\text {iv })}$ & 3640 & 4247 & 4665 & 4059 \\
\hline Pressão reduzida, $[-]^{\text {iv })}$ & 0,0963 & 0,2242 & 0,248 & 0,164 \\
\hline Temperatura a pressão ambiente, $\left[{ }^{\circ} \mathrm{C}\right]{ }^{\mathrm{iv})}$ & $-11,8$ & $-42,2$ & $-47,8$ & $-26,2$ \\
\hline$d T / d p$ Gradiente de Clausius-Clapeyron, $[K / k P a]^{\text {iv })}$ & 0,0976 & 0,0413 & 0,0347 & 0,0504 \\
\hline Viscosidade do líquido, $\times 10^{-6}[\mathrm{~kg} / \mathrm{ms}]^{\text {iv })}$ & 150 & 98,46 & 88,02 & 194,4 \\
\hline Viscosidade do vapor, $\times 10^{-6}[\mathrm{~kg} / \mathrm{ms}]^{\text {iv) }}$ & 7,739 & 8,737 & 9,074 & 11,97 \\
\hline Condutividade térmica do líquido, $[\mathrm{W} / \mathrm{mK}]^{\text {iv })}$ & 0,0889 & 0,09496 & 0,1125 & 0,08323 \\
\hline Condutividade térmica do vapor, $[\mathrm{W} / \mathrm{mK}]^{\text {iv })}$ & 0,0169 & 0,01897 & 0,01791 & 0,01456 \\
\hline Calor latente de vaporização, $[k J / k g]]^{\text {iv) }}$ & 329,1 & 335,3 & 334,9 & 177,8 \\
\hline Tensão superficial, $\times 10^{-3}[\mathrm{~N} / \mathrm{m}]^{\text {iv) }}$ & 9,857 & 6,91 & 7,094 & 8,028 \\
\hline Inventário de refrigerante no dissipador de calor / líquido, $[\mathrm{mg}]^{\text {i) }}$ & 165,8 & 148,4 & 152,1 & 363,9 \\
\hline Inventário de refrigerante no dissipador de calor / vapor, $[\mathrm{mg}]^{\text {i) }}$ & 2,75 & 6,23 & 7,36 & 9,76 \\
\hline Inventário de refrigerante no dissipador de calor / líquido-vapor, $[\mathrm{mg}]^{\mathrm{i}) \text {, ii), iv) }}$ & 30,7 & 58,58 & 67,51 & 57,37 \\
\hline ODP iii) & 0 & 0 & 0 & 0 \\
\hline GWP iii) & 3 & 3 & 3 & 1300 \\
\hline Inflamabilidade ${ }^{\text {iii })}$ & elevada & elevada & elevada & $\begin{array}{c}\text { não } \\
\text { inflamável }\end{array}$ \\
\hline LEL, [\%] $]^{\text {iii) }}$ & 1,8 & 2,1 & 2,4 & 5,6 \\
\hline UEL, $[\%]$ iii) & 8,4 & 9,5 & 11 & - \\
\hline
\end{tabular}

i) Estimativa baseada nas características geométricas do dissipador de calor avaliado no presente estudo.

ii) Estimativa baseada sobre a hipótese de densidade homogênea para $\mathrm{G}=330 \mathrm{~kg} / \mathrm{m}^{2} \mathrm{~s}$ e q" $=360 \mathrm{~kW} / \mathrm{m}^{2}$.

iii) Valores reportados por Tomczyk et al. (2016).

iv) Valores calculados com auxílio do EES (2003).

Apesar das potenciais vantagens dos hidrocarbonetos já ressaltadas, dados experimentais para a ebulição convectiva destes fluidos em dissipadores de calor baseados em microcanais são ainda necessários. Além disso, apenas os estudos de Pamitran et al. (2010) e Del Col et al. (2014) envolveram o levantamento de dados para o coeficiente de transferência de calor durante a ebulição convectiva de hidrocarbonetos (R290) em canais únicos de diâmetro reduzido (inferiores a $1 \mathrm{~mm}$ ) apesar da extensa busca realizada em periódicos e anais de evento.

Como indicado por Tibiriçá e Ribatski (2013), deve-se ressaltar que, sob condições de microescala, diferentes comportamentos de transferência de calor são observados para a ebulição convectiva em canais únicos e em dissipadores de calor baseados em multi-microcanais, ainda que considerando canais paralelos com área de seção transversal constante. A ebulição convectiva em configurações de multi-microcanais é suscetível a fluxo reverso, devido ao crescimento 
da bolha em condições de confinamento, a interação entre os canais vizinhos, relacionada à condução de calor através das aletas, e efeitos de má distribuição do fluido, decorrentes da influência das câmaras de entrada e saída. Frequentemente, restrições na entrada de cada canal são utilizadas para amortecer efeitos de instabilidades térmicas e minimizar a má distribuição de fluido. No entanto, este procedimento implica em incertezas adicionais sobre a caracterização do estado termodinâmico do fluido a jusante da restrição e, consequentemente, na estimativa do coeficiente de transferência de calor. Por outro lado, canais únicos favorecem a adequada caracterização dos resultados experimentais, pois a restrição ao escoamento é geralmente implementada através de uma válvula de agulha localizada a montante da entrada do canal e o estado termodinâmico do fluido é avaliado com base na temperatura e pressão do fluido, com ambas propriedades medidas a jusante da singularidade.

Neste contexto, este trabalho apresenta e analisa dados experimentais para o coeficiente de transferência de calor, perda de pressão e instabilidades térmicas durante a ebulição convectiva dos hidrocarbonetos $R 600 a$, R290 e $R 1270$ em um dissipador de calor baseado em multimicrocanais. Uma comparação entre o desempenho desses refrigerantes baseada em análise exergética também é apresentada. Os resultados foram obtidos para fluxos de calor de até $400 \mathrm{~kW} / \mathrm{m}^{2}$, velocidades mássicas de $165-823 \mathrm{~kg} / \mathrm{m}^{2} \mathrm{~s}$, temperaturas de saturação de 21 e $25^{\circ} \mathrm{C}$ e graus de sub-resfriamento do fluido na entrada do dissipador de 5,10 e $15^{\circ} \mathrm{C}$. Os resultados de hidrocarbonetos são comparados com dados experimentais para o R134 obtidos em estudo prévio elaborado por Do Nascimento et al. (2013), utilizando o mesmo dissipador de calor. Além disso, os resultados experimentais são comparados com métodos para previsão do coeficiente de transferência de calor e perda de pressão disponíveis na literatura.

\subsection{OBJETIVOS}

A presente tese possui como objetivo geral avaliar experimentalmente o desempenho termohidráulico da ebulição convectiva em um dissipador de calor baseado em multi-microcanais dos hidrocarbonetos R600a, R290 e R1270. O estudo também inclui uma análise ampla e crítica da literatura envolvendo o levantamento de dados experimentais para a perda de pressão e o coeficiente de transferência de calor durante a ebulição convectiva em dissipadores de calor baseados em multi-microcanais.

Como objetivos específicos apresentam-se os seguintes: (i) avaliar experimentalmente a perda de pressão e o coeficiente de transferência de calor durante a ebulição convectiva ao longo do dissipador de calor através de uma análise do efeito dos principais parâmetros experimentais; (ii) comparar os resultados experimentais do coeficiente de transferência de calor médio e perda de pressão com resultados de trabalhos prévios para o refrigerante R134a; (iii) comparar os resultados experimentais do coeficiente de transferência de calor e perda de pressão por atrito da região bifásica com métodos de previsão disponíveis na literatura; (iv) avaliar as 
irreversibilidades ao longo do dissipador de calor durante a ebulição convectiva através da análise de geração de entropia e da eficiência da Segunda Lei da Termodinâmica; (v) avaliar o desempenho termo-hidráulico dos refrigerantes R600a, R290 e R1270 relativamente ao $R 134 a$ com base em critérios objetivos de desempenho tais como: grau de superaquecimento para o início da ebulição, coeficiente de transferência de calor, perda de pressão e avaliação da eficiência do dissipador com base na Segunda Lei da Termodinâmica.

\subsection{ESTRUTURA DO TEXTO}

A estrutura deste texto compõe-se basicamente da motivação do trabalho, revisão bibliográfica, descrição da bancada e dos procedimentos experimentais adotados, apresentação dos resultados experimentais, conclusões e recomendações para trabalhos futuros. Estes tópicos encontram-se distribuídos da seguinte forma:

O Capítulo 2 apresenta o estado de arte da literatura sobre ebulição convectiva em dissipadores de calor baseados em multi-microcanais. Inicialmente, descrevem-se os parâmetros e conceitos básicos da ebulição convectiva. Após isto, são discutidos os estudos sobre padrões de escoamento, perda de pressão e transferência de calor em microcanais únicos. Em seguida, apresenta-se uma análise crítica dos estudos da literatura sobre dissipadores de calor baseados em multi-microcanais que envolvem visualização de padrões de escoamento, perda de pressão e transferência de calor. Posteriormente, apresenta-se uma análise dos estudos da literatura envolvendo investigações sobre o efeito do fluido na ebulição convectiva desenvolvidos em condições de micro-escala com ênfase naqueles sobre hidrocarbonetos. Finalmente, inclui-se uma análise da literatura sobre instabilidades térmicas em dissipadores de calor baseados em multi-microcanais.

O Capítulo 3 inclui a descrição da bancada e do procedimento experimental desenvolvido no presente projeto. Inicialmente, se apresenta a bancada experimental na qual foram realizados os experimentos, incluindo a apresentação do circuito principal, circuitos de rejeição de calor e do circuito de segurança e detecção de vazamentos. Em seguida é descrita detalhadamente a seção de testes que contém o dissipador de calor. Este item apresenta as características dos componentes, modificações adotadas na seção de testes para a execução deste estudo. Incluemse análises baseadas em simulações e cálculos realizados para montagem dos microcanais e sistema de aquecimento elétrico para avaliar as hipóteses adotadas na redução de dados. Finalmente, apresenta-se a metodologia experimental adotada e o procedimento de regressão de dados usado para estimar a perda de pressão bifásica e o coeficiente de transferência de calor médio, com base nas variáveis e parâmetros medidos durante os ensaios.

O Capítulo 4 apresenta a análise e discute os dados experimentais levantados neste estudo. Inicialmente, os resultados são apresentados segundo curvas de ebulição. Após apresenta-se a análise dos resultados para o coeficiente de transferência de calor global do dissipador e 
para a perda de pressão durante a ebulição convectiva, incluindo a comparação com métodos de previsão disponíveis na literatura. Uma análise e descrição dos resultados das oscilações verificadas durante os ensaios também é apresentada. Finalmente, incluí-se uma análise do desempenho do dissipador de calor para os refrigerantes avaliados baseada na eficiência da Segunda Lei da Termodinâmica.

O Capítulo 5 apresenta as conclusões obtidas a partir do presente estudo e indica recomendações para o desenvolvimento de trabalhos futuros. 


\section{REVISÃO BIBLIOGRÁFICA}

O presente capítulo tem como objetivo descrever criticamente o estado da arte sobre ebulição convectiva em dissipadores de calor baseados em multi-microcanais. Assim, visando fundamentar as discussões posteriores, inicialmente, são definidos e descritos os parâmetros e conceitos básicos utilizados na literatura sobre ebulição convectiva. Segue uma descrição da bibliografia sobre padrões de escoamento, perda de pressão e transferência de calor durante a ebulição convectiva em canais únicos de diâmetro reduzido. Em seguida, apresenta-se de forma esquemática uma descrição dos estudos experimentais disponíveis na literatura sobre a ebulição convectiva em dissipadores de calor baseados em multi-microcanais, envolvendo aspectos como visualização de padrões de escoamento, perda de pressão e transferência de calor. Posteriormente, apresenta-se uma análise dos estudos que tratam da investigação do efeito do fluido refrigerante na ebulição convectiva em condições de micro-escala com ênfase nos estudos sobre hidrocarbonetos. Finalmente, efetua-se uma análise crítica da literatura sobre instabilidades térmicas em dissipadores de calor baseados em multi-microcanais.

\subsection{INTRODUÇÃO}

\subsubsection{PARÂMETROS CARACTERÍSTICOS DO ESCOAMENTO BIFÁSICO}

Os parâmetros utilizados na caracterização de escoamento bifásico isotérmico são aplicados também na ebulição convectiva devido às similaridades hidrodinâmicas dos fenômenos. Destacam-se como diferenças a nucleação de bolhas junto à superfície e a evolução contínua e progressiva dos padrões de escoamento durante a ebulição convectiva, devido à elevação do título de vapor, inerente ao processo de transferência de calor para o fluido. Desta forma, visando embasar teoricamente os capítulos posteriores, estes parâmetros são apresentados neste item.

(a) Fração de vazio $\left(\alpha_{i D}\right)$ : de forma geral, a fração de vazio é definida como a média temporal da fração espacial instantânea da fase vapor, conforme a seguinte equação:

$$
\alpha_{i D}=\frac{1}{\Delta t} \int_{\Delta t} \frac{Y_{g}}{Y} d t
$$


onde $t$ é o tempo representativo do fenômeno, $i$ é a ordem da dimensão, $Y_{g}$ é a dimensão espacial característica na qual ocorre a presença da fase vapor e $Y$ é a dimensão espacial total característica na qual se dá o escoamento bifásico.

Para o caso unidimensional $(i=1)$, o valor de $\alpha_{1 D}$ corresponde à fração de vazio linear, dada pela razão entre o comprimento correspondente da fase vapor $\left(Y_{g}=L_{g}\right)$ e do comprimento total do escoamento bifásico $(Y=L)$.

Para o caso bidimensional $(i=2)$, o valor de $\alpha_{2 D}$ corresponde à fração de vazio superficial, definida como a razão das áreas correspondentes a fase vapor $\left(Y_{g}=A_{g}\right)$ e da seção transversal na qual ocorre o escoamento $(Y=A)$. Neste texto, de forma análoga à literatura, a fração de vazio superficial será denominada $\alpha$.

Para o caso tridimensional $(i=3)$, o valor de $\alpha_{3 D}$ corresponde à fração de vazio volumétrica dada pela razão entre os volumes ocupado pela fase vapor $\left(Y_{g}=\forall_{g}\right)$ e o correspondente a um determinado segmento de escoamento bifásico $(Y=\forall)$.

(b) Fração volumétrica $(\beta)$ : é definida como a razão entre as vazões volumétricas da fase vapor e da mistura, sendo dada pela seguinte equação:

$$
\beta=\frac{Q_{g}}{Q_{l}+Q_{g}}
$$

(c) Relação entre $\alpha$ e $\beta$ : através da equação da continuidade escrita para as fases pode-se obter uma relação entre as frações de vazio superficial e volumétrica dada pela seguinte equação:

$$
\frac{\beta}{1-\beta}=\frac{\alpha}{1-\alpha}\left(\frac{V_{g}}{V_{l}}\right)
$$

onde a relação $V_{g} / V_{l}$ é denominada de razão de escorregamento.

(d) Título de vapor $\left(x_{m}\right)$ : é definido como a razão entre a vazão mássica da fase vapor e da mistura binária líquido-vapor conforme a seguinte equação:

$$
x_{m}=\frac{\dot{m}_{\text {vapor }}}{\dot{m}_{\text {vapor }}+\dot{m}_{\text {liquido }}}
$$

(e) Título de vapor de equilíbrio termodinâmico $\left(x_{t}\right)$ : este parâmetro é dado pela seguinte equação:

$$
x_{t}=\frac{i_{\text {Local }}-i_{l}}{i_{l g}}
$$

onde $i_{\text {Local }}$ é a entalpia local da mistura, $i_{l}$ é a entalpia do líquido saturado e $i_{l g}$ é a entalpia do calor latente de vaporização estimadas para condições de saturação local.

Os títulos de vapor definidos por intermédio das Eqs. 2.4 e 2.5 tornam-se similares quando a mistura encontra-se em condições de equilíbrio termodinâmico. No presente 
estudo, quando não especificado, adota-se o símbolo $x$ para o título de vapor de equilíbrio termodinâmico.

(f) Velocidade mássica $(G)$ : é definida através da razão entre a vazão mássica e a área da seção transversal, podendo ser definida para cada fase $k$ através da seguinte equação:

$$
G_{k}=\frac{\dot{m}_{k}}{A}
$$

A velocidade mássica da mistura bifásica é dada pela soma das velocidades mássicas das fases.

(g) Velocidade superficial $(J)$ : também denominada de fluxo volumétrico, é definida como a razão entre a vazão volumétrica da fase $k$ e a área transversal do duto, conforme a seguinte equação:

$$
J_{k}=\frac{Q_{k}}{A}
$$

A velocidade superficial da mistura bifásica é dada pela soma das velocidades superficiais das fases.

\subsubsection{EBULIÇÃO CONVECTIVA EM CANAIS CONVENCIONAIS}

Collier e Thome (1994) definem a ebulição convectiva como um processo de transferência de calor sob condições de escoamento forçado com a mudança de fase do líquido para vapor. A Figura 2.1 ilustra alterações na distribuição de fases durante o processo de ebulição convectiva para um canal horizontal de diâmetro convencional $(D>3 \mathrm{~mm})$ aquecido uniformemente. Distribuições das fases com características similares são denominadas de padrões de escoamento.

Conforme a Figura 2.1, a ebulição tem início com o líquido em um estado termodinâmico correspondendo a uma temperatura média na seção inferior ao valor de saturação, à pressão local. Tal condição corresponde a um título de vapor de equilíbrio termodinâmico, definido segundo a Eq. 2.4, inferior a zero. À jusante da região de início da ebulição, o fluido alcança condições de saturação $\left(T_{f}=T_{s a t}\right)$ e, a partir daí, ocorre a redução da temperatura do fluido no estado saturado devido à perda de pressão. Inicialmente, para títulos de vapor reduzidos, predominam efeitos de ebulição nucleada na transferência de calor. Com incrementos adicionais do título de vapor e o aumento da fração de vazio, como resultado da elevação da população de bolhas, estas passam a coalescer formando pistões de vapor. A partir do padrão pistonado, parcela significativa da transferência de calor se deve a efeitos convectivos, ocorrendo a condução através do filme líquido e a evaporação na interface.

Vale destacar que, em tubulações posicionadas horizontalmente se verificam distribuições assimétricas tais como, o padrão estratificado e bolhas ou pistões de vapor concentrados na região superior do tubo, o qual ocorre devido aos efeitos gravitacionais. No caso do 
padrão estratificado, a transferência de calor acorre por intermédio dos mecanismos de ebulição nucleada e convecção forçada para a fase líquida na região inferior do tubo, e na região superior se dá através de convecção forçada para a fase vapor. A assimetria dada pela concentração de bolhas e pistões na região superior do tubo, favorece coeficientes de transferência de calor superiores para esta região do tubo, e no caso de concentração pistões ou bolhas alongadas, o filme líquido incrementa descendentemente ao longo do perímetro da seção transversal. Já, para velocidades elevadas do líquido na entrada da tubulação, os efeitos inerciais predominam sobre os efeitos gravitacionais favorecendo padrões de escoamento mais simétricos.

Com a elevação contínua do título de vapor ocorre a transição para o padrão anular, intensificando os efeitos convectivos, que se tornam predominantes. Além disso, o movimento relativo das fases, a velocidade superior da fase vapor, somado a ondulações interfaciais no filme líquido que escoa junto à parede, provoca o arrasto de gotículas de líquido para a região central do escoamento. Estas gotículas são denominadas de entranhamento de líquido (liquid entrainment). Estes fenômenos proporcionam a redução da espessura do filme líquido causando incremento adicionais ao coeficiente de transferência de calor. Entretanto, para títulos de vapor elevados o arrastro de gotículas de líquido pode promover uma secagem prematura da parede, causando o incremento da temperatura superficial, com a consequentemente redução drástica do coeficiente de transferência de calor. Finalmente, gotículas de líquido podem continuar dispersas na fase vapor, com a ausência de contato contínuo com a parede.

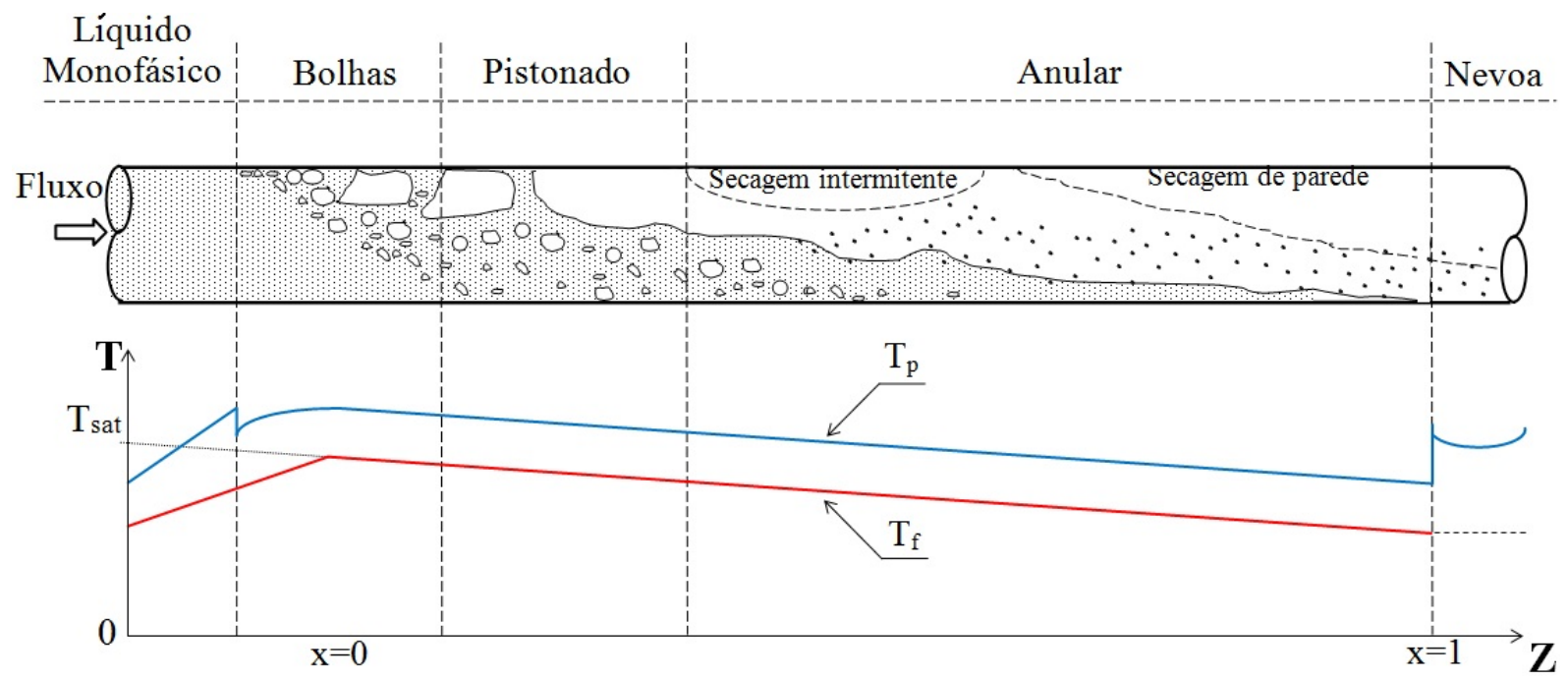

Figura 2.1 - Ilustração esquemática dos padrões de escoamento e da evolução das temperaturas da superfície e do fluido com o incremento do título de vapor,Collier e Thome (1994).

Para canais verticais, o efeito da gravidade promove a simetria do escoamento, o padrão estratificado e a secagem de parede não se verificam. De forma análoga ao escoamento horizontal, os padrões de escoamento e os mecanismos de transferência de calor se desenvolvem em função da variação do título de vapor. 


\subsection{EBULIÇÃO CONVECTIVA EM MICROCANAIS ÚNICOS}

Visando fundamentar as discussões neste texto e a avaliação de resultados experimentais através da comparação com métodos de previsão, este item apresenta uma revisão da literatura sobre a ebulição convectiva em microcanais únicos. É fato que teorias desenvolvidas baseadas em resultados para microcanais únicos são aplicadas a configurações compostas de multimicrocanais. No entanto, conforme indicado por Ribatski (2013) e Tibiriçá e Ribatski (2014), o processo de ebulição convectiva em multicanais diferencia-se do observado em canais únicos. Tal fato relaciona-se a fatores como, a interação do escoamento proveniente de distintos canais nas regiões das câmaras e interação térmica entre canais vizinhos através das aletas, no caso de multicanais. Além disso, o crescimento de bolhas em condições confinadas, também verificado em microcanais únicos, promove o fluxo reverso e, consequentemente, instabilidades térmicas. Assim, vale destacar que, embora os resultados em microcanais únicos indiquem tendência e comportamentos, sua extensão para multi-microcanais deve ser realizada com cautela.

\subsubsection{PADRÕES DE ESCOAMENTO EM MICROCANAIS ÚNICOS}

Durante a ebulição convectiva, os padrões de escoamento se desenvolvem progressivamente com o incremento do título de vapor. Assim, conforme foi ilustrado anteriormente para canais convencionais (Fig. 2.1), a importância relativa das forças atuantes e os mecanismos de transferência de calor preponderantes também se alteram, afetando o coeficiente de transferência de calor e a perda de pressão. Diferentes autores têm caracterizado padrões de escoamento distintos, não havendo até então uma classificação universal. A Figura 2.2 apresenta os padrões de escoamento para microcanais únicos caracterizados por Tibiriçá e Ribatski (2014). A análise desta figura em relação à Fig. 2.1, revela que para microcanais, o padrão estratificado não se verifica e para padrões pistonado e anular, a espessura do filme líquido apresenta maior simetria ao longo do perímetro do tubo.

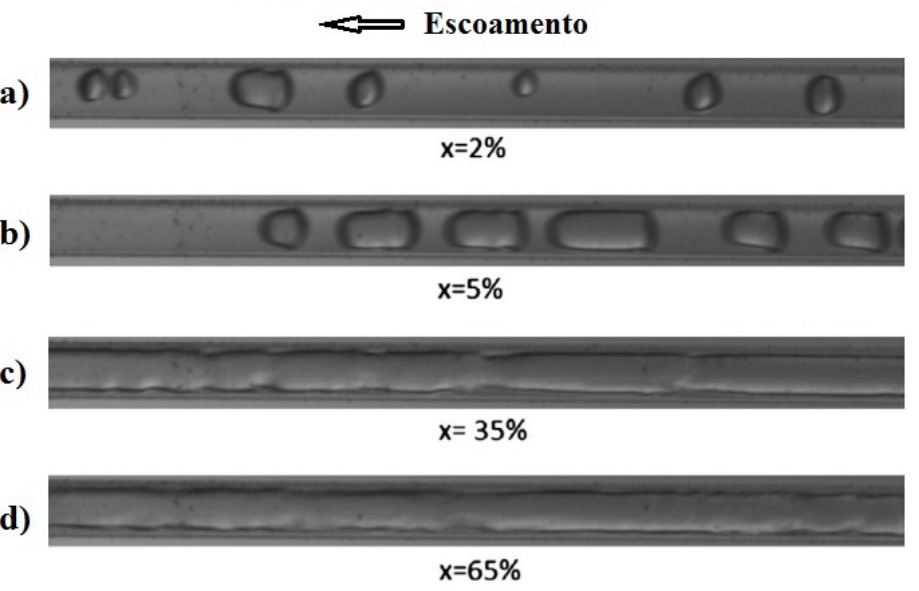

Figura 2.2 - Padrões de escoamento horizontais em microcanais segundo Tibiriçá e Ribatski (2014), R134a; $D=400$ [ $\mu \mathrm{m}]$. (a) Bolhas; (b) Pistonado; (c) Anular; (d) Anular. 
Os métodos utilizados para a classificação de padrões de escoamento podem ser subjetivos e objetivos. O método de previsão subjetivo se baseia na visualização e identificação por um observador do padrão de escoamento a partir de imagens obtidas com câmeras de alta velocidade e registros fotográficos. Uma vez realizada a identificação e classificação, mapas e correlações para as transições são elaborados. Os métodos objetivos são baseados na análise de sinais característicos do escoamento e podem basear-se em sinais transientes relacionados à pressão, fração de vazio e temperatura.

Barnea et al. (1983), baseados em classificações subjetivas, foram pioneiros ao propor modelos para as transições entre padrões de escoamento para canais de diâmetros reduzidos. Eles modificaram as transições entre padrões intermitente-estratificado e intermitente-anular no modelo de Taitel e Dukler (1976) para escoamentos horizontais. Para a transição intermitenteestratificado, eles adotaram uma fração de vazio superficial igual a 0,35, de forma distinta do valor proposto por Taitel e Dukler (1976), igual a 0,5. Para a transição intermitenteanular, Barnea et al. (1983) adotaram como critério o equilíbrio entre as forças gravitacionais e de tensão superficial de forma a manter uma ponte de líquido entre os pistões de vapor. Tal critério distingui-se da instabilidade de Kelvin-Helmholtz, conforme adotado por Taitel e Dukler (1976). Felcar et al. (2007), baseados em resultados da literatura, modificaram o método de Taitel e Dukler (1976) visando adaptá-lo a canais de diâmetro reduzido. Além da tensão superficial, os autores incluíram efeitos de molhabilidade, através do ângulo de contato do fluido, incluídos nos números adimensionais de Weber e Eötvos. Estes autores segregaram os resultados da literatura por eles levantados segundo os padrões bolhas dispersas, intermitente (incluindo bolhas alongadas e agitante), anular e estratificado.

Revellin e Thome (2007) utilizaram um método objetivo para classificação de padrões de escoamento em micro-escala baseado na frequência de bolha, definindo os seguintes padrões: bolhas isoladas, bolhas coalescentes, anular e secagem de parede. Com base em seus resultados, Revellin e Thome (2007) propuseram correlações para a determinação do título de vapor para as transições entre bolhas isoladas-bolhas coalescentes e bolhas coalescentes-anular. Tais correlações incluem os números adimensionais de Weber, Ebulição e Reynolds da fase líquida.

Ong e Thome (2009) somaram novos resultados aos dados de Revellin e Thome (2007) e propuseram novas correlações incluindo o efeito da pressão reduzida para determinar a transição entre os padrões de bolhas coalescentes e anular. Posteriormente, Ong e Thome (2011a) modificaram novamente este método incluindo efeitos relativos a transição entre comportamento de macro e micro-escala. Eles introduziram o número de Froude, relacionando os efeitos inerciais e gravitacional e, o Número de Confinamento, visando capturar alterações nos comportamentos da ebulição convectiva para condições confinadas.

Sempértegui-Tapia et al. (2013) investigaram experimentalmente padrões de escoamento em canais com diâmetro de 2,32 mm para os refrigerantes R245fa e R134a. As Figuras 2.3a, 
$2.3 \mathrm{~b}$ e 2.3 correspondem a uma comparação dos dados experimentais de Sempértegui-Tapia et al. (2013), classificados subjetivamente, com os modelos preditivos de Barnea et al. (1983), Felcar et al. (2007) e Ong e Thome (2009). De acordo com estas figuras, os mapas de padrões apresentam concordância razoável com as observações visuais destes autores. Neste mesmo estudo, Sempértegui-Tapia et al. (2013) desenvolveram mapas de padrões de escoamento utilizando um método objetivo de identificação baseado no algoritmo k-means. Este é um método que aglomera dados com características similares. Sempértegui-Tapia et al. (2013) aplicaram esta metodologia utilizando os sinais de intensidade de radiação e de pressão local na saída da seção de testes. Através desta análise, os autores propuseram critérios para as seguintes transições: (i) bolhas-Intermitente, (ii) intermitente-anular. As Figuras 2.4p, 2.4p e 2.4c apresentam a comparação entre os dados experimentais caracterizados subjetivamente e com o método objetivo com ambas segregações efetuadas por Sempértegui-Tapia et al. (2013). De acordo com estas figuras, o método k-means captura satisfatoriamente os dados caracterizados subjetivamente.

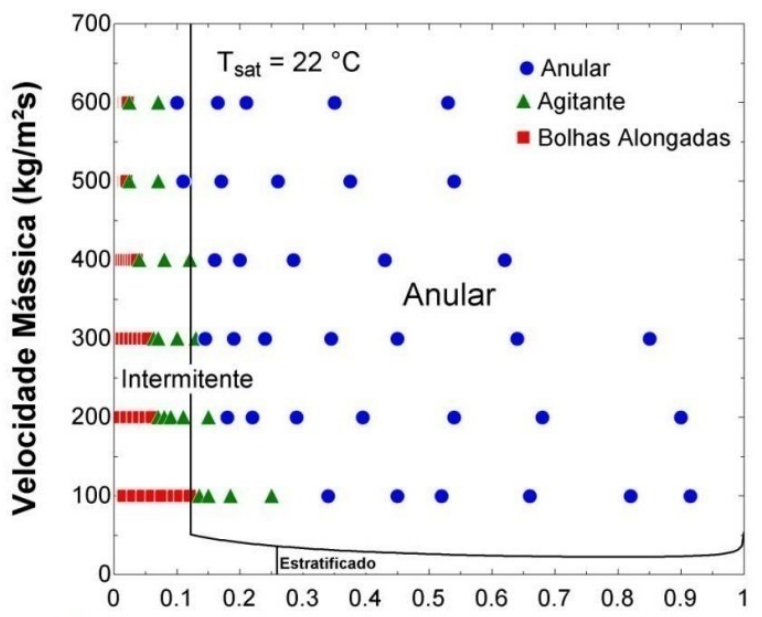

a)

Título de vapor (-)

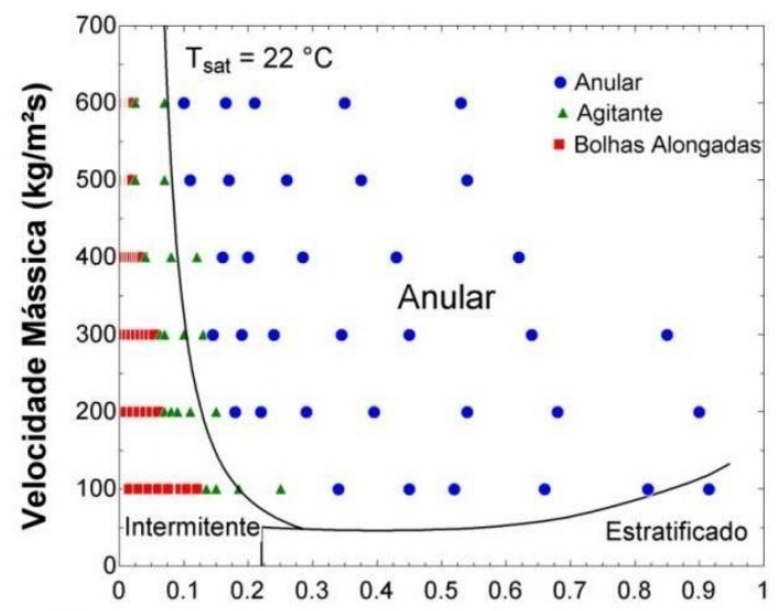

b)

Título de Vapor (-)

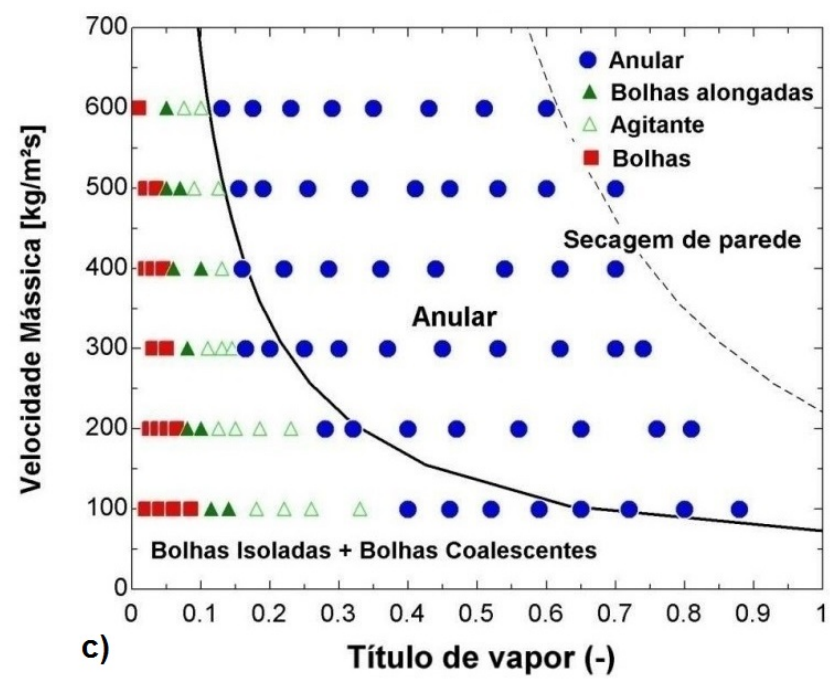

Figura 2.3 - Comparação de dados experimentais para padrões de escoamento horizontal de Sempértegui-Tapia et al. (2013) com métodos de previsão da literatura. Experimentais (símbolos), Modelo (linhas). (a) Barnea et al. (1983); (b) Felcar et al. (2007); (c) Ong e Thome (2009). 

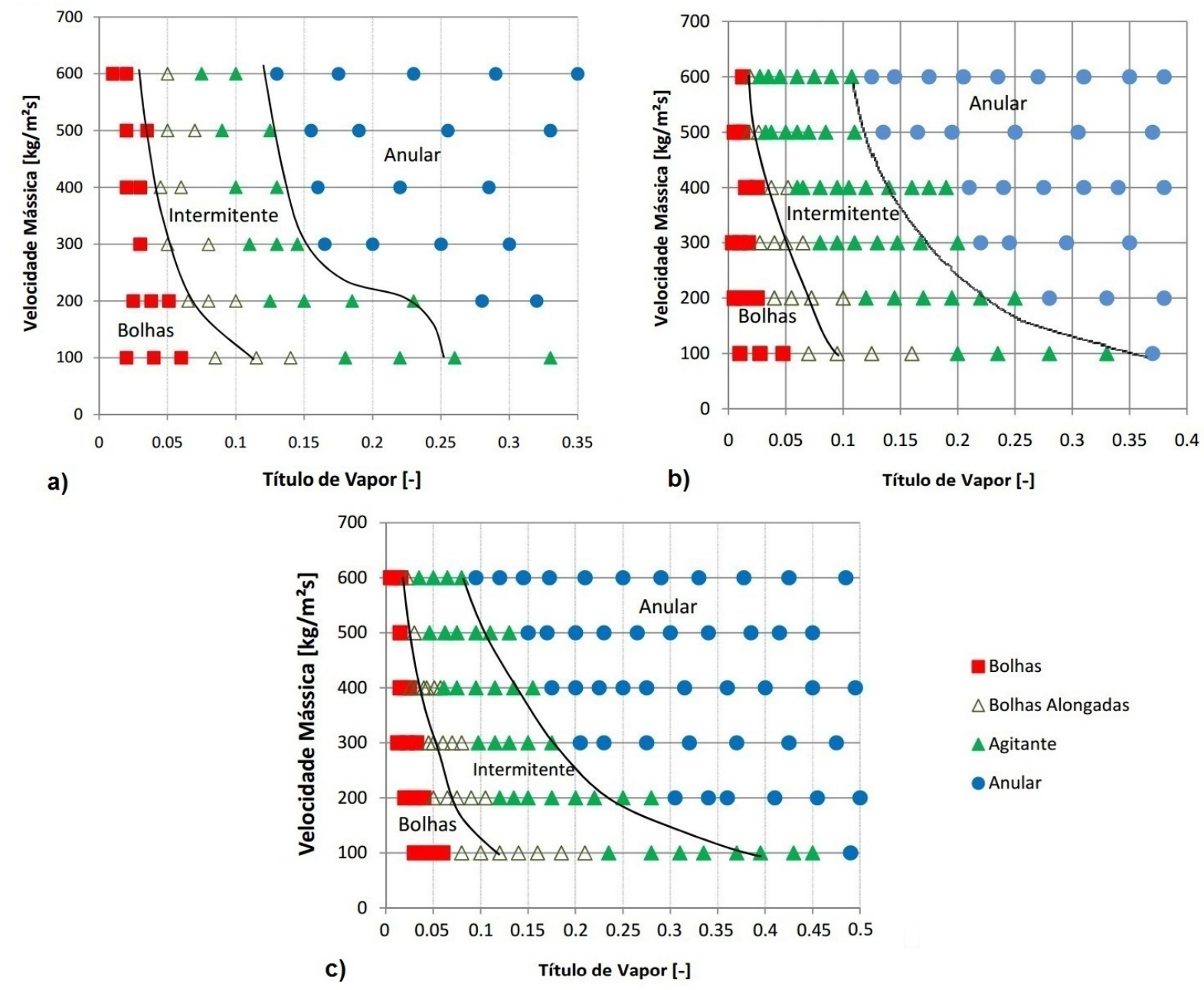

Figura 2.4 - Comparação de dados experimentais com método k-means para padrões de escoamento horizontal e $\mathrm{D}=2,32 \mathrm{~mm}$. Experimentais (símbolos) vs $k$-means (linhas), Sempértegui-Tapia et al. (2013). (a) R245fa e $T_{s a t}=31^{\circ} C$; (b) R134a e $T_{\text {sat }}=22^{\circ} C$; (c) $\mathrm{R} 134 \mathrm{a}$ e $T_{\text {sat }}=31^{\circ} \mathrm{C}$.

Recentemente, Chinnov et al. (2016) propuseram mapas de padrões de escoamento para um canal de seção transversal retangular com razões de aspecto reduzidas. Neste caso, as alturas dos canais variaram de $100-500 \mu \mathrm{m}$ e as larguras variaram de $9-40 \mathrm{~mm}$. O fluido líquido utilizado foi água e o gás foi ar ou nitrogênio. A Figura 2.6 corresponde a um mapa de padrões de escoamento bifásico para um canal de seção transversal igual a $0,42 \times 9 \mathrm{~mm}^{2}$. Como ilustra esta figura, os autores classificaram os seguintes padrões: (1) anular; (2) jato constante e intermitente; (3) bolhas; (4) estratificado; (5) pistonado; (6) agitante. Neste estudo, vale destacar o padrão de escoamento jato ilustrado na Fig. 2.5. Este padrão ocorreu para reduzidas velocidades superficiais do líquido com o gás escoando na região central do canal em forma de jato. Os autores observaram que o jato desenvolve-se de forma constante para velocidades superficiais reduzidas do líquido e do gás. Entretanto, como verifica-se na Fig. 2.7 quando se eleva a velocidade do líquido observa-se uma perda de estabilidade no padrão de escoamento tornando-se este um jato intermitente.

A comparação dos mapas ilustrados nas Figs. 2.6 e 2.7 revela que alterações na altura e na largura dos canais exercem efeito significativo nas transições entre os padrões de escoamento. 


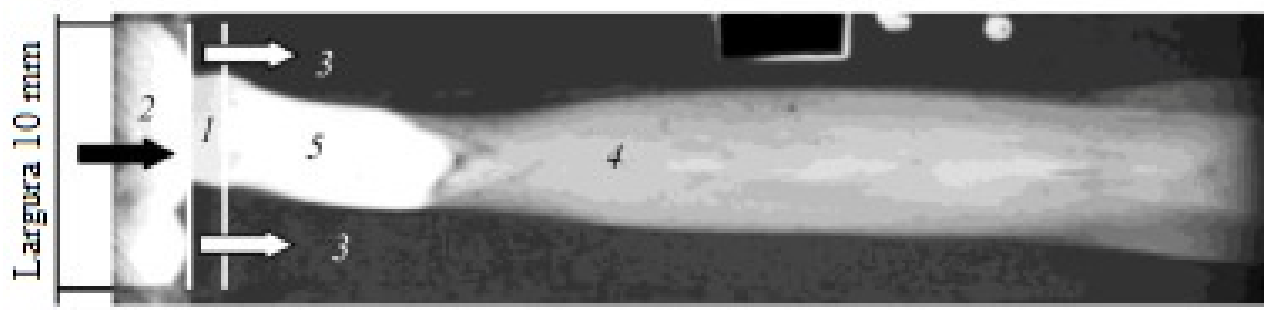

Figura 2.5 - Vista superior do padrão de escoamento jato em canal de $0,3 \times 10 \mathrm{~mm}^{2}$ para $J_{g}=3,3 \mathrm{~m} / \mathrm{s} \mathrm{e}$ $J_{l}=0,092 \mathrm{~m} / \mathrm{s}$ : (1) ranhura na parede inferior do canal para entrada do líquido; (2) entrada de gás; (3) líquido; (4) filme de líquido na parede superior do canal; (5) região seca na parede superior do canal.

Seta preta: direção do gás; setas brancas: direção do líquido. Chinnov et al. (2016).

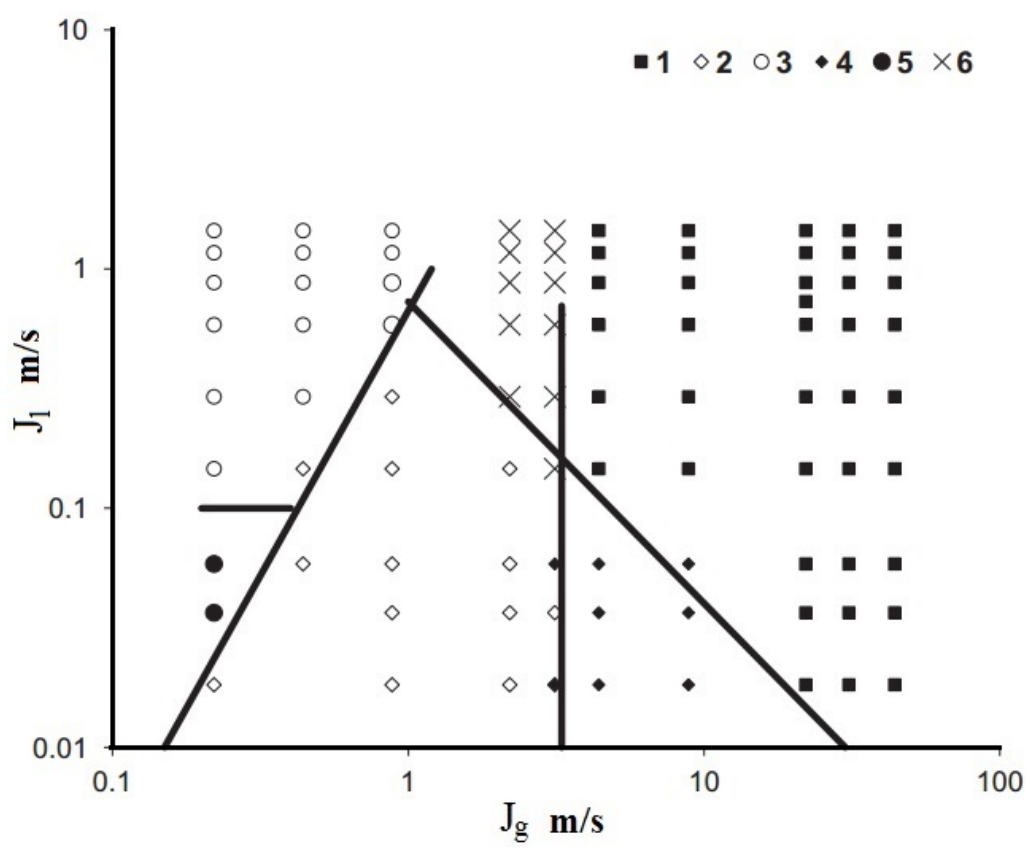

Figura 2.6 - Mapa de padrões de escoamento para um canal de seção transversal de $0,42 \times 9 \mathrm{~mm}^{2}$, Chinnov et al. (2016). (1) anular; (2) jato; (3) bolhas; (4) estratificado; (5) pistonado; (6) agitante.

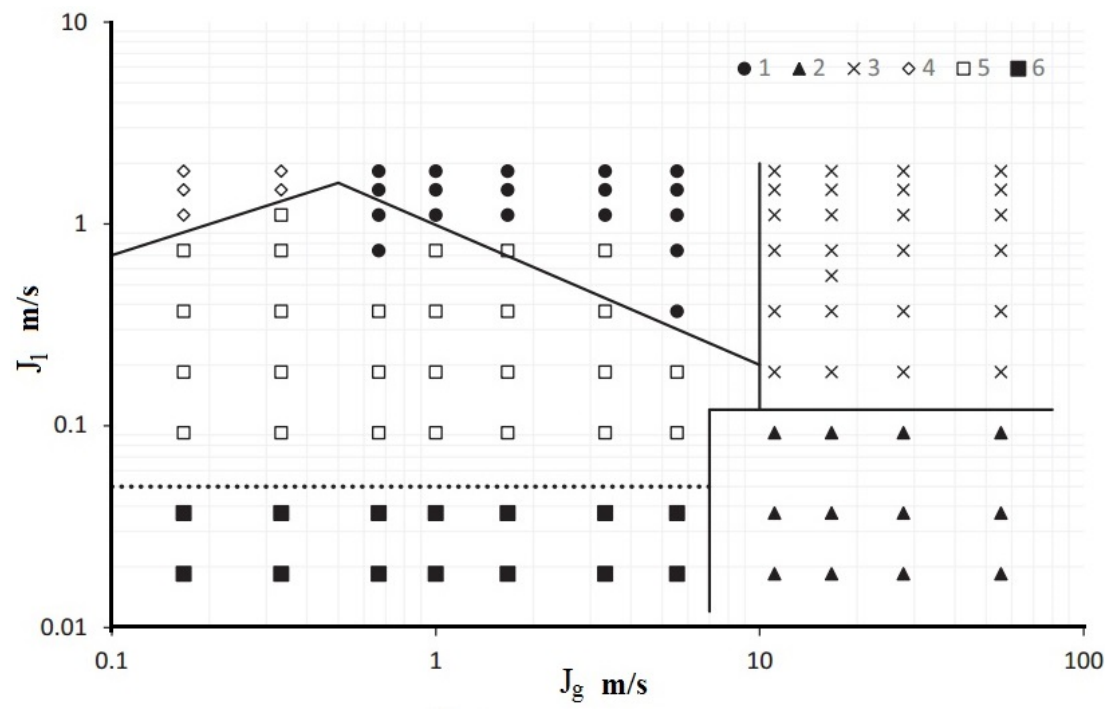

Figura 2.7 - Mapa de padrões de escoamento para um canal de seção transversal de $0,3 \times 10 \mathrm{~mm}^{2}$, Chinnov et al. (2016). (1) agitante; (2) estratificado; (3) anular; (4) bolhas; (5) jato intermitente; (6) jato constante. 
De uma forma geral, a análise apresentada neste item permite indicar que para canais de diâmetro reduzido, efeitos de tensão superficial e capilares tornam-se relevantes em relação aos gravitacionais na definição dos padrões de escoamento. Desta forma, os mecanismos responsáveis pelas transições entre padrões de escoamento se modificam com a redução do diâmetro e com a variação da geometria da seção transversal dos canais. Finalmente, considerando a geometria dos canais no presente estudo, a visualização e os mapas de padrões de escoamento que envolvam microcanais retangulares ainda se fazem necessários.

\subsubsection{PERDA DE PRESSÃO EM MICROCANAIS ÚNICOS}

O gradiente de perda de pressão total compõe-se de três parcelas, conforme indicado na seguinte equação:

$$
\frac{d p}{d z}=\left(\frac{d p}{d z}\right)_{g}+\left(\frac{d p}{d z}\right)_{a}+\left(\frac{d p}{d z}\right)_{f}
$$

onde, os subíndices das parcelas representam: $g=>$ gravitacional, $a=>$ aceleracional e $f=>$ perda devido ao atrito.

A queda de pressão gravitacional se deve à variações de cota do escoamento. No caso de escoamentos bifásicos esta parcela pode ser estimada pela seguinte equação:

$$
\left(\frac{d p}{d z}\right)_{g}=\left[\alpha \rho_{g}+(1-\alpha) \rho_{l}\right] g \operatorname{sen} \theta
$$

onde $\theta$ é o ângulo entre o eixo axial do tubo e o plano horizontal.

A redução de pressão devido à efeitos aceleracionais está relacionada a variação de energia cinética do fluxo mássico e, para escoamentos bifásicos e dutos com seção transversal constante é dada por:

$$
\left(\frac{d p}{d z}\right)_{a}=G^{2} \frac{d}{d z}\left[\frac{x}{\alpha \rho_{g}}+\frac{(1-x)^{2}}{(1-\alpha) \rho_{l}}\right]
$$

A perda de pressão por atrito durante o escoamento bifásico decorre da dissipação de energia devido à efeitos viscosos entre as camadas do fluido e entre as fases. Vários modelos e correlações são encontrados na literatura visando a avaliação da perda de pressão por atrito. Entre os métodos disponíveis destaca-se pela sua simplicidade o Modelo Homogêneo, o qual trata a mistura bifásica como um pseudo-fluido com propriedades ponderadas segundo as parcelas das fases, sendo adequado para padrões de escoamento contínuos. Neste modelo, a perda de pressão por atrito pode ser avaliada através da seguinte equação:

$$
\left(\frac{d p}{d z}\right)_{f}=f \frac{2 G^{2}}{\rho_{2 \phi}}
$$

onde $f$ é o fator de atrito e $\rho_{2 \phi}$ é a densidade da mistura bifásica. Na literatura, a densidade da mistura pode ser calculada através das seguintes equações: 


$$
\begin{aligned}
& \rho_{2 \phi}=\left(\frac{x}{\rho_{g}}+\frac{1-x}{\rho_{l}}\right)^{-1} \\
& \rho_{2 \phi}=x \rho_{g}+(1-x) \rho_{l} \\
& \rho_{2 \phi}=\alpha \rho_{g}+(1-\alpha) \rho_{l}
\end{aligned}
$$

Diversas correlações foram propostas na literatura para avaliação da viscosidade da mistura bifásica visando ajustar resultados experimentais para a perda de pressão por atrito através do Modelo Homogêneo. A Tabela 2.1 apresenta alguns dos métodos comumente citados na literatura para avaliação da viscosidade dinâmica da mistura bifásica. De uma maneira geral, estes métodos ponderam as viscosidades das fases líquido e gás. Como observa-se na tabela, a maioria dos métodos adota como parâmetros de ponderação o título de vapor e as densidades das fases líquido e gás. Apenas Owens (1961) considera que a viscosidade da mistura independe

\begin{tabular}{|c|c|c|}
\hline Autor & Equações principais & \\
\hline$\frac{\text { McAdams et al. }}{(1942)}$ & $\mu_{2 \phi}=\left(\frac{x}{\mu_{g}}+\frac{1-x}{\mu_{l}}\right)^{-1}$ & $(2.15)$ \\
\hline$\frac{\text { Davidson et al. }}{\text { (1943) }}$ & $\mu_{2 \phi}=\mu_{l}\left(1+x \frac{\rho_{l}-\rho_{g}}{\rho_{g}}\right)$ & (2.16) \\
\hline Akers et al. (1959) & $\mu_{2 \phi}=\mu_{l} \cdot\left[(1-x)+x\left(\frac{\rho_{l}}{\rho_{g}}\right)^{0,5}\right]^{-1}$ & (2.17) \\
\hline$\frac{\text { Chicchitti et al. }}{(1960)}$ & $\mu_{2 \phi}=x \mu_{g}+(1-x) \mu_{l}$ & $(2.18)$ \\
\hline Owens (1961) & $\mu_{2 \phi}=\mu_{l}$ & (2.19) \\
\hline Dukler et al. (1964) & $\mu_{2 \phi}=\rho_{2 \phi}\left[x v_{g} \mu_{g}+(1-x) v_{l} \mu_{l}\right]$ & (2.20) \\
\hline$\frac{\text { Beattie e Whalley }}{\text { (1982) }}$ & $\mu_{2 \phi}=\omega_{B} \mu_{g}+\left(1-\omega_{B}\right)(1+2,5 \omega) \mu_{l} ; \quad$ onde: $\quad \omega_{B}=\frac{x v_{g}}{v_{l}+x v_{l g}}$ & $(2.21)$ \\
\hline Lin et al. (1991) & $\mu_{2 \phi}=\mu_{l} \cdot \mu_{g} \cdot\left[\mu_{g}+x^{1,4}\left(\mu_{l}-\mu_{g}\right)\right]^{-1}$ & $(2.22)$ \\
\hline García et al. 2003, & $\mu_{2 \phi}=\mu_{l} \frac{\rho_{2 \phi}}{\rho_{l}} ; \quad$ onde $: \quad \rho_{2 \phi}=\alpha \rho_{g}+(1-\alpha) \rho_{l}$ & (2.23) \\
\hline
\end{tabular}
do título de vapor e é igual a viscosidade da fase líquida.

Tabela 2.1 - Métodos para a estimativa da viscosidade da mistura bifásica no Modelo Homogêneo. 
Apesar do desenvolvimento dos métodos de previsão para viscosidade da mistura bifásica focar em aplicações do Modelos Homogêneo para canais convencionais, eles são frequentemente utilizados para a previsão de perda de pressão por atrito em canais de diâmetro reduzido. Neste contexto, Ribatski et al. (2006), com base em um banco de dados amplo levantado da literatura, indicaram o modelo homogêneo com a viscosidade dinâmica da mistura bifásica calculada segundo Chicchitti et al. (1960), como um método que proporciona previsões satisfatórias dos resultados experimentais.

Além do Modelo Homogêneo, os métodos na literatura para a previsão da parcela de perda de pressão por atrito em escoamento bifásico podem ser classificados da seguinte forma: (i) métodos empíricos: baseados em uma simples interpolação entre as perdas de pressão monofásicas de cada fase; (ii) métodos fenomenológicos: consideram o desenvolvimento de um modelo analítico para o cálculo da perda de pressão para um determinado padrão de escoamento; (iii) métodos baseados em multiplicadores bifásicos: são métodos baseados no Modelo de Fases Separadas e consistem na estimativa da perda de pressão bifásica através do produto entre uma função denominada de multiplicador bifásico e a perda de pressão monofásica para uma das fases escoando no canal.

(i) Métodos empíricos

A Tabela 2.2 apresenta esquematicamente os métodos disponíveis na literatura classificados segundo este grupo. Entre eles, ressalta-se o método de Müller-Steinhagen e Heck (1986) segundo o qual a perda de pressão por atrito é dada através da interpolação entre os gradientes de perda de pressão por atrito das fases líquida e vapor, adotando o título de vapor como parâmetro de ponderação. Para o ajuste de seu método, estes autores levantaram aproximadamente 9300 dados experimentais para a perda de pressão disponíveis na literatura. Este método, apesar do seu desenvolvimento incluir apenas resultados para diâmetro superiores a $4 \mathrm{~mm}$, foi indicado por Ribatski et al. (2006), Sun e Mishima (2009), Cioncolini et al. (2009) e Kim e Mudawar (2012) como o mais preciso, considerando comparações com bancos de dados independentes.

Xu e Fang (2012) modificaram o método de Müller-Steinhagen e Heck (1986) visando sua aplicação em microcanais. Eles incluíram o Número de Confinamento, relacionando efeitos do diâmetro do canal e do diâmetro de desprendimento de uma bolha em um meio infinito. Eles ajustaram os coeficientes empíricos deste método com base em 2622 dados experimentais levantados na literatura.

Da Silva (2012) ajustou novos exponentes e coeficientes ao método de Müller-Steinhagen e Heck (1986) utilizando um banco de dados próprio para refrigerantes halogenados, incluindo 487 resultados experimentais. Posteriormente, Sempértegui-Tapia e Ribatski (2016) modificaram o método de Müller-Steinhagen e Heck (1986) visando sua aplicação em microcanais com secções transversais circular, quadrada e triangular. O ajuste destes autores incluiu 1468 dados experimentais para R134a, R1234ze(E), R1234yf e R600a. Vale destacar que este método 
recomenda o uso do diâmetro equivalente como comprimento característico para estimar o Número de Reynolds.

A Figura 2.8 ilustra uma comparação entre os métodos empíricos para previsão de perda de pressão considerando um microcanal com dimensão igual a da seção de testes utilizada neste estudo, correspondendo a $\mathrm{D}_{\mathrm{h}}=197 \mu \mathrm{m}, \mathrm{D}_{\text {eq }}=278,1 \mu \mathrm{m}$ e $\mathrm{L}=15 \mathrm{~mm}$. De acordo com esta figura, os métodos indicam inicialmente o incremento da perda de pressão por atrito com o aumento do título de vapor. Em títulos de vapor elevados, a perda de pressão por atrito apresenta um pico segundo os métodos de Xu e Fang (2012), Müller-Steinhagen e Heck (1986) e Sempértegui-Tapia e Ribatski (2016), a partir do qual seu valor decresce abruptamente com incrementos adicionais da parcela de vapor no escoamento. O método de Xu e Fang (2012) fornece valores superiores aos estimados através do método de Müller-Steinhagen e Heck (1986). Apenas o método proposto por Da Silva (2012) não fornece um pico na perda de pressão em títulos de vapor elevados.

Tabela 2.2 - Métodos empíricos para perda de pressão por atrito durante escoamento bifásico.

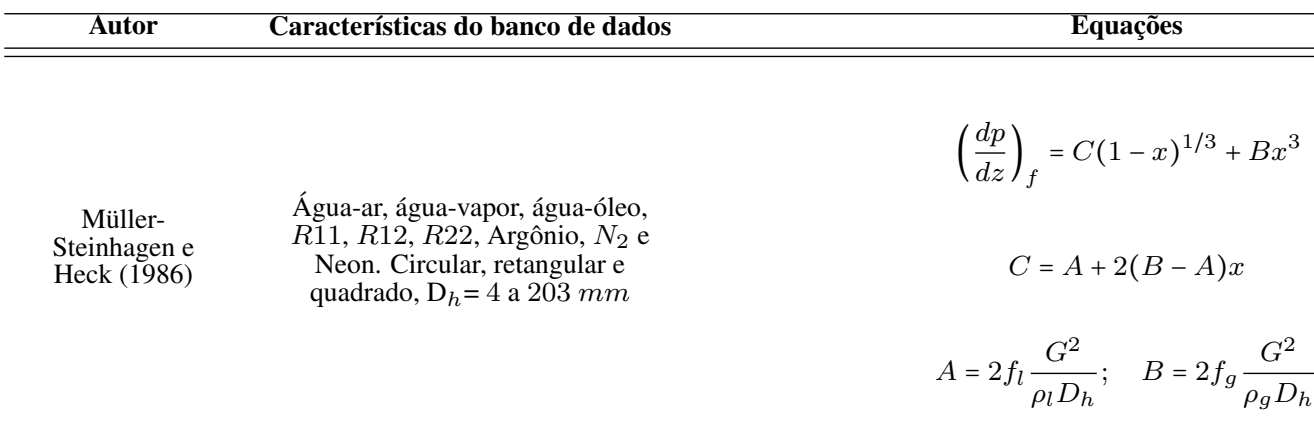

R11, R12, R22, R123, R134a, R32/R125, R507, R507A, R404A, R407C, R410A, R417A, R717, CO $\mathrm{D}_{h}=0,81$ a $19 \mathrm{~mm} . \mathrm{G}=25,4 \mathrm{a}$ $1150 \mathrm{~kg} / \mathrm{m}^{2} \mathrm{~s}$ e $q^{\prime \prime}=0,6$ a 150 $k W / m^{2}$

$\left(\frac{d p}{d z}\right)_{f}=\left[C(1-x)^{1 / 3}+B x^{3}\right]\left[1+1,54(1-x)^{0,5} C o^{-1,47}\right]$ 0,98

$$
\begin{gathered}
\left(\frac{d p}{d z}\right)_{f}=C(1-x)^{1 / 2,31}+B x^{2,31} \\
C=A+\omega(B-A) x \\
A=2 f_{l} \frac{G^{2}}{\rho_{l} D_{e q}} ; \quad B=2 f_{g} \frac{G^{2}}{\rho_{g} D_{e q}} \\
\omega=3,01 \cdot e^{-0,00464 \cdot R_{g 0} / 1000}
\end{gathered}
$$




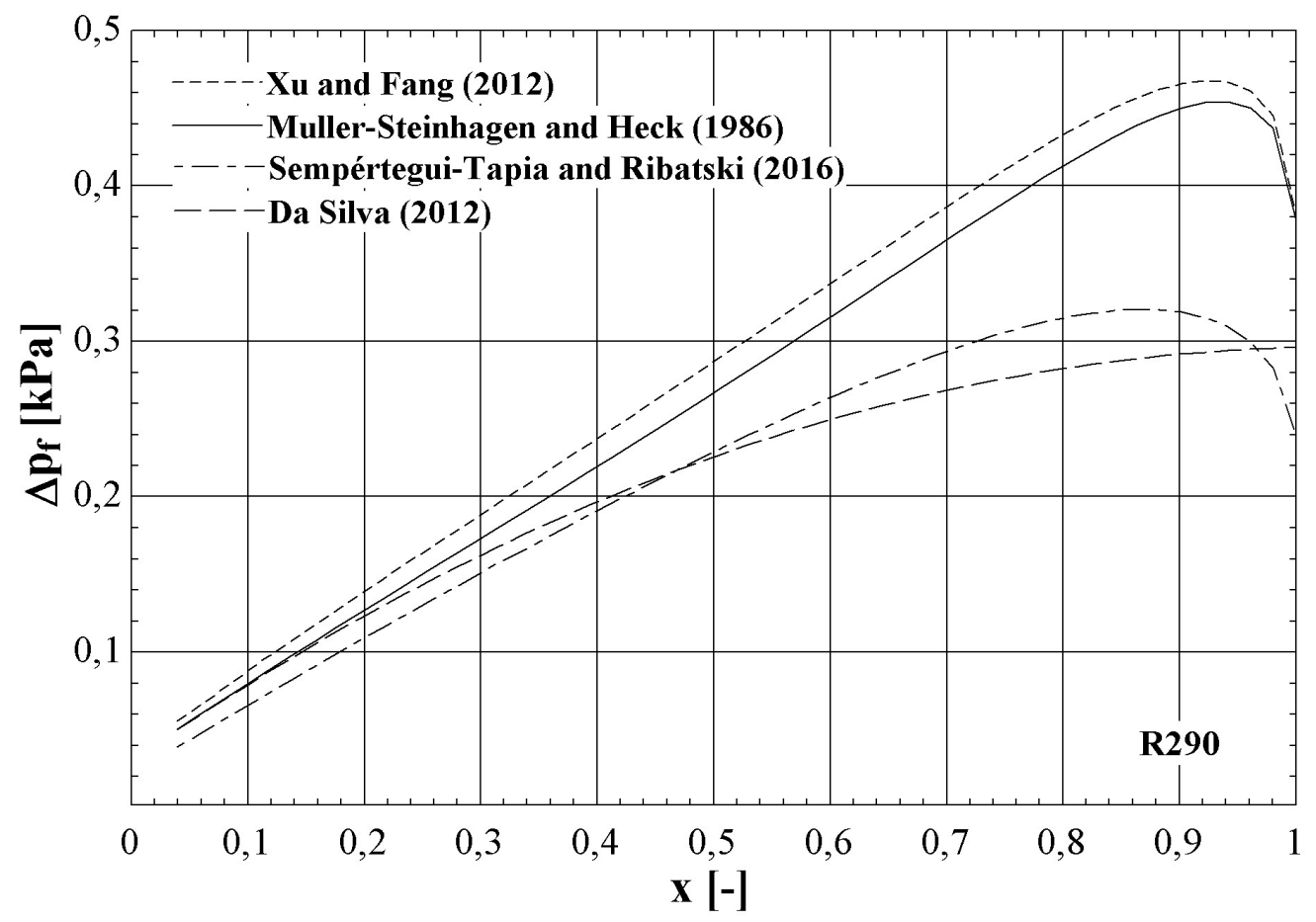

Figura 2.8 - Comparação entre os métodos empíricos para previsão da perda de pressão para um microcanal com dimensões de $\mathrm{D}_{\mathrm{h}}=197 \mu \mathrm{m}, \mathrm{D}_{\text {eq }}=278,1 \mu \mathrm{m}$ e $\mathrm{L}=15 \mathrm{~mm}, \mathrm{R} 290, T_{\text {sat }}=25^{\circ} \mathrm{C}$, $G=400 \mathrm{~kg} / \mathrm{m}^{2} \mathrm{~s}$.

\section{(ii) Métodos fenomenológicos}

Cioncolini et al. (2009) desenvolveram um modelo fenomenológico para previsão de perda de pressão por atrito em padrão anular, dado pelas equações apresentadas na Tabela 2.3 . desenvolvimento deste método se baseou em um banco de dados contendo 3908 resultados experimentais obtidos para canais com dimensões características de macro e micro-escala. Os autores segregaram o escoamento segundo as seguintes regiões: (i) filme líquido e (ii) região central compreendendo a fase vapor e contendo gotículas dispersas. Desta forma, ao assumirem distribuição uniforme de pressão na seção de testes, os autores desenvolveram o modelo baseados apenas na região central, correlacionando o fator de atrito bifásico como funções do Número de Weber referido a região central do escoamento e o Número de Reynolds do filme líquido, visando capturar efeitos de ondulações na interface. Cioncolini et al. (2009) verificaram que o método proposto proporciona previsões satisfatórias dos dados utilizados no seu desenvolvimento tanto para condições do macro como micro-escala.

Segundo Da Silva (2012), o método de Cioncolini et al. (2009) previu satisfatoriamente seus dados experimentais correspondentes ao padrão anular. Neste contexto, vale destacar que o padrão anular se desenvolve rapidamente em condições de confinamento e torna-se dominante para diâmetros reduzidos. 
Tabela 2.3 - Parâmetros e equações para previsão de perda de pressão por atrito segundo o método de Cioncolini et al. (2009).

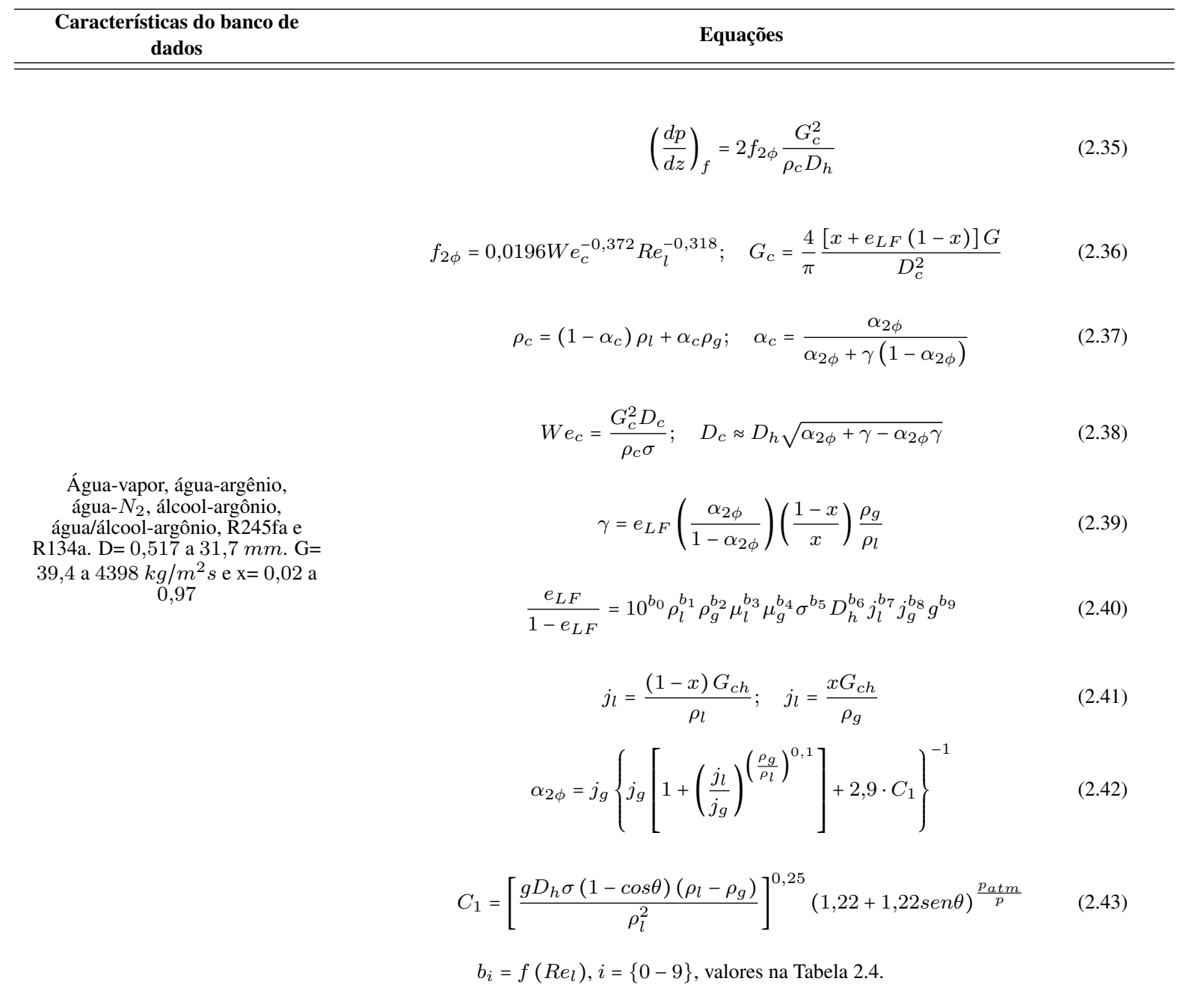

Tabela 2.4 - Parâmetros para estimar a fração de líquido dispersa no vapor segundo Oliemans et al. (1986).

\begin{tabular}{|c|c|c|c|c|c|c|c|c|c|c|}
\hline$R e_{l}$ & $b_{0}$ & $b_{1}$ & $b_{2}$ & $b_{3}$ & $b_{4}$ & $b_{5}$ & $b_{6}$ & $b_{7}$ & $b_{8}$ & $b_{9}$ \\
\hline Todos os valores & $-2,52$ & 1,08 & 0,18 & 0,27 & 0,28 & $-1,8$ & 1,72 & 0,7 & 1,44 & 0,46 \\
\hline $10^{2}-3 \times 10^{2}$ & $-0,69$ & 0,63 & 0,96 & $-0,8$ & 0,09 & $-0,88$ & 2,45 & 0,91 & $-0,16$ & 0,86 \\
\hline $3 \times 10^{2}-10^{2}$ & $-1,73$ & 0,94 & 0,62 & $-0,63$ & 0,5 & $-1,42$ & 2,04 & 1,05 & 0,96 & 0,48 \\
\hline $10^{3}-3 \times 10^{3}$ & $-3,31$ & 1,15 & 0,4 & $-1,02$ & 0,46 & -1 & 1,97 & 0,95 & 0,78 & 0,41 \\
\hline $3 \times 10^{3}-10^{4}$ & $-8,27$ & 0,77 & 0,71 & $-0,13$ & $-1,18$ & $-0,17$ & 1,16 & 0,83 & 1,45 & $-0,32$ \\
\hline $10^{4}-3 \times 10^{4}$ & $-6,38$ & 0,89 & 0,7 & $-0,17$ & $-0,55$ & $-0,87$ & 1,67 & 1,04 & 1,27 & 0,07 \\
\hline $3 \times 10^{4}-10^{5}$ & $-0,12$ & 0,45 & 0,25 & 0,86 & $-0,05$ & $-1,51$ & 0,91 & 1,08 & 0,71 & 0,21 \\
\hline
\end{tabular}

\section{(ii) Métodos baseados em multiplicadores bifásicos}

Lockhart e Martinelli (1949) foram pioneiros ao propor um modelo para previsão da perda de pressão baseado em multiplicadores bifásicos. Este método foi proposto com o intuito de correlacionar a perda de pressão por atrito do escoamento bifásico a partir do escoamento monofásico segundo as seguintes relações: 


$$
\begin{aligned}
\phi_{l}^{2} & =\frac{(d p / d z)_{2 \phi}}{(d p / d z)_{l}} \\
\phi_{g}^{2} & =\frac{(d p / d z)_{2 \phi}}{(d p / d z)_{g}}
\end{aligned}
$$

onde $(d p / d z)_{l}$ e $(d p / d z)_{g}$ são os gradientes de pressão da parcela de líquido ou gás escoando isoladamente através de um duto com a mesma dimensão. Na literatura também se definem multiplicadores bifásicos baseados na mistura gás-líquido escoando como uma das fases em um duto com as mesmas dimensões, dados pelas seguintes equações:

$$
\begin{aligned}
\phi_{l 0}^{2} & =\frac{(d p / d z)_{2 \phi}}{(d p / d z)_{l 0}} \\
\phi_{g 0}^{2} & =\frac{(d p / d z)_{2 \phi}}{(d p / d z)_{g 0}}
\end{aligned}
$$

O método de Lockhart e Martinelli (1949) foi proposto para canais convencionais, entretanto, procedimento similar é frequentemente utilizado para o desenvolvimento de métodos de previsão para condições de micro-escala. A partir dos multiplicadores bifásicos, definese também na literatura o parâmetro de Lockhart-Martinelli dado pela razão entre $\phi_{l}^{2}$ e $\phi_{g}^{2}$, assumindo escoamento turbulento para ambas fases e com o fator de atrito estimado segundo Blasius.

Posteriormente, baseado nos diagramas propostos por Lockhart e Martinelli (1949), Chisholm (1967) ajustou o método dado pelas Eqs. 2.48) e 2.49.

$$
\begin{aligned}
& \phi_{l}^{2}=1+\frac{C}{X}+\frac{1}{X^{2}} \\
& \phi_{g}^{2}=1+C X+X^{2}
\end{aligned}
$$

onde $\mathrm{C}$ é uma constante que depende dos regimes das fases do escoamento dadas na Tabela 2.5 .

Tabela 2.5 - Valores para a constante C de Chisholm $(1967)$.

\begin{tabular}{lccc}
\hline Parâmetro de Lockhart-Martinelli & Fase líquido & Fase gás & Constante C \\
\hline$X_{t t}$ & Turbulento & Turbulento & 20 \\
\hline$X_{l t}$ & Laminar & Turbulento & 12 \\
\hline$X_{t l}$ & Turbulento & Laminar & 10 \\
\hline$X_{l l}$ & Laminar & Laminar & 5 \\
\hline
\end{tabular}

De forma análoga ao parâmetro de Lockhart-Martinelli, Chisholm (1973) definiu o parâmetro " $\Gamma "$ dado pela razão dos multiplicadores $\phi_{l 0}^{2}$ e $\phi_{g 0}^{2}$. Este adimensional, relacionando 
propriedades de transporte das fases líquida e gás, foi incorporado ao seu método de previsão da perda de pressão por atrito indicado na Tabela 2.6 Posteriormente, Friedel (1979) incorporou efeitos inerciais, gravitacionais e tensão superficial através dos números adimensionais de Froude e Weber. Este método teve seu desenvolvimento baseado em um banco de dados experimentais contendo aproximadamente 25000 resultados.

Mishima e Hibiki (1996) foram pioneiros ao desenvolver um método para canais de diâmetro reduzido com base em multiplicadores bifásicos. Eles correlacionaram a contante $C$ de Chisholm (1967) como uma função do diâmetro hidráulico visando capturar efeitos relacionados ao confinamento do escoamento.

Métodos de previsão da perda de pressão por atrito para escoamentos bifásicos em microescala, baseados no ajuste de correlações para multiplicadores bifásicos utilizando bancos de dados extensos são frequentes na literatura. Parcela destes métodos incorpora adimensionais buscando caracterizar efeitos de confinamento.

A Tabela 2.6 apresenta, em ordem cronológica de proposição, os métodos para a previsão da perda de pressão por atrito baseados em multiplicadores bifásicos. De acordo com esta tabela, Tran et al. (2000), Hwang e Kim (2006), Megahed e Hassan (2009), Zhang et al. (2010), Li e $\mathrm{Wu}$ (2011) incluíram o Número de Confinamento no desenvolvimento de seus métodos.

Zhang e Webb (2001) incluíram os efeitos da pressão reduzida para avaliar o desempenho de três refrigerantes escoando em canais de alumínio e cobre. Del Col et al. (2013) foram os únicos a incluírem o efeito da rugosidade. Por outro lado, parcela significativa dos métodos foram desenvolvidos com base em resultados para canais únicos. Sun e Mishima (2009), Zhang et al. (2010), Li e Wu (2011) e Kim e Mudawar (2012) desenvolveram seus métodos para condições adiabáticas e incluíram dados para multi-canais para estimar as constantes experimentais de cada correlação. Qu e Mudawar (2003a), Lee e Mudawar (2005a), Lee e Garimella (2008) e Megahed e Hassan (2009) embora incluam dados para evaporação em multicanais, desenvolveram seus métodos para condições diabáticas. Neste caso, os problemas de discrepância se acentuam e não é surpresa que os métodos não se adequem para base de dados independentes.

Tabela 2.6 - Métodos de perda de pressão por atrito baseados em multiplicadores bifásicos

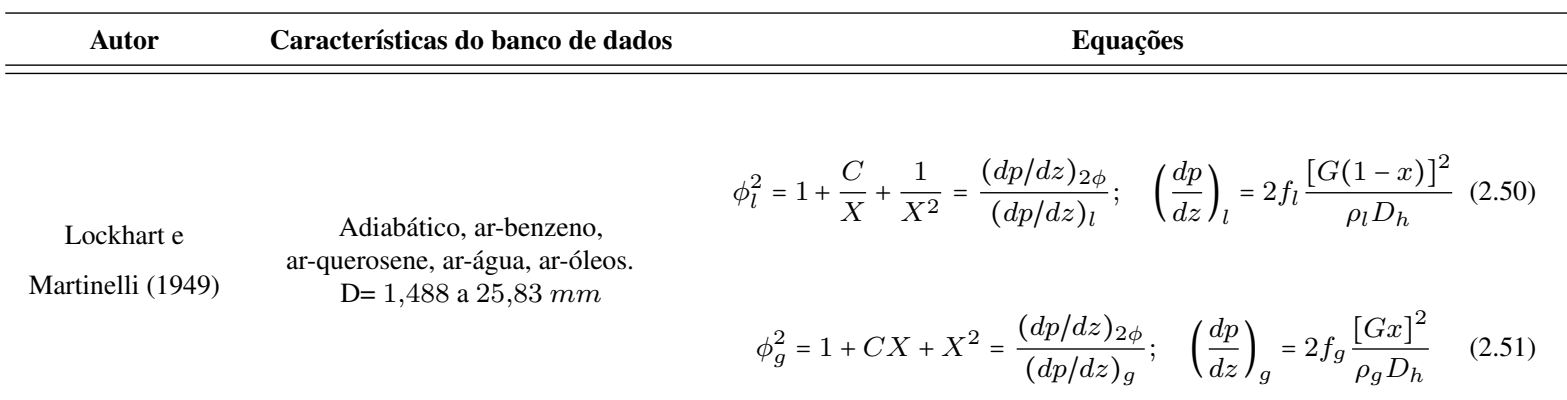


Tabela 2.6 (continuação). Métodos de perda de pressão por atrito baseados em multiplicadores bifásicos.

\begin{tabular}{|c|c|c|}
\hline Autor & $\begin{array}{l}\text { Características do banco de } \\
\text { dados }\end{array}$ & Equações \\
\hline \multirow{3}{*}{ Chisholm 1973 } & & $\phi_{l}^{2}=\frac{(d p / d z)_{2 \phi}}{(d p / d z)_{l o}}=1+\left(\Gamma^{2}-1\right)\left(B x^{\frac{2-n}{2}}(1-x)^{\frac{2-n}{2}}+x^{2-n}\right)$ \\
\hline & $\begin{array}{l}\text { Adiabático, água-ar, } \mathrm{D}=27 \mathrm{~mm} \text { e } \\
\mathrm{G}=190 \text { a } 6770 \mathrm{~kg} / \mathrm{m}^{2} \mathrm{~s}\end{array}$ & $\begin{aligned} \Gamma=\frac{(d p / d z)_{g o}}{(d p / d z)_{l o}} & =\left(\frac{v_{g}}{v_{l}}\right)^{0,5}\left(\frac{\mu_{g}}{\mu_{l}}\right)^{0,5} \\
n & =0,25\end{aligned}$ \\
\hline & & $\begin{array}{c}B=4,8=>(\Gamma \leq 9,5 \text { e } G \leq 500), \\
B=2400 / G=>(\Gamma \leq 9,5 \text { e } 500<G<1900), \\
B=55 / G^{0,5}=>(\Gamma \leq 9,5 \text { e } G \geq 1900), \\
B=520 /\left(\Gamma G^{0,5}\right)=>(9,5<\Gamma<28 \text { e } G \leq 600), \\
B=21 / \Gamma \Rightarrow(9,5<\Gamma<28 \text { e } G>600), \\
B=15000 /\left(\Gamma^{2} G^{0,5}\right) \Rightarrow(\Gamma \leq 28)\end{array}$ \\
\hline
\end{tabular}

$$
\begin{gathered}
\phi_{l o}^{2}=C_{2} \frac{\left(3,24 C_{3} C_{4}\right)}{F r_{2 \phi}^{0,045} W e_{2 \phi}^{0,035}} \\
C_{2}=(1-x)^{2}+x^{2}\left(\frac{\rho_{l} f_{g}}{\rho_{g} f_{l}}\right) ; \quad C_{3}=x^{0,78}(1-x)^{0,224} \\
C_{4}=\left(\frac{\rho_{l}}{\rho_{g}}\right)^{0,91}\left(\frac{\mu_{g}}{\mu_{l}}\right)^{0,19}\left(1-\frac{\mu_{g}}{\mu_{l}}\right)^{0,7} \\
F r_{2 \phi}=\frac{G^{2}}{g D_{h} \bar{\rho}^{2}} ; \quad W e_{2 \phi}=\frac{G^{2} D_{h}}{\bar{\rho} \sigma} \\
\bar{\rho}=\frac{1}{x v_{g}+(1-x) v_{l}}
\end{gathered}
$$

Adiabático, padrão anular, relação

Friedel (1979) de viscosidades $\mu_{l} / \mu_{g}$ inferiores a 1000 e x entre 0 e 1 .

$$
\phi_{l}^{2}=1+\frac{C}{X_{v v}}+\frac{1}{X_{v v}^{2}}
$$

Mishima e Hibiki Adiabático. água-ar, $\mathrm{D}=1$ a $4 \mathrm{~mm}$ (1996)

$$
\begin{gathered}
C=21\left(1-e^{-0,319 D_{h}}\right) \quad \text { para seção retangular } \\
C=21\left(1-e^{-0,333 D_{h}}\right) \quad \text { para seção circular } \\
X_{l l}=\left(\frac{\mu_{l}}{\mu_{g}}\right)^{0,5}\left(\frac{1-x}{x}\right)^{0,5}\left(\frac{v_{l}}{v_{g}}\right)^{0,5}
\end{gathered}
$$

$$
\begin{gathered}
\phi_{l}^{2}=1+\left(4,3 \Gamma^{2}-1\right)\left[\operatorname{Cox}^{0,875}(1-x)^{0,875}+x^{1,75}\right] \\
\Gamma=\left(\frac{\mu_{g}}{\mu_{f}}\right)^{0,5}\left(\frac{v_{g}}{v_{f}}\right)^{0,5}
\end{gathered}
$$$$
\phi_{l}^{2}=(1-x)^{2}+2,87 x^{2} p_{r}^{-1}+1,68 x^{0,8}(1-x)^{0,25} p_{r}^{-1,64}
$$

Adiabático, ar-água. $\mathrm{D}=0,78$ e

$$
\phi_{l}^{2}=1+\frac{C}{X_{l t}}+\frac{1}{X_{l t}^{2}}
$$

Lee e Lee 2001b)

$$
\mathrm{kg} / \mathrm{m}^{2} \mathrm{~s} \text {. Parâmetro de }
$$

$$
X_{l t}=\left(\frac{f_{l} R e_{g}^{0,25}}{0,079}\right)^{0,5}\left(\frac{1-x}{x}\right)^{0,5}\left(\frac{v_{l}}{v_{g}}\right)^{0,5}
$$


Tabela 2.6 (continuação). Métodos de perda de pressão por atrito baseados em multiplicadores bifásicos.

$$
\phi_{l}^{2}=\frac{1}{X_{l t}^{1,9}}
$$

$k P a, \mathrm{D}=2,98 \mathrm{~mm}, \mathrm{~L}$ aquecido $0,91 \mathrm{~m} \mathrm{e}$ $\mathrm{G}=50$ a $200 \mathrm{~kg} / \mathrm{m}^{2} \mathrm{~s}$.

$$
X_{l t}=\left(\frac{f_{l} R e_{g}^{0,2}}{0,046}\right)^{0,5}\left(\frac{1-x}{x}\right)^{0,5}\left(\frac{v_{l}}{v_{g}}\right)^{0,5}
$$

Qu e Mudawar (2003a)

Diabático, água, 21 microcanais paralelos de $231 \times 713 \mu m$ e $\mathrm{G}=134,9$ a 400,1 $\mathrm{kg} / \mathrm{m}^{2} \mathrm{~s}$.

$$
\begin{gathered}
\phi_{l}^{2}=1+\frac{C}{X_{l l}}+\frac{1}{X_{l l}^{2}} \\
C=21\left[1-e^{\left(-319 D_{h}\right)}\right](0,00418 G+0,0613) \\
X_{l l}=\left(\frac{\mu_{l}}{\mu_{g}}\right)^{0,5}\left(\frac{1-x}{x}\right)^{0,5}\left(\frac{v_{l}}{v_{g}}\right)^{0,5}
\end{gathered}
$$

Diabático, $R 134 a, 21$ microcanais paralelos de $231 \times 713 \mu \mathrm{m}, \mathrm{G}=127$ a 654 $\mathrm{kg} / \mathrm{m}^{2} \mathrm{~s}, q^{\prime \prime}=316$ a $938 \mathrm{~kW} / \mathrm{m}^{2}$ e títulos

$$
\begin{gathered}
\phi_{l}^{2}=1+\frac{C}{X}+\frac{1}{X^{2}} \\
C_{l l}=2,16 R e_{l}^{0,047} W e_{l}^{0,60} ; \quad C_{l t}=1,45 R e_{l}^{0,25} W e_{l}^{0,23}
\end{gathered}
$$

$$
\text { de vapor de } 0,001 \text { a } 0,25 \text {. }
$$

\begin{tabular}{|c|c|c|c|}
\hline$\frac{\text { Lee e Garimella }}{(2008)}$ & $\begin{array}{c}\text { Diabático, água deionizada, } 60,35,24 \text { e } 10 \\
\text { microcanais retangulares paralelos com } \\
\qquad D_{h}=162,5 \text { a } 570,9 \mu \mathrm{m} .\end{array}$ & $\begin{array}{c}\phi_{l}^{2}=1+\frac{C}{X_{l l}}+\frac{1}{X_{l l}^{2}} \\
C=2566 G^{0,5466} D_{h}^{0,8819}\left(1-e^{-319 D_{h}}\right)\end{array}$ & (2.80) \\
\hline$\frac{\text { Megahed e Hassan }}{2009}$ & $\begin{array}{c}\text { Diabático, } F C-72,10 \text { microcanais } \\
\text { retangulares paralelos com } D_{h}=247,9 \mu \mathrm{m}, \\
\mathrm{G}=341 \text { a } 531 \mathrm{~kg} / \mathrm{m}^{2} \mathrm{~s} \text { e } q^{\prime \prime}=60,4 \text { a } 130,6 \\
\mathrm{~kW} / \mathrm{m}^{2}\end{array}$ & $\begin{array}{c}\phi_{l}^{2}=1+\frac{C}{X}+\frac{1}{X^{2}} \\
C_{l l}=\frac{0,0053 R e_{l}^{0,934}}{C o^{0,7} X^{0,350}} \\
C_{l t}=\frac{0,0002 R e_{l}^{1,7}}{C o^{0,7} X^{2,48}}\end{array}$ & $\begin{array}{l}(2.82) \\
(2.83)\end{array}$ \\
\hline $\begin{array}{c}\text { Sun e Mishima } \\
(2009)\end{array}$ & $\begin{array}{l}2092 \text { pontos adiabáticos e diabáticos, } \\
R 123, R 134 a, R 22, R 236 e a, R 245 f a \\
R 404 a, R 407 C, R 410 a, R 507, C O_{2}, \\
\text { água e ar. } D_{h}=0,506 \text { a } 12 \mathrm{~mm}, R e_{l} \text { de } 10 \\
\text { a } 37000 \text { e } R e_{g} \text { de } 3 \text { a } 400000\end{array}$ & $\begin{array}{c}\phi_{l}^{2}=1+\frac{C}{X}+\frac{1}{X^{2}} \\
C=1,79\left(\frac{R e_{g}}{R e_{l}}\right)^{0,4}\left(\frac{1-x}{x}\right)^{0,5}\end{array}$ & $\begin{array}{l}(2.84) \\
(2.85)\end{array}$ \\
\hline Zhang et al. (2010) & $\begin{array}{l}2201 \text { pontos adiabáticos, ar- } N_{2} \text {-água, } \\
\text { ar-etanol, amônia e refrigerantes } \\
\text { halogenados. } D_{h}=0,07 \text { a } 6,25 \mathrm{~mm}\end{array}$ & $\begin{array}{c}\phi_{l}^{2}=1+\frac{C}{X}+\frac{1}{X^{2}} \\
C=21\left[e^{\left(\frac{-0,674}{C o}\right)}\right] \quad \text { líquido+gás } \\
C=21\left[e^{\left(\frac{-0,0,142}{C o}\right)}\right] \quad \text { com mudança de fase }\end{array}$ & $\begin{array}{l}(2.87) \\
(2.88)\end{array}$ \\
\hline
\end{tabular}

Adiabático, $R 134 a, \mathrm{D}=0,244,0,430 \mathrm{e}$ $0,792 \mathrm{~mm}, \mathrm{G}=140$ a $950 \mathrm{~kg} / \mathrm{m}^{2} \mathrm{~s}$ e

$$
\phi_{l}^{2}=1+\frac{C}{X}+\frac{1}{X^{2}}
$$

Hwang e Kim 2006 $\mathrm{X}=0,08$ a 0,95 .

$$
C=0,227 R e_{l o}^{0,452} X^{-0,32} C o^{-0,82}
$$




\begin{tabular}{|c|c|c|c|}
\hline Autor & $\begin{array}{l}\text { Características do banco de } \\
\text { dados }\end{array}$ & Equações & \\
\hline \multirow{4}{*}{ Li e Wu 2011 } & \multirow{4}{*}{$\begin{array}{l}769 \text { pontos adiabáticos, } R 290 \text {, } \\
R 717 \text {, nitrogênio e refrigerantes } \\
\text { halogenados. } D_{h}=0,148 \text { a } 3,25 \\
m m\end{array}$} & $\phi_{l}^{2}=1+\frac{C}{X}+\frac{1}{X^{2}}$ & $(2.89)$ \\
\hline & & $C=11,9 C o^{-0,9} \quad$ para $\quad C o \geq 0,816$ & $(2.90)$ \\
\hline & & $C=109,4\left(C o^{-2} R e_{l}^{0,5}\right)^{-0,56}$ & $(2.91)$ \\
\hline & & para $0,302 \leq C o<0,816$ & \\
\hline
\end{tabular}

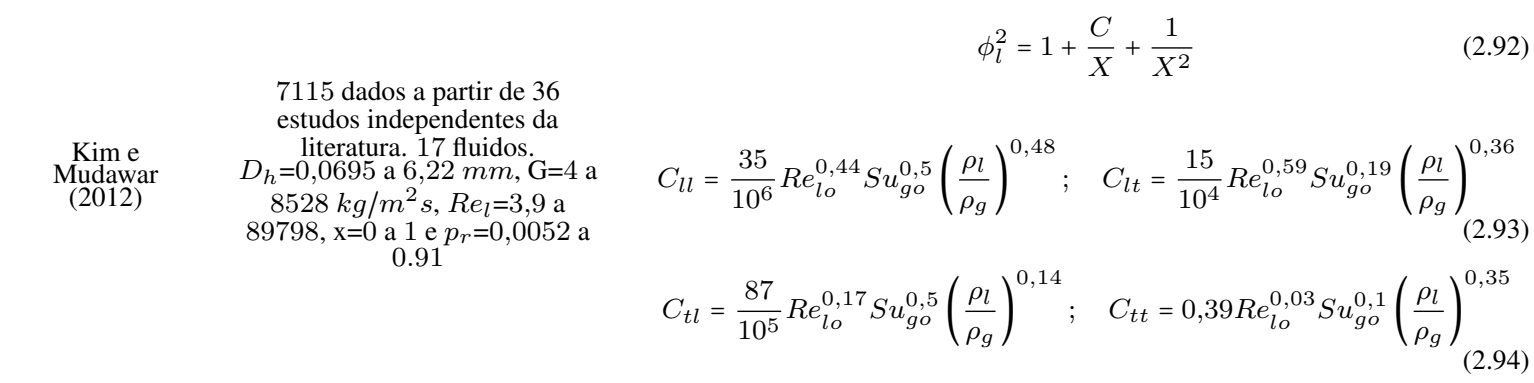

$$
\begin{gathered}
\phi_{l o}^{2}=Z+3,595 \cdot F \cdot H \cdot(1-E)^{W} \\
Z=(1-x)^{2}+x^{2}\left(\frac{\rho_{l}}{\rho_{g}}\right)\left(\frac{\mu_{g}}{\mu_{l}}\right)^{0,2} ; \quad F=(1-x)^{0,9525}+x^{0,414} \\
H=\left(\frac{\rho_{l}}{\rho_{g}}\right)^{1,132}\left(\frac{\mu_{g}}{\mu_{l}}\right)^{0,44}\left(1-\frac{\mu_{g}}{\mu_{l}}\right)^{3,542} ; \quad W=1,398 p_{r} \\
\quad E=0,015+0,44 \log _{10}\left[\frac{\rho_{g c}}{\rho_{l}}\left(\mu_{l} \frac{j_{l}}{\sigma}\right)^{2} 10^{4}\right] \\
\left(\frac{d p}{d z}\right)_{l o}=f_{l o} \frac{2 G^{2}}{\rho_{l} D_{h}} ; \quad f_{l o}=0,046\left(R e_{l o}\right)^{-0,2}+0,7 R R \\
\rho_{g c}=\frac{x+(1-x) E}{\frac{x}{\rho_{g}}+\left(\frac{1-x}{\rho_{l}}\right) E} ; \quad R R=2 \frac{R a}{D_{h}} ; \quad R a: \text { Se rugosidade média }
\end{gathered}
$$

A análise apresentada permite concluir que a maioria dos métodos levantados na literatura teve seu desenvolvimento baseado para escoamentos bifásicos em canais únicos. Métodos baseados em dados para multi-canais se verificam para alguns deles que incluem apenas dados para o ajuste de constantes experimentais. Desta forma, pela ausência de dados para multicanais no banco de dados utilizados pelos autores no desenvolvimento de métodos de previsão, efeitos inerentes a estas geometrias como efeitos de interação entre os canais, instabilidades térmicas e geometria dos plenums não têm sido aplicadas no desenvolvimento de métodos de previsão.

Finalmente, vale destacar que apesar dos autores terem utilizados bancos de dados extensos no desenvolvimento de seus métodos de previsão, apenas Sempértegui-Tapia e Ribatski (2016) incluem resultados para $\mathrm{R} 600 \mathrm{a}$ e $\mathrm{Li}$ e $\mathrm{Wu}$ (2011) para $\mathrm{R} 290$. 


\subsubsection{TRANSFERÊNCIA DE CALOR EM MICROCANAIS ÚNICOS}

É fato na literatura que as teorias desenvolvidas para escoamentos monofásicos em canais convencionais se aplicam a microcanais, conforme ressaltado por Morini (2004). Diferenças quando observadas decorrem de erros experimentais, processos de regressão de dados inadequados e pela desconsideração de mecanismos relevantes, como é o caso de efeitos conjugados de condução e convecção forçada. Por outro lado, no caso da transferência de calor por meio do mecanismo de ebulição convectiva comportamentos distintos são verificados em condições de micro e macro-escala. Além disso, resultados conflitantes se verificam ainda que consideradas apenas condições de micro-escala e, segundo Tibiriçá e Ribatski (2013), apenas recentemente autores têm concordado a respeito dos mecanismos de transferência de calor predominantes e dos comportamentos para o coeficiente de transferência de calor (CTC) com a variação de parâmetros experimentais.

De acordo com Thome (2008), durante a ebulição convectiva em condições de micro-escala, efeitos de gravidade tem sua importância relativa reduzida, enquanto aqueles relacionados a tensão superficial se elevam.

Parcela significativa dos resultados conflitantes entre os autores se devem, principalmente, a condições de instabilidades, inerentes ao escoamento bifásico em condições confinadas. Desta forma, coeficientes de transferência de calor distintos são obtidos ao realizar ensaios sob condições estáveis e na presença de instabilidades térmicas. No caso da ebulição estável, a superfície do canal se molha completamente postergando a secagem de parede para títulos de vapor elevados. Desta forma, o coeficiente de transferência de calor aumenta com o aumento do título de vapor. No entanto, no caso da ebulição em condições de instabilidades térmicas, a temperatura local da superfície do canal pode apresentar flutuações com elevadas amplitudes. Sob estas condições o filme líquido pode apresentar secagem intermitente ou romper-se, ainda que para títulos de vapor reduzidos, e consequentemente, o CTC decresce com o incremento do título de vapor.

A Figura 2.9 ilustra esquematicamente diferentes comportamentos para o coeficiente de transferência de calor com a variação de parâmetros experimentais indicados por Ribatski (2013) com base em análise da literatura. De acordo com o autor, o coeficiente de transferência de calor apresenta um comportamento definido na região a montante da secagem da parede, elevando-se com o aumento da temperatura de saturação e o decréscimo do diâmetro do tubo. Além disso, a maioria dos estudos concordam em que o incremento da velocidade mássica (i.a) e do fluxo de calor (ii.a) resultam no aumento do coeficiente de transferência de calor.

Neste contexto, diversos métodos de previsão para o coeficiente de transferência de calor têm sido propostos. Visando reportar uma descrição organizada destes métodos, uma análise é efetuada e as equações principais dos métodos são apresentadas em tabelas analogamente como foi efetuado na seção de perda de pressão. 


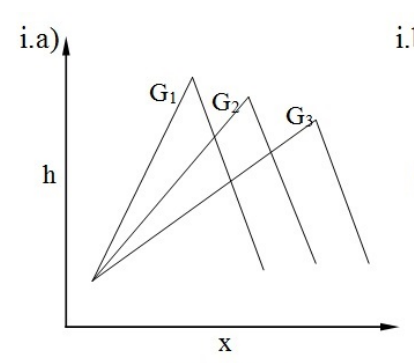

$\mathrm{G}_{1}>\mathrm{G}_{2}>\mathrm{G}_{3}$

h se eleva com $\mathrm{G}$ e a secagem de parede ocorre para títulos inferiores com $o$ incremento de $\mathrm{G}$

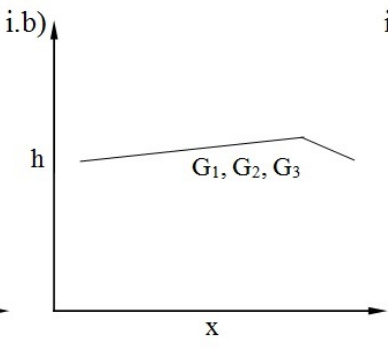

$\mathrm{G}_{1}>\mathrm{G}_{2}>\mathrm{G}_{3}$

$\mathrm{h}$ é aproximadamente independente de $\mathrm{G}$ e $\mathrm{x}$ até que condições de secagem de parede sejam alcançadas

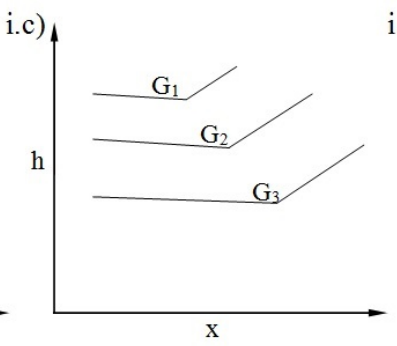

$\mathrm{G}_{1}>\mathrm{G}_{2}>\mathrm{G}_{3}$

h se eleva com $\mathrm{G}$ e apresenta um platô em títulos reduzidos e se eleva com $x$ para $\mathrm{x}$ elevados

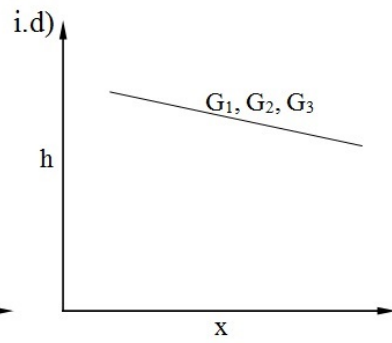

$\mathrm{G}_{1}>\mathrm{G}_{2}>\mathrm{G}_{3}$

$\mathrm{h}$ é aproximadamente independente de $\mathrm{G}$ e seu valor decresce com o incremento de $\mathrm{x}$
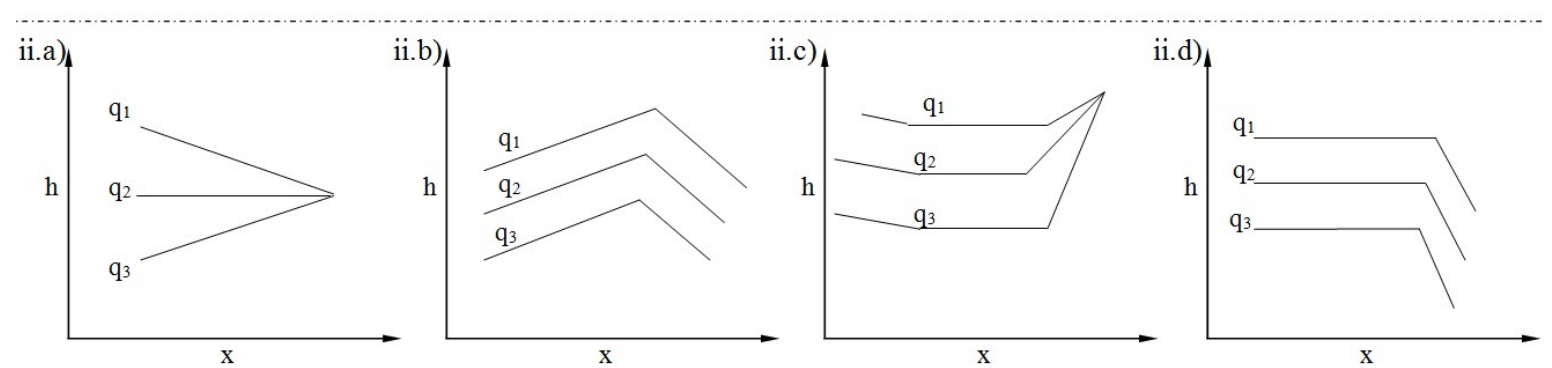

$\mathrm{q}_{1}>\mathrm{q}_{2}>\mathrm{q}_{3}$

$\mathrm{q}_{1}>\mathrm{q}_{2}>\mathrm{q}_{3}$

$\mathrm{q}_{1}>\mathrm{q}_{2}>\mathrm{q}_{3}$

$\mathrm{q}_{1}>\mathrm{q}_{2}>\mathrm{q}_{3}$

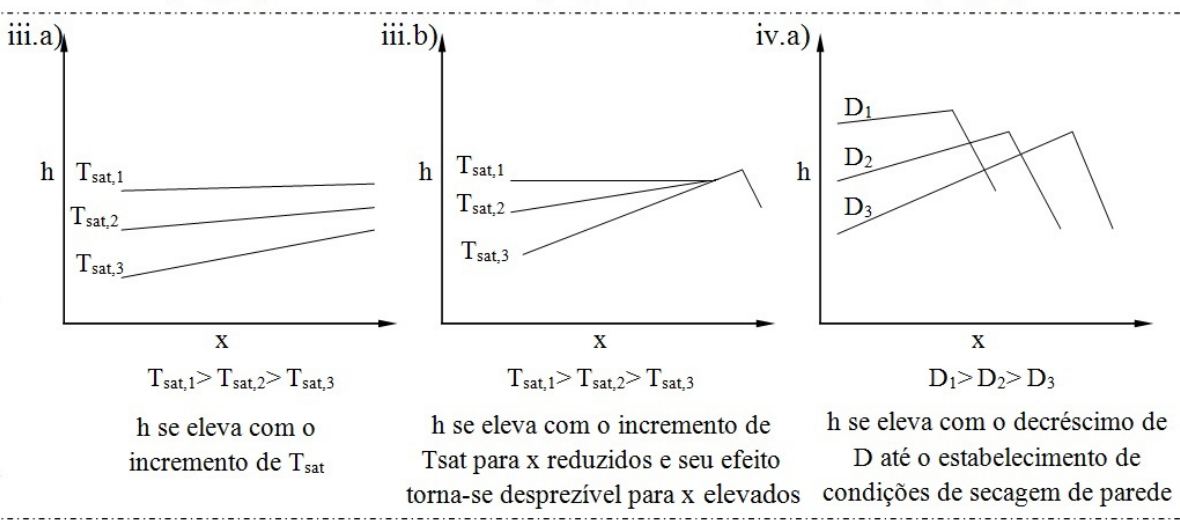

Figura 2.9 - Ilustração esquemática dos comportamentos indicados na literatura para o coeficiente de transferência de calor durante a ebulição convectiva em canais de diâmetro reduzido. Tendências indicadas por Ribatski (2013).

Os métodos para previsão do coeficiente de transferência de calor durante a ebulição convectiva podem ser classificados da seguinte forma: (i) métodos empíricos: consistem em funções baseadas em números adimensionais ajustadas a um banco de dados experimentais; (ii) métodos baseados na superposição de efeitos de ebulição nucleada e convectiva: consistem na adição dos efeitos convectivos e de ebulição nucleada, ponderados por fatores de intensificação de efeitos convectivos e supressão da nucleação de bolhas; (iii) métodos fenomenológicos: consistem em métodos analíticos visando estimar o coeficiente de transferência de calor para um determinado padrão de escoamento.

A seguir são descritos alguns métodos para previsão do coeficiente de transferência de calor durante a ebulição convectiva desenvolvidos para microcanais. Métodos propostos para canais convencionais, frequentemente aplicados na literatura para canais de diâmetro reduzido, também são descritos. 


\section{(i) Métodos empíricos}

A Tabela 2.7 apresenta, segundo ordem cronológica de proposição, os métodos empíricos desenvolvidos para previsão do coeficiente de transferência de calor durante a ebulição convectiva. Nela indicam-se as condições experimentais considerada no desenvolvimento e as equações que compõem os métodos. As bases de dados utilizadas para o desenvolvimento destes métodos envolvem escoamentos horizontais e verticais ascendentes e descendentes, ebulição convectiva de água, refrigerantes halogenados, misturas de fluido e uma parcela reduzida incluindo dados para hidrocarbonetos. Os métodos se baseiam em resultados para pressões de operação de 0,1034 a 17,237 $M P a$, velocidades mássicas de 10 a $8179 \mathrm{~kg} / \mathrm{m}^{2} \mathrm{~s}$, fluxos de calor de até $2280 \mathrm{~kW} / \mathrm{m}^{2}$ e títulos de vapor entre 0 a 1,0. Em particular, nesta tabela, alguns métodos foram desenvolvidos com base na correlação de Dittus Boelter para convecção forçada. Já os métodos Shah (1976) e Kandlikar (1990) foram desenvolvidos para canais convencionais.

Em geral, a maioria dos métodos empíricos levantados da literatura, se baseiam na combinação de adimensionais de forma a capturar, principalmente, efeitos inerciais, de ebulição, confinamento, tensão superficial, gravitacionais e convectivos. A partir de resultados experimentais, ajustam-se coeficientes e exponentes a estes adimensionais obtendo-se uma correlação, cuja abrangência depende da amplitude do banco de dados utilizado em seu desenvolvimento.

Shah (1976) desenvolveu um método que inclui os números de Froude, visando incluir efeitos de estratificação, e o número de Bond relacionando efeitos gravitacionais e de tensão superficial. Baseado neste método, Kandlikar (1990) ajustou novas constantes para um banco de dados mais extenso e incluiu um parâmetro para ponderar o efeito do fluido. Posteriormente, Kandlikar e Balasubramanian (2004) desenvolveram uma extensão do seu método desprezando a estratificação visando a aplicação em microcanais.

Lazarek e Black (1982) foram pioneiros ao desenvolver um método empírico para previsão do coeficiente de transferência de calor em canais de diâmetro reduzido. Os autores incluíram o Número Reynolds do líquido e o Número de Bond, neste caso visando capturar efeitos relacionados as forças de gravidade e de confinamento. Posteriormente, Tran et al. (1996) propuseram uma correlação similar relacionando efeitos inerciais e de tensão superficial através do Número de Webber. Yu et al. (2002) ajustaram novos coeficientes e exponentes para a correlação inicialmente proposta por Tran et al. (1996).

Yun et al. (2006) desenvolveram um método para previsão do coeficiente de transferência de calor visando incluir os efeitos combinados de confinamento, forças inerciais e ondulações na interface incluindo os números de Bond, Reynolds e Webber do líquido, respectivamente. Posteriormente, baseado neste método, Li e Wu (2010) ajustaram novos coeficientes e exponentes incluindo o número de Ebulição para capturar o efeito de nucleação de bolhas sobre o escoamento. 
Tabela 2.7 - Métodos empíricos para previsão do coeficiente de transferência de calor em ebulição convectiva.

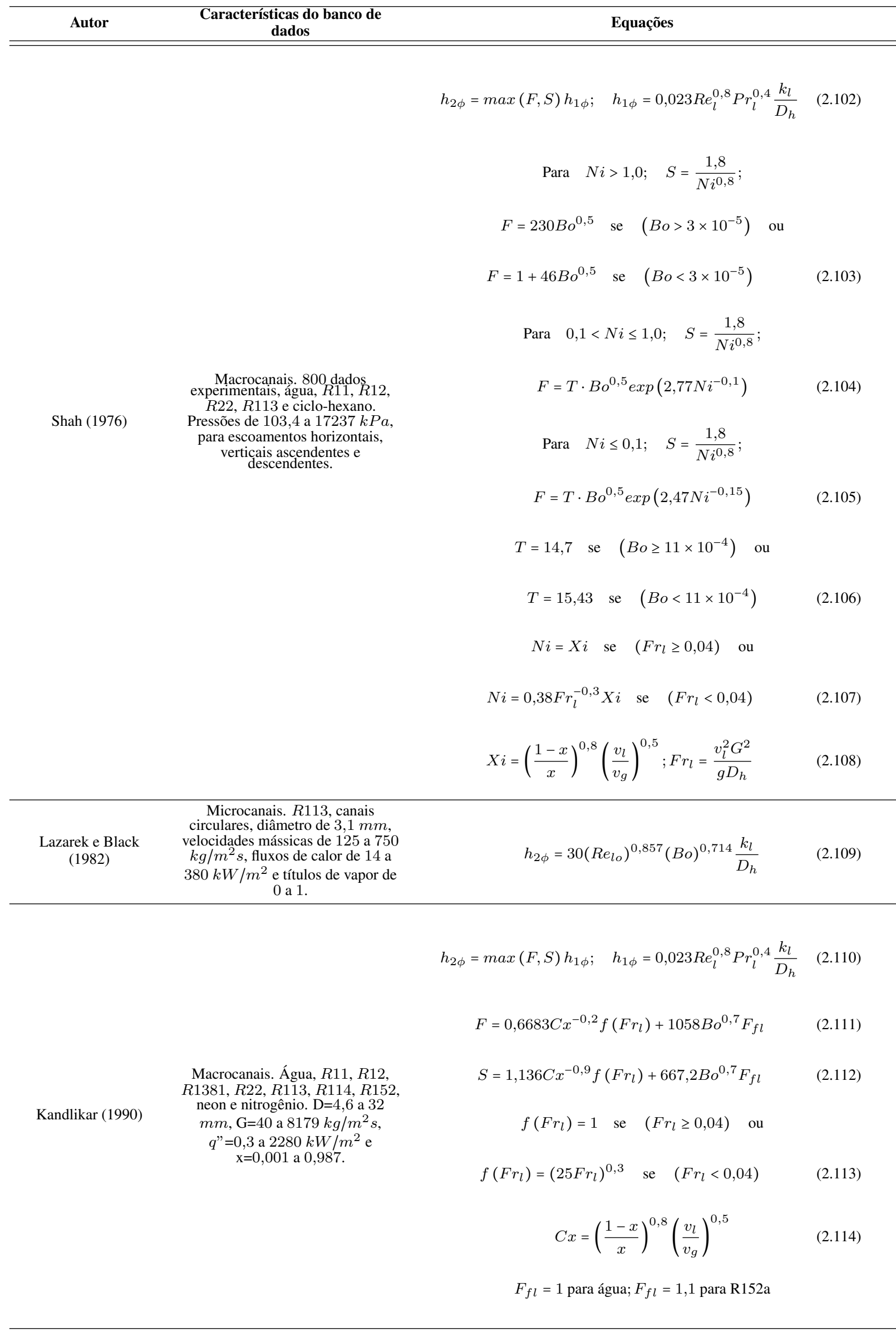


Tabela 2.7 (continuação). Métodos empíricos para previsão do coeficiente de transferência de calor em ebulição convectiva.

\begin{tabular}{|c|c|c|c|}
\hline Autor & $\begin{array}{l}\text { Características do banco de } \\
\text { dados }\end{array}$ & Equações & \\
\hline Tran et al. (1996) & $\begin{array}{l}\text { Microcanais. } R 12 . \text { Canais } \\
\text { retangulares e circulares, } \\
D_{h}=2,4 \text { e } 4,6 \mathrm{~mm}, \mathrm{G}=44 \text { a } \\
832 \mathrm{~kg} / \mathrm{m}^{2} s, q^{\prime \prime}=36 \text { a } 1290 \\
\mathrm{~kW} / \mathrm{m}^{2} \text { e x=0 a } 0,94 .\end{array}$ & $h_{2 \phi}=8,4 \times 10^{5}\left(B o^{2} W e_{l}\right)^{0,3}\left(\frac{v_{g}}{v_{l}}\right)^{-0,4}$ & $(2.115)$ \\
\hline$\frac{\text { Kew e Cornwell }}{1 \text { (1997) }}$ & $\begin{array}{c}\text { Microcanais. } R 141 \mathrm{~b} \text {. Canais } \\
\text { circulares, } \mathrm{D}=1,39 \text { a } 3,69 \\
m m, \mathrm{G}=188 \text { a } 1480 \mathrm{~kg} / \mathrm{m}^{2} \mathrm{~s} \\
q^{\prime \prime}=9,7 \text { a } 90 \mathrm{~kW} / \mathrm{m}^{2} \text { e x=0 a } \\
0,95 .\end{array}$ & $h_{2 \phi}=30 R e_{l}^{0,857} B o^{0,714} \frac{k_{l}}{D_{h}}(1-x)^{-0,143}$ & $(2.116)$ \\
\hline & & $h_{2 \phi}=\left(C_{1} C_{o}^{C_{2}}+C_{3} B_{o}^{C_{4}} F r_{l o}\right)(1-\bar{x})^{0,8} h_{l}$ & (2.117) \\
\hline \multirow[t]{3}{*}{ Yan e Lin 1998) } & $\begin{array}{l}\text { Microcanais. } R 134 a .28 \\
\text { canais circulares, } \mathrm{D}=2,0 \mathrm{~mm} \\
\mathrm{G}=50 \text { a } 200 \mathrm{~kg} / \mathrm{m}^{2} s, q^{\prime \prime}=5,0 \\
\text { a } 20 \mathrm{~kW} / \mathrm{m}^{2} \text { e x=0,1 a } 0,9 .\end{array}$ & $C_{o}=\left(\frac{1-\bar{x}}{\bar{x}}\right)^{0,8}\left(\frac{\rho_{g}}{\rho_{l}}\right)^{0,5} ; \quad h_{l}=4,364 \frac{D_{h}}{k_{l}}$ & $(2.118)$ \\
\hline & & $C_{m}=C_{m, 1} \operatorname{Re}_{l}^{C_{m, 2}} T_{r}^{C_{m, 3}} ; \quad m=\{1-4\}$ & $(2.119)$ \\
\hline & & $C_{m, 1}, C_{m, 2}$ e $C_{m, 3}:$ em Tabela 2.8 & \\
\hline
\end{tabular}

$$
\begin{aligned}
& h_{2 \phi}=F \cdot h_{1 \phi} \\
& h_{1 \phi}=N u_{4} \frac{k_{l}}{D_{h}} ; \quad F=10,3 \zeta^{0,398} \phi_{l}^{0,598} \\
& \phi_{l}=\left(1+\frac{C}{X_{v t}}+\frac{1}{X_{v t}^{2}}\right)^{0,5} ; \quad C=6,185 \times 10^{-2} R_{l o}^{0,726} \\
& X_{v t}=\left(\frac{f_{l}}{f_{g}}\right)^{0,5}\left(\frac{1-x}{x}\right)\left(\frac{v_{l}}{v_{g}}\right)^{0,5} \\
& f_{l}=\frac{24}{R e_{l}}\left(1-1,355 \zeta+1,947 \zeta^{2}-1,701 \zeta^{3}+0,956 \zeta^{4}-0,254 \zeta^{5}\right) \\
& f_{g}=\frac{0,079}{R e_{g}^{0,25}} ; \quad R e_{g}=\frac{G x D_{h}}{\mu_{g}} ; \quad \zeta=\frac{W_{c h}}{H_{c h}} \\
& N u_{4}=8,234\left(1-2,042 \zeta+3,085 \zeta^{2}-2,477 \zeta^{3}+1,058 \zeta^{4}-0,186 \zeta^{5}\right)
\end{aligned}
$$

\begin{tabular}{|c|c|}
\hline Yu et al. (2002) & $\begin{array}{c}\text { Método desenvolvido para } \\
\text { microcanais. Fluido usado: } \\
\text { água-etilenoglycol. Canais } \\
\text { circulares, diâmetro de } 2,98 \\
m m \text {, velocidades mássicas de } \\
50 \text { a } 200 \mathrm{~kg} / \mathrm{m}^{2} \mathrm{~s} \text {, fluxos de } \\
\text { calor de } 100 \text { a } 300 \mathrm{~kW} / \mathrm{m}^{2} \text { e } \\
\text { títulos de vapor de } 0 \text { a } 1,0 \text {. }\end{array}$ \\
\hline$\frac{\text { Warrier et al. }}{(2002)}$ & $\begin{array}{l}\text { Método desenvolvido para } \\
\text { microcanais. Fluido usado: } \\
F C 84 \text {. } 5 \text { canais retangulares, } \\
\text { diâmetro hidráulico de } 0,75 \\
m \mathrm{~m} \text {, velocidades mássicas de } \\
557 \text { a } 1600 \mathrm{~kg} / \mathrm{m}^{2} \mathrm{~s} \text {, fluxos } \\
\text { de calor de } 0 \text { a } 59,9 \mathrm{~kW} / \mathrm{m}^{2} \mathrm{e} \\
\text { títulos de vapor de } 0,03 \text { a } 0,5 \text {. }\end{array}$ \\
\hline
\end{tabular}

$$
h_{2 \phi}=6,4 \times 10^{6}\left(B o^{2} W e_{l}\right)^{0,24}\left(\frac{v_{g}}{v_{l}}\right)^{-0,2}
$$
títulos de vapor de 0,03 a 0,5 .

$$
\begin{gathered}
h_{2 \phi}=F \cdot h_{1 \phi} \\
h_{1 \phi}=N u_{4} \frac{k_{l}}{D_{h}} ; \quad F=1,0+6 B o^{1 / 16}+f(B o) x^{0,65} \\
f(B o)=-5,3(1-855 B o)
\end{gathered}
$$


Tabela 2.7 (continuação). Métodos empíricos para previsão do coeficiente de transferência de calor em ebulição convectiva.

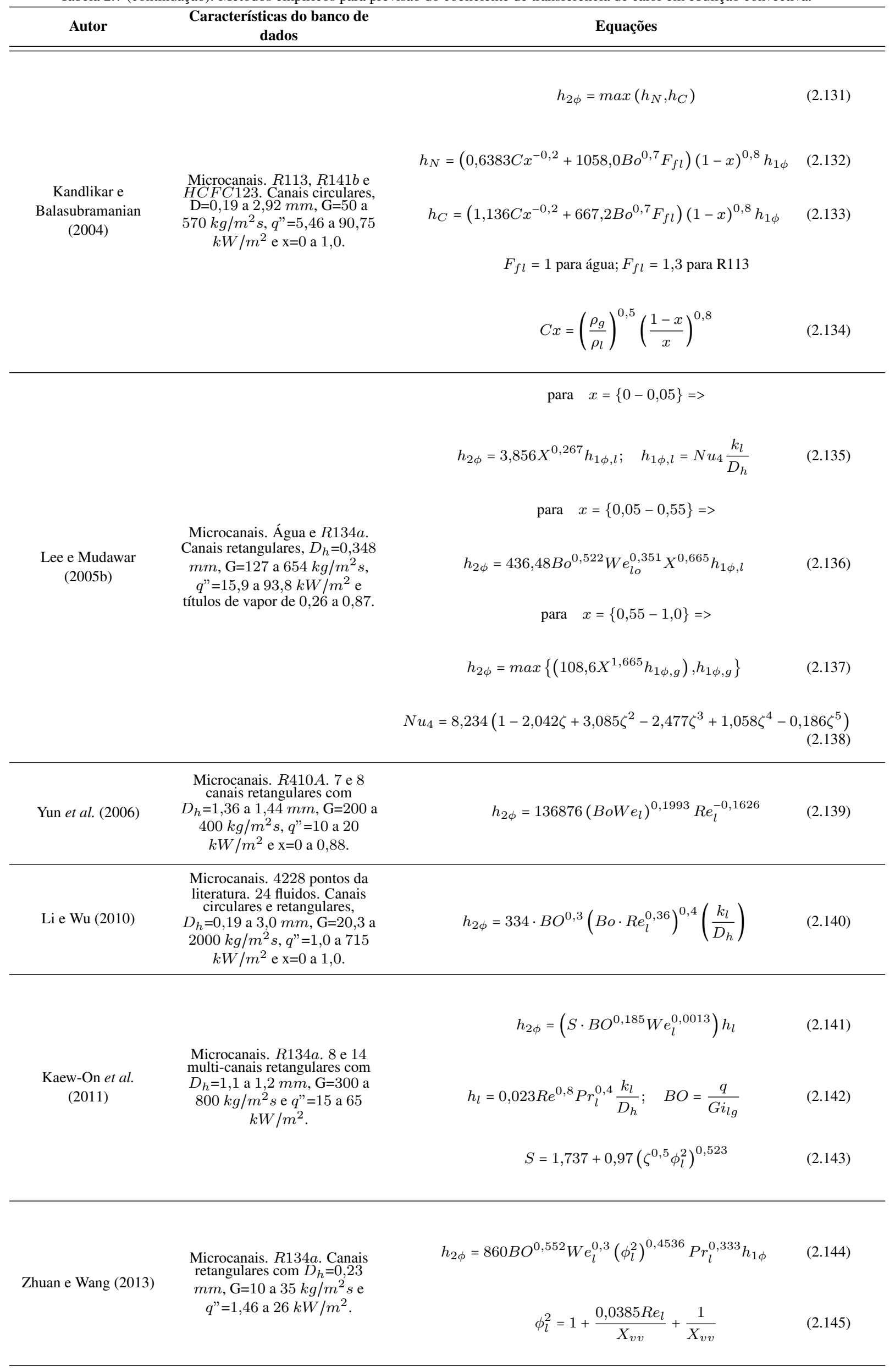


Tabela 2.8 - Valores das constantes para o método de Yan e Lin (1998).

\begin{tabular}{|c|c|c|c|c|c|c|c|c|c|}
\hline \multirow{2}{*}{$\begin{array}{l}C_{m}=C_{m, 1} R e_{l}^{C_{m, 2}} T_{r}^{C_{m, 3}} \\
m\end{array}$} & \multicolumn{3}{|c|}{$C_{0}>0,5$} & \multicolumn{3}{|c|}{$0,15<C_{0} \leq 0,5$} & \multicolumn{3}{|c|}{$C_{0} \leq 0,15$} \\
\hline & $C_{m, 1}$ & $C_{m, 2}$ & $C_{m, 3}$ & $C_{m, 1}$ & $C_{m, 2}$ & $C_{m, 3}$ & $C_{m, 1}$ & $C_{m, 2}$ & $C_{m, 3}$ \\
\hline 1 & 933,6 & 0,07575 & 26,19 & 47,3 & 0,3784 & 14,67 & 356600 & $-0,6043$ & 18,59 \\
\hline 2 & $-0,2$ & 0 & 0 & 2612,8 & 0 & 37,27 & 1409,1 & $-0,5506$ & 16,303 \\
\hline 3 & 41700 & 0,5731 & 34,98 & 100150 & 0 & 24,371 & 12,651 & 0,3257 & 10,118 \\
\hline 4 & 14,84 & $-0,0224$ & 13,92 & 3,99 & $-0,1937$ & 4,794 & 0,15 & 0 & 0 \\
\hline
\end{tabular}

(ii) Métodos baseados em superposição de efeitos de ebulição nucleada e convectiva

Chen (1966) foi pioneiro ao propor um método de previsão do coeficiente de transferência de calor em ebulição convectiva baseado na combinação de efeitos de ebulição nucleada e convectiva. Os métodos baseados em superposição de efeitos convectivos e de ebulição nucleada se compõe da adição destas parcelas segundo um exponente assintótico. A parcela devido à efeitos de ebulição nucleada, geralmente, compõe-se do produto entre o coeficiente de transferência de calor, estimado a partir de uma correlação para ebulição em piscina disponível na literatura, e um fator de supressão de efeitos de nucleação. Este tem como objetivo capturar o efeito da aceleração do escoamento, com o incremento do título de vapor, responsável pelo aumento do gradiente de temperaturas junto a parede, implicando na elevação do superaquecimento necessário à nucleação, e suprimindo assim, o crescimento e destacamento de bolhas. Já, a parcela convectiva se baseia no produto entre um coeficiente de transferência de calor, estimado através de correlações para convecção forçada no interior de tubos, e um fator de intensificação de efeitos convectivos, que visa capturar o incremento da transferência de calor resultante da aceleração do escoamento.

A Tabela 2.9 apresenta métodos da literatura baseados na superposição de efeitos convectivos e de ebulição segundo ordem cronológica de proposição. Segundo esta tabela, métodos baseados na superposição de efeitos foram propostos considerando resultados experimentais para escoamentos horizontais e verticais (ascendentes e descendentes), tendo como fluidos de trabalho água, refrigerantes halogenados e hidrocarbonetos, cobrindo velocidades mássicas de 12,4 a $8179,3 \mathrm{~kg} / \mathrm{m}^{2} \mathrm{~s}$ e fluxos de calor de até $2620 \mathrm{~kW} / \mathrm{m}^{2}$. Estes bancos de dados são geralmente utilizados no ajuste de exponentes e coeficientes associados aos fatores de supressão de efeitos de nucleação e intensificação de efeitos convectivos.

Nestes métodos, através do ajuste com base em dados experimentais, busca-se adequar o método a intensidade relativa com que efeitos convectivos se sobrepõem aos ebulitivos e viceversa com a variação do título de vapor. Desta forma, verificam-se na Tabela 2.9 expoentes assintóticos iguais a 1,2 e 3, indicando nesta ordem a intensidade relativa em que uma parcela da soma se sobrepõe a outra.

A maioria dos métodos propõem estimar o coeficiente de transferência de calor devido à efeitos de convecção forçada através da correlação de Dittus Boelter. Zhang et al. (2004) e Lee e Garimella (2008) consideram a correlação proposta por Shah e London (1978) para regime 
laminar em desenvolvimento térmico, a qual inclui um fator de forma para o caso de canais retangulares. Já, Liu e Garimella (2007) adotaram para seu método a correlação de Sieder e Tate (1936) para regime turbulento em desenvolvimento térmico.

Chen (1966) e Zhang et al. (2004) sugerem a correlação de Foster e Zuber (1955) para estimar o coeficiente de transferência de calor devido à efeitos de ebulição nucleada. Gungor e Winterton (1986) e Liu e Winterton(1991) recomendam o método proposto por Cooper (1984). Já, Liu e Garimella (2007) e Lee e Garimella (2008) estimaram este coeficiente de calor com o método de Gorenflo (1993) e, os métodos desenvolvidos por Saitoh et al. (2007), Tibiriçá (2011) e Kanizawa et al. (2016) se propõe utilizar a correlação de Stephan e Abdelsalam (1980) para calcular o coeficiente de transferência de calor devido à efeitos de ebulição nucleada.

De acordo com a Tabela 2.9, geralmente o fator de intensificação de efeitos convectivos se baseia no parâmetro de Lockhart-Martinelli, o qual foi desenvolvido considerando padrão de escoamento anular. Além disso, o fator de intensificação tem sido calculado incluindo o números de Reynolds e Prandtl para relacionar efeitos inerciais, viscosos e de difusão de calor através do filme líquido. Alguns métodos estimam o fator de intensificação incluindo os números adimensionais de Bond e Webber. Desta forma, buscam capturar efeitos de confinamento e ondulações interfaciais. Já para canais convencionais, apenas os métodos propostos por Gungor e Winterton (1986) e Liu e Winterton (1991) incluem o número de Froude para capturar esfeitos de estratificação do escoamento.

O fator de supressão de efeitos de ebulição nucleada é calculado implicitamente em função do fator de intensificação de efeitos convectivos, de forma a capturar a superposição dos efeitos. Além disso, a maioria dos métodos incluem o número de Reynolds do líquido considerando efeitos inerciais e viscosos da fase líquida no fator de supressão. Apenas o método de Kanizawa et al. (2016) inclui os números de Bond, para capturar efeitos de confinamento, e de Webber, para relacionar efeitos de ondulações interfaciais.

Tabela 2.9 - Métodos baseados na superposição de efeitos de ebulição nucleada e convectiva para previsão do coeficiente de transferência de calor.

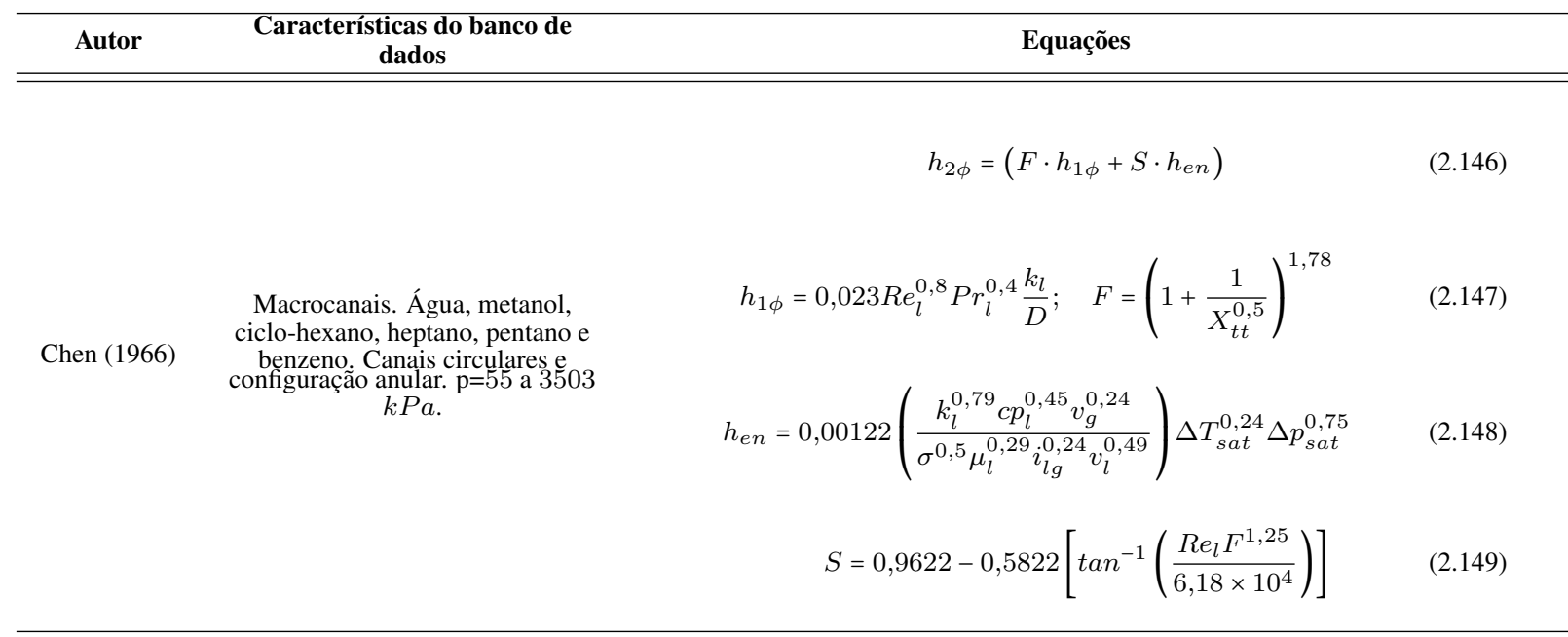


Tabela 2.9 (continuação). Métodos baseados na superposição de efeitos de ebulição nucleada e convectiva para previsão do coeficiente de transferência de calor.

Macrocanais. 4202 dados.

Água, $R 11, R 12, R 22, R 113$,

$R 114, R 134 a$, água + etileno-glicol. Canais circulares com $\mathrm{D}=2,95$ a 32

$\mathrm{mm}, \mathrm{G}$ de 12,4 a 8179,3

$\mathrm{kg} / \mathrm{m}^{2} \mathrm{~s}$ e $\mathrm{x}$ de 0,1 a 1,73 .

$$
\begin{gathered}
F=1+24000 B o^{1,16}+1,37\left(\frac{1}{X_{t t}}\right)^{0,86} ; \quad S=\left(1+\frac{1,15 F^{2}}{10^{6}} R e_{l}^{1,17}\right)_{(2.152)}^{-1} \\
\text { para } F r_{l} \leq 0,05
\end{gathered}
$$

$$
\begin{gathered}
F=\left[1+24000 B o^{1,16}+1,37\left(\frac{1}{X_{t t}}\right)^{0,86}\right] F r_{l}^{0,1-2 F r_{l}} \\
S=\left[\left(1+1,15 \times 10^{-6} F^{2} \operatorname{Re}_{l}^{1,17}\right)^{-1}\right] F r_{l}^{0,5}
\end{gathered}
$$

$$
h_{2 \phi}=\left[\left(F \cdot h_{1 \phi}\right)^{2}+\left(S \cdot h_{e n}\right)^{2}\right]^{0,5}
$$

Macrocanais. 4202 dados. Água, $R 11, R 12, R 22, R 113$, $R 114, R 134 a$, água + Liu e Winterton cen $\begin{gathered}\text { etileno-glicol. Canais } \\ \text { circulares com } \mathrm{D}=2,95 \text { a } 32\end{gathered}$ (1991) $\quad m m, p_{r}$ de 0,0023 a $0,895, \mathrm{G}$ de 12,4 a $8179,3 \mathrm{~kg} / \mathrm{m}^{2} \mathrm{~s}$, $q "=0,35$ a $2620 \mathrm{~kW} / \mathrm{m}^{2}$ e x entre 0 e 0,948 .

$$
F=\left[1+x \operatorname{Pr}_{l}\left(\frac{v_{g}}{v_{l}}-1\right)\right]^{0,35}
$$

$$
S=\left(1+0,055 F^{0,1} R e_{l o}^{0,16}\right)^{-1}
$$

para $F r_{l} \leq 0,05 ; \quad F=\left[1+x \operatorname{Pr}_{l}\left(\frac{v_{g}}{v_{l}}-1\right)\right]^{0,35} F r_{l}^{0,1-2 F r_{l}}$

$$
S=\left[\left(1+0,055 F^{0,1} \operatorname{Re}_{l o}^{0,16}\right)^{-1}\right] F r_{l}^{0,5}
$$

Microcanais. 1200 dados. Água, $R 11, R 12$, e $R 113$. Canais circulares e

Zhang et al. (2004) retangulares com $D_{h}=0,78$ a

$6,0 \mathrm{~mm}, \mathrm{p}=101$ a $1210 \mathrm{kPa}$,

$\mathrm{G}$ de 23,4 a $2939 \mathrm{~kg} / \mathrm{m}^{2} \mathrm{~s}$ e $q^{\prime \prime}=2,95$ a $2511 \mathrm{~kW} / \mathrm{m}^{2}$.

$$
\begin{gathered}
h_{2 \phi}=\left(F \cdot h_{1 \phi}+S \cdot h_{e n}\right) \\
h_{1 \phi}=\frac{k_{l}}{D_{h}} \max \left(N u_{1 \phi, l} ; N u_{1 \phi, t}\right) \quad \text { para } R e_{l}<2300 \\
h_{1 \phi}=\frac{k_{l}}{D_{h}} N u_{1 \phi, t} \quad \text { para } \quad R e_{l} \geq 2300 \\
h_{e n}=0,00122\left(\frac{k_{l}^{0,79} c p_{l}^{0,45} v_{g}^{0,24}}{\sigma^{0,5} \mu_{l}^{0,29} i_{l g}^{0,24} v_{l}^{0,49}}\right) \Delta T_{s a t}^{0,24} \Delta p_{s a t}^{0,75} \\
F=\max \left(0,64 \phi_{l} ; 1\right) ; \quad S=1+/\left(1+2,53 \cdot 10^{-6} \operatorname{Re}_{l}^{1,17}\right) \\
N u_{1 \phi, l}=4,36 ; \quad N u_{1 \phi, t}=0,023\left(\frac{k_{l}}{D_{h}}\right) R e_{l}^{0,8} \operatorname{Pr}_{l}^{0,4} \\
N u_{1 \phi}=8,234\left(1-2,042 \zeta+3,085 \zeta^{2}-2,477 \zeta^{3}+1,058 \zeta^{4}-0,186 \zeta^{5}\right)
\end{gathered}
$$


Tabela 2.9 (continuação). Métodos baseados na superposição de efeitos de ebulição nucleada e convectiva para previsão do coeficiente de transferência de calor

\begin{tabular}{|c|c|c|}
\hline Autor & $\begin{array}{c}\text { Características do banco de } \\
\text { dados }\end{array}$ & Equações \\
\hline
\end{tabular}

$$
\begin{aligned}
& h_{2 \phi}=\left(F \cdot h_{1 \phi}+S \cdot h_{e n}\right) \\
& h_{1 \phi}=0,023\left(\frac{k_{l}}{D_{h}}\right) \operatorname{Re}_{l}^{0,8} \operatorname{Pr}_{l}^{0,4} \\
& \text { Micro e macrocanais. } 2224 \\
& \text { dados experimentais. R134a. } \\
& \text { Saitoh et al. } \quad \begin{array}{c}
\text { Canais circulares com } \mathrm{D}=0,51 \\
\text { a } 10,92 \mathrm{~mm}, p_{r}=0,0862 \mathrm{a}
\end{array} \\
& \text { 2007) } 0,1204, \mathrm{G}=150 \text { a } 742 \\
& \mathrm{~kg} / \mathrm{m}^{2} \mathrm{~s}, q^{\prime \prime}=5 \text { a } 39 \mathrm{~kW} / \mathrm{m}^{2} \\
& \text { e } \mathrm{x}=0 \text { a } 0,948 \text {. } \\
& h_{e n}=207 \frac{k_{l}}{d_{b}}\left(\frac{q^{\prime \prime} d_{b}}{k_{l} T_{l}}\right)^{0,745}\left(\frac{\rho_{g}}{\rho_{l}}\right)^{0,581} \operatorname{Pr}_{l}^{0,533} \\
& F=1+\frac{(1 / X)^{l}}{1+W e_{g}^{m}} ; \quad S=\frac{1}{1+a\left(10^{-4} \operatorname{Re}_{l} F^{1,25}\right)^{n}} \\
& d_{b}=0,51\left[\frac{2 \sigma}{g\left(\rho_{l}-\rho_{g}\right)}\right]^{0,5}
\end{aligned}
$$

onde: $l=1,05 ; a=0,4 ; m=-0,4$ e $n=1,4$

$$
\begin{gathered}
h_{2 \phi}=\left(F \cdot h_{1 \phi}+S \cdot h_{e n}\right) \\
h_{1 \phi}=1,86\left[(1-x) \operatorname{Re}_{l} \operatorname{Pr}_{l} D_{h} / L\right]^{1 / 3}\left(\mu_{l} / \mu_{g}\right)\left(k_{l} / D_{h}\right) \\
h_{e n}=h_{0} F_{P F}\left(\frac{q}{q_{0}}\right)^{0,9-0,3 p_{r}^{0,15}}\left(\frac{R_{p}}{R_{p 0}}\right) \\
F_{P F}=1,73 p_{r}^{0,27}+\left(6,1+\frac{0,68}{1+p_{r}}\right) p_{r}^{2} \\
F=\zeta\left(\phi_{l}^{2}\right)^{1 / 4}\left(\frac{\mu_{2 \phi}}{\mu_{l}}\right)^{0,105}\left(\frac{C p_{2 \phi}}{C p_{l}}\right)^{1 / 4}\left(\frac{k_{2 \phi}}{k_{l}}\right)^{3 / 4} \operatorname{Pr}_{l}^{0,167} \\
\text { propriedades } 2 \phi: \quad \operatorname{prop} p_{2 \phi}=x \cdot \operatorname{prop}_{g}+(1-x) \operatorname{prop}_{l} \\
S=\exp \left[36,57+\frac{55746}{R e_{l} F^{3}}-\ln \left(R e_{l} F^{3}\right)\right] \\
h_{0}=5,6 k W / m^{2} K ; q_{0}=20 k W / m^{2} ; R_{p 0}=0,4 \mu m
\end{gathered}
$$$$
\text { Microcanais. Água. Canais }
$$$$
\text { Liu e Garimella retangulares com } D_{h}=0,384 \text { e }
$$$$
0,588 \mathrm{~mm}, \mathrm{G} \text { de } 221 \text { a } 128
$$$$
\mathrm{kg} / \mathrm{m}^{2} \mathrm{~s} \text { e } q^{\prime \prime} \text { até } 1290
$$$$
k W / m^{2} \text {. }
$$

Água deionizada, 60, 35, 24 e

10 microcanais retangulares

Lee e Garimella paralelos com $D_{h}=162,5$ a (2008) $570,9 \mu m, q "=10$ a 340 $k W / m^{2}$ e $\mathrm{x}=-0,0114 \mathrm{a}$

$$
0,1987 \text {. }
$$

$$
\begin{gathered}
h_{2 \phi}=\left[\left(F \cdot h_{1 \phi}\right)^{3}+\left(S \cdot h_{e n}\right)^{3}\right]^{1 / 3} \\
F=\left(\phi_{l}^{2}\right)^{0,2743}\left(c p_{2 \phi} / c p_{l}\right)^{0,2743}\left(k_{2 \phi} / k_{l}\right)^{0,7257} \\
S=4,6809-0,6705 \log \left(\frac{q^{" \prime} c h}{10^{6}}\right)+3,908\left(\frac{D_{h}}{0,001}\right) \\
h_{e n}=5600 F_{P F}\left(\frac{q}{20000}\right)^{0,9-0,3 p_{r}^{0,15}}\left(\frac{R_{p}}{R_{p 0}}\right) \\
h_{1 \phi}=\frac{8,234 k_{l}}{D_{h}}\left(1-2,042 \zeta+3,085 \zeta^{2}-2,477 \zeta^{3}+1,058 \zeta^{4}-0,186 \zeta^{5}\right)
\end{gathered}
$$


Tabela 2.9 (continuação). Métodos baseados na superposição de efeitos de ebulição nucleada e convectiva para previsão do coeficiente de transferência de calor.

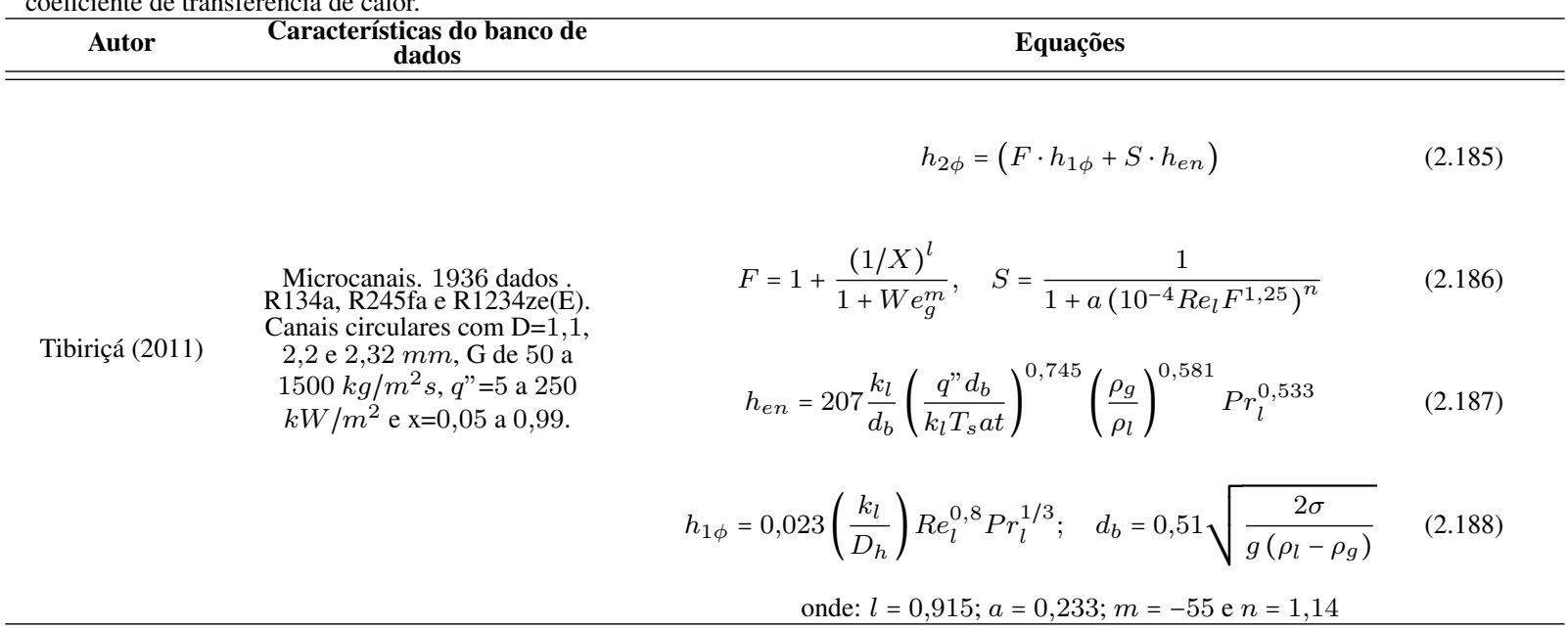

$$
\begin{gathered}
h_{2 \phi}=\left(F \cdot h_{1 \phi}+S \cdot h_{e n}\right) \\
h_{1 \phi}=0,023\left(\frac{k_{l}}{D}\right) \operatorname{Re}_{l}^{0,8} \operatorname{Pr}_{l}^{1 / 3} \\
\text { Hidrocarbonetos: } h_{e n}=0,0546 \frac{k_{l}}{d_{b}}\left[\left(\frac{\rho_{g}}{\rho_{l}}\right)^{0,5}\left(\frac{q^{\prime \prime} d_{b}}{k_{l} T_{s a t}}\right)\right]^{0,67} \times \\
\left(\frac{\rho_{l}-\rho_{g}}{\rho_{l}}\right)^{-4,33}\left[i_{l g} d_{b}^{2}\left(\frac{\rho_{l} C p_{l}}{k_{l}}\right)^{2}\right]^{0,248} \\
S=1,06\left(\frac{X^{-1,32}}{1+0,12\left(\operatorname{Re}_{2 p, \bmod } \cdot 10^{-4}\right)^{0,86}}\right) \\
d_{b}=0,51 \sqrt{\frac{2 \sigma}{g\left(\rho_{l}-\rho_{g}\right)}} ; \quad W e_{2 p, \bmod }=\operatorname{Re}_{l 0} F^{1,25}=\frac{\rho_{g} u_{g} D}{\sigma} ; \quad u_{g}=\frac{G x}{\rho_{g} \alpha} \\
\alpha=\left[1+1,021 F e_{m}^{-0,092}\left(\frac{\mu_{l}}{\mu_{g}}\right)^{-0,368}\left(\frac{\rho_{g}}{\rho_{l}}\right)^{1 / 3}\left(\frac{1-x}{x}\right)^{2 / 3}\right]^{-1}
\end{gathered}
$$$$
\text { experimentais. R134a, R245fa }
$$

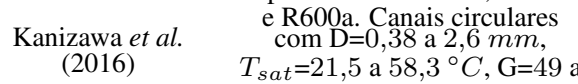$$
2200 \mathrm{~kg} / \mathrm{m}^{2} s, q^{\prime \prime}=5 \text { a } 185
$$$$
k W / m^{2} \text { e } \mathrm{x}=0,05 \text { a } 0,93 \text {. }
$$

(iii) Métodos fenomenológicos

Thome et al. (2004) foram pioneiros ao propor um método fenomenológico para estimar o CTC o qual se baseia na análise cíclica do processo de transferência de calor durante a passagem consecutiva de uma bolha alongada e um pistão de líquido. Neste método, o CTC é dado pela soma de três parcelas ponderadas segundo o tempo em que cada mecanismo se verifica. Estas parcelas correspondem aos seguintes mecanismos de transferência de calor: (i) convecção forçada para a fase líquida; (ii) convecção forçada para a fase vapor, no caso de ocorrer secagem do filme líquido; (iii) condução através do filme líquido e evaporação na interface líquido/vapor na região da bolha alongada. A Figura 2.10 apresenta um diagrama esquemático ilustrando os mecanismos de transferência de calor e as 3 regiões correspondentes, razão pela qual o modelo é denominado de 3-zonas. Equações para este método são apresentadas na Tabela 2.10. 
O modelo de Thome et al. (2004) foi ajustado com base em um banco de dados que inclui títulos de vapor até 0,9. Além disso, os autores utilizaram dados tanto para canais únicos como para multi-canais. Estes aspectos justificam o fato de que para alguns bancos de resultados experimentais de multi-canais, o modelo de 3-zonas preveja satisfatoriamente os dados.

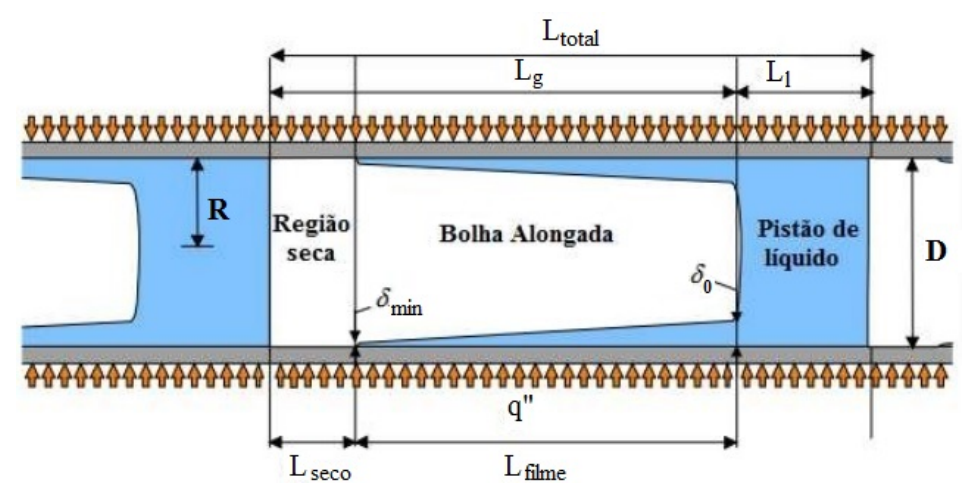

Figura 2.10 - Diagrama esquemático do modelo de 3-zonas proposto por Thome et al. (2004).

Dupont et al. (2004) propuseram a modificação da equação utilizada para calcular o coeficiente de transferência de calor para o filme líquido indicada no modelo de Thome et al. (2004). Isto é devido à elevada sensibilidade da relação logarítmica de $\delta_{0} / \delta_{\text {min }}$, na qual, quando $\delta_{\min } \rightarrow 0$, o coeficiente de transferência de calor para o filme tende ao infinito. Desta forma, Dupont et al. (2004) recomendam adotar $\delta_{\min }$ como a espessura média verificada durante o tempo do filme. O CTC para o filme líquido é definido pela seguinte relação:

$$
h_{\text {filme }}=\frac{k_{l}}{\delta_{0}-\delta_{\min }}
$$

Posteriormente, Cioncolini e Thome (2011) propuseram um método para previsão do CTC durante o padrão de escoamento anular em dutos circulares de diâmetro reduzido. Neste modelo, os autores assumem um filme líquido como axi-simétrico junto à superfície do duto e na região central consideraram escoamento de vapor com gotículas de líquido dispersas. Equações para este método são apresentadas na Tabela 2.10 .

Costa-Patry et al. (2012) combinaram os métodos para bolhas alongadas de Thome et al. (2004) e para escoamento anular de Cioncolini e Thome (2011) em um único método com a transição entre padrões caracterizada pelo critério de Ong e Thome (2011a) dado pela seguinte equação:

$$
x_{\text {trans-pistonado-anular }}=425\left(\frac{\rho_{g}}{\rho_{l}}\right)^{0,1} \frac{B o^{1,1}}{C o^{0,5}}
$$

Esta relação foi proposta considerando banco de dados com resultados para $R 134 a, R 245 \mathrm{fa}$. $R 236 f a$ e $R 1234 z e(E)$, diâmetros hidráulicos de 0,146 a 3,04 $\mathrm{mm}$, velocidades mássicas de 100 a $1100 \mathrm{~kg} / \mathrm{m}^{2} \mathrm{~s}$ e fluxos de calor de 8 a $260 \mathrm{~kW} / \mathrm{m}^{2}$.

Ao contrário de Thome et al. (2004), que ajustaram uma constante empírica, Costa-Patry et al. (2012) sugeriram o uso da rugosidade média do canal como espessura mínima do filme para 
o modelo de 3 zonas. Além disso, para canais retangulares recomendam calcular a espessura do filme líquido no modelo de Cioncolini e Thome (2011), com a razão entre a área do filme líquido e o perímetro do canal. Costa-Patry et al.(2012) também propuseram uma nova relação para calcular o coeficiente de transferência calor para o filme líquido incluindo um fator de correção no denominador com o intuito de evitar erros nos cálculos indicados por Dupont et al. (2004), quando $\delta_{0}=\delta_{\text {final }}$. Esta relação é dado pela seguinte equação:

$$
h_{\text {filme }}=\frac{k_{l}}{\delta_{0}-\delta_{\text {final }}+1 \cdot 10^{-9}} \ln \left(\frac{\delta_{0}}{\delta_{\text {final }}}\right)
$$

Tabela 2.10 - Métodos fenomenológicos para previsão do coeficiente de transferência de calor em ebulição convectiva.

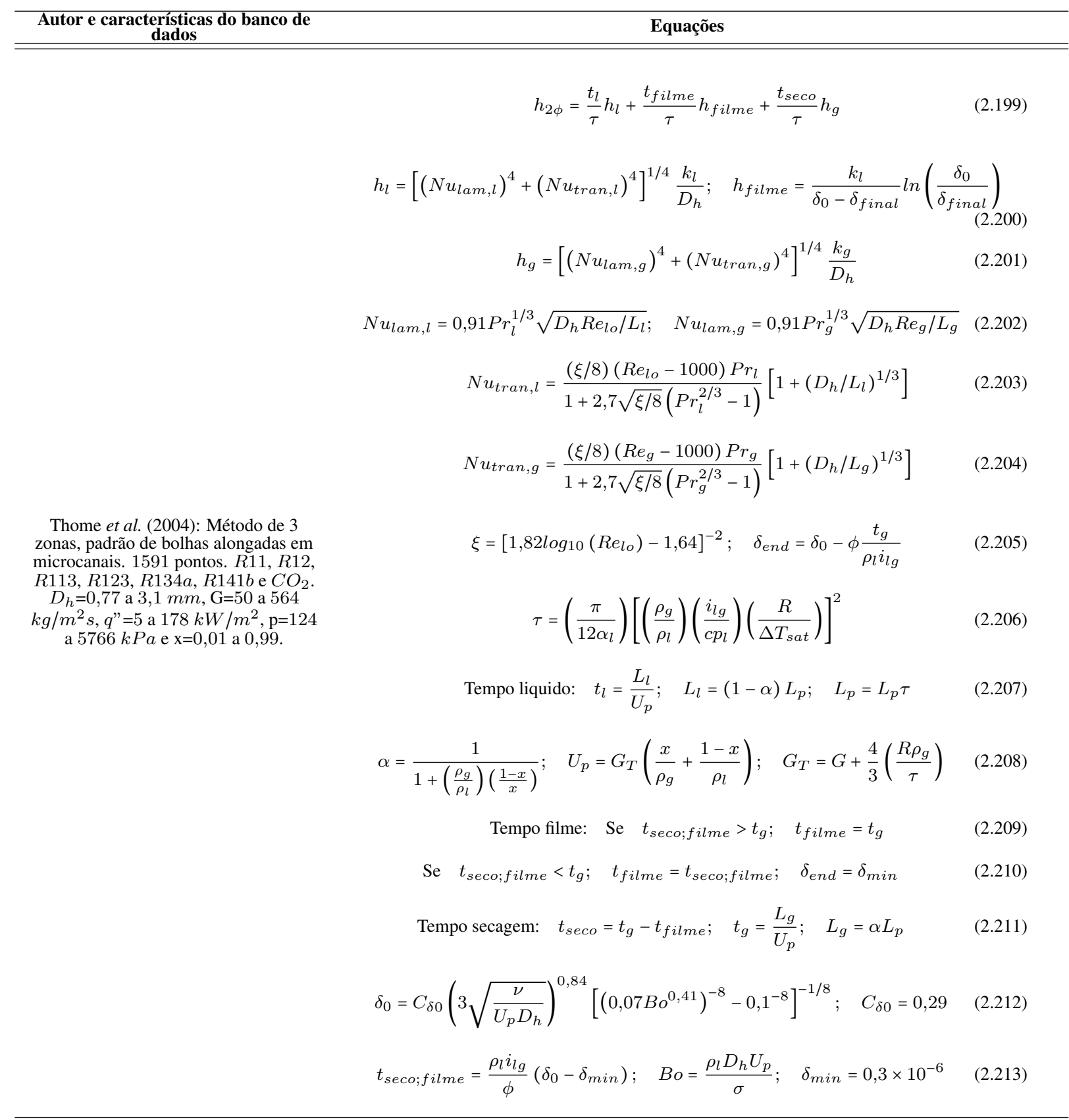


Tabela 2.10 (continuação). Métodos fenomenológicos para previsão do coeficiente de transferência de calor em ebulição convectiva.

$$
\begin{aligned}
& \text { Autor e características do banco de } \\
& \text { dados } \\
& \text { Equações } \\
& h_{2 \phi}=0,076 \cdot \frac{k_{l}}{\delta} \cdot\left(\delta^{+}\right)^{0,9} \cdot P r_{l}^{0,52} \\
& \delta=\frac{\mu_{l}}{\rho_{l} \sqrt{\tau_{p} \rho_{l}}} \delta^{+} \\
& \delta^{+}=\operatorname{Max}\left\{\sqrt{\frac{2(1-E)(1-x) G \cdot D}{4 \mu_{l}}} ; \frac{(1-E)(1-x) G \cdot D}{4 \mu_{l}}\right\} \\
& E=\left(1+279,6 \cdot W e_{\text {nucleo }}^{-0,8395}\right)^{-2,209} \\
& \tau_{p}=\frac{1}{2} f_{2 \phi} \cdot \rho_{\text {nucleo }} \cdot V_{\text {nucleo }}^{2} ; \quad f_{2 \phi}=0,0172 \cdot W e_{\text {nucleo }}^{-0,372} \\
& \rho_{\text {nucleo }}=\frac{x+E(1-x)}{\frac{x}{\rho_{g}}+E\left(\frac{1-x}{\rho_{l}}\right)} \\
& W e_{\text {nucleo }}=\frac{\rho_{\text {nucleo }} \cdot j_{g}^{2} D}{\sigma}
\end{aligned}
$$

\subsection{EBULIÇÃO CONVECTIVA EM MULTI-MICROCANAIS}

Esta seção apresenta uma análise dos estudos experimentais disponíveis na literatura sobre o escoamento monofásico e a ebulição convectiva em dissipadores de calor baseados em multimicrocanais. Tal análise se inicia com a apresentação de um quadro resumo, no qual são descritas as configurações geométricas avaliadas e as condições experimentais destes estudos, incluindo fluido refrigerante, pressão de operação, faixas de fluxo de calor e velocidade mássica. Em seguida, a seção inclui uma análise crítica de estudos sobre padrões de escoamento, perda de pressão e coeficiente de transferência de calor durante a ebulição convectiva em multimicrocanais.

\subsubsection{LITERATURA SOBRE DISSIPADORES DE CALOR BASEADOS EM MULTI- MICROCANAIS}

A Tabela 2.11 apresenta um resumo dos estudos experimentais sobre dissipadores de calor baseados em multi-microcanais. Conforme indicado nesta tabela, ensaios foram efetuados para escoamento monofásico de água e ar e para a ebulição convectiva de água, metanol, etanol, acetona, refrigerantes halogenados (R113, $R 134 a, R 123, R 124, R 410 A, R 21, R 22$, R245fa, R236fa e R1234ze), VertrelXF, HFE7100, FC77, FC72 e misturas de água 
e propanol. Entre os estudos levantados, não se verificam resultados para hidrocarbonetos em multi-microcanais. Segundo a tabela, dados foram levantados visando a investigação de padrões de escoamento, instabilidades térmicas, perda de pressão, campo de velocidades, fração de vazio, fluxo crítico de calor, resistência térmica global e coeficiente de transferência de calor.

Os resultados obtidos foram para pressões reduzidas entre 0,0004532 e 0,4188, velocidades mássicas de 20 até $15320 \mathrm{~kg} / \mathrm{m}^{2} \mathrm{~s}$ dissipando fluxos de calor de até $8 \mathrm{MW} / \mathrm{m}^{2}$ para velocidades mássicas de $1600 \mathrm{~kg} / \mathrm{m}^{2} \mathrm{~s}$. Desempenhos foram avaliados para dissipadores confeccionados em cobre, silício, aço inoxidável e alumínio, para comprimentos de canais entre 4,5 e 220 $m m$, seção transversal mínima de 30x30 $\mu m^{2}$ e contendo de 2 a 2214 canais com diâmetros equivalentes entre 0,0338 e 4,8 $\mathrm{mm}$. Ensaios foram realizados para escoamentos verticais ascendentes e descendentes, horizontais e inclinados.

Aproximadamente $75 \%$ dos estudos foram efetuados para dissipadores de calor com canais paralelos e área de seção transversal constante ao longo do comprimento do dissipador. Estes estudos envolveram canais com seções transversais retangulares (razões de aspecto entre 0,01 e $58,7)$, triangulares, hexagonais e circulares. Vale destacar que, geometrias com canais paralelos combinadas a regiões de plenums retangulares favorecem efeitos de má-distribuição do fluido e instabilidades térmicas devido ao crescimento de bolhas em condições de confinamento. Desta forma visando intensificar a transferência de calor, reduzir a perda de pressão, minimizar efeitos de instabilidades térmicas e reduzir o superaquecimento necessário para o início da ebulição (ONB-onset of nucleate boiling), foram também avaliadas geometrias distintas de canais paralelos, com seções transversais divergentes e superfícies de troca de calor modificadas de forma a criar sítios de nucleação.

Para uniformizar a distribuição do fluido e intensificar e transferência de calor, configurações baseadas em canais cruzados perpendiculares foram propostas por Kishimoto e Sasaki (1987), Colgan et al. (2007), Koşar e Peles (2007b) e Zhuan e Wang (2013). Também verificam-se na literatura com o mesmo objetivo, configurações constituídas de canais ramificados, distribuídos segundo fractais conforme proposto por Cullion et al. (2007), Henning et al. (2007), Krebs et al. (2010) e Daniels et al. (2011). Além destes estudos, soluções que envolvem expansões bruscas na entrada dos microcanais foram propostas por Kosar et al. (2006) e Schneider et al. (2007). Soluções com orifícios ou cavidades artificiais ao longo dos canais foram analisadas por Kandlikar et al. (2005) e Balasubramanian e Kandlikar (2005). Lu e Pan (2008, 2009 e 2011), Cho et al. (2010) e Balasubramanian et al. (2011)propuseram soluções com microcanais paralelos de seção transversal divergente.

A Figura 2.11 ilustra algumas configurações geométricas de distribuição de canais paralelos com distintas seções transversais. 
a)

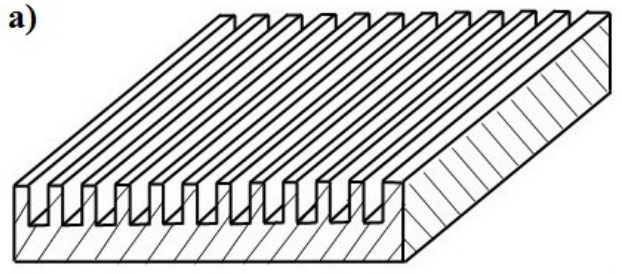

c)

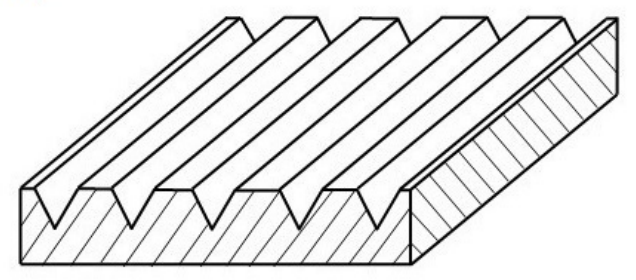

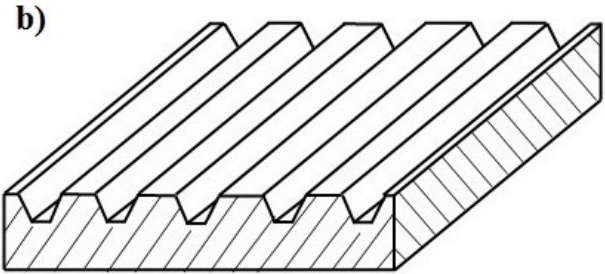

d)

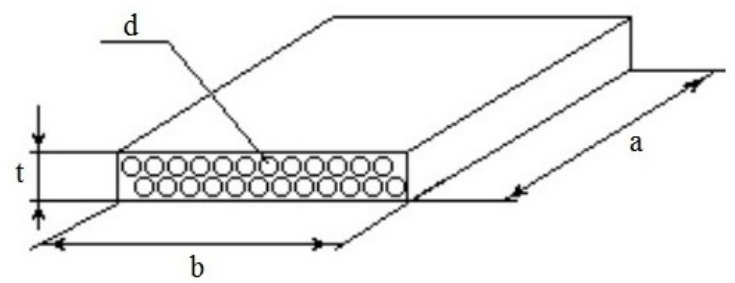

Figura 2.11 - Configurações de multi-microcanais paralelos: (a) paralelo retangular, Tuckerman e Pease (1981); (b) paralelo trapezoidal, Wu e Cheng (2004); (c) paralelo triangular, Hetsroni et al. (2001); (d) paralelo circular, Wexler et al. (2003).

Lu e Pan (2009) avaliaram dissipadores de calor com microcanais de seção transversal divergente. Além disso, os autores avaliaram dissipadores com sítios de nucleação ao longo da superfície inferior dos microcanais. Os microcanais divergentes induzem o escoamento em uma direção e reduzem o efeito de instabilidades térmicas devido a fluxo reverso da ebulição confinada. A Figura 2.12 ilustra a geometria dos dissipadores avaliados por Lu e Pan (2009).

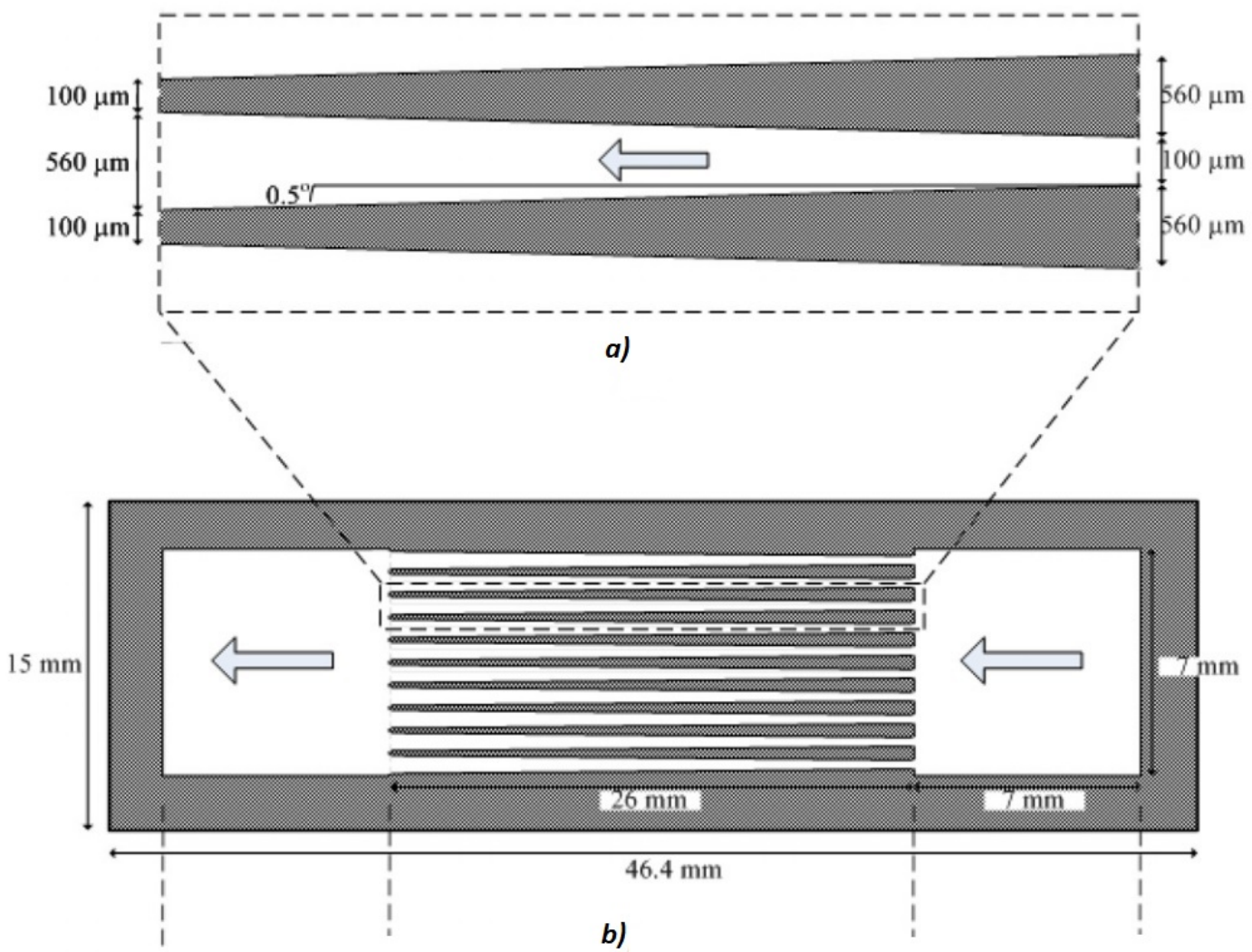

Figura 2.12 - Multi-microcanais com seção transversal divergente, Lu e Pan (2009). (a) Seção de um microcanal; (b) Plano Superior. 
Com o propósito de obter uma distribuição de fluido uniforme e assim, incrementar o coeficiente de transferência de calor, Kandlikar et al. (2005) e Balasubramanian e Kandlikar (2005) avaliaram dissipadores com canais paralelos contendo cavidades artificiais em suas superfícies e possuindo diferentes rugosidades. Também, para otimizar o processo de transferência de calor e amortecer os efeitos de instabilidades térmicas devido ao fluxo reverso, soluções que envolvem inclusão de restrições na entrada dos microcanais foram propostas por Kosar et al. (2006), Schneider et al. (2007), Szczukiewicz et al. (2012, 2013a, 2013b). Vale destacar que, a inclusão de restrições na entrada dos microcanais incrementa a perda de pressão.

A Figura 2.13 ilustra algumas configurações geométricas de distribuição de microcanais ramificados, fractal e cruzada.

a)

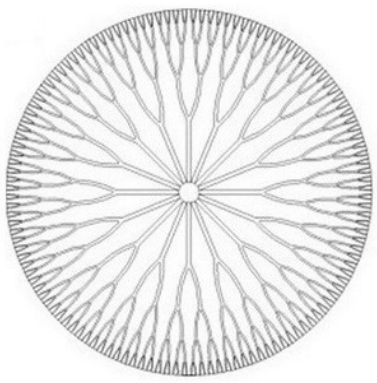

c)

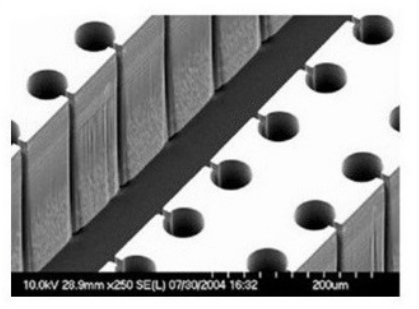

b)

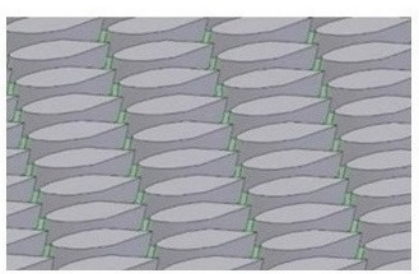

d)

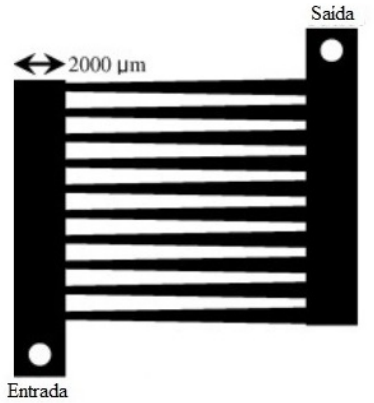

Figura 2.13 - Configurações de multi-microcanais modificados: (a) ramificado ou fractal Daniels et al. (2011); (b) cruzado micro-aleta Koşar e Peles (2007b); (c) paralelo retangular com orifícios, Kuo e Peles (2007); (d) paralelo retangular divergente Cho et al. (2010).

Tabela 2.11 - Estudos experimentais sobre dissipadores de calor baseados em multi-microcanais

\begin{tabular}{|c|c|c|c|c|c|c|c|c|c|}
\hline Autor (ano) & $\begin{array}{l}\text { Configuração/ } \\
\text { Geometria/ } \\
\text { Material }\end{array}$ & $\begin{array}{l}\text { Fluido/ } \\
\mathbf{N}^{\circ} \text { fases }\end{array}$ & $\begin{array}{c}\text { Dimensões } \\
{[\mu m]} \\
D_{h}, w \times h\end{array}$ & $\begin{array}{c}\mathbf{N}^{\circ} \\
\text { Canais }\end{array}$ & $\begin{array}{c}\text { L [mm]/ } \\
\text { Orien- } \\
\text { tação* }\end{array}$ & $\begin{array}{c}\text { Psat ou } \\
\text { Pin } \\
{[\mathrm{kPa}] /} \\
\text { Tsat(Tin) } \\
{\left[{ }^{\circ} \mathrm{C}\right]}\end{array}$ & $\begin{array}{c}\mathbf{q}^{\prime \prime} \\
{\left[\mathrm{kW} / \mathrm{m}^{2}\right]}\end{array}$ & $\underset{\left[\mathrm{kg} / \mathrm{m}^{2} \mathrm{~s}\right]}{\mathbf{G}}$ & $\begin{array}{c}\text { Parâmetro } \\
\text { de estudo } \\
* *\end{array}$ \\
\hline \multirow{3}{*}{\begin{tabular}{|l} 
Tuckerman e \\
Pease (1981)
\end{tabular}} & \multirow{3}{*}{$\begin{array}{l}\text { Paralelo / } \\
\text { Retangular/ } \\
\text { silício }\end{array}$} & \multirow{3}{*}{$\begin{array}{l}\text { Água/ } \\
1 \phi\end{array}$} & $53 \times 320$ & \multirow{3}{*}{100} & \multirow{3}{*}{$10 / \mathrm{H}$} & \multirow{3}{*}{$-/(23)$} & 1810 & 2622 & \multirow{3}{*}{ RT } \\
\hline & & & $55 \times 287$ & & & & 2770 & 3627 & \\
\hline & & & $50 \times 302$ & & & & 7900 & 5695 & \\
\hline \multirow{3}{*}{\begin{tabular}{|c|} 
Goldberg \\
$(1984)$
\end{tabular}} & Paralelo / & & $127 \times 12700$ & 25 & & & & & \multirow{3}{*}{ RT } \\
\hline & Retangular/ & $\mathrm{Ar} / 1 \phi$ & $254 \times 12700$ & 12 & $6,35 / \mathrm{H}$ & $-/(23)$ & 198,4 & 22 & \\
\hline & Cobre & & $635 \times 12700$ & 5 & & & & & \\
\hline$\frac{\text { Mahalingam }}{(1985)}$ & $\begin{array}{l}\text { Paralelo / } \\
\text { Retangular/ } \\
\text { Silício }\end{array}$ & $\begin{array}{c}\text { Ar - } \\
\text { Água/ } \\
1 \phi\end{array}$ & $200 \times 1700$ & 166 & $50 / \mathrm{H}$ & - & $\begin{array}{c}\text { Ar } \\
103,8 \\
\text { Água } \\
761,7\end{array}$ & $\begin{array}{c}\text { Ar } \\
23-50 \\
\text { Água } \\
425\end{array}$ & RT \\
\hline
\end{tabular}

*H=> Horizontal; VU=> Vertical escoamento ascendente; VD=> Vertical escoamento descendo; I=> Inclinado

**RT $=>$ Resistência térmica; INS $=>$ Instabilidades; $\mathrm{CT}=>$ Controle de temperatura; $\Delta p=>$ Perda de pressão; $\mathrm{FP}=>$ Padrões de escoamento; $\mathrm{h}=>$ Coeficiente de transferência de calor; $\mathrm{FCC}=>$ Fluxo crítico de calor ; FV=> Fração de vazio; TMM=> Transição macro micro-escala;

$\mathrm{RA}=>$ Razão de aspecto 
Tabela 2.11 (continuação). Estudos experimentais sobre dissipadores de calor baseados em multi-microcanais.

\begin{tabular}{|c|c|c|c|c|c|c|c|c|c|}
\hline Autor (ano) & $\begin{array}{l}\text { Configuração/ } \\
\text { Geometria/ } \\
\text { Material }\end{array}$ & $\begin{array}{l}\text { Fluido/ } \\
\mathbf{N}^{\circ} \text { fases }\end{array}$ & $\begin{array}{c}\text { Dimensões } \\
{[\mu m]} \\
D_{h}, w \times h\end{array}$ & $\begin{array}{c}\mathbf{N}^{\circ} \\
\text { Canais }\end{array}$ & $\underset{\substack{\text { Orien- } \\
\text { tação* }}}{\mathbf{L}[\mathrm{mm}] /}$ & $\begin{array}{c}\text { Psat ou } \\
\text { Pin[kPa]/ } \\
\text { Tsat(Tin) } \\
{\left[{ }^{\circ} \mathbf{C}\right]} \\
\end{array}$ & $\begin{array}{c}\mathbf{q}^{\prime \prime} \\
{\left[\mathrm{kW} / \mathbf{m}^{2}\right.}\end{array}$ & {$\left[\begin{array}{l}\mathbf{G} \\
{\left[\mathrm{kg} / \mathrm{m}^{2} \mathrm{~s}\right]}\end{array}\right.$} & $\begin{array}{c}\text { Parâmetro } \\
\text { de estudo } \\
* *\end{array}$ \\
\hline \begin{tabular}{c|} 
Iushimoto e \\
Ohsaki (1986)
\end{tabular} & $\begin{array}{c}\text { Paralelo/ } \\
\text { Retangular/ } \\
\text { Substrato } \\
\text { alumina }\end{array}$ & $\begin{array}{l}\text { Água/ } \\
1 \phi\end{array}$ & $800 \times 400$ & 29 & $86 / \mathrm{H}$ & $-/(25)$ & até 44,8 & até 1796 & RT \\
\hline $\begin{array}{c}\text { Sasaki e } \\
\text { Kishimoto } \\
1986)\end{array}$ & $\begin{array}{c}\text { Paralelo / } \\
\text { Retangular/ } \\
\text { Silício }\end{array}$ & $\begin{array}{l}\text { Água/ } \\
1 \phi\end{array}$ & $\begin{array}{c}70 \times 900 \\
140 \times 900 \\
340 \times 900 \\
20000 \times 900\end{array}$ & $\begin{array}{l}142 \\
71 \\
25 \\
1\end{array}$ & $24 / \mathrm{H}$ & - & até 1500 & - & $\mathrm{RT}, \Delta p$ \\
\hline Nayak et al. & $\begin{array}{l}\text { Paralelo / } \\
\text { Retangular/ } \\
\text { Cobre }\end{array}$ & $\stackrel{\text { Água/ }}{1 \phi}$ & $\begin{array}{l}5870 \times 100 \\
5870 \times 1000\end{array}$ & 6 & $50 / \mathrm{H}$ & $-/(20)$ & $\begin{array}{l}228- \\
865\end{array}$ & $\begin{array}{l}369- \\
5366\end{array}$ & $\mathrm{RT}, \Delta p$ \\
\hline $\begin{array}{c}\text { Kishimoto e } \\
\text { Sasaki (1987) }\end{array}$ & $\begin{array}{l}\text { Cruzado / - } \\
\text { / Silício }\end{array}$ & $\begin{array}{l}\text { Água/ } \\
1 \phi\end{array}$ & $\begin{aligned} S & =150 \\
D & =150 \\
L & =500 \\
H & =300 \\
\theta & =60^{\circ}\end{aligned}$ & - & $24 / \mathrm{H}$ & $-/(20)$ & até 1250 & - & CT \\
\hline Phillips 1990 & $\begin{array}{l}\text { Paralelo/ } \\
\text { Retangular/ } \\
\text { Silício }\end{array}$ & $\begin{array}{l}\text { Água/ } \\
1 \phi\end{array}$ & $\begin{array}{c}220 \times 165 \\
64 \times 245\end{array}$ & $\begin{array}{l}26 \\
50\end{array}$ & $10 / \mathrm{H}$ & $-/(20)$ & 340 & - & $\mathrm{RT}, \Delta p$ \\
\hline $\begin{array}{c}\text { Knight et al. } \\
1991)\end{array}$ & $\begin{array}{l}\text { Paralelo / } \\
\text { Retangular/ } \\
\text { Silício }\end{array}$ & $\begin{array}{l}\text { Água/ } \\
1 \phi\end{array}$ & $\begin{array}{c}61 \times 357 \\
173 \times 319\end{array}$ & $\begin{array}{c}83 \\
33\end{array}$ & $10 / \mathrm{H}$ & - & - & $\begin{array}{c}6860 \\
15320\end{array}$ & $\mathrm{RT}, \Delta p$ \\
\hline$\frac{\text { Knight et al. }}{\text { (1992) }}$ & $\begin{array}{l}\text { Paralelo / } \\
\text { Retangular/ } \\
\text { Silício }\end{array}$ & $\begin{array}{l}\text { Água/ } \\
1 \phi\end{array}$ & $\begin{array}{c}377 \times 365 \\
1889 \times 323\end{array}$ & $\begin{array}{l}22 \\
19\end{array}$ & $10 / \mathrm{H}$ & - & - & $\begin{array}{c}3633 \mathrm{e} \\
12,5\end{array}$ & $\mathrm{RT}, \Delta p$ \\
\hline $\begin{array}{c}\text { Peng e Wang } \\
\text { (1993) }\end{array}$ & $\begin{array}{c}\text { Paralelo/ } \\
\text { Retangular/ } \\
\text { Aço } \\
\text { Inoxidável }\end{array}$ & $\begin{array}{l}\text { Água/ } \\
1 \phi \text { e } 2 \phi\end{array}$ & $600 \times 700$ & 3 & $60 / \mathrm{H}$ & $\begin{array}{c}101 / 100 \\
(30-60)\end{array}$ & até 400 & $\begin{array}{l}1500- \\
4000\end{array}$ & $\mathrm{~h}$ \\
\hline$\frac{\text { Yu e Xin }}{(1994)}$ & $\begin{array}{l}\text { Paralelo / } \\
\text { Retangular / } \\
\text { Cobre }\end{array}$ & $\mathrm{Ar} / 1 \phi$ & $300 \times 5000$ & 60 & $40 / \mathrm{H}$ & - & 55.5 & 20 & $\mathrm{~h}$ \\
\hline \begin{tabular}{|c|} 
Bowers e \\
Mudawar \\
(1994a||1994b \\
e $1994 \mathrm{c})$
\end{tabular} & $\begin{array}{l}\text { Paralelo / } \\
\text { Circular/ } \\
\text { Cobre }\end{array}$ & $\begin{array}{l}\mathrm{R} 113 / \\
2 \phi\end{array}$ & $\begin{array}{c}2540 \mathrm{e} \\
510\end{array}$ & 3 e 14 & $28.6 / \mathrm{H}$ & $\begin{array}{c}139,8 / \\
(10-32)\end{array}$ & $\begin{array}{c}31-150 \\
120-480\end{array}$ & - & $\mathrm{FCC}, \Delta p$ \\
\hline$\frac{\text { Peng et al. }}{\text { (1996) }}$ & $\begin{array}{c}\text { Paralelo / } \\
\text { Retangular/ } \\
\text { Aço } \\
\text { Inoxidável }\end{array}$ & $\begin{array}{l}\text { Água- } \\
\text { Metanol/ } \\
2 \phi\end{array}$ & $\begin{array}{l}400 \times 200 \\
400 \times 300 \\
300 \times 200 \\
300 \times 300 \\
200 \times 200 \\
200 \times 300 \\
100 \times 200 \\
100 \times 300\end{array}$ & ${ }^{4} 6$ & $45 / \mathrm{H}$ & $\begin{array}{c}-/ \\
(17-27,5)\end{array}$ & $10-200$ & até 4000 & $\mathrm{~h}$ \\
\hline $\begin{array}{c}\text { Yan e Lin } \\
\text { (1998) }\end{array}$ & $\begin{array}{l}\text { Paralelo / } \\
\text { Circular/ - }\end{array}$ & $\begin{array}{l}\text { R134a/ } \\
1 \phi \text { e } 2 \phi\end{array}$ & 2000 & 28 & $200 / \mathrm{H}$ & $-/ 5-31(-)$ & $5-21$ & $50-200$ & $\mathrm{~h}, \Delta p$ \\
\hline $\begin{array}{c}\text { Qu e Mludawar } \\
\text { (2003b apud } \\
\text { Ravigururajan. } \\
\text { (1998) }\end{array}$ & $\begin{array}{c}\text { Paralelo / } \\
\text { Retangular/ } \\
-\end{array}$ & $\begin{array}{l}\mathrm{R} 124 / \\
2 \phi\end{array}$ & $20 \times 1000$ & 54 & $-/ \mathrm{H}$ & $-/(5-15)$ & - & - & $\mathrm{h}$ \\
\hline Rahman 2000) & $\begin{array}{c}\text { Paralelo e } \\
\text { Serpen- } \\
\text { tina(U)/ } \\
\text { Retangular/ } \\
\text { Silício }\end{array}$ & Água/ & $\begin{array}{l}1000 \times 278 \\
1000 \times 254 \\
1000 \times 221 \\
U 1000 \times 325 \\
U 1000 \times 193 \\
U 1000 \times 176\end{array}$ & $\begin{array}{l}12 \\
\mathrm{U} 4\end{array}$ & $46 / \mathrm{H}$ & $\begin{array}{c}10-550 / \\
(-)\end{array}$ & 1090 & $290-330$ & $\mathrm{~h}$ \\
\hline Qu et al. (2000) & $\begin{array}{l}\text { Paralelo/ } \\
\text { Trapezoi- } \\
\text { dal/ } \\
\text { Silício }\end{array}$ & $\begin{array}{l}\text { Água/ } \\
1 \phi\end{array}$ & $62-169$ & 5 & $30 / \mathrm{H}$ & $-/(-)$ & - & - & $\mathrm{h}$ \\
\hline $\begin{array}{c}\text { Jiang et al. } \\
\text { (2001) }\end{array}$ & $\begin{array}{l}\text { Paralelo/ } \\
\text { Triangular/ } \\
\text { Silício }\end{array}$ & Água/ & $\begin{array}{l}50 \\
100\end{array}$ & $\begin{array}{c}35 \\
34\end{array}$ & $18,6 / \mathrm{H}$ & $240 /(-)$ & - & - & $\mathrm{FP}, \mathrm{CT}$ \\
\hline $\begin{array}{c}\text { Hetsroni et al. } \\
\text { (2001) }\end{array}$ & $\begin{array}{l}\text { Paralelo / } \\
\text { Triangular/ } \\
\text { Silício }\end{array}$ & $\underset{2 \phi}{\text { Água/ }}$ & $\begin{array}{c}129 \\
103\end{array}$ & $\begin{array}{c}21 \\
26\end{array}$ & $15 / \mathrm{H}$ & - & $80-360$ & - & CT, FP \\
\hline $\begin{array}{c}\text { Hetsroni et al. } \\
\text { (2002) }\end{array}$ & $\begin{array}{l}\text { Paralelo / } \\
\text { Triangular/ } \\
\text { Silício }\end{array}$ & $\begin{array}{l}\text { Vertrel } \\
\mathrm{XF} / 2 \phi\end{array}$ & 157 & 21 & $15 / \mathrm{H}$ & $\begin{array}{c}101,3 / \\
20-22(-)\end{array}$ & $20-60$ & $148-290$ & $\mathrm{FP}, \Delta p$ \\
\hline $\begin{array}{l}\text { Hetsroni et al. } \\
\text { (2003) }\end{array}$ & $\begin{array}{l}\text { Paralelo / } \\
\text { Triangular/ } \\
\text { Silício } \\
\end{array}$ & $\underset{2 \phi}{\text { Água/ }}$ & $\begin{array}{c}129 \\
103 \\
161 \\
\end{array}$ & $\begin{array}{l}21 \\
26 \\
17 \\
\end{array}$ & $15 / \mathrm{H}$ & - & $\begin{array}{l}80-300 \\
90-360 \\
51-500 \\
\end{array}$ & - & FP \\
\hline $\begin{array}{c}\text { Wexler } \text { et al. } \\
\text { (2003) }\end{array}$ & $\begin{array}{c}\text { Paralelo / } \\
\text { Circular/ } \\
\text { Cobre }\end{array}$ & $\begin{array}{l}\text { Água/ } \\
2 \phi\end{array}$ & $\begin{array}{c}1800 \\
1100 \\
600 \\
80 \\
\end{array}$ & $\begin{array}{l}24 \\
28 \\
141 \\
2214 \\
\end{array}$ & $\begin{array}{l}29 \\
36 \\
29 \\
23 / \mathrm{H} \\
\end{array}$ & - & até 1500 & - & $\mathrm{h}$ \\
\hline $\begin{array}{c}\text { Niño et al. } \\
\text { 2003) }\end{array}$ & $\begin{array}{l}\text { Paralelo/ } \\
\text { Retangular/ } \\
\text { PVC }\end{array}$ & $\begin{array}{c}\mathrm{R} 134 \mathrm{a} / \\
2 \phi\end{array}$ & 1580 & 6 & $-/ \mathrm{H}$ & - & - & 50-300 & FP \\
\hline $\begin{array}{l}\text { Qu e Mudawar } \\
\text { 2003a|2003b } \\
\text { e 2003c) }\end{array}$ & $\begin{array}{l}\text { Paralelo / } \\
\text { Retangular/ } \\
\text { Cobre }\end{array}$ & $\begin{array}{l}\text { Água/ } \\
2 \phi\end{array}$ & $231 \times 713$ & 21 & $44.8 / \mathrm{H}$ & $\begin{array}{l}202,6 /(30 \\
\text { e } 60)\end{array}$ & - & $\begin{array}{l}134,9- \\
400,1\end{array}$ & $\begin{array}{l}\text { INS }, \mathrm{h} \\
\quad \Delta p\end{array}$ \\
\hline
\end{tabular}

$* \mathrm{H}=>$ Horizontal; VU $=>$ Vertical escoamento ascendente; VD $=>$ Vertical escoamento descendo; I=> Inclinado

**RT $=>$ Resistência térmica; INS $=>$ Instabilidades; $\mathrm{CT}=>$ Controle de temperatura; $\Delta p=>$ Perda de pressão; $\mathrm{FP}=>$ Padrões de escoamento;

$\mathrm{h}=>$ Coeficiente de transferência de calor; $\mathrm{FCC}=>$ Fluxo crítico de calor ; FV=> Fração de vazio; TMM=> Transição macro micro-escala;

$\mathrm{RA}=>$ Razão de aspecto 
Tabela 2.11 (continuação). Estudos experimentais sobre dissipadores de calor baseados em multi-microcanais.

\begin{tabular}{|c|c|c|c|c|c|c|c|c|c|}
\hline Autor (ano) & $\begin{array}{l}\text { Configuração/ } \\
\text { Geometria/ } \\
\text { Material }\end{array}$ & $\begin{array}{l}\text { Fluido/ } \\
\mathbf{N}^{\circ} \text { fases }\end{array}$ & $\begin{array}{c}\text { Dimensões } \\
{[\mu m]} \\
D_{h}, w \times h\end{array}$ & $\begin{array}{c}\mathbf{N}^{\circ} \\
\text { Canais }\end{array}$ & $\begin{array}{l}\mathbf{L}[\mathrm{mm}] / \\
\text { Orien- } \\
\text { tação* }\end{array}$ & $\begin{array}{c}\text { Psat ou } \\
\text { Pin[kPa] } / \\
\text { Tsat(Tin) } \\
{\left[{ }^{\circ} \mathbf{C}\right]} \\
\end{array}$ & $\stackrel{\mathbf{q}^{\prime \prime}}{\left[\mathrm{kW} / \mathbf{m}^{2}\right.}$ & {$\left[\begin{array}{l}\mathbf{G} \\
{\left[\mathrm{kg} / \mathbf{m}^{2} \mathbf{s}\right]}\end{array}\right.$} & $\begin{array}{l}\text { Parâmetro } \\
\text { de estudo } \\
* *\end{array}$ \\
\hline $\begin{array}{c}\text { Qu e } \\
\text { Mudawar } \\
(2004)\end{array}$ & $\begin{array}{l}\text { Paralelo / } \\
\text { Retangular/ } \\
\text { Cobre }\end{array}$ & Água/ & $215 \times 821$ & 21 & $44,8 / \mathrm{H}$ & $\begin{array}{l}202,6 /(30 \\
\text { e } 60)\end{array}$ & $\begin{array}{c}15- \\
184,5\end{array}$ & $86-368$ & FCC \\
\hline $\begin{array}{l}\text { Steinke e } \\
\text { Kandlikar } \\
(2004)\end{array}$ & $\begin{array}{l}\text { Paralelo/ } \\
\text { Retangular/ } \\
\text { Cobre }\end{array}$ & $\begin{array}{l}\text { Água/1 } \phi \\
\text { e } 2 \phi\end{array}$ & $\begin{array}{c}207, \\
214 \times 200\end{array}$ & 6 & $\begin{array}{c}57,15 / \\
\mathrm{H}\end{array}$ & $\begin{array}{l}126,6- \\
202,6 / \\
(22)\end{array}$ & $5-930$ & $\begin{array}{l}157- \\
1782\end{array}$ & h, INS \\
\hline $\begin{array}{l}\text { Yun et al. } \\
\text { (2004) }\end{array}$ & $\begin{array}{c}\text { Paralelo / } \\
\text { Retangular/ } \\
\text { Alumínio }\end{array}$ & $\mathrm{R} 410 \mathrm{~A} / 2 \phi$ & $\begin{array}{c}1440 \text { e } \\
1360\end{array}$ & $7_{8}$ & $-/ \mathrm{H}$ & $\begin{array}{c}-/ 0,5 \text { e } 10 \\
(-)\end{array}$ & $\begin{array}{c}10,15 \mathrm{e} \\
20\end{array}$ & $200-400$ & h, $\Delta p$ \\
\hline \begin{tabular}{|c|} 
Sempértegui- \\
Tap1a e \\
Ribatsk1 \\
(2013) apud \\
$\frac{\text { K1m et al. }}{(2004)}$
\end{tabular} & $\begin{array}{l}\text { Paralelo / } \\
\text { Retangular/ } \\
\text { Alumínio }\end{array}$ & $\mathrm{R} 22 / 2 \phi$ & $\begin{array}{c}1440 \text { e } \\
1360\end{array}$ & 7 & $-/ \mathrm{H}$ & $\begin{array}{c}-/ 5 \text { e } 15 \\
(-)\end{array}$ & $5-15$ & $200-600$ & $\mathrm{~h}$ \\
\hline$\frac{\text { Wu e Cheng }}{(2004)}$ & $\begin{array}{l}\text { Paralelo / } \\
\text { Trapezoidal/ } \\
\text { Silício }\end{array}$ & $\begin{array}{c}\text { Água e } \\
\text { Meta- } \\
\text { nol/ } \\
2 \phi\end{array}$ & 186 & 8 & $30 / \mathrm{H}$ & $-/ 100(-)$ & $135-226$ & $112-146$ & INS \\
\hline $\begin{array}{l}\text { Xu et al. } \\
(2005 \mathrm{a} \text { e } \\
2005 \mathrm{~b})\end{array}$ & $\begin{array}{l}\text { Paralelo / } \\
\text { Triangular/ } \\
\text { Silício }\end{array}$ & Acetona $/ 2 \phi$ & $\begin{array}{c}155,4 \\
300 \times 212\end{array}$ & 10 & $21,45 / \mathrm{H}$ & $(24-45)$ & $150-480$ & $64-600$ & h, FP \\
\hline$\frac{\mathrm{Xu} \text { et al. }}{(2005 \mathrm{c})}$ & $\begin{array}{c}\text { Paralelo / } \\
\text { Retangular/ } \\
\text { Cobre }\end{array}$ & $\begin{array}{c}\text { Água e } \\
\text { Meta- } \\
\text { nol/ } \\
2 \phi\end{array}$ & $300 \times 800$ & 26 & $50 / \mathrm{H}$ & $\begin{array}{c}-/(30,50 \\
\text { e } 70)\end{array}$ & $\begin{array}{l}130,7- \\
588,2\end{array}$ & $20-1200$ & INS \\
\hline $\begin{array}{c}\text { Zhang et al. } \\
(2005)\end{array}$ & $\begin{array}{c}\text { Paralelo / } \\
\text { Retangular/ - }\end{array}$ & $\underset{1 \phi}{\text { Água/ }}$ & $210 \times 2000$ & 21 & $15 / \mathrm{H}$ & - & $\begin{array}{l}277,7- \\
590,2\end{array}$ & $\begin{array}{l}189- \\
1893\end{array}$ & $\mathrm{RT}, \Delta p$ \\
\hline $\begin{array}{l}\text { Lee } \text { et al. } \\
\text { (2005) }\end{array}$ & $\begin{array}{l}\text { Paralelo/ } \\
\text { Retangular/ } \\
\text { Cobre }\end{array}$ & $\begin{array}{l}\text { Água/ } \\
1 \phi\end{array}$ & $\begin{array}{l}318,387 \\
501,575 \\
\text { e } 903\end{array}$ & 10 & $25,4 / \mathrm{H}$ & - & $\approx 450$ & - & $\mathrm{h}$ \\
\hline $\begin{array}{l}\text { Lee e } \\
\text { Mudawar } \\
(2005 \mathrm{a} \text { e } \\
2005 \mathrm{~b}\end{array}$ & $\begin{array}{l}\text { Paralelo / } \\
\text { Retangular/ } \\
\text { Cobre }\end{array}$ & $\begin{array}{c}\mathrm{R} 134 \mathrm{a} / \\
2 \phi\end{array}$ & $231 \times 713$ & 53 & $25,3 / \mathrm{H}$ & $\begin{array}{c}145,8- \\
668,6 / \\
(-)\end{array}$ & $316-938$ & $127-654$ & $\begin{array}{l}\mathrm{h}, \Delta p \\
\text { INS }\end{array}$ \\
\hline $\begin{array}{c}\text { Hetsroni et al. } \\
\text { 2005 }\end{array}$ & $\begin{array}{l}\text { Paralelo/ } \\
\text { Triangular/ } \\
\text { Silício }\end{array}$ & Água/ & 129 & 21 & $15 / \mathrm{H}$ & $-/ 100(-)$ & $80-330$ & $95-340$ & h, FP, INS \\
\hline$\frac{\text { Liu et al. }}{(2005 b)}$ & $\begin{array}{l}\text { Paralelo / } \\
\text { Retangular/ } \\
\text { Cobre }\end{array}$ & $\begin{array}{c}\text { Água } \\
\text { deioni- } \\
\text { zada/ } \\
2 \phi\end{array}$ & $275 \times 636$ & 25 & $25,4 / \mathrm{H}$ & $\begin{array}{c}-/ \\
(41,2-92)\end{array}$ & $\begin{array}{l}100,7- \\
731,6\end{array}$ & - & $\mathrm{h}$ \\
\hline \begin{tabular}{|c|} 
Kandlikar $e t$ \\
al.(2005)
\end{tabular} & $\begin{array}{l}\text { Paralelo / } \\
\text { Retangular/ } \\
\text { Cobre }\end{array}$ & $\begin{array}{l}\text { Água/ } \\
2 \phi\end{array}$ & $1054 \times 197$ & 6 & $63,5 / \mathrm{H}$ & - & $\begin{array}{c}298 \mathrm{e} \\
308\end{array}$ & 120 & INS \\
\hline \begin{tabular}{|c|} 
Balasubraman \\
e Kandlikar \\
(2005) \\
\end{tabular} & $\begin{array}{l}\text { Paralelo / } \\
\text { Retangular/ } \\
\text { Cobre }\end{array}$ & Água/ & $990 \times 207$ & 6 & $63,5 / \mathrm{H}$ & - & $208-316$ & $\begin{array}{c}112 \mathrm{e} \\
120\end{array}$ & $\begin{array}{l}\mathrm{FP}, \Delta p \\
\quad \mathrm{INS}\end{array}$ \\
\hline Kosar et al. & $\begin{array}{l}\text { Paralelo / } \\
\text { Retangular/ } \\
\text { Silício }\end{array}$ & Água/ & $200 \times 264$ & 5 & $10 / \mathrm{H}$ & $\begin{array}{l}101,3 / \\
100(-)\end{array}$ & $90-6140$ & 115-389 & INS , FCC \\
\hline $\begin{array}{c}\text { Yun et al. } \\
2006)\end{array}$ & $\begin{array}{l}\text { Paralelo / } \\
\text { Retangular/ } \\
\text { Silício }\end{array}$ & $\begin{array}{c}\mathrm{R} 410 \mathrm{~A} / \\
2 \phi\end{array}$ & $\begin{array}{c}1360 \mathrm{e} \\
1440\end{array}$ & 7 e 8 & $-/ \mathrm{H}$ & $\begin{array}{c}-/ 0 ; 5 \mathrm{e} \\
10(-)\end{array}$ & $10-20$ & $200-400$ & $\mathrm{~h}, \Delta p$ \\
\hline $\begin{array}{c}\text { Jones e } \\
\text { Garimella } \\
(2006)\end{array}$ & $\begin{array}{l}\text { Paralelo/ } \\
\text { Retangular/ } \\
\text { Silício }\end{array}$ & $\begin{array}{l}\text { Água/ } \\
1 \phi\end{array}$ & $110 \times 371$ & 67 & 9/ H & - & - & - & $\mu$-PIV \\
\hline $\begin{array}{l}\text { Chen e } \\
\text { Garimella } \\
\text { (2006) }\end{array}$ & $\begin{array}{l}\text { Paralelo / } \\
\text { Retangular/ } \\
\text { Silício }\end{array}$ & $\begin{array}{c}\mathrm{FC} 77 / \\
2 \phi\end{array}$ & $389 \times 389$ & 24 & $25,4 / \mathrm{H}$ & $-/ 97(71)$ & $\begin{array}{c}542, \\
673 \mathrm{e} \\
730\end{array}$ & - & $\mathrm{h}, \Delta p, \mathrm{FP}$ \\
\hline $\begin{array}{c}\text { Schneider et } \\
\text { al. }(2006 \mathrm{e} \\
2007)\end{array}$ & $\begin{array}{c}\text { Paralelo / } \\
\text { Retangular/ } \\
\text { Cobre }\end{array}$ & $\begin{array}{l}\mathrm{R} 123 / \\
2 \phi\end{array}$ & $200 \times 264$ & 5 & $10 / \mathrm{H}$ & - & $\begin{array}{l}390- \\
5580\end{array}$ & até 1814 & INS \\
\hline$\frac{\text { Chang e Pan }}{(2007)}$ & $\begin{array}{l}\text { Paralelo / } \\
\text { Retangular/ } \\
\text { Silício }\end{array}$ & $\begin{array}{l}\text { Água } \\
\text { deioni- } \\
\text { zada/ } \\
2 \phi\end{array}$ & $99,4 \times 76,3$ & 15 & $20 / \mathrm{H}$ & $\begin{array}{l}101,3 / \\
100(-)\end{array}$ & até 87,7 & até 110 & FP, INS \\
\hline$\frac{\text { Hardt et al. }}{(2007)}$ & $\begin{array}{c}\text { Paralelo / } \\
\text { Retangular/ } \\
\text { Polímero } \\
\text { Cycle Olefin, } \\
\text { Silício }\end{array}$ & $\begin{array}{c}2- \\
\text { propanol } \\
\text { e Água/ } \\
2 \phi\end{array}$ & $\begin{array}{l}50 \times 50 \\
30 \times 30\end{array}$ & 300,16 & $\begin{array}{c}64,5 \mathrm{e} \\
43,5 / \mathrm{H}\end{array}$ & $\begin{array}{c}-/ 82,3 \mathrm{e} \\
100(-)\end{array}$ & - & $\begin{array}{l}\text { até } \\
\approx 120\end{array}$ & FP \\
\hline $\begin{array}{c}\text { Liu e } \\
\text { Garimella } \\
(2007)\end{array}$ & $\begin{array}{l}\text { Paralelo / } \\
\text { Retangular/ } \\
\text { Cobre }\end{array}$ & $\underset{2 \phi}{\text { Água/ }}$ & $\begin{array}{l}275 \times 636, \\
406 \times 1063\end{array}$ & 25 & $25,4 / \mathrm{H}$ & - / (67-95) & até 1290 & $\begin{array}{l}221- \\
1283\end{array}$ & $\mathrm{~h}$ \\
\hline $\begin{array}{c}\text { Cullion } \text { et al. } \\
\text { (2007) }\end{array}$ & $\begin{array}{l}\text { Ramificado / } \\
\text { Retangular/ } \\
\text { Silício }\end{array}$ & $\begin{array}{l}\text { Água/ } \\
2 \phi\end{array}$ & 138 a 276 & $16-256$ & $\begin{array}{l}1,45 \mathrm{a} \\
5,8 / \mathrm{H}\end{array}$ & $107 /(88)$ & 58 & - & FV \\
\hline
\end{tabular}


Tabela 2.11 (continuação). Estudos experimentais sobre dissipadores de calor baseados em multi-microcanais.

\begin{tabular}{|c|c|c|c|c|c|c|c|c|c|}
\hline Autor (ano) & $\begin{array}{c}\text { Configuração/ } \\
\text { Geometria/ } \\
\text { Material }\end{array}$ & $\begin{array}{l}\text { Fluido/ } \\
\mathbf{N}^{\circ} \text { fases }\end{array}$ & $\begin{array}{c}\text { Dimensões } \\
{[\mu m]} \\
D_{h}, w \times x h\end{array}$ & $\begin{array}{c}\mathbf{N}^{\circ} \\
\text { Canais }\end{array}$ & $\begin{array}{l}\text { L [mm]/ } \\
\text { Orien- } \\
\text { tação* }\end{array}$ & $\begin{array}{c}\text { Psat ou } \\
\text { Pin[kPa]/ } \\
\text { Tsat(Tin) } \\
{\left[{ }^{\circ} \mathbf{C}\right]}\end{array}$ & $\begin{array}{c}\mathbf{q u}^{\prime \prime} \\
{\left[\mathrm{kW} / \mathrm{m}^{2}\right.}\end{array}$ & $\begin{array}{c}\mathbf{G} \\
{\left[\mathrm{kg} / \mathrm{m}^{2} \mathrm{~s}\right]}\end{array}$ & $\begin{array}{c}\text { Parâmetro } \\
\text { de estudo } \\
* *\end{array}$ \\
\hline $\begin{array}{c}\text { Garrity et al. } \\
2007 \text {. }\end{array}$ & $\begin{array}{c}\text { Paralelo / } \\
\text { Retangular/ - }\end{array}$ & $\begin{array}{c}\text { HFE- } \\
7100 / \\
2 \phi\end{array}$ & $1000 \times 1000$ & 56 & $115 / \mathrm{H}$ & $\begin{array}{c}101,3 / \\
61(-)\end{array}$ & até 32 & - & $\Delta p$ \\
\hline $\begin{array}{c}\text { Henning } \text { et al. } \\
2007 \text {. }\end{array}$ & $\begin{array}{c}\text { Ramificado / } \\
\text { Retangular/ } \\
\text { Aço } \\
\text { Inoxidável }\end{array}$ & $\begin{array}{c}\text { Água/ } \\
2 \phi\end{array}$ & $200 \times 100$ & 68,103 & $10 / \mathrm{H}$ & - & - & 49 & INS \\
\hline $\begin{array}{c}\text { Colgan } \text { et al. } \\
2007)\end{array}$ & $\begin{array}{c}\text { Cruzado / - / } \\
\text { Silício } \\
\end{array}$ & $\begin{array}{c}\text { Água/ } \\
1 \phi\end{array}$ & 104 a 143 & $18-31$ & $-/ \mathrm{H}$ & $\begin{array}{c}-/(-40 a \\
22)\end{array}$ & até 5000 & até 8674 & RT \\
\hline$\frac{\text { Koşar e Peles }}{2007 a}$ & $\begin{array}{c}\text { Paralelo / } \\
\text { Retangular/ } \\
\text { Silício } \\
\end{array}$ & $\begin{array}{c}\mathrm{R} 123 / \\
1 \phi \text { e } 2 \phi\end{array}$ & $200 \times 264$ & 5 & $10 / \mathrm{H}$ & $\begin{array}{c}227- \\
520 /(-)\end{array}$ & $\begin{array}{l}530- \\
1960\end{array}$ & $\begin{array}{l}291- \\
1118\end{array}$ & $\mathrm{FCC}, \mathrm{FP}$ \\
\hline$\frac{\text { Kuo e Peles }}{2007}$ & $\begin{array}{c}\text { Ramificado / } \\
\text { Retangular/ } \\
\text { Silício }\end{array}$ & $\begin{array}{c}\text { Água/ } \\
2 \phi\end{array}$ & $200 \times 253$ & 5 & $10 / \mathrm{H}$ & $\begin{array}{c}101,3 / \\
22(-)\end{array}$ & 6430 & 83-303 & $\mathrm{h}$ \\
\hline$\frac{\text { Koşar e Peles }}{2007 \mathrm{~b}}$ & $\begin{array}{c}\text { Cruzado / - / } \\
\text { Silício } \\
\end{array}$ & $\begin{array}{c}\text { R123/ } \\
1 \phi \text { e } 2 \phi\end{array}$ & $\approx 83$ & - & $-/ \mathrm{H}$ & - & $\begin{array}{l}190- \\
3120 \\
\end{array}$ & $\begin{array}{l}976- \\
2349 \\
\end{array}$ & $\begin{array}{c}\mathrm{h}, \mathrm{FCC}, \\
\text { FP } \\
\end{array}$ \\
\hline \begin{tabular}{|c|} 
Muwanga et \\
al. 2007)
\end{tabular} & $\begin{array}{l}\text { Paralelo e } \\
\text { Cruzado / } \\
\text { Retangular/ } \\
\text { Silício }\end{array}$ & $\begin{array}{c}\text { Água/ } \\
2 \phi\end{array}$ & $269 \times 283$ & 45 & $16 / \mathrm{H}$ & $\begin{array}{c}-/(70 \mathrm{e} \\
80)\end{array}$ & até $\approx 96$ & $91-228$ & INS \\
\hline$\frac{\text { Wang } \text { et al. }}{2007 \mathrm{e} 2008}$ & $\begin{array}{c}\text { Paralelo / } \\
\text { Trapezoidal/ } \\
\text { Silício }\end{array}$ & $\begin{array}{c}\text { Água/ } \\
2 \phi\end{array}$ & 186 & 8 & $30 / \mathrm{H}$ & $-/(35)$ & $\begin{array}{c}184,2- \\
497,8\end{array}$ & $\begin{array}{c}\text { até } \\
787,2\end{array}$ & FP, INS \\
\hline $\begin{array}{c}\text { Bertsch } \text { et al. } \\
2008 \mathrm{e} \\
2009 \mathrm{a}\end{array}$ & $\begin{array}{l}\text { Paralelo / } \\
\text { Retangular/ } \\
\text { Cobre }\end{array}$ & $\begin{array}{l}\mathrm{R} 134 \mathrm{a} \mathrm{e} \\
\mathrm{R}-245 \mathrm{fa} / \\
1 \phi \text { e } 2 \phi\end{array}$ & $\begin{array}{c}762 \times 1905 \\
381 \times 953\end{array}$ & 17 e 33 & $9,53 /-$ & $\begin{array}{c}145 \text { e } 630 \\
18-30 \\
(24,2 \mathrm{e} \\
23,2)\end{array}$ & $0-220$ & $20-350$ & h, FP \\
\hline$\frac{\text { Jang et al. }}{2008}$ & $\begin{array}{l}\text { Paralelo / } \\
\text { Circular/ } \\
\text { Cobre }\end{array}$ & $\begin{array}{c}\text { FC77/ } \\
2 \phi\end{array}$ & $\begin{array}{c}2000 \mathrm{e} \\
4000\end{array}$ & 9 & $100 /-$ & $\begin{array}{c}67,2- \\
181,8 / \\
(45-75)\end{array}$ & $5-300$ & $\begin{array}{c}132,7- \\
663,1\end{array}$ & $\mathrm{~h}, \Delta p$ \\
\hline \begin{tabular}{|c|} 
Agostini et al. \\
2008a 2008b \\
2008c
\end{tabular} & $\begin{array}{l}\text { Paralelo / } \\
\text { Retangular/ } \\
\text { Silício }\end{array}$ & $\begin{array}{c}\text { R245fa } \\
\text { e } \\
\text { R236fa/ } \\
2 \phi\end{array}$ & $223 \times 680$ & 67 & $20 / \mathrm{H}$ & $\begin{array}{l}141-273 \\
/(25-43)\end{array}$ & $36-2500$ & $\begin{array}{l}276- \\
1500\end{array}$ & $\begin{array}{c}\mathrm{h}, \Delta p, \\
\mathrm{FCC}\end{array}$ \\
\hline \begin{tabular}{|c|} 
Harirchian e \\
Garimella \\
2008 \\
2009 \\
2010 e 2012 \\
\end{tabular} & $\begin{array}{l}\text { Paralelo / } \\
\text { Retangular/ } \\
\text { Silício }\end{array}$ & $\begin{array}{c}\text { FC77/ } \\
2 \phi\end{array}$ & $\begin{array}{c}100 \times 100 \\
100 \times 220 \\
100 \times 400 \\
250 \times 400 \\
400 \times 100 \\
400 \times 220 \\
400 \times 400 \\
700 \times 400 \\
1000 \times 220 \\
1000 \times 400 \\
2200 \times 400 \\
5850 \times 400\end{array}$ & $\begin{array}{l}61 \\
63 \\
60 \\
35 \\
25 \\
25 \\
24 \\
14 \\
10 \\
10 \\
5 \\
2\end{array}$ & $12,7 / \mathrm{H}$ & $\begin{array}{c}101,3 / \\
97(-)\end{array}$ & até 650 & $\begin{array}{l}225- \\
1600\end{array}$ & $\begin{array}{c}\mathrm{h}, \Delta p, \\
\mathrm{TMM}, \mathrm{FP}\end{array}$ \\
\hline \begin{tabular}{|c|} 
Bogojevic et \\
al. $2008 \mathrm{e}$ \\
2009
\end{tabular} & $\begin{array}{l}\text { Paralelo / } \\
\text { Retangular/ } \\
\text { Silício }\end{array}$ & $\begin{array}{c}\text { Água/ } \\
2 \phi\end{array}$ & $150 \times 200$ & 40 & $15 / \mathrm{H}$ & $-/(54)$ & 213-713 & $97-325$ & INS \\
\hline $\begin{array}{c}\text { Dixit et al. } \\
2008\end{array}$ & $\begin{array}{c}\text { Paralelo / } \\
\text { Retangular/ } \\
\text { Silício }\end{array}$ & $\begin{array}{c}\text { Água/ } \\
1 \phi\end{array}$ & $50 \times 400$ & 300 & $10 / \mathrm{H}$ & - & 510 & 1041,5 & RT \\
\hline \begin{tabular}{|l|} 
Phillips \\
2008 \\
\end{tabular} & $\begin{array}{c}\text { Paralelo / } \\
\text { Retangular/ } \\
\text { Cobre }\end{array}$ & $\begin{array}{c}\text { Água/ } \\
1 \phi\end{array}$ & $178 \times 341$ & 26 & $\begin{array}{c}17,32 / \\
\mathrm{H}\end{array}$ & $-/(80)$ & - & - & $\mathrm{h}, \Delta p$ \\
\hline
\end{tabular}

$* \mathrm{H}=>$ Horizontal; VU=> Vertical escoamento ascendente; VD=> Vertical escoamento descendo; I=> Inclinado

**RT $=>$ Resistência térmica; INS $=>$ Instabilidades; $\mathrm{CT}=>$ Controle de temperatura; $\Delta p=>$ Perda de pressão; $\mathrm{FP}=>\mathrm{Padrões}$ de escoamento; $\mathrm{h}=>$ Coeficiente de transferência de calor; $\mathrm{FCC}=>$ Fluxo crítico de calor ; FV=> Fração de vazio; TMM=> Transição macro micro-escala; $\mathrm{RA}=>$ Razão de aspecto 
Tabela 2.11 (continuação). Estudos experimentais sobre dissipadores de calor baseados em multi-microcanais.

\begin{tabular}{|c|c|c|c|c|c|c|c|c|c|}
\hline Autor (ano) & $\begin{array}{c}\text { Configuração/ } \\
\text { Geometria/ } \\
\text { Material }\end{array}$ & $\begin{array}{c}\text { Fluido/ } \\
\mathbf{N}^{\circ} \text { fases }\end{array}$ & $\begin{array}{c}\text { Dimensões } \\
{[\mu m]} \\
D_{h}, w \times h\end{array}$ & $\begin{array}{c}\mathbf{N}^{\circ} \\
\text { Canais }\end{array}$ & $\begin{array}{l}\text { L [mm]/ } \\
\text { Orien- } \\
\text { tação* }\end{array}$ & $\begin{array}{c}\text { Psat ou } \\
\text { Pin[kPa]/ } \\
\text { Tsat(Tin) } \\
{\left[{ }^{\circ} \mathrm{C}\right]} \\
\end{array}$ & $\begin{array}{c}\mathbf{q}^{\prime \prime} \\
{\left[\mathrm{kW} / \mathbf{m}^{2}\right.}\end{array}$ & $\begin{array}{c}\mathbf{G} \\
{\left[\mathrm{kg} / \mathrm{m}^{2} \mathrm{~s}\right]}\end{array}$ & $\begin{array}{c}\text { Parâmetro } \\
\text { de estudo } \\
* *\end{array}$ \\
\hline $\begin{array}{c}\text { Lee e } \\
\text { Garimella } \\
2008)\end{array}$ & $\begin{array}{l}\text { Paralelo / } \\
\text { Retangular/ } \\
\text { Silício }\end{array}$ & $\begin{array}{c}\text { Água/ } \\
2 \phi\end{array}$ & $\begin{array}{c}98 \times 367 \\
108 \times 365 \\
100 \times 398 \\
243 \times 369\end{array}$ & $\begin{array}{c}60 \\
35 \\
24 \\
10\end{array}$ & $12,7 / \mathrm{H}$ & $-/(90-95)$ & $\begin{array}{l}100- \\
3400\end{array}$ & - & $\mathrm{h}, \Delta p$ \\
\hline$\frac{\text { Lu e Pan }}{2008 \mathrm{e} 2009}$ & $\begin{array}{c}\text { Paralelo / } \\
\text { Retangular } \\
\text { Divergente/ } \\
\text { Silício }\end{array}$ & $\begin{array}{c}\text { Água/ } \\
2 \phi\end{array}$ & $\begin{array}{c}h=76 \\
\theta_{d i v}= \\
0,5^{\circ}\end{array}$ & 10 & $26 / \mathrm{H}$ & - & $171-450$ & $99-297$ & $\begin{array}{c}\mathrm{FP}, \mathrm{INS}, \\
\quad \Delta p\end{array}$ \\
\hline $\begin{array}{c}\text { Lee e } \\
\text { Mudawar } \\
2009\end{array}$ & $\begin{array}{c}\text { Paralelo / } \\
\text { Retangular/ } \\
\text { Silício }\end{array}$ & $\begin{array}{l}\text { HFE7100/ } \\
2 \phi\end{array}$ & $\begin{array}{c}223 \times 305 \\
223 \times 527 \\
235 \times 577 \\
260 \times 1041\end{array}$ & $\begin{array}{c}24 \\
24 \\
11 \\
11\end{array}$ & $10 / \mathrm{H}$ & $\begin{array}{c}118-150 / \\
(-31 \mathrm{a} \\
20)\end{array}$ & $183-693$ & $\begin{array}{c}670- \\
2345,5\end{array}$ & $\begin{array}{l}\text { FCC, } \\
\text { TMM }\end{array}$ \\
\hline$\frac{\text { Singh et al. }}{2009}$ & $\begin{array}{c}\text { Paralelo / } \\
\text { Trapezoidal/ } \\
\text { Silício }\end{array}$ & $\begin{array}{c}\text { Água/ } \\
2 \phi\end{array}$ & 109 & 4 & $20 / \mathrm{H}$ & $-/(15-46)$ & $0-300$ & $44-1114$ & $\Delta p$ \\
\hline $\begin{array}{c}\text { Megahed e } \\
\text { Hassan } \\
2009\end{array}$ & $\begin{array}{c}\text { Paralelo / } \\
\text { Retangular/ } \\
\text { Silício }\end{array}$ & $\begin{array}{c}\mathrm{FC} 72 / \\
2 \phi\end{array}$ & $225 \times 276$ & 45 & $16 / \mathrm{H}$ & $\begin{array}{c}345 \text { e } 517 \\
\quad /(\approx 52)\end{array}$ & $\begin{array}{l}60,4- \\
130,6\end{array}$ & $341-531$ & $\Delta p$ \\
\hline Xu et al. & $\begin{array}{c}\text { Paralelo / } \\
\text { Triangular/ } \\
\text { Silício }\end{array}$ & $\begin{array}{c}\text { Acetona/ } \\
2 \phi\end{array}$ & 130 & 5 & $4,5 / \mathrm{H}$ & $-/(50-56)$ & $439-936$ & $378-898$ & INS \\
\hline $\begin{array}{c}\text { Hsieh e Lin } \\
2010\end{array}$ & $\begin{array}{c}\text { Paralelo / } \\
\text { Retangular/ } \\
\text { Cobre }\end{array}$ & $\begin{array}{c}\text { Água, } \\
\text { FC72/ } \\
2 \phi\end{array}$ & $100 \times 200$ & 75 & $30 / \mathrm{H}$ & $-/(15-64)$ & até 8000 & $\begin{array}{l}820- \\
1600\end{array}$ & $\begin{array}{c}\text { FP, INS, } \\
\text { FCC, } \\
\mu \mathrm{PIV}\end{array}$ \\
\hline $\begin{array}{c}\text { Borhani et al. } \\
2010\end{array}$ & $\begin{array}{c}\text { Paralelo / } \\
\text { Retangular/ } \\
\text { Silício }\end{array}$ & $\begin{array}{c}\mathrm{R} 245 \mathrm{fa} / \\
2 \phi\end{array}$ & $223 \times 680$ & 67 & $20 / \mathrm{H}$ & - & $20-260$ & 100 & FP, INS \\
\hline $\begin{array}{c}\text { Cho et al. } \\
\frac{(2010)}{}\end{array}$ & $\begin{array}{c}\text { Paralelo / } \\
\text { Retangular e } \\
\text { Divergente/ } \\
\text { Silício }\end{array}$ & $\begin{array}{c}\mathrm{R} 123 / \\
2 \phi\end{array}$ & $\begin{array}{c}300 \times 300 \\
\mathrm{e} \mathrm{h}=300 \\
\theta_{d i v}= \\
0,2864^{\circ}\end{array}$ & 33 & $20 / \mathrm{H}$ & - & $\begin{array}{l}40 \mathrm{e} \\
120\end{array}$ & $30-91$ & $\mathrm{CT}$ \\
\hline$\frac{\text { Koşar et al. }}{(2010)}$ & $\begin{array}{c}\text { Cruzado / - / } \\
\text { Silício }\end{array}$ & $\begin{array}{c}\text { Água e } \\
\text { R123/ } \\
2 \phi\end{array}$ & $\approx 83$ & - & $-/ \mathrm{H}$ & - & $\begin{array}{l}\text { até } \\
\approx 280\end{array}$ & $\begin{array}{l}351- \\
1351\end{array}$ & $\Delta p$, INS \\
\hline$\frac{\text { Krebs et al. }}{2010}$ & $\begin{array}{c}\text { Ramificado / } \\
\text { Retangular / } \\
\text { Silício }\end{array}$ & $\begin{array}{c}\mathrm{R} 123 / \\
2 \phi\end{array}$ & $\begin{array}{l}400 \times 250 \\
283 \times 250 \\
200 \times 250 \\
141 \times 250 \\
100 \times 250\end{array}$ & $16-256$ & $\begin{array}{l}1,62 \mathrm{a} \\
6,4 / \mathrm{H}\end{array}$ & $-/(9$ a 22$)$ & 15 e 65 & $300-800$ & $\mathrm{CT}$ \\
\hline $\begin{array}{c}\text { Lee } e t a l . \\
2010\end{array}$ & $\begin{array}{c}\text { Paralelo, } \\
\text { Radial e } \\
\text { Cruzado / } \\
\text { Retangular / } \\
\text { Alumínio }\end{array}$ & $\begin{array}{c}\text { Água/ } \\
2 \phi\end{array}$ & $\begin{array}{c}235 \times 710 \\
114 \times 710 \\
\theta_{R}= \\
11,25^{\circ}\end{array}$ & 48 & $24 / \mathrm{H}$ & $-/(5-30)$ & $60-380$ & $25-114$ & INS \\
\hline$\frac{\text { Mauro et al. }}{2010}$ & $\begin{array}{c}\text { Paralelo / } \\
\text { Retangular / } \\
\text { Cobre }\end{array}$ & $\begin{array}{c}\text { R134a, } \\
\text { R236fa } \\
\text { e } \\
\text { R245fa/ } \\
2 \phi\end{array}$ & $199 \times 256$ & 29 & $30 / \mathrm{H}$ & $\begin{array}{c}-/ 20-50 \\
(-)\end{array}$ & até 3300 & $\begin{array}{l}250- \\
1500\end{array}$ & $\mathrm{FCC}, \Delta p$ \\
\hline$\frac{\text { Park e Thome }}{2010}$ & $\begin{array}{c}\text { Paralelo / } \\
\text { Retangular / } \\
\text { Cobre }\end{array}$ & $\begin{array}{c}\text { R134a, } \\
\text { R236fa } \\
\text { e } \\
\text { R245fa/ } \\
2 \phi\end{array}$ & $\begin{array}{c}467 \times 4062 \\
199 \times 756\end{array}$ & 20 e 29 & $30 / \mathrm{H}$ & $\begin{array}{c}-/ 10-50 \\
(-)\end{array}$ & $\begin{array}{l}370- \\
3420\end{array}$ & $\begin{array}{l}100- \\
4000\end{array}$ & FCC \\
\hline
\end{tabular}

$* \mathrm{H}=>$ Horizontal; VU=> Vertical escoamento ascendente; VD=> Vertical escoamento descendo; I=> Inclinado

**RT $=>$ Resistência térmica; INS => Instabilidades; $\mathrm{CT}=>$ Controle de temperatura; $\Delta p=>$ Perda de pressão; $\mathrm{FP}=>\mathrm{Padrões} \mathrm{de} \mathrm{escoamento;}$ $\mathrm{h}=>$ Coeficiente de transferência de calor; $\mathrm{FCC}=>$ Fluxo crítico de calor ; FV => Fração de vazio; TMM=> Transição macro micro-escala;

RA $=>$ Razão de aspecto 
Tabela 2.11(continuação). Estudos experimentais sobre dissipadores de calor baseados em multi-microcanais.

\begin{tabular}{|c|c|c|c|c|c|c|c|c|c|}
\hline Autor (ano) & $\begin{array}{l}\text { Configuração/ } \\
\text { Geometria/ } \\
\text { Material }\end{array}$ & $\begin{array}{c}\text { Fluido/ } \\
\mathbf{N}^{\circ} \text { fases }\end{array}$ & $\begin{array}{c}\text { Dimensões } \\
{[\mu m]} \\
D_{h}, w \times h\end{array}$ & $\begin{array}{c}\mathbf{N}^{\circ} \\
\text { Canais }\end{array}$ & $\begin{array}{l}\text { L [mm]/ } \\
\text { Orien- } \\
\text { tação* }\end{array}$ & $\begin{array}{c}\text { Psat ou } \\
\text { Pin[kPa]/ } \\
\text { Tsat(Tin) } \\
{\left[{ }^{\circ} \mathrm{C}\right]}\end{array}$ & $\begin{array}{c}\mathbf{q}^{\prime \prime} \\
{\left[\mathrm{kW} / \mathbf{m}^{2}\right]}\end{array}$ & $\frac{\mathbf{G}}{\left[\mathrm{kg} / \mathrm{m}^{2} \mathrm{~s}\right]}$ & $\begin{array}{c}\text { Parâmetro } \\
\text { de estudo } \\
* *\end{array}$ \\
\hline \begin{tabular}{|l|} 
Balasubraman \\
et al. (2011) \\
\end{tabular} & $\begin{array}{c}\text { Paralelo / } \\
\text { Retangular } \\
\text { divergente / } \\
\text { Cobre }\end{array}$ & $\begin{array}{c}\text { Água/ } \\
2 \phi\end{array}$ & $\begin{array}{l}322 \times 1153 \\
\text { até } \\
2115 \times 1190\end{array}$ & 40 & $25 / \mathrm{H}$ & - / (90) & até 1400 & $100-133$ & $\mathrm{~h}, \Delta p$ \\
\hline \begin{tabular}{|l|} 
Kaew-On et \\
$a l .(2011)$
\end{tabular} & $\begin{array}{c}\text { Paralelo / } \\
\text { Retangular / } \\
\text { Cobre }\end{array}$ & $\begin{array}{c}\mathrm{R} 134 \mathrm{a} / \\
2 \phi\end{array}$ & $\begin{array}{l}1000 \times 1250 \\
1800 \times 900\end{array}$ & 8 e 14 & $220 / \mathrm{H}$ & $\begin{array}{c}405,506 \text { e } \\
608 /(90)\end{array}$ & $15-65$ & $300-800$ & $\mathrm{~h}, \Delta p$ \\
\hline $\begin{array}{c}\text { Bogojevic et } \\
a l .2011\end{array}$ & $\begin{array}{c}\text { Paralelo / } \\
\text { Retangular / } \\
\text { Silício }\end{array}$ & $\begin{array}{c}\text { R134a/ } \\
2 \phi\end{array}$ & $150 \times 273$ & 40 & $15 / \mathrm{H}$ & $-/(71)$ & $0-650$ & 173 & INS \\
\hline$\frac{\text { Hu et al. }}{2011 .}$ & $\begin{array}{c}\text { Paralelo / } \\
\text { Retangular / } \\
\text { Cobre }\end{array}$ & $\begin{array}{c}\text { FC72/ } \\
2 \phi\end{array}$ & $800 \times 2000$ & 14 & $20 / \mathrm{H}$ & $\begin{array}{c}73 \text { e } 101 / \\
(-)\end{array}$ & $25-140$ & $71-250$ & $\mathrm{~h}, \Delta p$ \\
\hline \begin{tabular}{|c|} 
Costa-Patry et \\
al. 2011a e \\
$2011 \mathrm{~b}$
\end{tabular} & $\begin{array}{l}\text { Paralelo / } \\
\text { Retangular / } \\
\text { Silício }\end{array}$ & $\begin{array}{c}\text { R236fa } \\
\text { e } \\
\text { R245fa/ } \\
2 \phi\end{array}$ & $85 \times 560$ & 135 & $12,3 / \mathrm{H}$ & $-/(30,5)$ & $\begin{array}{l}130- \\
1400\end{array}$ & $\begin{array}{l}499- \\
1100\end{array}$ & $\Delta p, \mathrm{~h}$ \\
\hline$\frac{\text { Daniels et al. }}{2011}$ & $\begin{array}{l}\text { Ramificado / } \\
\text { Retangular/ } \\
\text { Silício }\end{array}$ & $\begin{array}{l}\text { Água/ } \\
2 \phi\end{array}$ & 138 a 276 & $16-256$ & $\begin{array}{l}1,45 \mathrm{a} \\
5,8 / \mathrm{H}\end{array}$ & - & - & $\begin{array}{l}434- \\
3906\end{array}$ & $\mathrm{FV}, \Delta p$ \\
\hline$\frac{\text { Lu e Pan }}{2011}$ & $\begin{array}{c}\text { Paralelo / } \\
\text { Retangular } \\
\text { divergente/ } \\
\text { Silício }\end{array}$ & $\begin{array}{l}\text { Água/ } \\
2 \phi\end{array}$ & $\begin{array}{c}h=76 \\
\theta_{d i v}= \\
0,5^{\circ}\end{array}$ & 10 & $26 / \mathrm{H}$ & $-/(28-48)$ & $\begin{array}{l}\text { até } \\
\approx 450\end{array}$ & $99-297$ & $\Delta p, \mathrm{~h}$ \\
\hline$\frac{\text { Megahed }}{2011}$ & $\begin{array}{c}\text { Paralelo / } \\
\text { Retangular / } \\
\text { Silício }\end{array}$ & $\begin{array}{c}\mathrm{FC} 72 / \\
2 \phi\end{array}$ & $225 \times 276$ & 45 & $16 / \mathrm{H}$ & $\begin{array}{c}345 \mathrm{e} \\
517 /(-)\end{array}$ & $\begin{array}{c}7,2- \\
104,2\end{array}$ & $99-290$ & $\begin{array}{c}\Delta p, \mathrm{~h}, \mathrm{FP} \\
\text { INS }\end{array}$ \\
\hline \begin{tabular}{|l} 
Madhour et \\
al. (2011)
\end{tabular} & $\begin{array}{c}\text { Paralelo / } \\
\text { Retangular / } \\
\text { Cobre }\end{array}$ & $\begin{array}{c}\mathrm{R} 134 \mathrm{a} / \\
2 \phi\end{array}$ & $100 \times 680$ & 100 & $15 / \mathrm{H}$ & $\begin{array}{c}1700 / \\
(60-63)\end{array}$ & $\begin{array}{l}25,7- \\
1890\end{array}$ & $\begin{array}{l}205- \\
1000\end{array}$ & $\Delta p, \mathrm{~h}$ \\
\hline \begin{tabular}{|c|} 
Costa-Patry et \\
$a l .2012$
\end{tabular} & $\begin{array}{c}\text { Paralelo / } \\
\text { Retangular / } \\
\text { Cobre }\end{array}$ & $\begin{array}{l}\text { R134a, } \\
\text { R1234ze(E) } \\
\text { e } \\
\text { R245fa/ } \\
2 \phi\end{array}$ & $163 \times 1560$ & 52 & $13,2 / \mathrm{H}$ & $\begin{array}{c}-/ 30-50 \\
()\end{array}$ & $\begin{array}{c}3,95- \\
403\end{array}$ & $205-570$ & $\Delta p, \mathrm{~h}$ \\
\hline $\begin{array}{c}\text { Do } \\
\text { Nascimento } \\
2012 \\
\end{array}$ & $\begin{array}{c}\text { Paralelo / } \\
\text { Retangular / } \\
\text { Cobre }\end{array}$ & $\begin{array}{l}\mathrm{R} 134 \mathrm{a} / \\
1 \phi \text { e } 2 \phi\end{array}$ & $100 \times 500$ & 50 & $15 / \mathrm{H}$ & $-/ 25(-)$ & até 310 & $\begin{array}{l}400- \\
1500\end{array}$ & $\Delta p, \mathrm{~h}$ \\
\hline$\frac{\text { Wang et al. }}{2012}$ & $\begin{array}{c}\text { Paralelo / } \\
\text { Retangular / } \\
\text { Cobre }\end{array}$ & $\begin{array}{l}\text { HFE7100/ } \\
2 \phi\end{array}$ & $2005 \times 520$ & 7 & $\begin{array}{c}25,4 / \mathrm{H}, \\
\mathrm{VU}, \mathrm{VD} \\
\text { e I }\end{array}$ & $110 /(-)$ & $\begin{array}{l}25 \mathrm{e} \\
37,5\end{array}$ & $\begin{array}{c}100 \\
200 \mathrm{e} \\
300\end{array}$ & $h, F P$ \\
\hline \begin{tabular}{|c|} 
Szczukiewicz \\
$2012)$, \\
\begin{tabular}{|c|} 
Szczukiewicz \\
et al. (2012 \\
$2013 \mathrm{a}$ \\
$2013 \mathrm{~b}) \mathrm{e}$ \\
$2013 \mathrm{c})$
\end{tabular} \\
\end{tabular} & $\begin{array}{c}\text { Paralelo/ } \\
\text { Retangular / } \\
\text { Silício }\end{array}$ & $\begin{array}{l}\text { R245fa, } \\
\text { R236fa } \\
\text { e } \\
\text { R1234ze(E)/ } \\
\quad 2 \phi\end{array}$ & $100 \times 100$ & 67 & $10 / \mathrm{H}$ & $\begin{array}{l}\text { até } 1013 \text { / } \\
(-)\end{array}$ & até 486 & $\begin{array}{l}283- \\
2370\end{array}$ & $\begin{array}{c}\mathrm{h}, \Delta p, \\
\text { INS }\end{array}$ \\
\hline$\frac{\text { Alam et al. }}{2013}$ & $\begin{array}{l}\text { Paralelo e } \\
\text { microporo/ } \\
\text { Retangular / } \\
\text { Cobre }\end{array}$ & $\begin{array}{c}\text { Água/ } \\
2 \phi\end{array}$ & $216 \times 386$ & 30 & $12,7 / \mathrm{H}$ & $-/(85)$ & 0 e 85 & $\begin{array}{l}400- \\
1000\end{array}$ & $\begin{array}{l}\Delta p, \mathrm{~h}, \\
\text { INS }\end{array}$ \\
\hline \begin{tabular}{|c|}
\multicolumn{1}{|c|}{ Do } \\
Nascimento \\
et al. (2013) \\
\end{tabular} & $\begin{array}{c}\text { Paralelo / } \\
\text { Retangular / } \\
\text { Cobre }\end{array}$ & $\begin{array}{c}\mathrm{R} 134 \mathrm{a} / \\
2 \phi\end{array}$ & $100 \times 500$ & 50 & $15 / \mathrm{H}$ & $-/ 25(-)$ & até 310 & $\begin{array}{l}400- \\
1500\end{array}$ & h \\
\hline$\frac{\text { Fu et al. }}{2013 .}$ & $\begin{array}{c}\text { Paralelo/ } \\
\text { Retangular } \\
\text { divergente/ } \\
\text { Cobre }\end{array}$ & $\begin{array}{l}\text { HFE7100/ } \\
2 \phi\end{array}$ & $400-1120$ & 6 & $20,5 / \mathrm{H}$ & - / $61(-)$ & $\begin{array}{l}\text { até } \\
\approx 280\end{array}$ & $39-180$ & h, FCC \\
\hline
\end{tabular}

\footnotetext{
$* \mathrm{H}=>$ Horizontal; VU=> Vertical escoamento ascendente; VD=> Vertical escoamento descendo; I=> Inclinado

$* * \mathrm{RT}=>$ Resistência térmica; INS $=>$ Instabilidades; $\mathrm{CT}=>$ Controle de temperatura; $\Delta p=>$ Perda de pressão; $\mathrm{FP}=>$ Padrões de escoamento; $\mathrm{h}=>$ Coeficiente de transferência de calor; FCC $=>$ Fluxo crítico de calor ; FV=> Fração de vazio; TMM=> Transição macro micro-escala; $\mathrm{RA}=>$ Razão de aspecto
} 
Tabela 2.11 (continuação). Estudos experimentais sobre dissipadores de calor baseados em multi-microcanais.

\begin{tabular}{|c|c|c|c|c|c|c|c|c|c|}
\hline Autor (ano) & $\begin{array}{c}\text { Configuração/ } \\
\text { Geometria/ } \\
\text { Material }\end{array}$ & $\begin{array}{c}\text { Fluido/ } \\
\mathbf{N}^{\circ} \text { fases }\end{array}$ & $\begin{array}{c}\text { Dimensões } \\
{[\mu m]} \\
D_{h}, w \times x h\end{array}$ & $\begin{array}{c}\mathbf{N}^{\circ} \\
\text { Canais }\end{array}$ & $\begin{array}{l}\text { L [mm]/ } \\
\text { Orien- } \\
\text { tação* }\end{array}$ & $\begin{array}{c}\text { Psat ou } \\
\text { Pin[kPa]/ } \\
\text { Tsat(Tin) } \\
{\left[{ }^{\circ} \mathbf{C}\right]} \\
\end{array}$ & $\begin{array}{c}\mathbf{q}^{\prime \prime} \\
{\left[\mathrm{kW} / \mathbf{m}^{2}\right.}\end{array}$ & $\underset{\left[\mathrm{kg} / \mathrm{m}^{2} \mathrm{~s}\right]}{\mathbf{G}}$ & $\begin{array}{l}\text { Parâmetro } \\
\text { de estudo } \\
* *\end{array}$ \\
\hline$\frac{\text { Kuznetsov et }}{\text { al. (2013) }}$ & $\begin{array}{c}\text { Paralelo / } \\
\text { Retangular / } \\
\text { Aço } \\
\text { Inoxidável }\end{array}$ & $\begin{array}{c}\text { R21 e } \\
\text { R134a/ } \\
2 \phi\end{array}$ & $640 \times 2050$ & 10 & $\begin{array}{c}120 / \mathrm{H} \mathrm{e} \\
\mathrm{VU}\end{array}$ & $\begin{array}{c}152-1114 \\
/(-)\end{array}$ & $10-160$ & $33-190$ & h, FP \\
\hline$\frac{\text { Leão et al. }}{2013)}$ & $\begin{array}{c}\text { Paralelo / } \\
\text { Retangular / } \\
\text { Cobre }\end{array}$ & $\begin{array}{c}\mathrm{R} 245 \mathrm{fa} / \\
2 \phi\end{array}$ & $100 \times 500$ & 50 & $15 / \mathrm{H} \mathrm{e} \mathrm{I}$ & $180 /(-)$ & até 320 & $\begin{array}{l}400- \\
1000\end{array}$ & $\Delta p, \mathrm{~h}$ \\
\hline \begin{tabular}{|c|} 
Zhuan e \\
Wang 2013$)$
\end{tabular} & $\begin{array}{c}\text { Cruzado / } \\
\text { Retangular / } \\
\text { Cobre }\end{array}$ & $\begin{array}{c}\mathrm{R} 134 \mathrm{a} / \\
2 \phi\end{array}$ & $500 \times 150$ & - & $80,5 / \mathrm{H}$ & $\begin{array}{c}\text { 390,4- } \\
879,1 / \\
(8-32)\end{array}$ & $1,46-25$ & $10-35$ & $\mathrm{~h}$ \\
\hline$\frac{\text { Leão et al. }}{\text { (2014 }}$ & $\begin{array}{c}\text { Paralelo / } \\
\text { Retangular / } \\
\text { Cobre }\end{array}$ & $\begin{array}{c}\mathrm{R} 407 \mathrm{C} / \\
2 \phi\end{array}$ & $100 \times 500$ & 50 & $15 / \mathrm{H}$ & $-/ 25(-)$ & até 310 & $\begin{array}{l}400- \\
1500\end{array}$ & $\mathrm{~h}$ e INS \\
\hline $\begin{array}{l}\text { Lee } \text { et al. } \\
2014 \mathrm{a} \text { e } \\
2014 \mathrm{~b} \\
\end{array}$ & $\begin{array}{c}\text { Paralelo / } \\
\text { Retangular / } \\
\text { Cobre }\end{array}$ & $\begin{array}{l}\mathrm{FC} 72 / \\
2 \phi\end{array}$ & $231 \times 1000$ & 20 & $\begin{array}{c}152.4 / \mathrm{H}, \\
\mathrm{VU} \text { and } \\
\text { VD }\end{array}$ & $\begin{array}{c}101(202) / \\
56(-)\end{array}$ & $\begin{array}{l}21,4- \\
98,9\end{array}$ & $\begin{array}{l}151,5- \\
834,5\end{array}$ & $\begin{array}{c}\Delta p, \mathrm{~h}, \\
\text { INS e FP }\end{array}$ \\
\hline$\frac{\text { Leão et al. }}{2015}$ & $\begin{array}{c}\text { Paralelo / } \\
\text { Retangular / } \\
\text { Cobre }\end{array}$ & $\begin{array}{c}\mathrm{R} 245 \mathrm{fa} / \\
2 \phi\end{array}$ & $123 \times 494$ & 50 & $\begin{array}{l}15 / \mathrm{H}, \\
\text { VU e I }\end{array}$ & $180 /(-)$ & até 300 & $\begin{array}{l}300- \\
1000\end{array}$ & $\begin{array}{c}\Delta p, \mathrm{~h}, \\
\text { INS e FP }\end{array}$ \\
\hline \begin{tabular}{|c|} 
Woodcock et \\
$a l .(2015)$
\end{tabular} & $\begin{array}{c}\text { Micro-Aleta- } \\
\text { Piranha / - / } \\
\text { Silício }\end{array}$ & $\begin{array}{l}\text { HFE7000/ } \\
1 \phi \text { e } 2 \phi\end{array}$ & 150 & - & $2,5 / \mathrm{H}$ & $\begin{array}{c}142-284 / \\
(-)\end{array}$ & até 7000 & $\begin{array}{l}1200- \\
7000\end{array}$ & $\begin{array}{c}\Delta p, \mathrm{~h} \mathrm{e} \\
\text { FP }\end{array}$ \\
\hline$\frac{\text { Silvério et al. }}{2015}$ & $\begin{array}{c}\text { Paralelo / } \\
\text { Retangular / } \\
\text { Silício }\end{array}$ & $\begin{array}{l}\text { HFE7000/ } \\
1 \phi\end{array}$ & 96 & 27 & $\begin{array}{c}9,997 / \\
\mathrm{H}\end{array}$ & $-/(25)$ & até 108 & até 2727 & $\Delta p, \mathrm{~h}$ \\
\hline $\begin{array}{c}\text { Hsu et al. } \\
2015 .\end{array}$ & $\begin{array}{c}\text { Paralelo / } \\
\text { Retangular / } \\
\text { Cobre }\end{array}$ & $\begin{array}{l}\text { HFE7100/ } \\
2 \phi\end{array}$ & 440 & - & $\begin{array}{c}25 / \mathrm{H}, \\
\mathrm{VD}, \mathrm{VU} \\
\text { e I }\end{array}$ & - & 25 e 40 & $100-200$ & $\mathrm{~h}$ \\
\hline \begin{tabular}{|c|} 
Deng et al. \\
$2015 \mathrm{a}$ \\
$2015 \mathrm{c}$ \\
$2015 \mathrm{~b}$ \\
\end{tabular} & $\begin{array}{c}\text { Paralelo / } \\
\text { Circular e } \\
\text { Retangular / } \\
\text { Cobre }\end{array}$ & $\begin{array}{c}\text { Água } \\
\text { deioni- } \\
\text { zada/ } 1 \phi \\
\text { e } 2 \phi\end{array}$ & $\begin{array}{c}590,776 \\
\text { e } 781\end{array}$ & 14 & $45 / \mathrm{H}$ & $\begin{array}{c}-/(33,60 \\
\quad \text { e } 90)\end{array}$ & $\begin{array}{c}133, \\
200 \mathrm{e} \\
267\end{array}$ & $200-300$ & $\begin{array}{c}\Delta p, \mathrm{~h}, \\
\text { INS, FP, } \\
\text { RT }\end{array}$ \\
\hline $\begin{array}{l}\text { Law e Lee } \\
\frac{2015 \mathrm{a} e}{2015 \mathrm{~b}}\end{array}$ & $\begin{array}{c}\text { Paralelo / } \\
\text { Retangular e } \\
\text { oblíquo/ } \\
\text { Cobre }\end{array}$ & $\begin{array}{c}\mathrm{FC} 72 / \\
2 \phi\end{array}$ & $\begin{array}{c}350 \times 1190 \\
\mathrm{e} \\
340 \times 1170\end{array}$ & 40 & $25 / \mathrm{H}$ & - / $(29,5)$ & $140-420$ & $175-370$ & $\begin{array}{l}\Delta p, \mathrm{~h}, \\
\text { INS e } \\
\text { FCC }\end{array}$ \\
\hline$\frac{\text { Chai et al. }}{\text { (2015) }}$ & $\begin{array}{c}\text { Paralelo / } \\
\text { Retangular / } \\
\text { Silício }\end{array}$ & $\begin{array}{l}\text { Água } \\
\text { deioni- } \\
\text { zada e } \\
N_{2} / 2 \phi\end{array}$ & $100 \times 200$ & 10 & $10 / \mathrm{H}$ & $-/(20)$ & - & - & $\Delta p$ e FP \\
\hline$\frac{\text { Gan et al. }}{2015}$ & $\begin{array}{c}\text { Paralelo / } \\
\text { Triangular / } \\
\text { Silício }\end{array}$ & $\begin{array}{c}\text { Acetona/ } \\
2 \phi\end{array}$ & $\begin{array}{c}300 \times 212, \\
155,4\end{array}$ & 10 & $\begin{array}{c}21,45 / \\
\mathrm{H}\end{array}$ & $\begin{array}{l}130-160 / \\
(23-39,1)\end{array}$ & $\begin{array}{c}141,92- \\
481,08\end{array}$ & $\begin{array}{l}65,52- \\
289,61\end{array}$ & $\Delta p$ \\
\hline$\frac{\text { Xu et al. }}{\text { (2016) }}$ & $\begin{array}{c}\text { Ramificado / } \\
\text { Retangular / } \\
\text { Silício }\end{array}$ & $\begin{array}{l}\text { Água/ } \\
1 \phi\end{array}$ & 143 a 286 & - & $-/ \mathrm{H}$ & $-/(20)$ & 400 & $\begin{array}{c}200-600 \\
\mathrm{ml} / \mathrm{min}\end{array}$ & $\Delta p, \mathrm{~h}$ \\
\hline$\frac{\text { Markal et al. }}{(2016 \mathrm{a})}$ & $\begin{array}{c}\text { Paralelo / } \\
\text { Retangular / } \\
\text { Silício }\end{array}$ & $\begin{array}{l}\text { Água } \\
\text { deioni- } \\
\text { zada/ } \\
2 \phi\end{array}$ & $\begin{array}{c}70 \times 90, \\
90 \times 110, \\
110 \times 90, \\
190 \times 70, \\
230 \times 65, \\
300 \times 60\end{array}$ & 29 & $48 / \mathrm{H}$ & $-/(50)$ & $71-131$ & 151-324 & $\begin{array}{c}\Delta p, \text { INS, } \\
\text { FP, RA }\end{array}$ \\
\hline$\frac{\text { Markal et al. }}{(2016 \mathrm{~b}}$ & $\begin{array}{c}\text { Paralelo / } \\
\text { Retangular / } \\
\text { Silício }\end{array}$ & $\begin{array}{l}\text { Água } \\
\text { deioni- } \\
\text { zada/ } \\
2 \phi\end{array}$ & $150 \times 150$ & 29 & $48 / \mathrm{H}$ & $-/(50)$ & $\begin{array}{l}59,3- \\
84,1\end{array}$ & $\begin{array}{l}51,0- \\
92,6\end{array}$ & $\Delta p, \mathrm{~h}$ \\
\hline $\begin{array}{l}\text { Khoshvaght- } \\
\text { Aliabadi et al. } \\
\text { 2016 }\end{array}$ & $\begin{array}{c}\text { Paralelo } \\
\text { sinusoidal/ } \\
\text { Retangular / } \\
\text { Alumínio }\end{array}$ & $\begin{array}{l}\text { Água + } \\
\text { etileno- } \\
\text { glicol/ } \\
1 \phi\end{array}$ & $1000 \times 1000$ & 8 & $100 / \mathrm{H}$ & - & 25 & $3-24 \mathrm{~g} / \mathrm{s}$ & $\Delta p, \mathrm{~h}$ \\
\hline$\frac{\text { Chávez et al. }}{\text { (2017) }}$ & $\begin{array}{c}\text { Paralelo / } \\
\text { Retangular / } \\
\text { Cobre }\end{array}$ & $\begin{array}{c}\text { R600a, } \\
\text { R290, } \\
\text { R1270/ } \\
2 \phi\end{array}$ & $123 \times 494$ & 50 & $15 / \mathrm{H}$ & $\begin{array}{c}351,953 \\
\text { e } 1157 / \\
25(-)\end{array}$ & até 400 & $165-823$ & $\begin{array}{c}\Delta p, \mathrm{~h}, \\
\text { ONB e } \eta_{\mathrm{II}}\end{array}$ \\
\hline
\end{tabular}

$* \mathrm{H}=>$ Horizontal; VU=> Vertical escoamento ascendente; VD=> Vertical escoamento descendo; I=> Inclinado

**RT $=>$ Resistência térmica; INS $=>$ Instabilidades; $\mathrm{CT}=>$ Controle de temperatura; $\Delta p=>$ Perda de pressão; $\mathrm{FP}=>$ Padrões de escoamento; $\mathrm{h}=>$ Coeficiente de transferência de calor; $\mathrm{FCC}=>$ Fluxo crítico de calor ; FV => Fração de vazio; TMM=> Transição macro micro-escala;

$\mathrm{RA}=>$ Razão de aspecto; $\mathrm{ONB}=>$ início da ebulição; $\eta_{\mathrm{II}}=>$ Eficiência de Segunda Lei da Termodinâmica. 


\subsubsection{PADRÕES DE ESCOAMENTO EM MULTI-MICROCANAIS}

Estudos sobre padrões de escoamento em configurações compostas por multi-microcanais tem sido desenvolvidos utilizando, de uma maneira geral, denominações similares as utilizadas para canais únicos. No entanto, o processo de desenvolvimento dos padrões com o incremento do título de vapor e, consequentemente, suas transições são afetadas pela configuração do dissipador, geometria de distribuição de canais e principalmente, pela interação do escoamento provindo de diferentes microcanais nas regiões das câmaras. Em multi-microcanais é comum a presença de fluxos reversos devido à ebulição, sendo denominado por alguns autores de "ebulição explosiva" devido ao rápido crescimento das bolhas em condições confinadas estando assim relacionados a presença das instabilidades térmicas no escoamento. No caso de canais únicos, tais efeitos são amortizados com o uso, a montante e a jusante da seção de testes, de válvulas de agulha de forma a impor restrições ao escoamento e perdas de pressão localizada, conforme indicado por Ribatski (2013).

Niño et al. (2003), para a configuração de multi-microcanais descrita na Tabela 2.11 . propuseram um procedimento inovador para a caracterização de padrões de escoamento, que resultaram em mapas de padrões denominados de probabilísticos. Em vez de classificar o padrão para uma determinada velocidade mássica e título de vapor, eles obtiveram a fração de tempo em que um padrão de escoamento se verifica ao longo do comprimento dos canais. Este mapa inclui o fato dos padrões de escoamento variarem ao longo do tempo, principalmente devido à presença de instabilidades. A Figura 2.14 apresenta dois mapas probabilísticos para padrões de escoamento em multi-microcanais propostos por Niño et al. (2003).
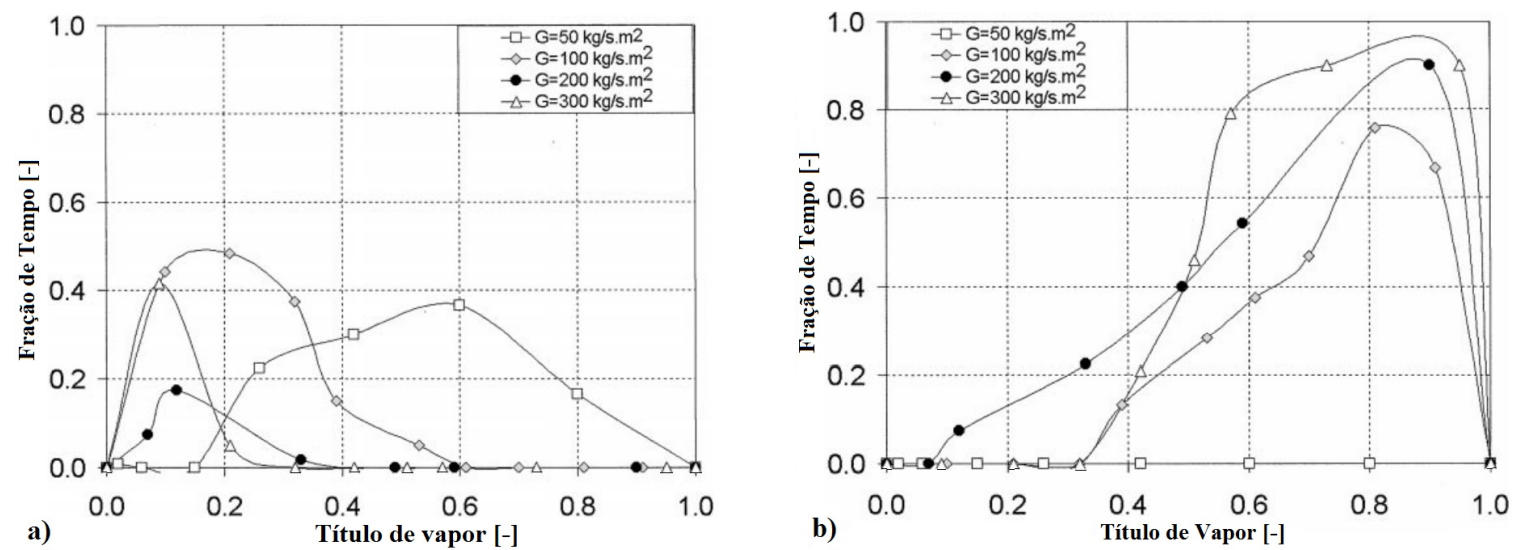

Figura 2.14 - Mapas probabilísticos de padrão de escoamento para R134a segundo Niño et al. (2003).

(a) Pistonado; (b) Anular.

A Figura 2.14 ilustra um mapa de padrão de escoamento, indicando as curvas para a fração de tempo como função do título de vapor no qual se verifica a presença do padrão pistonado ao longo dos canais. Nesta figura observa-se que para $G=50 \mathrm{~kg} / \mathrm{m}^{2} \mathrm{~s}$, o padrão pistonado se verifica para títulos de vapor entre 0,17 e 1 . Já para $G$ superior a $300 \mathrm{~kg} / \mathrm{m}^{2} \mathrm{~s}$, este se verifica para títulos de vapor entre 0 e 0,3 . Analogamente, a Fig. 2.14p ilustra o mapa probabilístico 
que representa a presença do padrão anular. A Figura 2.15 ilustra o registro fotográfico dos padrões de escoamento correspondentes aos mapas probabilísticos descritos anteriormente para diferentes velocidades mássicas e títulos de vapor. Niño et al. (2003) propuseram uma metodologia para classificação de padrões de escoamento sob instabilidades em multi-canais. No entanto, vale destacar que o fato deste método ser avaliado para padrões de escoamento ao longo dos microcanais, implica que os mapas dependem da configuração dos microcanais.

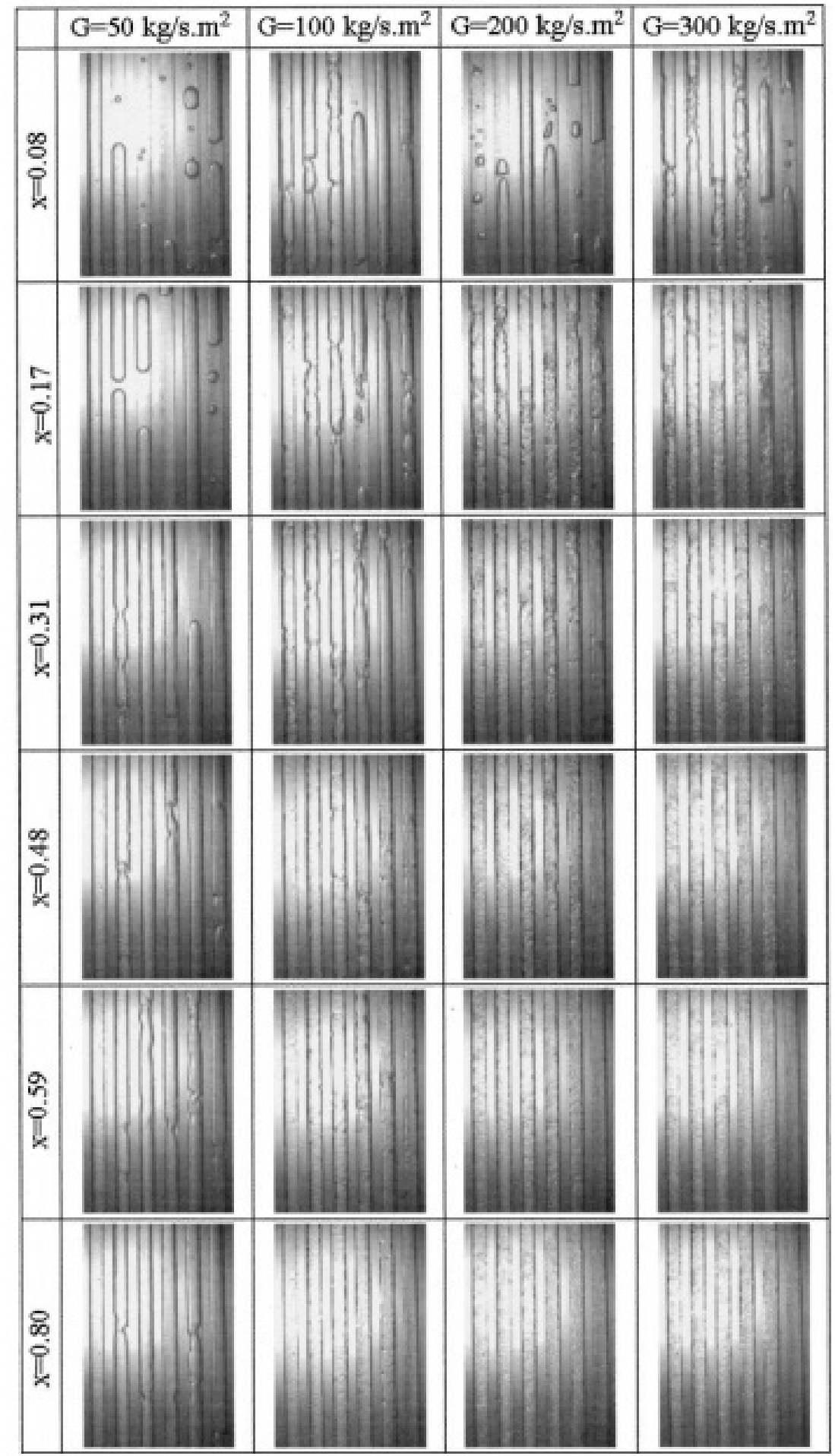

Figura 2.15 - Visualizações de padrões de escoamento horizontal para R134 em multi-microcanais levantados por Niño et al. (2003). 
Hetsroni et al. (2001, 2002 e 2003) observaram padrões de escoamento em um dissipador de calor baseado em multi-microcanais paralelos de seção triangular. Eles verificaram que para o padrão anular, o filme líquido distribui-se simetricamente segundo geometria anular em torno da fase vapor. Segundo os autores, o padrão de bolhas é suprimido devido ao efeito da redução do diâmetro e os cantos da seção triangular, os quais favorecem a nucleação e a imediata coalescência de bolhas e, consequentemente, a transição para o padrão anular.

Xu et al. (2005a e 2005b) também investigaram padrões de escoamentos em configurações de multi-microcanais para seções transversais triangulares utilizando a acetona como fluido de trabalho. Eles observaram os seguintes padrões de escoamento: (i) Intermitente com bolhas dispersas, as quais apresentam menor probabilidade de serem verificadas; (ii) Pistonado em sentido reverso arrastando o líquido; (iii) Bolhas agrupadas em pares ou trios com arraste de líquido; (iv) Anular, o qual é o padrão verificado com maior frequência.

Em multi-microcanais retangulares, Chen e Garimella (2006) observaram a variação dos padrões de escoamento em função do fluxo de calor. Eles visualizaram para faixas de fluxos de calor entre 94 e $189 \mathrm{~kW} / \mathrm{m}^{2}$ a nucleação de bolhas na parede, as quais cresceram, desprenderam e deslocaram-se. Este fenômeno se verificou em canais vizinhos. Para fluxos de calor próximos a $360 \mathrm{~kW} / \mathrm{m}^{2}$, observou-se pistões de vapor, a ebulição tornou-se intensa e as bolhas e pistões colapsaram gerando bolhas alongadas. Para fluxos de calor entre 360 e $389 \mathrm{~kW} / \mathrm{m}^{2}$, observaram o padrão intermitente de bolhas alongadas. Estes padrões encontram-se ilustrados na Fig. 2.16 Chen e Garimella (2006) também observaram que, para fluxos de calor próximos a $427 \mathrm{~kW} / \mathrm{m}^{2}$, o padrão de escoamento tornou-se agitante. A partir daí, para fluxos de calor entre 536 e $617 \mathrm{~kW} / \mathrm{m}^{2}$ o padrão anular predominou com a presença do padrão agitante tornandose desprezível. Já para fluxos superiores a $617 \mathrm{~kW} / \mathrm{m}^{2}$ os autores visualizaram apenas líquido disperso no vapor produzindo a secagem parcial da parede.
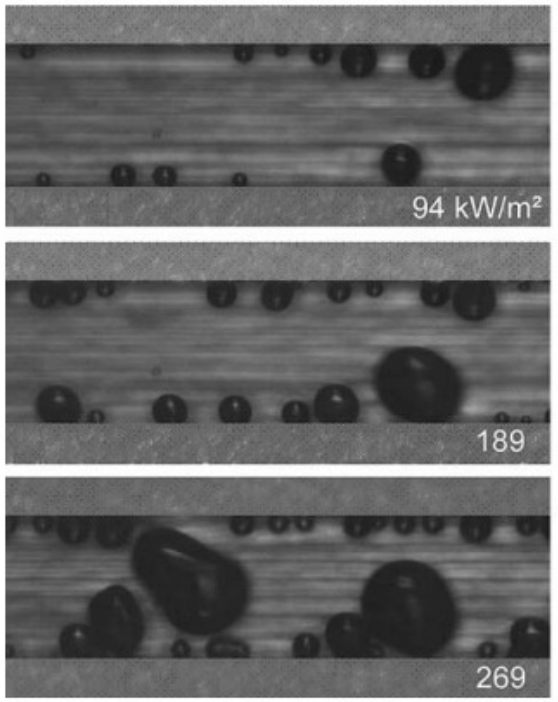
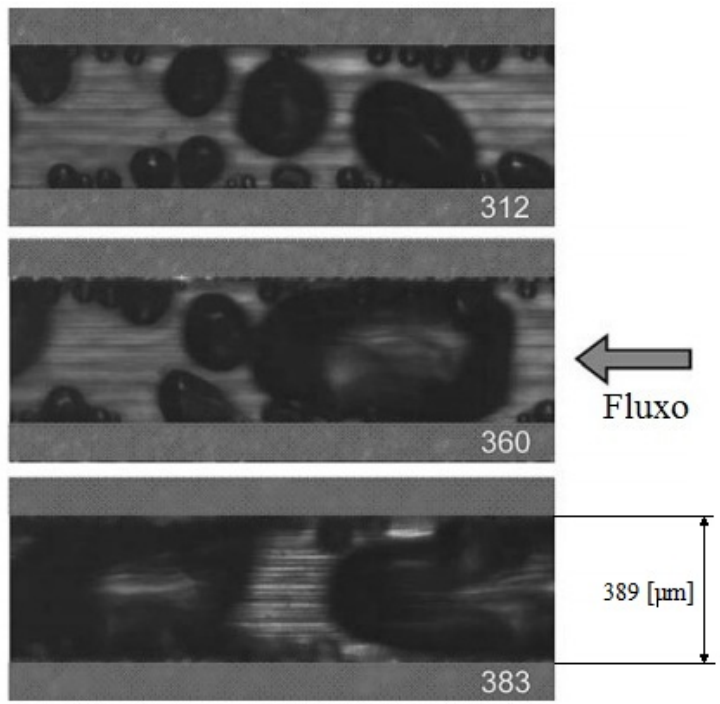

Figura 2.16 - Padrões de escoamento observados por Chen e Garimella (2006) para multi-microcanais e fluxos de calor reduzido. 
Koşar e Peles (2007b) visualizaram padrões de escoamento em configurações de multimicro-aletas com escoamento cruzado, verificando os padrões de bolhas, intermitente ondulado e anular com gotículas dispersas na fase vapor. Eles propuseram um mapa de escoamento tendo nos eixos coordenados o número de Reynolds do líquido e de Ebulição para especificar os limites de transição entre os padrões observados. A Figura 2.17 ilustra os padrões de escoamento verificados na região de saída das micro-aletas. O registro fotográfico encontrase na coluna direita e na esquerda encontram-se ilustrações esquemáticas dos padrões. Segundo Koşar e Peles (2007b), para números reduzidos de Ebulição observam-se bolhas de tamanho reduzido circundadas pela fase líquida (Fig. 2.17a). Para números de Ebulição intermediários, uma camada de líquido espessa apresentando interface ondulada, envolve as micro-aletas com a fase de vapor contento gotículas escoando na região central entre as aletas (Fig. 2.17b). Para números de Ebulição superiores, o padrão de escoamento é anular e se distingue do padrão anterior pela presença de um filme líquido de reduzida espessura em contato com as microaletas e uma elevada quantidade de gotículas de líquido entranhadas no vapor (Fig. 2.17k). Segundo Koşar e Peles (2007b), para os padrões de escoamento segundo bolhas e intermitente ondulado, predomina o mecanismo de transferência de calor por ebulição nucleada, enquanto para o padrão anular com gotículas de líquido predominam efeitos convectivos.

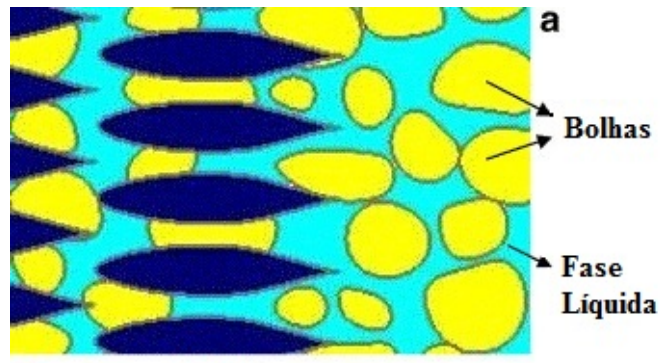

Desenho em CAD

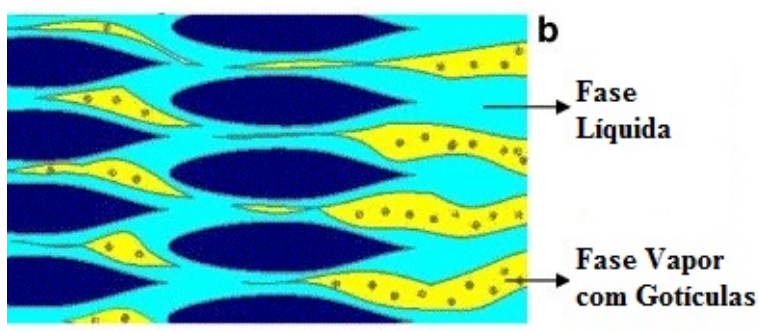

Desenho em CAD

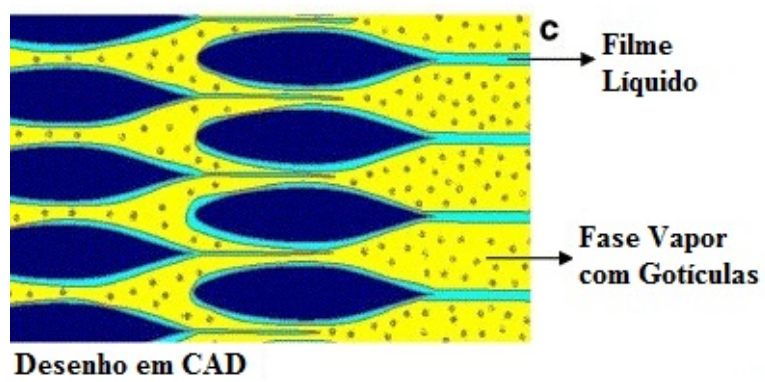

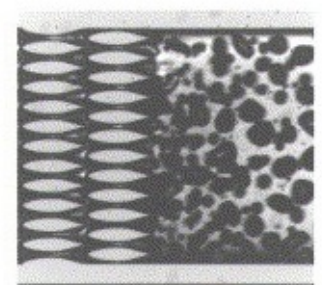

Imagem Alta Velocidade

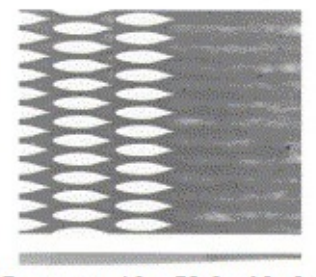

Imagem Alta Velocidade

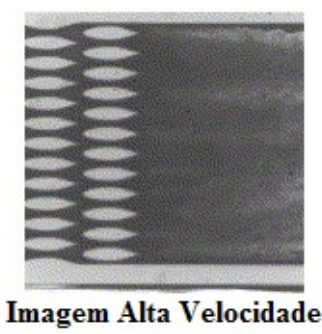

Figura 2.17 - Padrões de escoamento para configuração de multi-microcanais com escoamento cruzado, Koşar e Peles (2007b). (a) Bolhas; (b) Intermitente ondulado; (c) Anular com gotículas. 
Destaca-se a investigação experimental de Harirchian e Garimella (2009), na qual os autores analisaram padrões de escoamentos para diferentes razões de aspectos, correspondendo a diâmetros hidráulicos entre 100 e $5850 \mu \mathrm{m}$. Eles propuseram um mapa de escoamento, ilustrado na Fig. 2.18 tendo nos eixos coordenados a velocidade mássica e o fluxo de calor. A classificação de padrões por eles proposta se baseia em resultados para comprimentos de escoamento de $12,7 \mathrm{~mm}$ e grau de sub-resfriamento do fluido refrigerante na entrada da seção de testes de $5{ }^{\circ} \mathrm{C}$.

Em geral, Harirchian e Garimella (2009) identificaram padrões de escoamento do tipo bolhas, pistonado, agitante, anular fino e anular. Segundo os autores, o desenvolvimento progressivo dos padrões depende da velocidade mássica, fluxo de calor e a área de seção transversal. Com o aumento da velocidade mássica, aumenta-se a faixa de fluxo de calor em que um determinado padrão se verifica. Harirchian e Garimella (2009) concluíram que, para diâmetros hidráulicos inferiores a , o padrão bolhas é suprimido para títulos de vapor reduzidos, coalescendo de forma imediata para bolhas alongadas $250 \mu \mathrm{m}$. Este fenômeno foi observado também no estudo proposto por Hetsroni et al. (2001, 2002 e 2003), conforme descrito anteriormente.
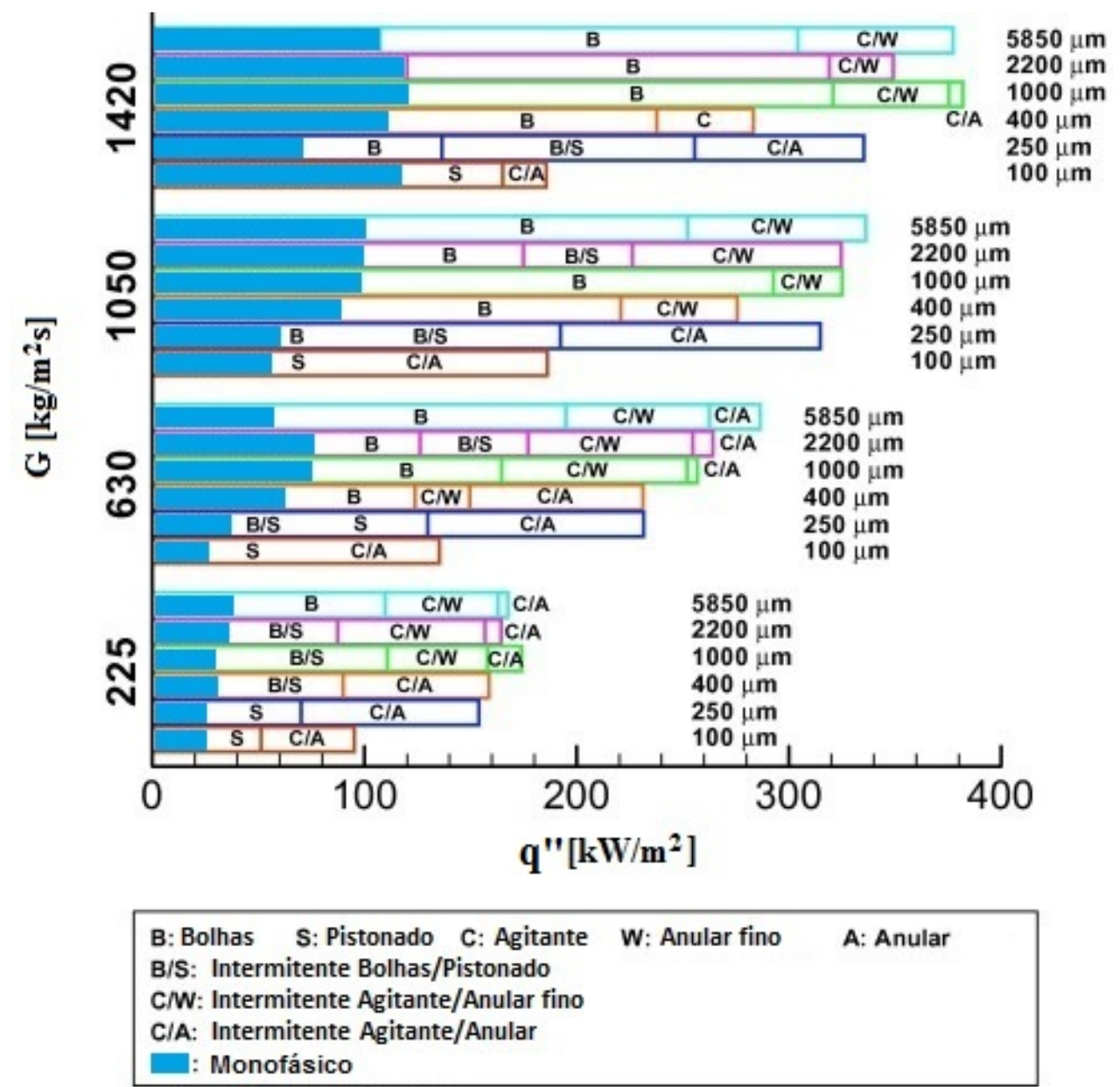

Figura 2.18 - Mapa de padrões de escoamento para configurações de multi-microcanais proposto por Harirchian e Garimella (2009). 
Recentemente, Wang et al. (2012) realizaram uma visualização dos padrões de escoamento em multi-microcanais para o dissipador de calor posicionado segundo diferentes inclinações. A Figura 2.19 ilustra os registros fotográficos dos padrões de escoamento levantados por Wang et al. (2012). Para escoamento horizontal, velocidade mássica de $100 \mathrm{~kg} / \mathrm{m}^{2} \mathrm{~s}$, título de vapor de 0,45 e fluxo de calor de $25 \mathrm{~kW} / \mathrm{m}^{2}$ observou-se o padrão pistonado. Com a elevação do ângulo de inclinação para $45^{\circ}$, o padrão de escoamento tornou-se anular e assimétrico, devido ao aumento da velocidade da fase vapor em relação ao líquido ocasionado pela ação das forças de empuxo e gravidade sobre o escoamento. $\mathrm{O}$ aumento do ângulo para $90^{\circ}$ tornou o escoamento simétrico, reduzindo a espessura do filme líquido entre os pistões de vapor e a parede. Neste caso, as forças de empuxo agiram de forma a elevar a velocidade dos pistões de vapor e, combinadas as forças de atrito em direção contrária ao escoamento, reduziram o tamanho dos pistões. Segundo os autores, com base na análise das imagens do escoamento obtida com uma câmera de alta velocidade os pistões de vapor apresentaram velocidades superiores para escoamentos ascendentes. Para escoamento descendente, a força devido à efeitos de flutuação, contrária à direção do escoamento, tende a reduzir a velocidade do pistão de vapor. Com o aumento da velocidade mássica, para escoamento horizontal e para inclinação de $45^{\circ}$, o padrão pistonado verifica-se com pistões de comprimento superior, diâmetro inferior e ondulações no filme líquido.

A Fig. 2.19p ilustra um diagrama esquemático indicando para as distintas inclinações, o grau de simetria dos pistões de vapor e a direção das forças de empuxo e atrito relativas ao sentido do escoamento. Como ilustra esta figura, o escoamento apresenta simetria para fluxos horizontais e verticais. Já a inclinação de $\pm 45^{\circ}$, favorece a assimetria. De acordo com Wang et al. (2012), para escoamento vertical ascendente, ondulações no filme líquido significativas são ausentes e o padrão torna-se simétrico. Isto resulta na redução de instabilidades térmicas e no incremento do coeficiente de transferência de calor. Comportamento similar foi constatado por Leão et al. (2015).
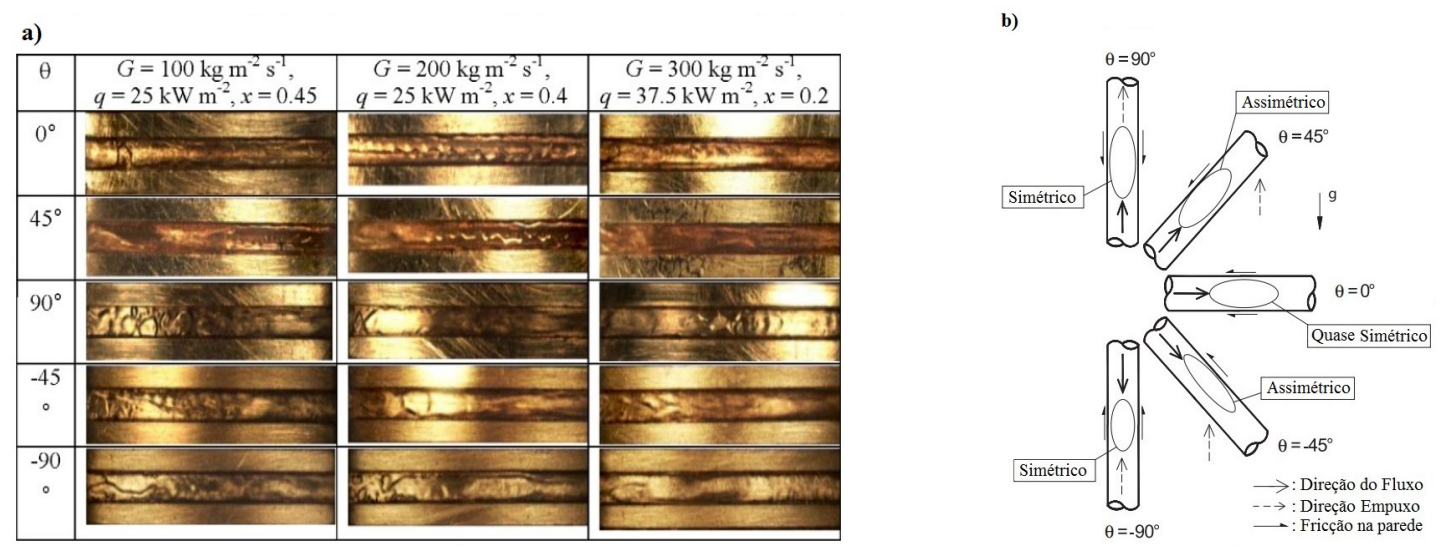

Figura 2.19 - Efeito do ângulo de inclinação nos padrões de escoamento para configuração de multi-microcanais, Wang et al. (2012). (a) imagens dos padrões; (b) diagramas esquemáticos do efeito da inclinação no padrão pistonado. 


\subsubsection{PERDA DE PRESSÃO EM MULTI-MICROCANAIS}

Inicialmente este item apresenta os procedimentos implementados na literatura para previsão da perda de pressão em dissipadores de calor baseados na ebulição convectiva em multimicrocanais. Além disso, esta seção apresenta uma análise sobre estudos envolvendo levantamentos experimentais de resultados para a perda de pressão em dissipadores de calor baseados em multi-microcanais. As condições experimentais cobertas por tais estudos encontram-se esquematicamente descritas na Tabela 2.11. Este item também inclui comparações entre resultados experimentais para a perda de pressão por atrito e métodos para sua previsão levantados na literatura e descritos no item 2.2 .2

\subsubsection{AVALIAÇÃO DA PERDA DE PRESSÃO EM MULTI-MICROCANAIS}

A avaliação da perda de pressão por atrito ao longo de um dissipador de calor no qual ocorre ebulição convectiva em multi-microcanais trata-se de uma tarefa complexa em que várias hipóteses simplificadores são adotadas. No entanto, destaca-se a importância de sua correta avaliação na análise do desempenho dos dissipadores pois, conforme indicado por Gan et al. (2015), a perda de pressão bifásica por atrito corresponde a mais do $75 \%$ da perda de pressão ao longo de um dissipador de calor.

Conforme o procedimento adotado por Bowers e Mudawar (1994a), Qu e Mudawar (2003a), Lee e Mudawar (2005a), Lee e Garimella (2008) e, recentemente, por Leão et al. (2015) (ver Tabela 2.11 para detalhes destes estudos), para dissipadores de calor com microcanais paralelos em que o fluido no plenum de entrada encontra-se sub-resfriado, verificam-se duas regiões: monofásica, envolve o plenum de entrada, a seção de entrada dos microcanais, com a contração do escoamento e o comprimento dos canais necessário para o início da ebulição; bifásica, ocorrendo a partir do início da ebulição até a saída dos microcanais, compreendendo ainda a expansão abrupta ao final dos microcanais e o plenum de saída. Geralmente, nestes estudos, a partir da perda de pressão total, avaliada através de um transdutor diferencial de pressão, obtémse a parcela de perda de pressão por atrito subtraindo do valor medido, as perdas de pressão localizadas, a parcela monofásica e a perda de pressão devido à aceleração do escoamento.

Vale destacar que, conforme destacado por Qu e Mudawar (2003a) e Leão et al. (2015), instabilidades são frequentes em multi-microcanais. Estas modificam as características do escoamento durante a ebulição convectiva, sendo assim necessárias algumas hipóteses simplificadoras para a determinação da parcela de perda de pressão devido ao atrito. Geralmente, estas hipóteses são as seguintes: escoamento uniformemente distribuído, início da ebulição a uma mesma distância da entrada da seção de testes para todos os canais, fluxo de calor uniformemente distribuído ao longo do dissipador e ausência de instabilidades.

Qu e Mudawar (2003a) e Leão et al. (2015) estimaram o comprimento monofásico resolvendo simultaneamente para elementos discretos, uma equação de balanço de energia e a corre- 
lação de perda de pressão monofásica proposta por Shah e London (1978) para escoamento em canais retangulares em desenvolvimento hidrodinâmico. Para cada elemento, o procedimento adotado por eles verifica a correspondência entre a pressão e a temperatura de saturação com o início da região bifásica ocorrendo quando a pressão local se torna inferior a pressão de saturação avaliada a partir do balanço de energia.

Lee e Garimella (2008) assumiram uma variação linear da temperatura de saturação para uma hipótese de fluxo de calor uniformemente distribuído ao longo dos microcanais. Baseado nesta hipótese, obtiveram uma relação linear entre a temperatura de saturação e comprimento do canal dada pela Eq. 2.221. Para esta relação, são conhecidas as temperaturas locais na entrada e saída dos canais. Para obter o comprimento monofásico e a temperatura de saturação, esta equação é resolvida simultaneamente com a equação de balanço de energia para a condição $T_{\text {fluido }}=T_{\text {sat }}\left(z=L_{\text {monofásico }}\right)$.

$$
T_{\text {sat }}(z)=\left(1-\frac{z}{L}\right) T_{\text {sat }}\left(p_{\text {entrada }}\right)+\frac{z}{L} T_{\text {sat }}\left(p_{\text {saída }}\right)
$$

Para o escoamento na entrada do dissipador de calor idealizado como sub-resfriado, uniformemente distribuído e ausente de instabilidades responsáveis do fluxo reverso de vapor, a perda de pressão na região das contrações é estimada na literatura através de correlações para escoamento monofásico. Uma descrição ampla destas correlações encontram-se em Blevins (1984) e White (1998). Em geral, tais correlações são funções das propriedades do fluido e a relação das áreas transversais das regiões a montante e a jusante da contração.

Qu e Mudawar (2003a) e Leão et al. (2015) estimaram a perda de pressão localizada na contração durante o escoamento monofásico através das correlações propostas por Blevins (1984) e White (1998), respectivamente. Nos dois estudos, os autores avaliaram a perda de pressão local em contrações localizadas entre multi-microcanais retangulares e um plenum de geometria retangular. No entanto, de acordo com Gan et al. (2015), tal perda de pressão corresponde a valores inferiores a $1 \%$ da perda de pressão total ao longo do dissipador.

$\mathrm{Na}$ literatura, a recuperação de pressão da saída dos canais é geralmente determinada através de correlações desenvolvidas para escoamento bifásico. Leão et al. (2015) calcularam a recuperação de pressão através da correlação proposta por Wang et al. (2010). Este método foi desenvolvido com base em 282 dados experimentais obtidos a partir de 5 estudos da literatura. Ele considera a relação de áreas das seções transversais dos microcanais e do plenum de saída e os efeitos de propriedades do fluidos, fornecendo ainda desvios superiores a $29 \%$ para a perda de pressão experimental. Desta forma, constata-se que resultados experimentais para recuperação de pressão nas expansões, envolvendo canais de diâmetro reduzido, ainda são necessários para o desenvolvimento de correlações mas precisas. A Tabela 2.12 apresenta as bases de dados disponíveis na literatura para recuperação de pressão na expansão abrupta durante escoamento bifásico. 
Tabela 2.12 - Dados experimentais disponíveis na literatura para expansões abruptas durante escoamento bifásico, Wang et al. (2010)

\begin{tabular}{|c|c|c|c|c|c|}
\hline Parâmetros & $\begin{array}{l}\text { Abdelall et al. } \\
\text { (2005) }\end{array}$ & $\begin{array}{c}\text { Chalfi e } \\
\text { Ghiaasiaan (2008) }\end{array}$ & \begin{tabular}{|l|l|} 
Mendler 1963 \\
\end{tabular} & McGee (1966) & $\begin{array}{c}\text { Schmidt e Friedel } \\
(1996)\end{array}$ \\
\hline $\mathrm{N}^{\circ}$ dados & 14 & 24 & 90 & 64 & 90 \\
\hline $\mathrm{N}^{\circ}$ canais & 1 & 1 & 3 & 3 & 2 \\
\hline \begin{tabular}{l|l|}
$\mathrm{G}$ & $\mathrm{kg} / \mathrm{m}^{2} \mathrm{~s}$
\end{tabular} & $3074-4212$ & $506-664$ & $692-5642$ & $524-2480$ & $1000-3000$ \\
\hline Fluidos & água-ar & água-ar & água-vapor & água-vapor & água-ar \\
\hline Diâmetro $[\mathrm{mm}]$ & 0,84 & 0,84 & $9,55,12,9$ e 17,63 & 8,64 e 11,68 & 17,2 e 19 \\
\hline $\begin{array}{ll}\text { Tensão } & \text { Superficial } \\
{[N / m]} & \\
\end{array}$ & 0,276 & 0,276 & $\begin{array}{c}0,145,0,264 \mathrm{e} \\
0,493\end{array}$ & $\begin{array}{c}0,332,0,546 \mathrm{e} \\
0,607\end{array}$ & 0,0568 e 0,0937 \\
\hline Bo & 0,095 & 0,095 & 19,8 a 92,1 & 13,5 a 30,7 & 40 a 48,8 \\
\hline$\Delta p_{\text {expansão }}$ & 0,726 a 4,62 & 0,801 a 3,71 & 0,575 a 15,6 & 0,069 a 14,4 & 0,2 a 36 \\
\hline
\end{tabular}

Estudos que envolvem a inclusão de restrições na entrada dos microcanais de forma a minimizar a programação de efeitos de instabilidade térmica foram apresentados por Kosar et al. (2006) e Szczukiewicz et al. (2012, 2013a, 2013b e 2013c). Nestes casos, a inclusão de restrições na entrada dos microcanais produz um incremento da perda de pressão localizada na entrada dos microcanais. Estes autores propuseram estimar a perda de pressão da restrição através de correlações usadas para contrações e expansões correspondentes as regiões a jusante e a montante na restrição, respectivamente. Kosar et al. (2006) usaram a correlação de Shah e London (1978). Já os demais autores avaliaram a perda de pressão na restrição através da correlação de White (1998).

\subsubsection{COMPARAÇÃO DOS BANCOS DE DADOS PARA $\Delta \boldsymbol{P}_{\text {ATRITO }}$ PARA MULTI- MICROCANAIS E MÉTODOS DE PREVISÃO}

A Tabela 2.13 apresenta resultados de comparações disponíveis na literatura entre os métodos de previsão da perda de pressão por atrito e resultados levantados para a ebulição convectiva em dissipadores de calor baseados em multi-microcanais.

Vale destacar que os métodos de previsão de perda de pressão indicados na Tabela 2.13 foram desenvolvidos com base no modelo homogêneo e parcela deles consideram banco de dados envolvendo resultados experimentais levantados para canais únicos. Qu e Mudawar (2003a), Lee e Mudawar (2005a), Lee e Garimella (2008), Megahed e Hassan (2009) e Kim e Mudawar (2012) consideram banco de dados levantados a partir de resultados experimentais em multimicrocanais. É fato que as condições experimentais cobertas pelo banco de dados utilizado no ajuste dos coeficientes e exponentes destes métodos determinam as características operacionais para o qual eles são indicados.

Os estudos experimentais listados na Tabela 2.13 envolvem configurações de multi-canais paralelos, com apenas Daniels et al. (2011) tratando de uma configuração ramificada. Entre estes estudos, quinze foram realizados em microcanais com seção transversal retangular, dois estudos para seção circular, dois para seção triangular e apenas um em trapezoidal. Todos estes estudos utilizaram o diâmetro hidráulico como dimensão característica ao implementarem os métodos. 


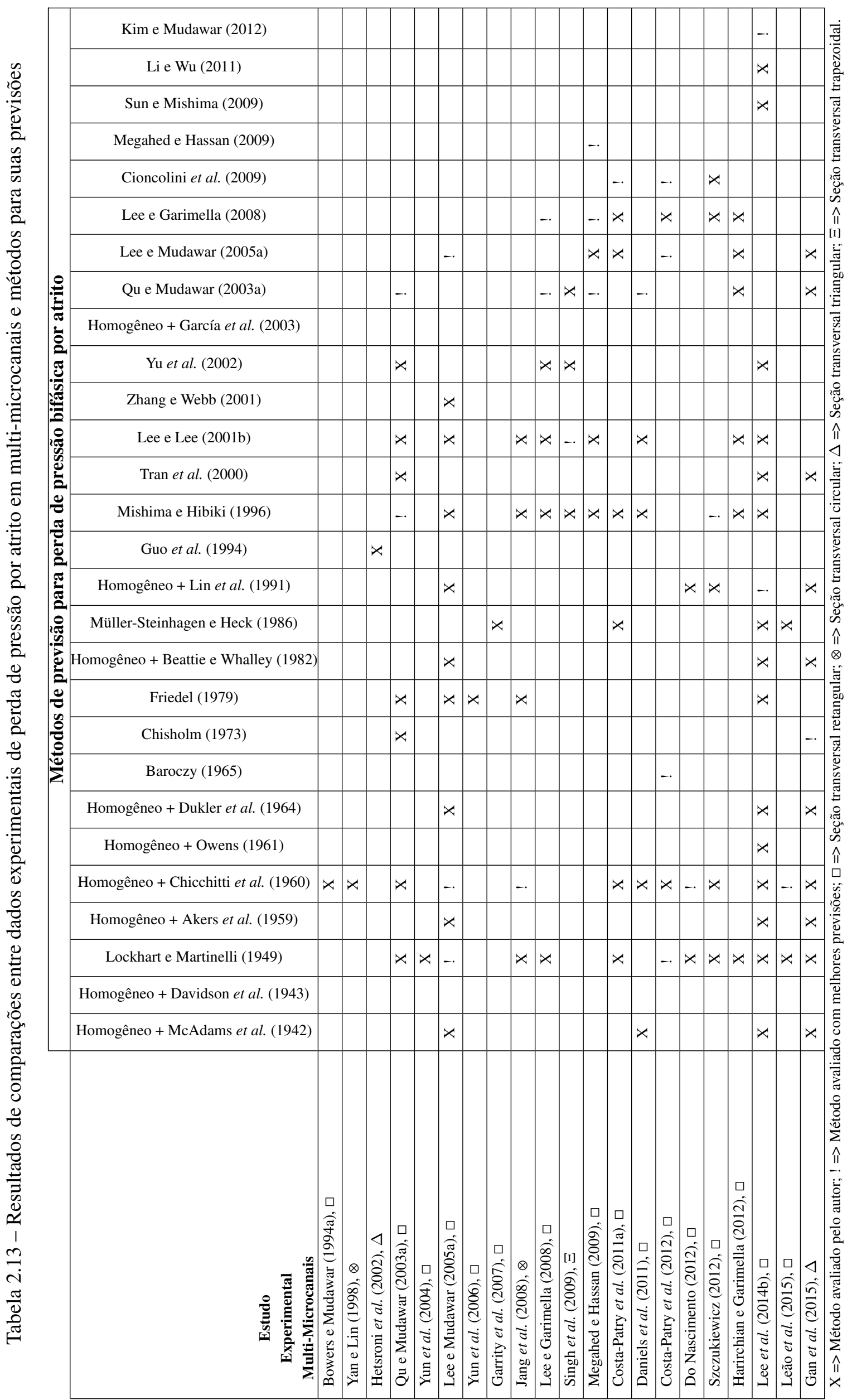


Uma análise da Tabela 2.13, permite observar que os métodos de previsão mais frequentemente comparados com dados experimentais são: Lockhart e Martinelli (1949), Homogêneo + Chicchitti et al. (1960) e Mishima e Hibiki (1996). Entre estes métodos, apenas o método de Mishima e Hibiki (1996) foi desenvolvido considerando condições de micro-escala.

Mishima e Hibiki (1996) propuseram uma correlação para canais retangulares baseada em dados para escoamentos de água-ar. Esta condição explica o fato do método se adequar aos resultados experimentais levantados por Qu e Mudawar (2003a), pra escoamento bifásico de água em canais retangulares.

Lee e Mudawar (2005a) e Do Nascimento (2012) levantaram dados experimentais contendo resultados para títulos de vapor reduzidos. Esta condição favorece a presença do padrão bolhas para o qual o Modelo Homogêneo torna-se razoável, justificando as melhores previsões constatadas por estes autores através do modelo Homogêneo com a viscosidade da mistura bifásica de Chicchitti et al. (1960).

Segundo Costa-Patry et al. (2011a), o método de Cioncolini et al. (2009) apresenta melhores previsões para títulos de vapor elevados, condições em que se verifica o padrão anular. Para títulos de vapor inferiores, condição para a qual se observa os padrões bolhas alongadas e pistonado, estes autores sugerem o método de Lockhart e Martinelli (1949). Tal procedimento parece incorreto pois para canais convencionais, o método de Lockhart e Martinelli (1949) geralmente é indicado para padrão anular.

Curiosamente, o método de Qu e Mudawar (2003a) cujo desenvolvimento se baseou em resultados para canais paralelos, prevê os dados de Daniels et al. (2011) levantados para um dissipador de calor baseado em uma configuração ramificada de multi-microcanais, com desvio médio de $3,7 \%$. Em tais configurações geométricas espera-se comportamentos distintos em relação a canais paralelos, devido à perdas de pressão locais, relacionadas as bifurcações do escoamento.

Com base na análise apresentada, é possível concluir que resultados levantados para a perda de pressão por atrito em configurações de multi-microcanais tem sido comparados com métodos de previsão disponíveis na literatura, com alguns deles prevendo satisfatoriamente bancos de dados independente. Os métodos de previsão disponíveis se baseiam, na maioria das vezes, em dados para seções de testes com geometrias, condições experimentais e refrigerantes diferentes aos considerados nas comparações. Desta forma, não é surpresa que os métodos proporcionem previsões insatisfatórias. Além disso, a maioria dos métodos foram desenvolvidos com base em resultados para canais únicos, sendo desprezados efeitos relacionados a interações entre canais vizinhos, conexões e ramificações intermediárias e conectividade nas regiões dos plenums afetam o escoamento. Finalmente, destacar que métodos de previsão de perda de pressão durante ebulição convectiva que considerem simultaneamente tais efeitos não se verificam na literatura. 


\subsubsection{TRANSFERÊNCIA DE CALOR EM MULTI-MICROCANAIS}

Esta seção se inicia com a descrição de procedimentos de regressão de dados experimentais utilizados na literatura para estimar o coeficiente de transferência de calor a partir dos parâmetros medidos. Em seguida, são apesentados resultados da literatura envolvendo comparações de métodos de previsão e dados experimentais para o coeficiente de transferência de calor durante a ebulição convectiva em multi-microcanais.

\subsubsection{AVALIAÇÃO DO COEFICIENTE DE TRANSFERÊNCIA DE CALOR EM MULTI- MICROCANAIS}

$\mathrm{Na}$ literatura, autores adotam para o cálculo e análise do CTC em um dissipador de calor baseado em multi-microcanais paralelos diferentes método de regressão de dados. Além disso, métodos distintos de aquecimento são adotados. Neste contexto, conforme ressaltado por Leão et al. (2015), devido à impossibilidade de avaliação do fluxo de calor e da velocidade mássica em cada microcanal adota-se distribuição uniforme, desprezando-se efeitos de escoamento reverso devido à instabilidade e de má-distribuição associados a região dos plenums. Tais fatos podem influenciar os resultados obtidos para a temperatura superficial e do fluido, o fluxo de calor, comprimento da região monofásica, perdas para o ambiente e, como consequentemente, do CTC para a ebulição convectiva.

O método de aquecimento para dissipadores de calor se baseiam principalmente na aplicação de potência elétrica. A Tabela 2.14 apresenta estudos da literatura sobre dissipadores de calor e o método de aquecimento implementado.

Tabela 2.14 - Métodos de aquecimento para dissipadores de calor baseados em multi-microcanais verificados na literatura.

\begin{tabular}{|c|c|}
\hline Autor & Método de aquecimento \\
\hline Tuckerman e Pease (1981) & Filme depositado em forma de serpentina \\
\hline Bowers e Mudawar (1994c) & Resistência de cartucho \\
\hline Hetsroni et al. (2001) & Filme depositado em forma de serpentina \\
\hline Qu e Mudawar (2003b) & Resistência de cartucho \\
\hline Steinke e Kandlikar (2004) & Resistência de cartucho \\
\hline Chen e Garimella (2006) & Resistência de cartucho \\
\hline Henning et al. (2007) & Resistência de cartucho \\
\hline Agostini et al. (2008a) & Filme depositado em forma de serpentina \\
\hline Cho et al. (2010), & Resistência de cartucho \\
\hline Szczukiewicz et al. (2013c) & Filme depositado em forma de serpentina \\
\hline Do Nascimento et al. (2013) & Resistência elétrica a pressão \\
\hline Leão et al. 2015 & Resistência elétrica a pressão \\
\hline Markal et al. (2016b) & Resistência de cartucho \\
\hline
\end{tabular}

Bowers e Mudawar (1994c), Qu e Mudawar (2003b) e Steinke e Kandlikar (2004) utilizaram resistências do tipo cartucho posicionadas na base do dissipador de calor. Eles assumiram fluxo 
de calor uniformes atingindo valor máximo de $480 \mathrm{~kW} / \mathrm{m}^{2}$. Já, Cho et al. (2010) consideraram aquecedor com resistência variável em cada cartucho, fornecendo fluxos de calor não uniformes na base do dissipador.

Hetsroni et al. (2001), Agostini et al. (2008a) e Szczukiewicz et al. (2013c) aqueceram a seção de testes através de resistências consistindo em filmes de material condutor em forma de serpentina depositadas quimicamente na base do dissipador de calor. Agostini et al. (2008a), através deste método, atingiram fluxos de calor de até $2500 \mathrm{~kW} / \mathrm{m}^{2}$ na base do dissipador. Hetsroni et al. (2001) e Szczukiewicz et al. (2013c) investigaram o efeito do aquecimento não uniforme (hot spots) no desempenho de dissipadores de calor.

Aquecimento através de resistência elétrica em forma de serpentina pressionada contra a base do dissipador foi implementado por Do Nascimento et al. (2013) e Leão et al. (2015). Estes autores preencheram os espaços vazios entre a superfície do dissipador de calor e a resistência com nanopartículas de alumina. Através deste método de aquecimento, os autores atingiram fluxos de calor de até $320 \mathrm{~kW} / \mathrm{m}^{2}$ na base do dissipador (footprint).

As perdas para o ambiente têm sido avaliadas a partir da relação entre o calor transferido para o fluido e o calor aplicado a seção de testes. Assim, se estabelece a relação $\%_{\text {perdas }}=$ $100\left(1-Q_{\text {fluido }} / Q_{\text {aplicado }}\right)$, onde o calor transferido para o fluido é determinado através de um balanço de energia entre a entrada e a saída do dissipador sob condições monofásicas. Os valores reportados pelos autores flutuam entre 4 e $15 \%$. Autores que aplicaram tal metodologia são Lee e Garimella (2008), Agostini et al. (2008a), Do Nascimento et al. (2013) e Leão et al. (2015). Para condições de ebulição convectiva, as perdas de calor para o ambiente decrescem devido ao incremento do coeficiente de transferência de calor interno. Os autores mencionados anteriormente assumem perdas nulas ou entre 2 e $5 \%$ para condições de escoamento bifásico.

Tamanna e Lee (2015) estimaram a perda de calor com a seção de testes em vácuo, levantando uma curva que relaciona o calor dissipado com a diferença de temperatura entre a parede e o ambiente. Este procedimento consistiu em aumentar gradualmente a potência de aquecimento da seção de testes e, assumiu-se que para uma determinada diferença de temperatura entre a superfície do dissipador e o ambiente, a potência de aquecimento aplicada transfere-se para o ambiente através de convecção natural a partir da superfície externa do isolamento. O ensaio é realizado até atingir a temperatura superficial de forma a cobrir as condições experimentais. Método similar para estimar a perda de calor para o ambiente foi adotado no presente estudo.

A temperatura do dissipador é geralmente avaliada a partir de termopares fixados no inferior de sua superfície. Os valores fornecidos são corrigidos com base na Lei de Fourier assumindo condução unidimensional desde a localização dos termopares até a superfície externa dos microcanais em contato com o fluido. Do Nascimento et al. (2013) e Leão et al. (2015) adotam este método para estimar a temperatura superficial. A desvantagem deste método é a imprecisão 
na avaliação da resistência térmica de contato entre os termopares e o dissipador de calor e, o seu efeito intrínseco no campo de temperaturas na região.

Szczukiewicz et al. (2013c) avaliaram a temperatura superficial através de imagens de termografia infra-vermelha. A partir do campo de temperatura na face do dissipador oposta aos microcanais, estimou-se a temperatura na superfície inferior dos canais baseados na Lei de Fourier, considerando aquecimento uniforme e fluxo de calor unidimensional.

A temperatura do fluido é avaliada através dos seguintes métodos: (i) avaliação da temperatura média, procedimento adotado por Do Nascimento et al. (2013) e Leão et al. (2015). No caso de apenas escoamento monofásico ao longo do dissipador, a temperatura do fluido é dada pela média aritmética entre as temperaturas de entrada e saída do fluido determinadas através de termopares localizados nas câmaras de entrada e saída. Já para escoamento com a presença de ebulição convectiva, a temperatura do fluido é ponderada segundo os comprimentos das regiões monofásica e bifásica. Estes comprimentos são determinados através da resolução simultânea das equações de balanço de energia e uma correlação para perda de pressão monofásica. (ii) avaliação da temperatura local, procedimento adotado por Lee e Garimella (2008) e Szczukiewicz et al. (2013c), no qual assumiram um gradiente constante da temperatura de saturação tanto para a região monofásica como para região sob ebulição convectiva. Com base nesta hipótese, calcula-se a temperatura do fluido através da Eq. 2.221 descrita no item 2.3.3.1.

Lee e Garimella (2008), Harirchian e Garimella (2012), Do Nascimento et al. (2013) e Leão et al. (2015), para a comparação de resultados experimentais com métodos de previsão do CTC para ebulição convectiva, assumiram variação linear do título de vapor ao longo dos microcanais como resultado do fluxo de calor uniformemente distribuído e o fluido sob condições saturadas. Tais comparações consideram apenas a região do dissipador correspondente ao seu comprimento em que se assume a presença do mecanismo de ebulição convectiva.

\subsubsection{COMPARAÇÃO DOS BANCOS DE DADOS PARA CTC MÉDIO PARA MULTI- MICROCANAIS E MÉTODOS DE PREVISÃo}

A Tabela 2.15ilustra resultados da literatura de comparações entre métodos de previsão e dados experimentais para o coeficiente de transferência de calor durante a ebulição convectiva em dissipadores de calor baseados em multi-microcanais. Resultados de comparações envolvendo o método proposto e o banco de dados utilizado em seu ajuste não foram incluídos.

Os trabalhos experimentais listados na Tabela 2.15, envolvem dezenove estudos para multimicrocanais paralelos com seção transversal retangular, dois para canais circulares paralelos e um para micro-aletas (piranha).

Entre os métodos de previsão listados na Tabela 2.15, três foram desenvolvidos para ebulição em piscina (Cooper (1984), Hwang e Yao (1986) e Gorenflo (1993)), sete baseados em resultados experimentais para canais convencionais (Chen (1966), Shah (1976), Gungor e Winterton 
(1986), Hsu (1987), Kandlikar (1990), Liu e Winterton (1991) e Steiner e Taborek (1992)), três para banco de tubos (Dowlati et al. (1996), Gupta et al. (1995) e Gupta(2005)), um para micro e macrocanais (Saitoh et al. (2007)), um para micro-aletas em forma de piranha (Koşar et al. (2005)), e vinte e dois para microcanais sendo baseados apenas em resultados para canais únicos (Lazarek e Black (1982), Tran et al. (1996), Kew e Cornwell (1997), Warrier et al. (2002), Yu et al. (2002), Zhang et al. (2004), Kandlikar e Balasubramanian (2004), Peters e Kandlikar (2007) e Tibiriçá (2011)), somente para dados em multi-microcanais (Yan e Lin (1998), Lee e Lee (2001a), Lee e Mudawar (2005b), Yun et al. (2006), Liu e Garimella (2007), Lee e Garimella (2008), Kaew-On et al. (2011) e Zhuan e Wang (2013)) e resultados para canais únicos e multimicrocanais (Thome et al. (2004), Li e Wu (2010), Bertsch et al. (2009b) e Kim e Mudawar (2013)). Alguns dos métodos de previsão encontram-se previamente descritos nas Tabelas 2.7 . 2.9 e 2.10

A razão pela qual autores comparam resultados experimentais com métodos de previsão desenvolvidos para macrocanais se deve ao fato de alguns mecanismos de transferência de calor preponderantes em macrocanais estarem presentes em microcanais, assim como a ocorrência de padrões de escoamento similares como bolhas, pistonado e anular. Comparações com métodos elaborados para ebulição em piscina se devem ao fato de, em diâmetros reduzidos, os efeitos da rugosidade se incrementarem elevando a densidade de sítios ativos de nucleação, intensificando efeitos de ebulição nucleada.

Entre os métodos de previsão listados na Tabela 2.15, destaca-se o modelo de três zonas proposto por Thome et al. (2004), o qual proporcionou melhores previsões de 4 bancos de dados independentes. Este modelo foi elaborado com base no padrão de escoamento de bolhas alongadas, o qual é típico em dissipadores de calor, pois estes apresentam comprimentos reduzidos de forma que títulos de vapor correspondentes ao padrão anular são não frequentes.

Segundo a Tabela 2.15, os métodos mais frequentes em comparações com dados experimentais para multi-canais foram os de Tran et al. (1996) e Warrier et al. (2002) avaliados dez e nove vezes, respectivamente. Tal fato se justifica em razão destes métodos possuírem implementação simples e suas proposições terem ocorrido a mais de 15 anos. No entanto, vale destacar que o método de Tran et al. (1996) fornece um coeficiente de transferência de calor constante e independente do título de vapor, comportamento típico da predominância de efeitos de ebulição.

Embora, segundo os parâmetros estatísticos, o método de Yu et al.(2002) forneça as menores desvios para os dados de Qu e Mudawar (2003b), o método de Warrier et al. (2002) é o que melhor captura a tendência destes resultados experimentais.

Os resultados de Lee e Mudawar (2005b) e Kaew-On et al. (2011) não foram previstos satisfatoriamente por nenhum dos métodos com os quais foram comparados. Tal fato decorre dos bancos de dados para os métodos por eles avaliados considerarem no seu desenvolvimento apenas condições de ebulição em piscina e outros para microcanais únicos. 


\begin{tabular}{|c|c|c|c|c|c|c|c|c|c|c|c|c|c|c|c|c|c|c|c|c|c|c|}
\hline & Kim e Mudawar (2013) & & & & & & & & & & & & & & & & & & & -. & & \\
\hline & Zhuan e Wang (2013) & & & & & & & & & & & & & & & & & & -. & & & \\
\hline & Tibiriçá (2011) & & & & & & & & & & & & & & & & & 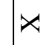 & & & $x$ & \\
\hline & Kaew-On et al. (2011) & & & & & & & & & & & & & $x$ & & & & & & & & \\
\hline & Li e Wu (2010) & & & & & & & & & & & & & & & & & & & & -. & \\
\hline & Bertsch et al. (2009b) & & & & & & & & & & & & & & & $x$ & - & & & & $x$ & \\
\hline & Lee e Garimella (2008) & & & & & & & & & & & .. & & & & & & & & & & \\
\hline & Saitoh et al. (2007) & & & & & & & & & & & & $x$ & & & & & & & & $x$ & \\
\hline & Peters e Kandlikar (2007) & & & & & & & & & & $x$ & & & & & & & & & & & \\
\hline & Liu e Garimella (2007) & & & & & & - & & & & $x$ & & & & & & & & & & & \\
\hline & Yun et al. (2006) & & & & & . & & & & & & & $x$ & & & & & & & & & \\
\hline |ृ & Koşar et al. (2005) & & & & & & & - & & & & & & & & & & & & & & \\
\hline E & Gupta 2005) & & & & & & & $x$ & & & & & & & & & & & & & & \\
\hline 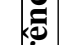 & Lee e Mudawar (2005b) & & & & & & & - & & $x$ & & & $x$ & & $x$ & $x$ & $x$ & & & & & \\
\hline th & Kandlikar e Balasubramanian (2004) & & & & & & & & & $x$ & & $x$ & $x$ & & & $x$ & & & -. & & & 10 \\
\hline 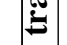 & Zhang et al. (2004) & & & & & & & & & $x$ & $x$ & & $x$ & & & & & & & & & R \\
\hline E & Thome et al. (2004) & & & & & & & & & -. & & & $x$ & & &.- & -. & -. & & & $x$ & 命 \\
\hline 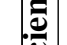 & Warrier et al. (2002) & & -. & & $x$ & & - & & & & $x$ & $x$ & $x$ & $x$ & $x$ & & & & & $x$ & & 0 \\
\hline 泀 & Yu et al. (2002) & & -. & & $x$ & & $x$ & & & & & $x$ & & $x$ & $x$ & & & & & & & lo \\
\hline $\mathbb{g}$ & Lee e Lee (2001a) & & $x$ & & $x$ & & & & & & & & $x$ & & $x$ & & & & & $x$ & & $\frac{\pi}{\leq}$ \\
\hline 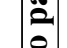 & Yan e Lin (1998) & $x$ & & & & & & & & & & & & & & & & & & & & 8 \\
\hline 悉 & Kew e Cornwell[1997], & & & & & & & & & & & & & $x$ & & & & & & & & $\bar{a}$ \\
\hline 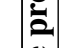 & Tran et al. (1996) & & $x$ & & $x>$ & $x$ & & & & & $x$ & & $x$ & $x$ & $x$ & & $x$ & & & $x$ & & :F \\
\hline $\mid$ & Dowlati et al. (1996) & & & & & & & $x$ & & & & & & & & & & & & & & $\bar{g}$ \\
\hline 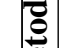 & Gupta et al. (1995) & & & & & & & $x$ & & & & & & & & & & & & & & $\approx$ \\
\hline$\sum$ & Gorenflo (1993) & & & & & $x$ & & & & & $x$ & & $x$ & & & & & & & & & $\frac{8}{4}$ \\
\hline & Steiner e Taborek (1992) & & $x$ & & & & & & & & & $x$ & & & & & & & & & & \\
\hline & Liu e Winterton 1991) & & $x$ & & $x$ & & & & & & & & -. & & $x \mid$ & & & $x$ & & & $x$ & 函 \\
\hline & Kandlikar (1990) & & $x$ & & & & $x$ & & $x$ & & & & & &.- & & & & & & & 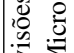 \\
\hline & Hsu (1987) & & & & & & & $x$ & & & & & & & & & & & & & & \\
\hline & Hwang e Yao (1986) & & & & & & & $x$ & 4 & & & & & & & & & & & & & \\
\hline & Gungor e Winterton (1986) & & $x$ & & & & $x$ & & & & $x$ & & & & $x$ & & & & & $x$ & & ह \\
\hline & Cooper (1984) & & & & & $x>>$ & & & & & -. & & -. & & & & & & & $x$ & & \\
\hline & Lazarek e Black (1982) & & $x$ & & $x>$ & $x$ & & & & & & & $x$ & $x$ & $x$ & & & & & $x$ & & $=$ \\
\hline & Shah (1976) & & $x$ & & $x$ & & - & & & & $x$ & & $x$ & & & & & & & $x$ & & \\
\hline & Chen (1966) & & $x$ & & $x$ & & $x$ & & & & $x$ & $x$ & & $x$ & & & & & & $x$ & & \\
\hline & 竞 & 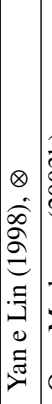 & 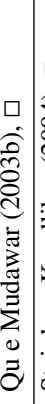 & & 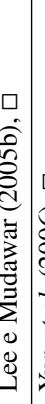 & 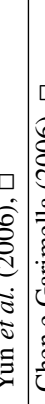 & 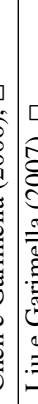 & & 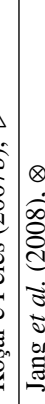 & 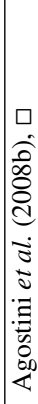 & 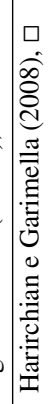 & 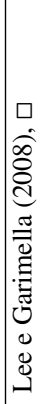 & 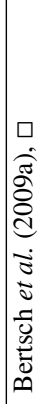 & 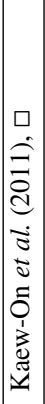 & 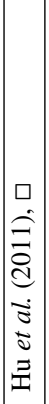 & 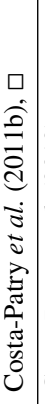 & 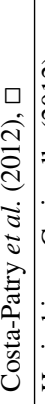 & 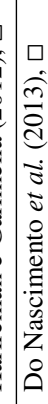 & 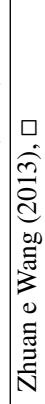 & 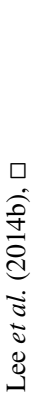 & 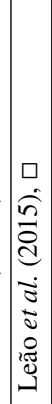 & 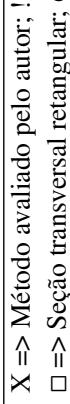 \\
\hline
\end{tabular}


Os resultados de Zhuan e Wang (2013) foram previstos satisfatoriamente pelo método de Kandlikar e Balasubramanian (2004). É curioso o fato destes autores obterem tal resultado pois eles avaliaram também as correlações de Krishnamurthy e Peles (2008) e Qu e Siu-Ho (2009), as quais foram desenvolvidas para micro-aletas e, desta forma envolverem condições mais similares ao escoamento cruzado investigado por Zhuan e Wang (2013). Tais resultados podem estar relacionados ao fato dos resultados levantados por Zhuan e Wang (2013) envolverem velocidades mássicas de 10 a $35 \mathrm{~kg} / \mathrm{m}^{2}$ s e o método Kandlikar e Balasubramanian (2004) implementado por eles ser recomendado para $R e_{l} \leq 100$.

O modelo de 3-zonas apresentou as melhores previsões dos dados experimentais de Harirchian e Garimella (2008), Costa-Patry et al. (2011b), Costa-Patry et al. (2012) e Do Nascimento et al. (2013). Estes autores implementaram este método adotando a rugosidade superficial como mínima espessura do filme líquido, ao contrário de Dupont et al. (2004) que adota um valor fixo, ajustado com base em seu banco de dados. Vale destacar que a rugosidade foi avaliada por Costa-Patry et al. (2011b) a partir de imagens tomadas da parede do canal através de microcopia eletrônica obtendo um valor médio de $67 \mathrm{~nm}$ com desvio padrão de $22 \mathrm{~nm}$, isto é cerca de $33 \%$ do valor da rugosidade medida.

Harirchian e Garimella (2012) modificaram a previsão de espessura mínima do filme líquido incluindo efeitos de capilaridade (número Capilar). Os autores avaliaram o método original de Thome et al. (2004) com os valores de espessura mínima do filme fornecidos Dupont et al. (2004), prevendo 35,9\% dos dados dentro de $\pm 30 \%$ com MAE $=41,2 \%$. Já, utilizando a espessura mínima do filme líquido segundo a modificação por eles proposta, obtiveram melhores previsões para o coeficiente de transferência de calor com $\lambda_{ \pm 30}=81,1 \%$ e MAE $=17,8 \%$.

Segundo Do Nascimento et al. (2013), devido à inclusão de resultados experimentais envolvendo bancos de dados para multi-microcanais para ajustar o método de 3-zonas, possíveis efeitos relacionados com configurações de multi-microcanais incluindo instabilidades térmicas, seriam incorporados pelo método através de suas constantes empíricas.

Bertsch et al. (2009a) obtiveram melhores previsões através dos métodos de Liu e Winterton (1991) e Cooper (1984). Segundo Bertsch et al. (2009a), seus dados experimentais apresentaram coeficientes de transferência de calor determinados predominantemente por efeitos de ebulição nucleada. Além disso, a correlação de Liu e Winterton (1991) baseia-se na superposição de efeitos de ebulição nucleada e convectivos, sendo a correlação de Cooper (1984) neste método adotada para calcular a parcela associada a ebulição nucleada. Assim, considerando que dados em multi-microcanais são obtidos para títulos de vapor reduzidos não é surpreendente que os métodos de Liu e Winterton (1991) e Cooper (1984) apresentem em conjunto melhores previsões.

Com base na análise apresentada, conclui-se que os métodos de previsão disponíveis na literatura não preveem satisfatoriamente o CTC devido à ebulição convectiva em multi-microcanais 
quando comparados a banco de dados independentes. Os métodos disponíveis, em sua maioria, foram desenvolvidos com base em dados para canais únicos e não incluem fenômenos típicos da ebulição convectiva em multi-microcanais. Para estas configurações, conforme ressaltado por Do Nascimento et al. (2013), interações entre canais vizinhos e a geometria dos plenums exercem efeitos relevantes sobre o escoamento, implicando em fenômenos não capturados por estes métodos de previsão.

\subsection{EBULIÇÃO CONVECTIVA DE HIDROCARBONETOS EM MI- CROCANAIS}

Esta seção se inicia com a descrição dos estudos experimentais focados em avaliar o efeito de fluido refrigerante na ebulição convectiva em dissipadores de calor baseados em multimicrocanais. A partir desta análise constata-se a ausência de estudos para hidrocarbonetos. Com base neste fato, na continuidade da seção, são analisados apenas estudos envolvendo a ebulição convectiva de hidrocarbonetos em microcanais únicos, fluidos cuja análise do desempenho é o objetivo do presente trabalho.

\subsubsection{ESTUDOS SOBRE EFEITO DO FLUIDO NA EBULIÇÃO CONVECTIVA EM MULTI-MICROCANAIS}

Conforme indicado, são raros os estudos na literatura comparando o desempenho de fluidos refrigerantes durante a ebulição convectiva em dissipadores de calor baseados em multimicrocanais. Apenas Leão et al. (2016) realizaram tal análise envolvendo a comparação de um hidrocarboneto (R600a) com refrigerantes halogenados.

Neste contexto, Peng et al. (1996) estudaram o efeito da concentração de metanol em água no coeficiente de transferência de calor verificando CTCs superiores para os fluidos puros. Estes autores destacaram o drástico aumento do superaquecimento necessário ao início da ebulição com a aumento da concentração de metanol.

Yun et al. (2004) verificaram coeficientes de transferência de calor superiores para R410A em relação ao $\mathrm{CO}_{2}$ (R744). Também verificaram que os efeitos no CTC da velocidade mássica, fluxo de calor e temperatura de saturação são relativamente inferiores para o R410A em relação ao $\mathrm{CO}_{2}$ (R744).

Bertsch et al. (2008 e 2009a) observaram CTCs para o R134 superiores ao R245fa. Segundo eles, este fato se deve à elevada massa molecular e tensão superficial do R245fa, o que resulta no CTC inferior para este refrigerante quando os efeitos de ebulição nucleada são predominantes. Além disso, eles observaram que o ONB é deslocado para fluxos de calor superiores, com o aumento da velocidade mássica para ambos os fluidos. Este comportamento, também foi verificado por Leão et al. (2016). 
Agostini et al. (2008a 2008b e 2008c) compararam o desempenho dos HFCs, R245fa e R236fa em termos do coeficiente de transferência de calor. De acordo com eles, o CTC é independente do título de vapor e aumenta marginalmente com a velocidade mássica para o R245fa, sendo independente da velocidade mássica para o R236fa. Além disso, eles observaram que o CTC incrementa com o aumento da pressão de saturação, particularmente para o R236fa.

Costa-Patry et al. (2011a) avaliaram a transferência de calor e a perda de pressão durante a ebulição convectiva dos refrigerantes R236fa e R245fa. Eles verificaram que o R245fa proporciona perdas de pressão superiores ao R236fa devido ao volume específico da fase vapor ser inferior para este último. Segundo os autores, a redução de pressão ao longo dos microcanais aumenta quase linearmente com o título de vapor e a perda de pressão total é afetada apenas marginalmente pela velocidade mássica para ambos os fluidos.

Costa-Patry et al. (2012) foram pioneiros em realizar um estudo incluindo refrigerantes com baixo GWP em um dissipador de calor baseado em multi-microcanais. Eles avaliaram o desempenho do R1234ze(E), R134a e R245fa. Posteriormente, Szczukiewicz et al. (2013a, 2013 b e 2013c) compararam o efeito de R1234ze(E),R236fa e R245fa. Em geral, os autores concordam que o refrigerante R1234ze(E) apresenta CTC superior aos demais refrigerantes avaliados.

\subsubsection{ESTUDOS SOBRE HIDROCARBONETOS EM MICROCANAIS}

Constata-se número reduzido de estudos relacionados a investigação da ebulição convectiva em microcanais únicos evolvendo HCs. A Tabela 2.16 descreve esquematicamente estes estudos. De acordo com esta tabela, testes foram realizados para ebulição convectiva do R600, R600a, R290 e misturas de R600/R290. O desempenho destes HCs foi comparado com o dos refrigerantes R134a, R410A, R717, R744, R22 e R1234yf. Testes foram realizados para canais com diâmetros entre 0,1484 e 3,0 mm tanto para escoamento com orientação vertical como horizontal. Estes estudos envolveram investigação dos padrões de escoamento, perda de pressão, CTC, fluxo crítico de calor e condições de secagem de parede cobrindo temperaturas de saturação entre 0 e $43{ }^{\circ} \mathrm{C}$, títulos de vapor de equilíbrio termodinâmico de 0 a 1,15 , velocidades mássicas de 50 a $1000 \mathrm{~kg} / \mathrm{m}^{2} \mathrm{~s}$ e fluxos de calor de até $315 \mathrm{~kW} / \mathrm{m}^{2}$.

Em geral, de forma análoga aos demais fluidos, os autores listados na Tabela 2.16 verificaram que o CTC para os HCs se eleva com o incremento da velocidade mássica, do fluxo de calor, temperatura de saturação e com a redução do diâmetro do canal. Para perdas de pressão verifica-se seu aumento com o incremento da velocidade mássica, título de vapor e com o decréscimo da temperatura de saturação. De uma maneira geral, segundo estes estudos, o fluxo de calor necessário para atingir a secagem de parede se eleva com o incremento da velocidade mássica, com a redução do título de vapor, com o incremento do diâmetro e, com a variação da temperatura de saturação, apresenta uma variação marginal. 
Tabela 2.16 - Estudos experimentais sobre ebulição convectiva de HCs em microcanais

\begin{tabular}{|c|c|c|c|c|c|c|c|}
\hline Autor (ano) & $\begin{array}{c}\text { Diâmetro } \\
\text { [mm]/ } \\
\text { orientação }\end{array}$ & Fluido & $\begin{array}{c}\text { Psat }[\mathbf{k P a}] / \\
\text { Tsat }\left[{ }^{\circ} \mathbf{C}\right]\end{array}$ & $\begin{array}{c}\text { Título de } \\
\text { vapor/ Tp } \\
{\left[{ }^{\circ} \mathbf{C}\right]} \\
\end{array}$ & $\begin{array}{c}\mathbf{q}^{\prime \prime} \\
{\left[\mathrm{kW} / \mathbf{m}^{2}\right.}\end{array}$ & $\underset{\left[\mathrm{kg} / \mathrm{m}^{2} \mathrm{~s}\right]}{\mathbf{G}}$ & $\begin{array}{c}\text { Parâmetro } \\
\text { de estudo } \\
* * \\
\end{array}$ \\
\hline$\frac{\text { Wen e Ho }}{2005}$ & $\begin{array}{c}2,46 / \\
\text { Horizontal }\end{array}$ & $\begin{array}{c}R 600, R 290 \mathrm{e} \\
\text { mistura de } \\
R 600 / R 290\end{array}$ & $-/ 6$ & $\begin{array}{c}0-0,86 / \\
7,5-14\end{array}$ & $5-21$ & $250-500$ & $\Delta p$ e h \\
\hline $\begin{array}{c}\text { Field e Hrnjak } \\
2007)\end{array}$ & $\begin{array}{c}0,148 / \\
\text { Horizontal }\end{array}$ & $\begin{array}{c}R 134 a, R 410 A, \\
R 290 \text { e } R 717\end{array}$ & $\begin{array}{c}\text { 690-1794/ } \\
-\end{array}$ & $0-1,0 /-$ & - & $300-700$ & $\Delta p$ \\
\hline $\begin{array}{c}\text { Choi et al. } \\
\text { (2009) }\end{array}$ & $\begin{array}{l}1,5 \text { e } 3,0 / \\
\text { Horizontal }\end{array}$ & $R 290$ & $-/ 10,5$ e 0 & até $1,0 /$ - & $5-20$ & $50-400$ & $\Delta p$ e h \\
\hline$\frac{\text { Pamitran et al. }}{2010}$ & $\begin{array}{c}0,5,1,5 \text { e } 3,0 / \\
\text { Horizontal }\end{array}$ & $\begin{array}{l}\text { R22, R134a, } \\
\text { R410A, R290 e } \\
\text { R744 }\end{array}$ & $-/ 0-15$ & $0-1,0 /-$ & $5-40$ & $50-600$ & $\mathrm{FP}$ e $\Delta p$ \\
\hline$\frac{\text { Pamitran et al. }}{\text { (2011) }}$ & $\begin{array}{l}1,5 \text { e } 3,0 / \\
\text { Horizontal }\end{array}$ & $\begin{array}{l}\text { R290, R717 e } \\
\text { R744 }\end{array}$ & $-/ 0-10$ & até $1,0 /$ - & $5-70$ & $50-600$ & $\Delta p$ e h \\
\hline $\begin{array}{c}\text { Maqbool et al. } \\
\text { (2012) }\end{array}$ & $\begin{array}{c}1,70 \text { e } 1,224 / \\
\text { Vertical }\end{array}$ & R290 & $\begin{array}{c}-/ 23,33 \mathrm{e} \\
43\end{array}$ & $0-1,15 /-$ & $5-276$ & $100-500$ & FCC e $x_{s e c}$ \\
\hline $\begin{array}{l}\text { Maqbool et al. } \\
\end{array}$ & $1,70 /$ Vertical & R290 & $\begin{array}{c}-/ 23,33 \mathrm{e} \\
43 \\
\end{array}$ & $0-1,1 /-$ & $5-280$ & $100-500$ & $\Delta p$ e h \\
\hline$\frac{\text { Copetti et al. }}{2013}$ & 2,6 / Horizontal & R600a/R134a & $-/ 22$ & $\begin{array}{c}\text { até } \approx 0,8 / \\
7,5-14\end{array}$ & $44-95$ & $240-440$ & $\Delta p \mathrm{e} \mathrm{h}$ \\
\hline $\begin{array}{c}\text { Del Col et al. } \\
\text { (2014) }\end{array}$ & $\begin{array}{c}0,96 / \\
\text { Horizontal } \\
\end{array}$ & R290 & $1106 / 31$ & $0,05-0,6 /-$ & $10-315$ & $100-1000$ & $\Delta p$ e h \\
\hline $\begin{array}{l}\text { Choi et al. } \\
\text { 2014 }\end{array}$ & $\begin{array}{l}1,5 \text { e } 3,0 / \\
\text { Horizontal }\end{array}$ & $\begin{array}{c}\text { R290, R717, } \\
\text { R744 e R1234yf }\end{array}$ & $-/ 0$ a 10 & até $1,0 /$ - & $5-60$ & $50-600$ & $\mathrm{~h}$ \\
\hline $\begin{array}{c}\text { Anwar et al. } \\
2015\end{array}$ & $\begin{array}{c}0,64 \text { a } 1,70 / \\
\text { Vertical }\end{array}$ & $\begin{array}{l}\text { R134a, R152a, } \\
\text { R1234yf, R22, } \\
\text { R245fa, R290 e } \\
\text { R600a }\end{array}$ & $-/ 23-43$ & até $\approx 1,1 /$ - & $18-276$ & $50-600$ & $x_{\text {sec }}$ \\
\hline \begin{tabular}{|c|} 
Sempértegui- \\
Tapia e \\
Ribatski 2016 \\
\end{tabular} & $\begin{array}{c}0,878(\square), \\
0,634(\Delta) \mathrm{e} \\
1,1(O) / \\
\text { Horizontal }\end{array}$ & $\begin{array}{l}\text { R134a, R600a, } \\
\text { R1234yf e } \\
\text { R1234ze(E) }\end{array}$ & $-/ 31$ e 41 & $\begin{array}{c}0,05-0,95 / \\
-\end{array}$ & - & $100-1600$ & $\Delta p$ \\
\hline
\end{tabular}

Wen e Ho (2005) verificaram coeficientes de transferência de calor para o R290, R600, R290/R600 cerca de 1,66-1,96, 1,28-1,38 e 1,57-1,88 vezes superiores ao R134, respectivamente, para fluxos de calor e velocidade mássica similares. Wen e Ho (2005) também indicaram que a perda de pressão por atrito para o R600, R290/R600 e R290 são 1,41-1,60, 1,32-1,50 e 1,22-1,40 vezes inferiores, respectivamente, aos valores observados para o R134a.

Copetti et al. (2013) e Sempértegui-Tapia e Ribatski (2016) também verificaram que o R600a fornece CTC e perdas de pressão superiores ao R134a. O R1234yf, cotado como possível substituto do R134a em aplicações envolvendo condicionamento de ar automotivo, também apresentou CTCs inferiores aos hidrocarbonetos (neste caso o R290, segundo o estudo de Choi et al. (2014)).

De uma maneira geral, os HCs apresentam CTCs superiores aos HCFCs e HFCs. Pamitran et al. (2011) e Choi et al. (2014) observaram valores superiores do CTC para o R717 em relação ao R290. No entanto, entre os HCs, os autores coincidem no fato do R290 apresentar coeficientes de transferência de calor superiores e perdas de pressão por atrito inferiores ao R600a. 


\subsection{INSTABILIDADES TÉRMICAS EM MULTI-MICROCANAIS}

\subsubsection{INTRODUÇÃO}

Instabilidades durante escoamento bifásico podem ser fenômenos indesejados causando problemas de operação, controle e vibrações mecânicas de componentes do sistema. Segundo Boure et al. (1973), estes fenômenos são classificados de forma geral como instabilidades estáticas e dinâmicas. Tibiriçá et al. (2015) descreve as instabilidades térmicas em multimicrocanais como de tipo dinâmicas, ressaltando em particular, oscilações causadas por volumes compressíveis, escoamento reverso e interação do escoamento na região dos plenums.

Kakaç et al. (1990) definem a estabilidade térmica como a propriedade do sistema de resistir as alterações de temperatura sem alterar seu regime operacional. Desta forma, instabilidades térmicas podem estar relacionadas a fenômenos responsáveis por alterações térmicas do sistema, através de oscilações na vazão, pressão e temperatura que podem ocorrer segundo distintas frequências.

Segundo Kakaç e Bon (2008), oscilações de vazão e pressão do sistema são indesejáveis, pois causam vibrações mecânicas, dificuldade para controle do sistema e, em circunstâncias extremas, perturbam as características de transferência de calor, podendo causar danos irreversíveis à superfície. No contexto de dissipadores de calor baseados na ebulição convectiva em multi-microcanais, os fenômenos que causam instabilidades térmicas podem estar relacionados a má distribuição do fluido, "ebulição explosiva" e fluxo reverso associados ao crescimento de bolhas em condições confinadas. A Figura 2.20, elaborada por Hetsroni et al. (2003), apresenta um esquema de instabilidade térmica do fluido durante a ebulição convectiva, ilustrando o crescimento "explosivo" da bolha e a secagem periódica da superfície em multi-microcanais paralelos de seção triangular, Hetsroni et al. (2003).

Escoamento monofásico

Início do crescimento

rápido da bolha

Secagem intermitente
Vista Superior
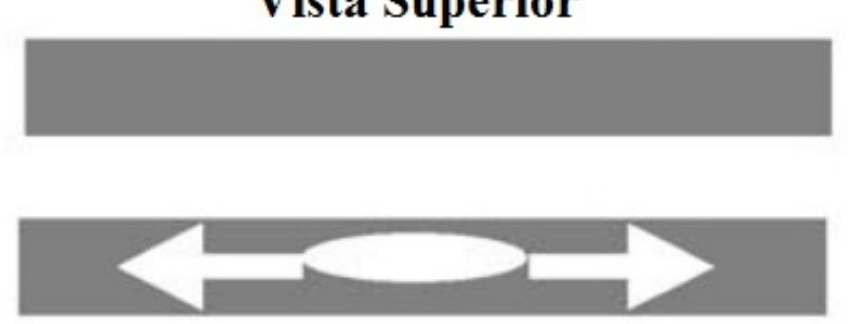

Seção transversal
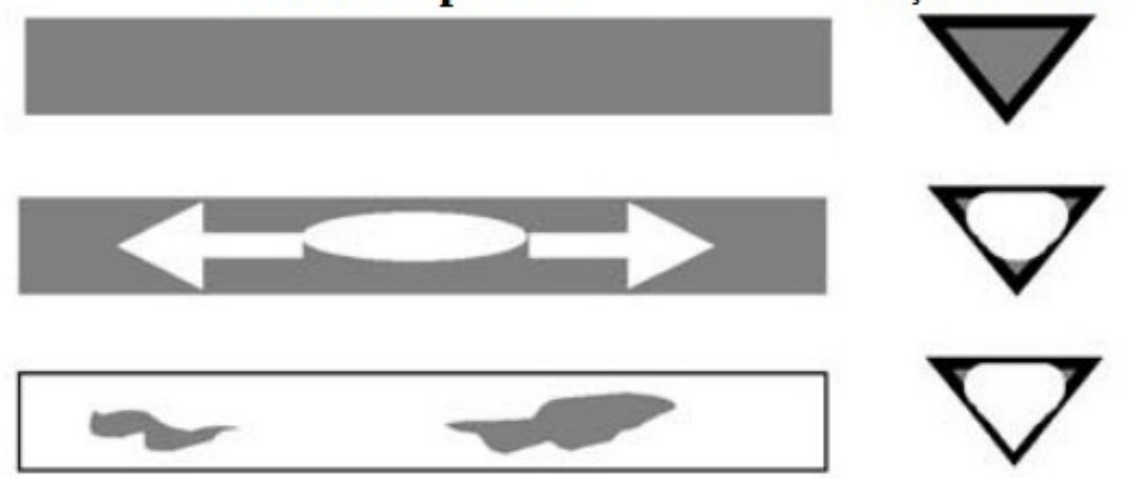
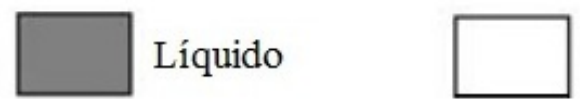

Vapor

Figura 2.20 - Ilustração esquemática do fenômeno de crescimento "explosivo" de bolhas em condições confinadas, Hetsroni et al. (2003). 
Parcela dos estudos sobre instabilidades térmicas listados na Tabela 2.11 dedicou-se apenas a visualizações da má distribuição do fluido, da "ebulição explosiva" e a ocorrência de fluxo reverso e seus efeitos no desempenho do dissipador. Outra parcela significativa buscou o desenvolvimento de geometrias e soluções de forma a minimizar este problema.

\subsubsection{VISUALIZAÇÕES DO ESCOAMENTO EM CONDIÇÕES DE INSTABILIDA- DES TÉRMICAS}

Yin et al. (2014) observaram que a taxa de crescimento de bolhas em condições sem restrição é drasticamente inferior comparada com o crescimento confinado. Eles observaram que a taxa de crescimento da bolha diminui com o aumento do seu tamanho até alcançar condições de confinamento, enquanto a taxa de alongamento aumenta com o incremento das dimensões da bolha confinada. De acordo com Yin et al. (2014), a forma inicial de bolhas nucleadas no canto do canal influência significativamente o processo de crescimento da bolha.

Hetsroni et al. (2001, 2002, 2003 e 2005) efetuaram um extenso estudo sobre instabilidades térmicas durante a ebulição convectiva em condições confinadas para multi-microcanais. Uma vez estabelecido o processo de ebulição, eles indicaram a existência de zonas secas periódicas devido ao surgimento intermitente de pontos de maior aquecimento (hot spots). No caso de fluxos de calor uniformes, as instabilidades causam irregularidades na distribuição da temperatura da superfície aquecida do dispositivo tanto na direção do escoamento como na direção transversal aos microcanais. Já para fluxo de calor não uniforme, as irregularidades na distribuição de temperatura se elevam drasticamente.

Hetsroni et al. (2002) indicam que reduções no CTC estão associadas a comportamentos oscilatórios da temperatura do fluido, da parede e pressão relacionadas a efeitos de instabilidades térmicas como produto do rápido crescimento da fração de vapor e colapso de bolhas ("Ebulição Explosiva").

A Figura 2.21 ilustra oscilações da diferença de pressão entre a entrada e saída do dissipador, e da temperatura do fluido na saída do dissipador observadas por Hetsroni et al. (2002). Nela nota-se que a elevação do fluxo de calor em apenas $4 \mathrm{~kW} / \mathrm{m}^{2}$ e do título de vapor em 0,04 , faz com que efeitos de instabilidades resultem na elevação das oscilações de pressão e temperatura de valores marginais para variações em torno de $\pm 2 \mathrm{kPa}$ e até $-0,7^{\circ} \mathrm{C}$.

Hetsroni et al. (2003) investigaram o crescimento de bolhas confinadas em condições de $\Delta \mathrm{T}_{\max }=6^{\circ} \mathrm{C}$. Neste estudo, para q" $=0,832 \mathrm{~kW} / \mathrm{m}^{2}$ e $\mathrm{J}_{\mathrm{l}}=0,046 \mathrm{~m} / \mathrm{s}$, o início do crescimento de bolhas foi observado próximo do plenum de saída. Já para velocidades superficiais e fluxos de calor superiores foi observado que os sítios de nucleação distribuem-se ao longo dos microcanais. A partir daí aparece escoamento instável caracterizado por vapor retornando ao plenum de entrada, intensificando as oscilações de pressão e temperaturas da parede e do fluido no plenum de saída. 
A Figura 2.22, elaborada por Hetsroni et al. (2003), ilustra a distribuição de fases durante a ebulição convectiva em microcanais paralelos. Nela observa-se a presença de vapor apenas em parcela dos microcanais, apresentando diferentes comprimentos monofásicos.
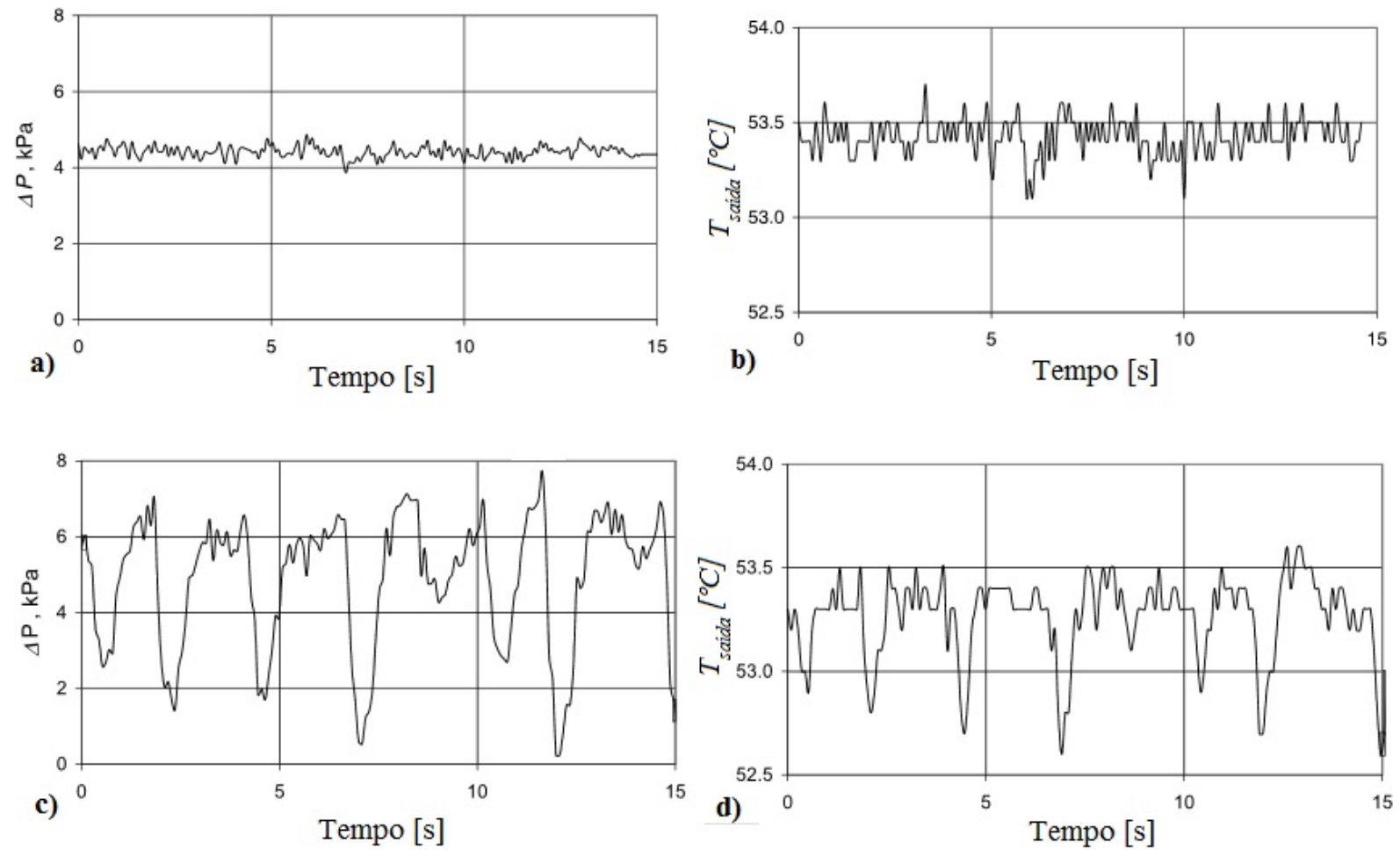

Figura 2.21 - Oscilações da diferença de pressão e temperatura na saída segundo Hetsroni et al. (2002). (a) e (b) G $=148 \mathrm{~kg} / \mathrm{m}^{2} \mathrm{~s}$, q" = $32 \mathrm{~kW} / \mathrm{m}^{2}$ e x =0,14; (a) e (b) $\mathrm{G}=148 \mathrm{~kg} / \mathrm{m}^{2} \mathrm{~s}, \mathrm{q}^{\prime \prime}=36 \mathrm{~kW} / \mathrm{m}^{2} \mathrm{e}$

$$
\mathrm{x}=0,18
$$

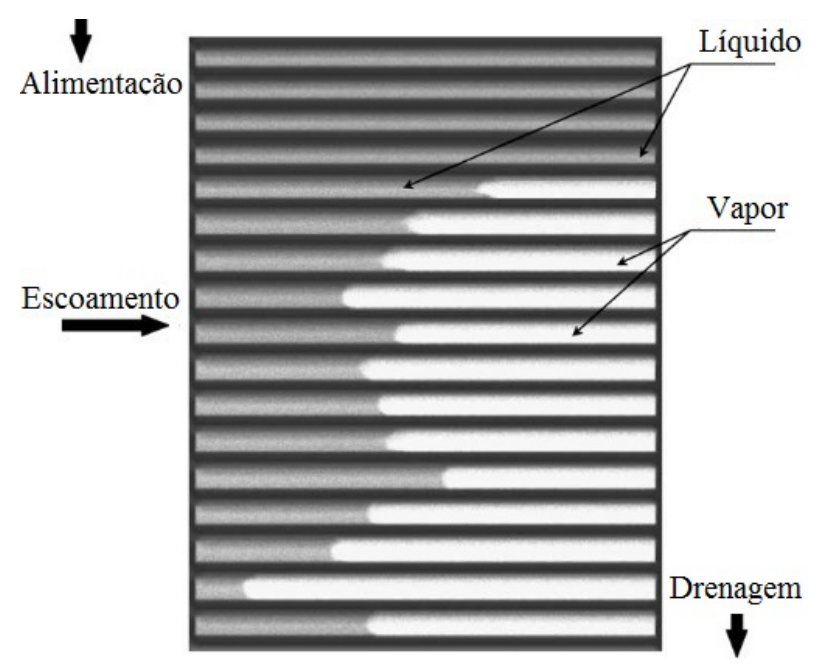

Figura 2.22 - Ilustração da distribuição de fases durante a ebulição convectiva em microcanais paralelos, Hetsroni et al. (2003).

Hetsroni et al. (2005) observaram que oscilações relacionadas a diferença de pressão entre a entrada e saída do dissipador se elevam com o incremento do título de vapor médio. Por outro lado, Hetsroni et al. (2005) investigaram a "ebulição explosiva" e a secagem intermitente 
baseados na inspeção de registros fotográficos levantados a partir de uma câmera de alta velocidade. Eles observaram que na condição de início da ebulição (ONB), a bolha se expande tanto no sentido do escoamento, assim como no sentido reverso, conforme ilustrado na Fig. 2.20. Este fenômeno, segundo eles, é responsável pelo desenvolvimento de instabilidades no escoamento e ao aumento das oscilações de pressão. Hetsroni et al. (2005) também visualizaram a secagem intermitente da superfície ainda que para títulos de vapor reduzidos, ressaltando que os microcanais se encontram parcialmente secos de forma cíclica.

As Figuras 2.23 e 2.24 elaboradas por Qu e Mudawar (2004) e Bogojevic et al. (2008 e 2009), respectivamente, ilustram o fluxo reverso de vapor na região do plenum de entrada. $\mathrm{O}$ fenômeno observado nas figuras faz com que o vapor que escoa em direção reversa, retorne ao plenum de entrada, misturando-se com o líquido nesta região causando o aumento da sua temperatura na entrada dos microcanais, assim, a ocorrência cíclica deste fenômeno causa oscilações na temperatura.

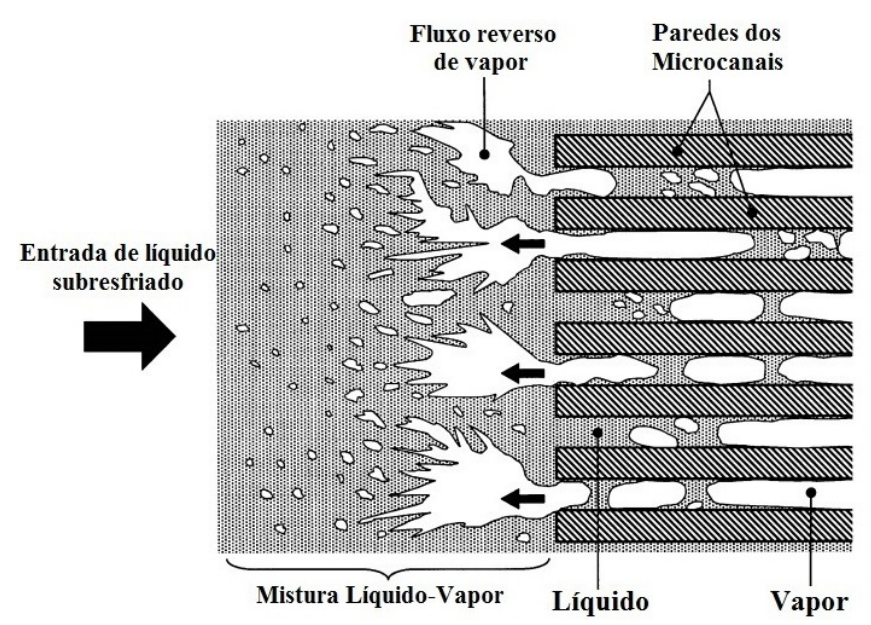

Figura 2.23 - Ilustração esquemática de fluxo reverso de vapor na câmara de entrada, Qu e Mudawar (2004).

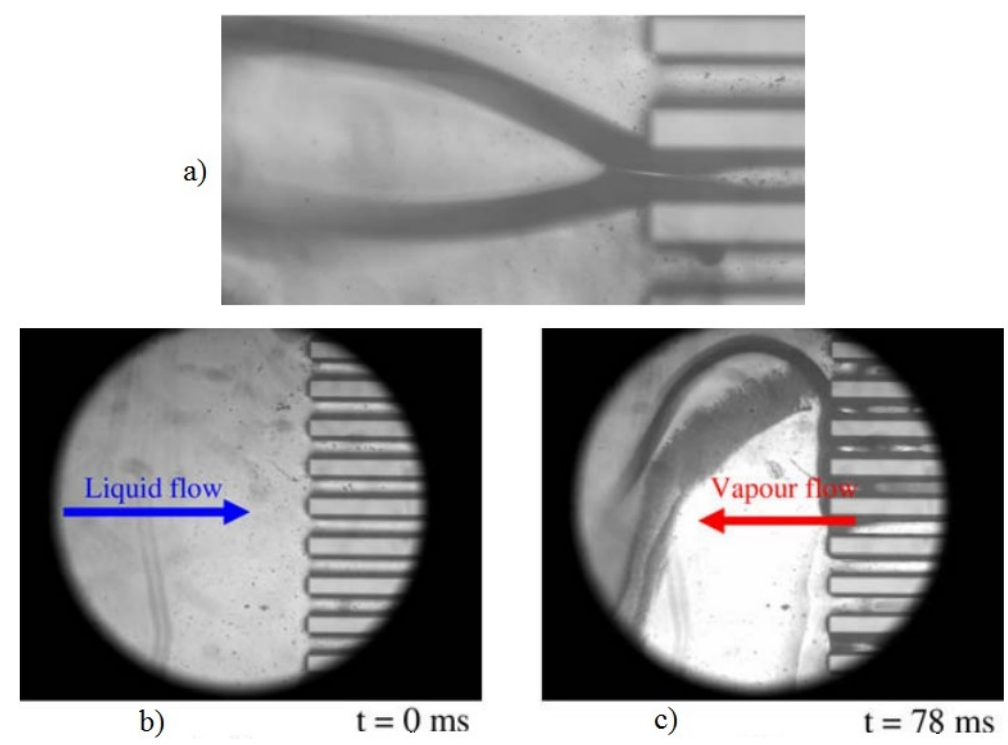

Figura 2.24 - Imagens da ebulição e escoamento reverso na câmara de entrada, Bogojevic et al. (2009). 
Em geral, os autores concordam que a amplitude das oscilações da temperatura do fluido na saída do dissipador, se eleva com o decréscimo da velocidade mássica e a pressão reduzida e com o incremento do fluxo de calor e do título de vapor.

Wu e Cheng (2004), Lee e Mudawar (2005a) e Chen e Garimella (2006) verificaram um incremento na amplitude das oscilações com o aumento do fluxo de calor implicando na redução do fluxo crítico de calor.

O aumento da velocidade mássica, conforme indicado por Lee e Mudawar (2005a), incrementa as oscilações. Por outro lado, segundo Chen e Garimella (2006), a variação da velocidade mássica não tem efeito sobre as oscilações de pressão para escoamento totalmente desenvolvido. Já, Megahed (2011), Leão et al. (2014) e Leão et al. (2015) observaram que a amplitude das oscilações aumenta com a redução da velocidade mássica.

Bogojevic et al. (2008 e 2009) observaram que instabilidades térmicas se intensificam para razões entre o fluxo de calor e velocidade mássica, em faixas entre 2,62 e $3,44 \mathrm{~kJ} / \mathrm{kg}$ para temperatura do fluido na entrada de $25^{\circ} \mathrm{C}$ e para razões desde 0,99 a $1,55 \mathrm{~kJ} / \mathrm{kg}$ para temperatura de entrada de $71^{\circ} \mathrm{C}$.

Wu e Cheng (2004) analisaram padrões de escoamento submetidos a condições de ebulição instáveis e avaliaram seus efeitos sobre as amplitudes das oscilações da pressão, temperatura e velocidade mássica. Os padrões característicos foram os seguintes: (1) líquido-bolhas intermitente (fluxo de calor e velocidade mássica reduzidas), (2) anular contínuo (fluxo de calor e velocidade mássica intermediários) e (3) líquido-anular-vapor intermitente (fluxo de calor elevado e velocidade mássica reduzida). Foram medidas simultaneamente, as oscilações periódicas de temperatura da parede, temperatura de entrada e saída do fluido, pressões de entrada e saída e velocidade mássica. Segundo Wu e Cheng (2004), as amplitudes de oscilação de pressão e velocidade mássica verificadas para o padrão de escoamento (3) são superiores e sob condições do padrão (1) são inferiores. Wu e Cheng (2004) concluíram que o período de oscilação (incluindo os três modos) depende da intensidade do fluxo de calor e da velocidade mássica.

\subsubsection{GEOMETRIAS PARA REDUZIR EFEITOS DE INSTABILIDADES}

Para determinadas condições operacionais, configurações de dissipadores baseados em multi-microcanais paralelos de seção retangular favorecem a distribuição não uniforme do fluido principalmente para escoamentos horizontais. Além disso, tal comportamento pode ser intensificado por geometrias ou configurações de plenums de entrada e saída que favorecem a propagação efeitos de instabilidades. Neste contexto, a localização e configuração da entrada do fluido pode favorecer efeitos de má-distribuição do fluido nos microcanais. Além disso, a configuração da entrada do fluido pode favorecer a presença de volumes compressíveis.

Wang et al. 2007 e 2008) realizaram um estudo extenso sobre instabilidades em multi- 
microcanais paralelos de seção trapezoidal. Eles avaliaram o efeito da configuração de alimentação e drenagem do fluido aos microcanais. As configurações avaliadas encontram-se ilustradas na Fig. 2.25 e consistem em: (a) disposição perpendicular aos microcanais; (b) paralela sem restrições; (c) paralela com restrições. Wang et al. (2008) concluíram que para as configurações do tipo (a) e (b) sem restrições na entrada dos microcanais, as oscilações de temperatura e pressão são intensificadas devido ao crescimento rápido da bolha em condições de confinamento resultando em escoamento reverso. Para a configuração (c) foi possível alcançar condições de ebulição com ausência de oscilações de pressão e temperatura e sem o escoamento de vapor em fluxo reverso. A restrição pode também, impor um escoamento anular logo a jusante dela, eliminando desta forma, o crescimento de bolhas em condições confinadas. Assim, Wang et al. (2008) recomendaram esta configuração para aplicações em multi-microcanais e fluxos de calor elevados de forma a evitar flutuações de temperatura. Entretanto, estes autores ressaltaram que o grau de estrangulamento na restrição deve ser avaliado criteriosamente de forma a apresentar perda de pressão adequada ao projeto.

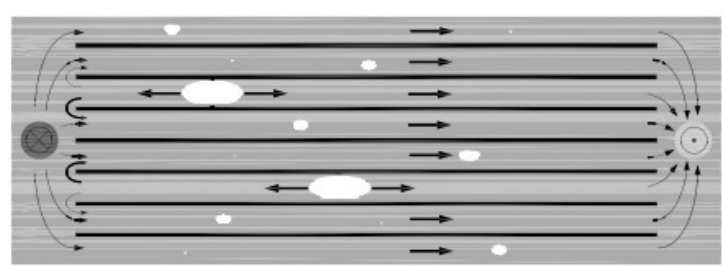

a)

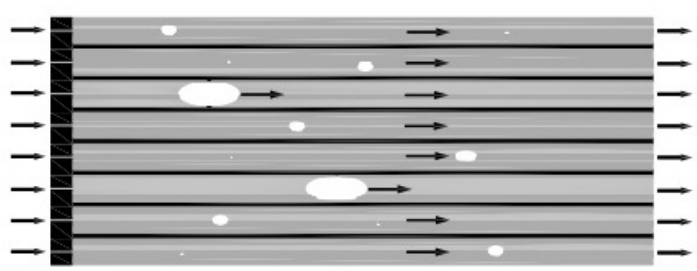

c)

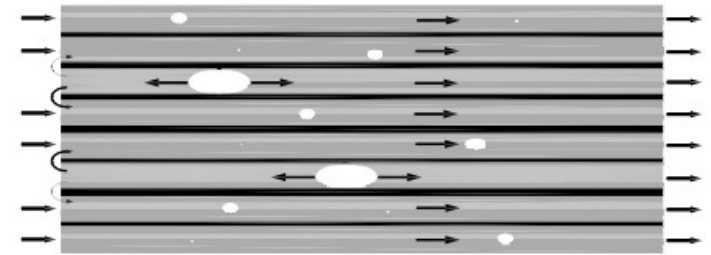

b)

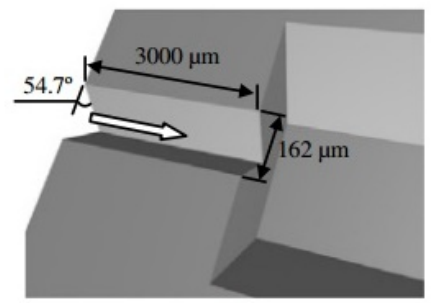

d)

Figura 2.25 - Configurações de entrada e saída de fluido avaliadas por Wang et al. (2008). (a) Perpendicular; (b) Paralela sem restrição; (c) Paralela com restrições; (d) Detalhe de restrição.

Cho et al. (2010) analisaram o efeito da combinação das configurações dos plenums e da geometria da seção transversal do canal nas instabilidades térmicas. A Fig. 2.26 ilustra as configurações de multi-microcanais avaliadas por Cho et al. (2010): (a) Plenums retangulares com canais de seção constante; (b) plenums trapezoidais com canais de seção constante; (c) plenums retangulares com canais de seção divergente; (d) plenums trapezoidais com canais de seção divergente. Neste estudo, eles concluíram que uma configuração de plenums trapezoidais combinadas com microcanais de seção divergente proporcionam decréscimo na perda de pressão e uma melhor distribuição do fluido refrigerante com maior uniformidade de temperatura superficial, implicando na redução de efeitos de instabilidades. 


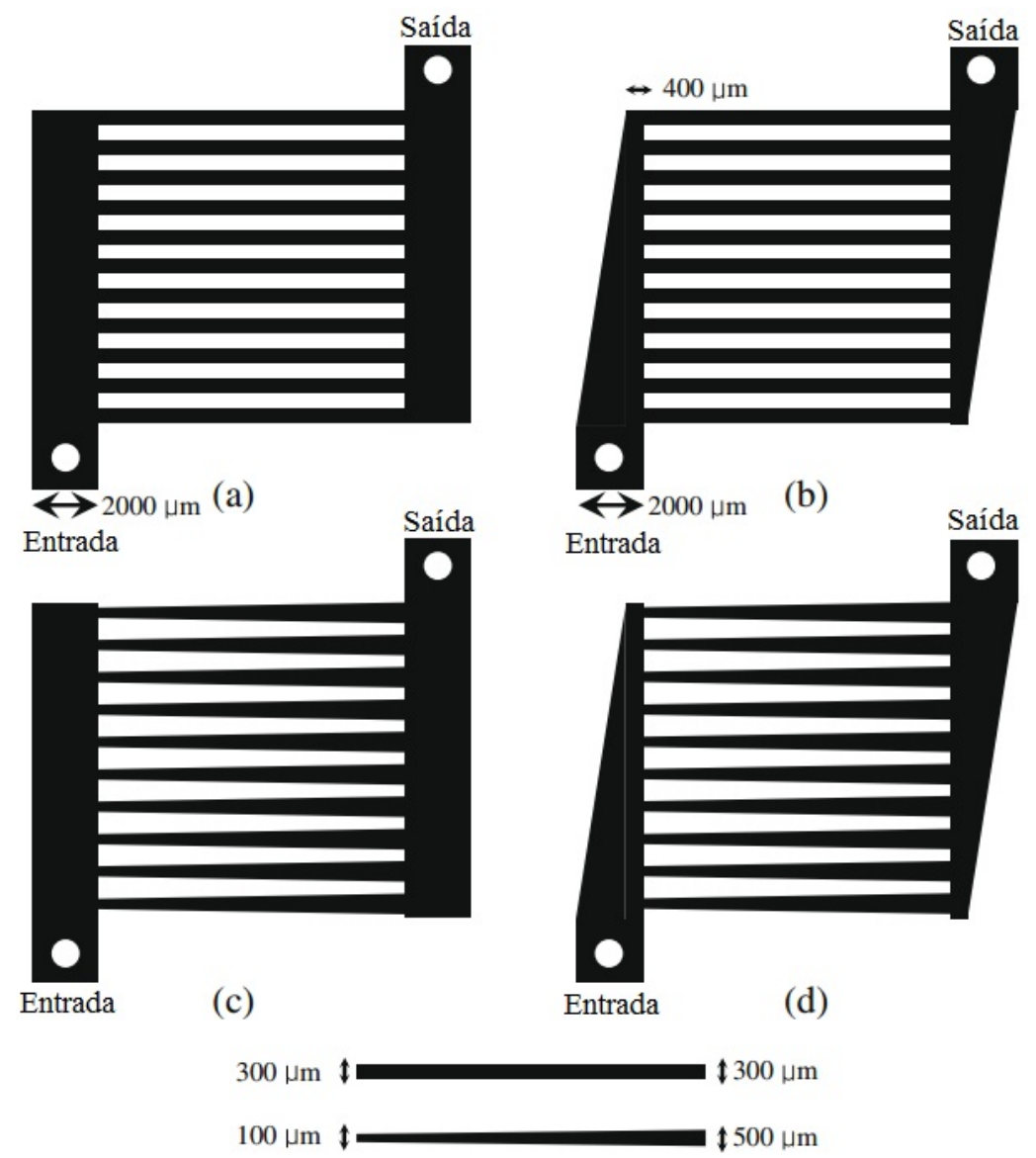

Figura 2.26 - Geometria de dissipadores de calor avaliadas por Cho et al. (2010).

Lu e Pan (2008, 2009 e 2011) e Balasubramanian et al. (2011) também avaliaram dissipadores com canais de seção divergente verificando comportamentos similares aos observados por Cho et al. (2010). Vale destacar que, canais divergentes reduzem o fluxo reverso de vapor gerado pela "ebulição explosiva".

Visando uniformizar a distribuição do fluido e amortecer efeitos de instabilidade térmica, configurações baseadas em micro-aletas hexagonais para escoamento cruzado, foram propostas por Kishimoto e Sasaki (1987) e Colgan et al. (2007) para escoamento monofásico e Koşar e Peles (2007b) para ebulição convectiva. Através desta geometria, eles obtiveram uma melhor distribuição de fluido e coeficientes de transferência de calor superiores, tendo como penalidade a intensificação da perda de pressão.

Cullion et al. (2007), Henning et al. (2007), Krebs et al. (2010) e Daniels et al. (2011) propuseram geometrias compostas de multi-microcanais ramificados distribuídos segundo fractais. Destaca-se que tais geometrias para escoamento monofásico favorecem a uniformidade da distribuição do refrigerante. No entanto para ebulição convectiva, conforme ilustrada na Fig. 2.27, Cullion et al. (2007) observaram bolhas estacionárias nas bifurcações, responsáveis pela obstrução do escoamento. Além disso, o diâmetro hidráulico dos canais se eleva no sentido da região periférica na saída do dissipador para a entrada na região central, conforme ilustrado na Fig. 2.27b. Tal característica favorece o fluxo reverso. 


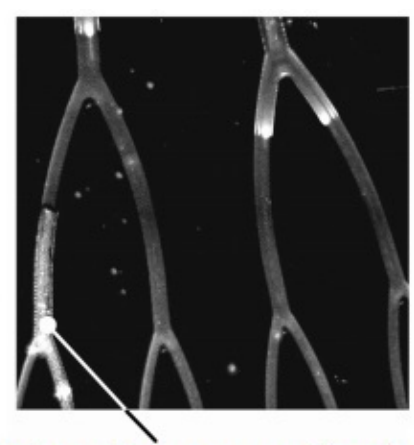

Pistão de vapor estacionario

a)

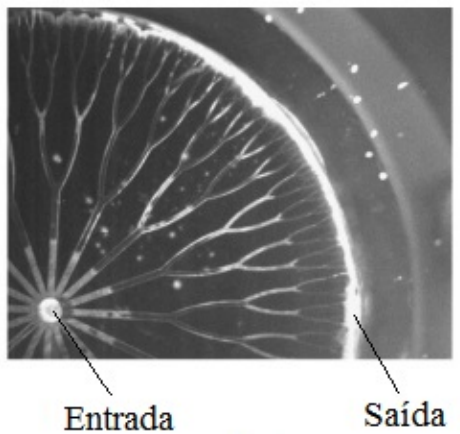

b)

Figura 2.27 - Dissipadores de calor com distribuição de canais segundo fractais. (a) Vapor estacionário, Cullion et al. (2007) e (b) Dimensões de diâmetros convergentes, Daniels et al. (2011).

Visando amortecer efeitos de instabilidades térmicas, soluções envolvendo restrições e expansões bruscas na entrada dos microcanais, conforme ilustradas na Fig. 2.28, foram propostas por Kosar et al. (2006) e Schneider et al. (2007) e mais recentemente por Szczukiewicz et al. (2013a e 2013b). Kosar et al. (2006) adotaram micro-colunas na entrada de cada microcanal de forma a proporcionarem orifícios com larguras correspondentes a 1/10 da largura dos microcanais. Estes orifícios proporcionam expansões bruscas a jusante do seu posicionamento reduzindo o efeito de ebulição "explosiva" e suprimindo o fluxo reverso. No entanto tal solução proporciona elevado incremento na perda de pressão total do dissipador.

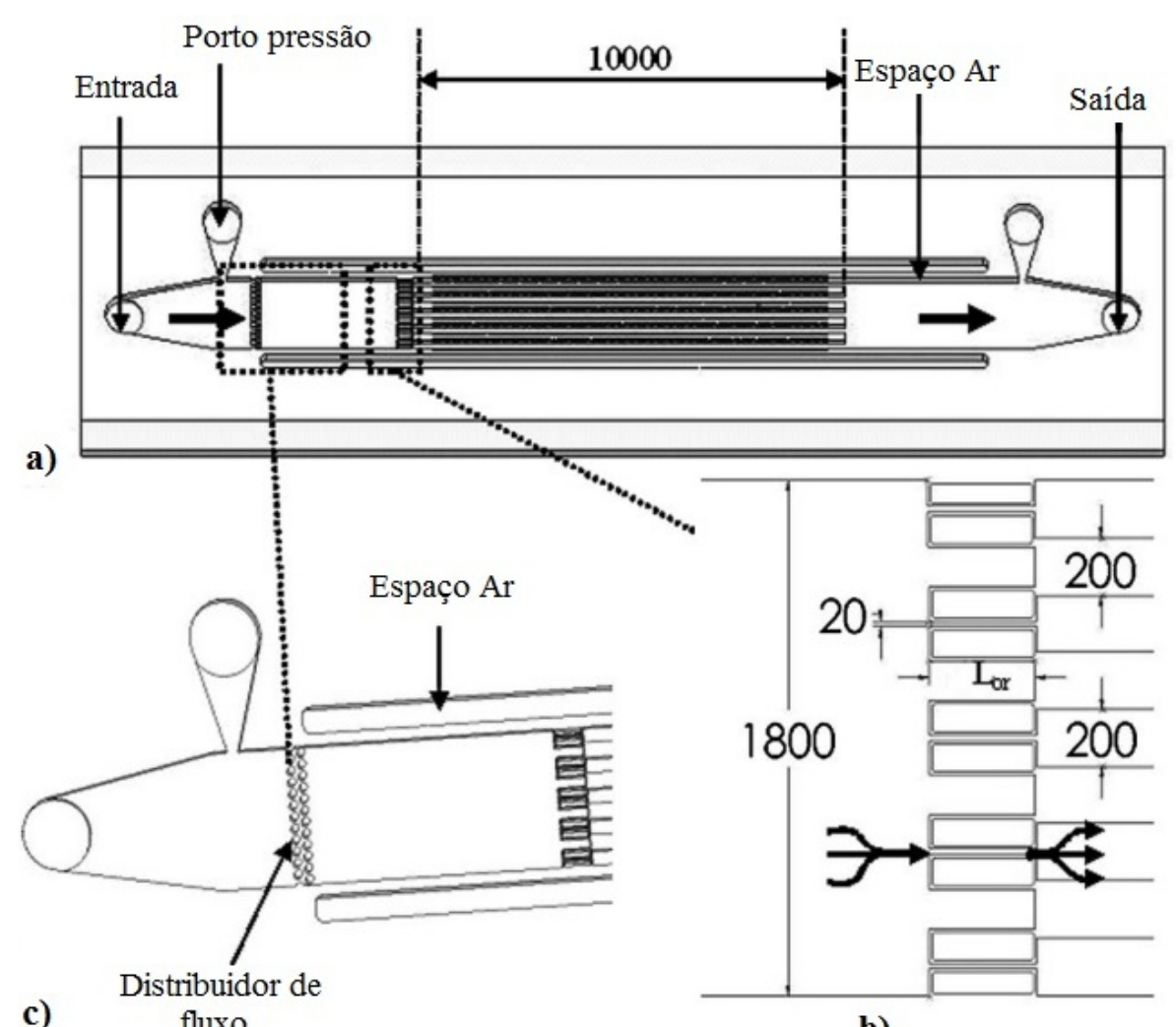

b)

Figura 2.28 - Dissipador com restrições na entrada dos microcanais, Kosar et al. (2006) e Schneider et al. (2007). (a) Vista superior, (b) Geometria do orifício, (c) Colunas para distribuição de fluido, (d) Vista superior das restrições. (unidades em $\mu m$ ). 
Recentemente Szczukiewicz et al. (2013a e 2013b) analisaram o efeito do tamanho relativo das restrições na entrada dos microcanais na intensidade das instabilidades térmicas e na supressão do fluxo reverso. Neste extenso estudo, Szczukiewicz et al. (2013a e 2013b) avaliaram diversas restrições com razão de dimensões $e_{\text {prop }}=w_{\text {canal }} / w_{\text {restrição }}$ de $1,0,1,33,2$ e 4 , onde $e_{\text {prop }}=w_{\text {canal }} / w_{\text {restrio. }}$ A Figura 2.29 ilustra a configuração com restrições proposta pelos autores. Nela é possível observar a configuração geométrica das restrições. Estes autores concluíram que restrições com $e_{\text {prop }}$ iguais a 2 e 4 apresentam maior efetividade na redução do efeito de instabilidades e reduzem significativamente o fluxo reverso de vapor, favorecendo maior uniformidade na distribuição do fluido.

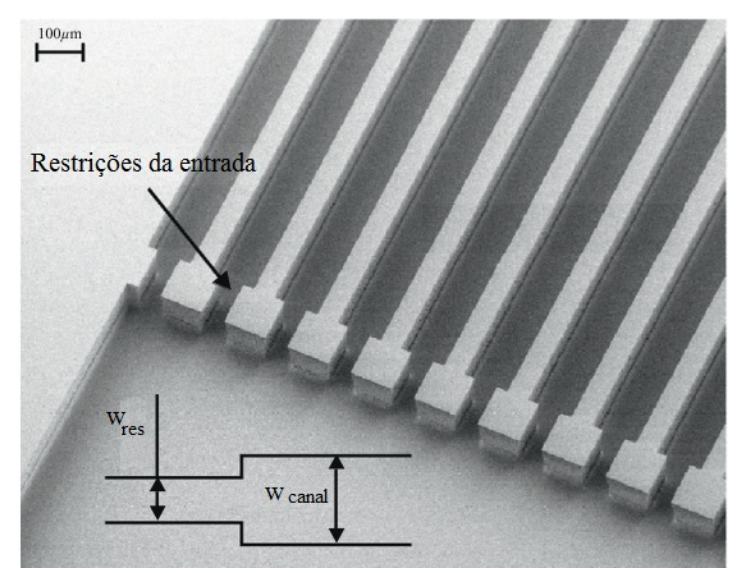

Figura 2.29 - Configuração de dissipador segundo Szczukiewicz et al. (2013a e 2013b).

A inclusão de orifícios ao longo da superfície dos canais, atuando como pontos de nucleação, de forma a coibir a ebulição explosiva e proporcionar uma rápida coalescência de bolhas foi também avaliada por Kandlikar et al. (2005). A Figura 2.30 ilustra as imagens do escoamento obtidas por estes autores para canais com e sem sítios de nucleação artificiais. Na imagem à esquerda, correspondendo à superfície sem cavidades artificiais, observa-se a nucleação no canto do canal e o crescimento da bolha em ambas direções. Já, na imagem a direita para a superfície com cavidades artificiais, a nucleação da bolha ocorre na região central do canal e não se verifica o fluxo reverso. Posteriormente, Lu e Pan (2009) realizaram um estudo do efeito de instabilidades incluindo orifícios de nucleação artificiais somado a canais com seção transversal divergente. Eles avaliaram três configurações de dissipador: (i) canais divergentes lisos, (ii) canais divergentes com sítios de nucleação a partir da região intermediária dos canais e (iii) canais divergentes com sítios de nucleação ao longo de todo o comprimento. Lu e Pan (2009) constataram para estas configurações, que a inclusão de orifícios promove a supressão do fluxo reverso e redução na amplitude das oscilações da temperatura e da pressão de entrada. Os autores, concluíram que a configuração (ii) induz a uniformidade na distribuição do fluido, proporcionando um melhor desempenho, considerando aspectos relacionados ao amortecimento de efeitos de instabilidades. 


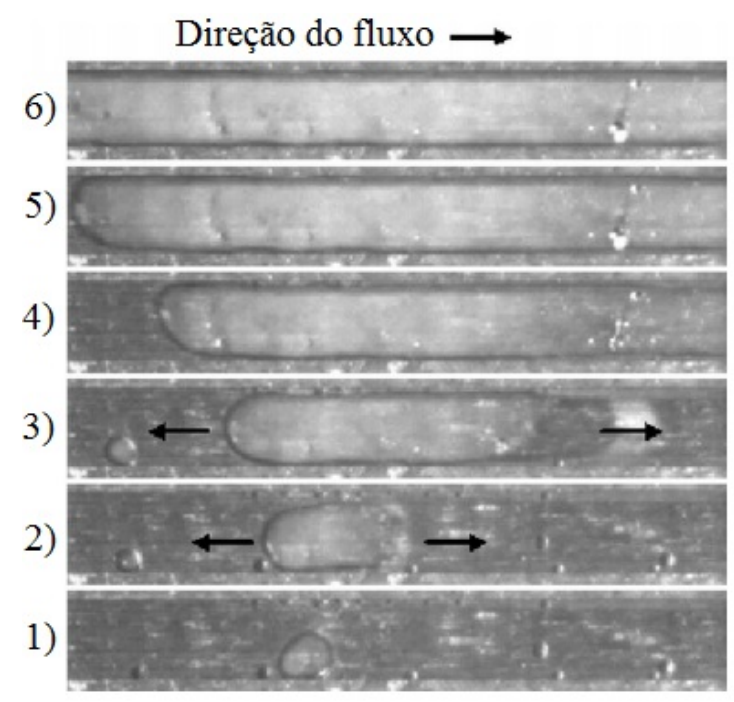

a)

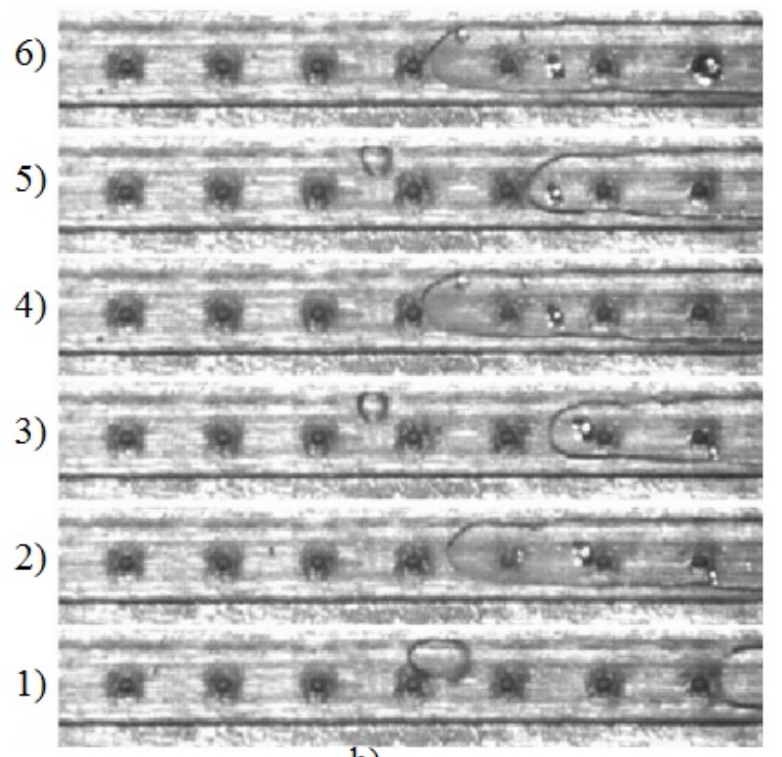

b)

Figura 2.30 - Sequência de imagens ilustrando o crescimento de uma bolha em um microcanal, intervalo de tempo de 1,17 ms, Kandlikar et al. (2005). (a) Microcanal liso; (b) Microcanal com sítios artificiais de nucleação.

Wang et al. (2012) e Leão et al. (2015) investigaram o efeito da orientação do escoamento durante a ebulição convectiva em dissipadores de calor baseados em multi-microcanais. Eles observaram que efeitos de fluxo reverso são reduzidos para o dissipador de calor posicionado verticalmente com escoamento ascendente. Estas observações indicam que o efeito de gravidade e o posicionamento relativo a esta força devem ser considerados no desenho de configurações multi-microcanais.

Conforme anteriormente mencionado, Lee et al. (2010) indicaram que em condições similares de velocidade mássica e fluxo de calor, as oscilações devido à efeitos de instabilidades decrescem com a adoção de restrições na entrada dos microcanais.

Lee et al. (2010), baseados no modelo para prever condições de instabilidades apresentado por Kandlikar (2004), propuseram um parâmetro adimensional para avaliar o efeito do crescimento de bolhas confinadas sobre as instabilidades térmicas que causam oscilações nas temperaturas de parede e do fluido na câmara de entrada.

O parâmetro proposto por Lee et al. (2010) se baseia no equilíbrio entre as forças que atuam sobre a bolha durante o seu crescimento em condições confinadas. Estas forças são as seguintes: (i) devido à inércia do escoamento líquido e (ii) devido à ebulição, conforme esquematicamente ilustrado na Fig. 2.31. De acordo com a Fig. 2.31, $F_{\text {inercial }}$ e $F_{\text {ebulição }}$ representam as forças inerciais e de ebulição, respectivamente. Também, a avaliação deste parâmetro inclui efeitos de expansão da bolha para canais divergentes e orifícios na entrada dos microcanais. A Figura 2.31 ilustra o esquema representativo da força de expansão da bolha $F_{\text {expansão }}$ em um canal divergente e, a Fig. 2.31, ilustra a restrição e a força $F_{\text {orif }}$ devido à inclusão desta restrição. 


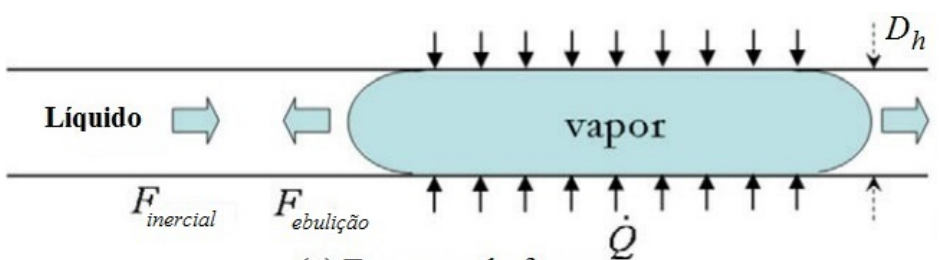

(a) Esquema de forças

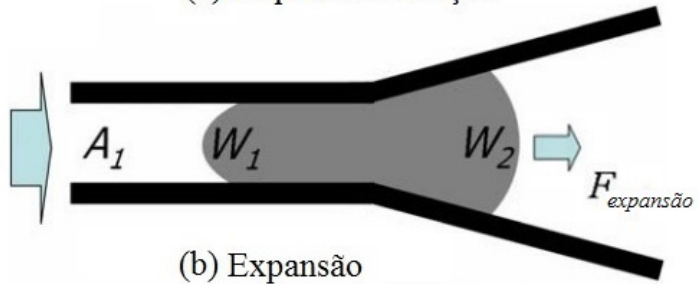

(b) Expansão

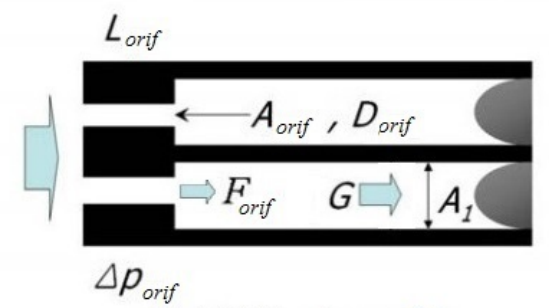

(c) Orifícios de restrição

Figura 2.31 - Esquema de forças atuando durante o crescimento da bolha, Lee et al. (2010).

O parâmetro proposto por Lee et al. (2010) é dado segundo a seguinte equação:

$$
R=\sqrt{\frac{F_{\text {ebulição }}}{F_{\text {inercial }}+F_{\text {expansão }}+F_{\text {orif }}}}=\sqrt{\frac{\rho_{g}\left(\frac{\dot{Q}}{\rho_{g} i_{l g}} \frac{1}{A_{1}+A_{2}}\right)^{2} A_{1}}{\rho_{l}\left(\frac{G}{\rho_{l}}\right)^{2} A_{1}+F_{\text {expansão }}+F_{\text {orif }}}}
$$

A Figura 2.32 ilustra o efeito da velocidade mássica no parâmetro de instabilidade, conforme proposto por Lee et al. (2010). A implementação deste método, foi efetuada para um canal com secção transversal de 100x100 $\mu \mathrm{m}^{2}$, comprimento de $15 \mathrm{~mm}, r_{0}$ relação entre a largura de restrição e largura do canal variando de 0 a 1,0 , temperaturas de saturação de $31^{\circ} \mathrm{C}$, subresfriamento do fluido na entrada de $5^{\circ} \mathrm{C}$ e para os fluidos R134a e R245fa. A presente análise considera também como parâmetro restritivo, a ocorrência de fluxo crítico de calor previsto segundo o modelo de Katto e Ohno (1984). Neste caso, os resultados ilustrados na Fig. 2.32 correspondem a fluxos de calor inferiores ao crítico.

De acordo com a Fig. 2.32, o intervalo de condições estáveis aumenta com o aumento da velocidade mássica. Uma análise baseada na figura e na Eq. 2.222 revela que, ao aumentar o fluxo de calor as forças de ebulição se elevam e a região estável decresce. A redução do diâmetro do canal implica no aumento do parâmetro de instabilidade, reduzindo a região estável. Comportamentos similares foram observados por Wang et al. (2008), Lee et al. (2010), Szczukiewicz et al. (2013a e 2013b).

De acordo com a Fig. 2.32 para o refrigerante R134a, uma razão entre as dimensões igual a 0,6 é suficiente para evitar o fluxo reverso. Já, para razões superiores a 0,8 , o fluxo inverso 
ocorre independentemente da condição analisada. Segundo a Fig. 2.32p para o R245fa, observase a impossibilidade de fluxo reverso para valores de $r_{0}$ inferiores a 0,3 , tornando-se provável para razões superiores a 0,36 . O fato do R134a possuir um volume específico da fase vapor inferior ao R245fa resulta na redução do efeito de ebulição e, consequentemente, no decréscimo da força de ebulição, resultando em regiões correspondentes a escoamento estável superiores para o R134a em relação ao R245fa.
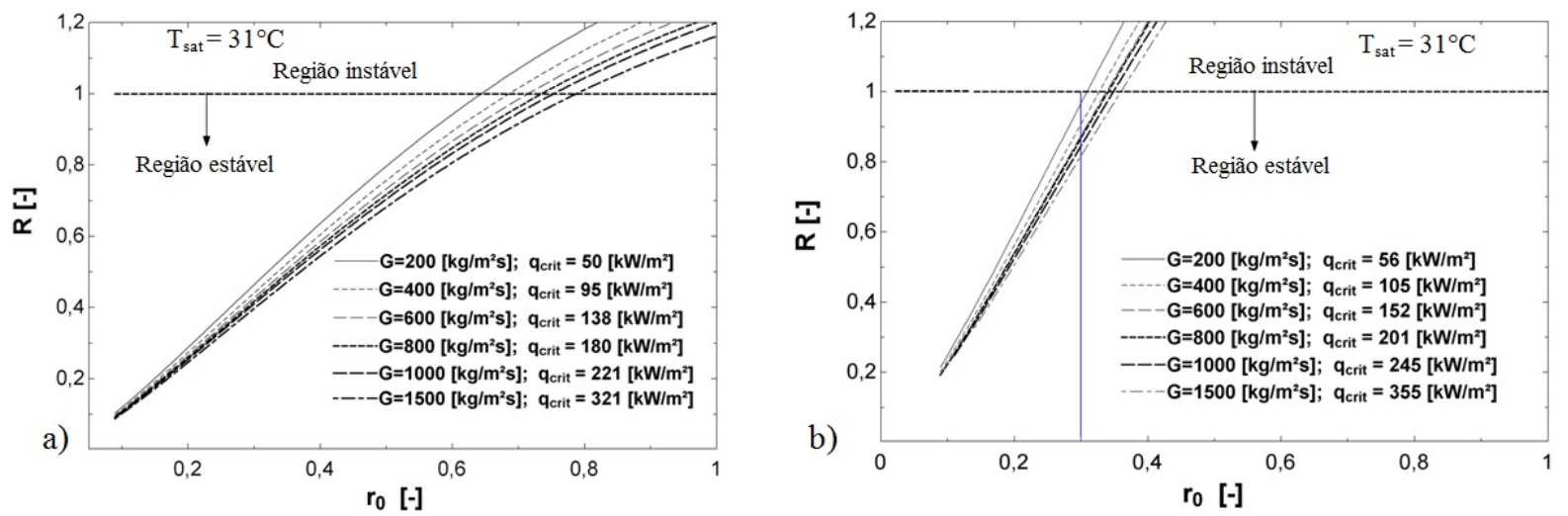

Figura 2.32 - Parâmetro $R$. a) R134a, b) R245fa

A Figura 2.33 ilustra a variação da perda de pressão associada às variações da restrição na entrada para o fluido R245fa. Como esperado, verifica-se que a perda de pressão local aumenta com a redução da razão $r_{0}$.

De acordo com as Figs. 2.32 p. e 2.33 , para $r_{0}=0.3$ não há escoamento reverso, encontrando-se na região estável para todas as condições de velocidade mássica. Para valores inferiores a $1000 \mathrm{~kg} / \mathrm{m}^{2} \mathrm{~s}$ a perda de pressão local é inferior a $6 \mathrm{kPa}$, o qual representa aproximadamente ao $5 \%$ da perda de pressão total (Fig. 2.33b).
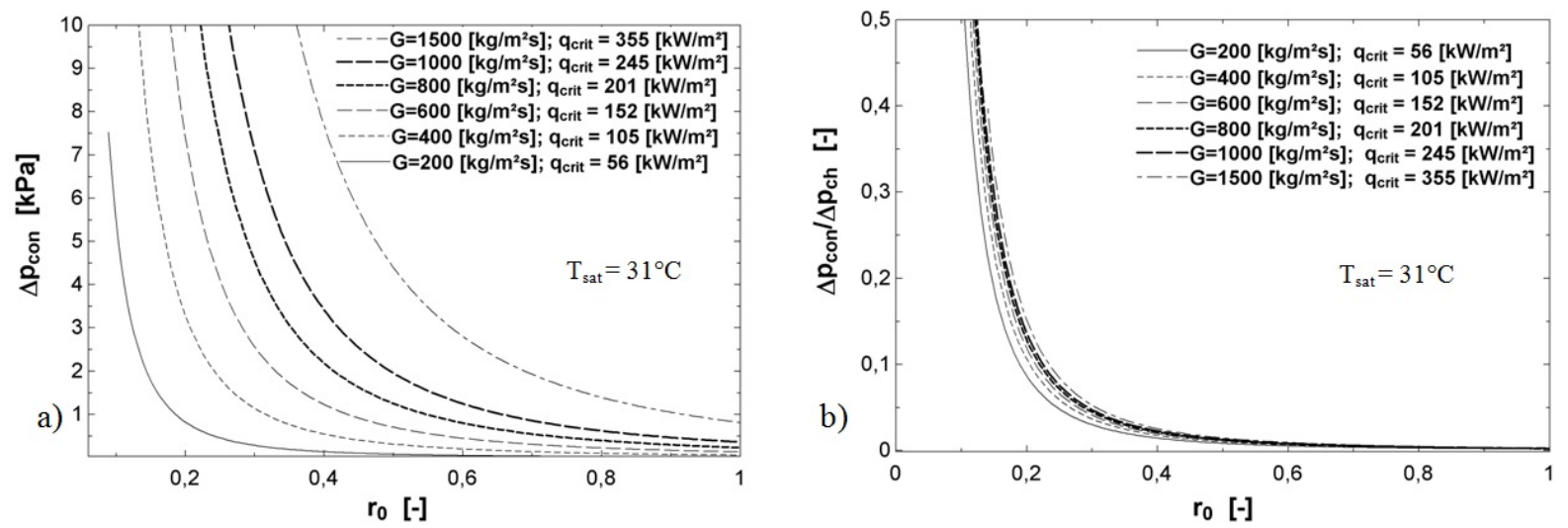

Figura 2.33 - Perda de pressão para o R245fa. a) perda na restrição, b) razão entre as perdas locais da restrição e a total.

De acordo com Blevins (1984), a geometria da restrição tem um efeito relevante na perda de pressão. Este autor também ressalta que, a contração abrupta na restrição implica em perdas de pressão locais superiores se comparadas a entradas suaves. A Fig. 2.34p, ilustra 
algumas possibilidades para a fabricação da restrição de entrada propostas por Blevins (1984). Nesta figura são indicados os coeficientes de perda localizada $K a, K b$ e $K c$ associados, respectivamente, a geometria com borda viva, inclinada e arredondado na entrada da restrição. Estes coeficientes são indicados de acordo com a seguinte ordem de incremento: $K c, K b$ e $K a$.
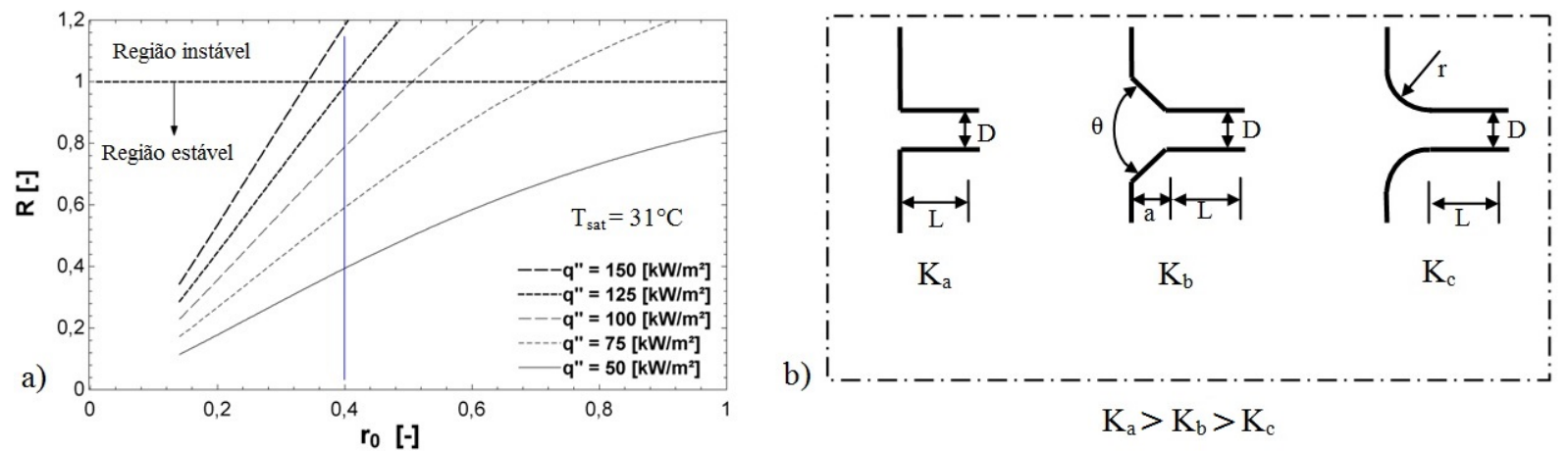

Figura 2.34 - Efeito do fluxo de calor no parâmetro de instabilidade. G=600 $\mathrm{kg} / \mathrm{m}^{2} \mathrm{~s}$; fluido: R245fa.

b) diagrama esquemático para restrições e constantes locais de perda de pressão, Blevins (1984).

\subsubsection{CONCLUSÕES DA ANÁLISE DE INSTABILIDADES TÉRMICAS EM MULTI- MICROCANAIS}

No item 2.5 analisou-se a literatura sobre instabilidades térmicas devido ao crescimento da bolha em condições confinadas em dissipadores de calor baseados em multi-microcanais. Através da análise efetuada conclui-se que alterações na geometria e configuração dos microcanais possibilita a redução dos efeitos das instabilidades térmicas. Tais alterações permitem o aumento significativo do coeficiente de transferência de calor, do fluxo crítico de calor com um incremento da penalização na perda de pressão razoável.

Condições experimentais, características dos fluidos refrigerantes, posicionamento do dissipador de calor afetam os efeitos de instabilidades térmicas devido à ebulição "explosiva".

O parâmetro de instabilidade definido por Lee et al. (2010) parece ser adequado como ferramenta de projeto de dissipador de calor aplicado ao dimensionamento das restrições na entrada dos canais. No entanto, estudos adicionais visando a análise parametrizada dos fatores experimentais neste parâmetro de forma a caracterizar experimentalmente as condições ausentes de instabilidade ainda são necessários. 


\section{BANCADA E PROCEDIMENTO EXPERIMENTAL}

Este capítulo apresenta a descrição da bancada experimental, dos procedimentos adotados durante os ensaios e os métodos implementados para a regressão dos dados.

\subsection{DESCRIÇÃO DO APARATO EXPERIMENTAL}

A bancada experimental utilizada neste estudo, ilustrada na Fig. 3.1. foi desenvolvida visando o estudo da ebulição convectiva em multi-microcanais e encontra-se localizada no Laboratório de Engenharia Térmica e fluidos do Departamento de Engenharia Mecânica da Escola de Engenharia de São Carlos. Seu circuito principal foi projetado e construído por Do Nascimento (2012) e utilizado também por Leão (2014). Este item descreve o aparato experimental e indica as especificações técnicas dos componentes do circuito. Ele também apresenta os circuitos auxiliar, de compressão e de rejeição de calor. Neste estudo, por envolver fluidos inflamáveis, um sistema de detecção de vazamento e segurança foi implementado o qual também é descrito neste item. Finalmente, atenção especial é dada na descrição da seção de teste.

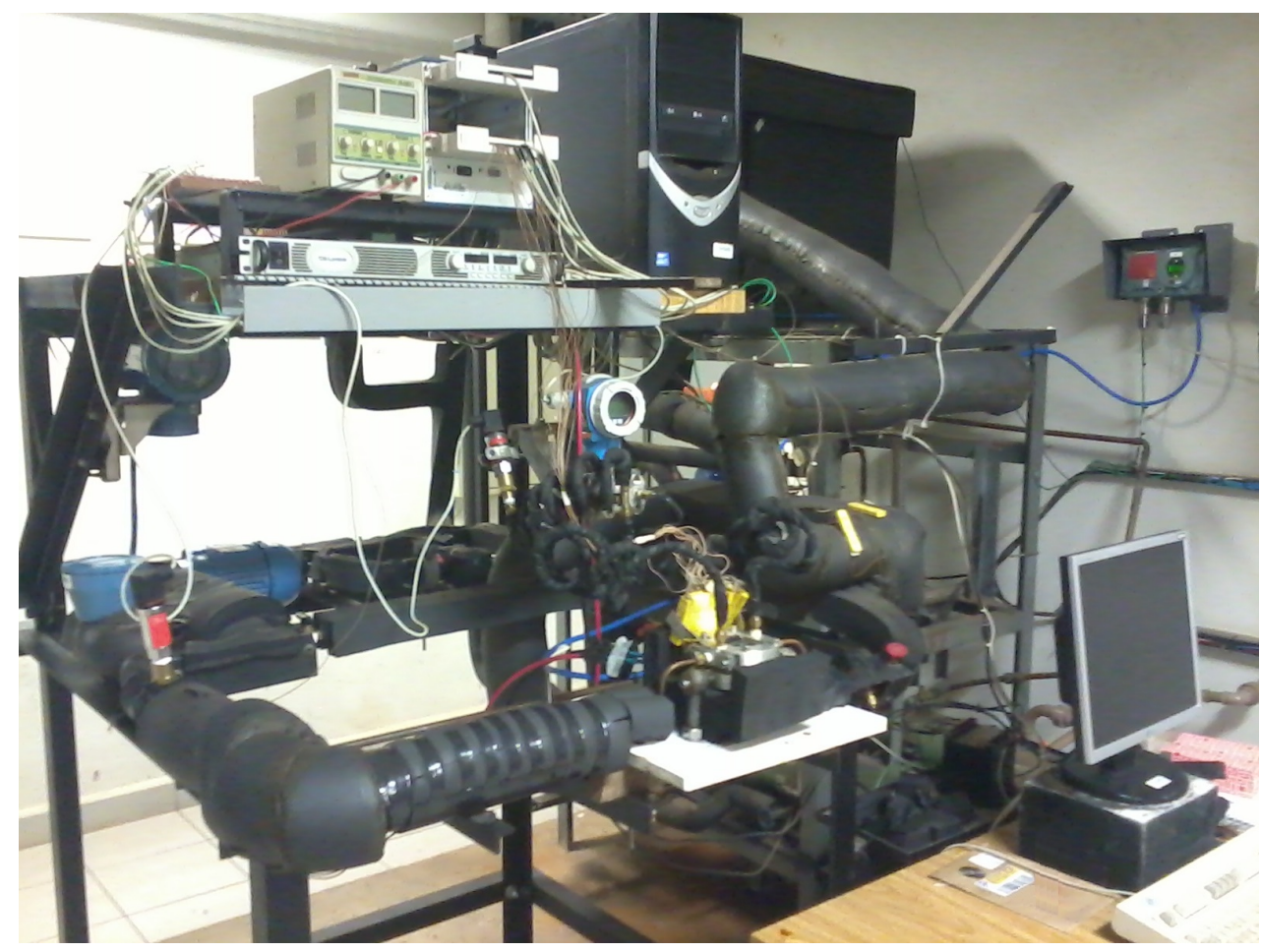

Figura 3.1 - Registro fotográfico do aparato experimental. 


\subsubsection{CIRCUITO PRINCIPAL}

\subsubsection{DESCRIÇÃO FUNCIONAL}

Desenvolveu-se o circuito principal com o intuito de condicionar a vazão, fluxo de calor, temperatura, pressão e título de vapor do refrigerante na seção de testes, de forma a possibilitar a investigação do processo de ebulição convectiva no dissipador de calor baseado em multimicrocanais. A Fig. 3.2 ilustra o diagrama do circuito principal, indicando os componentes principais e as tomadas de medida de pressão absoluta, diferença de pressão, temperatura e vazão mássica.

Como indicado na Figura 3.2 no circuito principal, à jusante da conexão com a linha do reservatório, através da manobra das válvulas VIII, IX e X, apresenta-se a possibilidade de circular o fluido refrigerante por um filtro secador, procedimento adotado em casos de manutenção do circuito principal e da seção de testes e carga de fluido refrigerante. Tal procedimento se dá de forma a eliminar particulados e impurezas que possam bloquear o escoamento através dos microcanais da seção de testes. À jusante desta ramificação (linha By-pass) existe um visor de líquido, cuja função é possibilitar a verificação da existência de vapor à montante da microbomba, o que pode levar a danificação da mesma.

A microbomba de engrenagens, que opera sem a necessidade de lubrificante, é responsável pelo deslocamento do fluido de testes no circuito principal. Sua rotação e, consequentemente, a vazão através da seção de testes é controlada com base no sinal emitido pelo medidor de vazão tipo Coriolis, a partir do sistema de aquisição de dados, atuando em um variador de frequência que alimenta um motor elétrico, cujo eixo encontra-se acoplado magneticamente ao eixo da bomba. Após o medidor de vazão mássica tipo Coriolis, o qual se encontra à jusante da microbomba de engrenagens, o circuito principal bifurca-se em uma linha alternativa (Bypass) conectando esta região à entrada do condensador e, a uma segunda linha conectando até a seção de testes. A determinação da linha atuante se dá através da manobra das válvulas IV e I e utiliza-se a linha alternativa apenas após procedimentos de manutenção e limpeza do circuito principal.

A Válvula I, do tipo agulha, impõe uma perda de pressão localizada de forma a reduzir a propagação de efeitos de instabilidades térmicas a partir da seção de testes. À jusante da Válvula I encontra-se o Visor B de líquido, localizado à montante do pré-aquecedor e cuja função é permitir a checagem da existência de vapor no escoamento, ainda que em condições sub-resfriadas. Isto permite determinar corretamente a entalpia do fluido de testes na entrada do pré-aquecedor através de medidas de pressão e temperatura a partir do transdutor de pressão absoluta $p_{1}$ e do micro-termopar $T_{1}$ em contato com o escoamento. À jusante do pré-aquecedor, na câmara de entrada da seção de testes, determina-se novamente a pressão e a temperatura local do fluido de testes. Um transdutor de pressão diferencial encontra-se conectado às câmaras de entrada e saída da seção de testes de forma a medir a perda de pressão ao longo deste dispositivo. 
A temperatura local do refrigerante é também determinada na câmara de saída da seção de testes.

Toda a linha do circuito principal, seus componentes e a seção de testes encontram-se isolados termicamente com lã de rocha, no caso de superfícies aquecidas e espuma de isolante elastomérico da Armaflex de espessura igual a $20 \mathrm{~mm}$.

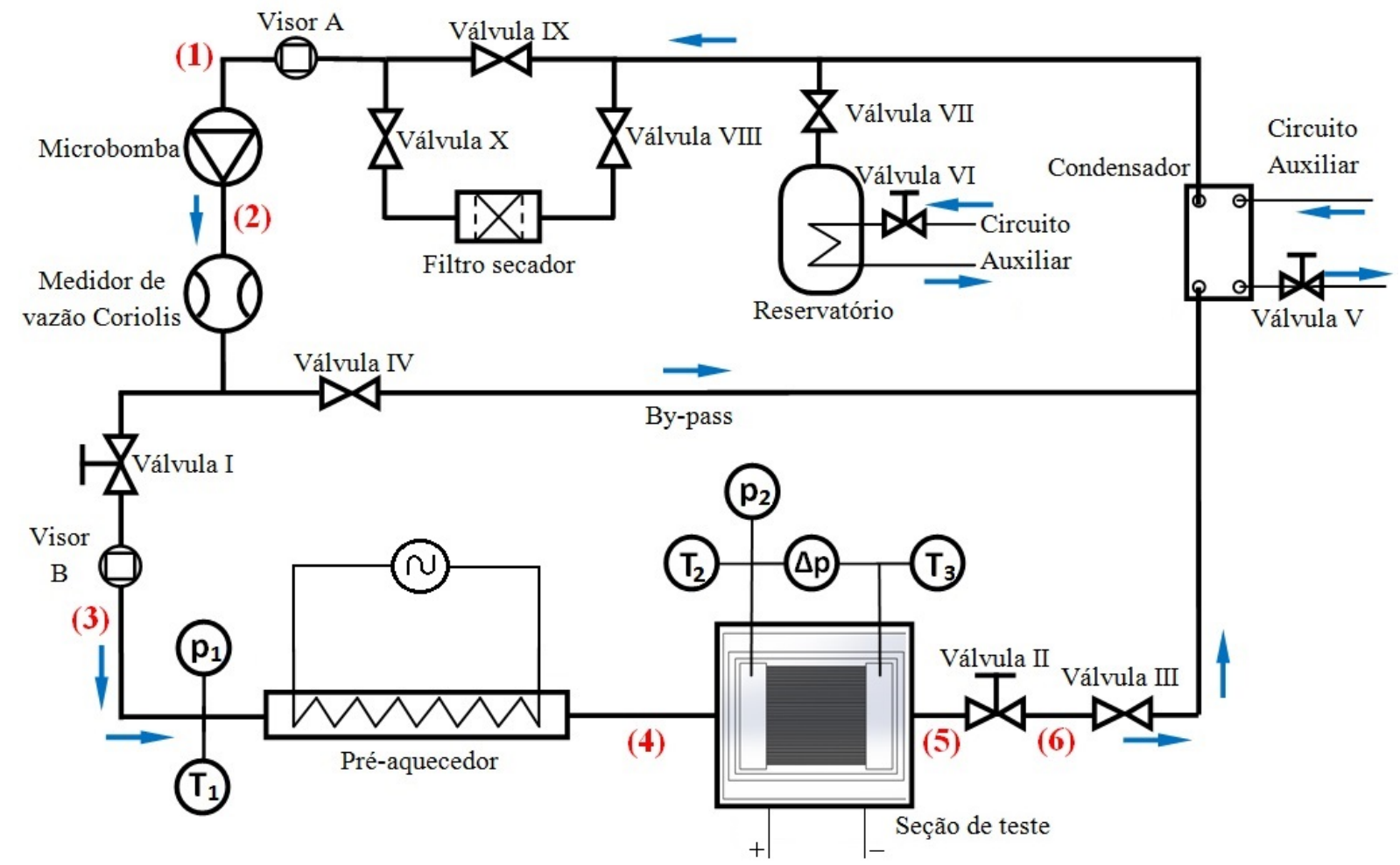

Figura 3.2 - Diagrama do circuito principal.

A Fig. 3.3 apresenta o diagrama esquemático de pressão versus entalpia ( $p$ vs $i$ ) ilustrando os processos termodinâmicos aos quais o fluido de testes é submetido ao longo do circuito principal. Neste diagrama desprezam-se as perdas de pressão e trocas de calor ao longo das linhas do circuito. Os números indicados na Fig. 3.3 correspondem às posições ao longo do circuito principal correspondentes a Fig. 3.2 .

A partir da entrada da microbomba, o processo 1 - 2 corresponde a elevação da pressão do fluido refrigerante no estado líquido através deste equipamento. A partir daí, tem-se processos de perda de pressão localizadas correspondendo ao medidor de vazão tipo Coriolis e a Válvula I do tipo agulha indicados no diagrama $p$ vs $i$ pelo processo $2-3$. O processo $3-4$ corresponde ao escoamento do fluido de testes através do pré-aquecedor. Nele, o fluido refrigerante subresfriado é aquecido até alcançar o grau de sub-resfriamento desejado na entrada da seção de testes. O processo $4-5$ representa dissipação de calor para o fluido refrigerante na seção de testes. Neste processo, correspondendo a entrada e a saída da seção de testes, observa-se uma variação do gradiente de pressão devido à intensificação da perda de pressão no processo de evaporação com o aumento do título de vapor de equilíbrio termodinâmico. O processo $5-6$ 
está relacionado à perda de pressão local devido à Válvula II de tipo agulha. Finalmente, o ciclo se completa com o processo 6 - 1 que ocorre em um trocador de placas no qual o fluido refrigerante é condensado e resfriado através da rejeição de calor para a circuito auxiliar.

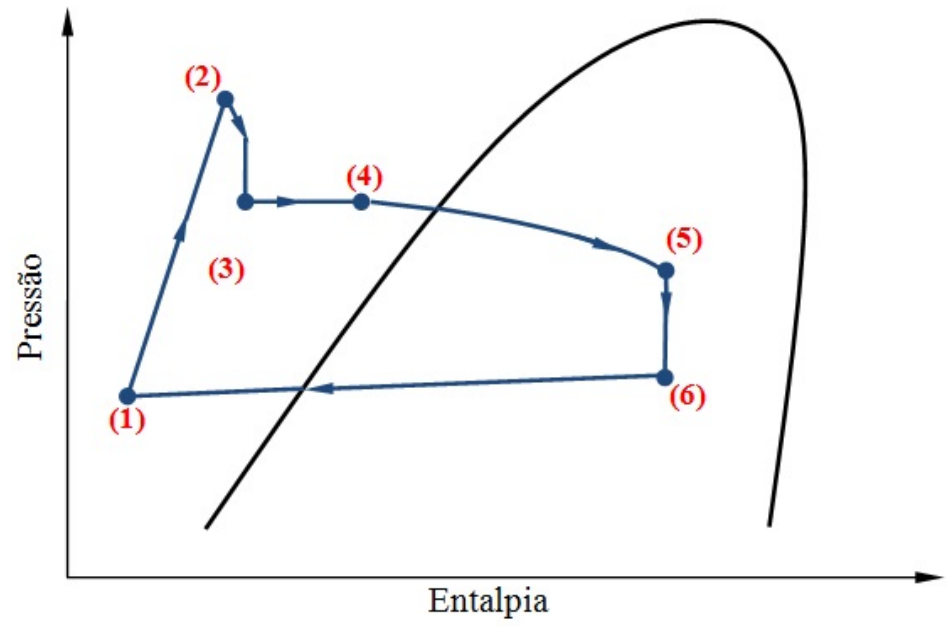

Figura 3.3 - Diagrama p-i ilustrando os processos termodinâmicos do fluido de testes ao longo do circuito principal.

\subsubsection{ESPECIFICAÇÃO DOS COMPONENTES}

A Tabela 3.1 apresenta descrições detalhadas das características e especificações técnicas dos componentes do circuito principal. Parcela significativa dos componentes foram adqueridas através de provedores externos e suas especificações são aquelas fornecidas pelos fabricantes, exceto a junção dos termopares tipo K, o Visor B e o reservatório de fluido que foram fabricados no laboratório.

Tabela 3.1 - Componentes do circuito principal

\begin{tabular}{|c|c|c|}
\hline Componente & Especificações principais & Características e observações \\
\hline Microbomba de engrenagem & $\begin{array}{l}\text { Fabricante: Micropump } \\
\text { Modelo: GA-T23J8KS4 } \\
\text { Deslocamento volumétrico nominal: } 0,092 \\
m l / r e v\end{array}$ & $\begin{array}{l}\text { Possibilita uma vazão continua com oscilações } \\
\text { desprezíveis de pressão. } \\
\text { Acoplada magneticamente ao motor trifásico e } \\
\text { opera sem óleo lubrificante. }\end{array}$ \\
\hline Motor trifásico & $\begin{array}{l}\text { Fabricante: WEG } \\
\text { Potência: } 0,25 C V / 220 \mathrm{~V}\end{array}$ & $\begin{array}{l}\text { Alimentado e controlado através do variador de } \\
\text { frequência. } \\
\text { Rotação nominal de } 3340 \mathrm{rpm} \text { a } 60 \mathrm{~Hz} \text {. }\end{array}$ \\
\hline Variador de frequência & $\begin{array}{l}\text { Fabricante: ABB } \\
\text { Modelo: ACS150-01E-02A4-2 } \\
\text { Potência: } 0,5[C V]\end{array}$ & Permite uma frequência máxima: $90 \mathrm{~Hz}$. \\
\hline Medidor de vazão & $\begin{array}{l}\text { Tipo: Coriolis } \\
\text { Fabricante: Micromotion } \\
\text { Modelo: CMF010M313NQBZPZZ } \\
\text { Intervalo nominal de vazão: } 0-84 \mathrm{~kg} / \mathrm{h}\end{array}$ & $\begin{array}{l}\text { Erro associado à medida de vazões mássicas } \\
\text { superiores ao valor nominal, } 0,1 \%\end{array}$ \\
\hline Válvulas de agulha & $\begin{array}{l}\text { Fabricante: Swagelok } \\
\text { Modelo: B-1RS4 } \\
\text { Material: Latão } \\
2 \text { válvulas no circuito principal } \\
\text { Diâmetro: } 1 / 4 "\end{array}$ & $\begin{array}{l}\text { Válvula I é usada para impor uma perda de } \\
\text { pressão localizada e reduzir a propagação de } \\
\text { instabilidades na seção de teste. } \\
\text { Válvula II usa-se para reduzir as flutuações na } \\
\text { pressão devido à instabilidades térmicas na seção } \\
\text { de teste e para regulação da pressão na linha. }\end{array}$ \\
\hline
\end{tabular}


Tabela 3.1 (continuação). Componentes do circuito principal.

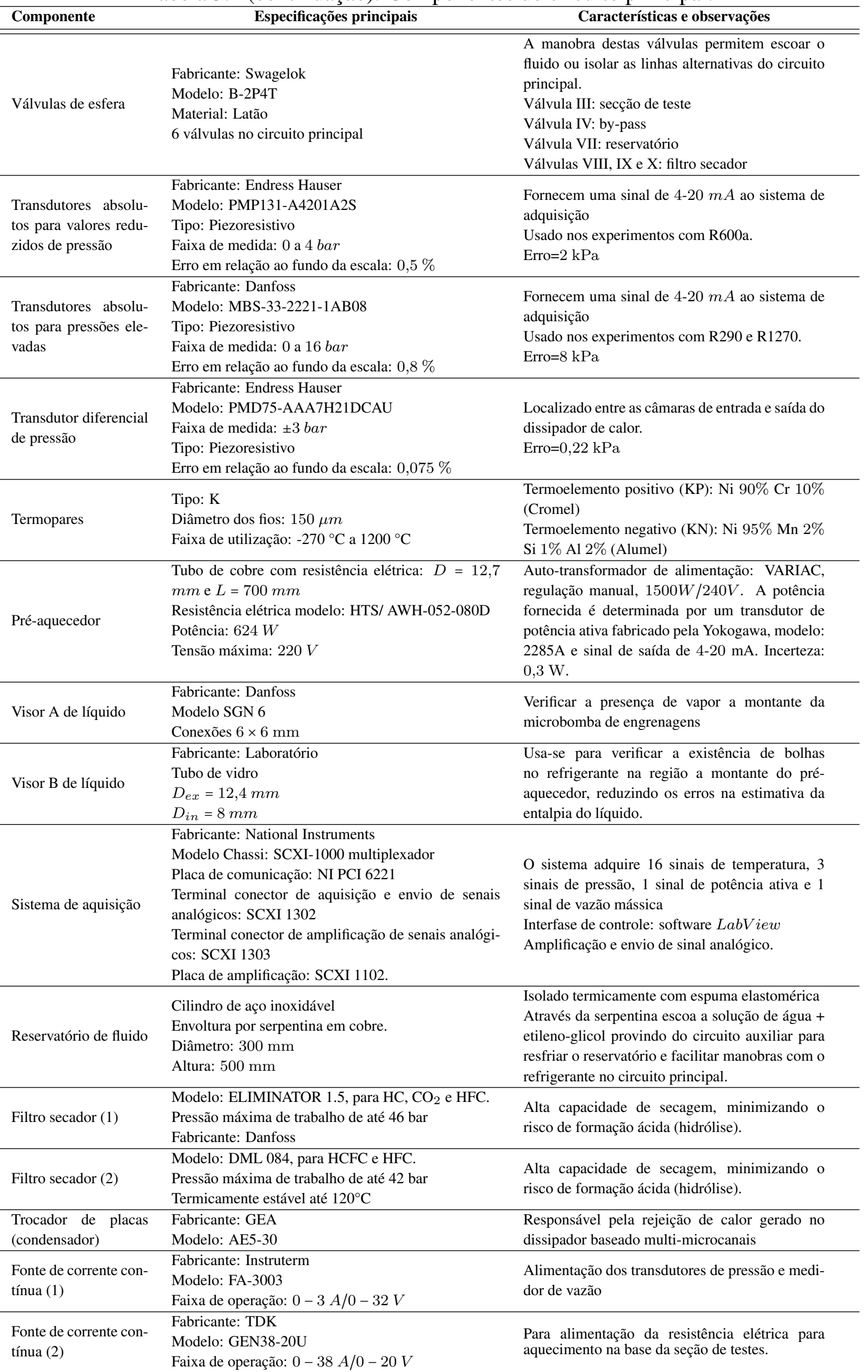




\subsubsection{CIRCUITOS AUXILIAR, COMPRESSÃO E REJEIÇÃO DE CALOR}

A Figura 3.4 ilustra diagramas esquemáticos dos seguintes circuitos auxiliares: (i) circuito secundário, responsável pelo resfriamento do fluido de testes no circuito principal; (ii) circuito de compressão de vapor, responsável pela refrigeração da solução anticongelante do circuito secundário; (iii) circuito de rejeição de calor, proporciona a dissipação para o ambiente do calor gerado nos demais circuitos principal e auxiliares.

O circuito secundário resfria o fluido de testes através do condensador de placas do circuito principal. Ele é também responsável pelo resfriamento do fluido de testes localizado no reservatório através da serpentina em contato com ele. Utiliza-se tal procedimento para a transferência do fluido de testes a partir do circuito principal ao de recipientes comerciais para o reservatório de refrigerante.

O circuito auxiliar fornece solução anticongelante de $33 \%$ de etileno-glicol em água a uma temperatura de até $-19^{\circ} \mathrm{C}$. Neste circuito, uma bomba centrífuga desloca a solução anticongelante a partir de um tanque em aço inoxidável com capacidade de $0,15 \mathrm{~m}^{3}$.

A solução de etileno-glicol em água circula através de um evaporador de placas no qual é resfriada a partir de um sistema de refrigeração a compressão de vapor. O controle de temperatura da solução anticongelante se dá a partir de um controlador PID, com base na temperatura determinada por uma termo-resistência de platina Pt100 localizada no tanque, que atua em um relé de estado sólido que alimenta uma resistência elétrica imersa na solução.

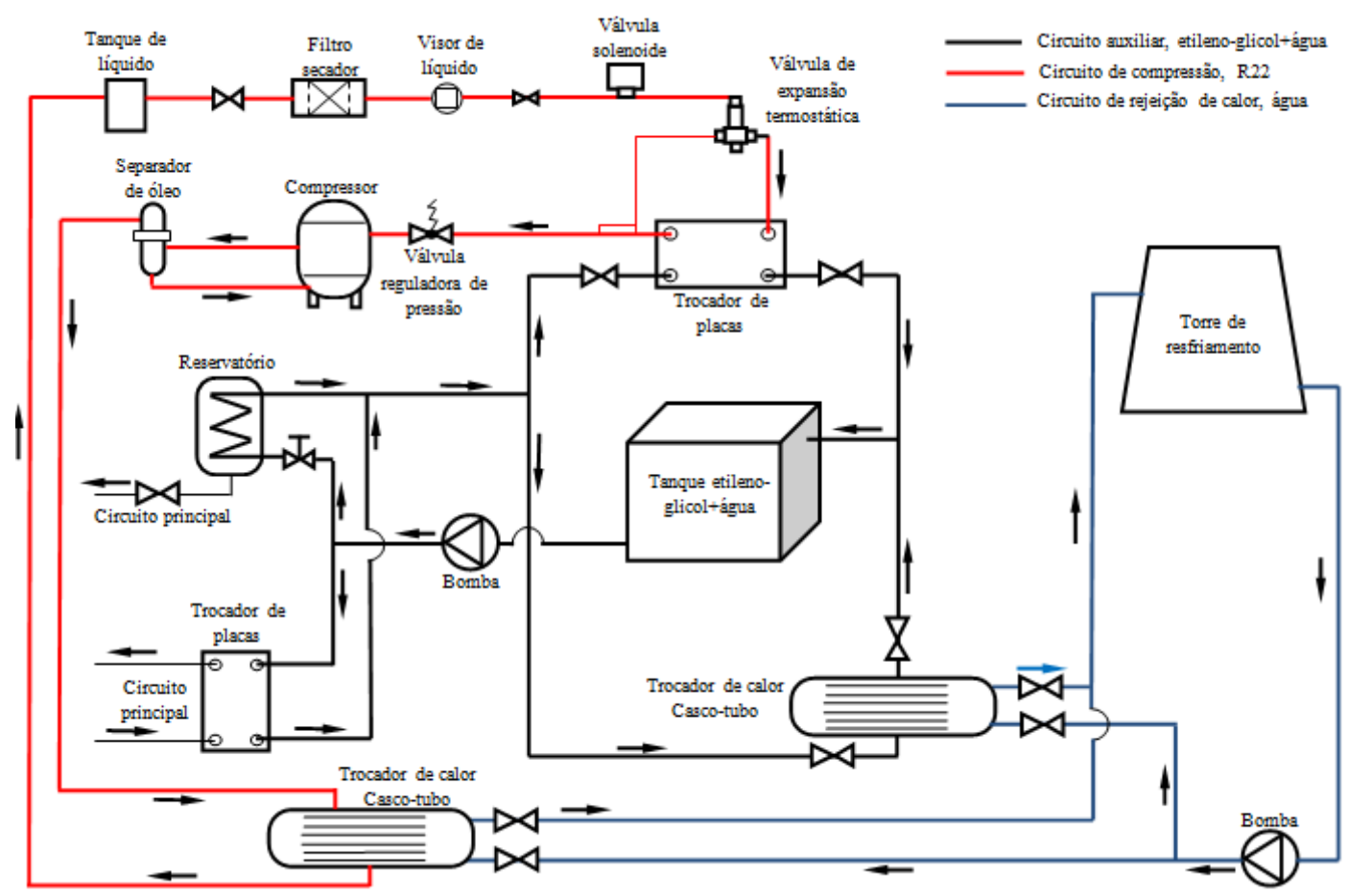

Figura 3.4 - Esquema de circuitos auxiliar e de rejeição de calor. 
O circuito de compressão opera continuamente com refrigerante R22. Sua operação se baseia em um compressor hermético com capacidade de $1,7 \mathrm{~kW}$ a $23^{\circ} \mathrm{C}$. Uma válvula reguladora na aspiração de pressão localizada a montante do compressor é utilizada no controle de pressão do fluido refrigerante do compressor durante a partida. O fluido refrigerante é condensado em um trocador de calor do tipo casco-tubo no qual rejeita calor para a água proveniente da torre de resfriamento localizada no ambiente externo do laboratório.

\subsubsection{SISTEMA DE SEGURANÇA}

A Figura 3.5 ilustra o diagrama esquemático do sistema para detecção de vazamento utilizado nos ensaios com refrigerantes inflamáveis. Este é composto de um sensor semicondutor com sensibilidade para gás, que atua por difusão de moléculas, e um Transmissor modelo SD-705GP fabricado pela Nakayama, configurado para detectar hidrocarbonetos. O sensor encontra-se instalado $40 \mathrm{~cm}$ abaixo da seção de testes. O transmissor, fixado na parede da sala, apresenta as seguintes saídas: (i) corrente de 4 a $20 \mathrm{~mA}$ com sinal proporcional a concentração de gases; (ii) relê normalmente aberto para alimentação do alarme indicando vazamento; e (iii) relê também normalmente aberto para indicar falhas do equipamento de segurança.

A saída indicadora de vazamento está conectada à bobina de uma contatora que ativa o sistemas de exaustão de ar e, simultaneamente, os alarmes sonoro e luminoso. O nível de concentração para ativação do alarme em caso de vazamento é mostrado continuamente na tela do transmissor. O fabricante do equipamento recomenda um nível máximo para ativação do alarme inferior a $10 \%$ do LEЦ円 em ppm. No presente estudo regulou-se um nível de $6 \%$ do LEL, considerando neste caso o isobutano.

O sistema de exaustão pode ser também acionado por um interruptor manual, procedimento adotado durante a manutenção da bancada carga e descarga de refrigerante.

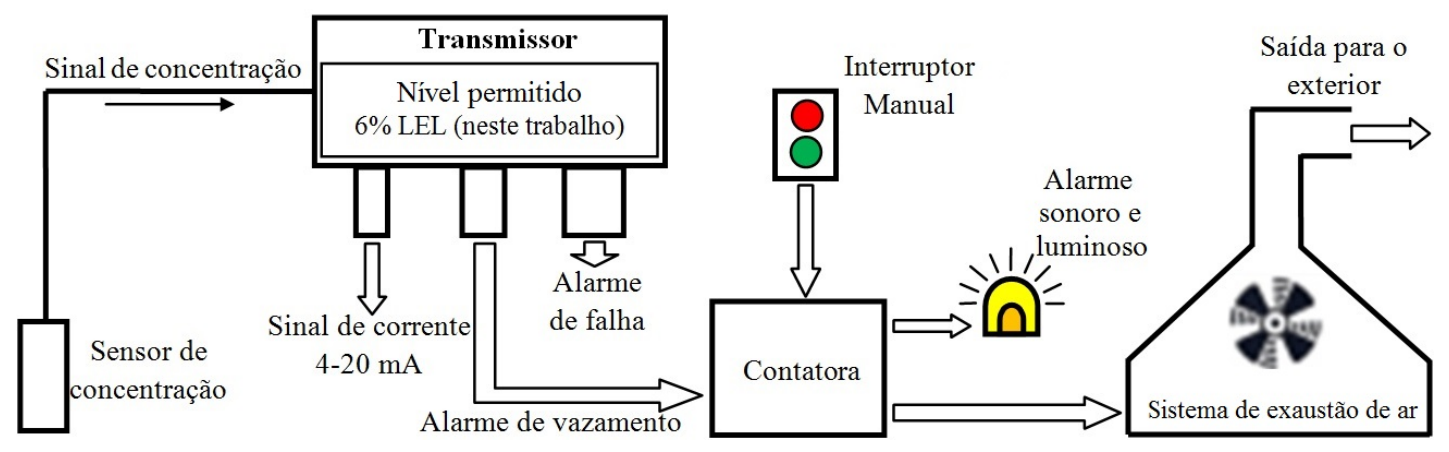

Figura 3.5 - Esquema do sistema para detecção de vazamento e acionamento do sistema de exaustão.

\subsubsection{SEÇÃO DE TESTES}

A seção de testes foi fabricada no contexto do projeto de mestrado desenvolvido por Do Nascimento (2012). Ele realizou experimentos em uma seção de testes posicionada e

\footnotetext{
${ }^{1}$ LEL: Lower Explosive Limit, (Limite inferior de explosividade).
} 
configurada para escoamento horizontal do R134a. Posteriormente, Leão (2014) modificou a seção de testes adequando as conexões para avaliar o efeito da direção do escoamento no desempenho do dissipador de calor. Ele realizou ensaios para os refrigerantes R245fa e R407C. Para o presente estudo, a seção de testes foi fixada horizontalmente, com suas conexões configuradas segundo as modificações realizadas por Leão (2014). A Fig. 3.6 apresenta um registro fotográfico da seção de testes. Nela, observa-se as conexões laterais para alimentação e drenagem do fluido, conexões superiores para avaliação da diferença de pressão entre as câmaras de entrada e saída e a localização dos conectores de termopares.

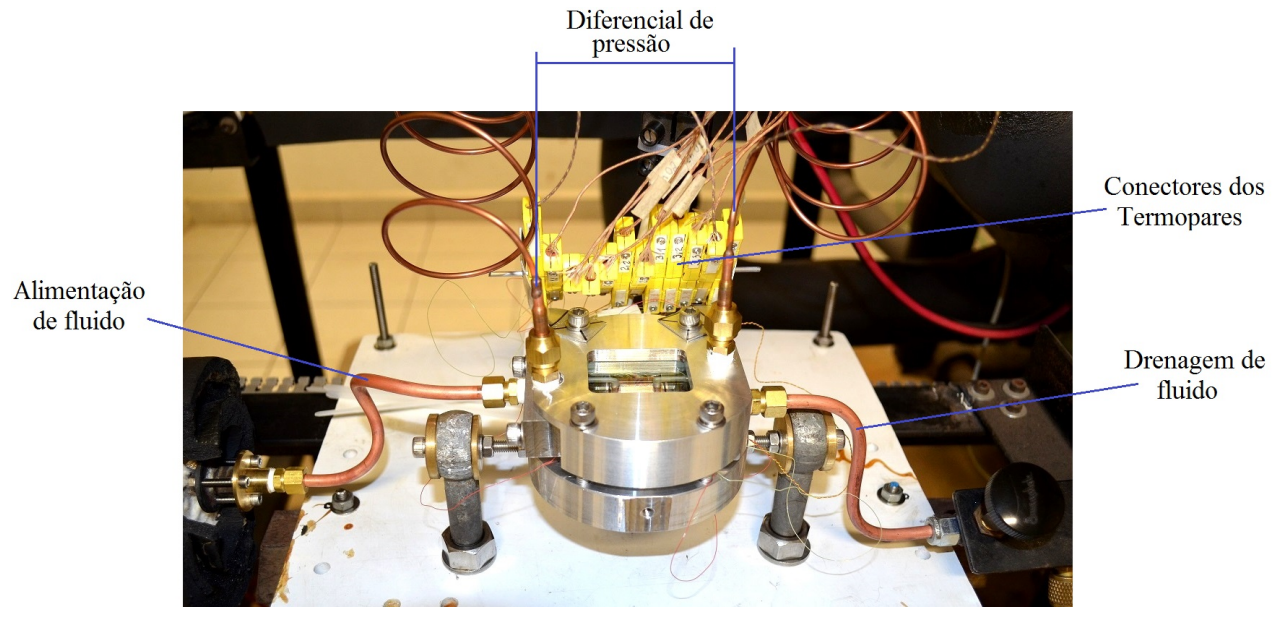

Figura 3.6 - Registro fotográfico da seção de testes montada na bancada.

\subsubsection{DESCRIÇÃO DA SEÇÃO DE TESTES}

A Figura 3.7 ilustra uma vista explodida da seção de testes contento o dissipador no qual encontram-se usinados os microcanais.

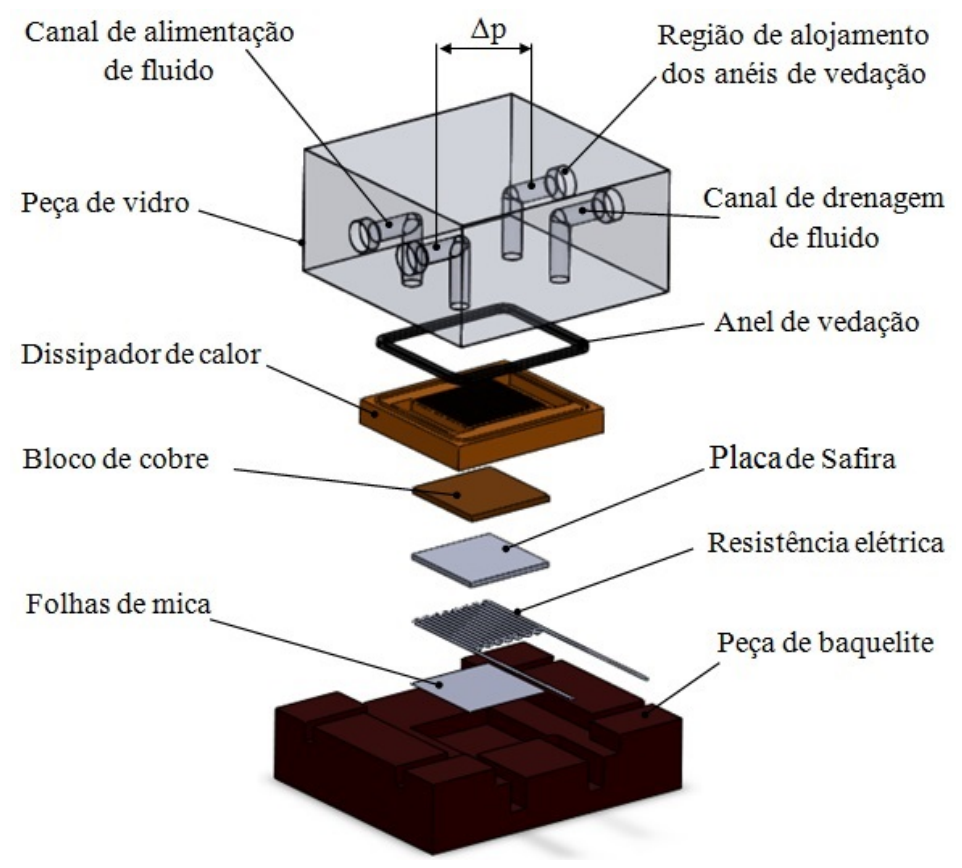

Figura 3.7 - Vista explodida dos componentes da seção de testes. 
A Figura 3.8 apresenta um corte da seção de testes ilustrando seus componentes. Nela encontra-se um bloco maciço de cobre com uma espessura de $2 \mathrm{~mm}$ entre a placa de safira e o dissipador de calor. Este bloco tem como objetivo uniformizar a distribuição do fluxo de calor na face inferior do dissipador. Com o objetivo de reduzir a resistência térmica de contato na seção de testes, adicionou-se camadas de pasta térmica de $\mathrm{Al}_{2} \mathrm{O}_{3}$ entre a pedra de safira e o bloco de cobre e entre a base do dissipador de calor e o bloco de cobre.

De acordo com a Fig. 3.8, para efetuar a vedação entre o vidro e o dissipador de calor, foi usinado um canal com seção transversal retangular de 1,0 $\mathrm{mm}$ de largura e profundidade de 0,7 mm. Neste canal aloja-se um anel de vedação com diâmetro de 1,0 $\mathrm{mm}$. Vale destacar que a diferença de $0,3 \mathrm{~mm}$ entre a profundidade do canal e o diâmetro do anel de vedação permite que a borracha ultrapasse a superfície superior do dissipador, de forma a pressionar a superfície inferior da peça de vidro produzindo a vedação.

Conforme ilustrado na Fig. 3.8, a região contendo os microcanais é coberta por uma peça de vidro de forma a possibilitar a visualização do escoamento. Ela possui área de base de 40x50 mm² e espessura de $15 \mathrm{~mm}$. Nela encontram-se usinados quatro canais com diâmetro 3,5 mm. Dois destes canais têm como função a alimentação e a drenagem de fluido a partir das câmaras de entrada e saída, respectivamente. Os outros dois canais, localizados em posições diametralmente opostas, encontram-se conectados ao transdutor diferencial de pressão e com o transdutor de pressão absoluta conectado ao canal posicionado acima da câmara de entrada.

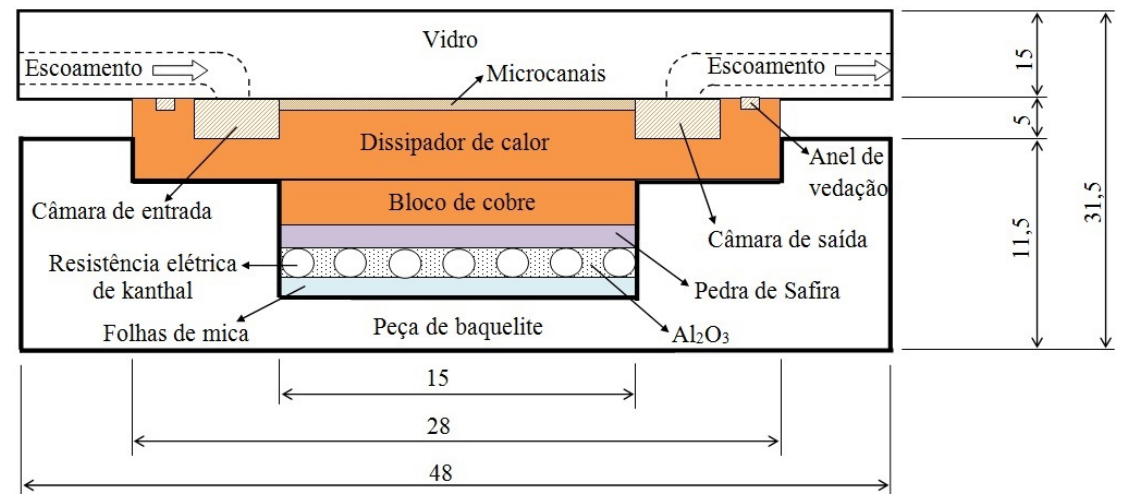

Figura 3.8 - Ilustração de corte da seção de testes, cotas em milímetros.

A Figura 3.9 apresenta o registro fotográfico da peça de vidro, contendo um termopar localizado para medir a temperatura do fluido e dos anéis de vedação externa. Conforme mostrado nesta figura, para realizar a vedação externa ao vidro, os quatro canais descritos anteriormente contém chanfros, fabricados externamente, para alojamento dos anéis de vedação de VITON com diâmetro interior de $3,0 \mathrm{~mm}$. De forma a medir as temperaturas do fluido nas câmaras de entrada e saída, dois termopares, com diâmetro de junta quente de $150 \mu \mathrm{m}$, foram inseridos nestas câmaras através dos canais do vidro. Estes termopares foram fixados separadamente dos canais e junto à parede inferior do vidro, de forma que não influenciem a distribuição do escoamento. 


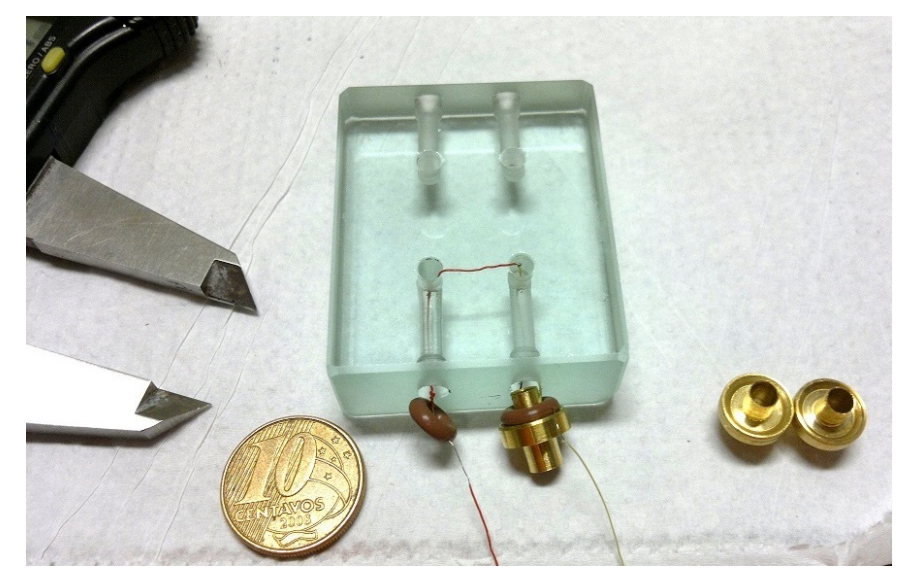

Figura 3.9 - Registro fotográfico da peça de vidro contendo termopar para medir a temperatura do fluido.

O aquecimento da seção de testes se dá através de uma resistência elétrica de Kanthal de $0,5 \Omega$ em forma de serpentina. Visando o isolamento elétrico e térmico desta resistência, ela encontra-se entre duas placas, sendo a inferior de mica e a superior de safira. Os vazios entre estas duas placas são preenchidas com nanopartículas de alumina. A placa de mica é composta de três camadas com espessura próxima a $50 \mu \mathrm{m}$. Já a placa de safira possui espessura de 1,2 $\mathrm{mm}$. Vale destacar que a safira apresenta uma condutividade térmica de $35-40 \mathrm{~W} / \mathrm{mK}$, a qual é aproximadamente cem vezes superior a condutividade térmica da mica com $0,35 \mathrm{~W} / \mathrm{mK}$. Desta forma favorece a maior parcela do fluxo de calor na direção dos microcanais.

\section{Descrição do dissipador de calor}

Segundo a análise dos estudos da literatura descritos na Tabela 2.11, os materiais mais frequentemente utilizados em dissipadores de calor baseados em multi-microcanais são o cobre, silício e alumínio. Um número reduzido de estudos foram realizados para dissipadores de calor fabricados em aço inoxidável.

O cobre apresenta valores reduzidos de resistividade elétrica e de expansão térmica comparado com outros metais condutores. Por outro lado, apresenta uma elevada condutividade térmica e após o silício, apresenta facilidade de aplicar técnicas de fabricação aos MEMs.

A Figura 3.10a ilustra uma comparação entre a condutividade térmica do cobre e outros metais frequentemente utilizados em MEMs. Nela observa-se que a condutividade do cobre é superior aos outros metais, além disso, seu valor varia apenas em cerca de $0,5 \%$ para uma alteração de temperatura de $300^{\circ} \mathrm{C}$.

Materiais com elevada expansão térmica não são recomendados para dissipadores de calor pois tal característica implica em deformações térmicas que modificam a geometria dos microcanais. Além disso, pode causar deformações na superfície inferior do dissipador elevando a resistência térmica de contato entre este dispositivo e o objeto resfriado.

Neste contexto, a Fig. 3.10p compara a expansão térmica linear de alguns materiais. Nela constata-se que a expansão do sicílio é inferior comparada aos outros materiais para 
temperaturas entre 0 e $300{ }^{\circ} \mathrm{C}$. No entanto, vale destacar que o cobre apresenta uma expansão térmica de apenas $0,13 \%$ para uma variação de temperatura de $100{ }^{\circ} \mathrm{C}$, valor equivalente a $0,65 \mu \mathrm{m}$ para cada $500 \mu \mathrm{m}$. Tal valor pode ser considerado desprezível assumindo temperaturas de operação inferiores a $80^{\circ} \mathrm{C}$ no presente estudo.
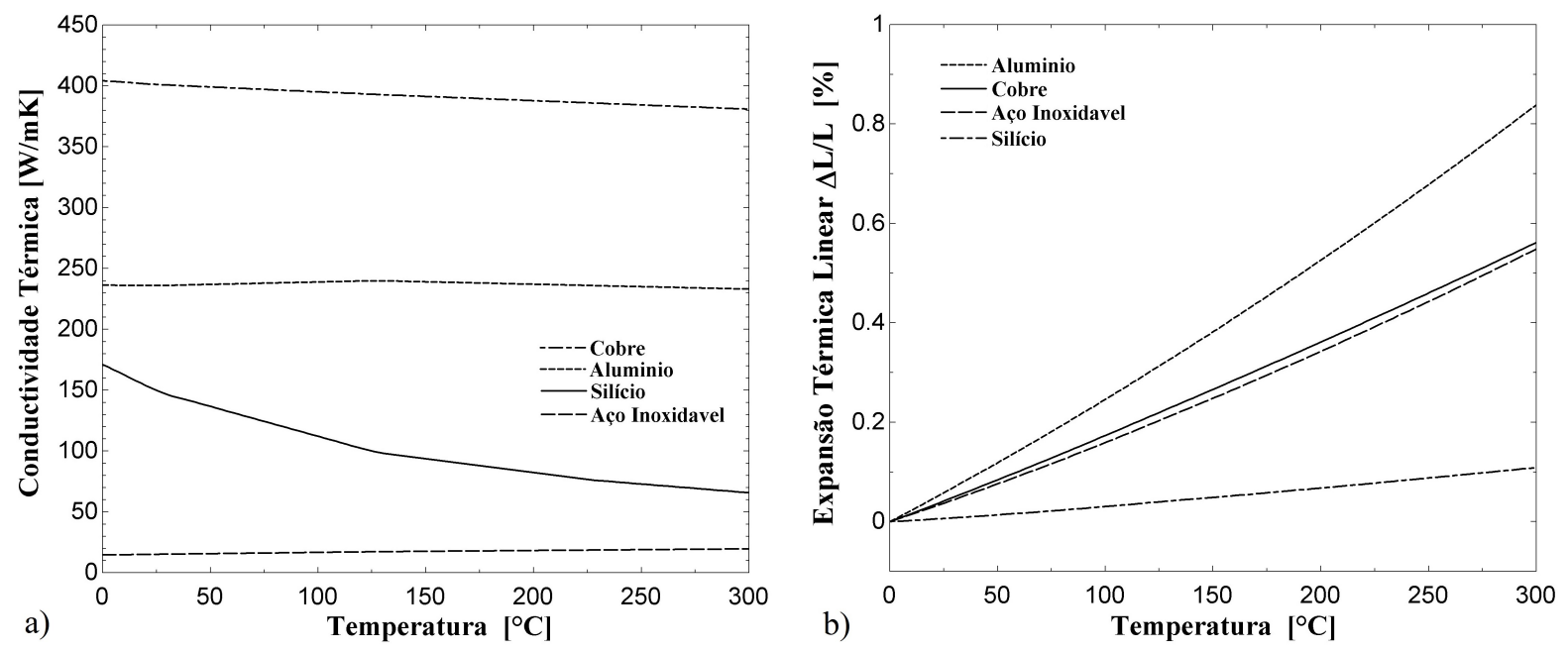

Figura 3.10 - Propriedades do cobre comparado com outros materiais. (a) Condutividade térmica; (b) Expansão térmica linear. Curvas levantadas com o EES (2003).

O dissipador de calor foi fabricado em um bloco de cobre de $28 \times 25 \times 4 \mathrm{~mm}^{3}$ no qual foram usinados cinquenta microcanais distribuídos em uma área de $15 \times 15 \mathrm{~mm}^{2}$ centrada no bloco. A Figura 3.11 ilustra um registro fotográfico de uma vista superior do dissipador de calor. Nesta figura observam-se os plenums (câmaras) de entrada e saída localizados nas regiões à montante e jusante dos microcanais, respectivamente. Estes plenums foram fabricados através de fresamento de topo e apresentam as seguintes dimensões: 4,0 $\mathrm{mm}$ de largura, $16 \mathrm{~mm}$ de comprimento e $2 \mathrm{~mm}$ de profundidade. A Figura $3.11 \mathrm{~b}$ ilustra as dimensões médias dos microcanais, os quais foram usinados através de micro-fresamento por disco de serra fabricados pela Zecha com diâmetros de 15 a $20 \mathrm{~mm}$ e uma espessura de $100 \mu \mathrm{m}$. Segundo o fabricante, estas serras apresentam erros máximos em suas medidas de 5,0 $\mu \mathrm{m}$.

a)

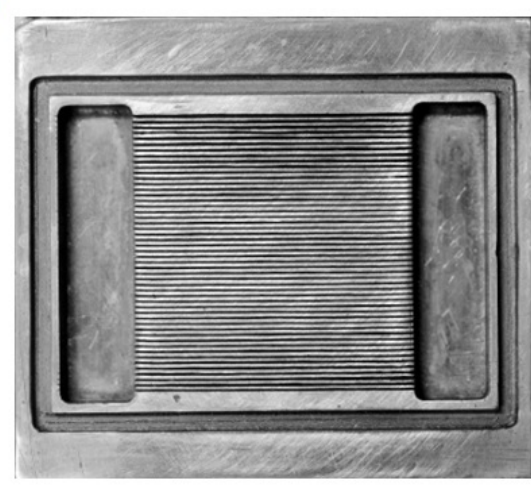

b)

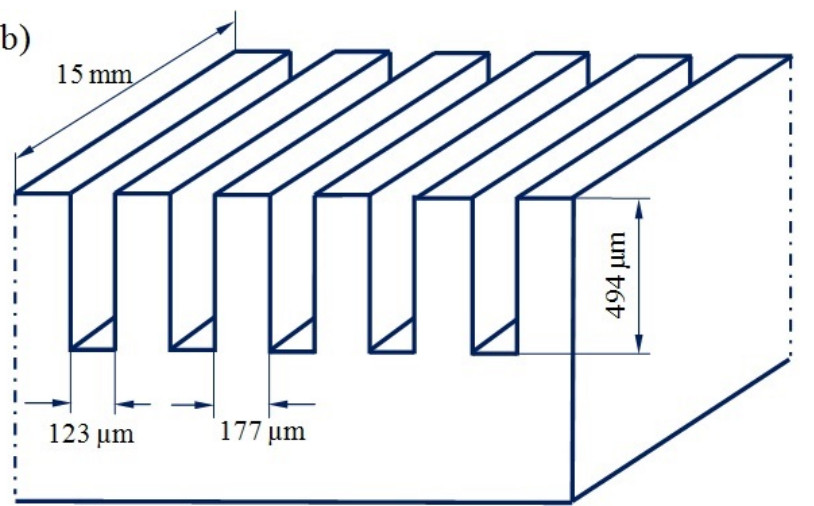

Figura 3.11 - Detalhes do dissipador de calor. a) vista superior do dissipador de calor; b) dimensões dos microcanais. 
As dimensões ilustradas na Fig. 3.11 foram avaliadas por Leão et al. (2015) através de um projetor de perfis Nikon, modelo V-20A com codificador de resolução linear de 1,0 $\mu \mathrm{m}$. No caso da avaliação da profundidade e largura dos canais e a distância entre canais consecutivos, fez-se uso de um espelho com inclinação de $45^{\circ}$ posicionado nos plenums. Foram realizadas três medições que apresentaram desvios padrões de $15,4 \mu \mathrm{m}$ para a largura dos canais, $22,9 \mu \mathrm{m}$ para a profundidade e $12,7 \mu \mathrm{m}$ para a distância entre canais consecutivos.

A medição de temperatura na superfície inferior do dissipador de calor é realizada através de nove termopares tipo K, distribuídos segundo uma matriz de $3 \times 3$ na área da base do dissipador de calor. Os termopares encontram-se distantes ente si de $4,5 \mathrm{~mm}$ e o diâmetro da junta quente de $150 \mu \mathrm{m}$. Por outro lado, os fios foram instalados em nove ranhuras usinadas diagonalmente aos microcanais conforme ilustrado na Fig. 3.12

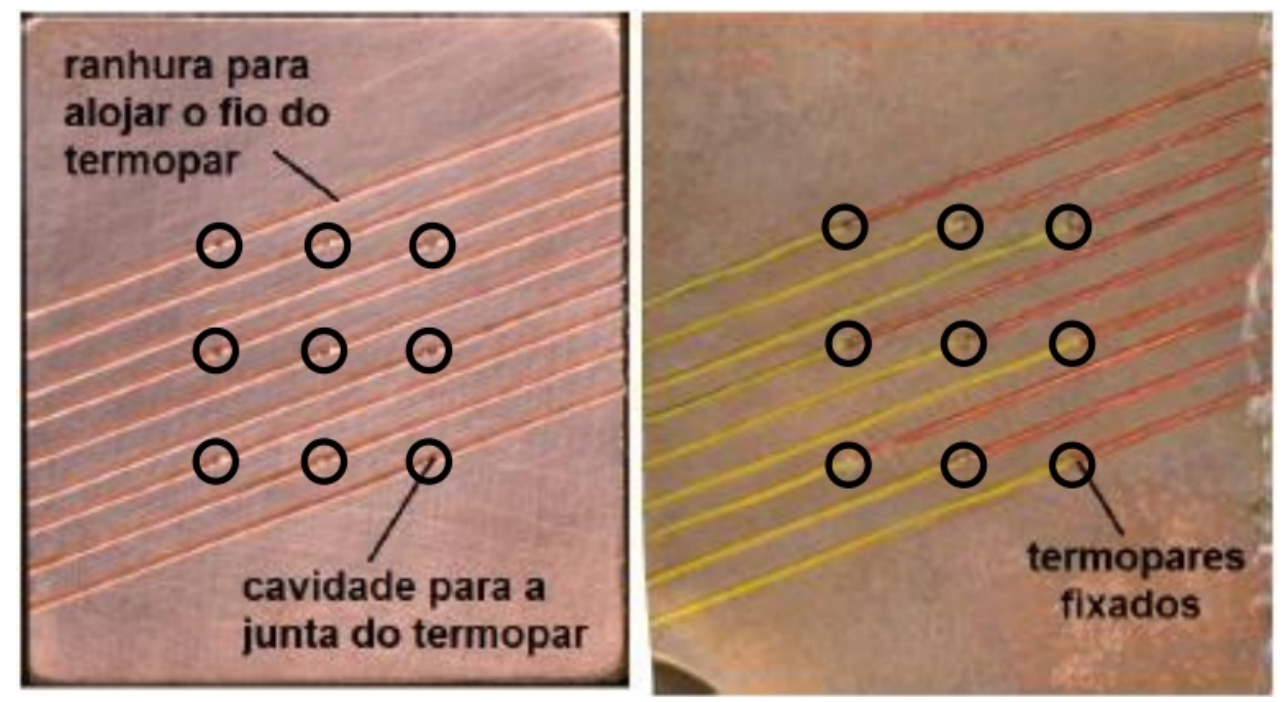

Figura 3.12 - Ilustração dos termopares fixados na superfície inferior do dissipador de calor. Do Nascimento (2012)

A rugosidade superficial no interior dos canais foi avaliada através de um gerador de perfis ópticos Veeco Wyko, modelo NT1100. Para isto, canais similares foram usinados adotando o mesmo procedimento em um segundo bloco de cobre. Estes canais foram fabricados visando ter acesso óptico para medir a rugosidade na superfície lateral do microcanal, a qual corresponde à parcela predominante $(89 \%)$ da área aquecida em contato com o fluido. As medições foram realizadas em três posições distintas da superfície lateral do microcanal e os valores médios encontrados foram: Rugosidade Média: $\mathrm{Ra}=0,29 \mu \mathrm{m}$; Rugosidade Média Quadrática: $\mathrm{Rq}=0,35 \mu \mathrm{m}$; Altura Máxima da Rugosidade $\mathrm{Rq}=3.23 \mu \mathrm{m}$. Tais medições foram realizadas no Laboratório de Engenharia de Precisão do Departamento de Engenharia Mecânica da Escola de Engenharia de São Carlos. A Figura 3.13 ilustra a textura superficial das superfícies laterais dos canais. 

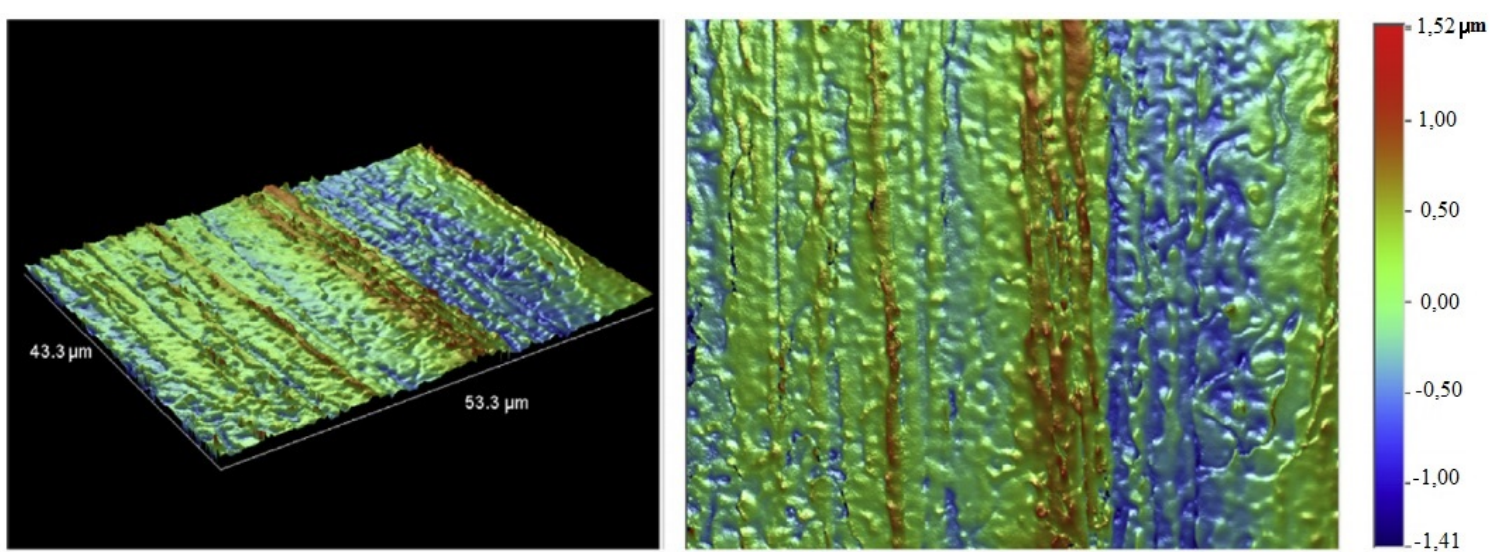

Figura 3.13 - Micro-perfil óptico da superfície de um microcanal. Leão et al. (2015).

\subsubsection{AVALIAÇÃO DE EFEITOS DE CONDUÇÃO NA DISTRIBUIÇÃO DE TEM- PERATURAS DA SEÇÃO DE TESTES}

Visando verificar a validade das hipóteses de fluxo de calor uniforme e unidimensional na base inferior do dissipador, desenvolveu-se neste estudo um programa em linguagem FORTRAN baseado no Método de Diferenças Finitas para simulação bidimensional com profundidade constante. Foi resolvida numericamente a equação de calor na forma de Laplace segundo é descrita por Bergman et al. (2011). Nesta análise, adotou-se as seguintes hipóteses e condições de contorno: (1) condução de calor bidimensional; (2) superfícies laterais adiabáticas; (3) fluxo de calor imposto na superfície inferior; (4) regime permanente; (5) temperatura na superfície superior do bloco.

A Figura 3.14 apresenta o modelo geométrico bidimensional do bloco de cobre. Nela indicase as condições de contorno aplicadas em uma malha distribuída uniformemente de acordo a uma matriz de $27 \times 27$ nós.

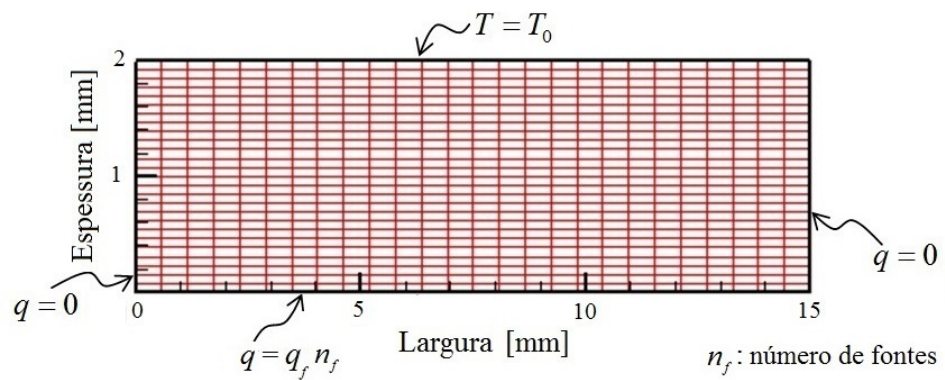

Figura 3.14 - Modelo geométrico bidimensional do bloco de cobre indicando condições de contorno para simulação.

No caso da hipótese (3), o fluxo de calor é aplicado na parede inferior distribuído em fontes $2^{2}$ distantes de $1,0 \mathrm{~mm}$. Esta forma de distribuição busca simular a localização dos fios da resistência em forma de serpentina utilizada para o aquecimento da seção de testes. Os valores de fluxo de calor para as fontes foram calculados através da seguinte equação:

\footnotetext{
${ }^{2}$ Estas fontes são aplicadas em elementos de área dados pela multiplicação entre a largura da Diferença Finita e a profundidade do bloco. (não são fontes pontuais).
} 


$$
q_{f}=\frac{\dot{Q}_{b}}{n_{f} \cdot d A}
$$

onde $\dot{Q}_{b}$ é a taxa de calor aplicada na base do bloco, $n_{f}$ é o número de fontes e $d A$ é o elemento diferencial de área dado pela largura do elemento vezes a profundidade do bloco. Simulações foram efetuadas para potências de aquecimento de $\dot{q}_{f}=44,222$ e $444 \mathrm{~kW} / \mathrm{m}^{2}$.

Em relação a hipótese (5), adotou-se temperatura uniforme e constante na superfície de contato entre o bloco de cobre e a base do dissipador de calor igual a $20{ }^{\circ} \mathrm{C}$.

A Figura 3.15 ilustra o resultados para simulação da condução de calor para $\dot{q}_{f}=44 \mathrm{~kW} / \mathrm{m}^{2}$. Nela as linhas isotérmicas tornam-se paralelas e uniformes a partir de $0,5 \mathrm{~mm}$ da região aquecida. Resultados para fluxos de calor superiores são ilustrados nas Figs. 3.15b e 3.15k onde as linhas isotérmicas atingem distribuição similar a partir de $0,3 \mathrm{~mm}$ da região de imposição do fluxo de calor. A elevada difusão de calor que torna as linhas isotérmicas paralelas se deve à alta condutividade térmica do cobre. Assim, conclui-se que uma espessura de 1,0 mm, a qual é inferior a adotada neste estudo para atingir uma distribuição de temperaturas uniforme.
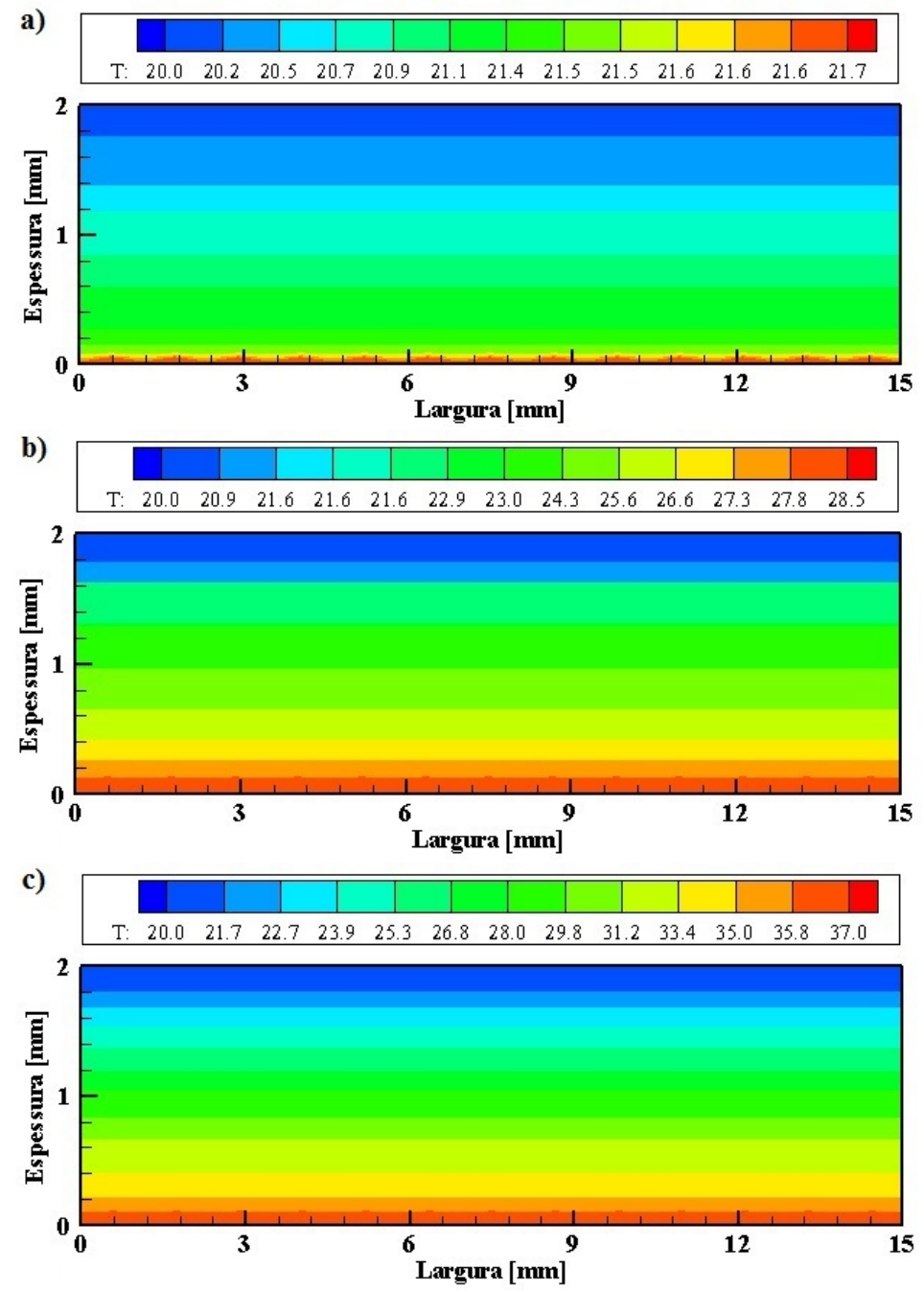

Figura 3.15 - Distribuição de temperaturas no bloco de cobre para $\mathrm{T}_{0}=20^{\circ} \mathrm{C}$. a) $\dot{\mathrm{q}}_{\mathrm{f}}=44 \mathrm{~kW} / \mathrm{m}^{2}$, b) $\left.\dot{\mathrm{q}}_{\mathrm{f}}=222 \mathrm{~kW} / \mathrm{m}^{2}, \mathrm{c}\right) \dot{\mathrm{q}}_{\mathrm{f}}=444 \mathrm{~kW} / \mathrm{m}^{2}$. 
Um segundo programa ${ }^{3}$ foi desenvolvido considerando condução bidimensional utilizando linguagem FORTRAN baseado no Método híbrido de Volumes de Controle formado por Elementos Finitos, CVFEM (Control Volume Finite Element Method). Através deste programa buscou-se analisar o efeito das regiões dos plenums sobre a distribuição de temperaturas ao longo do dissipador de calor. A malha foi implementada através do programa Easy Mesh, desenvolvido por Niceno (1995).

De acordo com Baliga e Patankar (1983), o CVFEM é um método híbrido que combina a capacidade de conservação do método de Volumes Finitos e a flexibilidade topológica do Método de Elementos Finitos. Desta forma, é possível capturar as variações de parâmetros físicos e geométricos do modelo. Neste caso, foi resolvida numericamente a equação de calor na forma de Laplace segundo é descrita por Bergman et al. (2011).

A Figura 3.16 ilustra a malha elaborada e as condições de contorno adotadas: (1) Condução de calor bidimensional; (2) Convecção de calor nas superfícies das câmaras; (3) Fluxo de calor uniforme na base do trocador; (4) Regime permanente. (5) Convecção de calor na superfície dos microcanais. Para estas hipóteses, foram analisadas condições de escoamento monofásico e com presença de ebulição convectiva.

Em relação a hipótese (3), adotou-se fluxo de calor uniforme na base del trocador de calor baseado na análise anterior da distribuição de temperaturas no bloco de cobre. Através desta análise, verificou-se a uniformidade do fluxo de calor transferido a partir do bloco de cobre para a base do dissipador de calor.

Como indica-se na Fig. 3.16, considerou-se altura total constante ao longo do dissipador. Vale destacar que a diferença entre a altura da região central e extremidades do dissipador é de $500 \mu \mathrm{m}$, a qual é desprezível uma vez que as diferenças de temperatura correspondentes a esta diferença de altura não são relevantes para a análise efetuada.

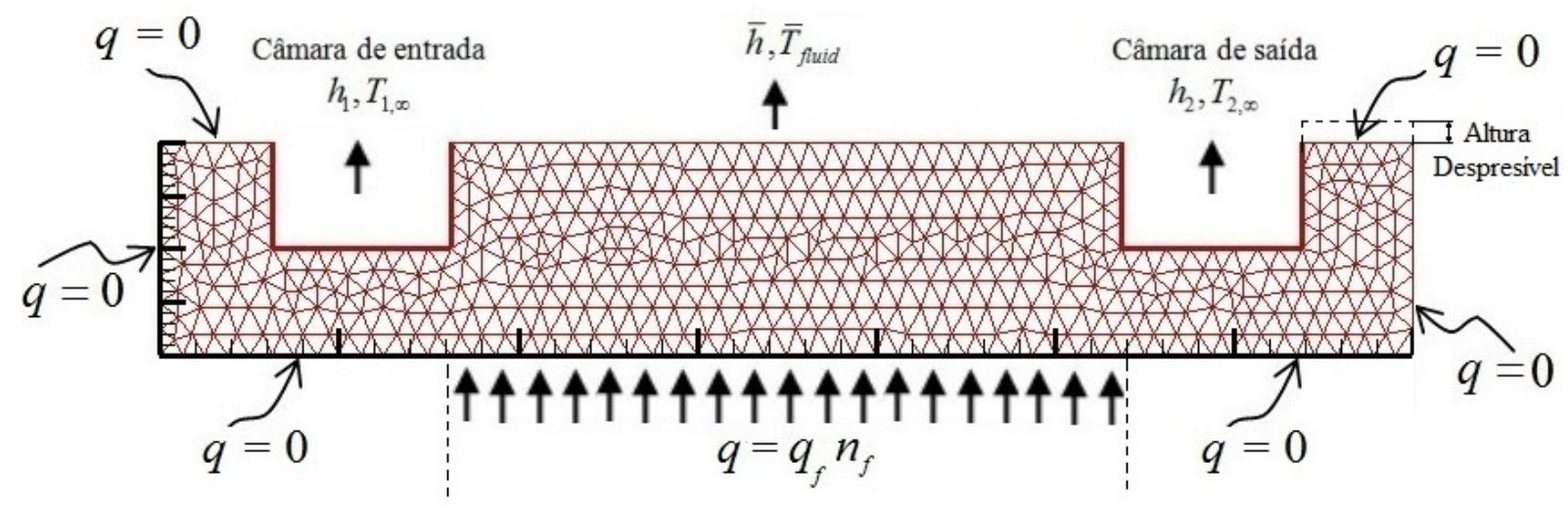

Figura 3.16 - Modelo geométrico bidimensional do trocador de calor indicando condições de contorno para simulação.

\footnotetext{
${ }^{3}$ Validação, convergência, análise de malha e sensibilidade para este programa encontram-se detalhados na dissertação de mestrado de Chávez (2009).
} 
A Tabela 3.2 apresenta um resumo das condições de contorno aplicadas na simulação do do efeito das câmaras 2D. Os valores adotados foram estimados a partir de condições ensaiadas para refrigerante isobutano e calculadas com auxílio do programa EES (2003).

Tabela 3.2 - Resumo das condições simuladas para verificar o efeito das câmaras.

\begin{tabular}{|c|c|c|c|c|c|}
\hline & \multirow[b]{2}{*}{ Parâmetro } & \multicolumn{4}{|c|}{ Condições de contorno } \\
\hline & & $\begin{array}{c}\text { Câmara de } \\
\text { entrada }\end{array}$ & Microcanais & $\begin{array}{c}\text { Câmara de } \\
\text { saída }\end{array}$ & $\begin{array}{l}\text { Base do } \\
\text { trocador }\end{array}$ \\
\hline \multirow{3}{*}{$1 \phi$} & Coeficiente de transferência de calor, $\left[\mathrm{W} / \mathrm{m}^{2} K\right]$ & 1807 & 3030 & 1814 & - \\
\hline & Temperatura do fluido, $\left[{ }^{\circ} \mathrm{C}\right]$ & 20,26 & 21,68 & 22,81 & - \\
\hline & Fluxo de calor, $\left[\mathrm{kW} / \mathrm{m}^{2}\right]$ & - & - & - & 40 \\
\hline \multirow{3}{*}{$2 \phi$} & Coeficiente de transferência de calor, $\left[\mathrm{W} / \mathrm{m}^{2} \mathrm{~K}\right]$ & 1806 & 12340 & 13912 & - \\
\hline & Temperatura do fluido, $\left[{ }^{\circ} \mathrm{C}\right]$ & 20,26 & 23,68 & 22,81 & - \\
\hline & Fluxo de calor, $\left[\mathrm{kW} / \mathrm{m}^{2}\right]$ & - & - & - & 380 \\
\hline
\end{tabular}

Nas Figuras 3.17 e 3.18, nota-se que a diferença de temperaturas entre a base do dissipador e a superfície superior é de até $0,6^{\circ} \mathrm{C}$ para condições de escoamento monofásico. Entretanto, para condições de escoamento bifásico a diferença de temperatura é de $3,6{ }^{\circ} \mathrm{C}$. Esta diferença decorre do fato de que durante o escoamento com a presença de ebulição convectiva, fluxos de calor superiores são dissipados. Baseado nesta análise, também é possível constatar a necessidade de incluir um fator de correção para estimar a temperatura na superfície dos microcanais a partir da medida dos termopares localizados na base do dissipador.

A Figura 3.17 ilustra os efeitos das câmaras sobre a distribuição de temperaturas correspondentes a condições de contorno baseada em escoamento monofásico. De acordo com esta figura, para escoamento monofásico ao longo do dissipador, a distribuição de temperatura é aproximadamente simétrica. Tal comportamento decorre da variação de temperatura do fluido refrigerante com coeficientes de transferência de calor próximos as regiões das câmaras de entrada e saída do dissipador. Já na Fig. 3.18 na presença de ebulição convectiva, a distribuição de temperaturas se inverte apresentando valores superiores comparado a distribuição obtida para condições monofásicas. Para ambas as condições, a região inferior das câmaras apresenta linhas isotérmicas aproximadamente perpendiculares a superfície inferior dos plenums. Isto indica que parcelas superiores do fluxo de calor transferido para a região das câmaras são transferidos por condução axial ao longo da região inferior dos plenums.

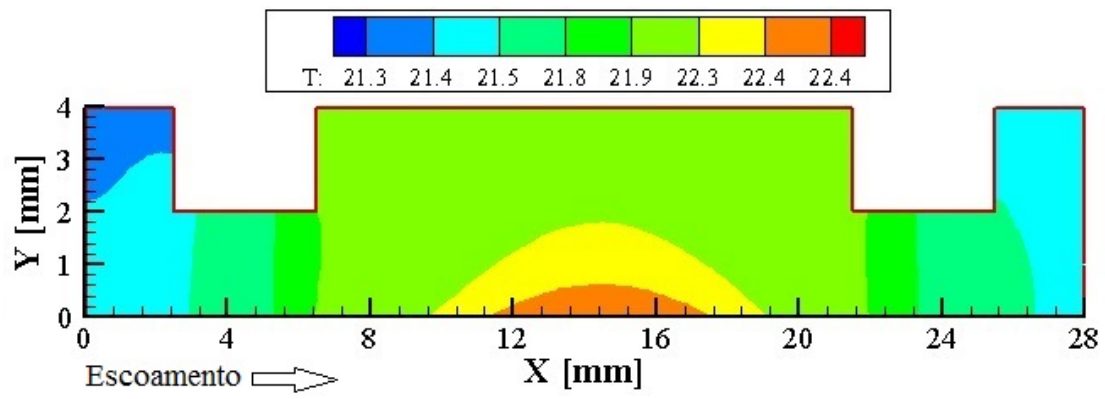

Figura 3.17 - Distribuição de temperaturas no dissipador de calor para condições de escoamento monofásico. 


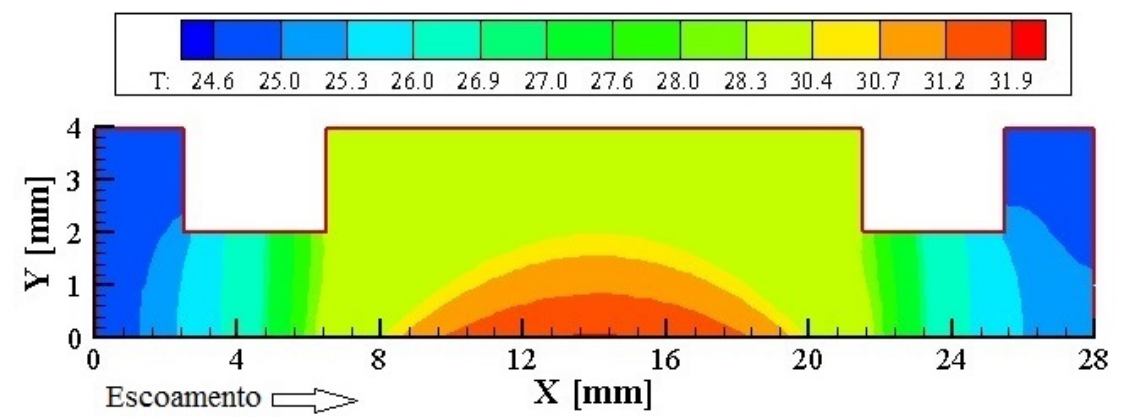

Figura 3.18 - Distribuição de temperaturas no dissipador de calor para condições de ebulição convectiva.

A Figura 3.19 ilustram o volume de controle adotado para avaliar o calor transferido na direção axial para a região das câmaras. A Fig. 3.19 p, indica o balanço do calor transferido no volume de controle avaliado para um elemento de malha com $\mathrm{dx}=480 \mu \mathrm{m}$ na horizontal, cinco elementos com dy $=400 \mu \mathrm{m}$ na vertical e condutividade térmica de $400 \mathrm{~W} / \mathrm{mK}$. Os valores calculados para o calor transferido para os plenums e suas porcentagens em relação ao calor aplicado na base são apresentados na Tabela 3.3. De acordo com esta tabela, a taxa de calor transferido na câmara de entrada é marginalmente superior ao calor transferido para a câmara de saída, para condições de escoamento monofásico. Já para escoamento com a presença de ebulição convectiva, a taxa de calor transferido na câmara de saída torna-se superior. Este comportamento decorre do incremento do coeficiente de transferência de calor sob condições de ebulição convectiva na câmara de saída.

a)

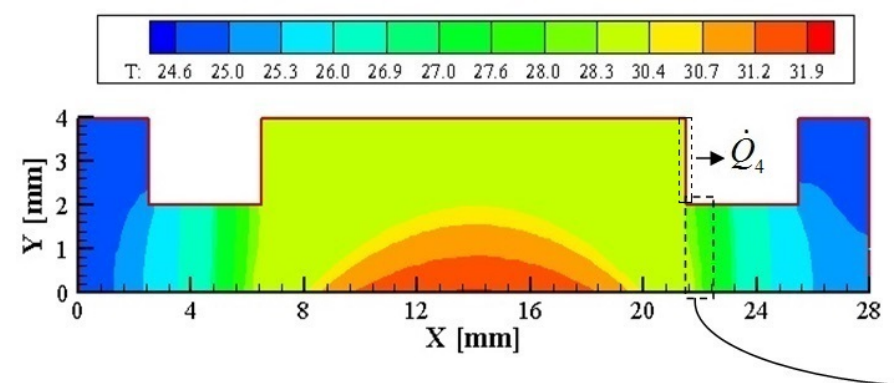

b)

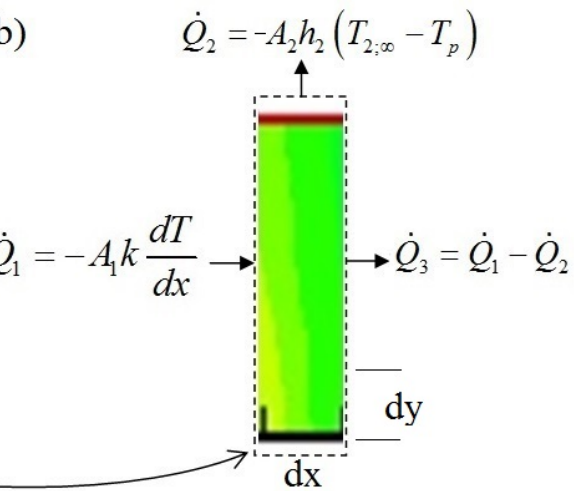

Figura 3.19 - Ilustração dos volumes de controle adotado para calcular calor transferido para as câmaras. a) dissipador de calor; b) volume de controle.

Tabela 3.3 - Resultados numéricos de calor axial transferido para as câmaras.

\begin{tabular}{cccc}
\hline \multirow{3}{*}{$1 \phi$} & Taxa de Calor, $[\boldsymbol{W}]$ & $\begin{array}{c}\text { Calor transferido para a } \\
\text { câmara de entrada }\end{array}$ & $\begin{array}{c}\text { Calor transferido para a } \\
\text { câmara de saída }\end{array}$ \\
\cline { 2 - 4 } & $\dot{Q}_{1}$ & $0,51(5,6 \%)$ & $0,35(3,8 \%)$ \\
\cline { 2 - 4 } & $\dot{Q}_{4}$ & $0,37(4,1 \%)$ & $0,41(4,5 \%)$ \\
\hline \multirow{3}{*}{$2 \phi$} & Total $1 \phi$ & $0,88(9,7 \%)$ & $0,76(8,6 \%)$ \\
\cline { 2 - 4 } & $\dot{Q}_{1}$ & $3,80(4,4 \%)$ & $4,50(5,3 \%)$ \\
\cline { 2 - 4 } & $\dot{Q}_{4}$ & $0,39(0,5 \%)$ & $3,11(3,6 \%)$ \\
\cline { 2 - 4 } & Total $2 \phi$ & $4,19(4,9 \%)$ & $7,61(8,9 \%)$ \\
\hline
\end{tabular}


Baseada na análise anterior, observou-se que a distribuição de temperaturas não apresenta simetria em relação as câmaras de entrada e saída do dissipador. Por outro lado, se determinou que o calor axial dissipado para as câmaras apresenta valores inferiores a $10 \%$ do calor total dissipado. Além disso, vale destacar que no presente estudo, a temperatura da parede é medida a partir dos termopares fixados na base do dissipador de calor. Desta forma, para estimar a temperatura da parede, pode-se corrigir a temperatura medida através de uma correlação de condução de calor desde a localização dos termopares até a superfície inferior dos microcanais. Esta correlação para corrigir a temperatura poderia se basear na condução bidimensional considerando o calor axial dissipado para as câmaras de entrada e saída. No entanto, assumindo a condução axial pouco relevante, uma correção adequada para determinar a temperatura na superfície dos canais poderia ser a Lei de Fourier para o caso unidimensional.

A distribuição de fluxo de calor e temperatura no dissipador também foi avaliada através de uma análise de condução tridimensional. A Figura 3.20 ilustra uma vista isométrica do dissipador de calor, com a malha de elementos finitos 3D do tipo tetraédricos. A simulação foi realizada através do programa Autodesk Simulation Multiphysics 4 . A Figura 3.20 ilustra o modelo geométrico avaliado. Na Fig. 3.20 p constam as condições de contorno adotadas para a simulação, cujos valores são apresentados na Tabela 3.2 . Os valores de coeficientes de transferência de calor e de temperaturas nas regiões das câmaras e nos microcanais foram especificados com base nos dados experimentais levantados neste estudo. Considerou-se a resistência elétrica de Kanthal com geometria quadrada a partir da qual o calor era dissipado.

a)
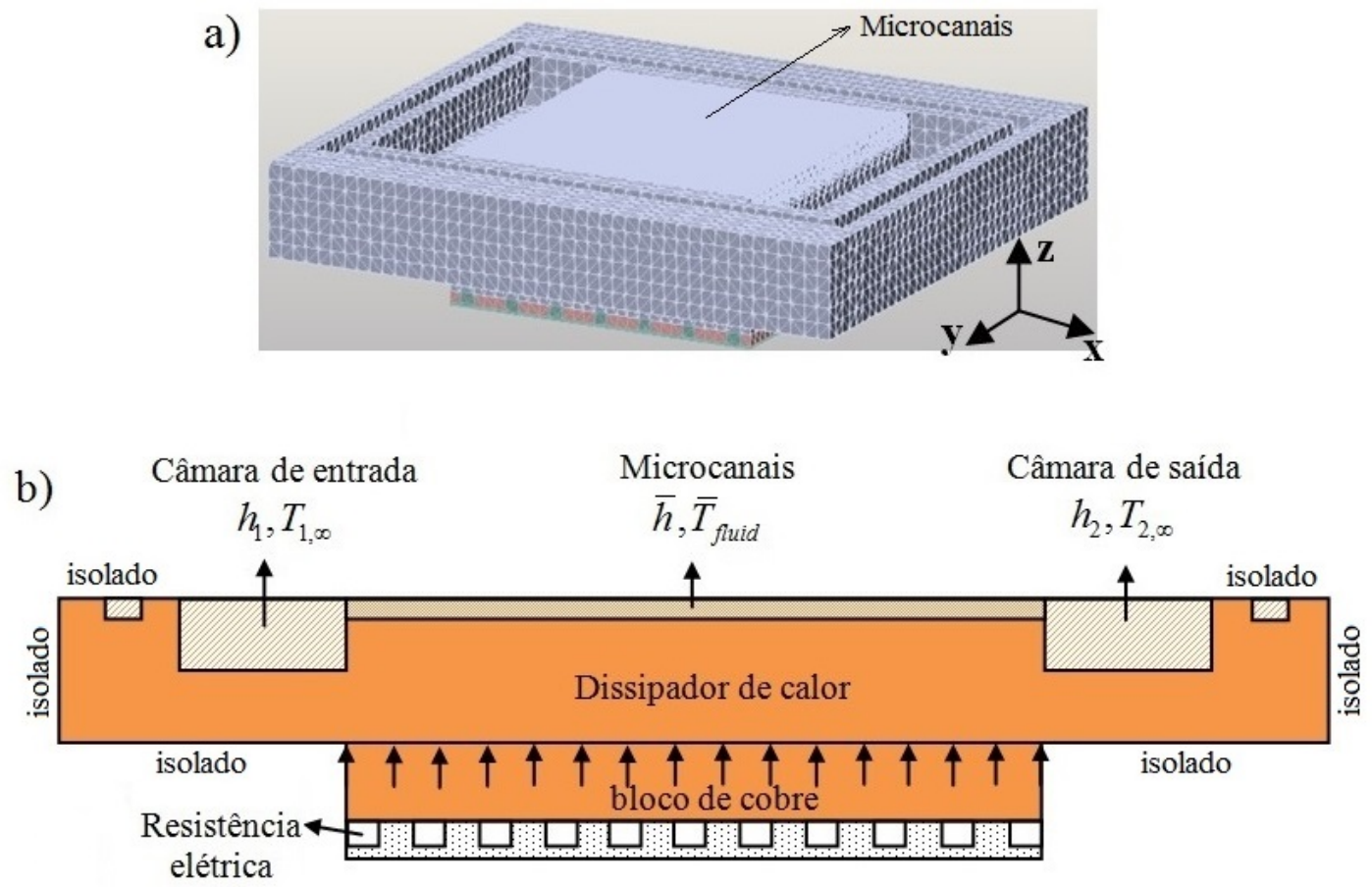

Figura 3.20 - Modelo geométrico para simulação de condução de calor 3D. a) Indicação de condições de contorno; b) Malhado 3D com elementos finitos.

\footnotetext{
${ }^{4}$ Análise de convergência para a malha e sensibilidade foi efetuada até obter variações de temperaturas de $5 \%$.
} 
A Figura 3.21 apresenta a distribuição de temperaturas na região inferior do dissipador em contato com o bloco de cobre. Para escoamento monofásico através da análise das isotérmicas, nota-se uma região central com temperaturas superiores correspondente a região dos microcanais, sob a qual encontram-se a resistência de aquecimento. Também nota-se a região da câmara de drenagem de fluido com temperaturas superiores às observadas na câmara de alimentação. As Figs. $3.21 \mathrm{p}$ e $3.21 \mathrm{~d}$ ilustram as curvas de temperatura levantadas da região central ao longo da base do dissipador. Notam-se também diferenças de temperatura entre as regiões das câmaras de entrada e saída de apenas $0,5^{\circ} \mathrm{C}$. Tais comportamentos estão relacionados a condições de escoamento monofásico correspondendo a coeficientes de transferência de calor aproximadamente iguais nas câmaras de entrada e saída e uma potência de aquecimento de apenas $9 \mathrm{~W}$. No caso da presença de ebulição convectiva nos microcanais e no plenum de saída, observa-se temperaturas superiores no plenum de entrada em relação ao de saída e esta diferença eleva-se significativamente em relação a condições de escoamento monofásico, alcançando valores de até $4,0^{\circ} \mathrm{C}$.
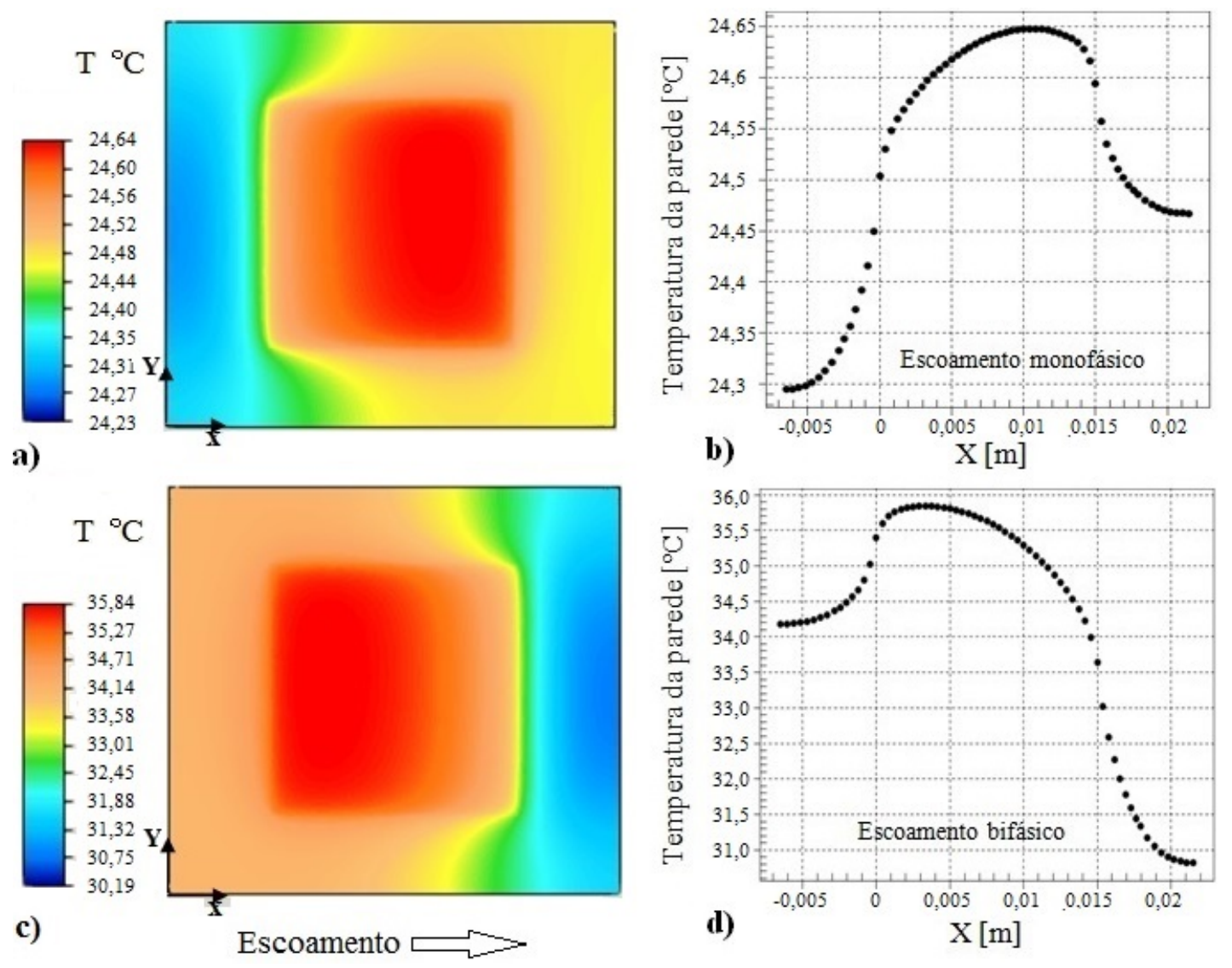

Figura 3.21 - Distribuição de temperatura na base do dissipador de calor.

De acordo com a Fig. 3.21, na região correspondente a área aquecida (footprint) observa-se uma diferença de temperatura marginal para condições de escoamento monofásico. Já, para condições de escoamento sob ebulição convectiva observa-se uma diferença de temperatura de $1,5^{\circ} \mathrm{C}$ entre o inicial e final da região aquecida (footprint). Desta forma, constata-se ser 
adequado estimar o coeficiente de transferência de calor médio ao longo do dissipador, como a média aritmética dos valores fornecidos pelos termopares localizados na base. Isto decorre do fato dos nove termopares estarem distribuídos na superfície inferior do dissipador de forma a capturar o efeito das variações de temperatura constatadas na presente análise.

Visando analisar a distribuição de temperaturas na região dos microcanais, efetuou-se uma simulação de condução de calor tridimensional em um microcanal com dimensões similares a do dissipador avaliado no presente estudo. A Fig. 3.22 ilustra o modelo geométrico simulado. Devido à simetria, a simulação foi efetuada apenas para a seção ilustrada na Fig. 3.22b com as condições de contornos apresentadas no item (c) da mesma figura.
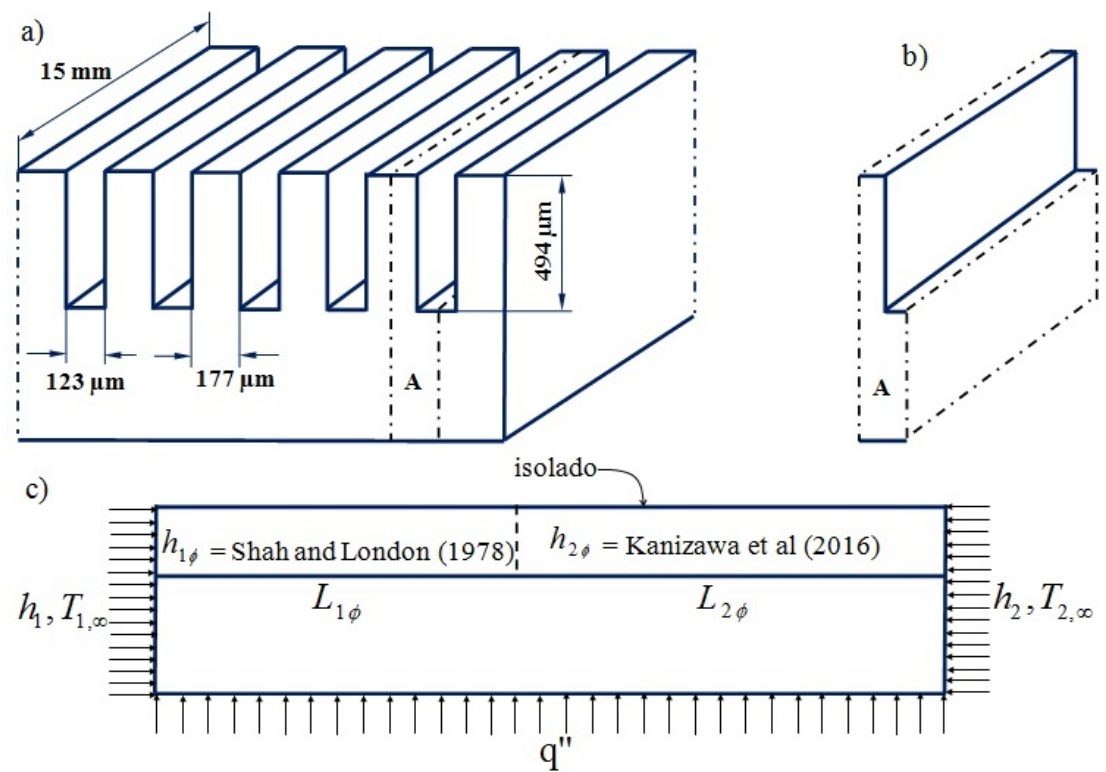

Figura 3.22 - Ilustração esquemática da geometria para avaliar a condução de calor ao longo do microcanal 3D. a) Indicação da seção "A"; b) Seção "A"; c) Indicação de condições de contorno.

A Tabela 3.4 apresenta um resumo das condições de contorno indicadas na Fig. 3.22 k. Simulações foram efetuadas para condições sob ebulição convectiva. Fluxo de calor uniforme foi aplicado na superfície inferior do canal. Ao longo das superfícies interiores do canal adotouse a correlação de Stephan e Preuber (1979) para o cálculo do coeficiente de transferência de calor na região monofásica e o método de Kanizawa et al. (2016) para ebulição convectiva. $\mathrm{O}$ coeficiente de transferência de calor e as propriedades do fluido variam ao longo do canal em função do título de vapor, cujo gradiente ao longo do dissipador é constante.

Os valores das condições de contorno foram levantados a partir de condições experimentais ensaiadas para R600a, para velocidade mássica de $330 \mathrm{~kg} / \mathrm{m}^{2} \mathrm{~s}$, grau de sub-resfriamento do líquido na entrada da seção de testes de $5{ }^{\circ} \mathrm{C}$, temperatura de saturação de $25^{\circ} \mathrm{C}$ e comprimento monofásico de 2,2 mm, calculado através da solução simultânea das equações de balanço de energia e a correlação de perda de pressão de Shah e London (1978). As simulações e análises dos seus resultados foram realizadas com os programas Opem Foam e ParaView, respectivamente. 
Tabela 3.4 - Condições de contorno simuladas para o microcanal 3D.

\begin{tabular}{|c|c|c|c|c|c|}
\hline & \multirow[b]{3}{*}{ Parâmetro } & \multirow{2}{*}{\multicolumn{4}{|c|}{ Condições de contorno }} \\
\hline & & & & & \\
\hline & & $\begin{array}{c}\text { Superfície de } \\
\text { entrada do } \\
\text { microcanal }\end{array}$ & Superfície interior do microcanal & $\begin{array}{l}\text { Superfície de } \\
\text { saída do } \\
\text { microcanal }\end{array}$ & $\begin{array}{l}\text { Base da } \\
\text { seção A }\end{array}$ \\
\hline \multirow{3}{*}{$2 \phi$} & $\begin{array}{l}\text { Coeficiente de transferência de ca- } \\
\text { lor, }\left[W / m^{2} K\right]\end{array}$ & 1806 & $\begin{array}{l}\text { Stephan e Preuber (1979) para } 1 \phi, \\
\text { Kanizawa } \text { et al. 2016) para } 2 \phi\end{array}$ & 13912 & - \\
\hline & Temperatura do fluido, $\left[{ }^{\circ} \mathrm{C}\right]$ & 20,26 & $T_{\text {sat }}$ & 22,81 & - \\
\hline & Fluxo de Calor, $\left[\mathrm{kW} / \mathrm{m}^{2}\right]$ & - & - & - & 380 \\
\hline
\end{tabular}

A Figura 3.23 ilustra seis curvas de distribuição de temperaturas ao longo do microcanal com a presença de ebulição convectiva. Estas curvas de temperatura correspondem as posições indicadas esquematicamente na Fig. $3.23 \mathrm{~b}$.

De acordo com a Fig. 3.23 a a temperatura superficial se eleva ao longo da região monofásica como resultado do coeficiente de transferência de calor inferior. A partir de $\mathrm{X}=6,5 \mathrm{~mm}$, a temperatura decresce até a saída do microcanal como resultado do incremento do coeficiente de transferência de calor sob condições de ebulição convectiva. Neste caso, esperava-se a redução de temperatura a partir de $\mathrm{X}=2,2 \mathrm{~mm}$, no entanto, a região de transição entre 2,2 e $6,5 \mathrm{~mm}$ na qual a temperatura incrementa, pode estar associada a efeitos de condução ao longo do microcanal.
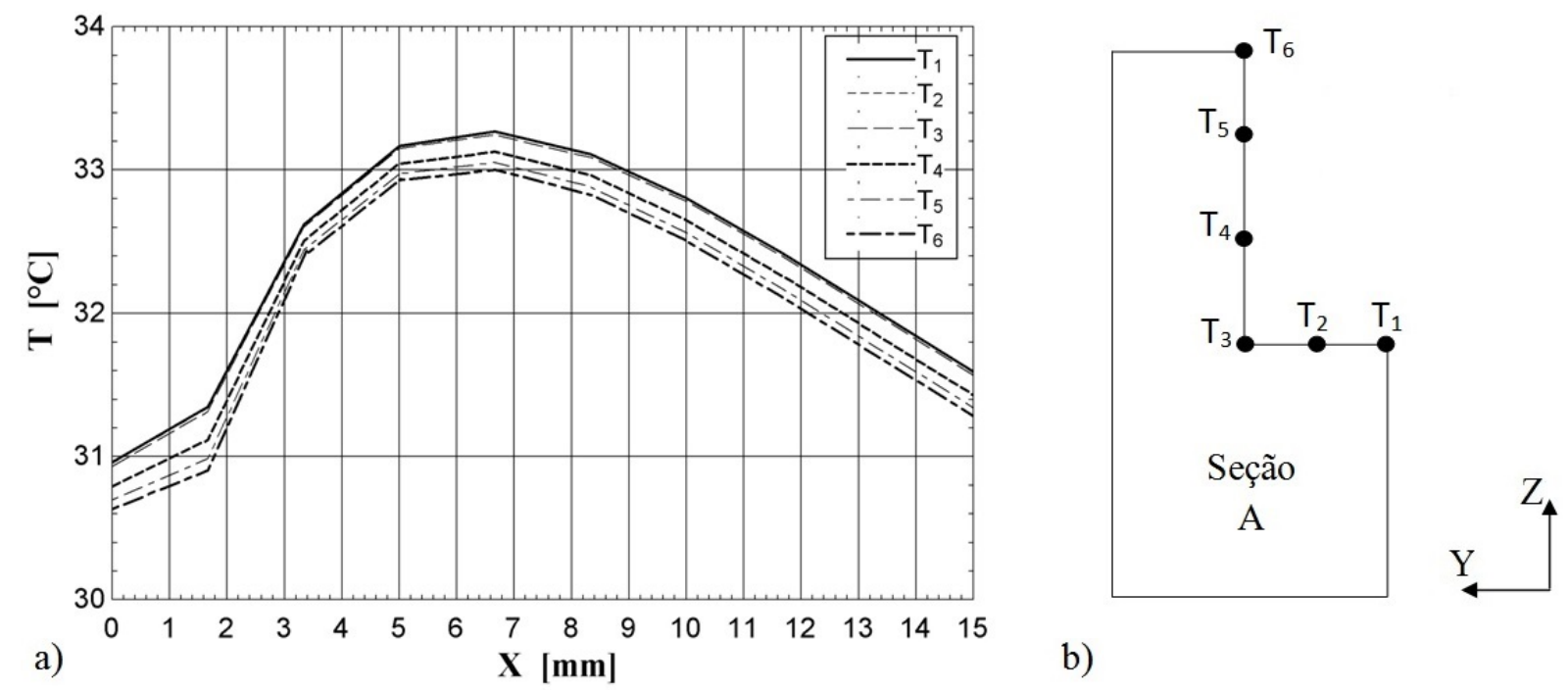

b)

Figura 3.23 - Temperatura da parede ao longo do microcanal para escoamento bifásico. a) curvas de temperatura; b) esquema da seção transversal do microcanal.

Através da simulação efetuada, verificaram-se diferencias reduzidas entre a superfície inferior do microcanal e a ponta da aleta, a qual corresponde a uma eficiência de $96 \%$. Desta forma, constatou-se que a temperatura na superfície inferior dos microcanais é adequada para representar a temperatura média na superfície total dos microcanais. 


\subsection{PROCEDIMENTO EXPERIMENTAL}

Durante os testes experimentais adotou-se o seguinte procedimento:

(i) Alimentação elétrica da bomba de engrenagens, do medidor de vazão de Coriolis, do transdutor diferencial de pressão, do sistema de adquisição e da fonte de corrente contínua do circuíto principal;

(ii) Liga-se o computador pessoal, a interface do programa de LabView e verificam-se, na tela do computador, se os sinais dos instrumentos e termopares estão sendo recebidas;

(iii) Aciona-se a torre de resfriamento do circuito de rejeição de calor. Em seguida aciona-se a bomba centrífuga, a termo-resistência do tanque de água com etileno-glicol, o compressor e a válvula solenoide do circuito de compressão;

(iv) Alimenta-se o VARIAC responsável pelo controle da potência no pré-aquecedor. Estabelecese a temperatura desejada no reservatório da solução de água-etileno glicol através do controlador PI no circuíto secundário;

(v) Abre-se as válvulas de esfera na linha do circuito principal para permitir a circulação do fluido através da seção de testes. Aciona-se via computador, o variador de frequência para controle da microbomba de engrenagens;

(vi) Aciona-se o motor da bomba de engrenagens e fixa-se a velocidade mássica através de interface LabView, a qual manterá a vazão no valor desejado através do controlador PI. Esta manobra é acompanhada da regulação manual das válvulas agulha a jusante e a montante da seção de testes. Desta forma, a temperatura de saturação na entrada do dissipador de calor é mantida no valor desejado;

(vii) Fixa-se a potência do VARIAC de forma a atingir o sub-resfriamento desejado na entrada do dissipador de calor;

(viii) Estabelece-se a potência elétrica de aquecimento no dissipador de calor a qual é gerenciada pela fonte de corrente contínua, controlada a partir do programa LabView. Os dados experimentais são adqueridos em regime permanente. Este regime caracteriza-se através da indicação das medidas de temperatura com variações inferiores as incertezas experimentais dos termopares. O período constatado para atingir o regime permanente é superior a $4,0 \mathrm{~min}$. 


\subsection{PROCEDIMENTO DE TRATAMENTO DE DADOS}

Parâmetros característicos da ebulição convectiva e do escoamento bifásico como o coeficiente de transferência de calor e a perda de pressão são estimados a partir de variáveis primárias medidas na bancada experimental. Para isto é necessário o emprego de procedimentos de tratamento de dados. A descrição dos procedimentos adotados no presente estudo é o objetivo deste item.

\section{Potência de aquecimento efetiva}

Este parâmetro refere-se a potência de aquecimento efetiva transferida para o fluido na região do dissipador de calor compreendendo os microcanais. Ela é dada pela seguinte equação:

$$
\dot{Q}_{\text {efetivo }}=\dot{Q}_{\text {elétrico }}-\dot{Q}_{\text {ambiente }}-\dot{Q}_{\text {câmaras }}
$$

onde $\dot{Q}_{\text {elétrico }}$ é a potência fornecida pela fonte de corrente contínua, $\dot{Q}_{\text {ambiente }}$ é a taxa de calor transferida para o ambiente e $\dot{Q}_{\text {câmaras }}$ é a taxa de calor transferido nas câmaras.

A potência fornecida pela fonte de energia DC para a resistência elétrica, $\dot{Q}_{\text {elétrico}}$, foi estimada a partir do produto estimado entre a corrente elétrica e a tensão. Estes valores são fornecidos pela fonte de energia para o sistema de aquisição de dados. A fonte de energia DC possui um sistema de sensoriamento remoto de compensação para a queda de tensão de cabos de energia e conexões com o fio da resistência de Kanthal.

Estimou-se a perda de calor para o ambiente com o interior da seção de testes em vácuo, adotando-se o seguinte procedimento: (i) aplicou-se uma determinada potência de aquecimento a seção de testes; (ii) aguardou-se até estabilização da temperatura superficial do dissipador de calor; (iii) uma vez atingido o regime permanente, assumiu-se para a diferença de temperatura entre a superfície do dissipador e o ambiente que a potência de aquecimento aplicada transferese para o ambiente através de convecção natural a partir da superfície externa do isolamento; (iv) elevou-se a potência aplicada e obteve-se uma nova temperatura superficial de equilíbrio; (v) repetiu-se este procedimento até uma temperatura superficial de $60{ }^{\circ} \mathrm{C}$ de forma a cobrir as condições experimentais correspondentes ao presente estudo.

Uma vez levantada a curva $\dot{Q}_{\text {ambiente }} \propto\left(\bar{T}_{\text {superfície }}-T_{\text {ambiente }}\right)$, onde $\bar{T}_{\text {superfície é a média }}$ aritmética das temperaturas fornecidas pelos termopares fixados no dissipador de calor e $T_{\text {ambiente }}$ é a temperatura ambiente fornecida por um termopar localizado na bancada a $30 \mathrm{~cm}$ da seção de testes, obtém-se através de regressão linear uma relação entre a perda de calor para o ambiente e $\left(\bar{T}_{\text {superfície }}-T_{\text {ambiente }}\right)$ dada em termos dos números adimensionais de Nusselt e Rayleigh. Esta relação apresenta um coeficiente de correlação $R^{2}=0,93$ e é dada pela seguinte equação: 


$$
N u=187,86 \cdot R a^{-0,37}
$$

onde o Número de Rayleigh é definido como:

$$
R a=\frac{g \cdot \beta_{a r}\left(\bar{T}_{\text {superfície }}-T_{\text {ambiente }}\right) L^{3}}{\nu_{a r} \cdot \alpha_{a r}}
$$

onde $\beta_{a r}$ é coeficiente de expansão volumétrica, $L$ é a dimensão característica adotada como a razão entre o volume e a área superficial da seção de testes, incluindo o isolamento, $\nu_{a r}$ é a viscosidade cinemática e $\alpha_{a r}$ é a difusividade térmica, avaliadas a temperatura do ar externo.

A Figura 3.24 ilustra uma comparação entre os resultados experimentais e a Eq. 3.3.

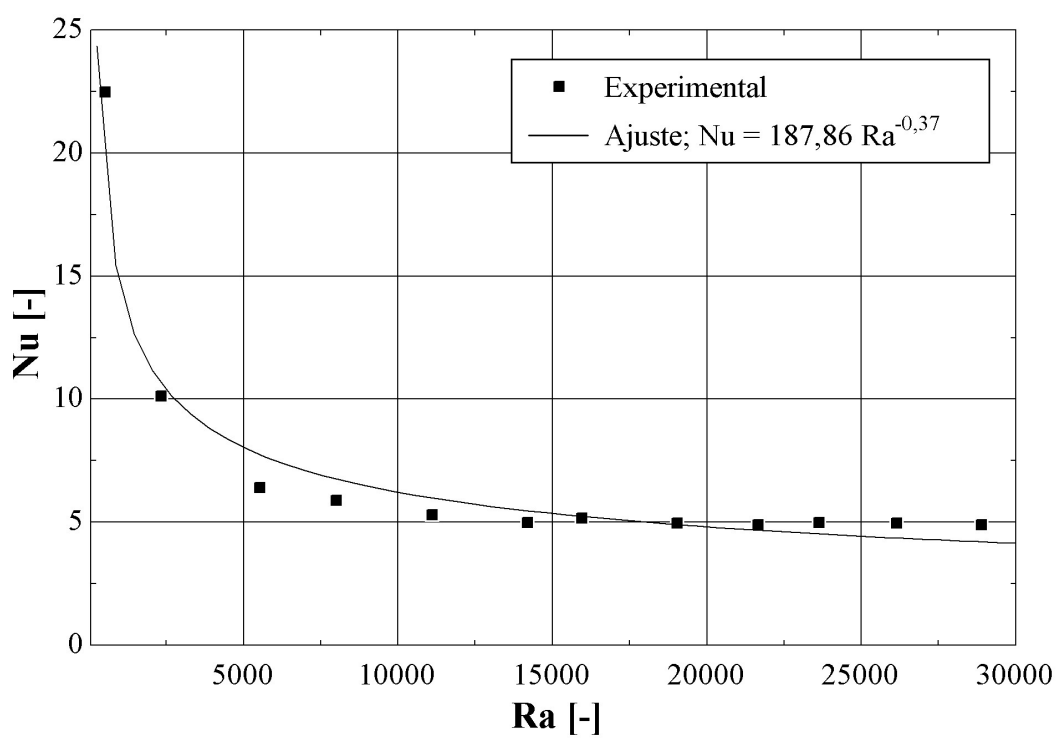

Figura 3.24 - Comparação entre os dados experimentais e a curva ajustada no presente estudo para previsão da perda de calor por convecção natural.

O calor transferido através das câmaras é dado pela soma do calor transferido nas câmaras de entrada e saída. O calor transferido em cada câmara foi calculado segundo o procedimento adotado em estudos prévios realizados por Do Nascimento (2012) e Leão (2014). Estes autores assumiram as câmaras atuando como aletas dissipando calor apenas nas regiões em contato com o fluido, tendo em sua base a temperatura média dos valores indicados pelos termopares fixados no dissipador. A Figura 3.25 ilustra um diagrama ilustrativo das câmaras e de suas idealizações como aletas conforme proposto por Do Nascimento (2012).

Para condições de contorno ilustradas na Fig. 3.25, o calor transferido através da aleta é dado pela seguinte relação indicada por Bergman et al. (2011):

$$
\dot{Q}_{i}=\sqrt{h_{i} P_{\text {câmara }} k_{c u} A_{t ; \text { câmara }}}\left(\bar{T}_{\text {parede }}-T_{\text {fluido } ; i}\right) \tanh \left(\sqrt{\frac{h_{i} P_{\text {câmara }}}{k_{c u} A_{t ; \text { câmara }}}} L_{\text {câmara;aleta }}\right)
$$


onde o subíndice "i" corresponde a câmara avaliada (entrada ou saída), $P_{\text {câmara, a dimensão }}$ característica do contorno transversal da aleta e $L_{\text {câmara;aleta }}$ corresponde ao comprimento da câmara como aleta, conforme ilustrado na Fig. 3.25.

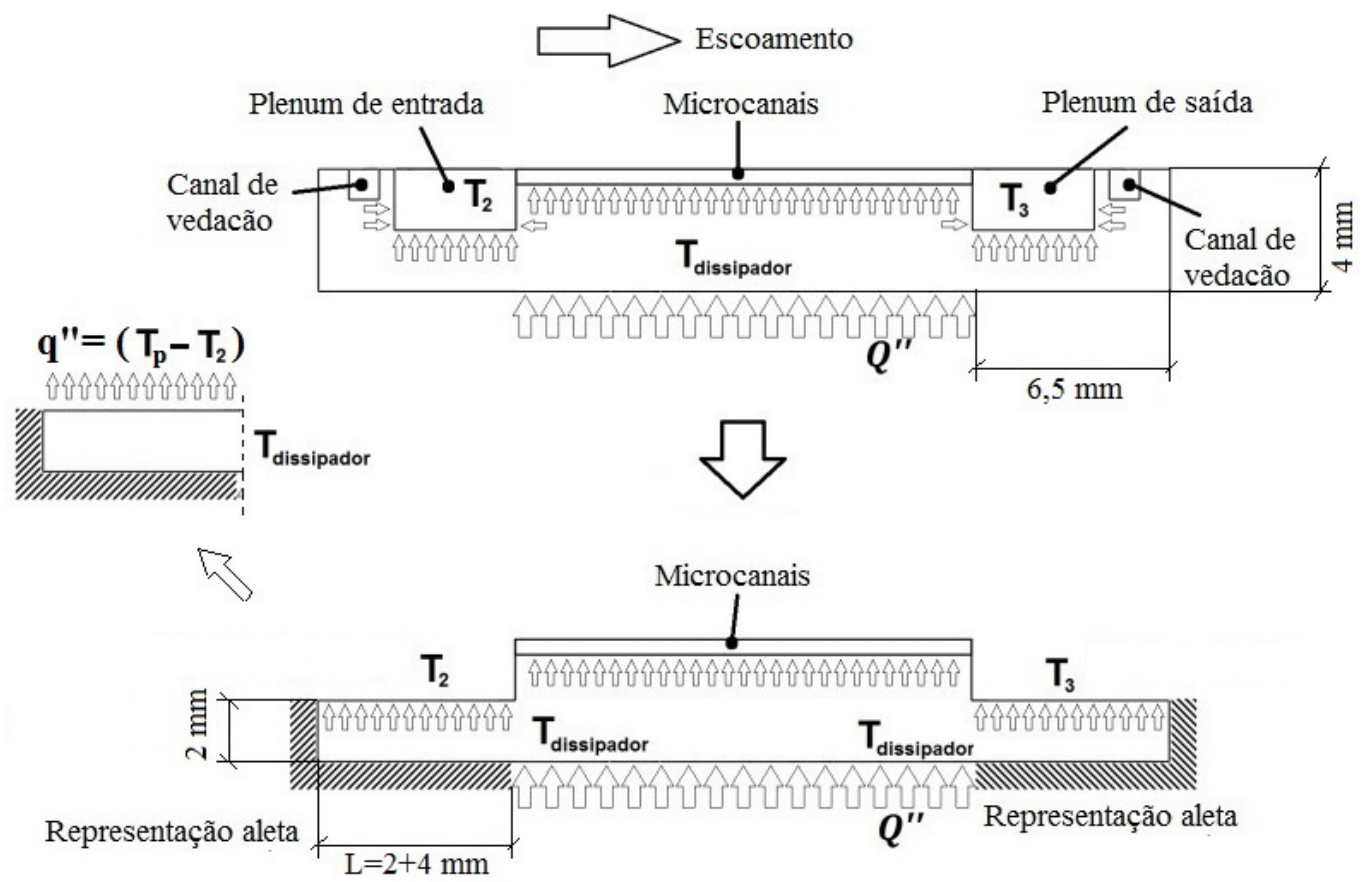

Figura 3.25 - Vista em corte do dissipador de calor ilustrando as condições de contorno adotadas para a avaliação das perdas de calor nas regiões das câmaras, Do Nascimento(2012).

Nesta análise, desprezou-se a troca de calor através da superfície superior em contato com o vidro. Os coeficientes de transferência de calor são estimados através das correlações de Stephan e Preuber (1979) para escoamento monofásico em desenvolvimento térmico e Li e Wu (2010) para ebulição convectiva. Adotou-se tais correlações com base em resultados apresentados por Leão et al. (2015). Estes autores indicaram tais métodos como aqueles que apresentam as melhores previsões de seus resultados.

\section{Temperatura média da parede}

Adotou-se como temperatura superficial a média aritmética das temperaturas fornecidas pelos termopares fixados na face inferior do dissipador corrigida segundo Fourier, considerando condução unidimensional conforme a seguinte equação:

$$
\bar{T}_{p}=\bar{T}_{b a s e}-\frac{q^{\prime \prime}{ }_{\text {base }} \Delta y}{k_{C u}}
$$

onde $\Delta y$ é a distância entre o termopares e a superfície inferior dos microcanais, $\bar{T}_{b a s e}$ é a média aritmética das temperaturas medidas pelos termopares localizados na superfície inferior do dissipador, $q$ " base é o fluxo de calor na base no dissipador (footprint) e $k_{C u}$ é a condutividade térmica do cobre. 
As Figuras 3.26 a 3.28 ilustram a variação da temperatura indicada pelos termopares fixados no dissipador, conforme denominação adotada na Fig. 3.29. No presente estudo, conforme indicação dada por Do Nascimento (2012), a temperatura indicada pelo $T_{31}$ foi desprezada devido à apresentar valores sistematicamente superiores aos demais, conforme ilustrado na Fig. 3.26 Tal comportamento se justifica pelo fato deste termopar ser fixado em cavidade na qual ocorreu quebra de broca e, devido à impossibilidade de remoção dela, o termopar foi fixado em contato com o aço da ferramenta. Assim, o campo de temperaturas na proximidade do termopar é afetado pela condutividade térmica do aço da ferramenta, a qual apresenta uma ordem de grandeza inferior ao do cobre.

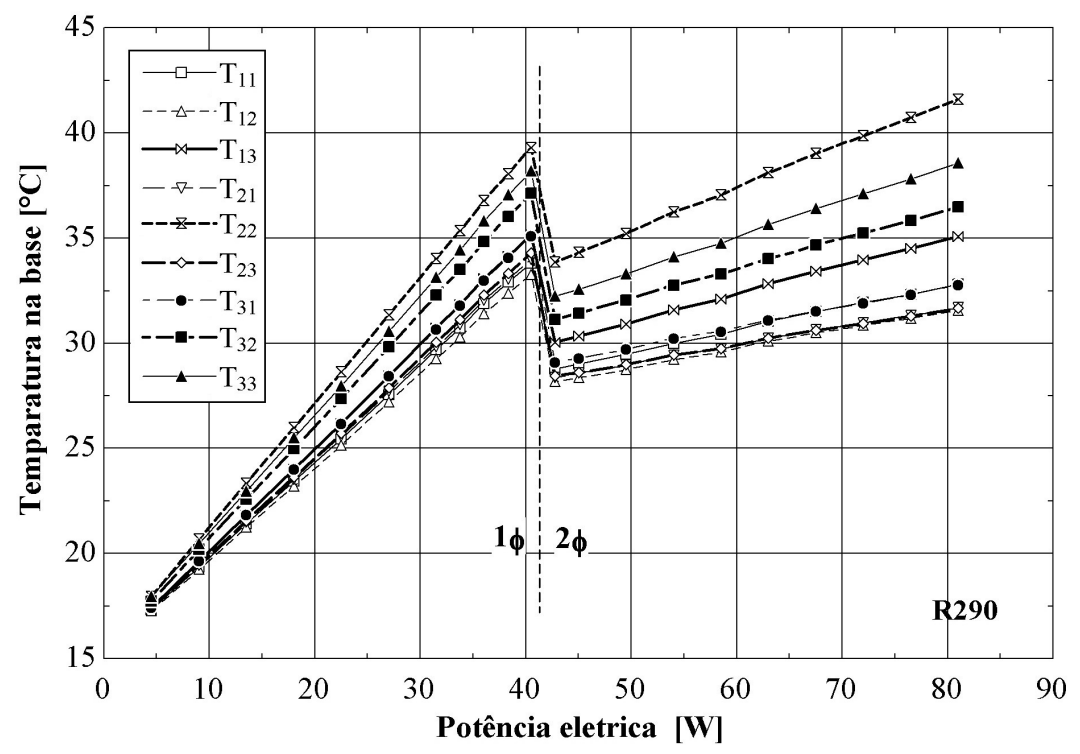

Figura 3.26 - Temperaturas indicadas pelos termopares localizados na base do dissipador para R290, $\mathrm{G}=330\left[\mathrm{~kg} / \mathrm{m}^{2} \mathrm{~s}\right]$ e $\Delta T_{\text {sub }}=10\left[{ }^{\circ} \mathrm{C}\right]$.

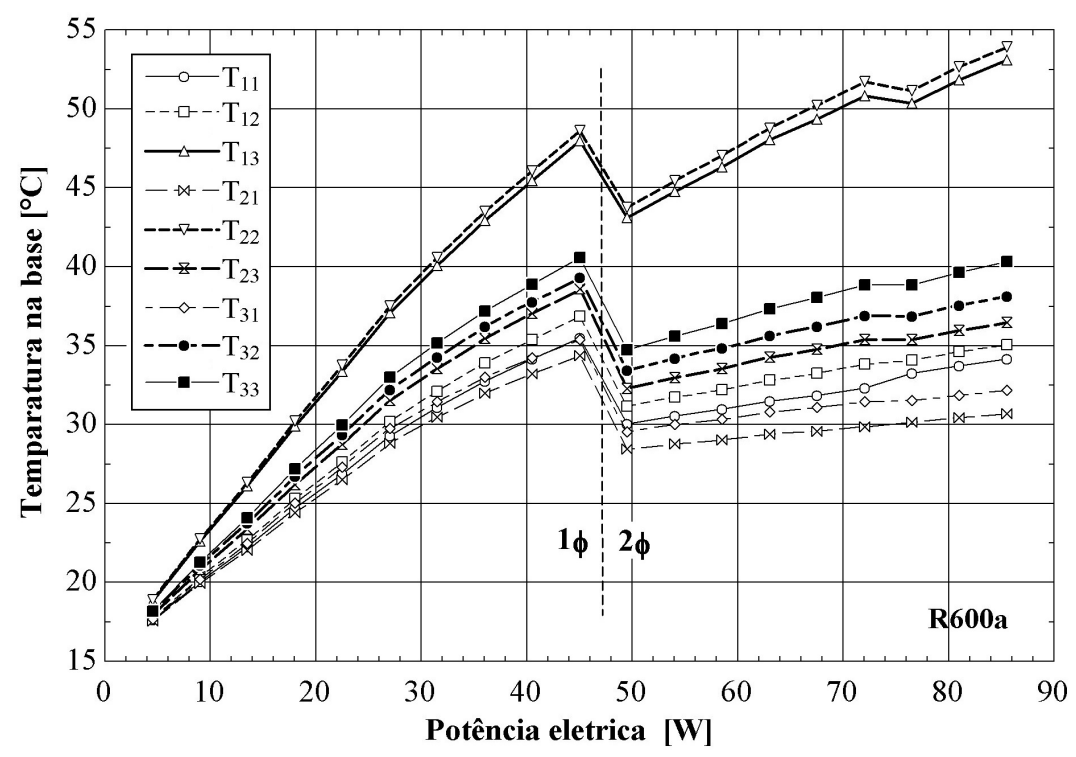

Figura 3.27 - Temperaturas indicadas pelos termopares localizados na base do dissipador para R600a, $\mathrm{G}=330\left[\mathrm{~kg} / \mathrm{m}^{2} \mathrm{~s}\right]$ e $\Delta T_{\text {sub }}=10\left[{ }^{\circ} \mathrm{C}\right]$. 


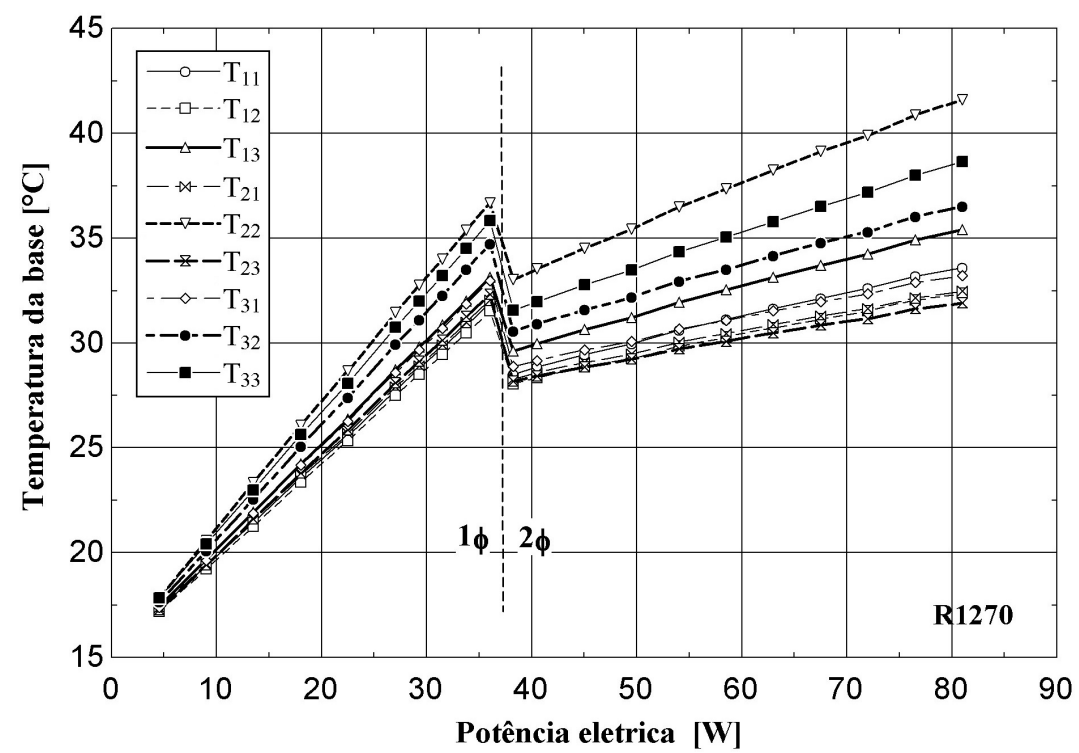

Figura 3.28 - Temperaturas indicadas pelos termopares localizados na base do dissipador para R1270, $\mathrm{G}=330\left[\mathrm{~kg} / \mathrm{m}^{2} \mathrm{~s}\right]$ e $\Delta T_{\text {sub }}=10\left[{ }^{\circ} \mathrm{C}\right]$.

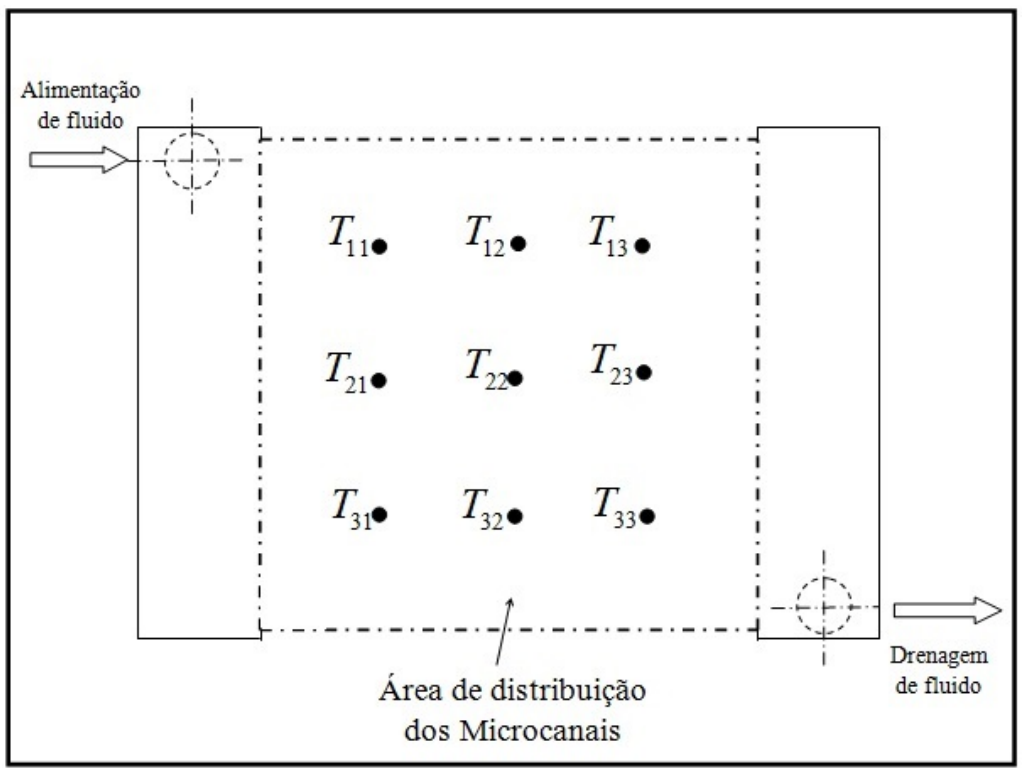

Figura 3.29 - Distribuição de juntas quentes dos termopares.

As temperaturas indicadas pelos termopares $T_{13}, T_{22}, T_{32}$ e $T_{33}$, conforme ilustrado na Fig. 3.26 também são substancialmente superiores aos demais. Diferenças devido à efeitos de má-distribuição do fluido refrigerante e ebulição local não justificam tal comportamento. Conforme ilustrado por Do Nascimento (2012), a combinação de elevados fluxos de calor com distinções na resistência térmica de contato entre o dissipador e a junta quente do termopar, inerentes ao processo de fixação destes transdutores, ainda que reduzidas, parecem justificar tal comportamento. Assim, a combinação de fluxos de calor elevados e resistências térmicas distintas favorecem diferenças de temperaturas elevadas entre os termopares da superfície. A Figura 3.30 ilustra o efeito da resistência térmica de contato sobre a temperatura medida por um termopar avaliada segundo a Eq. 3.7p. De acordo com esta figura, constata-se o efeito 
significativo da variação da resistência térmica de contato sobre a temperatura do termopar ainda para fluxos de calor reduzidos.

$$
T_{\text {Termopar }}=T_{\text {cobre }}+R_{t c} \cdot q^{\prime \prime}
$$

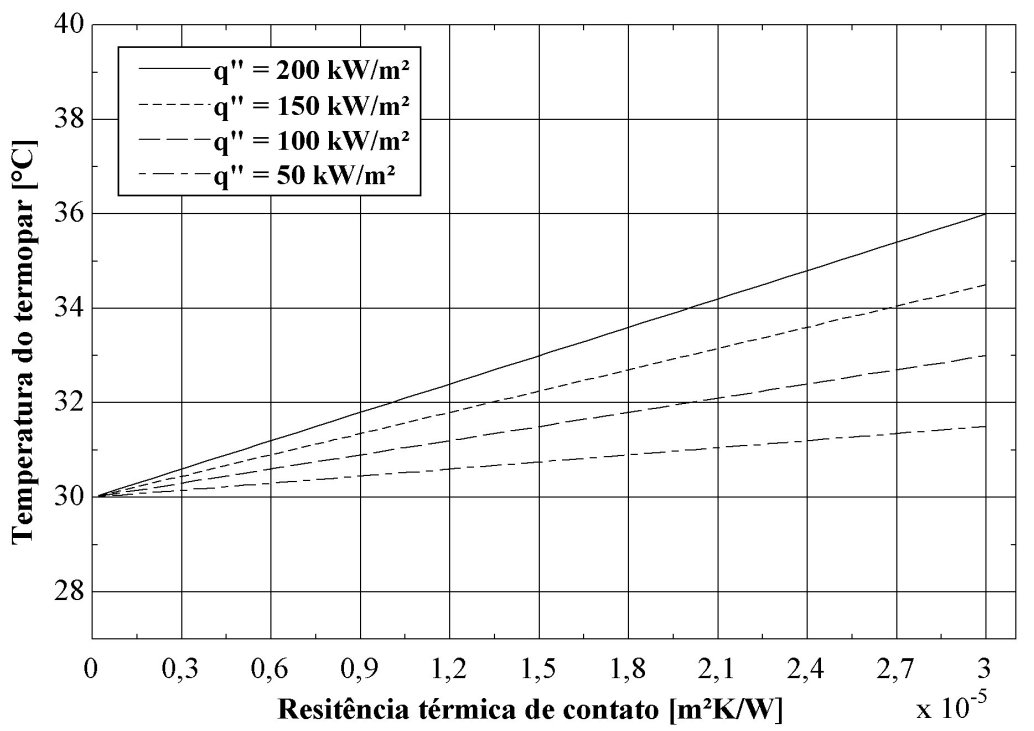

Figura 3.30 - Efeito da resistência térmica de contato sobre a temperatura medida por um termopar.

Desta forma, para o presente estudo optou-se por analisar o desempenho do dissipador de calor considerando a média aritmética das temperaturas dos termopares indicando valores inferiores conforme a seguinte equação:

$$
\bar{T}_{\text {base }}=\frac{T_{11}+2 T_{12}+T_{21}+2 T_{23}}{6}
$$

Devido somente a primeira coluna apresentar dois termopares com medições adequadas para o cálculo da temperatura média, os termopares $T_{12}$ e $T_{23}$ tiveram seu valor multiplicado por dois na Eq. 3.8 de forma a ponderar os pesos de cada coluna.

\section{Temperatura média do fluido}

No caso de apenas escoamento monofásico ao longo do dissipador, a temperatura média do fluido $\bar{T}_{f}$ é dada pela média aritmética entre as temperaturas de entrada e saída do fluido determinadas nas câmaras de entrada e saída conforme a seguinte equação:

$$
\bar{T}_{f}=\frac{T_{\text {entrada }}+T_{\text {saída }}}{2}
$$

Para escoamento bifásico, a temperatura do fluido é ponderada segundo os comprimentos das regiões monofásica e bifásica, segundo a seguinte relação. 


$$
\bar{T}_{f}=\frac{L_{1 \phi} T_{f 1 \phi}+\left(L_{\text {microcanais }}-L_{1 \phi}\right) T_{f 2 \phi}}{L_{\text {microcanais }}}
$$

onde o comprimento monofásico $L_{1 \phi}$ é calculado através da solução simultânea das equações de balanço de energia e a correlação de perda de pressão de Shah e London (1978), para escoamento laminar em desenvolvimento simultâneo, conforme descrito nas Eqs. 3.11 a 3.13. Para esta estimativa assume-se fluxo de calor uniforme ao longo dos microcanais e transferência de calor apenas através da superfície de cobre em contato com o fluido.

$$
\begin{gathered}
T_{\left(z=L_{1 \phi}\right)}=T_{\text {sat }}=T_{\left(p=p_{\text {sat }}\right)} \\
L_{1 \phi}=\frac{\dot{m}}{50 \cdot P_{\text {aquecido }} \cdot q^{\prime \prime}{ }_{\text {efetivo }}}\left[i_{l\left(T=T_{\text {sat }}\right)}-i_{l ; \text { entrada }}\right] \\
p_{\text {sat }}=p_{\left(z=L_{1 \phi}\right)}=p_{\text {entrada }}-L_{1 \phi}\left(\frac{d p}{d z}\right)_{\text {Shah e London(1978) }}
\end{gathered}
$$

$\mathrm{Na}$ Eq. 3.10, a temperatura do fluido na região monofásica $T_{f 1 \phi}$ corresponde a média entre a temperatura de entrada e a temperatura do fluido para o início da ebulição $T_{\left(z=L_{1 \phi}\right)}$ dada pelo estado de saturação. Assume-se a temperatura do fluido na região bifásica $T_{f 2 \phi}$ como a média entre a temperatura de início da ebulição e a temperatura ao final dos microcanais dadas na câmara de saída. Assim, estas temperaturas médias são avaliadas segundo as seguintes equações:

$$
\begin{aligned}
T_{f 1 \phi} & =\frac{T_{\text {entrada }}+T_{\left(z=L_{1 \phi}\right)}}{2} \\
T_{f 2 \phi} & =\frac{T_{\left(z=L_{1 \phi}\right)}+T_{\text {saída }}}{2}
\end{aligned}
$$

\section{Título de vapor médio}

O título de vapor médio ao longo do dissipador é dado pela média aritmética dos valores correspondentes as câmaras de entrada e saída, conforme a seguinte equação:

$$
\bar{x}=\frac{x_{\text {entrada }}+x_{\text {saída }}}{2}
$$

onde $x_{\text {entrada }}$ e $x_{\text {saída }}$ são títulos de vapor de equilíbrio termodinâmico, conforme definido no item 2.1.1, dados pelas seguintes equações: 


$$
\begin{aligned}
x_{\text {entrada }} & =\frac{i_{\text {entrada }}-i_{l ; \text { entrada }}}{i_{l g ; \text { entrada }}} \\
x_{\text {saída }} & =\frac{i_{\text {saída }}-i_{l ; \text { saída }}}{i_{l g ; \text { saída }}}
\end{aligned}
$$

onde a entalpia $i_{\text {entrada }}$ é determinada em função da temperatura e pressão de entrada do fluido na seção de testes. A entalpia na câmara de saída é estimada através de um balanço de energia $\left(i_{\text {sá́da }}=i_{\text {entrada }}+\dot{Q}_{\text {efetivo }} / \dot{m}\right)$. Assim, substituindo esta relação na Eq. 3.18 considerando o calor efetivo adicionado ao fluido através do fluxo de calor imposto e a entalpia de entrada, tem-se o título de vapor de equilíbrio termodinâmico na saída do dissipador dado pela seguinte equação:

$$
x_{\text {saída }}=\frac{1}{i_{l g ; \text { saída }}}\left[\left(i_{\text {entrada }}-i_{l \text {;saída }}\right)+\frac{\dot{Q}_{\text {efetivo }}}{\dot{m}}\right]
$$

\section{Velocidade mássica}

A velocidade mássica é dada pela razão entre a vazão mássica fornecida pelo medidor de vazão tipo Coriolis e a área de seção transversal total dos microcanais, a qual corresponde a cinquenta vezes a área transversal de um único microcanal. Logo, a velocidade mássica é dada pela seguinte equação:

$$
G=\frac{\dot{m}}{50 A_{\text {microcanal }}}
$$

onde $A_{\text {microcanal }}$ corresponde ao produto entre a largura e a profundidade do microcanal.

Desta forma, adotou-se a hipótese de distribuição uniforme de fluido refrigerante entre os 50 microcanais.

\section{Perda de pressão}

A perda de pressão devido à efeitos de atrito na região bifásica é dada pela perda de pressão total fornecida pelo transdutor diferencial medida subtraídas as perdas de pressão da região monofásica, a perda de pressão devido à aceleração do escoamento e as perdas locais devido à contração e recuperação de pressão na expansão nas câmaras de entrada e saída, respectivamente, conforme a seguinte equação: 


$$
\Delta p_{2 \phi}=\Delta p_{\text {medido }}-\Delta p_{1 \phi}-\Delta p_{\text {aceleracional }}-\Delta p_{\text {contração }}-\Delta p_{\text {expansão }}
$$

onde a perda de pressão monofásica $\Delta p_{1 \phi}$ é calculada através do método de Shah e London (1978) para escoamento em desenvolvimento simultâneo no interior de canais retangulares. A perda de pressão devido à aceleração do escoamento, inerente ao processo de evaporação, é estimada através da Eq. 2.10 com a fração de vazio superficial calculada através do método recentemente proposto por Kanizawa e Ribatski (2016).

As perdas de pressão locais devido à contração na entrada dos canais e a recuperação de pressão devido à expansão na saída dos canais foram calculadas através do método proposto por Chalfi e Ghiaasiaan (2008) desenvolvida para condições de micro-escala tanto para escoamento monofásico como bifásico. De acordo com estes autores, a perda de pressão na contração e a recuperação de pressão nas câmaras de entrada e saída são dadas respectivamente por:

$$
\begin{aligned}
& \Delta p_{\text {contração }}=\left(K_{\text {contração }}+1-\varsigma^{2}\right) \frac{G^{2}}{2 \rho_{\text {entrada }}} ; \text { monofásico } \\
& \Delta p_{\text {expansão }}=\left(K_{\text {expansão }}+\varsigma^{2}-1\right) \frac{G^{2}}{2 \rho_{\text {saída }}} ; \quad \text { monofásico } \\
& \Delta p_{\text {expansão }}=\varsigma(\varsigma-1) \frac{G^{2}}{\rho_{2 \phi}} ; \quad \text { bifásico }
\end{aligned}
$$

Vale destacar a ausência neste estudo de resultados para condições bifásicas na câmara de entrada justificando a ausência acima de uma correlação para tal situação.

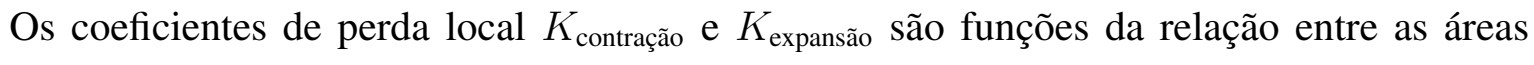
transversais de um único microcanal e da câmara, $\varsigma$, segundo as seguintes equações:

$$
\begin{gathered}
K_{\text {contração }}=\left[\frac{\varsigma-1}{1,08(\varsigma-1)+0,5371}\right]^{2} \\
K_{\text {contração }}=(1-\varsigma)^{2}
\end{gathered}
$$

A densidade $\rho_{2 \phi}$ na Eq. 3.24 é estimada como proposto por Chalfi e Ghiaasiaan (2008) segundo a seguinte equação:

$$
\rho_{2 \phi}=\left[\frac{1-x_{\text {saída }}^{2}}{\rho_{l ; \text { saída }}\left(1-\alpha_{\text {saída }}\right)}+\frac{x_{\text {saída }}^{2}}{\rho_{g ; \text { saída }} \alpha_{\text {saída }}}\right]^{-1}
$$

onde a fração de vazio superficial, no presente estudo, é avaliada segundo Kanizawa e Ribatski (2016). 


\section{Coeficiente de transferência de calor médio}

Neste estudo estimou-se o coeficiente de transferência de calor médio através da Lei de Resfriamento de Newton definido com base nas áreas, efetiva de transferência de calor e da base (footprint), segundo as seguintes equações:

$$
\begin{gathered}
\bar{h}=\frac{q^{\prime} \text { efetivo }}{\Delta T} \\
\bar{h}_{\text {base }}=\frac{q^{\prime \prime} \text { base }}{\Delta T}
\end{gathered}
$$

onde $\Delta T$ é a diferença entre as temperaturas médias da parede e do fluido dada por:

$$
\Delta T=\bar{T}_{p}-\bar{T}_{f}
$$

Com o objetivo de comparar os resultados experimentais para o coeficiente de transferência de calor durante a ebulição convectiva com os métodos de previsão disponíveis na literatura, definiu-se o coeficiente de transferência de calor correspondente a região bifásica, dado pela seguinte equação:

$$
\bar{h}_{2 \phi}=\frac{q^{\prime \prime} \text { efetivo }}{\Delta T_{2 \phi}}
$$

onde $\Delta T_{2 \phi}$ é a diferença entre as temperaturas médias da parede e do fluido na região bifásica dada por:

$$
\Delta T_{2 \phi}=\bar{T}_{p}-T_{f 2 \phi}
$$

onde $T_{f 2 \phi}$ encontra-se definido na Eq. 3.15.

O coeficiente de transferência de calor médio, segundo os métodos de previsão, calcula-se apenas para o comprimento bifásico dividido em 10 elementos discretos. Para cada elemento discreto estima-se um coeficiente de transferência de calor local baseado na variação das propriedades locais. Estas propriedades são calculadas iterativamente em função da variação da pressão de saturação do fluido e do título de vapor. O título de vapor local em cada elemento é calculado através do balanço de energia, segundo a hipótese de fluxo de calor uniforme ao longo do comprimento bifásico. Assim, o coeficiente de transferência de calor médio teórico é dado pela seguinte equação:

$$
\bar{h}_{\text {pred }}=\frac{1}{10} \sum h_{i}
$$

Para estimar o número de elementos discretos, uma análise de sensibilidade foi efetuada. Nesta análise, para 7 e 8 elementos, verificou-se que os valores de coeficientes de transferência de calor não apresentam diferenças significativas. Já para 15 elementos discretos, o tempo de processamento numérico foi 30 a 40 minutos superior ao tempo verificado para 10 elementos. Desta forma, conclui-se que 10 elementos é suficiente para procesamento de dados. 


\section{Eficiência da Segunda Lei da Termodinâmica e geração de entropia}

A eficiência de $2 \circ$ Lei da Termodinâmica foi adotada segundo a definição dada por Bejan (1996) e Çengel (2009), a qual é dada pela seguinte relação:

$$
\eta_{\mathrm{II}}=1-\frac{\left(\dot{E}_{W}\right)_{d e s}}{\left(\dot{E}_{W}\right)_{r e v}}
$$

onde $\left(\dot{E}_{W}\right)_{\text {des }}$ é a exergia destruída e $\left(\dot{E}_{W}\right)_{\text {rev }}$ é a exergia fornecida durante o processo, dada pela soma das exergias associadas ao escoamento $\left(\dot{E}_{\psi}\right)$ e ao calor efetivo $\left(\dot{E}_{\dot{Q}}\right)$, conforme as seguintes equações:

$$
\begin{gathered}
\dot{E}_{\psi}=\dot{m} \cdot \Delta \psi \\
\dot{E}_{\dot{Q}}=\left(1-\frac{T_{L}}{T_{H}}\right) \dot{Q}_{\text {efetivo }}
\end{gathered}
$$

onde $T_{L}$ e $T_{H}$ são, respectivamente, as temperaturas absolutas do fluido na entrada e saída da seção de testes. $\Delta \psi$ é a variação de exergia ao longo do dissipador de calor, a qual se estima de acordo a seguinte equação:

$$
\Delta \psi=\left(i_{\text {saída }}-i_{\text {entrada }}\right)+T_{0}\left(s_{\text {saída }}-s_{\text {entrada }}\right)+\frac{G^{2}}{2}\left(\frac{1}{\rho_{\text {saída }}^{2}}-\frac{1}{\rho_{\text {entrada }}^{2}}\right)
$$

onde $T_{0}$ é a temperatura absoluta mínima de referência do processo, neste caso da entrada da seção de testes.

Como definido por Bejan (1996) e Çengel (2009), a exergia destruída é dada pela seguinte equação:

$$
\left(\dot{E}_{W}\right)_{d e s}=T_{0} \dot{S}_{g e r}
$$

onde $\dot{S}_{g e r}$ é a irreversibilidade total gerada ao longo do dissipador de calor, dada pela soma entre as irreversibilidades geradas nas câmaras $\dot{S}_{g e r ; c}$ e a entropia gerada ao longo microcanais $\dot{S}_{g e r ; m}$ de acordo a seguinte equação:

$$
\dot{S}_{g e r}=\dot{S}_{g e r ; c}+\dot{S}_{g e r ; m}
$$

O volume dos microcanais corresponde a $18 \%$ do volume das câmaras. Desta forma, assumiu-se que a velocidade do escoamento na região das câmaras é suficientemente reduzida comparada com a velocidade no interior dos microcanais. Neste caso, as câmaras são consideradas como reservatórios, nos quais, acorre transferência de calor a temperatura do fluido constante. De acordo com Çengel (2009), a geração de entropia em um reservatório devido transferência de calor isotérmica é dada pela razão entre a taxa de calor transferido e a temperatura absoluta do reservatório. Assim, as irreversibilidades geradas nas câmaras são dadas pela seguinte equação: 


$$
\dot{S}_{g e r ; c}=\frac{\dot{Q}_{c e}}{T_{c e}}+\frac{\dot{Q}_{c s}}{T_{c s}}
$$

onde $\dot{Q}_{c e}$ e $\dot{Q}_{c s}$ são as taxas de calor transferidas nas câmaras de entrada e saída do dissipador de calor, respectivamente. $T_{c e}$ e $T_{c s}$ são as temperaturas absolutas do fluido na entrada e saída do dissipador, as quais são medidas pelos termopares localizados nestas câmaras.

Devido ao processo de mudança de fase ocorrer ao longo dos microcanais, apresentando uma parcela monofásica e uma outra com presença de ebulição convectiva, a entropia gerada ao longo dos microcanais foi definida como a soma das irreversibilidades de cada parcela e da taxa de geração de vapor, segundo a equação seguinte:

$$
\dot{S}_{g e r ; m}=\dot{S}_{g e r ; 1 \phi}+\dot{S}_{g e r ; 2 \phi}+\dot{S}_{g e r ; i_{l g}}
$$

onde $\dot{S}_{g e r ; 1 \phi}$ é a irreversibilidade gerada ao longo comprimento monofásico, $\dot{S}_{g e r ; 2 \phi}$ é irreversibilidade gerada ao longo do comprimento sob condições de ebulição convectiva e $\dot{S}_{g e r ; i_{l g}}$ é irreversibilidade gerada pela mudança de fase.

De acordo com Bejan e Pfister (1980), a entropia gerada em uma tubulação ao longo de um trocador de calor pode ser calculada como a combinação dos efeitos de irreversibilidade devido à diferença de temperatura no processo de transferência de calor $\left(\dot{S}_{g e r ; \Delta T}\right)$ e a irreversibilidade devido à perda de pressão $\left(\dot{S}_{g e r ; \Delta p}\right)$. Desta forma, incluindo esta definição na Eq. 3.41), a geração de entropia ao longo dos microcanais é dada pelas seguintes equações:

$$
\begin{gathered}
\dot{S}_{g e r ; m}=\left(\dot{S}_{g e r ; \Delta T}+\dot{S}_{g e r ; \Delta p}\right)_{1 \phi}+\left(\dot{S}_{g e r ; \Delta T}+\dot{S}_{g e r ; \Delta p}\right)_{2 \phi}+\dot{S}_{g e r ; i_{l g}} \\
\dot{S}_{g e r ; m}=\left(\frac{q^{\prime \prime}{ }_{\text {efetivo }} A \Delta \bar{T}}{T^{2}}+\frac{\dot{m} \Delta p}{\rho T}\right)_{1 \phi}+\left(\frac{q^{\prime \prime}{ }_{\text {efetivo }} A \Delta \bar{T}}{T^{2}}+\frac{\dot{m} \Delta p}{\rho T}\right)_{2 \phi}+\dot{S}_{g e r ; i_{l g}}
\end{gathered}
$$

onde $q "$ efetivo é o fluxo de calor efetivo nos microcanais, $A$ é a área superficial em contato com o fluido, $T$ é a temperatura absoluta média do fluido, $\Delta p$ é a perda de pressão ao longo dos microcanais incluindo as perdas localizadas na contração e expansão dos canais e $\rho$ é a densidade média.

Além da evaporação nos microcanais do presente estudo poder ser considerada um processo aproximadamente isotérmico, ocorre uma taxa de geração de entropia devido à quantidade de massa líquida mudando de fase. Desta forma, como definido por Çengel (2009), a entropia gerada devido à mudança de fase é calculada através da seguinte equação:

$$
\dot{S}_{g e r ; i_{l g}}=\frac{\dot{m}_{v a p o r} i_{l g}}{T}
$$

onde $i_{l g}$ é a entalpia de vaporização do fluido e a vazão mássica de vapor $\dot{m}_{\text {vapor }}$ corresponde a 
taxa de geração de vapor ao longo do comprimento sob condições de ebulição convectiva. Neste caso, $\dot{m}_{\text {vapor }}$ estima-se como a vazão mássica média de vapor $\left(\dot{\bar{m}}_{v}\right)$ ao longo do comprimento bifásico de acordo com o teorema do valor médio dado na seguinte equação:

$$
\dot{\bar{m}}_{v}=\frac{1}{L_{2 \phi}} \int_{0}^{L_{2 \phi}} \dot{m}_{\text {vapor }}(z) d z
$$

onde $\dot{m}_{\text {vapor }}(z)$ depende da variação do título de vapor ao longo do comprimento bifásico, obtido a partir de um balanço de energia segundo a hipótese de fluxo de calor uniforme ao longo do comprimento bifásico. Assim, integrando a Eq. 3.45, a vazão mássica média de vapor é dada pela seguinte relação:

$$
\dot{\bar{m}}_{v}=\frac{x_{\text {saída }} \dot{m}}{2}
$$

Vale destacar que a vazão mássica média de vapor da Eq. 3.46 não depende do comprimento do canal. Desta forma, estima-se a taxa de geração de vapor média desde o início da ebulição (título de vapor, $x=0$ ) até a saída dos microcanais (título de vapor, $x=x_{\text {saída }}$ ), incluindo assim, a taxa de geração de vapor na câmara de saída sob condições de ebulição.

Finalmente, a entropia total gerada ao longo dos microcanais é dada pela seguinte equação:

$$
\dot{S}_{g e r ; m}=\left\{\frac{q^{\prime \prime} A \Delta \bar{T}}{T^{2}}+\frac{\dot{m} \Delta p}{\rho T}\right\}_{1 \phi}+\left\{\frac{q^{\prime \prime}{ }_{\text {efetivo }} A \Delta \bar{T}}{T^{2}}+\frac{\dot{m} \Delta p}{\rho T}\right\}_{2 \phi}+\frac{x_{\text {saída }} \dot{m} \cdot i_{l g}}{2 T}
$$

\section{Parâmetro de instabilidade}

Visando fundamentar a análise dos efeitos de instabilidades térmicas sobre a amplitude das oscilações verificadas na medida dos instrumentos, calcula-se as forças associadas ao crescimento de bolhas em condições de confinamento. Estas forças são estimadas com base no parâmetro de instabilidade proposto por Kandlikar (2004) e posteriormente modificado por Lee et al. (2010), o qual caracteriza condições em que tais efeitos de instabilidades térmicas tornam-se desprezíveis.

O parâmetro de instabilidade considera o equilíbrio de forças inerciais relacionadas ao escoamento do líquido segundo seu sentido principal $\left(F_{\text {inercial }}\right)$ e do crescimento da bolha $\left(F_{\text {ebulição }}\right)$ como resultado do processo de ebulição. Segundo indicado pelos autores, este método pode ser empregado para análise de processos de evaporação com números de Bond reduzidos, como é o caso do presente estudo que envolve números de Bond inferiores a 0,05. Desta forma, as forças são dadas pelas seguintes equações:

$$
F_{\text {ebulição }}=\frac{1}{\rho_{g ; L_{1 \phi}} A_{\text {microcanal }}}\left(\frac{\dot{Q}_{\text {microcanal }}}{i_{l g ; L_{1 \phi}}}\right)^{2}
$$




$$
F_{\text {inercial }}=\frac{G^{2}}{\rho_{l ; L_{1 \phi}}} A_{\text {microcanal }}
$$

Onde,

$$
\dot{Q}_{\text {microcanal }}=q^{\prime \prime}{ }_{\text {efetivo }}(2 H+W)\left(L_{\text {microcanal }}-L_{1 \phi}\right)
$$

Desta forma, conforme proposto por Lee et al. (2010) na implementação deste critério, assume-se fluxos de calor uniforme ao longo da superfície do cobre, comprimento da bolha igual ao comprimento bifásico, crescimento da bolha se da no sentido reverso e na direção do escoamento e despreza-se os efeitos relacionados a restrição na entrada e a expansão devido aos canais retos. Além disso, condições de escoamento com efeitos de instabilidade térmicas desprezíveis ocorrem para $0 \leq R_{\text {ins }}<1,0$, onde:

$$
R_{\text {ins }}=\sqrt{\frac{F_{\text {ebulição }}}{F_{\text {inercial }}}}
$$

\subsection{DETERMINAÇÃO DE INCERTEZAS}

A Tabela 3.5 apresenta as incertezas de parâmetros medidos durante os ensaios experimentais. Analogamente aos estudos de Do Nascimento (2012) e Leão (2014), os termopares foram calibrados e suas incertezas estimadas segundo o procedimento proposto por Abernethy e Thompson (1973). As incertezas dos sensores e demais dispositivos de medida foram avaliadas segundo especificações técnicas fornecidas pelos fabricantes.

Tabela 3.5 - Incertezas dos parâmetros medidos.

\begin{tabular}{lccc}
\hline & \multicolumn{3}{c}{ Incerteza } \\
\cline { 2 - 4 } Parâmetro & R600a & R290 & R1270 \\
\hline Profundidade do microcanal, $[\mu \mathrm{m}]$ & 22,9 & 22,9 & 22,9 \\
\hline Largura do microcanal, $[\mu \mathrm{m}]$ & 15,4 & 15,4 & 15,4 \\
\hline Comprimento do microcanal, $[\mu \mathrm{m}]$ & 5,0 & 5,0 & 5,0 \\
\hline Temperatura, $\left[{ }^{\circ} \mathrm{C}\right]$ & 0,15 & 0,15 & 0,15 \\
\hline Potência elétrica, $[\mathrm{W}]$ & 0,05 & 0,05 & 0,05 \\
\hline Pressão, $[\mathrm{kPa}]$ & 2,0 & 8,0 & 8,0 \\
\hline Diferença de Pressão, $[\mathrm{kPa}]$ & 0,22 & 0,22 & 0,22 \\
\hline Vazão mássica, $[\mathrm{g} / \mathrm{s}]$ & 0,024 & 0,024 & 0,024 \\
\hline
\end{tabular}

A análise de propagação de incertezas nos parâmetros calculados foi efetuada segundo Taylor e Kuyatt (1994). Neste método, assume-se que as medições individuais são aleatórias e não estão correlacionadas e a incerteza na quantidade calculada é estimada através da seguinte equação:

$$
U_{Y}=\sqrt{\sum_{i=1}^{n}\left(\frac{\partial Y}{\partial X_{i}}\right)^{2} U_{X_{i}}}
$$


onde $U_{Y}$ corresponde a incerteza da variável $Y$ e $U_{X_{i}}$ a incerteza da variável medida $X_{i}$. A análise e cálculo de propagação de incertezas foi realizada com auxílio do programa Engineering Equation Solver (EES) e os resultados obtidos são apresentados na Tabela 3.6.

Tabela 3.6 - Incertezas dos parâmetros calculados.

\begin{tabular}{lccc}
\hline \multirow{2}{*}{ Parâmetro } & \multicolumn{3}{c}{ Incerteza } \\
\cline { 2 - 4 } & R600a & R290 & R1270 \\
\hline Temperatura da parede, $\left[{ }^{\circ} \mathrm{C}\right]$ & 0,40 & 0,40 & 0,40 \\
\hline Temperatura do fluido, $\left[{ }^{\circ} \mathrm{C}\right]$ & 0,20 & 0,20 & 0,20 \\
\hline Diferença de temperatura, $\left[{ }^{\circ} \mathrm{C}\right]$ & 0,40 & 0,40 & 0,40 \\
\hline Grau de sub-resfriamento, $\left[{ }^{\circ} \mathrm{C}\right]$ & 0,30 & 0,30 & 0,30 \\
\hline Velocidade mássica, $[\%]$ & 13,0 & 13,0 & 13,0 \\
\hline Fluxo de calor efetivo, $[\%]$ & 4,5 & 5,1 & 5,1 \\
\hline Coeficiente de transferência de calor, $[\%]$ & 4,0 a 11,0 & 5,0 a 13,0 & 5,0 a 14,0 \\
\hline
\end{tabular}

De acordo com a Tabela 3.6, vale destacar que diferenças entre as incertezas calculadas para o coeficiente de transferência de calor com relação aos fluidos, se devem ao efeito dos refrigerantes operar em a pressões diferentes de acordo com a seguinte ordem crescente R600, R290 e R1270. Desta forma, são necessários transdutores absolutos para pressões elevadas, os quais incluem incertezas superiores. 


\section{ANÁLISE DOS RESULTADOS EXPERIMENTAIS}

Este capítulo apresenta a análise e discussão dos resultados experimentais levantados neste estudo. Inicialmente, descrevem-se as condições ensaiadas e apresentam resultados para a transferência de calor e perda de pressão para escoamento monofásico, utilizados na validação do aparato e procedimento experimental. Em seguida, os resultados são apresentados segundo curvas de ebulição. Uma análise paramétrica dos efeitos dos parâmetros experimentais sob estas curvas é realizada. Segue a descrição de resultados para o coeficiente de transferência de calor, cuja análise inclui a comparação com métodos de previsão do CTC para o mecanismo de ebulição convectiva. Finalmente, são descritos os resultados para a perda de pressão, os quais também são comparados aos métodos de previsão disponíveis na literatura. O capítulo inclui ainda, com base nos resultados experimentais, uma análise comparativa do desempenho dos refrigerantes baseada na $2 \circ$ Lei da Termodinâmica para o dissipador avaliado neste estudo. $\mathrm{O}$ capítulo finaliza com a análise das oscilações induzidas pela ebulição convectiva.

\subsection{DESCRIÇÃO DO BANCO DE DADOS EXPERIMENTAIS}

Neste estudo, resultados foram levantados para condições de escoamento monofásico ao longo do dissipador e também com parcela do comprimento dos canais submetida a ebulição convectiva. Dados em condições monofásica foram utilizados na validação da bancada e do procedimento experimental através de comparações com métodos de previsão de perda de pressão e do coeficiente de transferência de calor reconhecidos na literatura como precisos. As Tabelas. $4.1 \mathrm{e} 4.2$ apresentam as condições experimentais avaliadas neste estudo.

Tabela 4.1 - Condições experimentais ensaiadas para escoamento monofásico

\begin{tabular}{lccc}
\cline { 2 - 4 } Parâmetro & \multicolumn{3}{c}{ Condições de ensaio } \\
\cline { 2 - 4 } & R600a & R290 & R1270 \\
\hline Pressão absoluta na entrada do dissipador, $[\mathrm{kPa}]$ & 351 & 859 e 953 & 1046 e 1157 \\
\hline Reynolds, $[-]$ & 100 a 1500 & 100 a 1600 & 100 a 1800 \\
\hline Velocidade mássica, $\left[\mathrm{kg} / \mathrm{m}^{2} \mathrm{~s}\right]$ & 100 a 823 & 125 a 658 & 125 a 658 \\
\hline Sub-resfriamento líquido, $\left[{ }^{\circ} \mathrm{C}\right]$ & 5 & 5 & 5 \\
\hline Fluxo de calor, $\left[\mathrm{kW} / \mathrm{m}^{2}\right]$ & 0 a 80 & 0 a 80 & 0 a 80 \\
\hline
\end{tabular}


Tabela 4.2 - Condições experimentais ensaiadas com a presença do mecanismo de ebulição convectiva.

\begin{tabular}{lccc} 
& \multicolumn{3}{c}{ Condições de ensaio } \\
\cline { 2 - 4 } Parâmetro & R600a & R290 & R1270 \\
\hline Temperatura de saturação, $\left[{ }^{\circ} \mathrm{C}\right]$ & 25 & 21 e 25 & 21 e 25 \\
\hline Pressão absoluta na entrada do dissipador, $[\mathrm{kPa}]$ & 351 & 859 e 953 & 1046 e 1157 \\
\hline Velocidade mássica, $\left[\mathrm{kg} / \mathrm{m}^{2} \mathrm{~s}\right]$ & 165 a 823 & 165 a 658 & 165 a 658 \\
\hline Sub-resfriamento do líquido na entrada do dissipador, $\left[{ }^{\circ} \mathrm{C}\right]$ & 5 e 10 & 5,10 e 15 & 5 e 10 \\
\hline Potência de aquecimento, $[\mathrm{W}]$ & 0 a 90 & 0 a 90 & 0 a 90 \\
\hline Fluxo de calor na base, $\left[\mathrm{kW} / \mathrm{m}^{2}\right]$ & 0 a 400 & 0 a 400 & 0 a 400 \\
\hline Fluxo de calor efetivo, $\left[\mathrm{kW} / \mathrm{m}^{2}\right]$ & 0 a 89 & 0 a 93 & 0 a 88 \\
\hline Inventário de fluido no reservatório, $[\mathrm{kg}]$ & 1,90 & 1,75 & 1,60 \\
\hline Tempo necessário para desativar núcleos, $[\mathrm{h}]$ & 12 & 12 & 12 \\
\hline
\end{tabular}

\subsection{VALIDAÇÃO DO PROCEDIMENTO EXPERIMENTAL E DO MÉ- TODO DE REGRESSÃO DE DADOS}

A Figura 4.1 ilustra a variação do fator de atrito segundo Darcy com o número de Reynolds de acordo com os dados experimentais e previsões estimadas através do método de Shah e London (1978). Utilizou-se este método para comparação pois, embora desenvolvido para canais circulares, foi proposto para escoamento laminar em desenvolvimento. Na sua implementação, conforme sugerido por Sempértegui-Tapia e Ribatski (2016), utilizou-se como dimensão característica o diâmetro equivalente. Nota-se na Figura 4.1. que os dados experimentais e as previsões coincidem satisfatoriamente. Resultados para o Nusselt médio experimental e previsões segundo o método de Stephan e Preuber (1979), encontram-se ilustrados na Fig. 4.2 para os refrigerantes R290 e R600a. De forma análoga ao fator de atrito, nota-se nesta figura que a diferença entre os dados empíricos e as previsões é sistematicamente inferior as incertezas experimentais. Vale destacar que o método de Stephan e Preuber (1979) também foi proposto para escoamento laminar, região de desenvolvimento térmico e fluxo de calor uniforme, sendo implementado neste estudo adotando-se como dimensão característica o diâmetro equivalente.

A Tabela 4.3 apresenta os parâmetros estatísticos resultantes da comparação entre os dados experimentais para escoamento monofásico e os métodos de previsão considerando a totalidade do banco de dados levantado. Segundo esta tabela, o método de Shah e London (1978) prevê $83,3 \%$ dos dados experimentais para o fator de atrito com desvios inferiores a $20 \%$. No caso do método de Stephan e Preuber (1979), 81,5 \% dos dados são previstos com desvios inferiores a $30 \%$. Assim, conclui-se que os resultados obtidos são satisfatórios considerando que os métodos de previsão foram desenvolvidos para canais circulares e não incluem efeitos de má distribuição do fluido refrigerante entre os canais. Isto indica que a bancada e o procedimento experimental utilizado são adequados aos objetivos do presente estudo. 


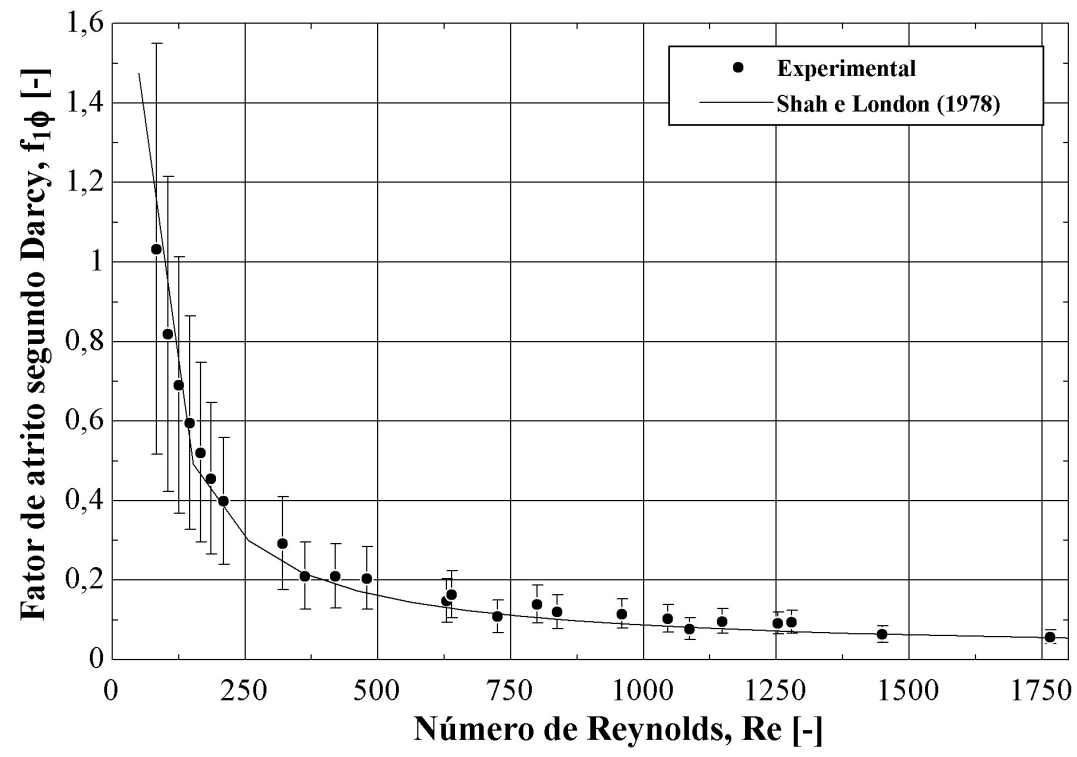

Figura 4.1 - Comparação dos resultados experimentais para o fator de atrito do Darcy com o método de previsão de Shah e London(1978).

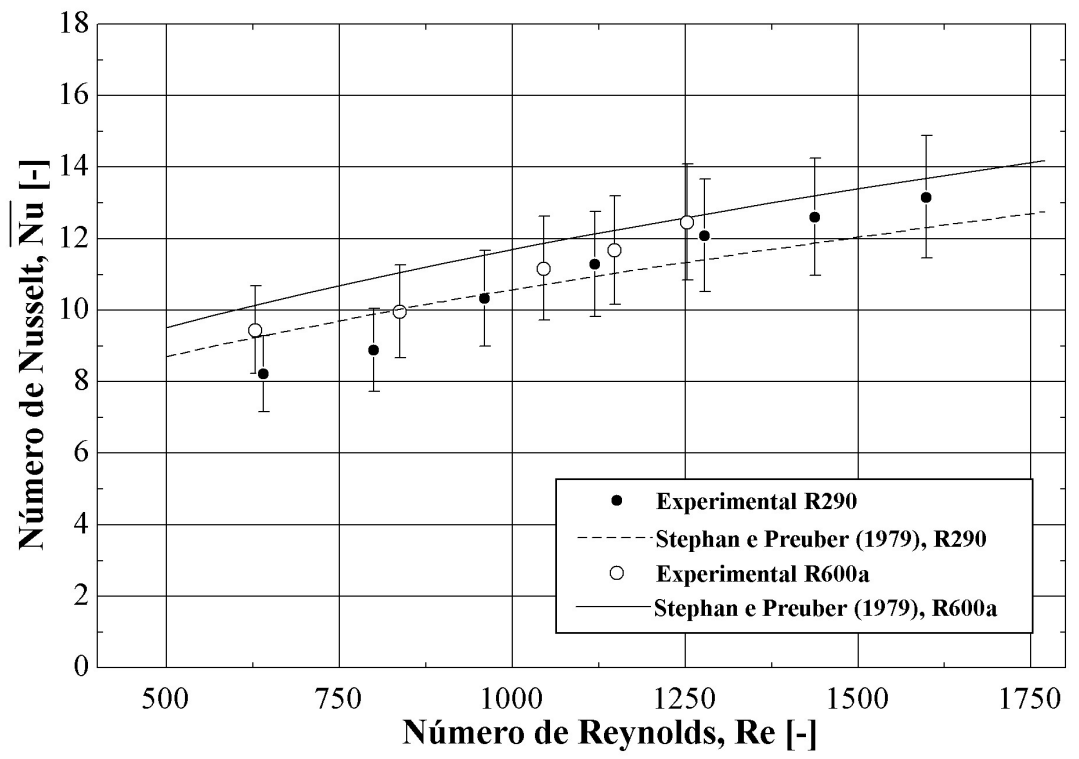

Figura 4.2 - Comparação dos resultados experimentais para o Número de Nusselt médio com o método de previsão de Stephan e Preuber (1979).

Tabela 4.3 - Parâmetros estatísticos resultantes da comparação entre os dados experimentais e métodos de previsão para escoamento monofásico.

\begin{tabular}{|c|c|c|c|c|}
\hline \multirow[b]{3}{*}{ Refrigerante } & \multicolumn{2}{|c|}{ Fator de atrito segundo } & \multicolumn{2}{|c|}{ Nusselt médio segundo } \\
\hline & Shal & (1978) & Stepha & $\mathbf{r}(1979)$ \\
\hline & MAE [\%] & $\lambda \pm 20 \%[\%]$ & MAE [\%] & $\lambda \pm 30 \%[\%]$ \\
\hline R600a & 14,4 & 84,6 & 26,4 & 75,0 \\
\hline R290 & 21,8 & 66,7 & 18,4 & 90,0 \\
\hline R1270 & 3,0 & 100 & 19,4 & 77,8 \\
\hline Total & 13,9 & 83,3 & 21,1 & 81,5 \\
\hline
\end{tabular}




\subsection{RESULTADOS SEGUNDO CURVAS DE EBULIÇÃO}

Neste estudo, curvas de ebulição foram obtidas através do incremento gradual (I) do fluxo de calor, a partir de um valor nulo até um valor máximo e, uma vez atingido, tem seu valor progressivamente reduzido até um fluxo de calor nulo (D).

As Figuras 4.3 a 4.8 ilustram curvas de ebulição para os hidrocarbonetos avaliados no presente estudo para temperatura de saturação de $25^{\circ} \mathrm{C}$ e velocidade mássica de $330 \mathrm{~kg} / \mathrm{m}^{2} \mathrm{~s}$. Nestas figuras, para as curvas obtidas com o incremento do fluxo de calor (I), notam-se descontinuidades a partir de um determinado superaquecimento da superfície. Este comportamento se deve a necessidade de um excesso de superaquecimento para a ativação das cavidades na superfície com o consequente início do processo de ebulição nucleada. Denomina-se este fenômeno na literatura inglesa por onset of nucleate boiling (ONB). Para as curvas obtidas com a redução do fluxo de calor (D), as cavidades já se encontram ativas, fazendo com que as curvas obtidas com o aumento e redução do fluxo de calor apresentem comportamentos distintos.

\section{Efeito do grau de sub-resfriamento do líquido}

As Figuras 4.3 a 4.5 ilustram o efeito do grau de sub-resfriamento do líquido na entrada do dissipador de calor sobre as curvas de ebulição. De acordo com estas figuras, com o incremento do grau de sub-resfriamento, as curvas de ebulição se deslocam para a direita. Desta forma, em condições nas quais se verifica ebulição convectiva ao longo do dissipador com o aumento do sub-resfriamento do líquido, um superaquecimento superior da parede é necessário para se dissipar um mesmo fluxo de calor.

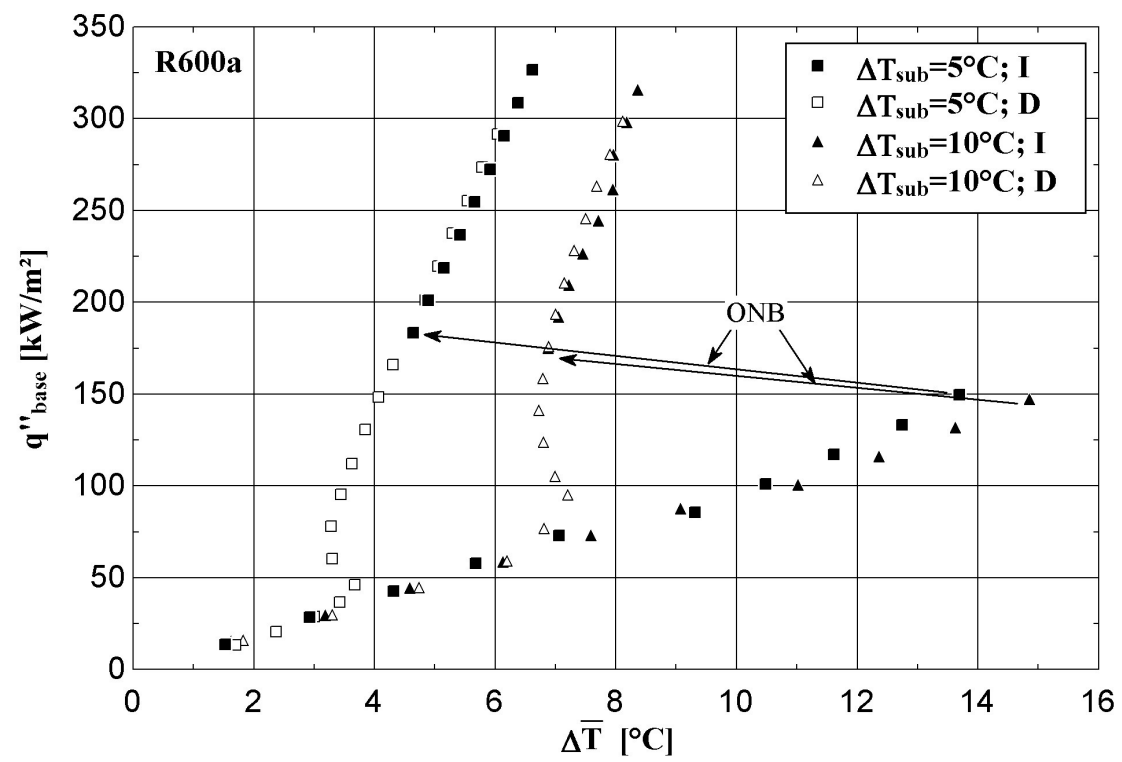

Figura 4.3 - Efeito do sub-resfriamento do líquido nas curvas de ebulição para o R600a,

$$
\mathrm{G}=330 \mathrm{~kg} / \mathrm{m}^{2} \text { s e } T_{\text {sat }}=25^{\circ} \mathrm{C} \text {. }
$$




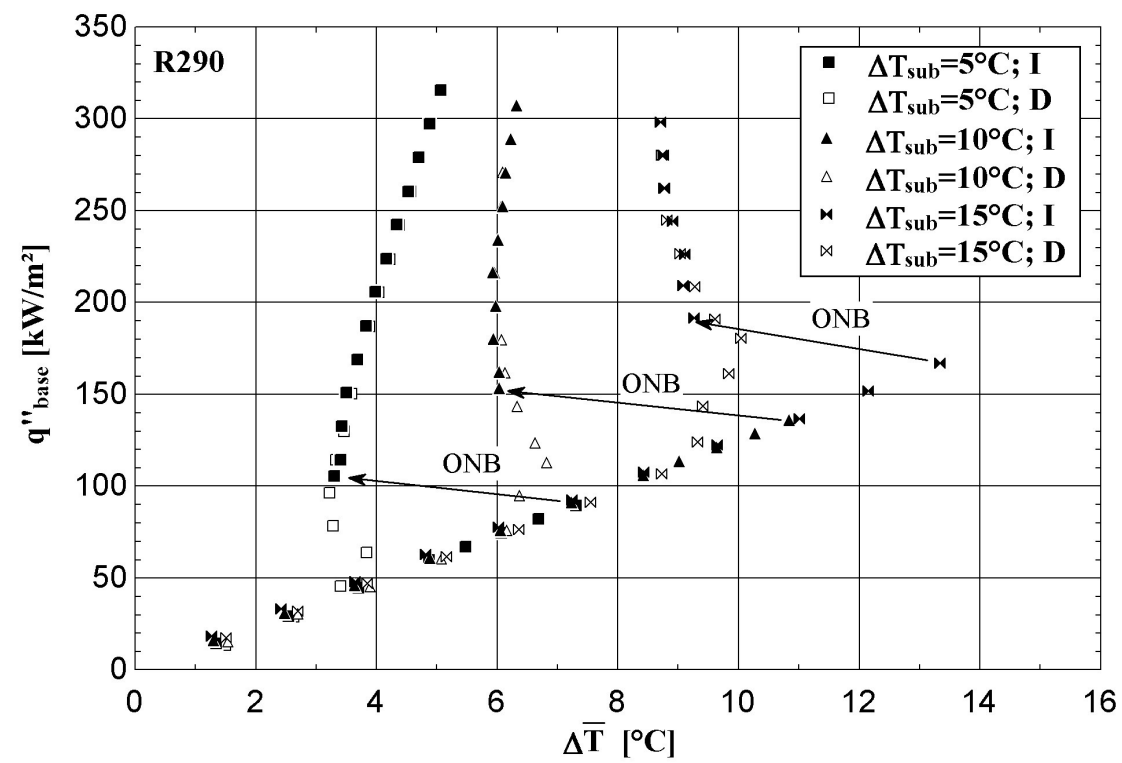

Figura 4.4 - Efeito do sub-resfriamento do líquido nas curvas de ebulição para o R290, G = $330 \mathrm{~kg} / \mathrm{m}^{2} \mathrm{~S}$ e $T_{\text {sat }}=25^{\circ} \mathrm{C}$.

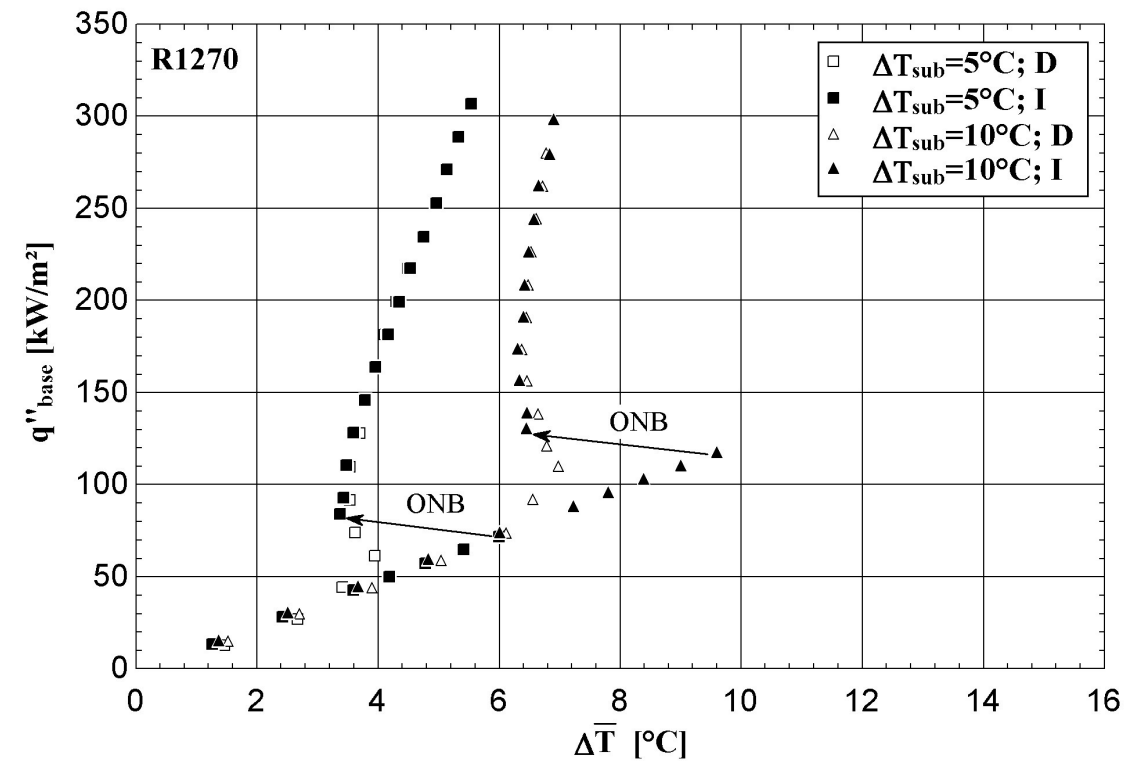

Figura 4.5 - Efeito do sub-resfriamento do líquido nas curvas de ebulição para o R1270, $\mathrm{G}=330 \mathrm{~kg} / \mathrm{m}^{2}$ s e $T_{\text {sat }}=25^{\circ} \mathrm{C}$.

\section{Efeito do fluido refrigerante}

Devido à possibilidade de substituição do R134a por hidrocarbonetos, a Fig. 4.6 compara curvas de ebulição obtidas para este HFC por Do Nascimento et al. (2013) com os resultados levantados neste estudo para hidrocarbonetos. Nela nota-se valores de $\Delta \bar{T}_{\text {ONB }}$ para o refrigerante halogenado inferiores aos hidrocarbonetos. No caso destes, o $\Delta \bar{T}_{\text {ONB }}$ decresce segundo a seguinte ordem R600a, R290 e R1270, fato também constatado através da comparação dos 
resultados ilustrados nas Figs. 4.3 a 4.5. Este comportamento está relacionado a pressão reduzida inferior do R600a em relação aos demais fluidos.

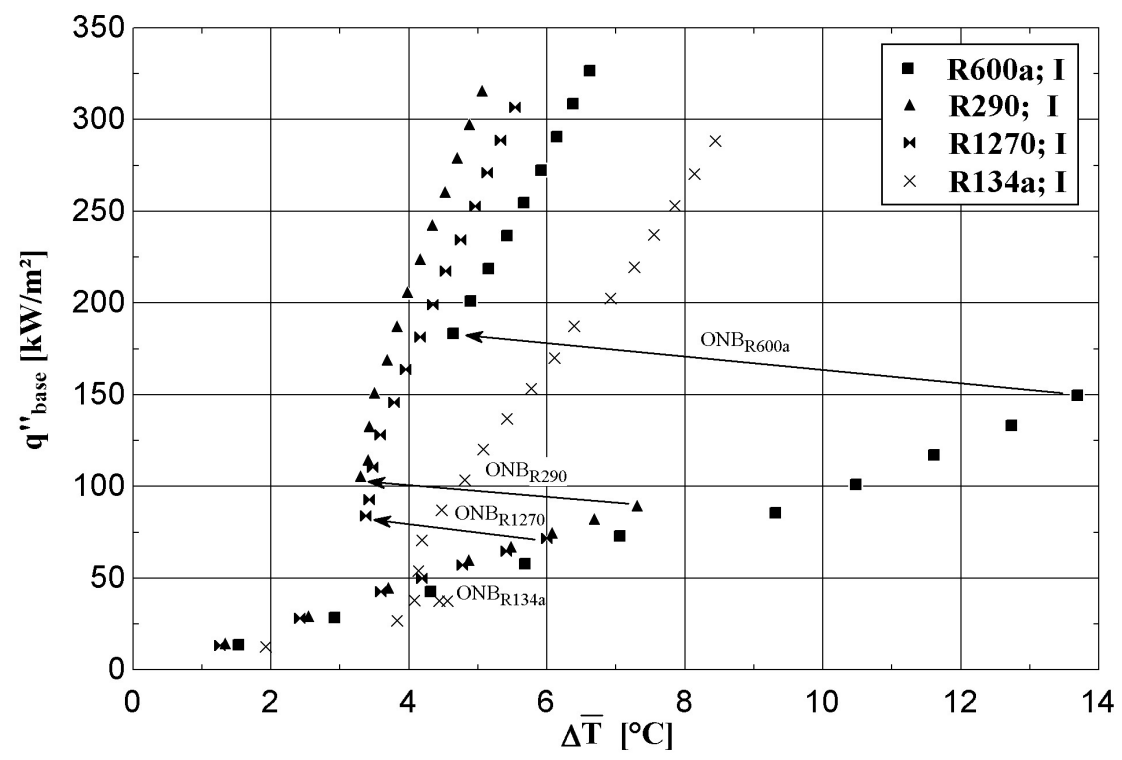

Figura 4.6 - Efeito do fluido sobre as curvas de ebulição para $T_{\text {sat }}=25^{\circ} \mathrm{C}$ e $\mathrm{G}=330 \mathrm{~kg} / \mathrm{m}^{2} \mathrm{~s}$.

O modelo de Bergles e Rohsenow (1964) é dado pela seguinte equação:

$$
\Delta \bar{T}_{\mathrm{ONB}}=\frac{q_{\text {efetivo }}}{\bar{h}}-\sqrt{\frac{8 \cdot \sigma \cdot T_{\text {sat }} \cdot q^{\prime \prime}{ }_{\text {efetivo }}}{\rho_{g} \cdot i_{l g} \cdot k_{l}}}
$$

Segundo este modelo, o superaquecimento mínimo da parede necessário para o ONB é função direta da tensão superficial e inversamente proporcional a densidade do vapor. Para os fluidos avaliados neste estudo, verifica-se através da Tab. 1.1] que o R600a apresenta tensão superficial superior ao R1270 e R290. Além disso, a densidade do vapor do R600a é inferior aos demais fluidos e se eleva progressivamente segundo a seguinte ordem: R290, R1270 e R134a. Isto implica em um incremento no grau de superaquecimento da parede para o ONB segundo a seguinte ordem decrescente R600a, R290, R1270 e R134a, para velocidades mássicas inferiores a $658 \mathrm{~kg} / \mathrm{m}^{2} \mathrm{~s}$.

A Tabela 4.4 apresenta a comparação entre resultados experimentais e o método para previsão do ONB proposto por Bergles e Rohsenow (1964). Este método foi implementado considerando o coeficiente de transferência de calor monofásico médio para a condição experimental anterior àquela em que o ONB foi verificado.

Segundo a Tabela 4.4. o método proposto prevê satisfatoriamente os dados experimentais com desvios inferiores a $20 \%$, embora, de uma maneira geral os subestime. Além disso, notase que a ordem decrescente para os refrigerantes do $\Delta \bar{T}_{\text {ONB }}$ fornecido pelo modelo e a observada experimentalmente são similares. 
Tabela 4.4 - Comparação entre resultados experimentais e estimados através do método Bergles e Rohsenow (1964) para $\Delta \bar{T}_{\text {ONB }}$.

\begin{tabular}{|c|c|c|c|c|c|c|c|}
\hline Fluido & $\begin{array}{c}\mathrm{G} \\
{\left[\mathrm{kg} / \mathrm{m}^{2} \mathrm{~s}\right]}\end{array}$ & $\begin{array}{c}\bar{h} \\
{\left[\mathrm{~kW} / \mathrm{m}^{2} K\right]}\end{array}$ & $\begin{array}{c}q " \text { "efetivo } \\
{\left[\mathrm{kW} / \mathrm{m}^{2}\right]}\end{array}$ & $T_{\text {sat }}[K]$ & $\begin{array}{c}\Delta \bar{T}_{\mathrm{ONB}} \\
\text { pred. }[K]\end{array}$ & $\begin{array}{c}\Delta \bar{T}_{\mathrm{ONB}} \\
\exp [\mathrm{K}]\end{array}$ & $\begin{array}{c}\Delta \bar{T}_{\text {erro }} \\
{[\%]}\end{array}$ \\
\hline \multirow{3}{*}{ R600a } & 330 & 2,95 & 40,42 & 298,3 & 11,8 & 13,7 & $-13,7$ \\
\hline & 494 & 3,23 & 40,02 & 298,2 & 10,5 & 12,4 & $-15,2$ \\
\hline & 658 & 3,76 & 40,43 & 298,3 & 8,9 & 10,7 & $-17,5$ \\
\hline \multirow{3}{*}{ R290 } & 330 & 3,30 & 24,11 & 298,1 & 6,5 & 7,3 & $-10,7$ \\
\hline & 494 & 4,38 & 31,21 & 298,2 & 6,3 & 7,1 & $-12,4$ \\
\hline & 658 & 6,34 & 64,35 & 298,2 & 8,9 & 10,2 & $-12,5$ \\
\hline \multirow{3}{*}{$\mathrm{R} 1270$} & 330 & 3,23 & 19,34 & 298,2 & 5,4 & 6,0 & $-10,0$ \\
\hline & 494 & 4,16 & 28,22 & 298,2 & 6,1 & 6,8 & $-10,6$ \\
\hline & 658 & 6,13 & 62,05 & 298,2 & 9,1 & 10,1 & $-10,6$ \\
\hline \multirow{2}{*}{$\mathrm{R} 134 \mathrm{a}$} & 330 & 2,23 & 10,13 & 298,8 & 3,9 & 4,6 & $-13,8$ \\
\hline & 494 & 2,42 & 15,33 & 298,3 & 5,6 & 6,3 & $-12,3$ \\
\hline
\end{tabular}

\section{Efeito da velocidade mássica}

As Figuras 4.7 e 4.8 ilustram o efeito da velocidade mássica para dados obtidos com o incremento do fluxo de calor para o R290 e R1270, respectivamente. De acordo com estas figuras, o superaquecimento da parede necessário para o ONB aumenta com o incremento da velocidade mássica. Tal comportamento se deve a ausência das condições de superaquecimento do fluido para o estabelecimento do ONB ao longo dos canais, pois as velocidades mássicas superiores postergam o estabelecimento das condições necessárias para a ativação das cavidades com a consequente nucleação de bolhas, pois implicam em gradientes de temperatura superiores e temperaturas médias do fluido inferiores considerando o fluxo de calor e o comprimento aquecido fixos. Além disso, as curvas de ebulição se deslocam para a direita com o incremento da velocidade mássica. Este comportamento se deve ao incremento da parcela do dissipador de calor sob condições monofásicas, decorrente do aumento da velocidade mássica a temperatura sub-resfriada, implicando em um $\Delta \bar{T}_{\text {ONB }}$ superior para dissipar o mesmo fluxo de calor.

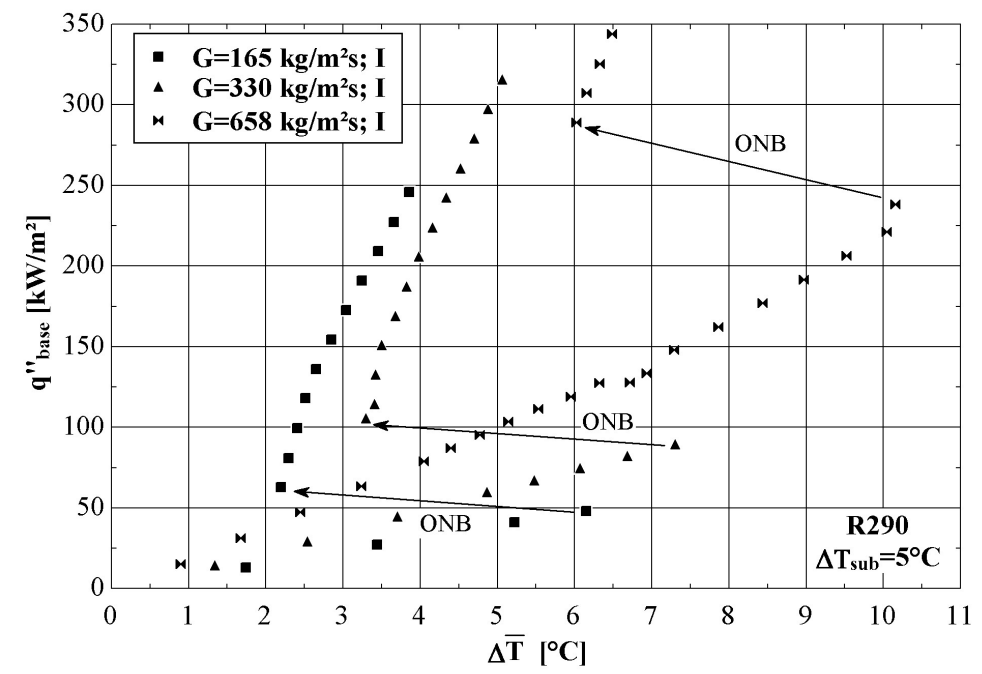

Figura 4.7 - Efeito da velocidade mássica nas curvas de ebulição para o R290, $T_{\text {sat }}=25^{\circ} \mathrm{C}$ e $\Delta T_{\text {sub }}=5$ ${ }^{\circ} \mathrm{C}(\mathrm{I})$. 


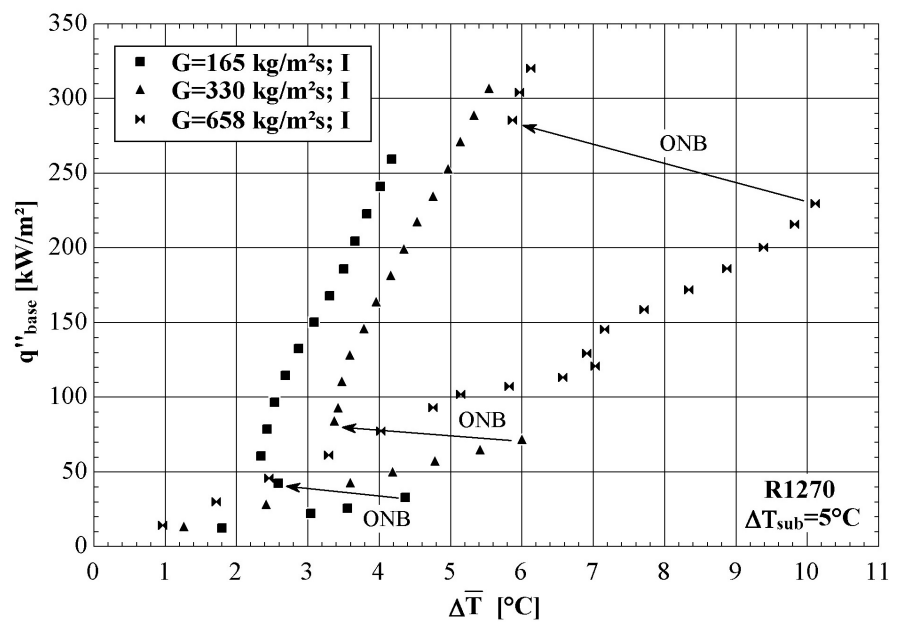

Figura 4.8 - Efeito da velocidade mássica nas curvas de ebulição para o R1270, $T_{\text {sat }}=25^{\circ} \mathrm{C} \mathrm{e}$ $\Delta T_{\text {sub }}=5{ }^{\circ} \mathrm{C}(\mathrm{I})$.

\subsection{RESULTADOS PARA O COEFICIENTE DE TRANSFERÊNCIA DE CALOR}

Este item apresenta, inicialmente, os resultados para o coeficiente de transferência de calor (CTC) através de uma análise paramétrica do efeito dos parâmetros experimentais. Em seguida apresenta uma comparação dos resultados experimentais com métodos de previsão disponíveis na literatura para previsão do coeficiente de transferência de calor através do mecanismo de ebulição convectiva. Neste item, são considerados apenas resultados obtidos em condições de redução do fluxo de calor a partir de um valor máximo.

\subsubsection{ANÁLISE PARAMÉTRICA DO EFEITO DOS PARÂMETROS EXPERIMEN- TAIS NO CTC}

As Figuras 4.10 a 4.15ilustram os resultados para CTC médio. Estas figuras incluem retas que segregam os dados em duas regiões caracterizadas pelos símbolos $1 \phi$ e $2 \phi$. Neste caso, "1 $\phi "$ indica a ausência de bolhas e sítios de nucleação ao longo do dissipador perceptíveis a partir das imagens obtidas com a câmera de alta velocidade e com auxílio de lentes com elevada distância focal (AF Micro-NIKKOR 60mm f/2.8D Lens da Nikon). A transição da região $2 \phi$ para $1 \phi$ é caracterizada pela aparente desativação dos sítios de nucleação na região de saída dos microcanais. Vale destacar que para dados levantados com a redução de q" base, esta região é a última a ter seus sítios de nucleação aparentemente desativados. A Figura 4.9 ilustra a nucleação de bolhas na região terminal dos microcanais. No entanto, apesar da desativação aparente dos sítios, a presença de efeitos de ebulição se caracteriza por coeficientes de transferência de calor para condições de decréscimo de $q "$ base superiores aos obtidos para condições de incremento do fluxo de calor em valores inferiores ao ONB, em que o mecanismo de transferência de calor é a convecção forçada monofásica. 


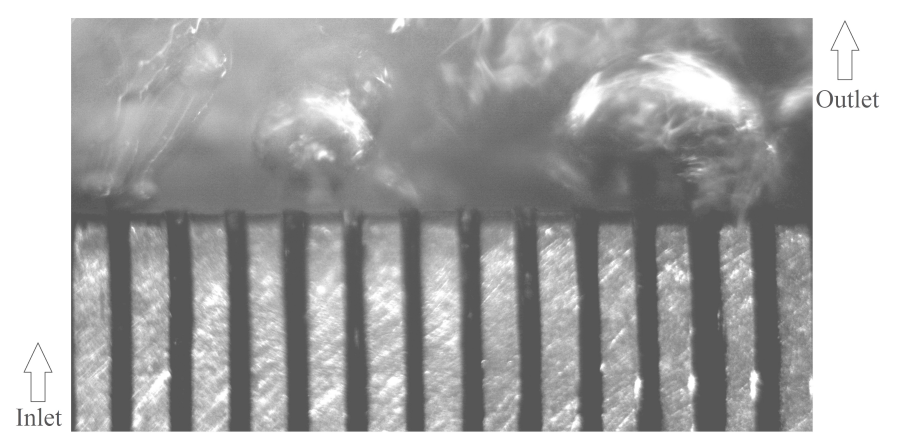

Figura 4.9 - Início da nucleação de bolhas na região terminal dos microcanais para R600a, $T_{\text {sat }}=25$

${ }^{\circ} \mathrm{C}, \Delta T_{\text {sub }}=5{ }^{\circ} \mathrm{C}, \mathrm{G}=165 \mathrm{~kg} / \mathrm{m}^{2} \mathrm{~s}$ e $q^{\prime \prime}{ }_{\text {base }}=63,61 \mathrm{~kW} / \mathrm{m}^{2}$ (D).

\section{Efeito da velocidade mássica}

As Figuras 4.10 a 4.12 ilustram o efeito da velocidade mássica no comportamento do coeficiente de transferência de calor médio com variações do fluxo de calor para os hidrocarbonetos avaliados no presente estudo. De acordo com estas figuras, na região $1 \phi$ constatase o incremento do CTC médio com a elevação velocidade mássica. Tal comportamento inverte-se na região $2 \phi$, na qual verifica-se o decréscimo do CTC médio com o aumento da velocidade mássica. Embora na região $1 \phi$, efeitos de ebulição ainda estejam presentes, esta inversão se justifica, pois com a redução de $q$ " base, efeitos de convecção forçada tornam-se progressivamente predominantes, justificando CTCs superiores com a elevação da vazão ainda que para escoamento em regime laminar, pois o comprimento de desenvolvimento térmico se eleva com o aumento do Reynolds, elevando o $\bar{h}_{\text {médio }}$.

O fato ilustrado nas Figs. 4.10 a 4.12, segundo o qual o coeficiente de transferência de calor médio se eleva com a redução da velocidade mássica na presença de ebulição convectiva para um fluxo de calor fixo, decorre do comprimento do dissipador de calor em condições de escoamento monofásico decrescer com a redução da velocidade mássica.

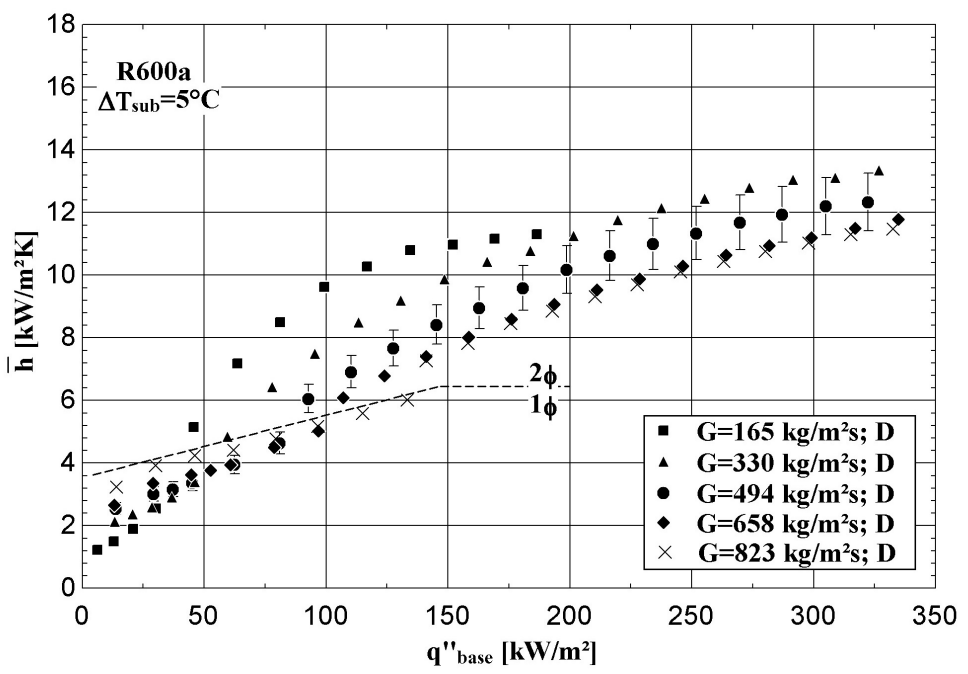

Figura 4.10 - Efeito da velocidade mássica sobre o comportamento do coeficiente de transferência de calor médio com a variação do fluxo de calor para R600a, $T_{\text {sat }}=25^{\circ} \mathrm{C}, \Delta T_{\text {sub }}=5{ }^{\circ} \mathrm{C}$ e (D). 


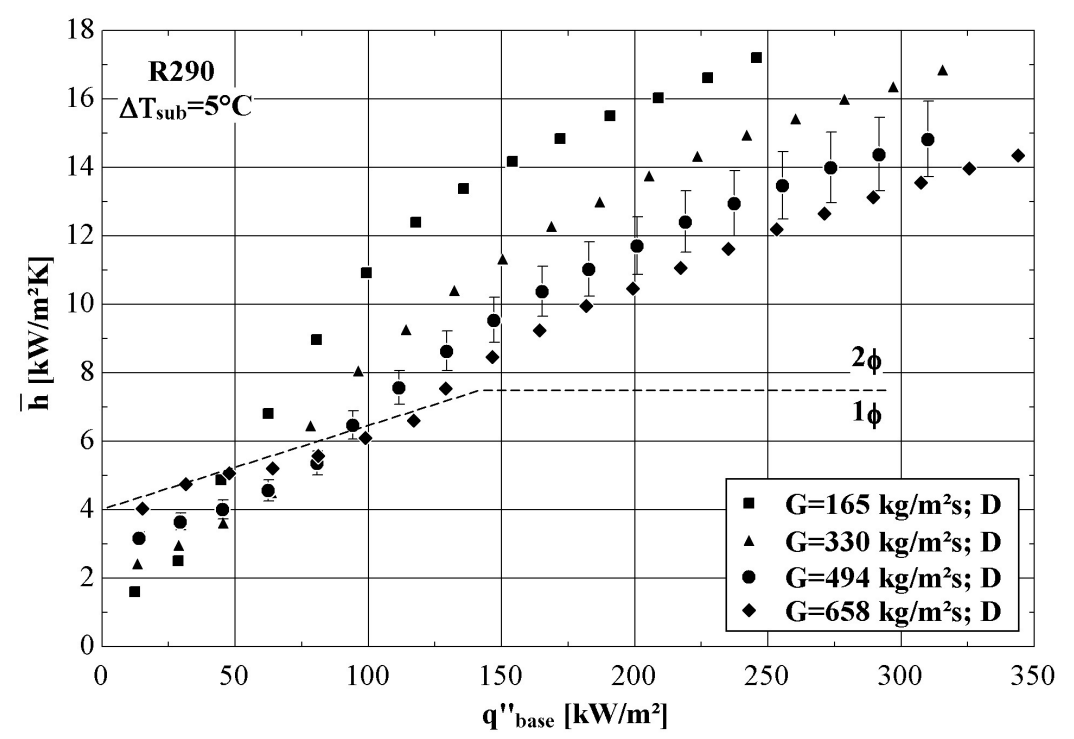

Figura 4.11 - Efeito da velocidade mássica sobre o comportamento do coeficiente de transferência de calor médio com a variação do fluxo de calor para R290, $T_{\text {sat }}=25^{\circ} \mathrm{C}, \Delta T_{\text {sub }}=5{ }^{\circ} \mathrm{C}$ (D).

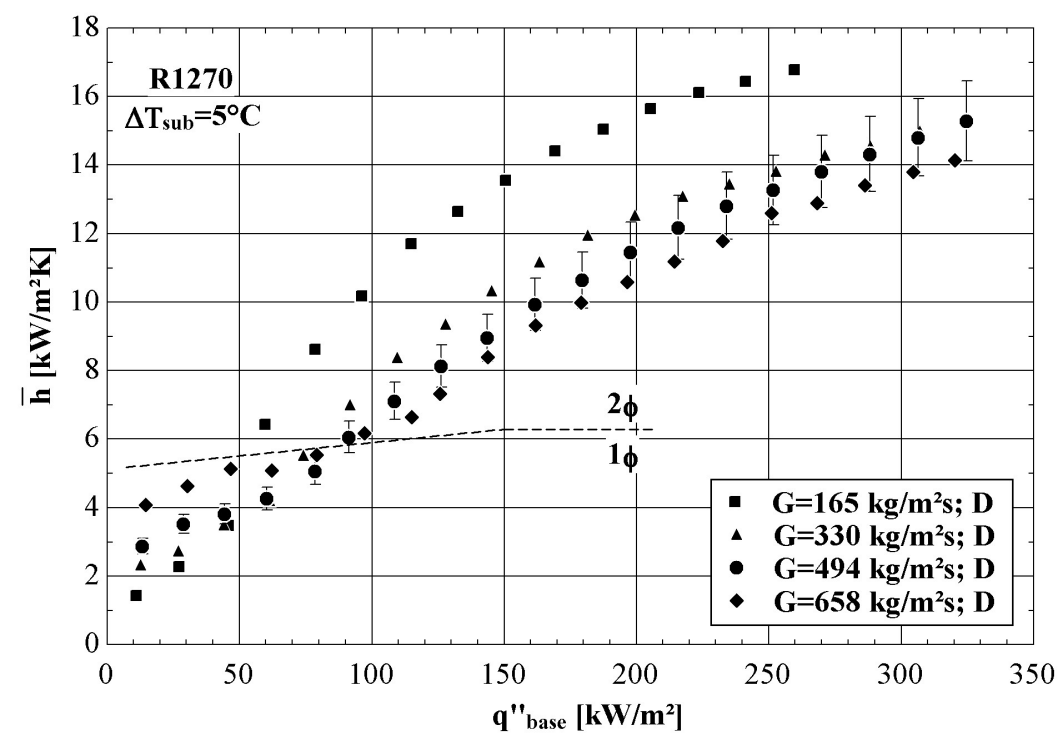

Figura 4.12 - Efeito da velocidade mássica sobre o comportamento do coeficiente de transferência de calor médio com a variação do fluxo de calor para R1270, $T_{\text {sat }}=25^{\circ} \mathrm{C}$ e $\Delta T_{\text {sub }}=5{ }^{\circ} \mathrm{C}$ (D).

\section{Efeito do fluido refrigerante}

As Figuras 4.13 e 4.14 ilustram comparações entre os refrigerantes avaliados neste estudo do comportamento do coeficiente de transferência de calor médio com a variação do fluxo de calor. De acordo com estas figuras, o coeficiente de transferência de calor médio se eleva com o incremento do fluxo de calor para as condições caracterizadas por $1 \phi$ e $2 \phi$. Na região correspondente a $1 \phi$ não se observam diferenças significativas entre CTCs dos fluidos avaliados no presente estudo. Já na região $2 \phi$, o gradiente do coeficiente de transferência de calor com 
o fluxo de calor eleva-se em relação a região $1 \phi$ e valores distintos são observados para os refrigerantes.

De acordo com as Figs. 4.13 e 4.14 na região 2 $\phi$, o R290 e o R1270 fornecem CTCs médios superiores comparados ao R600a. Em geral, os hidrocarbonetos fornecem CTCs superiores ao R134a para uma velocidade mássica fixa. Este comportamento se justifica a partir da análise das propriedades dos fluidos indicadas na Tab. 1.1. Nesta tabela observa-se para hidrocarbonetos, condutividade térmica e calor latente de vaporização superiores. Além disso, apresentam densidade e viscosidade da fase vapor inferiores.

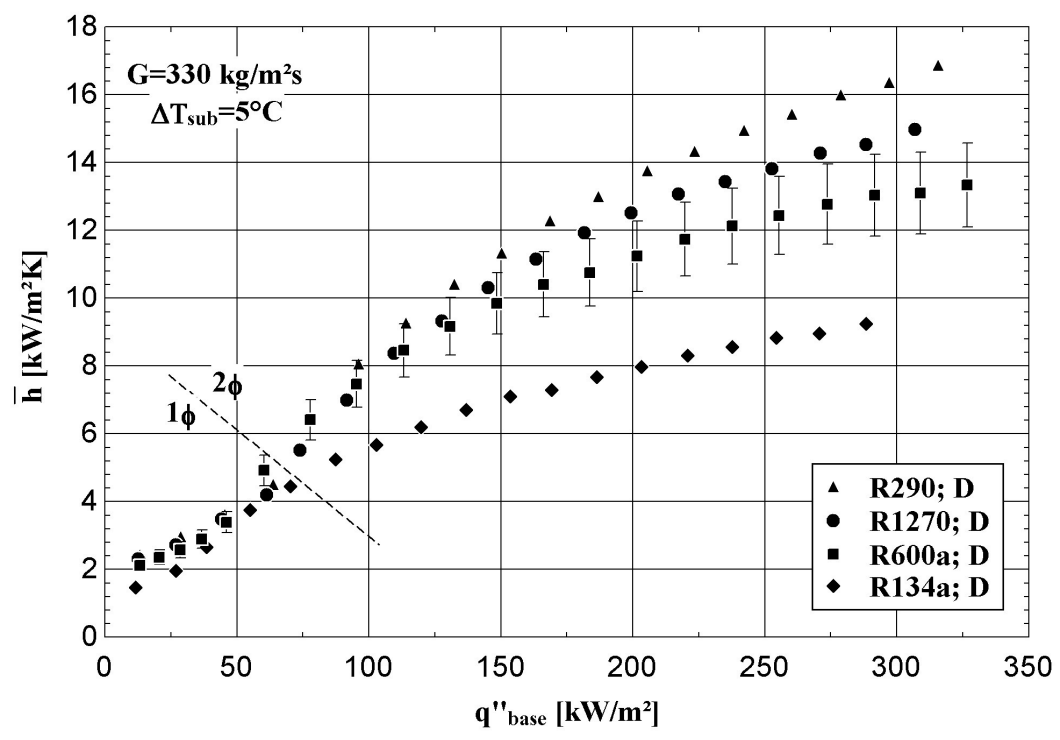

Figura 4.13 - Efeito do fluido sobre o comportamento do coeficiente de transferência de calor médio com a variação do fluxo de calor para $\mathrm{G}=330 \mathrm{~kg} / \mathrm{m}^{2} \mathrm{~s}, T_{\text {sat }}=25^{\circ} \mathrm{C}, \Delta T_{\text {sub }}=5{ }^{\circ} \mathrm{C}$.

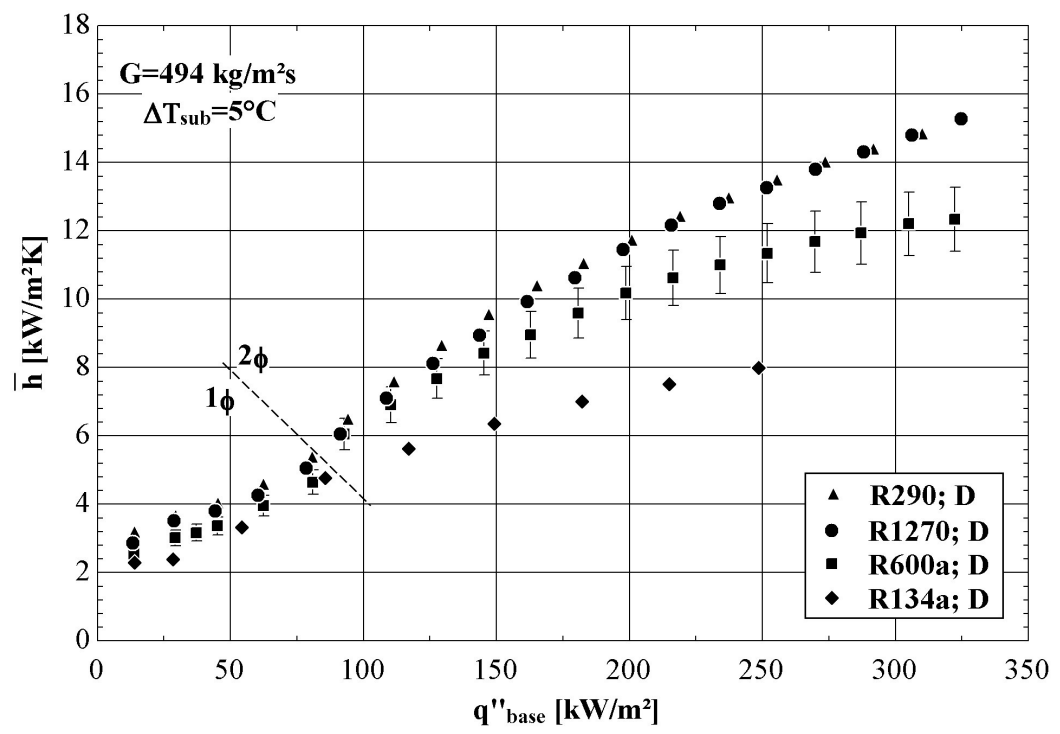

Figura 4.14 - Efeito do fluido sobre o comportamento do coeficiente de transferência de calor médio com a variação do fluxo de calor para $\mathrm{G}=494 \mathrm{~kg} / \mathrm{m}^{2} \mathrm{~s}, T_{\text {sat }}=25^{\circ} \mathrm{C}, \Delta T_{\text {sub }}=5{ }^{\circ} \mathrm{C}$.

A ordem decrescente para o CTC médio, segundo o mecanismo de ebulição nucleada em piscina avaliada de acordo com o método de Cooper (1984), é R1270, R290, R134a e R600a, conforme ilustrado na Fig. 4.15. No entanto, como observa-se nas Figs. 4.13 e 4.14 
a ordem decrescente apresentada para CTC médio com a presença de ebulição convectiva é R290, R1270, R600a e R134a. Tal resultado permite especular que no CTC durante a ebulição convectiva dos refrigerantes R290 sobre o R1270 e R600a sobre o R134a predominam efeitos convectivos. Este comportamento se deve a estes refrigerantes apresentarem volumes específicos da fase vapor superiores aos fluidos R1270 e R134a, o qual implica no incremento da velocidade da fase vapor para uma mesma velocidade mássica.

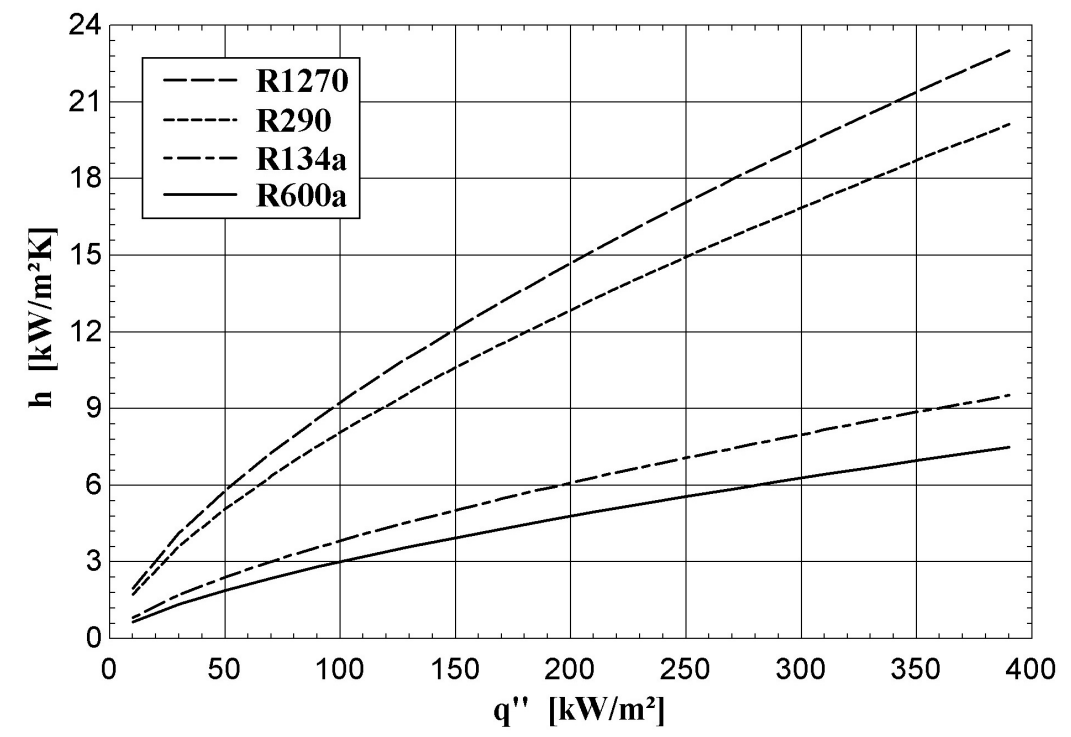

Figura 4.15 - Coeficiente de transferência de calor para ebulição nucleada em piscina estimado através do método de Cooper (1984) para $T_{\text {sat }}=25^{\circ} \mathrm{C}$ e $R p=1 \mu \mathrm{m}$.

\section{Efeito do grau de sub-resfriamento do líquido}

As Figuras 4.16 e 4.17 ilustram o efeito do grau de sub-resfriamento do fluido sobre o CTC médio para os fluidos R290 e R1270, respectivamente. De acordo com estas figuras, na região $1 \phi$, o grau de sub-resfriamento do fluido na entrada do dissipador de calor afeta apenas marginalmente o CTC caracterizando seu comportamento por um platô. No entanto, a partir de um determinado fluxo de calor, o gradiente do CTC se intensifica, com esta mudança de comportamento ocorrendo para fluxos superiores com o incremento do grau de sub-resfriamento na câmara de entrada. Para graus de sub-resfriamento de 10 e $15^{\circ} \mathrm{C}$, o gradiente do CTC se altera ainda na região com ausência de nucleação de bolhas. Enquanto, para $\Delta T_{\text {sub }}=5^{\circ} \mathrm{C}$, a alteração do CTC ocorre na transição da região $1 \phi$ para $2 \phi$.

De uma maneira geral, nas Figs. 4.16 e 4.17, constata-se na região $2 \phi$, o incremento do CTC com a redução de $\Delta T_{\text {sub }}$. Este comportamento se deve ao fato do dissipador de calor ter a parcela de sua superfície sob condições de ebulição convectiva reduzida com o incremento do grau de sub-resfriamento do fluido na câmara de entrada. 


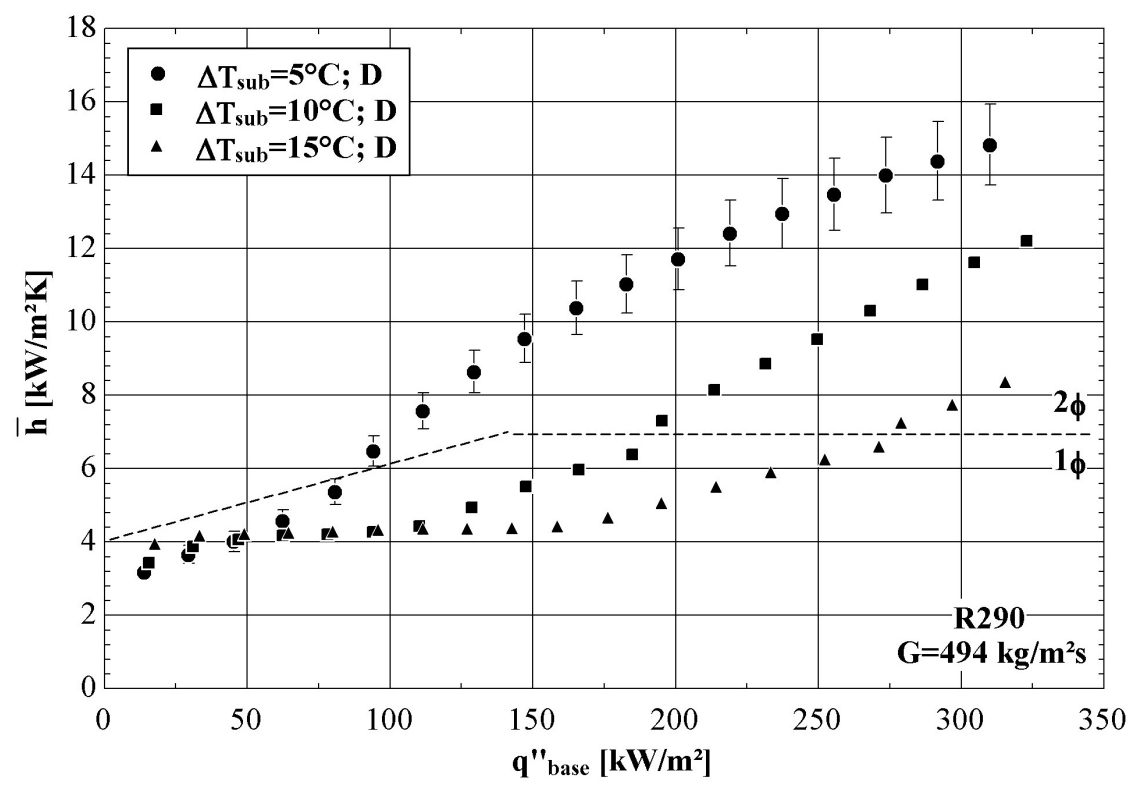

Figura 4.16 - Efeito do grau de sub-resfriamento do fluido na entrada da seção de testes sobre o comportamento do coeficiente de transferência de calor médio com a variação do fluxo de calor para o $\mathrm{R} 290, \mathrm{G}=494 \mathrm{~kg} / \mathrm{m}^{2}$ s e $T_{\text {sat }}=25^{\circ} \mathrm{C}(\mathrm{D})$.

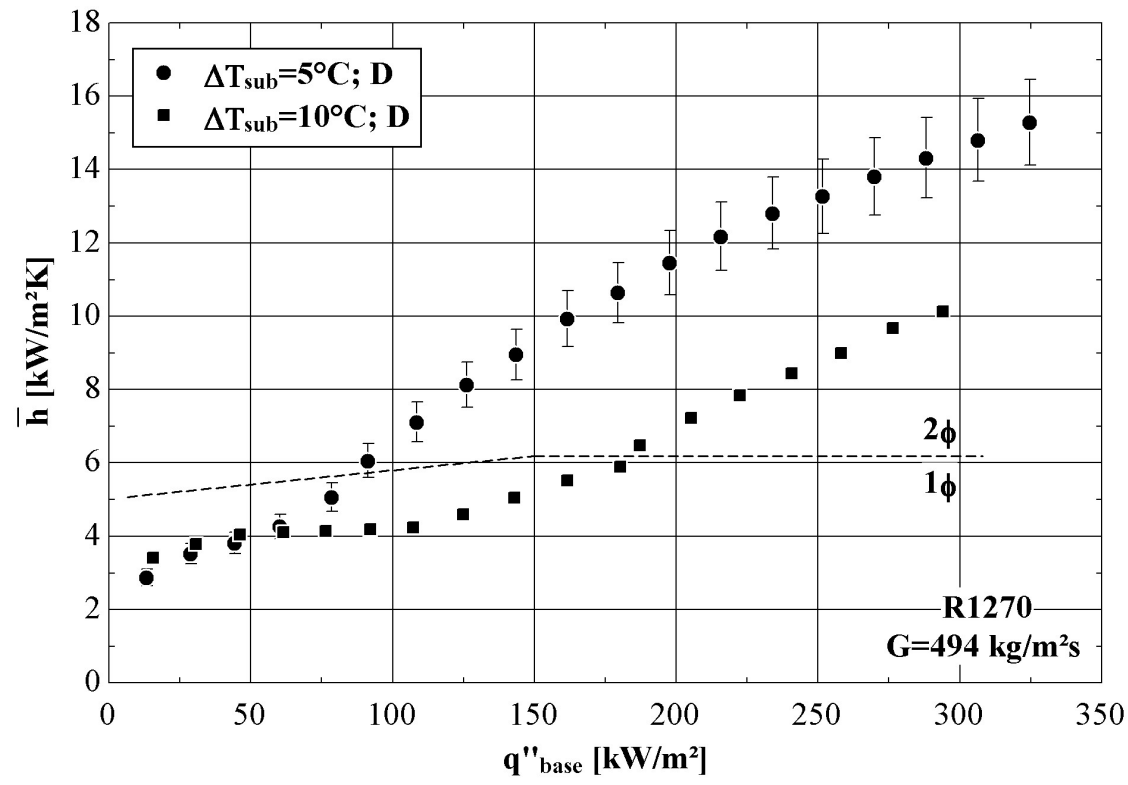

Figura 4.17 - Efeito do grau de sub-resfriamento do fluido na entrada da seção de testes sobre o comportamento do coeficiente de transferência de calor médio com a variação do fluxo de calor para $\mathrm{R} 1270, \mathrm{G}=494 \mathrm{~kg} / \mathrm{m}^{2} \mathrm{~s}$ e $T_{\text {sat }}=25^{\circ} \mathrm{C}$ (D).

\section{Efeito da temperatura de saturação}

As Figuras 4.18 e 4.19 ilustram o efeito da temperatura de saturação sobre o CTC médio para os fluidos R290 e R1270, respectivamente. De acordo com esta figura, conforme já anteriormente mencionado, não são observadas variações significativas do CTC para fluxo de calor correspondentes a região $1 \phi$. Uma vez evidenciada a ebulição ao longo dos canais 
correspondendo a região $2 \phi$, diferenças marginais no CTC são inicialmente observadas com o incremento da temperatura de saturação de 21 para $25^{\circ} \mathrm{C}$. Esta diferença no CTC médio se eleva com o incremento do fluxo de calor.

De acordo com as Figs. 4.18 e 4.19 , verificam-se CTC médios superiores para temperaturas de saturação inferiores, dado um fluxo de calor fixo e uma velocidade mássica de $165 \mathrm{~kg} / \mathrm{m}^{2} \mathrm{~s}$. Entretanto, para velocidades mássicas de $494 \mathrm{~kg} / \mathrm{m}^{2} \mathrm{~s}$, observa-se o incremento dos CTC médios com o incremento da temperaturas de saturação. Para velocidades mássicas de $330 \mathrm{~kg} / \mathrm{m}^{2}$ s, o efeito da temperatura de saturação no CTC torna-se apenas marginal.

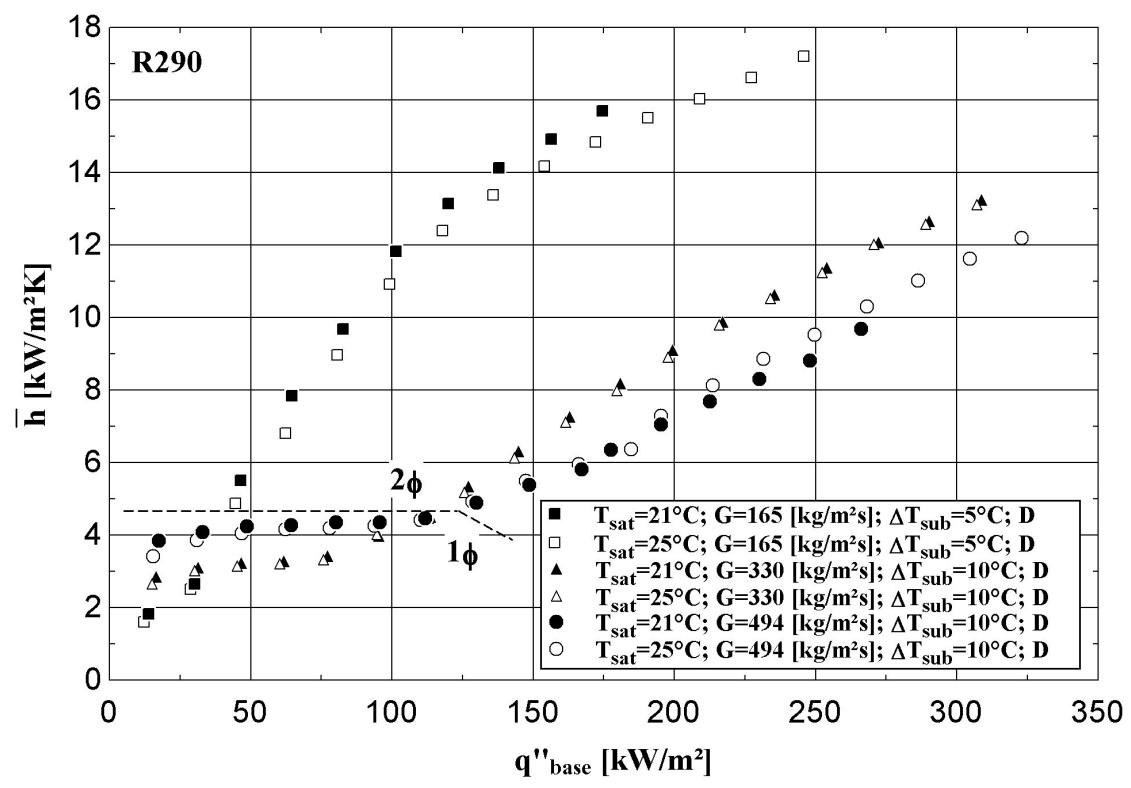

Figura 4.18 - Ilustração do efeito de $T_{\text {sat }}$ no comportamento do CTC com o fluxo de calor para R290.

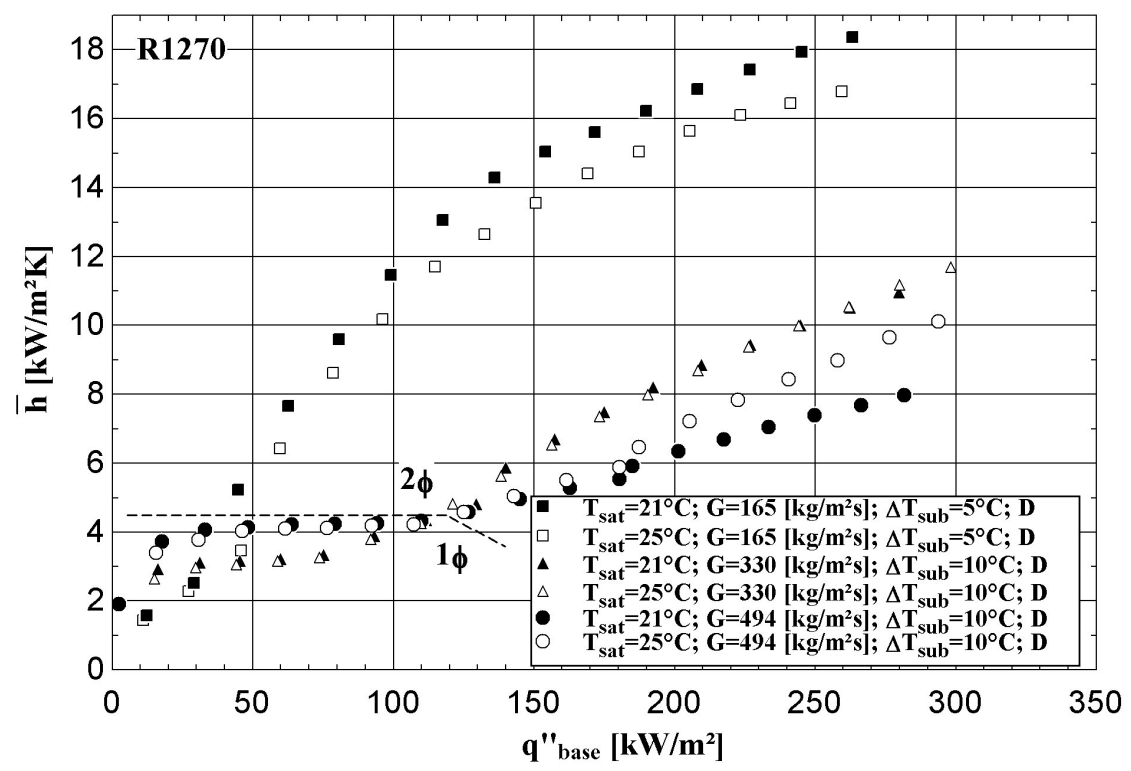

Figura 4.19 - Ilustração do efeito de $T_{\text {sat }}$ no comportamento do CTC com o fluxo de calor para R1270. 
De acordo com Ribatski (2013), na literatura verifica-se como comportamento mais frequente, o incremento do CTC com o aumento da temperatura de saturação. De forma análoga aos resultados para velocidades mássicas de $494 \mathrm{~kg} / \mathrm{m}^{2} \mathrm{~s}$. Especula-se que o comportamento oposto observado para velocidades mássicas de $165 \mathrm{~kg} / \mathrm{m}^{2} \mathrm{~s}$ possa estar relacionado a efeitos de instabilidades térmicas e a má-distribuição do fluido entre os canais. Além disso, ressalta-se que, o decréscimo da temperatura de saturação implica no incremento de um $10 \%$ do volume específico do vapor e, consequentemente, na velocidade do escoamento. Desta forma, a elevada velocidade do vapor favorece a redução da espessura do filme líquido suprimindo efeitos de ebulição nucleada e incrementando efeitos convectivos, o qual resulta no incremento do CTC médio para um determinado fluxo de calor.

\subsubsection{COMPARAÇÃO COM MÉTODOS DE PREVISÃO DO CTC}

Neste estudo, seis métodos de previsão do CTC disponíveis na literatura foram comparados com os dados experimentais levantados neste estudo. Tal comparação envolve apenas a região do dissipador correspondente ao mecanismo de ebulição convectiva. Os métodos avaliados foram selecionados considerando aqueles que apresentaram melhores previsões segundo a análise da revisão bibliográfica levantada neste estudo. Em particular, o método proposto por Kanizawa et al. (2016) foi considerado devido à incluir dados para hidrocarbonetos no seu desenvolvimento. O procedimento utilizado para calcular o CTC médio segundo os métodos da literatura encontra-se descrito no Capítulo 3 .

A Tabela 4.5 apresenta os parâmetros estatísticos resultantes das comparações entre o CTC experimental e as previsões segundo os métodos da literatura. De acordo com esta tabela, o método proposto por Kanizawa et al. (2016) apresenta melhores resultados, prevendo 72,3\% dos dados com desvios entre $\pm 30 \%$. Em particular, este método proporciona melhores previsões para os refrigerantes R600a e R1270. Para o R290, o método proposto por Li e Wu (2010) é o que apresenta melhores previsões com $\mathrm{MAE}=9,1 \%$ e $\lambda_{ \pm 30 \%}=95,9 \%$.

Tabela 4.5 - Parâmetros estatísticos de comparação para coeficiente de transferência de calor bifásico

\begin{tabular}{|c|c|c|c|c|c|c|c|c|}
\hline \multirow[b]{3}{*}{ Método de previsão } & \multicolumn{8}{|c|}{ Fluido } \\
\hline & \multicolumn{2}{|c|}{ R600a } & \multicolumn{2}{|c|}{ R290 } & \multicolumn{2}{|c|}{ R1270 } & \multicolumn{2}{|c|}{ Total } \\
\hline & $\begin{array}{c}\text { MAE } \\
{[\%]}\end{array}$ & $\begin{array}{c}\lambda[\%] \\
\pm 30[\%]\end{array}$ & $\begin{array}{c}\text { MAE } \\
{[\%]}\end{array}$ & $\begin{array}{c}\lambda[\%] \\
\pm 30[\%]\end{array}$ & $\begin{array}{c}\text { MAE } \\
{[\%]}\end{array}$ & $\begin{array}{c}\lambda[\%] \\
\pm 30[\%]\end{array}$ & $\begin{array}{c}\text { MAE } \\
{[\%]}\end{array}$ & $\begin{array}{c}\lambda[\%] \\
\pm 30[\%]\end{array}$ \\
\hline Liu e Winterton (1991) & 29,9 & 57,2 & 29,7 & 56,2 & 21,5 & 74,8 & 26,6 & 63,6 \\
\hline Thome et al. (2004) & 52,8 & 00,0 & 44,5 & 6,9 & 28,3 & 65,5 & 40,6 & 27,4 \\
\hline Saitoh et al. (2007) & 23,8 & 70,6 & 33,7 & 47,0 & 26,2 & 64,2 & 28,0 & 60,2 \\
\hline Li e Wu (2010) & 31,3 & 54,4 & 9,1 & 95,9 & 41,2 & 35,0 & 27,6 & 61,0 \\
\hline Kim e Mudawar (2013) & 18,3 & 84,4 & 31,4 & 65,0 & 56,5 & 31,3 & 37,4 & 57,5 \\
\hline Kanizawa et al. $(2016)$ & 17,7 & 80,0 & 26,8 & 64,5 & 21,3 & 76,0 & 22,1 & 72,3 \\
\hline
\end{tabular}

As Figuras 4.20 4.21 ilustram comparações entre o CTC experimental e as correspondentes previsões segundo os métodos de Li e Wu (2010) e Kanizawa et al. (2016), respectivamente.

De uma maneira geral, segundo a Fig. 4.20 o método de Li e Wu (2010) superestima os 
resultados experimentais obtidos para os refrigerantes R600a e R1270. Entretanto, para R290 os resultados são estimados equitativamente ao longo da reta com inclinação de $45^{\circ}$. Segundo a Fig. 4.21, o método de Kanizawa et al. (2016) subestima a maioria dos resultados experimentais para R290 e, para R600a e R1270 os resultados são estimados equitativamente e distribuídos ao longo da mesma reta.

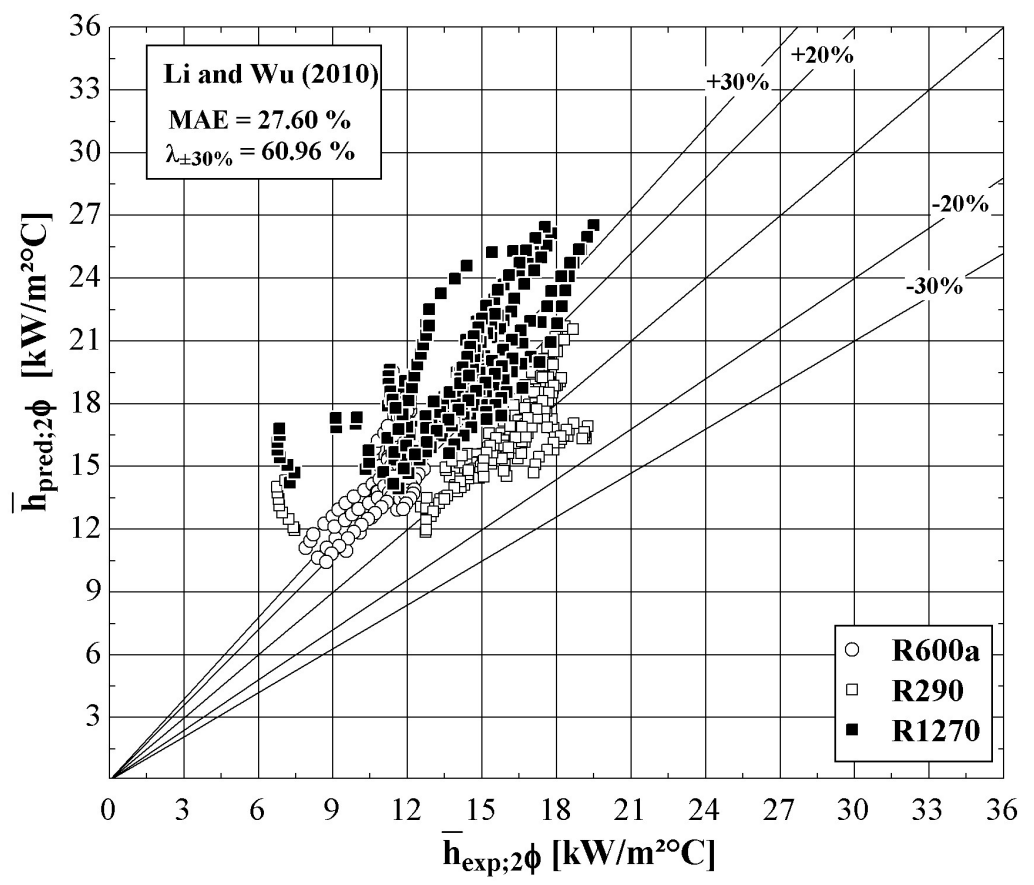

Figura 4.20 - Comparação entre o coeficiente de transferência de calor experimental e resultados determinados através do método de previsão de Li e Wu (2010).

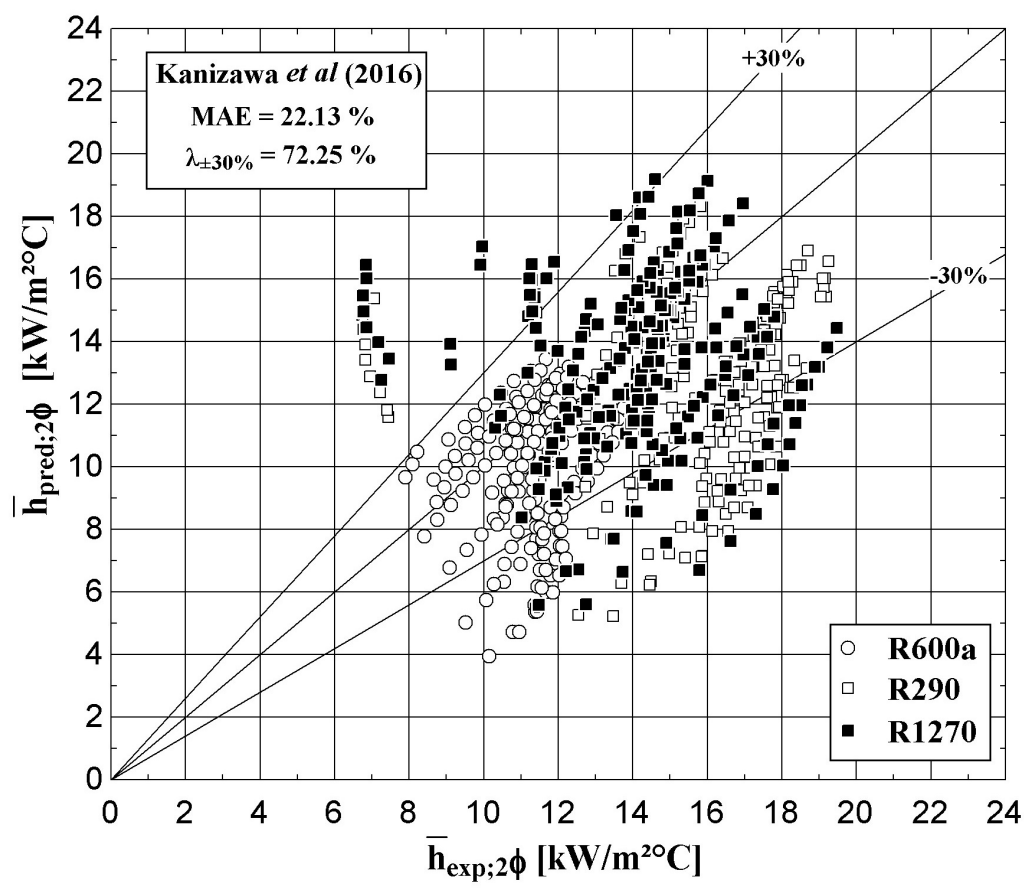

Figura 4.21 - Comparação entre o coeficiente de transferência de calor experimental e resultados determinados através do método de previsão de Kanizawa et al. (2016). 
A correlação de $\mathrm{Li}$ e Wu (2010) se baseia no ajuste de constantes empíricas que incluem uma parcela de resultados para a ebulição convectiva do R290 em canais únicos e outra parcela para água, R744 e R134a em multi-microcanais. Além disso, parcela significativa do banco de dados usado no desenvolvimento do método considera números de Reynolds da fase líquida inferiores a 5000, similares as condições do presente estudo.

O método proposto por Kanizawa et al. (2016) foi desenvolvido incluindo parcela de resultados experimentais obtidos para R600a. Além disso, os autores recomendam usar a correlação de Stephan e Abdelsalam (1980) desenvolvida especificamente para estimar o coeficiente de transferência de calor do mecanismo de ebulição nucleada em piscina de hidrocarbonetos. Desta forma, o cálculo de constantes empíricas no desenvolvimento do método considera condições próximas a do presente estudo.

A Figura 4.22 ilustra a variação do CTC com o título de vapor médio ao longo do comprimento bifásico, segundo os resultados experimentais obtidos no presente estudo e métodos de previsão disponíveis na literatura. De acordo com esta figura, de forma análoga aos resultados experimentais, os métodos da literatura também indicam o aumento do CTC com o incremento do título de vapor médio.

Nas Figuras 4.22 a 4.22 para $G=165 \mathrm{~kg} / \mathrm{m}^{2} \mathrm{~s}$, respectivamente, o método proposto por Li e Wu (2010) superestima os resultados experimentais dos refrigerantes R600a e R1270 e os métodos propostos por Liu e Winterton (1991), Thome et al. (2004), Saitoh et al. (2007) e Kanizawa et al. (2016) subestimam o CTC experimental para estes fluidos. Já, na Fig. 4.22. para o fluido R290, apenas o método proposto por Li e Wu (2010) prevê adequadamente estes resultados experimentais.

De acordo com a Fig. 4.22 p para $\mathrm{G}=658 \mathrm{~kg} / \mathrm{m}^{2} \mathrm{~s}$ e o fluido R600a, o método proposto por Kanizawa et al. (2016) prevê satisfatoriamente os resultados experimentais. Entretanto, conforme a Fig. 4.22d, o método de Li e Wu (2010) estima adequadamente o CTC experimental para o R290. Já para R1270, o método de Liu e Winterton (1991) prevê satisfatoriamente estes resultados conforme ilustra a Fig. 4.22.

Conforme indicado por Kandlikar e Balasubramanian (2004) e Lee et al. (2010), para velocidades mássicas reduzidas os efeitos de instabilidades térmicas relacionados ao crescimento abrupto de bolhas confinadas no interior dos microcanais se intensificam promovendo fluxo reverso. Este efeito, combinado à interação do escoamento entre canais vizinhos na região das câmaras não são incorporados pelos métodos de previsão do CTC desenvolvidos com base em resultados para canais únicos. Baseado nestas observações, torna-se razoável o fato dos métodos listados na Tabela 4.5 não preverem adequadamente os resultados sob condições de velocidades mássicas reduzidas. 

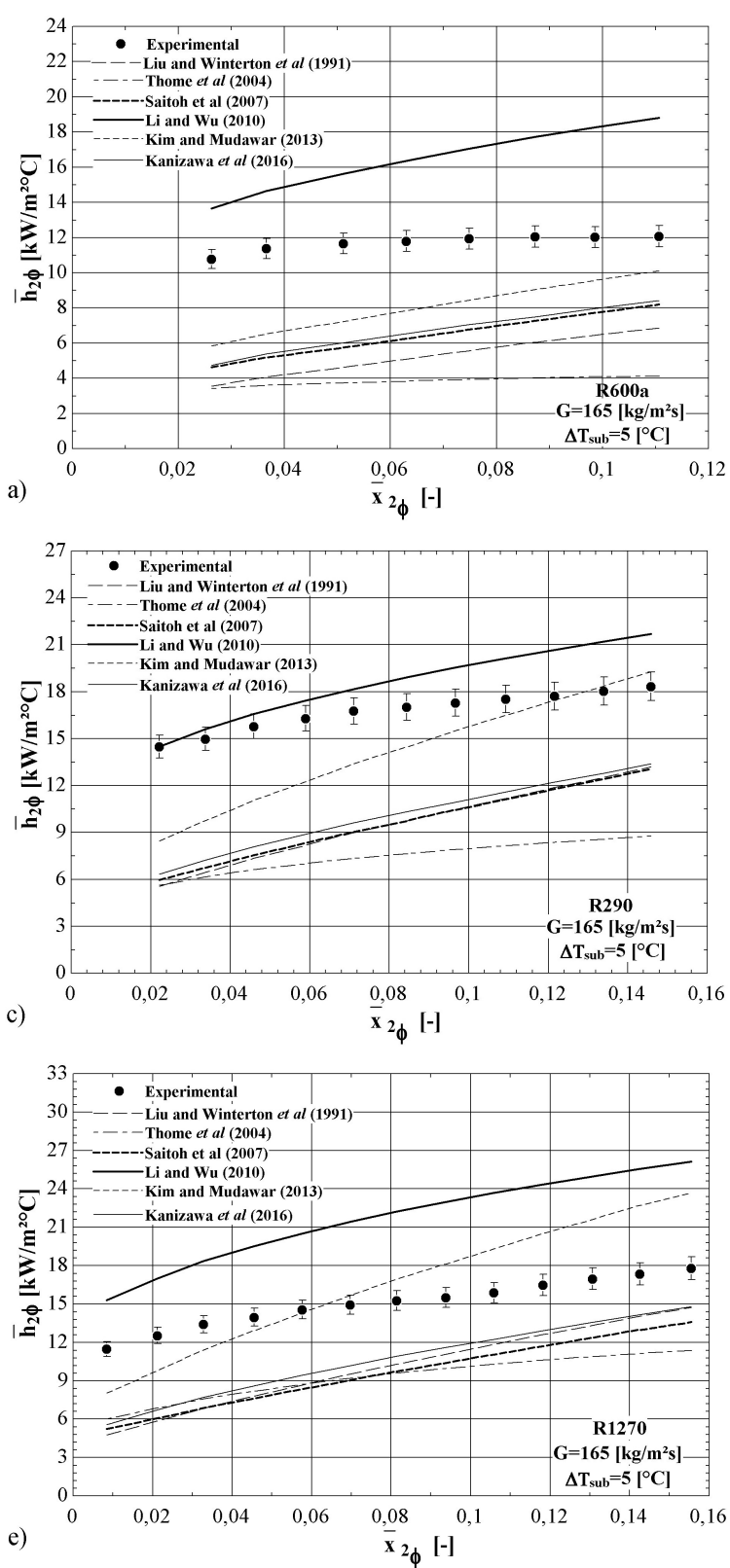
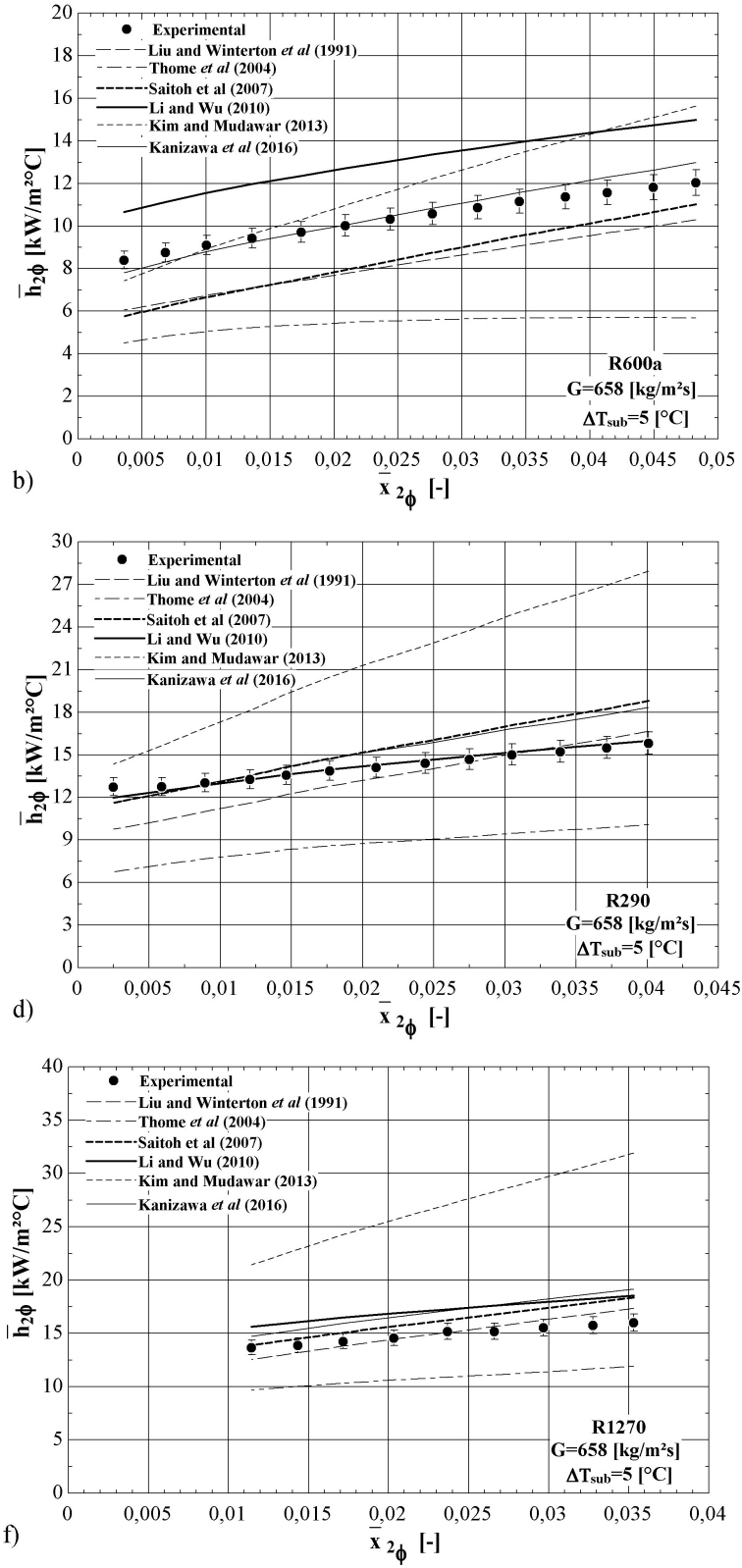

Figura 4.22 - Comparação das tendências do CTC com a variação do título de vapor médio, segundo os resultados experimentais levantados neste estudo e métodos de previsão da literatura.

Em geral, previsões satisfatórias verificam-se para velocidades mássicas elevadas, com desvios superiores para os métodos de Thome et al. (2004) e Kim e Mudawar (2013). Para vazões superiores, efeitos de instabilidades térmicas são amortizados reduzindo interações nas regiões das câmaras. Por outro lado, os métodos têm sido desenvolvidos com base em canais únicos e incluindo apenas uma parcela reduzida ou nula de dados experimentais para hidrocarbonetos. Desta forma, não é surpresa que os métodos não se adequem aos resultados experimentais levantados no presente estudo. 


\subsection{PERDA DE PRESSÃO}

Este item descreve os resultados obtidos neste estudo para a perda de pressão ao longo do dissipador de calor. Estes resultados são analisados parametricamente buscando-se identificar os efeitos dos parâmetros experimentais. O item ainda inclui a comparação dos resultados experimentais com os principais métodos de previsão da perda de pressão por atrito para escoamentos bifásicos disponíveis na literatura.

\subsubsection{ANÁLISE PARAMÉTRICA DOS EFEITOS DOS PARÂMETROS EXPERI- MENTAIS NA PERDA DE PRESSÃo}

\section{Efeito do grau de sub-resfriamento do líquido}

A Figura 4.23 ilustra o efeito do sub-resfriamento do fluido, na entrada da seção de testes, no comportamento da perda de pressão total com a variação do fluxo de calor. Nesta figura, nota-se o decréscimo da perda de pressão com o incremento do fluxo de calor independentemente do fluido refrigerante, para condições de escoamento monofásico ao longo do dissipador de calor. Tal comportamento deve-se a redução da viscosidade do líquido com o aumento da temperatura média do escoamento com o incremento da curva de ebulição. Verifica-se também na Fig. 4.23 que, a partir do fluxo de calor correspondente ao superaquecimento necessário para o início da ebulição, ocorre um incremento abrupto da perda de pressão a medida que aumenta-se $q$ " base. Assim, uma vez estabelecida a ebulição convectiva em parcela do dissipador, a perda de pressão se eleva com o aumento do fluxo de calor. Este comportamento está relacionado ao incremento do título de vapor médio ao longo do dissipador e o consequente aumento da velocidade média do escoamento. Efeitos de histerese caracterizados por distinções entre as curvas obtidas com incremento e decréscimo do fluxo de calor, também se verificam para a perda de pressão, de forma análoga ao observado no item 4.3 para as curvas de ebulição.

Finalmente, segundo a Fig. 4.23 o incremento do sub-resfriamento do fluido na entrada da seção de testes desloca as curvas $\Delta p_{T}$ vs. $q$ " base para a direita. Este comportamento implica na redução da perda de pressão total com o incremento de $\Delta T_{\text {sub }}$ para um determinado fluxo de calor dissipado. Ele decorre da redução da parcela do comprimento dos canais sob efeito de ebulição convectiva e consequentemente do título de vapor médio com o aumento de $\Delta T_{s u b}$. 

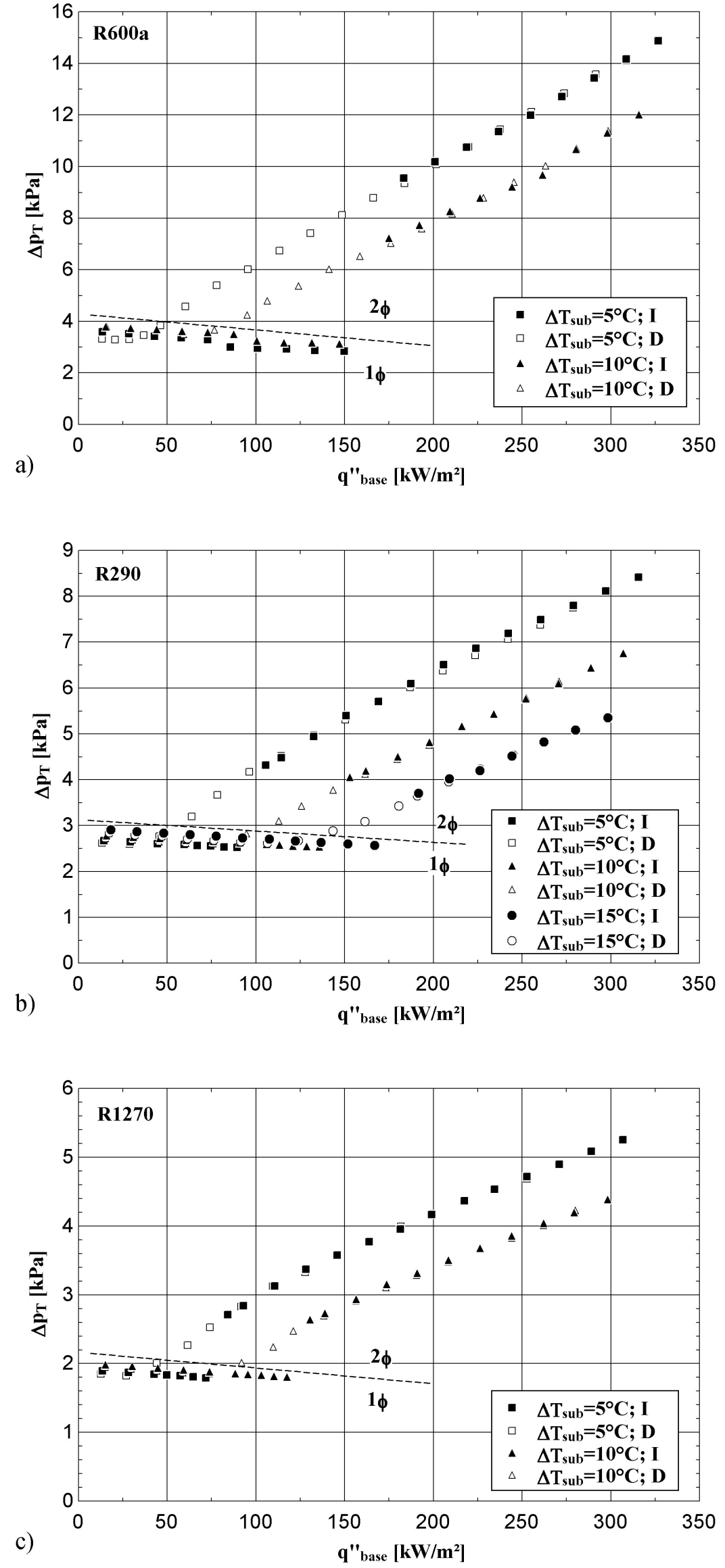

Figura 4.23 - Ilustração do efeito do sub-resfriamento do líquido sobre o comportamento da perda de pressão com a variação do fluxo de calor para $T_{\text {sat }}=25^{\circ} \mathrm{C}$ e $G=330 \mathrm{~kg} / \mathrm{m}^{2} \mathrm{~s}$. a) R600a; b) R290; c) 


\section{Efeito da velocidade mássica}

A Figura 4.24 ilustra o efeito da velocidade mássica no comportamento da perda de pressão total com a variação do fluxo de calor. Como esperado, para escoamento monofásico, a queda de pressão total aumenta com o incremento da velocidade mássica, dado um valor fixo do fluxo de calor. Este comportamento se deve ao incremento das forças de atrito nas regiões de perda localizada ao longo dos microcanais. Já para condições sob ebulição convectiva, para um determinado fluxo de calor se observa o aumento da perda de pressão total com o incremento da velocidade mássica. Este comportamento está relacionado ao fato de o aumento da velocidade mássica implicar na redução do título de vapor médio, e consequentemente um comprimento monofásico superior.

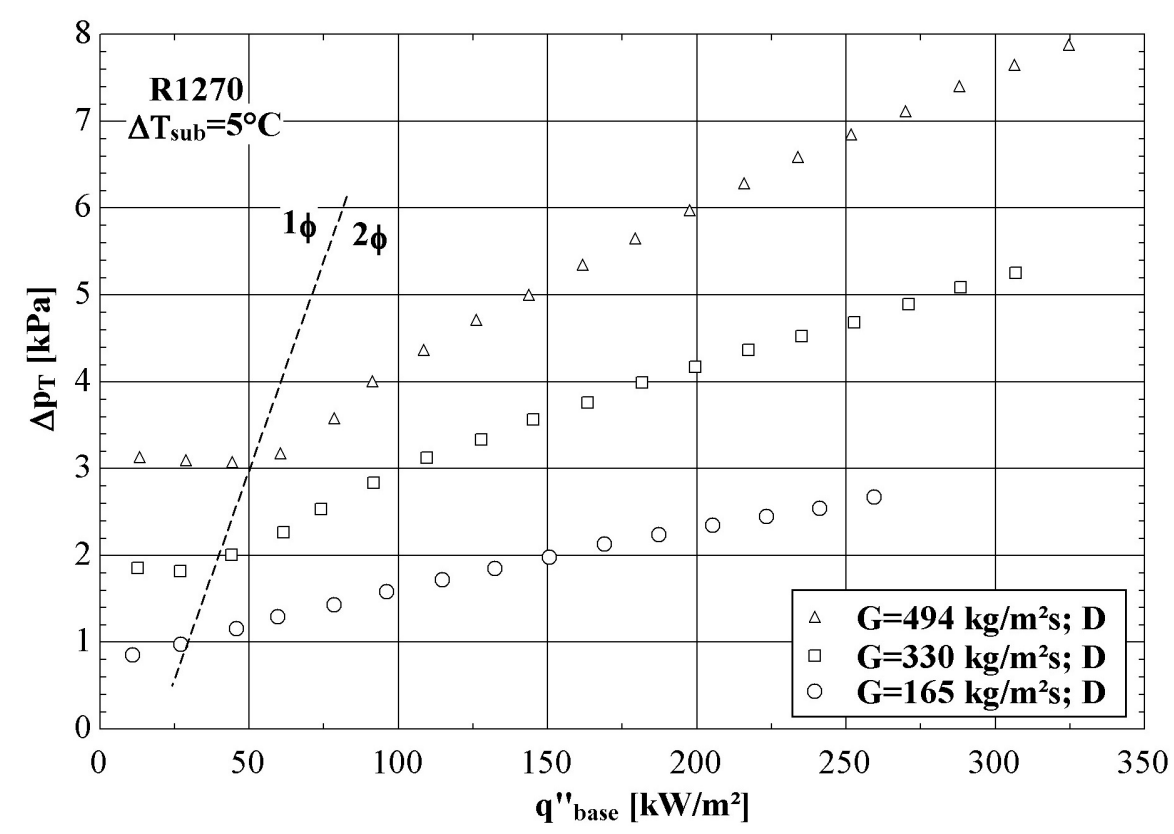

Figura 4.24 - Ilustração do efeito da velocidade mássica sobre o comportamento da perda de pressão com a variação do fluxo de calor para R1270, $T_{\text {sat }}=25^{\circ} \mathrm{C}$ e $\Delta T_{\text {sub }}=5{ }^{\circ} \mathrm{C}$

\section{Efeito do fluido refrigerante}

A Figura 4.25 ilustra comparações dos comportamentos da perda de pressão total com a variação do fluxo de calor para os fluidos avaliados no presente estudo e o R134a (Do Nascimento (2012)) para distintas velocidades mássicas. De acordo com esta figura, para a dissipação de fluxos de calor similares, os refrigerantes avaliados apresentam a seguinte ordem decrescente de perda de pressão: R134a, R600a, R290 e R1270. Valores superiores de $\Delta p_{T}$ para o R600a estão relacionados ao seu elevado volume específico para a fase vapor, implicando em uma velocidade superior do escoamento bifásico, e consequentemente uma perda de pressão superior. No caso do R134a, embora com volume específico da fase vapor inferior aos hidrocarbonetos, ele apresenta calor latente de evaporação razoavelmente inferior, de forma que 
seu título de vapor médio é superior aos demais fluidos implicando em uma maior velocidade do escoamento bifásico. A Figura 4.26 ilustra os comportamentos da perda de pressão total com a variação do título de vapor médio. Nela nota-se a seguinte ordem decrescente de perda de pressão: R600a, R134a, R290 e R1270. Neste contexto, o resultado levantado neste estudo para multi-microcanais, quando escritos em função do título de vapor médio, coincidem com os comportamento relativos constatados por Copetti et al. (2013) e Sempértegui-Tapia e Ribatski (2016) para canais únicos. Estes autores indicam que o refrigerante R600a apresenta valores superiores de perda de pressão em relação ao R134a.

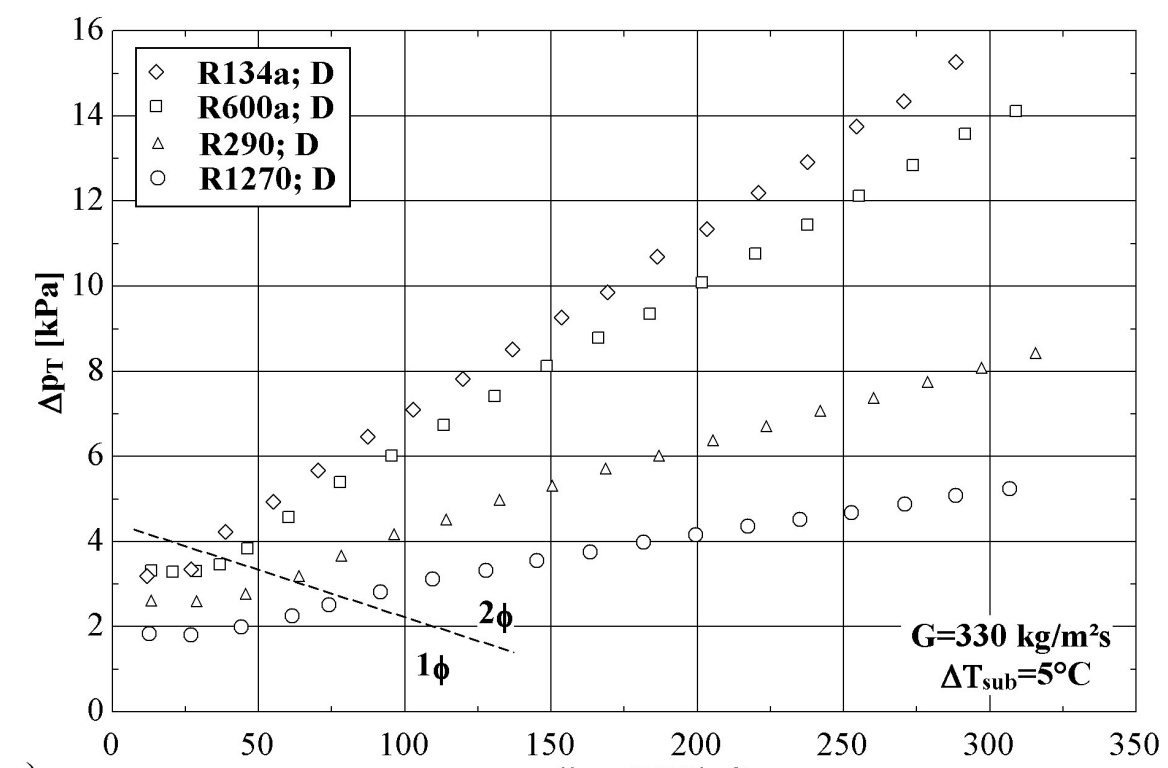

a)

$\mathbf{q}$ "base $\left[\mathbf{k W} / \mathbf{m}^{2}\right]$

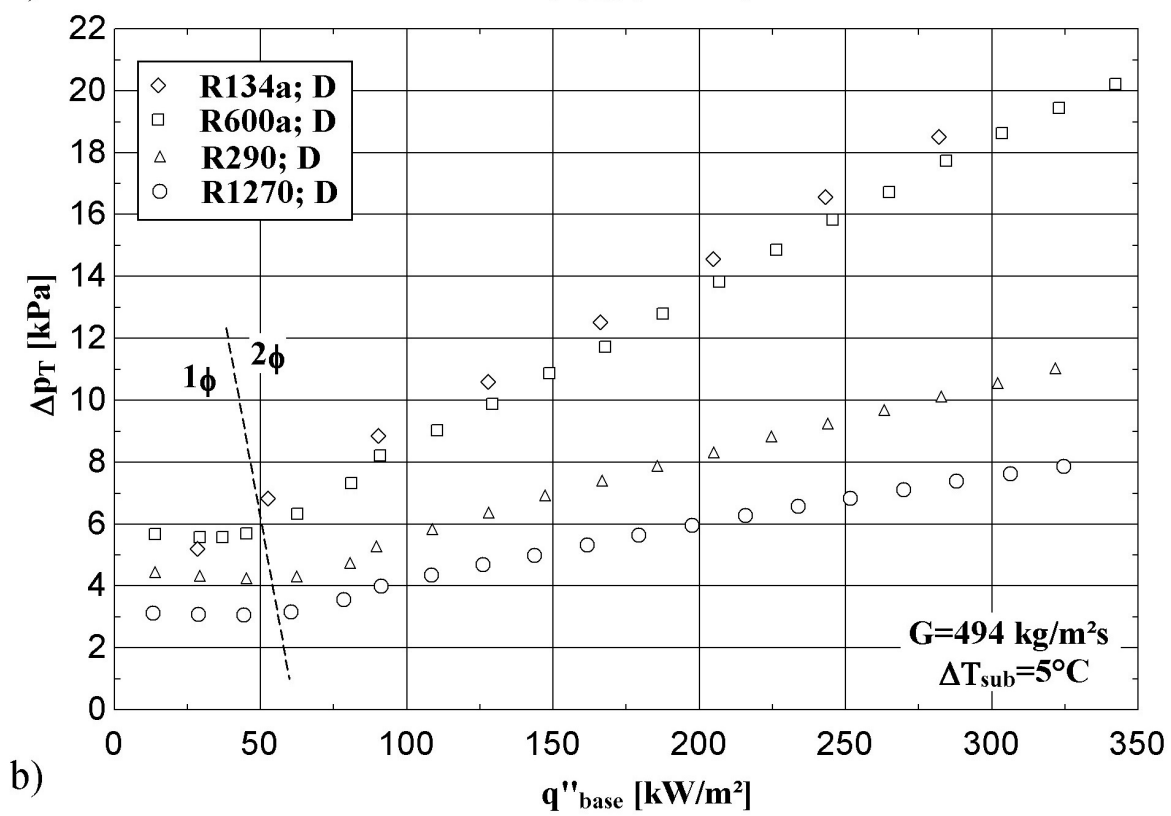

Figura 4.25 - Ilustração do efeito do fluido refrigerante sobre o comportamento da perda de pressão total com o decréscimo do fluxo de calor. $T_{\text {sat }}=25^{\circ} \mathrm{C}$. a) $330 \mathrm{~kg} / \mathrm{m}^{2} \mathrm{~s}$; b) $494 \mathrm{~kg} / \mathrm{m}^{2} \mathrm{~s}$. 


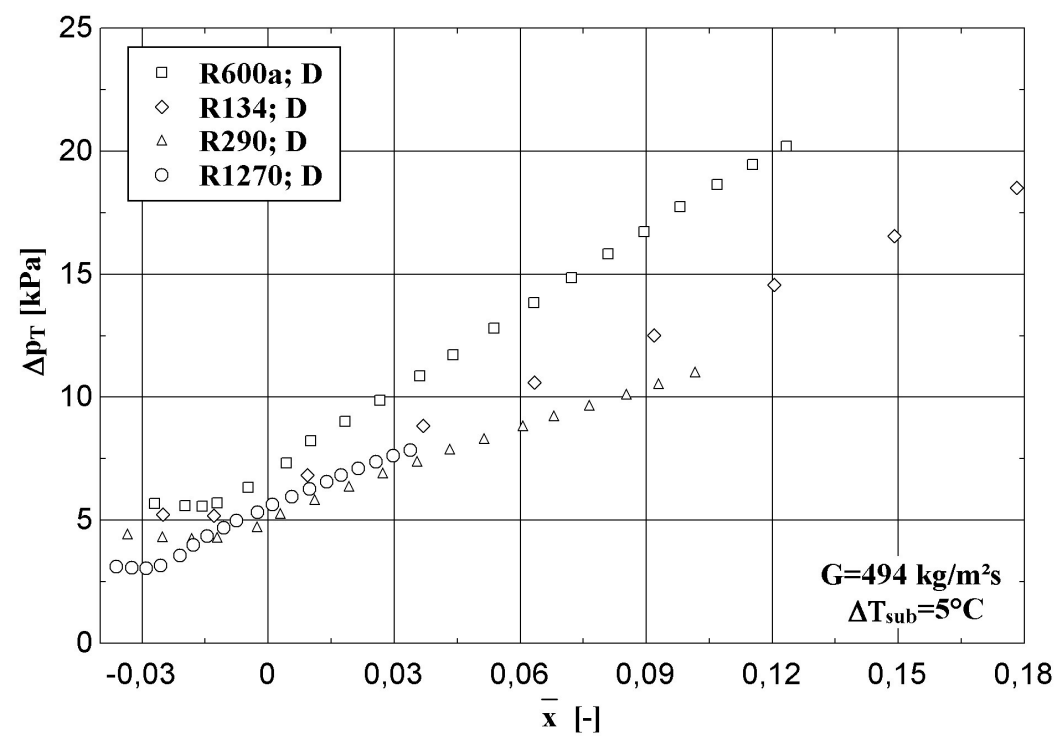

Figura 4.26 - Ilustração do efeito do fluido refrigerante sobre o comportamento da perda de pressão total com a variação do título de vapor médio para $T_{\text {sat }}=25^{\circ} \mathrm{C}$ e $G=494 \mathrm{~kg} / \mathrm{m}^{2} \mathrm{~s}$.

\subsubsection{COMPARAÇÃO ENTRE OS RESULTADOS EXPERIMENTAIS E MÉTODOS DE PREVISÃO PARA PERDA DE PRESSÃO POR ATRITO BIFÁSICA}

Este item apresenta uma análise sobre a capacidade de nove métodos disponíveis na literatura para estimativa da perda de pressão por atrito em preverem os resultados experimentais obtidos neste estudo para a região do dissipador envolvendo escoamento bifásico.

Para esta comparação, os métodos da literatura foram implementados ao longo do comprimento bifásico do dissipador correspondente a um canal discretizado segundo 10 elementos assumindo-se distribuição uniforme de fluido refrigerante entre os canais. Para cada elemento calculou-se o título de vapor local, a partir de balanço de energia considerando distribuição uniforme de fluxo de calor, fração de vazio superficial segundo o método de Kanizawa e Ribatski (2016) (no caso de modelos não homogêneos), as propriedades do fluido com base na pressão local e a perda de pressão aceleracional através da Eq. 2.10.

A Tabela 4.6 apresenta os resultados dos parâmetros estatísticos levantados a partir da comparação de perda de pressão por atrito bifásica experimental e os valores determinados através dos métodos de previsão. De acordo com esta tabela, os métodos não fornecem resultados estatísticos satisfatórios para a base de dados levantada neste estudo. O modelo homogêneo com a viscosidade da mistura bifásica segundo Beattie e Whalley (1982) apresentou, ainda que insatisfatória, a melhor previsão dos resultados proporcionando $\lambda_{ \pm 30 \%}=32,2 \%$.

A Figura 4.27 ilustra comparações entre a perda de pressão por atrito bifásica experimental e as correspondentes previsões segundo o Modelo Homogêneo com a viscosidade da mistura bifásica dada por Beattie e Whalley (1982). De acordo esta figura, o método subestima os resultados experimentais para R600a e R290. Já no caso do R1270 apenas parcela reduzida dos dados é superestimada, com a maioria sendo subestimada. 
Tabela 4.6 - Parâmetros estatísticos de comparação para perda de pressão bifásica

\begin{tabular}{|c|c|c|c|c|c|c|c|c|}
\hline \multirow[b]{3}{*}{ Método de previsão } & \multicolumn{8}{|c|}{ Fluido } \\
\hline & \multicolumn{2}{|c|}{ R600a } & \multicolumn{2}{|c|}{$\mathbf{R 2 9 0}$} & \multicolumn{2}{|c|}{ R1270 } & \multicolumn{2}{|c|}{ Total } \\
\hline & $\begin{array}{l}\text { MAE } \\
{[\%]}\end{array}$ & $\begin{array}{c}\lambda[\%] \\
\pm 30[\%]\end{array}$ & $\begin{array}{l}\text { MAE } \\
{[\%]}\end{array}$ & $\begin{array}{c}\lambda[\%] \\
\pm 30[\%]\end{array}$ & $\begin{array}{l}\text { MAE } \\
{[\%]}\end{array}$ & $\begin{array}{c}\lambda[\%] \\
\pm 30[\%]\end{array}$ & $\begin{array}{l}\text { MAE } \\
{[\%]}\end{array}$ & $\begin{array}{c}\lambda[\%] \\
\pm 30[\%]\end{array}$ \\
\hline Lockhart e Martinelli $\mid$ & 70,2 & 0,0 & 67,4 & 2,3 & 40,3 & 13,3 & 60,8 & 4,6 \\
\hline Homogêneo + Chicchitti et al. $(1960)$ & 44,7 & 29,1 & 57,6 & 12,4 & 25,9 & 61,1 & 45,8 & 29,2 \\
\hline Homogêneo + Beattie e Whalley (1982) & 44,2 & 28,5 & 54,7 & 16,6 & 27,3 & 63,3 & 44,7 & 32,2 \\
\hline Müller-Steinhagen e Heck (1986) & 64,3 & 0,0 & 67,2 & 1,8 & 39,5 & 18,9 & 59,9 & 4,6 \\
\hline Qu e Mudawar (2003a) & 59,4 & 0,6 & 60,3 & 1,8 & 33,5 & 56,7 & 55,4 & 15,6 \\
\hline Cioncolini et al. (2009) & 86,2 & 0,0 & 85,0 & 0,0 & 57,7 & 24,4 & 76,5 & 5,2 \\
\hline Del Col et al. (2013) & 59,2 & 0,0 & 68,4 & 1,4 & 41,2 & 18,9 & 59,9 & 4,4 \\
\hline Sempértegui-Tapia e Ribatski $(2016)$ & 71,2 & 0,0 & 73,8 & 2,3 & 50,3 & 5,6 & 66,7 & 1,9 \\
\hline
\end{tabular}

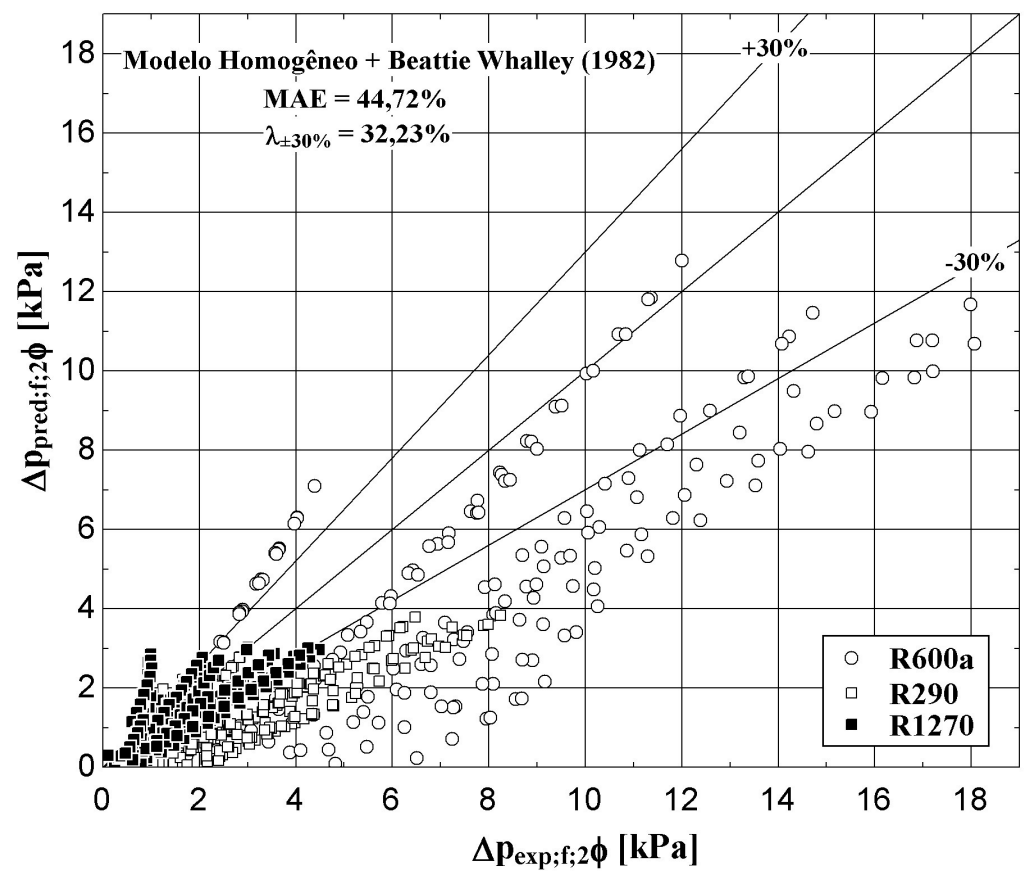

Figura 4.27 - Comparação dos resultados experimentais com método de predição Homogêneo + Beattie e Whalley (1982) para perda de pressão por atrito bifásica.

Vale destacar, entre os métodos avaliados, apenas Del Col et al. (2013) e SempérteguiTapia e Ribatski (2016) incluíram dados experimentais levantados respectivamente para R290 e R600a em seus desenvolvimentos. Neste contexto, a proposição de novos métodos que incluam resultados para hidrocarbonetos em seu banco de dados são ainda necessários. Vale destacar que, apenas o método de Qu e Mudawar (2003a) foi desenvolvido para multi-microcanais, no entanto, contando apenas com dados para ebulição convectiva do água.

Neste contexto, os resultados observados são esperados, pois como indicado por Tibiriçá e Ribatski (2013), os métodos desenvolvidos para escoamentos bifásicos em canais individuais e condições de macro-escala não são adequados para a previsão de queda de pressão em multimicrocanais. Vários aspectos típicos dos mecanismos de ebulição convectiva em dissipadores de calor baseados em multi-microcanais, como a má distribuição de fluido e instabilidades térmicas não são capturados pelos métodos desenvolvidos para canais individuais. 


\subsection{ANÁLISE COMPARATIVA DO DESEMPENHO DOS REFRIGE- RANTES BASEADA NA $2^{\circ}$ LEI DA TERMODINÂMICA}

Esta seção apresenta uma análise do desempenho termo-hidráulico do dissipador de calor baseada na $2 \circ$ Lei da Termodinâmica. Inicialmente, apresenta-se uma introdução na qual se destaca a importância das análises baseadas em exergias e compara-se relativamente as irreversibilidades associadas aos processos de transferência de calor e perda de pressão. Finalmente, são analisados os resultados para a eficiência da $2 \circ$ Lei.

\subsubsection{INTRODUÇÃO}

A importância de uma análise baseada na $2 \circ$ Lei da Termodinâmica, se destaca a partir dos seguintes aspectos: (i) permite o desenvolvimento de trocadores de calor incluindo um parâmetro adicional de desenho, com avaliação dos fluxos de energia entre a superfície dos microcanais e o fluido refrigerante, incorporando efeitos de transferência de calor e de fricção. Shah e Sekulic (2003) ressaltam a importância do desenho de trocadores de calor com base em um critério envolvendo a $2 \circ$ Lei que, segundo eles, fornece informação adicional descrevendo o processo de transporte de energia. (ii) o processo de transferência de calor durante a ebulição convectiva em dissipadores de calor baseados em microcanais, apresenta elevadas perdas de pressão, o qual implica em uma variação significativa da temperatura de saturação sendo isto, uma característica representativa do refrigerante, pois envolve a alteração da diferença de temperatura entre a parede do microcanal e o fluido. Este fato não é caracterizado por uma análise da transferência de calor baseada apenas em refrigerantes que fornecem CTC similares e diferentes perdas de pressão. Este aspecto também é indicado por Cavallini et al. (2010) em sua análise comparativa do desempenho de refrigerantes considerando termos de penalização com base nas perdas de exergia. Neste contexto, Bejan e Pfister (1980) e Bejan (1982, 1996 e 1997) ressaltam a importância de avaliar a conservação de energia útil (exergia, o trabalho disponível) ao analisar os processos de fluxo de energia e, avaliar técnicas de intensificação da transferência de calor, o qual pode ser medido em termos de taxa de geração de entropia (irreversibilidade, destruição exergia) no dispositivo de transferência de calor no qual é aplicada.

As Figuras 4.28 a 4.32 apresentam os resultados obtidos através da análise baseada na 2 Lei da Termodinâmica. Os dados apresentados nestas figuras correspondem apenas a condições de redução progressiva do fluxo de calor (D) e foram distribuídos segundo as regiões $1 \phi$ e $2 \phi$ descritas no item 4.4.1. Uma análise de exergia para condições de incremento progressivo de fluxo de calor (I) não é apresentada, pois parece razoável avaliar o dissipador em condições nas quais os sítios de nucleação encontram-se ativos, correspondendo a uma condição operacional típica. No caso de resultados indicando efeitos de histerese corresponderia à apenas uma condição de início de operação. 


\subsubsection{IRREVERSIBILIDADES}

Inicialmente, uma análise para determinar os efeitos relativos da transferência de calor e de perda de pressão sobre a irreversibilidade gerada foi efetuada. Tal análise foi efetuada com base no Número de Bejan $(B e)$, dado pela seguinte equação:

$$
B e=\frac{1}{1+N_{i}}
$$

onde $N_{i}$ é conhecido na literatura como o número de intensificação dos efeitos de entropia gerada no processo e corresponde à razão entre as irreversibilidades devido à perda de pressão e à transferência de calor, $N_{i}=\dot{S}_{g e r ; \Delta p} / \dot{S}_{g e r ; \Delta T}$. Desta forma, para Be próximos a unidade, os efeitos predominantes correspondem a irreversibilidades geradas devido à diferenças de temperatura durante o processo de transferência de calor. Já, para valores de $B e$ próximos a zero, os efeitos predominantes correspondem a irreversibilidades geradas na perda de pressão.

No presente estudo, verificou-se Números de Bejan entre $0,97 e B e \leq 0,99$. Desta forma, verifica-se que os efeitos predominantes sobre as irreversibilidades ao longo do dissipador estão relacionados ao processo de transferência de calor. Vale destacar que, embora a irreversibilidade diretamente associada ao decréscimo da pressão seja reduzida, ela afeta a irreversibilidade associada à diferença de temperatura no processo de transferência de calor devido à variação da temperatura de saturação ao longo dos canais com a diminuição da pressão de saturação.

As Figuras 4.28 e 4.29 ilustram o comportamento da taxa de geração de entropia experimental com a variação do fluxo de calor para os hidrocarbonetos avaliados no presente estudo e o R134a. Nesta figuras, sob condições correspondentes a $1 \phi$ ao longo do dissipador de calor, a taxa de geração de entropia aumenta apenas marginalmente com o aumento do fluxo de calor. Além disso, os refrigerantes apresentam comportamentos próximos.

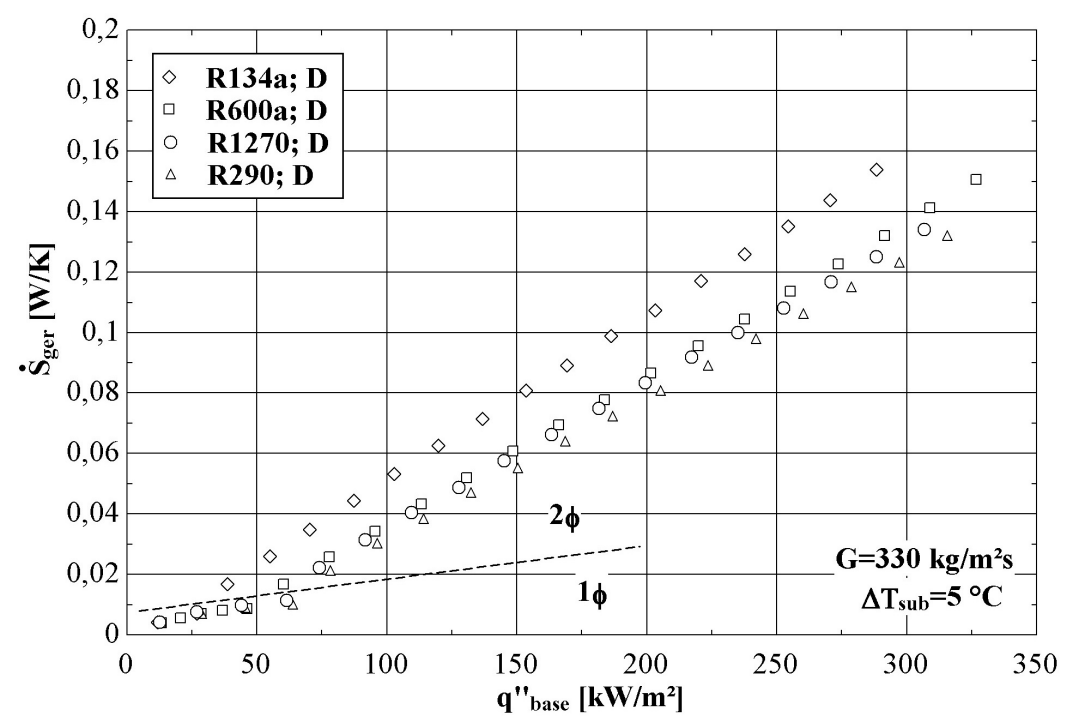

Figura 4.28 - Ilustração do efeito do fluido refrigerante sobre a taxa de geração de entropia com a variação do fluxo de calor para $G=330 \mathrm{~kg} / \mathrm{m}^{2} \mathrm{~s}$. 
O gradiente de taxa de geração de entropia com a variação do fluxo de calor na presença de ebulição convectiva ao longo dos canais correspondente a região $2 \phi$, é superior a região $1 \phi$, e apresenta valores aproximadamente constantes. Além disso, de acordo com a Fig. 4.28, o refrigerante R134a fornece a maior taxa de geração de entropia para um fluxo de calor fixo comparado com os hidrocarbonetos. Segundo a Fig. 4.28, para a velocidade mássica de $330 \mathrm{~kg} / \mathrm{m}^{2} \mathrm{~s}$, as diferenças de geração de entropia entre os hidrocarbonetos são marginais. No entanto, para uma velocidade mássica de $658 \mathrm{~kg} / \mathrm{m}^{2} \mathrm{~s}$, como mostrado na Fig. 4.29, o refrigerante R600a apresenta uma taxa de geração de entropia nitidamente superior ao R290 e ao R1270. Estes dois fluidos apresentam taxas de geração de entropia próximas independentes da velocidade mássica.

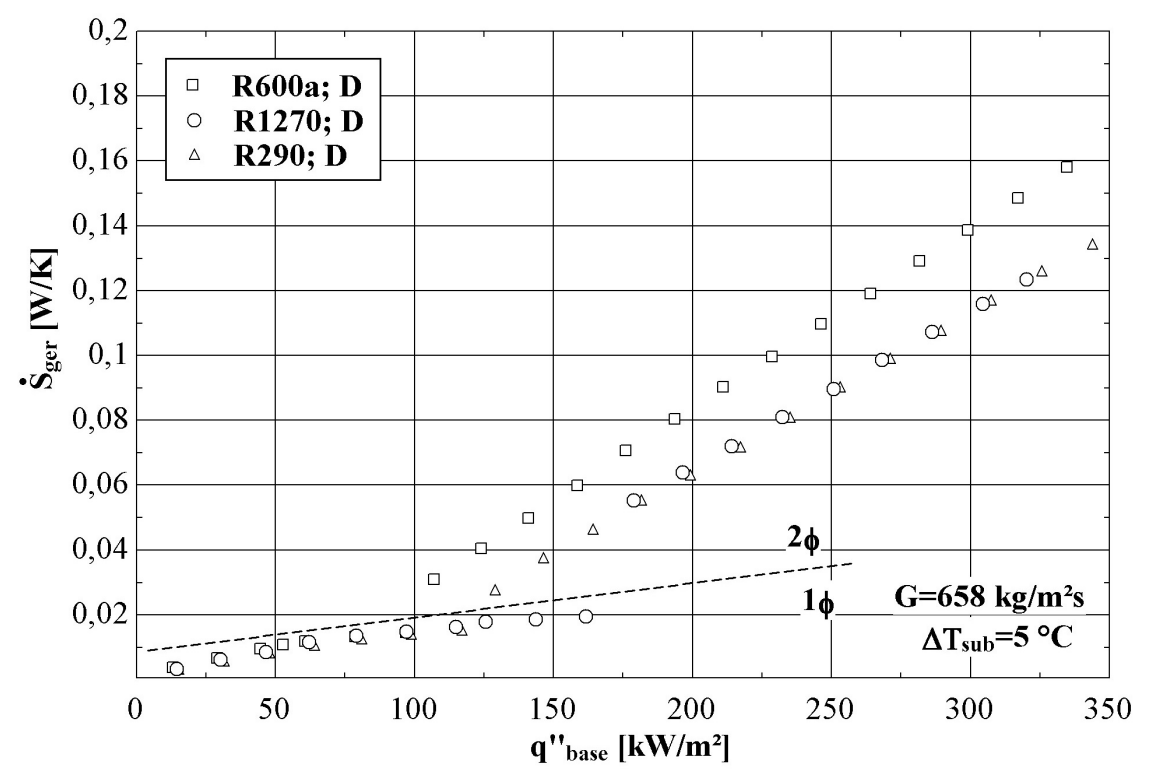

Figura 4.29 - Ilustração do efeito do fluido refrigerante sobre a taxa de geração de entropia com a variação do fluxo de calor para $G=658 \mathrm{~kg} / \mathrm{m}^{2} \mathrm{~s}$.

\subsubsection{EFICIÊNCIA DE ACORDO COM A $2^{\circ}$ LEI DA TERMODINÂMICA}

As Figuras 4.30 a 4.32 ilustram o comportamento da Eficiência da Segunda Lei com a variação do fluxo de calor para diferentes condições experimentais. De acordo com estas figuras, em condições correspondentes a $2 \phi$, a Eficiência da Segunda Lei diminui com o aumento do fluxo de calor e tende para um valor assintótico para fluxos de calor elevados, quando a razão entre as exergias destruída e fornecida tende para um valor constante.

Um comportamento curioso é observado nas Figs. 4.30 a 4.32 para os dados obtidos em condições de redução progressiva do fluxo de calor. De acordo com estas figuras, para escoamento sob condições correspondentes a região $1 \phi, \eta_{I I}$ apresenta um "platô" caracterizado por um aumento marginal da Eficiência da Segunda Lei com a elevação do fluxo de calor. Para condições caracterizadas pela região $2 \phi$ ao longo dos canais, $\eta_{I I}$ diminui com o aumento do fluxo de calor. 
De acordo com a Fig. 4.30, $\eta_{I I}$ decresce com a redução do grau de sub-resfriamento do líquido na entrada da seção de testes. Este comportamento está associado ao fato da redução da temperatura na entrada do dissipador resulta no incremento de exergia destruída. Este efeito é predominante comparado com o incremento da diferença de temperatura verificado para graus de sub-resfriamento superiores.

Segundo a Fig. 4.31, a Eficiência da Segunda Lei aumenta com o incremento da velocidade mássica. Este resultado pode ser explicado com base na comparação das Figs. 4.28 e 4.29 . a partir da qual constata-se que a taxa de geração de entropia diminui com o aumento da velocidade mássica.

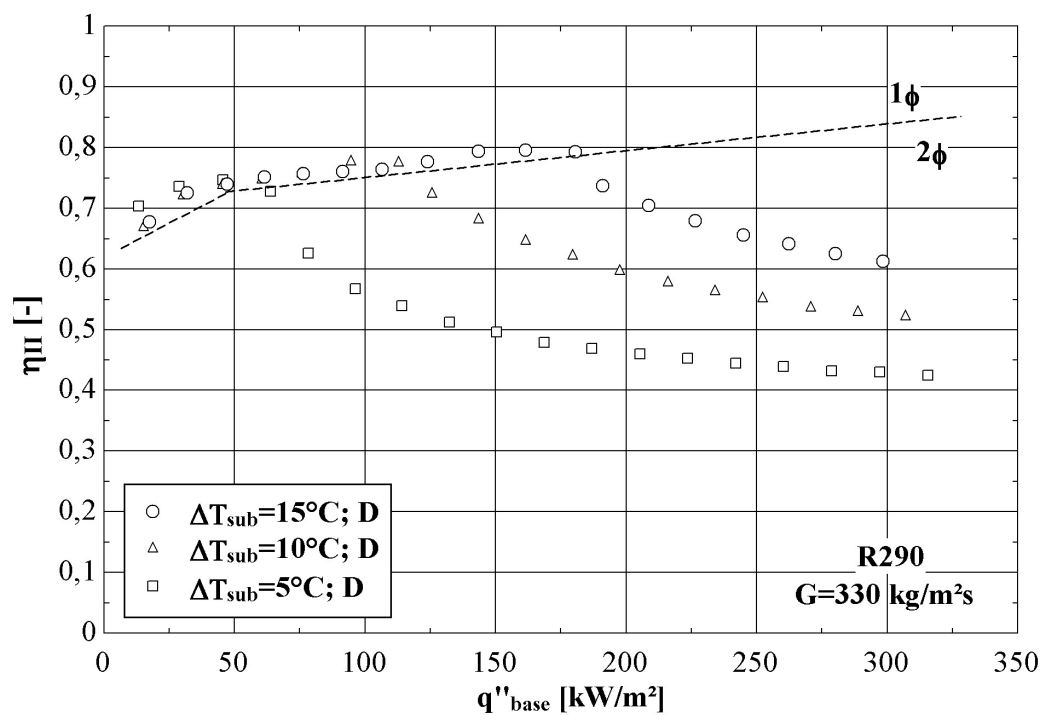

Figura 4.30 - Ilustração do efeito do grau de sub-resfriamento líquido no comportamento da Eficiência da $2^{\circ}$ Lei com o decréscimo gradual do fluxo de calor. R290, $T_{\text {sat }}=25^{\circ} \mathrm{C}$ e $G=330 \mathrm{~kg} / \mathrm{m}^{2} \mathrm{~s}$.

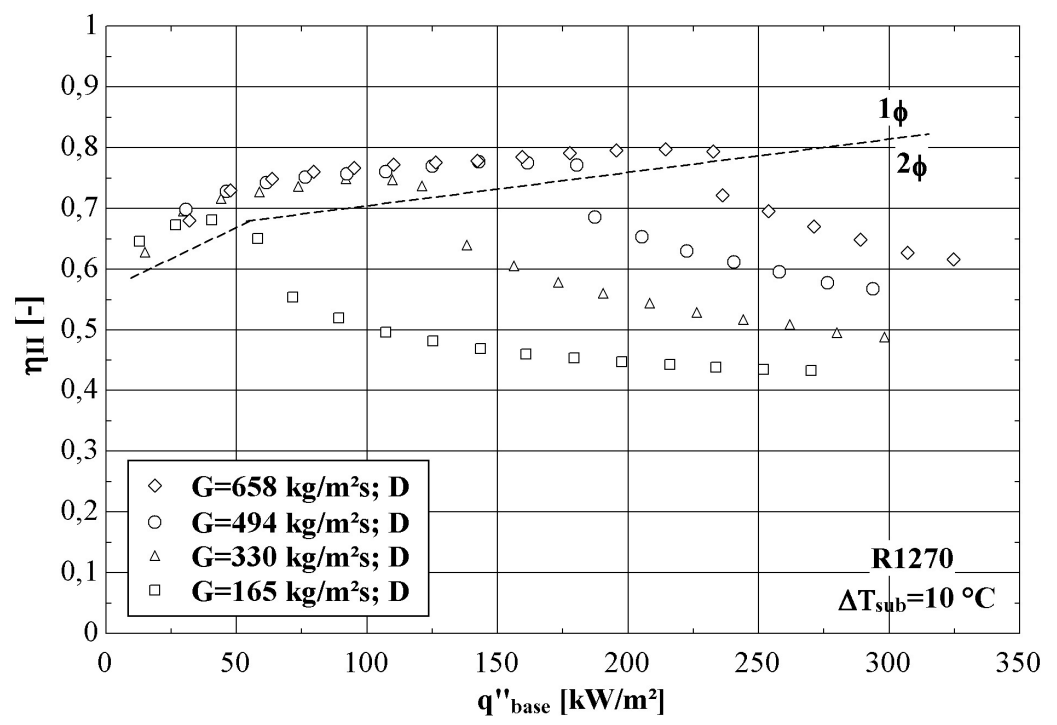

Figura 4.31 - Ilustração do efeito da velocidade mássica sobre o comportamento da Eficiência da $2^{\circ}$ Lei com o decréscimo gradual do fluxo de calor. R1270, $T_{\text {sat }}=25^{\circ} \mathrm{C}$ e $\Delta T_{\text {sub }}=10{ }^{\circ} \mathrm{C}$. 
A Figura 4.32 ilustra o efeito do fluido sobre o comportamento da Eficiência da Segunda Lei com a variação do fluxo de calor. De acordo com esta figura, a ordem decrescente para a Eficiência da Segunda Lei é a seguinte: R290, R1270/R600a e R134a. Este resultado devese principalmente aos coeficientes de transferência de calor superiores fornecidas pelo R290, como indicado anteriormente. Resultados similares para o R1270 e o R600a estão relacionados com o coeficiente de transferência de calor elevado de ambos os fluidos e a contribuição relativamente reduzida da perda de pressão para a ineficiência do processo, tal como mostrado através da análise do Número Bejan. O desempenho inferior do R134a em comparação com os hidrocarbonetos deve-se a este refrigerante fornecer coeficientes de transferência de calor inferiores e uma maior perda de pressão para um fluxo de calor fixo.

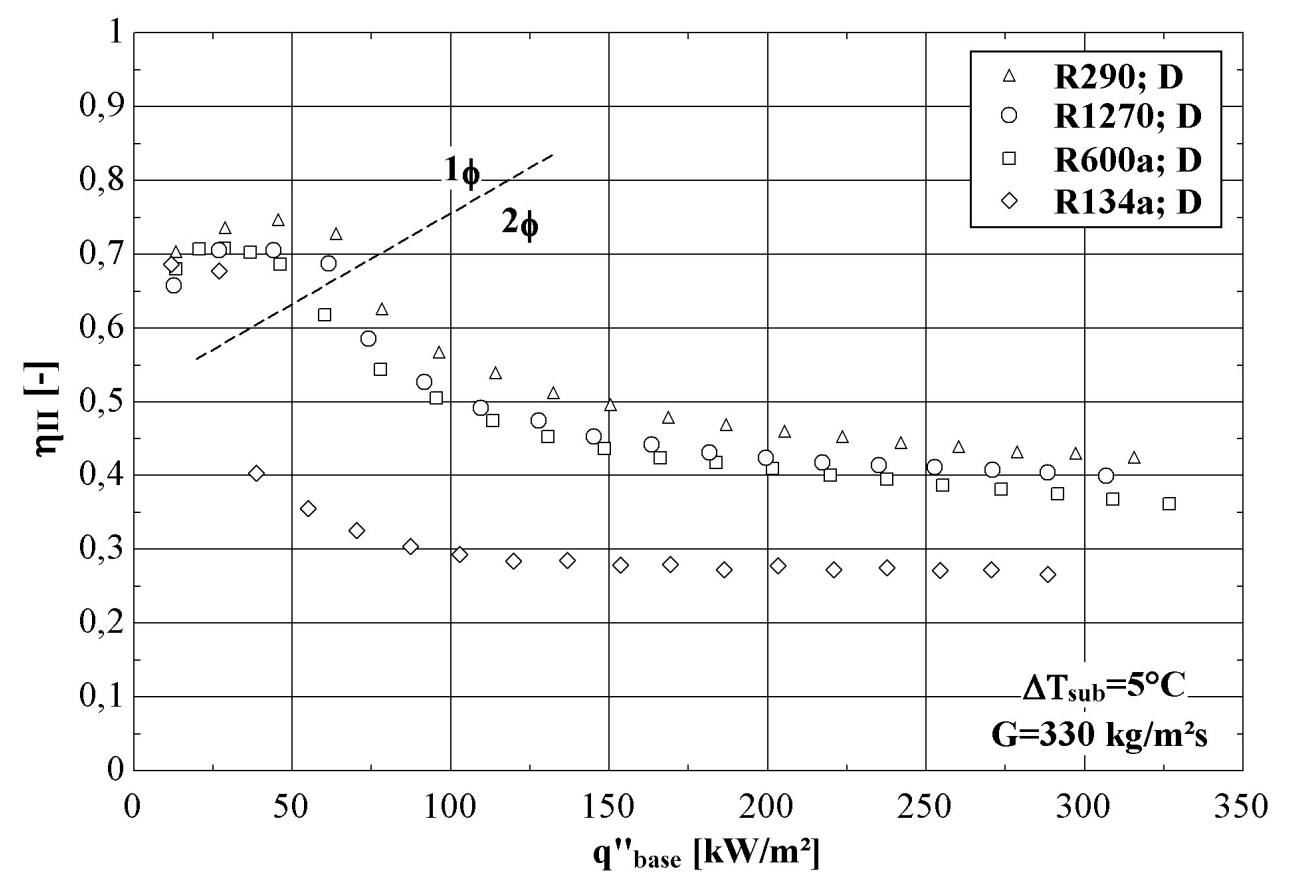

Figura 4.32 - Ilustração do efeito do fluido refrigerante sobre o comportamento da Eficiência da $2^{\circ}$ Lei com o decréscimo gradual do fluxo de calor. $G=330 \mathrm{~kg} / \mathrm{m}^{2} \mathrm{~s}, T_{\text {sat }}=25{ }^{\circ} \mathrm{C}$ e $\Delta T_{\text {sub }}=5{ }^{\circ} \mathrm{C}$.

\subsection{ANÁLISE DAS INSTABILIDADES TÉRMICAS DURANTE A EBU- LIÇÃO CONVECTIVA}

Uma análise das oscilações durante a ebulição convectiva foi efetuada. Esta análise se baseia nos sinais fornecidos pelo transdutor diferencial de pressão, transdutor de pressão absoluta conectado a entrada do dissipador de calor e o termopar localizado na saída deste.

Segundo os fabricantes, os tempos de resposta do transdutor diferencial de pressão, transdutor de pressão absoluta e termopar na câmara de saída correspondem a 40, 20 e $5 \mathrm{~ms}$, respectivamente. Desta forma, estes transdutores são adequados para a análise da oscilação de fenômenos com frequência de até $50 \mathrm{~Hz}$. 
As Figuras 4.33, 4.34 e 4.35 ilustram o sinal do termopar localizado na saída da seção de testes, transdutor de pressão absoluta e diferencial de pressão, respectivamente. Nelas, compara-se o sinal de cada transdutor para condições de escoamento monofásico com o sinal obtida sob a presença de ebulição convectiva. De acordo com a Fig. 4.33, as frequências e a amplitude das oscilações para condições de escoamento monofásico e ebulição convectiva são distintas. Desta forma, contata-se que uma parcela das oscilações não são resultado das instabilidades durante a ebulição convectiva e do crescimento de bolhas em condições confinadas.

De acordo com a Fig. 4.34 o valor da amplitude média do sinal para condições monofásicas corresponde a um $1 \%$ da magnitude das oscilações obtidas para escoamento com a presença de ebulição convectiva. Desta forma, contata-se que as oscilações são resultado das instabilidades durante a ebulição convectiva e do crescimento de bolhas em condições confinadas. Por outro lado, como foi indicado, o transdutor de pressão absoluta utilizado para o R600a é diferente ao transdutor utilizado para os refrigerantes R290 e R1270. Isto não têm efeito sobre as oscilações, pois os valores poderiam ser normalizados com base no fundo de escala, no entanto, apresentam incertezas diferentes para cada fluido, como mostrado na Tabela 3.5. Desta forma, para estudo e análise comparativa de oscilações, não foi utilizado este transdutor.

Segundo a Fig. 4.35, a amplitude do sinal obtida durante escoamento monofásico apresenta valores próximos ao sinal fornecido para escoamento com a presença de ebulição convectiva. Este comportamento deve-se principalmente ao fato do efeito chegar ao mesmo tempo dos dois lados do sensor, anulando a diferença no interior do canal de dimensão reduzida. Desta forma, o transdutor diferencial de pressão não será usado na análise comparativa de oscilações, devido a impossibilidade de identificar o efeito da ebulição convectiva neste sinal.

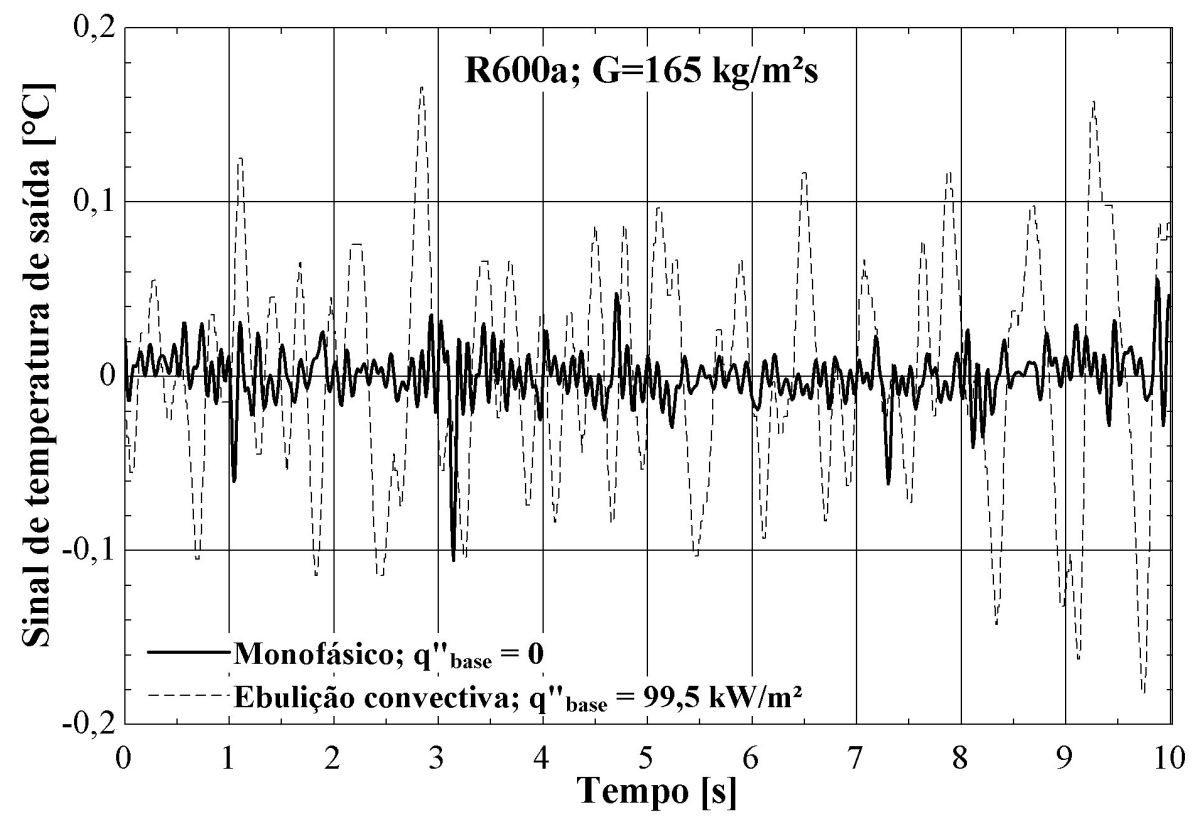

Figura 4.33 - Sinal do termopar localizado na saída da seção de testes para escoamento monofásico e com a presença de ebulição convectiva para R600a. 


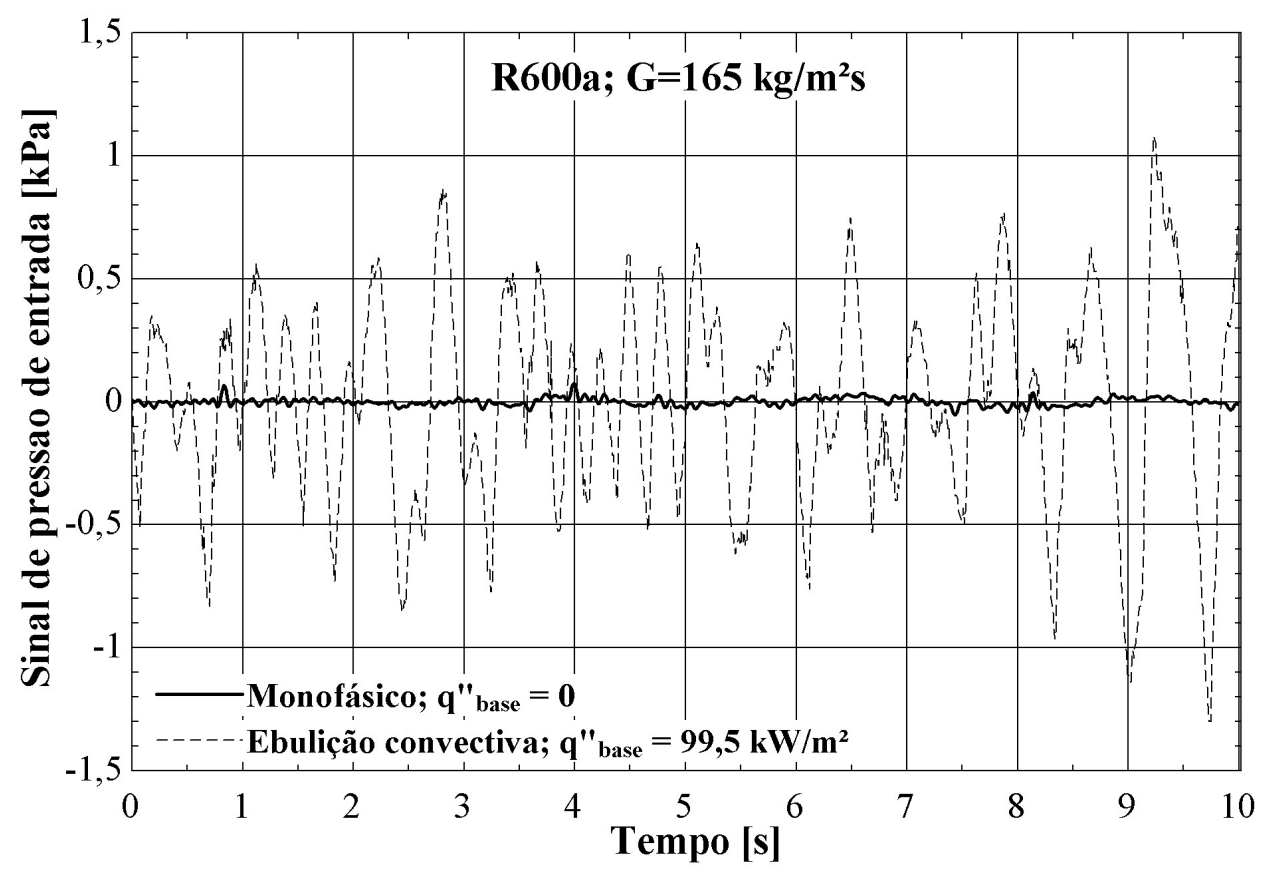

Figura 4.34 - Sinal do transdutor de pressão absoluta para escoamento monofásico e com a presença de ebulição convectiva para R600a.

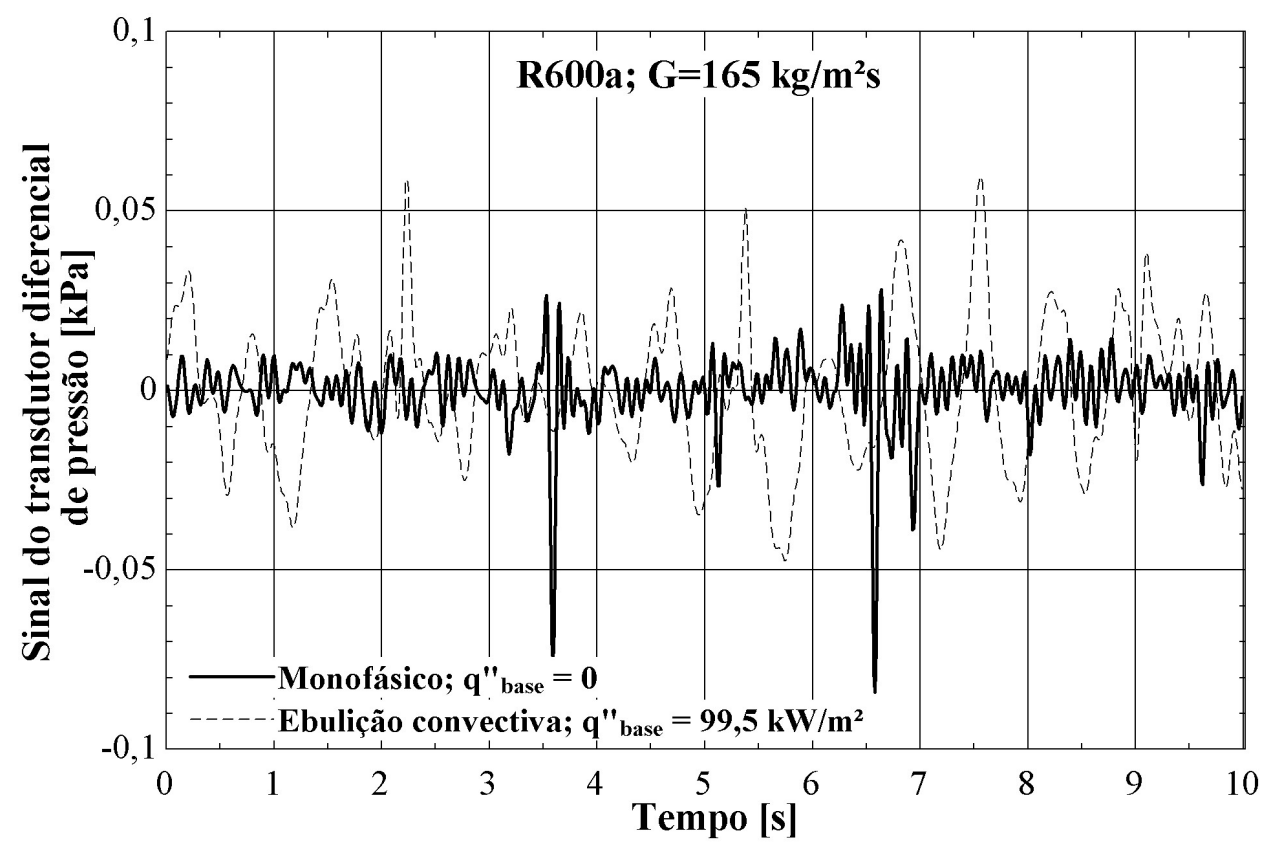

Figura 4.35 - Sinal do transdutor diferencial de pressão para escoamento monofásico e com a presença de ebulição convectiva para R600a.

As Figuras 4.36a, 4.36 e 4.36 ilustram respectivamente os sinais de pressão absoluta, temperatura e transdutor diferencial de pressão para o R600a. As Figs. 4.36 b, 4.36 d e 4.36f, apresentam as Transformadas de Fourier (FFT: fast Fourier transform) no domínio da frequência dos sinais mencionados. 
De acordo com as FFTs ilustradas nas Figs. 4.36 , 4.36d e 4.36f, verificam-se oscilações com amplitudes máximas a uma frequência de $1,5 \mathrm{~Hz}$ para os três sinais correspondentes a pressão absoluta, temperatura e transdutor diferencial de pressão. Desta forma, constata-se que pode ser identificada a amplitude e a frequência de oscilação a partir de destes sinais. No entanto, devido ao termopar na câmara de saída apresentar tempos de resposta inferiores, no seu sinal pode ser identificado o efeito da ebulição convectiva e foi utilizado para realizar todos os testes, resultados neste estudo são descritos apenas com base neste sinal.

As Figuras 4.36 $\mathrm{p}$, 4.36 $\mathrm{d}$ e $4.36 \mathrm{f}$ foram elaboradas com a temperatura da saída normalizada segundo a distribuição normal N[0,1]. Entretanto, para as Figs. 4.37 a 4.42, as temperaturas da saída do dissipador foram normalizadas segundo a razão entre a amplitude e a norma da amplitude do sinal.
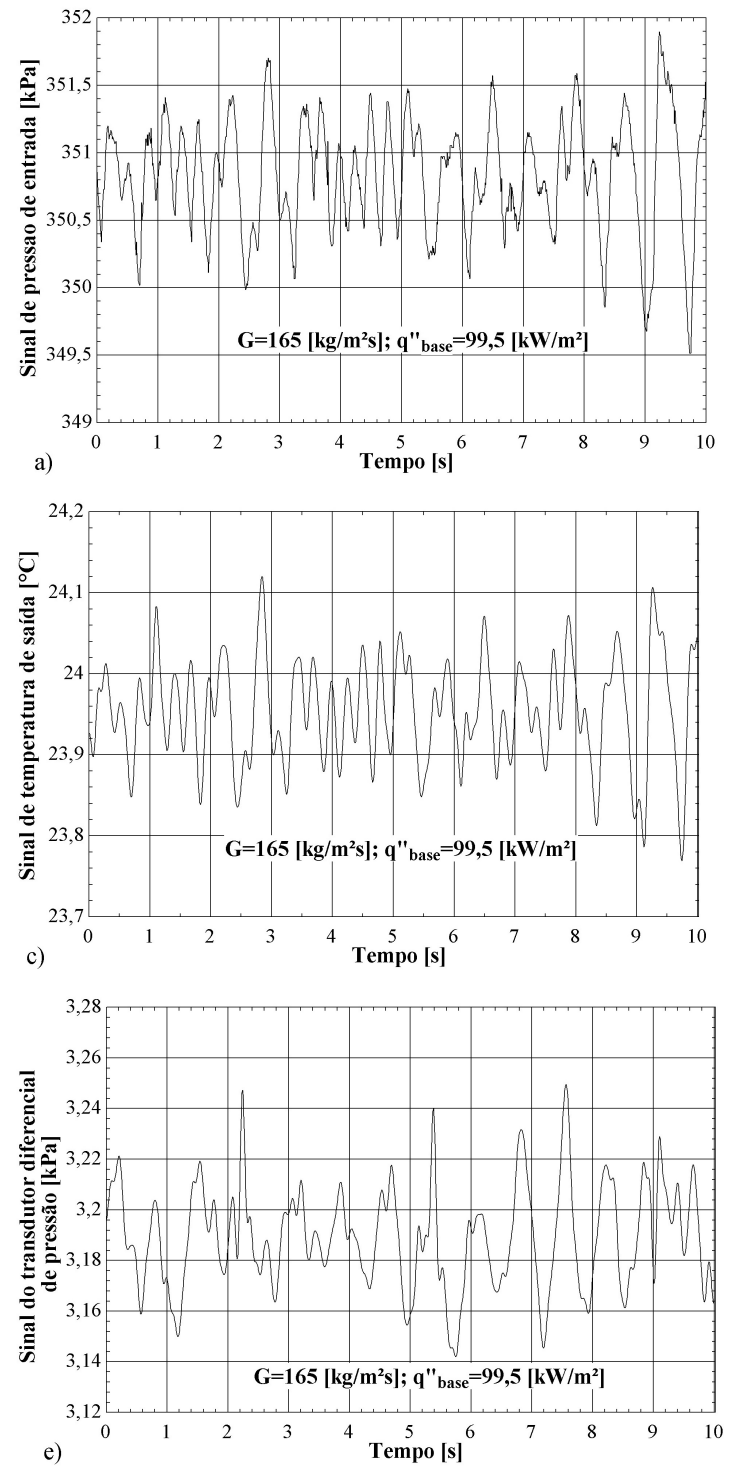
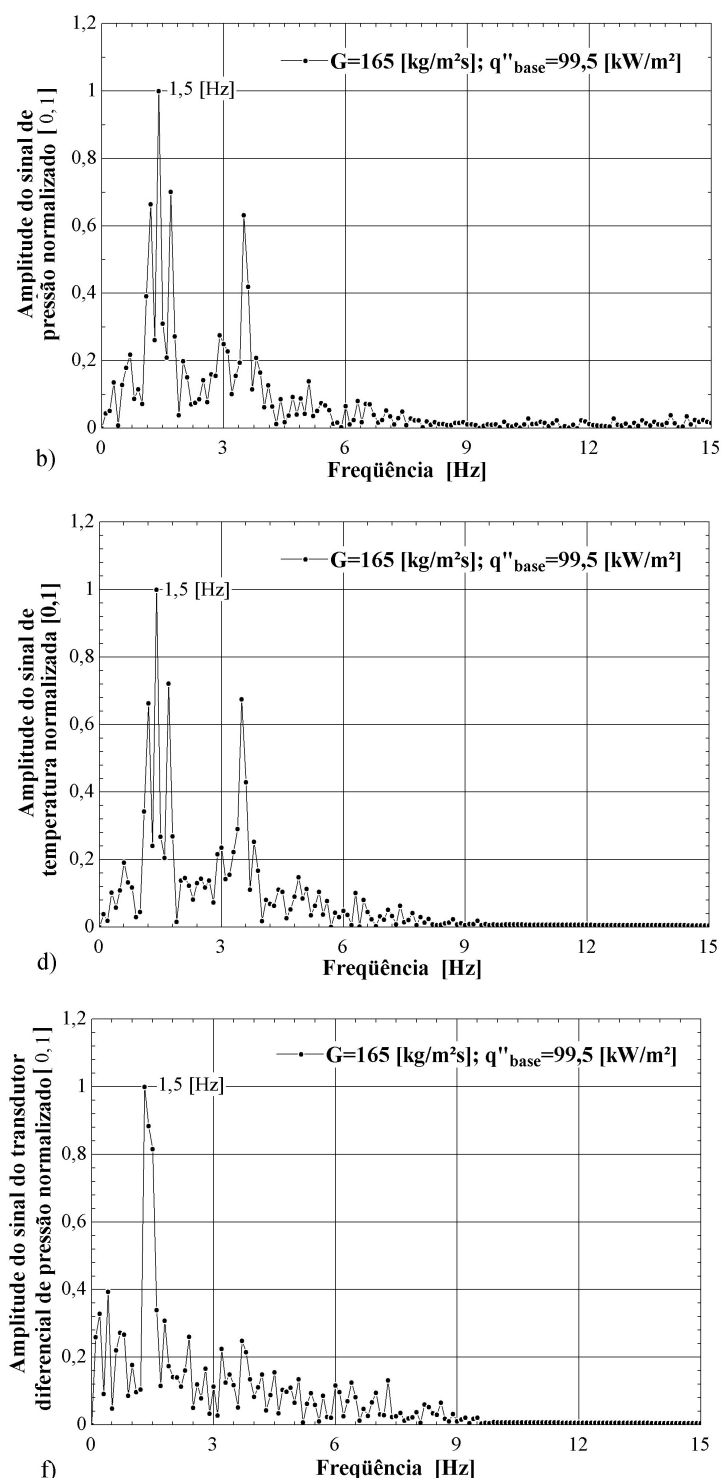

Figura 4.36 - Sinais de pressão absoluta, temperatura e diferencial de pressão para R600a. a) transdutor de pressão absoluta, b) FFT do sinal de pressão absoluta, c) termopar da saída. d) FFT do sinal do termopar de saída, e) transdutor diferencial de pressão. f) FFT do sinal do transdutor diferencial de pressão. 


\section{Efeito do fluxo de calor}

A Figura 4.37ilustra o efeito do fluxo de calor na FFT dos sinais de temperatura na câmara de saída para o R290. Nesta figura observa-se um incremento na frequência de oscilação como resultado do incremento da potência de aquecimento. Este comportamento deve-se à elevação da intensidade do processo de ebulição o qual decorre do incremento da frequência do desprendimento de bolhas. Na Figura 4.37 observa-se um aumento na amplitude das oscilações devido ao incremento do fluxo de calor. Isto se deve ao fato do incremento das forças relacionadas ao crescimento de bolhas em condições confinadas. A Tabela 4.7 apresenta os resultados obtidos para forças 1 associadas ao crescimento da bolha em condições confinadas e para o parâmetro de instabilidade com a variação do fluxo de calor, conforme descrito no item 3.3. De acordo com esta tabela, a força inercial do líquido sobre a bolha se mantém aproximadamente constante. Entretanto, a força de ebulição do crescimento da bolha se eleva como resultado da intensificação do processo de ebulição associado ao incremento do fluxo de calor, com a consequente elevação da amplitude das oscilações.

De acordo a Tabela 4.7, constata-se valores inferiores a 1 para o parâmetro de instabilidade, o qual indica que não ocorre escoamento reverso de bolhas para estas condições experimentais. Além disso, verifica-se um incremento do parâmetro de instabilidade com o incremento do fluxo de calor. Isto decorre do incremento da força de ebulição de crescimento da bolha. No entanto, a força inercial do líquido mantém-se constante pois está associada principalmente a velocidade mássica.

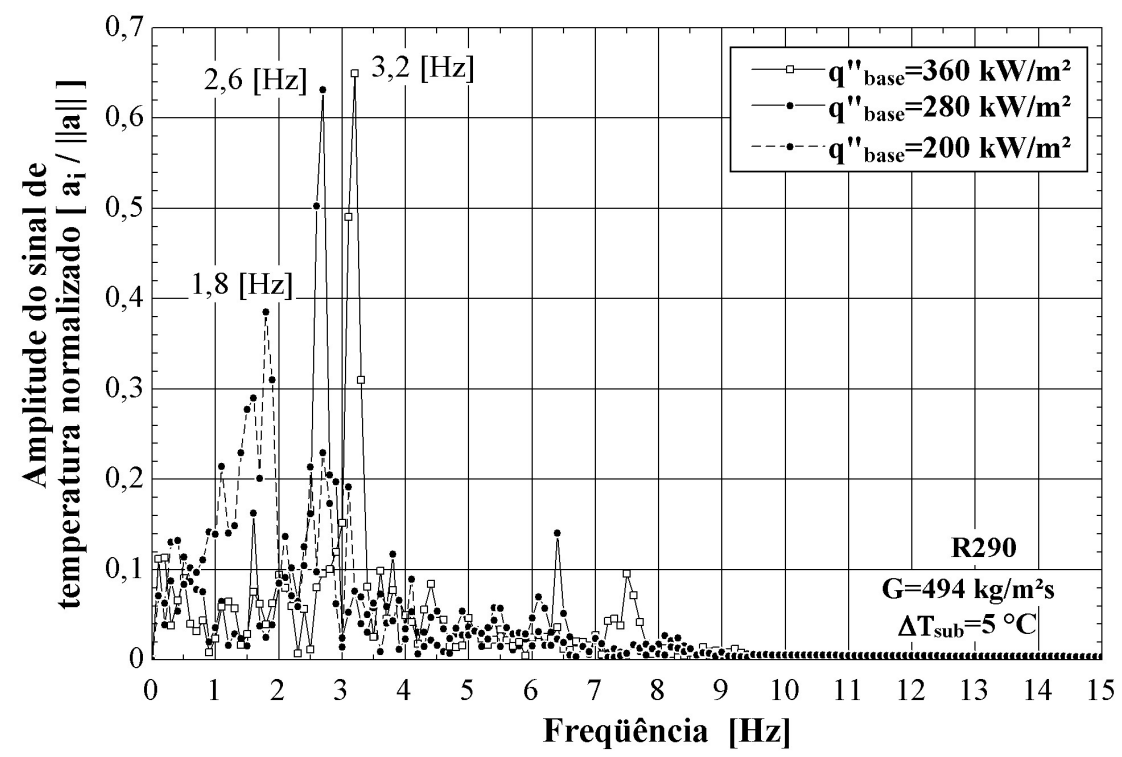

Figura 4.37 - Ilustração do efeito do fluxo de calor na FFT dos sinais de temperatura na câmara de saída para o R290, $G=494 \mathrm{~kg} / \mathrm{m}^{2} \mathrm{~s}$ e $\Delta T_{\text {sub }}=5^{\circ} \mathrm{C}$.

\footnotetext{
${ }^{1}$ Forças específicas baseadas na área de seção transversal de um microcanal, $\left[\mathrm{N} / \mathrm{m}^{2}\right]$.
} 
Tabela 4.7 - Resultados do efeito do fluxo de calor sobre forças associadas ao crescimento de bolhas e o parâmetro de instabilidade para R290, $\mathrm{G}=494 \mathrm{~kg} / \mathrm{m}^{2} \mathrm{~s}, T_{\text {sat }}=25^{\circ} \mathrm{C}$ e $\Delta T_{\text {sub }}=5{ }^{\circ} \mathrm{C}$.

\begin{tabular}{lccc}
\hline Fluxo de calor $\left[\boldsymbol{k} \boldsymbol{W} / \boldsymbol{m}^{\mathbf{2}}\right]$ & $\boldsymbol{F}_{\text {inercial }}\left[\boldsymbol{N} / \boldsymbol{m}^{\mathbf{2}}\right]$ & $\boldsymbol{F}_{\text {ebulição }}\left[\mathbf{N} / \boldsymbol{m}^{\mathbf{2}}\right]$ & Parâmetro R $[-]$ \\
\hline 200 & 494,0 & 13,94 & 0,21 \\
\hline 280 & 494,9 & 51,35 & 0,32 \\
\hline 360 & 495,4 & 115,5 & 0,48 \\
\hline
\end{tabular}

\section{Efeito da velocidade mássica}

A Figura 4.38 ilustra para o R1270, o efeito da velocidade mássica na FFT do sinal de temperatura na câmara de saída. Nesta figura, observa-se um incremento na frequência de oscilação com o aumento da velocidade mássica. De acordo com Leão (2014), este comportamento pode estar relacionado ao fato do incremento da velocidade mássica intensificar a supressão do processo de nucleação. Entretanto, caso os sítios de nucleação encontremse ativos, o incremento da velocidade mássica favorece o desprendimento de bolhas com dimensões reduzidas podendo aumentar o colapso desta, o que pode causar a elevação da frequência de oscilação. Para verificar esta hipótese, a Tabela 4.8 apresenta os resultados obtidos para forças associadas ao crescimento da bolha em condições confinadas e para o parâmetro de instabilidade com a variação da velocidade mássica. Nesta tabela, constata-se o decréscimo da força de ebulição do crescimento da bolha como resultado do incremento da velocidade mássica, o qual corrobora a supressão dos efeitos de ebulição nucleada elevando-se os efeitos convectivos e, consequentemente, o incremento na frequência das oscilações.

Por intermédio da Tabela 4.8, constata-se valores superiores a 1 para o parâmetro de instabilidade durante velocidades mássicas reduzidas. Já, para velocidades mássicas superiores ocorre uma redução do parâmetro de instabilidade apresentando valores inferiores a 1 . Isto indica que ocorre escoamento reverso de bolhas, elevando-se os efeitos de instabilidades para velocidades mássicas reduzidas. Este comportamento também foi verificado por Lee et al. (2010) e Leão et al. (2015) e decorre da superposição de forças de ebulição sobre as inerciais.

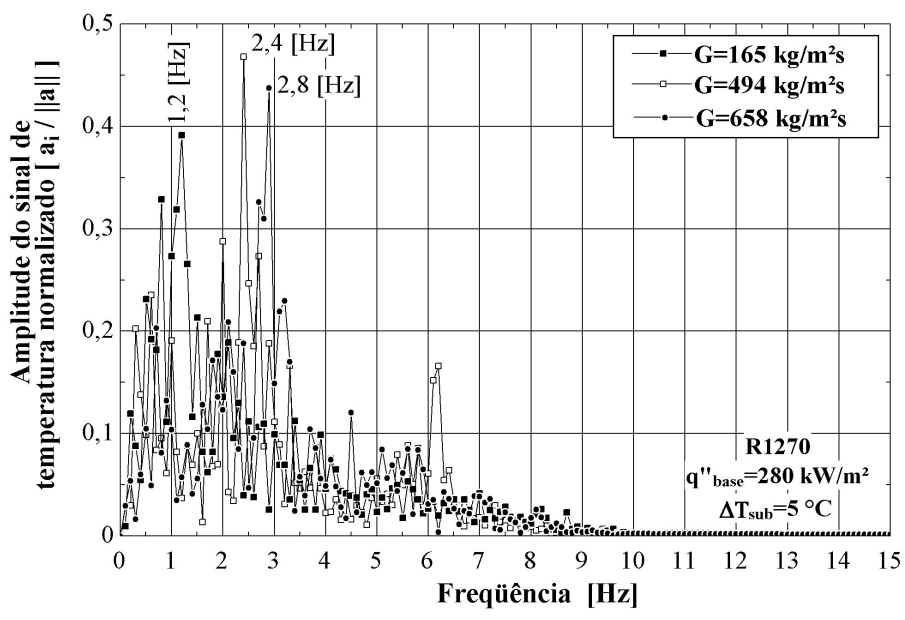

Figura 4.38 - Ilustração do efeito da velocidade mássica na FFT dos sinais de temperatura na câmara de saída para o R1270, $q^{\prime \prime}$ base $=280 \mathrm{~kW} / \mathrm{m}^{2}$ e $\Delta T_{\text {sub }}=5^{\circ} \mathrm{C}$. 
Tabela 4.8 - Resultados do efeito da velocidade mássica sobre forças associadas ao crescimento de bolhas e o parâmetro de instabilidade para R1270, $q^{\prime \prime}$ base $=280 \mathrm{~kW} / \mathrm{m}^{2}, T_{\text {sat }}=25^{\circ} \mathrm{C}$ e $\Delta T_{\text {sub }}=5^{\circ} \mathrm{C}$.

\begin{tabular}{lccc}
\hline Velocidade mássica $\left[\boldsymbol{k g} / \boldsymbol{m}^{\mathbf{2}} \boldsymbol{s}\right]$ & $\boldsymbol{F}_{\text {inercial }}\left[\boldsymbol{N} / \boldsymbol{m}^{\mathbf{2}}\right]$ & $\boldsymbol{F}_{\text {ebulição }}\left[\boldsymbol{N} / \boldsymbol{m}^{\mathbf{2}}\right]$ & Parâmetro R [-] \\
\hline 165 & 53,83 & 90,07 & 1,29 \\
\hline 494 & 482,5 & 43,07 & 0,30 \\
\hline 658 & 859,2 & 15,19 & 0,13 \\
\hline
\end{tabular}

\section{Efeito do grau de sub-resfriamento do líquido}

A Figura 4.39 ilustra o efeito do grau de sub-resfriamento na FFT do sinal de temperatura na câmara de saída para o R290. Nesta figura, observa-se uma redução na frequência de oscilação com o aumento do grau de sub-resfriamento do fluido na entrada do dissipador de calor. Este resultado deve-se ao fato das condições sub-resfriadas do fluido reduzirem a intensidade da ebulição convectiva. Neste caso, especula-se que as condições de sub-resfriamento superior favorecem a supressão de efeitos de nucleação de bolhas resultando na redução de frequência de desprendimento destas.

Na Figura 4.39 observa-se a redução da amplitude de oscilação com o decréscimo do grau de sub-resfriamento do fluido na entrada da seção de testes. Este comportamento pode estar relacionado ao fato da temperatura média do fluido aumentar com o decréscimo do grau de subresfriamento do fluido, resultando na redução das forças de nucleação. Tal fato é constatado através dos valores das forças indicadas na Tabela 4.9. Nela observa-se que a força de ebulição do crescimento da bolha decresce com o incremento do grau de sub-resfriamento do líquido.

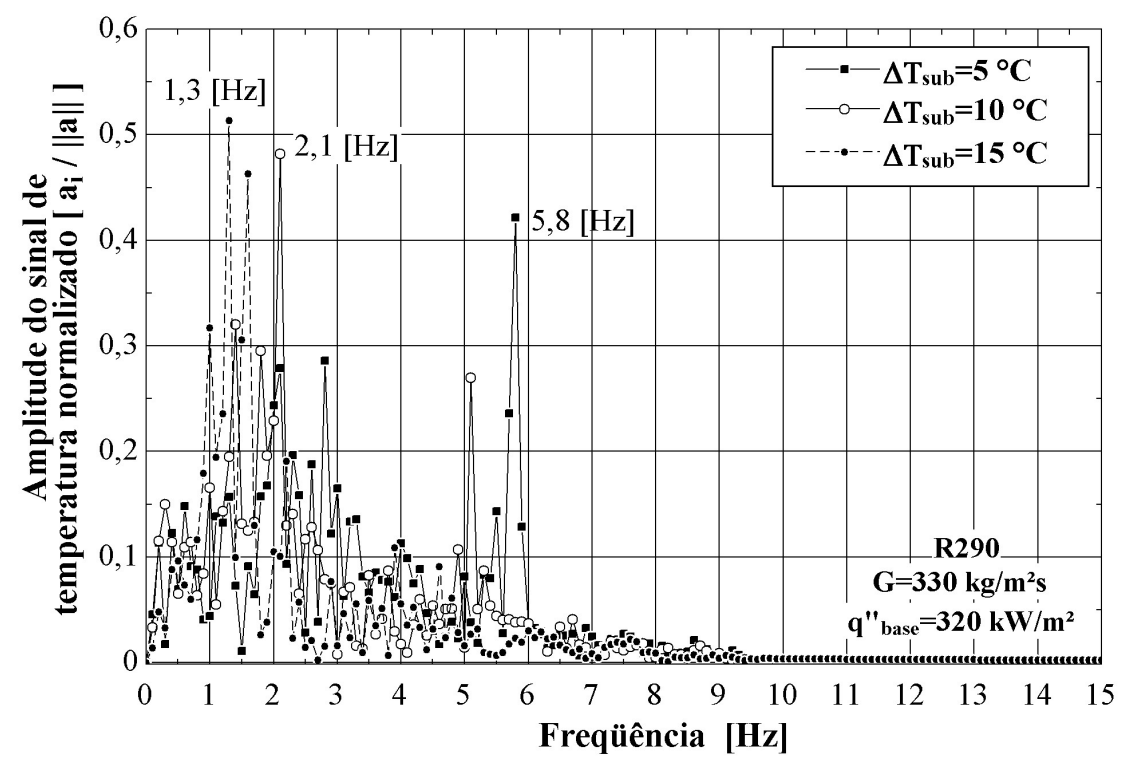

Figura 4.39 - Ilustração do efeito do grau de sub-resfriamento do fluido na FFT dos sinais de temperatura na câmara de saída para o R290, $q^{\prime \prime}$ base $=320 \mathrm{~kW} / \mathrm{m}^{2}$ e $G=494 \mathrm{~kg} / \mathrm{m}^{2} \mathrm{~s}$. 
Tabela 4.9 - Resultados do efeito do grau de sub-resfriamento do líquido sobre forças associadas ao crescimento de bolhas e o parâmetro de instabilidade para R290, $q^{\prime \prime}$ base $=320 \mathrm{~kW} / \mathrm{m}^{2}, T_{\text {sat }}=25^{\circ} \mathrm{C} \mathrm{e}$ $\mathrm{G}=330 \mathrm{~kg} / \mathrm{m}^{2} \mathrm{~s}$.

\begin{tabular}{lccc}
\hline Grau de sub-resfriamento $\left[{ }^{\circ}\right] \mathbf{C}$ & $\boldsymbol{F}_{\text {inercial }}\left[\mathbf{N} / \boldsymbol{m}^{\mathbf{2}}\right]$ & $\boldsymbol{F}_{\text {ebulição }}\left[\mathbf{N} / \boldsymbol{m}^{\mathbf{2}}\right]$ & Parâmetro R [-] \\
\hline 5 & 495,6 & 78,08 & 0,40 \\
\hline 10 & 496,3 & 19,67 & 0,20 \\
\hline 15 & 495,6 & 0,68 & 0,04 \\
\hline
\end{tabular}

\section{Efeito do fluido refrigerante}

A Figura 4.40ilustra o efeito do fluido refrigerante na FFT do sinal de temperatura na câmara de saída. De acordo com esta figura, verifica-se frequências de oscilação segundo a seguinte ordem de incremento R1270, R290 e R600a. Este comportamento está relacionado ao fato do R600a operar a pressão reduzida inferior e apresentar um volume específico da fase vapor superior, o qual resulta em velocidades do vapor superiores e, consequentemente, se eleva a frequência das oscilações. Na Figura 4.40 observam-se amplitudes de oscilação superiores para o R290. Tal comportamento pode estar relacionado ao fato deste fluido apresentar um calor latente superior e tensão superficial inferior, o qual favorece a velocidade do desprendimento de bolhas causando incremento na amplitude das oscilações.

A Tabela 4.10 apresenta resultados do efeito do fluido refrigerante sobre forças associadas ao crescimento de bolhas e o parâmetro de instabilidade. De acordo a esta tabela, o R290 apresenta valores superiores de forças inerciais do líquido. Entretanto, o R1270 apresenta valores inferiores para a força de ebulição associada ao crescimento de bolhas. O R600a apresenta valores superiores do parâmetro de instabilidade, o qual resulta no incremento de efeitos do fluxo reverso de bolhas. Vale destacar que, o parâmetro de instabilidade apresenta a mesma ordem de incremento que as frequências de oscilação verificadas na Fig. 4.40.

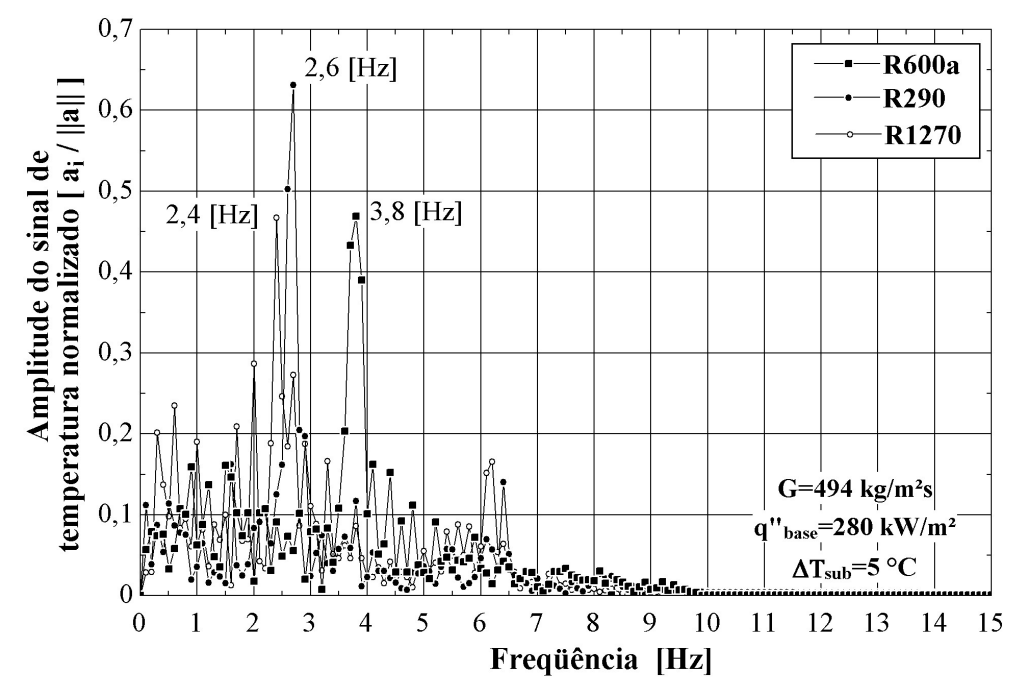

Figura 4.40 - Ilustração do efeito do fluido refrigerante na FFT dos sinais de temperatura na câmara de saída para $q^{\prime \prime}$ base $=280 \mathrm{~kW} / \mathrm{m}^{2}, G=494 \mathrm{~kg} / \mathrm{m}^{2} \mathrm{~s}$ e $\Delta T_{\text {sub }}=5^{\circ} \mathrm{C}$. 
Tabela 4.10 - Resultados do efeito do fluido refrigerante sobre forças associadas ao crescimento de bolhas e o parâmetro de instabilidade para $q^{\prime \prime}$ base $=280 \mathrm{~kW} / \mathrm{m}^{2}, T_{\text {sat }}=25^{\circ} \mathrm{C}, \mathrm{G}=494 \mathrm{~kg} / \mathrm{m}^{2} \mathrm{~s} \mathrm{e} \Delta T_{\text {sub }}=5^{\circ} \mathrm{C}$.

\begin{tabular}{lccc}
\hline Fluido refrigerante & $\boldsymbol{F}_{\text {inercial }}\left[\boldsymbol{N} / \boldsymbol{m}^{\mathbf{2}}\right]$ & $\boldsymbol{F}_{\text {ebulição }}\left[\boldsymbol{N} / \boldsymbol{m}^{\mathbf{2}}\right]$ & Parâmetro R [-] \\
\hline R600a & 442,9 & 131,4 & 0,54 \\
\hline R290 & 494,9 & 51,35 & 0,32 \\
\hline R1270 & 482,5 & 43,07 & 0,30 \\
\hline
\end{tabular}

\section{Efeito da temperatura de saturação}

As Figuras 4.41 e 4.42 ilustram o efeito da temperatura de saturação na FFT do sinal de temperatura na câmara de saída. De acordo com esta figura, verifica-se frequências de oscilação inferiores para temperaturas de saturação superiores, o qual se deve à redução do volume específico da fase vapor e da tensão superficial com o incremento de $T_{\text {sat }}$ resultando na supressão dos efeitos de nucleação e frequência de desprendimento bolhas.

Nas Figuras 4.41 e 4.42 observa-se um incremento da amplitude das oscilações para temperaturas de saturação superiores. A Tabela 4.11 apresenta os resultados do efeito da temperatura de saturação sobre forças associadas ao crescimento de bolhas e o parâmetro de instabilidade. Nela, constata-se o incremento das forças associadas ao processo de ebulição com o decréscimo da temperatura de saturação, o qual é um comportamento contrário ao esperado, pois o incremento da força de ebulição está relacionado ao aumento da amplitude das oscilações. Tal comportamento pode estar associado ao fato dos fluidos apresentarem densidades do vapor superiores com a elevação da temperatura de saturação. Desta forma, incrementam as forças inerciais das bolhas e, consequentemente, eleva-se a amplitude das oscilações.

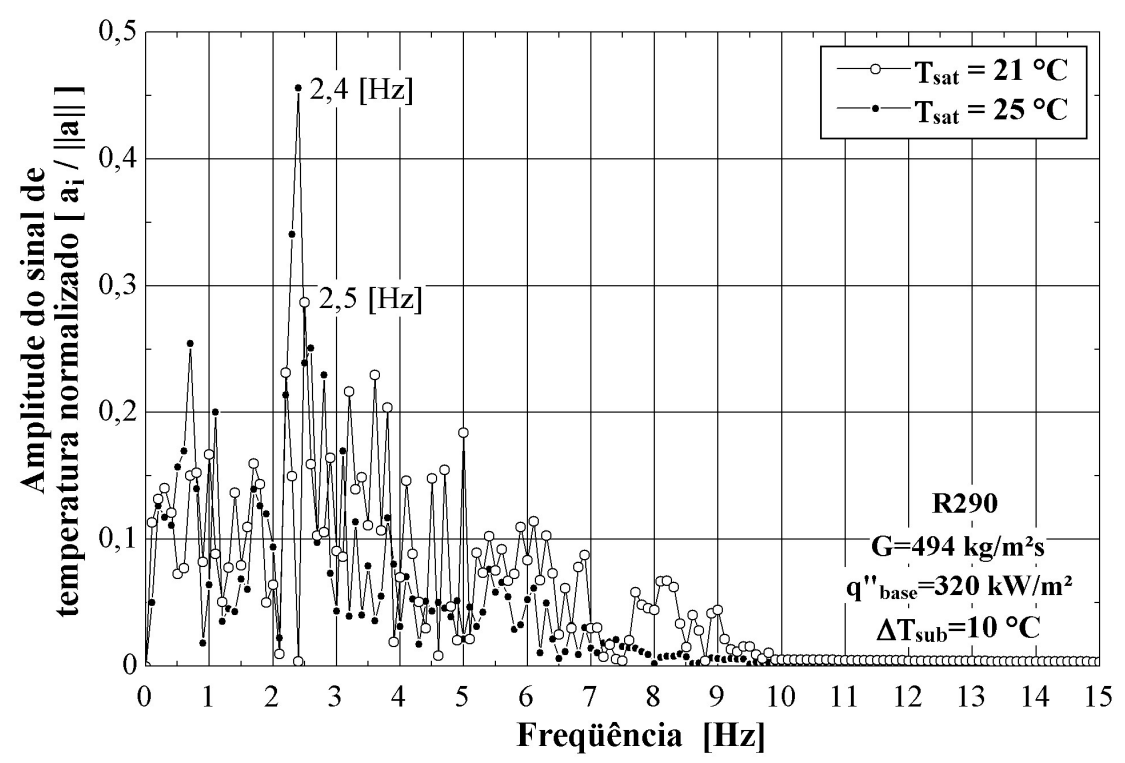

Figura 4.41 - Ilustração do efeito da temperatura de saturação na FFT dos sinais de temperatura na câmara de saída para o R290, $q$ " base $=320 \mathrm{~kW} / \mathrm{m}^{2}, G=494 \mathrm{~kg} / \mathrm{m}^{2} \mathrm{~s}$ e $\Delta T_{\text {sub }}=10^{\circ} \mathrm{C}$. 


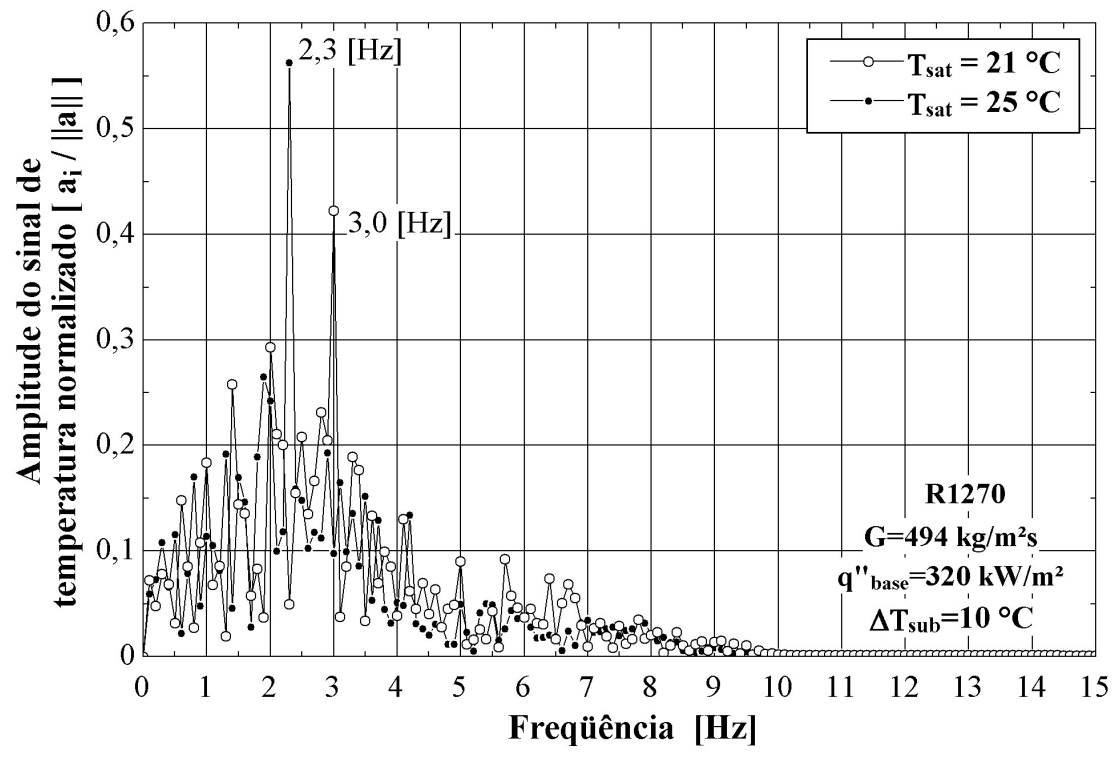

Figura 4.42 - Ilustração do efeito da temperatura de saturação na FFT dos sinais de temperatura na câmara de saída para o R1270, $q^{\prime \prime}$ base $=320 \mathrm{~kW} / \mathrm{m}^{2}, G=494 \mathrm{~kg} / \mathrm{m}^{2} \mathrm{~s}$ e $\Delta T_{\text {sub }}=10^{\circ} \mathrm{C}$.

Tabela 4.11 - Resultados do efeito da temperatura de saturação sobre forças associadas ao crescimento de bolhas e o parâmetro de instabilidade para $q^{\prime \prime}$ base $=320 \mathrm{~kW} / \mathrm{m}^{2}, \mathrm{G}=494 \mathrm{~kg} / \mathrm{m}^{2} \mathrm{~s}$ e $\Delta T_{\text {sub }}=10^{\circ} \mathrm{C}$.

\begin{tabular}{lccc}
\hline $\boldsymbol{T}_{\boldsymbol{s a t}}$ (Fluido) & $\boldsymbol{F}_{\text {inercial }}\left[\boldsymbol{N} / \boldsymbol{m}^{\mathbf{2}}\right]$ & $\boldsymbol{F}_{\text {ebulição }}\left[\boldsymbol{N} / \boldsymbol{m}^{\mathbf{2}}\right]$ & Parâmetro R [-] \\
\hline $21{ }^{\circ} \mathrm{C}(\mathrm{R} 290)$ & 486,4 & 22,83 & 0,22 \\
\hline $25^{\circ} \mathrm{C}(\mathrm{R} 290)$ & 496,3 & 19,67 & 0,20 \\
\hline $2{ }^{\circ} \mathrm{C}(\mathrm{R} 1270)$ & 476,6 & 13,75 & 0,17 \\
\hline $25^{\circ} \mathrm{C}(\mathrm{R} 1270)$ & 482,7 & 12,48 & 0,16 \\
\hline
\end{tabular}




\section{CONCLUSÕES E RECOMENDAÇÕES}

O presente estudo envolveu a campanha experimental para análise da transferência de calor e perda de pressão de hidrocarbonetos (R600a, R290 e R1270) durante a ebulição convectiva em um dissipador de calor baseado em multi-microcanais. Realizou-se, inicialmente, ampla revisão da literatura focando em estudos experimentais relacionados à ebulição convectiva. No presente estudo obteve-se resultados para o coeficiente de transferência de calor e perda de pressão em dissipadores de calor constituídos de multi-microcanais para fluxo de calor de até $400 \mathrm{~kW} / \mathrm{m}^{2}$, velocidades mássicas de 165 a $823 \mathrm{~kg} / \mathrm{m}^{2} \mathrm{~s}$, graus de sub-resfriamentos do fluido na seção de entrada do dissipador de 5,10 e $15{ }^{\circ} \mathrm{C}$ e temperaturas de saturação de 21 e $25{ }^{\circ} \mathrm{C}$. Além disso, realizou-se uma análise da Eficiência da $2^{\circ}$ Lei da Termodinâmica dos fluidos estudados visando caracterizar aquele com melhor desempenho segundo um critério objetivo. Finalmente, através da análise de oscilações dos sinais de temperatura na câmara de entrada, pressão e perda de pressão investigou-se o efeito de instabilidades térmicas através da caracterização de suas frequências e amplitudes.

De forma geral, os objetivos inicialmente propostos para este estudo foram alcançados e sua realização permite as conclusões e recomendações para trabalhos futuros apresentadas neste capítulo.

\subsection{CONCLUSÕES}

As principais conclusões extraídas do presente estudo são as seguintes:

$\diamond$ Verificou-se através da análise da literatura a necessidade de investigações, visando caracterizar o efeito do fluido refrigerante na ebulição convectiva no interior de dissipadores de calor baseados em multi-microcanais, em particular sobre hidrocarbonetos, para os quais estudos não foram verificados.

$\diamond$ As curvas de ebulição, levantadas neste estudo, apresentam descontinuidade para dados levantados com o incremento progressivo de fluxo de calor a partir de um valor nulo. Tal comportamento se deve à necessidade de um excesso de superaquecimento para ativação das cavidades. Para dados obtidos com a redução do fluxo de calor a partir de um valor máximo, as cavidades já se encontram ativas e a curva se apresenta contínua; 
$\diamond \mathrm{O}$ superaquecimento da parede necessário para o ONB aumenta com o incremento da velocidade mássica e do grau de sub-resfriamento do líquido na entrada da seção de testes. Tal comportamento se deve a ausência das condições para o ONB ao longo dos canais, pois velocidades mássicas e graus de sub-resfriamentos superiores atrasam a ativação das cavidades para a nucleação de bolhas;

$\diamond$ O superaquecimento necessário para o início da ebulição para refrigerante halogenado R134a é inferior ao dos hidrocarbonetos. No caso destes fluidos o $\Delta \bar{T}_{\mathrm{ONB}}$ decresce segundo a seguinte ordem: R600a, R290 e R1270. O método proposto por Bergles e Rohsenow (1964) prevê satisfatoriamente os dados experimentais do $\Delta \bar{T}_{\mathrm{ONB}}$, embora, de maneira geral, os subestime;

$\diamond$ Em condições em que se verifica a ebulição ao longo do dissipador constata-se gradientes superiores de fluxo de calor com a variação do superaquecimento da superfície para os hidrocarbonetos em relação ao R134a;

$\diamond \mathrm{O}$ coeficiente de transferência de calor médio varia apenas marginalmente em condições de escoamento monofásico com o aumento do fluxo de calor e para uma determinada velocidade mássica. Este comportamento se deve à variação das propriedades com o incremento da temperatura média do fluido, implicando no aumento do comprimento de desenvolvimento térmico e, consequentemente, do coeficiente de transferência de calor médio;

$\diamond$ Em condições com mudança de fase, observa-se o incremento do coeficiente de transferência de calor médio com a redução da velocidade da mássica para um fluxo de calor fixo. Este comportamento decorre do aumento da parcela do dissipador de calor sob condições de ebulição convectiva com a redução da velocidade mássica;

$\diamond$ De uma maneira geral, o coeficiente de transferência de calor fornecido pelos refrigerantes avaliados neste estudo incluindo o R134a apresenta a seguinte ordem decrescente: R290, R1270, R600a e R134a. Para velocidades mássicas de $494 \mathrm{~kg} / \mathrm{m}^{2} \mathrm{~s}$ e inferiores, o refrigerante R290 fornece coeficientes de transferência de calor médios superiores. Entretanto, para as velocidades mássicas de $658 \mathrm{~kg} / \mathrm{m}^{2} \mathrm{~s}$, o coeficiente de transferência de calor médio fornecido por R1270 se eleva até valores similares aos verificados para o R290;

$\diamond \mathrm{O}$ coeficiente de transferência de calor médio decresce com o incremento da temperatura de saturação dada uma velocidade mássica de $165 \mathrm{~kg} / \mathrm{m}^{2}$ s. Já, para uma velocidade mássica de $494 \mathrm{~kg} / \mathrm{m}^{2} \mathrm{~s}$, o CTC médio se eleva com o aumento de $T_{\text {sat }}$. Para velocidades mássicas de $330 \mathrm{~kg} / \mathrm{m}^{2} \mathrm{~s}$ não foram observados efeitos significativos de $T_{\text {sat }}$. O comportamento observado para velocidades mássicas de $494 \mathrm{~kg} / \mathrm{m}^{2} \mathrm{~s}$. No entanto, o efeito contrário observado para $\mathrm{G}=165 \mathrm{~kg} / \mathrm{m}^{2} \mathrm{~s}$ se justifica no fato de existência de instabilidades térmicas e escoamento mal distribuído, cujos efeitos se acrescentam para velocidades reduzidas; 
$\diamond \mathrm{O}$ método proposto por Kanizawa et al. (2016) forneceu melhores previsões dos resultados experimentais prevendo $72,3 \%$ dos dados com desvios entre $\pm 30 \%$. Em particular, este método proporciona melhores previsões para os CTC dos refrigerantes $R 600 a$ e $R 1270$. Já o método proposto por $\mathrm{Li} \mathrm{e} \mathrm{Wu}$ (2010) proporciona as melhores previsões dos dados para $R 290$ resultando em um MAE de $9,12 \%$ e $\lambda_{ \pm 30 \%}=95,85 \%$;

$\diamond$ Em escoamento monofásico, a perda de pressão total diminui marginalmente com o aumento do fluxo de calor para uma velocidade mássica fixa devido à variação das propriedades de transporte do fluido com o incremento da temperatura média do escoamento;

$\diamond$ Para valores fixos de velocidade mássica e fluxo de calor, a perda de pressão total com presença de ebulição convectiva ao longo dos canais decresce com o aumento do grau de subresfriamento do fluido. Tal comportamento se deve ao incremento da superfície do dissipador sob condições monofásicas para um grau de sub-resfriamento superior, o qual resulta na redução da parcela do dissipador sob condições de ebulição convectiva e consequentemente CTCs inferiores;

$\diamond$ Para condições com a presença de ebulição convectiva ao longo dos canais o refrigerante $R 600 a$ apresenta perdas de pressão superiores aos demais, com o fluido $R 1270$ apresentando as perdas pressão inferiores;

$\diamond$ Os métodos para previsão de perda de pressão bifásica por atrito disponíveis na literatura, não fornecem resultados satisfatórios dos resultados experimentais obtidos neste estudo. $\mathrm{O}$ modelo homogêneo com a viscosidade dinâmica da mistura bifásica determinada segundo a correlação proposta por Beattie e Whalley (1982), o qual apresentou as melhores previsões entre os métodos avaliados, concordou com apenas $32,2 \%$ dos dados com erro entre $\pm 30 \%$. Tal resultado explica-se no fato de aspectos típicos dos mecanismos de ebulição convectiva em dissipadores de calor baseados em multi-microcanais, como a má distribuição de fluido e instabilidades térmicas decorrentes do escoamento reverso, os quais não são capturados pelos métodos desenvolvidos para canais individuais;

$\diamond$ A frequência das oscilações decresce com o aumento do grau de sub-resfriamento do fluido na entrada da seção de testes e a redução do fluxo de calor e da velocidade mássica. Além disso, a frequência de oscilação decresce com o aumento da pressão operacional do fluido, isto é, o refrigerante R1270, que opera a uma pressão superior apresenta oscilações com frequências inferiores;

$\diamond$ Baseado em análises de Segunda Lei da Termodinâmica, constatou-se que as irreversibilidades devido à transferência de calor são predominantes comparada com aquelas devido à perda de pressão. O parâmetro $\eta_{I I}$ decresce com a redução do grau de sub-resfriamento do 
líquido na entrada da seção de testes. Esta análise também revelou desempenhos superiores para R290 independentemente da velocidade mássica e grau de sub-resfriamento líquido na entrada da seção de testes. Em geral, o desempenho dos fluidos apresenta a seguinte ordem decrescente: R290, R1270, R600a, R134a;

\subsection{RECOMENDAÇÕES PARA TRABALHOS FUTUROS}

O presente estudo envolveu uma análise ampla da perda de pressão e o coeficiente de transferência de calor de hidrocarbonetos durante a ebulição convectiva em um dissipador de calor baseado em multi-microcanais. Entretanto, diversos temas não foram explorados ou não aprofundados. Desta forma podem ser consideradas para trabalhos futuros, as seguintes recomendações:

$\diamond$ Avaliar os efeitos da rugosidade sobre o coeficiente de transferência de calor e perda de pressão. Este parâmetro caracteriza a superfície dos canais e para condições de microescala pode modificar os mecanismos de ebulição e as características hidrodinâmicas do escoamento;

$\diamond$ Realizar visualizações por intermédio de câmera de alta velocidade de forma avaliar os padrões de escoamento. Neste caso, recomenda-se avaliar dissipadores de calor com microcanais de profundidade inferiores para se obter melhor visualização no escoamento ao interior dos canais. Além disso, fabricar microcanais em silício ajudaria a melhorar a iluminação e, consequentemente, obter melhores visualizações;

$\diamond$ Desenhar e fabricar dissipadores de calor com microcanais paralelos com diferentes razões de aspecto de forma a avaliar efeitos da geometria dos microcanais no desempenho térmico;

$\diamond$ Desenhar e fabricar dissipadores de calor com diferentes geometrias do plenums de forma avaliar os efeitos de instabilidades térmicas relacionadas a estas geometrias e conectividade com os canais;

$\diamond$ Avaliar dissipadores de calor baseados em microcanais com seção transversal divergente. Desta forma, estudar o efeito de fluxo reverso e amortecimento de instabilidades térmicas;

$\diamond$ Avaliar inclusão de restrições na entrada dos microcanais, orifícios artificiais de nucleação e configurações que envolvam soluções que modificam a superfície dos canais, o qual inclui perdas de pressão localizadas, mas intensifica a transferência de calor;

$\diamond$ Desenhar e fabricar novos dissipadores de calor baseados em configurações complexas de microcanais. Neste caso, configurações que envolvam soluções bio-inspiradas apresentam-se promissoras. Os elementos da natureza que podem ser utilizados para mimetizar geometrias 
são nervuras vasculares de folhas de vegetais, distribuição arterial de sistemas biológicos humanos, armazenamento de mel das abelhas, distribuição hidráulica dos rios na busca do mar, etc;

$\diamond$ Ampliar o banco de dados para velocidades mássicas inferiores a $150 \mathrm{~kg} / \mathrm{m}^{2} \mathrm{~s}$ visando aplicar a tecnologia de microcanais em processos que operam em velocidades mássicas reduzidas. Estas aplicações podem ser: o gerenciamento térmico de células combustíveis, fotovoltaicas e espaços restritos a uso de bombas. Vale destacar que para velocidades mássicas reduzidas aumentam os efeitos de instabilidades térmicas;

$\diamond$ Desenvolver métodos de previsão de instabilidades térmicas que possam ser utilizados como ferramentas de projeto de dissipadores de calor de forma a incluir tais efeitos na previsão do coeficiente de transferência de calor e da perda de pressão.;

$\diamond$ Ampliar o banco de dados para títulos de vapor superiores na saída do dissipador e avaliar condições de fluxo de crítico calor. 


\section{REFERÊNCIAS BIBLIOGRÁFICAS}

ABDELALL, F.; HAHN, G.; GHIAASIAAN, S.; ABDEL-KHALIK, S.; JETER, S.; YODA, M.; SADOWSKI, D. Pressure drop caused by abrupt flow area changes in small channels. Experimental Thermal and Fluid Science, v. 29, n. 4, p. 425 - 434, 2005. ISSN 0894-1777.

ABERNETHY, R.; THOMPSON, J. Handbook of Uncertainty in Gas Turbine Measurements. Air Force Systems Command, Arnold Engineering Development Center, 1973. (Technical report). Disponível em: <https://books.google.com.br/books?id=QuRntwAACAAJ $>$.

AGOSTINI, B.; REVELLIN, R.; THOME, J. R.; FABBRI, M.; MICHEL, B.; CALMI, D.; KLOTER, U. High heat flux flow boiling in silicon multi-microchannels - part iii: Saturated critical heat flux of r236fa and two-phase pressure drops. International Journal of Heat and Mass Transfer, v. 51, n. 21-22, p. 5426 - 5442, 2008 c.

AGOSTINI, B.; THOME, J. R.; FABBRI, M.; MICHEL, B.; CALMI, D.; KLOTER, U. High heat flux flow boiling in silicon multi-microchannels - part i: Heat transfer characteristics of refrigerant r236fa. International Journal of Heat and Mass Transfer, v. 51, n. 21-22, p. 5400 $5414,2008 \mathrm{a}$.

AGOSTINI, B.; THOME, J. R.; FABBRI, M.; MICHEL, B.; CALMI, D.; KLOTER, U. High heat flux flow boiling in silicon multi-microchannels - part ii: Heat transfer characteristics of refrigerant r245fa. International Journal of Heat and Mass Transfer, v. 51, n. 21-22, p. 5415 $5425,2008 b$.

AKERS, W.; DEANS, H.; CROSSER, O. Condensation heat transfer within horizontal tubes. Chem. Eng. Prog. Symposium Ser., v. 55, p. 171-176., 1959.

ALAM, T.; LEE, P. S.; YAP, C. R.; JIN, L. A comparative study of flow boiling heat transfer and pressure drop characteristics in microgap and microchannel heat sink and an evaluation of microgap heat sink for hotspot mitigation. International Journal of Heat and Mass Transfer, v. 58, n. $1-2$, p. $335-347,2013$.

ANWAR, Z.; PALM, B. E.; KHODABANDEH, R. Dryout characteristics of natural and synthetic refrigerants in single vertical mini-channels. Experimental Thermal and Fluid Science, v. 68 , p. $257-267,2015$. ISSN 0894-1777.

BALASUBRAMANIAN, K.; LEE, P.; JIN, L.; CHOU, S.; TEO, C.; GAO, S. Experimental investigations of flow boiling heat transfer and pressure drop in straight and expanding microchannels - a comparative study. International Journal of Thermal Sciences, v. 50, n. 12, p. $2413-2421,2011$.

BALASUBRAMANIAN, P.; KANDLIKAR, S. G. Experimental study of flow patterns, pressure drop, and flow instabilities in parallel rectangular minichannels. Heat Transfer Engineering, v. 26, n. 3, p. 20-27, 2005.

BALIGA, B. R.; PATANKAR, S. V. A control volume finite-element method for twodimensional fluid flow and heat transfer. Numerical Heat Transfer, v. 6, n. 3, p. 245-261, 1983. 
BARNEA, D.; LUNINSKI, Y.; TAITEL, Y. Flow pattern in horizontal and vertical two phase flow in small diameter pipes. The Canadian Journal of Chemical Engineering, Wiley Subscription Services, Inc., A Wiley Company, v. 61, n. 5, p. 617-620, 1983.

BAROCZY, C. A systematic correlation for two-phase pressure drop. In: SER., C. E. P. S. (Ed.). In: AIChE 8th National Heat Transfer Conference. Los Angeles, USA. [S.1.: s.n.], 1965. v. 62, p. 232-249.

BEATTIE, D.; WHALLEY, P. A simple two-phase flow frictional pressure drop calculation method. Int. J. Multiphase Flow, v. 8, p. 83-87, 1982.

BEJAN, A. Second-law analysis in heat transfer and thermal design. In: HARTNETT, J. P.; IRVINE, T. F. (Ed.). Elsevier, 1982, (Advances in Heat Transfer, v. 15). p. 1 - 58. Disponível em: <http://www.sciencedirect.com/science/article/pii/S0065271708701722>

BEJAN, A. Entropy generation minimization: The new thermodynamics of finite-size devices and finite-time processes. Journal of Applied Physics, v. 79, n. 3, p. 1191-1218, 1996.

BEJAN, A. Advanced engineering thermodynamics. J. Wiley \& Sons, 1997. (WileyInterscience publication). ISBN 9780471148807. Disponível em: <https://books.google.com.br/books?id=D-NSAAAAMAAJ $>$.

BEJAN, A.; PFISTER, P. A. Evaluation of heat transfer augmentation techniques based on their impact on entropy generation. Letters in Heat and Mass Transfer, v. 7, n. 2, p. 97 - 106, 1980. ISSN 0094-4548.

BERGLES, A. E.; ROHSENOW, W. M. The determination of forced-convection surface-boiling heat transfer. ASME. J. Heat Transfer., v. 86, n. 3, p. 365-372, 1964.

BERGMAN, T.; INCROPERA, F.; LAVINE, A.; DEWITT, D. Fundamentals of Heat and Mass Transfer. [S.1.]: Wiley, 2011.

BERTSCH, S. S.; GROLL, E. A.; GARIMELLA, S. V. Refrigerant flow boiling heat transfer in parallel microchannels as a function of local vapor quality. International Journal of Heat and Mass Transfer, v. 51, n. 19-20, p. 4775 - 4787, 2008.

BERTSCH, S. S.; GROLL, E. A.; GARIMELLA, S. V. Effects of heat flux, mass flux, vapor quality, and saturation temperature on flow boiling heat transfer in microchannels. International Journal of Multiphase Flow, v. 35, n. 2, p. 142 - 154, 2009a.

BERTSCH, S. S.; GROLL, E. A.; GARIMELLA, S. V. A composite heat transfer correlation for saturated flow boiling in small channels. International Journal of Heat and Mass Transfer, v. 52, n. 7-8, p. $2110-2118,2009$ b.

BLEVINS, R. Applied fluid dynamics handbook. Van Nostrand Reinhold Co., 1984. ISBN 9780442212964. Disponível em: <https://books.google.com.br/books?id=GZUAAAAMAAJ $>$.

BOGOJEVIC, D.; SEFIANE, K.; WALTON, A.; LIN, H.; CUMMINS, G. Two-phase flow instabilities in a silicon microchannels heat sink. International Journal of Heat and Fluid Flow, v. 30, n. 5 , p. $854-867,2009$.

BOGOJEVIC, D.; SEFIANE, K.; WALTON, A.; LIN, H.; CUMMINS, G.; KENNING, D.; KARAYIANNIS, T. Experimental investigation of non-uniform heating effect on flow boiling instabilities in a microchannel-based heat sink. International Journal of Thermal Sciences, v. 50, n. 3, p. $309-324,2011$. 
BOGOJEVIC, D.; SEFIANE, K.; WALTON, A. J.; LIN, G. C. H. Two-phase flow instabilities in microchannels. In: ECI International Conference on Heat Transfer and Fluid Flow in Microscale, Whistler, Canada. [S.1.: s.n.], 2008.

BORHANI, N.; AGOSTINI, B.; THOME, J. R. A novel time strip flow visualisation technique for investigation of intermittent dewetting and dryout in elongated bubble flow in a microchannel evaporator. International Journal of Heat and Mass Transfer, v. 53, n. 21-22, p. 4809 - 4818, 2010.

BOURE, J.; BERGLES, A.; TONG, L. Review of two-phase flow instability. Nuclear Engineering and Design, v. 25, n. 2, p. 165 - 192, 1973. ISSN 0029-5493.

BOWERS, M.; MUDAWAR, I. High flux boiling in low flow rate, low pressure drop minichannel and micro-channel heat sinks. International Journal of Heat and Mass Transfer, v. 37, n. 2 , p. $321-332,1994 a$.

BOWERS, M.; MUDAWAR, I. Two-phase electronic cooling using mini-channel and microchannel heat sinks: Part 1-design criteria and heat diffusion constraints. J. Electron. Packag., v. 116(4), p. 290-297, 1994b.

BOWERS, M.; MUDAWAR, I. Two-phase electronic cooling using mini-channel and microchannel heat sinks: Part 2-flow rate and pressure drop constraints. J. Electron. Packag., v. 116(4), p. 298-305, 1994c.

CAVALLINI, A.; BROWN, J. S.; COL, D. D.; ZILIO, C. In-tube condensation performance of refrigerants considering penalization terms (exergy losses) for heat transfer and pressure drop. International Journal of Heat and Mass Transfer, v. 53, n. 13-14, p. 2885 - 2896, 2010. ISSN 0017-9310.

ÇENGEL, Y. Termodinámica. McGraw-Hill Interamericana de España S.L., 2009. (Educación / McGraw Hill). ISBN 9789701072868. Disponível em: <https://books.google.com.br/books?id=Y-lhcgAACAAJ $>$.

CHAI, L.; WANG, L.; ZHOU, M.; XIA, G. Two-phase flow pattern and pressure drop in silicon multi-microchannel with expansion-constriction cross-section. Experimental Thermal and Fluid Science, v. 60, p. 241 - 251, 2015. ISSN 0894-1777.

CHALFI, T. Y.; GHIAASIAAN, S. Pressure drop caused by flow area changes in capillaries under low flow conditions. International Journal of Multiphase Flow, v. 34, n. 1, p. 2 - 12, 2008. ISSN 0301-9322.

CHANG, K.; PAN, C. Two-phase flow instability for boiling in a microchannel heat sink. International Journal of Heat and Mass Transfer, v. 50, n. 11-12, p. 2078 - 2088, 2007.

CHÁVEZ, C. A. Simulacion bidimensional de esfuerzos de secado en la madera a traves de CVFEM. Dissertação (Mestrado), 2009.

CHÁVEZ, C. A.; LEÃ£O, H. L.; RIBATSKI, G. Evaluation of thermal-hydraulic performance of hydrocarbon refrigerants during flow boiling in a microchannels array heat sink. Applied Thermal Engineering, v. 111, p. 703 - 717, 2017. ISSN 1359-4311.

CHEN, J. Correlation for boiling heat transfer to saturated fluids in convective flow. $I \& E C$ Process Design Develop., v. 5, p. 322-329, 1966. 
CHEN, T.; GARIMELLA, S. V. Measurements and high-speed visualizations of flow boiling of a dielectric fluid in a silicon microchannel heat sink. International Journal of Multiphase Flow, v. 32 , n. 8 , p. $957-971,2006$.

CHICCHITTI, A.; LOMBARDI, M.; SILVESTRI, M.; SOLDAINI, G.; ZAVATTARELLI, R. Two-phase cooling experiments-pressure drop, heat transfer and burnout measurements. Energ. Nucl., v. 7, p. 407-425, 1960.

CHINNOV, E.; RON'SHIN, F.; KABOV, O. Two-phase flow patterns in short horizontal rectangular microchannels. International Journal of Multiphase Flow, v. 80, p. 57 - 68, 2016. ISSN 0301-9322.

CHISHOLM, D. A theoretical basis for the lockhart-martinelli correlation for two-phase flow. International Journal of Heat and Mass Transfer, v. 10, n. 12, p. 1767-1778, 1967. ISSN 00179310.

CHISHOLM, D. Pressure gradients due to friction during the flow of evaporating two-phase mixtures in smooth tubes and channels. International Journal of Heat and Mass Transfer, v. 16, n. 2 , p. $347-358,1973$.

CHO, E. S.; CHOI, J. W.; YOON, J. S.; KIM, M. S. Experimental study on microchannel heat sinks considering mass flow distribution with non-uniform heat flux conditions. International Journal of Heat and Mass Transfer, v. 53, n. 9-10, p. 2159 - 2168, 2010. ISSN 0017-9310.

CHOI, K.-I.; OH, J.-T.; SAITO, K.; JEONG, J. S. Comparison of heat transfer coefficient during evaporation of natural refrigerants and r-1234yf in horizontal small tube. International Journal of Refrigeration, v. 41, p. 210 - 218, 2014. ISSN 0140-7007.

CHOI, K.-I.; PAMITRAN, A.; OH, J.-T.; SAITO, K. Pressure drop and heat transfer during twophase flow vaporization of propane in horizontal smooth minichannels. International Journal of Refrigeration, v. 32, n. 5, p. 837 - 845, 2009. ISSN 0140-7007.

CIONCOLINI, A.; THOME, J. R. Algebraic turbulence modeling in adiabatic and evaporating annular two-phase flow. International Journal of Heat and Fluid Flow, v. 32, n. 4, p. 805 - 817, 2011. ISSN 0142-727X.

CIONCOLINI, A.; THOME, J. R.; LOMBARDI, C. Unified macro-to-microscale method to predict two-phase frictional pressure drops of annular flows. International Journal of Multiphase Flow, v. 35, n. 12, p. 1138 - 1148, 2009.

COLGAN, E.; FURMAN, B.; GAYNES, M.; GRAHAM, W.; LABIANCA, N.; MAGERLEIN, J.; POLASTRE, R.; ROTHWELL, M.-B.; BEZAMA, R. J.; CHOUDHARY, R.; MARSTON, K.; TOY, H.; WAKIL, J.; ZITZ, J.; SCHMIDT, R. A practical implementation of silicon microchannel coolers for high power chips. IEEE Transactions on Components and Packaging Technologies, v. 30, n. 2, p. 218-225, 2007.

COLLIER, J. G.; THOME, J. R. Convective Boiling and Condensation. 3rd edition. ed. Walton Street, Oxford OX2 6DP: United States by Oxford University Press Inc., New York, 1994.

COOPER, M. G. Heat flow rates in saturated nucleate pool boiling - a wide-ranging examination using reduced properties. In: HARTNETT, J. P.; IRVINE, T. F. (Ed.). [S.1.]: Elsevier, 1984, (Advances in Heat Transfer, v. 16). p. $157-239$. 
COPETTI, J.; MACAGNAN, M.; ZINANI, F. Experimental study on r-600a boiling in $2.6 \hat{A} \mathrm{~mm}$ tube. International Journal of Refrigeration, v. 36, n. 2, p. 325 - 334, 2013. ISSN 0140-7007. SI: New Developments in Boiling and Condensation.

COSTA-PATRY, E.; OLIVIER, J.; MICHEL, B.; THOME, J. R. Two-phase flow of refrigerants in $85 \hat{\mathrm{I}}^{1 / 4 \mathrm{~m}}$-wide multi-microchannels: Part ii - heat transfer with 35 local heaters. International Journal of Heat and Fluid Flow, v. 32, n. 2, p. $464-476,2011$ b.

COSTA-PATRY, E.; OLIVIER, J.; NICHITA, B. A.; MICHEL, B.; THOME, J. R. Two-phase flow of refrigerants in $85 \hat{\mathrm{I}} 1 / 4 \mathrm{~m}$-wide multi-microchannels: Part i - pressure drop. International Journal of Heat and Fluid Flow, v. 32, n. 2, p. 451 - 463, 2011 a.

COSTA-PATRY, E.; OLIVIER, J.; THOME, J. R. Heat transfer charcacteristics in a copper micro-evaporator and flow pattern-based prediction method for flow boiling in microchannels. Frontiers in Heat and Mass Transfer, v. 3, p. 013002, 2012.

CULLION, R.; PENCE, D.; LIBURDY, J.; NARAYANAN, V. Void fraction variations in a fractal-like branching microchannel network. Heat Transfer Engineering, v. 28, n. 10, p. 806816, 2007.

DA SILVA, J. D. Estudio teorico-experimental da pressão durante a ebulição convectiva de refrigerantes halogenados no interior de microcanais circulares. Dissertação (Mestrado) Escola de Engenharia de Sao Carlos, Universidade de São Paulo, 2012.

DANIELS, B. J.; LIBURDY, J. A.; PENCE, D. V. Experimental studies of adiabatic flow boiling in fractal-like branching microchannels. Experimental Thermal and Fluid Science, v. 35, n. 1, p. $1-10,2011$.

DARABI, J.; OHADI, M.; DEVOE, D. An electrohydrodynamic polarization micropump for electronic cooling. Microelectromechanical Systems, Journal of, IEEE, v. 10, n. 1, p. 98-106, 2001.

DAVIDSON, P.; HARDIE, C.; HUMPHREYS, R.; MARKSON, A.; A.R., M.; RAVESE, T. Studies of heat transmission through boiler tubing at pressures from 500 to 3300 pounds. $J$. Heat Transfer., v. 65, p. 553-591., 1943.

DEL COL, D.; BISETTO, A.; BORTOLATO, M.; TORRESIN, D.; ROSSETTO, L. Experiments and updated model for two phase frictional pressure drop inside minichannels. International Journal of Heat and Mass Transfer, v. 67, p. 326 - 337, 2013. ISSN 0017-9310.

DEL COL, D.; BORTOLATO, M.; BORTOLIN, S. Comprehensive experimental investigation of two-phase heat transfer and pressure drop with propane in a minichannel. International Journal of Refrigeration, v. 47, p. 66 - 84, 2014. ISSN 0140-7007.

DENG, D.; WAN, W.; TANG, Y.; SHAO, H.; HUANG, Y. Experimental and numerical study of thermal enhancement in reentrant copper microchannels. International Journal of Heat and Mass Transfer, v. 91, p. 656 - 670, 2015. ISSN 0017-9310.

DENG, D.; WAN, W.; TANG, Y.; WAN, Z.; LIANG, D. Experimental investigations on flow boiling performance of reentrant and rectangular microchannels- a comparative study. International Journal of Heat and Mass Transfer, v. 82, p. 435 - 446, 2015. ISSN 0017-9310.

DENG, D.; XIE, Y.; HUANG, Q.; TANG, Y.; HUANG, L.; HUANG, X. Flow boiling performance of omega-shaped reentrant copper microchannels with different channel sizes. Experimental Thermal and Fluid Science, v. 69, p. 8 - 18, 2015. ISSN 0894-1777. 
DIXIT, P.; LIN, N.; MIAO, J.; WONG, W. K.; CHOON, T. K. Silicon nanopillars based 3d stacked microchannel heat sinks concept for enhanced heat dissipation applications in \{MEMS \} packaging. Sensors and Actuators A: Physical, v. 141, n. 2, p. 685-694, 2008.

DO NASCIMENTO, F. J. Estudio teorico experimental da transferencia de calor e perda de pressão en um dissipador de calor baseado em microcanais. Dissertação (Mestrado) — Escola de Engenharia de Sao Carlos, Universidade de São Paulo, 2012.

DO NASCIMENTO, F. J.; LEÃO, H. L. S. L.; RIBATSKI, G. An experimental study on flow boiling heat transfer of r134a in a microchannel-based heat sink. Experimental Thermal and Fluid Science, v. 45, n. 0, p. 117 - 127, 2013.

DOWLATI, R.; KAWAJI, M.; CHAN, A. Two-phase crossflow and boiling heat transfer in horizontal tube bundles. J. Heat Transfer, v. 118, p. 124-131, 1996.

DUKLER, A.; WICKS, M.; CLEVELAND, R. Pressure drop and hold-up in two-phase flow part-a. a comparison of existing correlations and part-b. an approach through similarity analysis. AIChE J., v. 10, p. 38-51, 1964.

DUPONT, V.; THOME, J.; JACOBI, A. Heat transfer model for evaporation in microchannels. part ii: comparison with the database. International Journal of Heat and Mass Transfer, v. 47, n. 14-16, p. 3387 - 3401, 2004. ISSN 0017-9310.

EES. Engineering Equation Solver (EES), versão Academica. [S.1.: s.n.], 2003.

FELCAR, H. O. M.; RIBATSKI, G.; JABARDO, J. M. S. A gas-liquid flow pattern predictive method for macro- and mini-scale round channels. In: In: 10th UK National Heat Transfer Conference, Edinburgh, UK. [S.1.: s.n.], 2007.

FIELD, B. S.; HRNJAK, P. Adiabatic two-phase pressure drop of refrigerants in small channels. Heat Transfer Engineering, v. 28, n. 8-9, p. 704-712, 2007.

FOSTER, H. K.; ZUBER, N. Bubble dynamics and boiling heat transfer. AIChE Journal, v. 1, p. 531-535, 1955.

FRIEDEL, L. . Improved friction pressure drop correlations for horizontal and vertical twophase pipe flow. In: In: European Two-Phase Flow Group Meeting, paper E2, Ispra, Italy. [S.1.: s.n.], 1979.

FU, B.-R.; LEE, C.-Y.; PAN, C. The effect of aspect ratio on flow boiling heat transfer of hfe-7100 in a microchannel heat sink. International Journal of Heat and Mass Transfer, v. 58, n. $1-2$, p. $53-61,2013$.

GAN, Y.; XU, J.; YAN, Y. An experimental study of two-phase pressure drop of acetone in triangular silicon micro-channels. Applied Thermal Engineering, v. 80, p. 76 - 86, 2015. ISSN 1359-4311.

GARCÍA, F; GARCÍA, R.; PADRINO, J.; MATA, C.; TRALLERO, J.; JOSEPH, D. Power law and composite power law friction factor correlations for laminar and turbulent gas-liquid flow in horizontal pipelines. International Journal of Multiphase Flow, v. 29, n. 10, p. 1605 1624, 2003.

GARRITY, P. T.; KLAUSNER, J. F.; MEI, R. A flow boiling microchannel evaporator plate for fuel cell thermal management. Heat Transfer Engineering, v. 28, n. 10, p. 877-884, 2007. 
GOLDBERG, N. Narrow channel forced air heat sink. IEEE TRANSACTIONS ON COMPONENTS, HYBRIDS, AND MANUFACTURING TECHNOLOGY, v. 7, n. 1, p. 154-159, 1984.

GORENFLO, D. Vdi gesellschaft verfahrenstechnic und chemieingenieurwesen. Düsseldorf: English translation of VDI, p. p. Ha4-Ha18, 1993.

GUNGOR, K.; WINTERTON, R. A general correlation for flow boiling in tubes and annuli. Int. J. Heat Mass Transfer, v. 29, p. 351-358, 1986.

GUO, L.; CHEN, X.; ZHANG, S.; FENG, Z. Correlation for predicting pressure drop of single and two-phase flow through horizontal helically coiled tubes. In: FLOW, P. of the Third International Symposium on M.; CHINA., H. T. X. (Ed.). [S.1.: s.n.], 1994. p. 514-521.

GUPTA, A. Enhancement of boiling heat transfer in a $5 \times 3$ tube bundle. International Journal of Heat and Mass Transfer, v. 48, n. 18, p. 3763 - 3772, 2005.

GUPTA, A.; SAINI, J.; VARMA, H. Boiling heat transfer in small horizontal tube bundles at low cross-flow velocities. International Journal of Heat and Mass Transfer, v. 38, n. 4, p. 599 $-605,1995$.

HARDT, S.; SCHILDER, B.; TIEMANN, D.; KOLB, G.; HESSEL, V.; STEPHAN, P. Analysis of flow patterns emerging during evaporation in parallel microchannels. International Journal of Heat and Mass Transfer, v. 50, n. 1-2, p. 226 - 239, 2007.

HARIRCHIAN, T.; GARIMELLA, S. V. Microchannel size effects on local flow boiling heat transfer to a dielectric fluid. International Journal of Heat and Mass Transfer, v. 51, n. 15-16, p. $3724-3735,2008$.

HARIRCHIAN, T.; GARIMELLA, S. V. Effects of channel dimension, heat flux, and mass flux on flow boiling regimes in microchannels. International Journal of Multiphase Flow, v. 35, n. 4, p. $349-362,2009$.

HARIRCHIAN, T.; GARIMELLA, S. V. A comprehensive flow regime map for microchannel flow boiling with quantitative transition criteria. International Journal of Heat and Mass Transfer, v. 53, n. 13-14, p. 2694-2702, 2010.

HARIRCHIAN, T.; GARIMELLA, S. V. Flow regime-based modeling of heat transfer and pressure drop in microchannel flow boiling. International Journal of Heat and Mass Transfer, v. 55, n. 4 , p. $1246-1260,2012$.

HENNING, T.; BRANDNER, J. J.; SCHUBERT, K.; LORENZINI, M.; MORINI, G. L. Low-frequency instabilities in the operation of metallic multi-microchannel evaporators. Heat Transfer Engineering, v. 28, n. 10, p. 834-841, 2007.

HETSRONI, G.; MOSYAK, A.; POGREBNYAK, E.; SEGAL, Z. Explosive boiling of water in parallel micro-channels. International Journal of Multiphase Flow, v. 31, n. 4, p. 371 - 392, 2005.

HETSRONI, G.; MOSYAK, A.; SEGAL, Z. Nonuniform temperature distribution in electronic devices cooled by flow in parallel microchannels. Components and Packaging Technologies, IEEE Transactions on, v. 24, n. 1, p. 16-23, 2001.

HETSRONI, G.; MOSYAK, A.; SEGAL, Z.; ZISKIND, G. A uniform temperature heat sink for cooling of electronic devices. International Journal of Heat and Mass Transfer, v. 45, n. 16, p. $3275-3286,2002$. 
HETSRONI, G.; MOSYAK, A.; SEGAL, Z.; POGREBNYAK, E. Two-phase flow patterns in parallel micro-channels. International Journal of Multiphase Flow, v. 29, n. 3, p. 341 - 360, 2003.

HSIEH, S.-S.; LIN, C.-Y. Subcooled convective boiling in structured surface microchannels. Journal of Micromechanics and Microengineering, v. 20, n. 1, p. 015027, jan. 2010.

HSU, J.-T. A parametric study of boiling heat transfer in a horizontal tube bundle. Tese (Doutorado) - Ph.D. Dissertation. University of Wisconsin-Milwaukee, Milwaukee, WI., 1987.

HSU, L.-C.; CION, S.-W.; LIN, K.-W.; WANG, C.-C. An experimental study of inclination on the boiling heat transfer characteristics of a micro-channel heat sink using hfe-7100. International Communications in Heat and Mass Transfer, v. 62, p. 13 - 17, 2015. ISSN 07351933.

HU, X.; LIN, G.; CAI, Y.; WEN, D. Experimental study of flow boiling of fc-72 in parallel minichannels under sub-atmospheric pressure. Applied Thermal Engineering, v. 31, n. 17-18, p. $3839-3853,2011$.

HWANG, T.; YAO, S. Cross flow heat transfer in tube bundles at low reynolds numbers. J. Heat Transfer, v. 108, p. 697-700, 1986.

HWANG, Y. W.; KIM, M. S. The pressure drop in microtubes and the correlation development. International Journal of Heat and Mass Transfer, v. 49, n. 11-12, p. 1804 - 1812, 2006.

INTEL. Produtos, processadores. Março 2016. Disponível em: <http://www.intel.com.br/content/www/br/pt/homepage.html?_ga=1.32544958.1097244214.1459323987>.

IUSHIMOTO, T.; OHSAKI, T. Vlsi packaging technique using liquid-cooled channels. IEEE TRANSACTIONS ON COMPONENTS, HYBRIDS, AND MANUFACTURING TECHNOLOGY, v. 9 , n. 4 , p. $328-335,1986$.

JANG, Y.; PARK, C.; LEE, Y.; KIM, Y. Flow boiling heat transfer coefficients and pressure drops of fc-72 in small channel heat sinks. International Journal of Refrigeration, v. 31, n. 6, p. $1033-1041,2008$.

JIANG, L.; WONG, M.; ZOHAR, Y. Forced convection boiling in a microchannel heat sink. Microelectromechanical Systems, Journal of, v. 10, n. 1, p. 80-87, 2001.

JONES, B.; GARIMELLA, S. V. Infrared micro-particle image velocimetry in a silicon microchannel heat sink. International Heat Transfer Conference 13, v. 0, 2006.

KAEW-ON, J.; SAKAMATAPAN, K.; WONGWISES, S. Flow boiling heat transfer of r134a in the multiport minichannel heat exchangers. Experimental Thermal and Fluid Science, v. 35, n. 2 , p. $364-374,2011$.

KAKAÇ, S.; BON, B. A review of two-phase flow dynamic instabilities in tube boiling systems. International Journal of Heat and Mass Transfer, v. 51, n. 3-4, p. 399 - 433, 2008.

KAKAÇ, S.; VEZIROGLU, T.; PADKI, M.; FU, L.; CHEN, X. Investigation of thermal instabilities in a forced convection upward boiling system. Experimental Thermal and Fluid Science, v. 3, n. 2, p. 191-201, 1990.

KANDLIKAR, S. A general correlation for saturated two-phase flow boiling heat transfer inside horizontal and vertical tubes. J. Heat Transfer., v. 112, n. 1, p. 219-228, 1990. 
KANDLIKAR, S. Heat transfer mechanisms during flow boiling in microchannels. ASME J. Heat Transfer., v. 126, p. 8-16, 2004.

KANDLIKAR, S.; KUAN, W.; WILLISTEIN, D.; BORRELLI, J. Stabilization of flow boiling in microchannels using pressure drop elements and fabricated nucleation sites. J. Heat Transfer., v. 128 , n. 4 , p. 389-396, 2005.

KANDLIKAR, S. G.; BALASUBRAMANIAN, P. An extension of the flow boiling correlation to transition, laminar, and deep laminar flows in minichannels and microchannels. Heat Transfer Engineering, v. 25, n. 3, p. 86-93, 2004.

KANIZAWA, F. T.; RIBATSKI, G. Void fraction predictive method based on the minimum kinetic energy. Journal of the Brazilian Society of Mechanical Sciences and Engineering, v. 38, n. 1, p. 209-225, 2016. ISSN 1806-3691.

KANIZAWA, F. T.; TIBIRIÇÁ, C. B.; RIBATSKI, G. Heat transfer during convective boiling inside microchannels. International Journal of Heat and Mass Transfer, v. 93, p. 566 - 583, 2016. ISSN 0017-9310.

KATTO, Y.; OHNO, H. An improved version of the generalized correlation of critical heat flux for the forced convective boiling in uniformly heated vertical tubes. International Journal of Heat and Mass Transfer, v. 27, n. 9, p. 1641 - 1648, 1984. ISSN 0017-9310.

KEW, P. A.; CORNWELL, K. Correlations for the prediction of boiling heat transfer in smalldiameter channels. Applied Thermal Engineering, v. 17, n. 8-10, p. 705 - 715, 1997.

KHOSHVAGHT-ALIABADI, M.; SAHAMIYAN, M.; HESAMPOUR, M.; SARTIPZADEH, O. Experimental study on cooling performance of sinusoidal-wavy minichannel heat sink. Applied Thermal Engineering, v. 92, p. 50 - 61, 2016. ISSN 1359-4311.

KIM, N.-H.; SIM, Y.-S.; MIN, C.-K. Convective boiling of r-22 in a flat extruded aluminum multi-port tube. ASME 2nd International Conference on Microchannels and Minichannels, $\mathrm{p}$. 507-513, 2004.

KIM, S.-M.; MUDAWAR, I. Universal approach to predicting two-phase frictional pressure drop for adiabatic and condensing mini/micro-channel flows. International Journal of Heat and Mass Transfer, v. 55, n. 11-12, p. 3246 - 3261, 2012.

KIM, S.-M.; MUDAWAR, I. Universal approach to predicting saturated flow boiling heat transfer in mini-micro-channels-part ii. two-phase heat transfer coefficient. International Journal of Heat and Mass Transfer, v. 64, p. 1239 - 1256, 2013. ISSN 0017-9310.

KISHIMOTO, T.; SASAKI, S. Cooling characteristics of diamond-shaped interrupted cooling fin for high-power lsi devices. Electronics Letters, v. 23, n. 9, p. 456-457, 1987.

KNIGHT, R.; GOODLING, J.; HALL, D. Optimal thermal design of forced convection heat sinks-analytical. J. Electron. Packag., v. 113(3), p. 313-321, 1991.

KNIGHT, R.; HALL, D.; GOODLING, J.; JAEGER, R. Heat sink optimization with application to microchannels. Components, Hybrids, and Manufacturing Technology, IEEE Transactions on, v. 15, n. 5, p. 832-842, 1992.

KOŞAR, A.; KUO, C.; PELES, Y. Boiling heat transfer in rectangular microchannels with reentrant cavities. Int. J. Heat Mass Transfer, v. 48, n. 23, p. 4867-4886, 2005. 
KOSAR, A.; KUO, C.-J.; PELES, Y. Suppression of boiling flow oscillations in parallel microchannels by inlet restrictors. J. Heat Transfer, v. 128(3), p. 251-260, 2006.

KOŞAR, A.; OZDEMIR, M. R.; KESKINOZ, M. Pressure drop across micro-pin heat sinks under unstable boiling conditions. International Journal of Thermal Sciences, v. 49, n. 7, p. $1253-1263,2010$.

KOŞAR, A.; PELES, Y. Critical heat flux of r-123 in silicon-based microchannels. Journal of Heat Transfer, v. 129, p. 844-851, 2007a.

KOŞAR, A.; PELES, Y. Boiling heat transfer in a hydrofoil-based micro pin fin heat sink. International Journal of Heat and Mass Transfer, v. 50, n. 5-6, p. 1018 - 1034, $2007 \mathrm{~b}$.

KREBS, D.; NARAYANAN, V.; LIBURDY, J.; PENCE, D. Spatially resolved wall temperature measurements during flow boiling in microchannels. Experimental Thermal and Fluid Science, v. 34, n. 4, p. $434-445,2010$. <ce:title>ECI International Conference on Heat Transfer and Fluid Flow in Microscale $</$ ce:title $>$.

KRISHNAMURTHY, S.; PELES, Y. Flow boiling of water in a circular staggered micro-pin fin heat sink. International Journal of Heat and Mass Transfer, v. 51, n. 5-6, p. 1349 - 1364, 2008.

KUO, C.-J.; PELES, Y. Local measurement of flow boiling in structured surface microchannels. International Journal of Heat and Mass Transfer, v. 50, n. 23-24, p. 4513 - 4526, 2007.

KUZNETSOV, V. V.; SHAMIRZAEV, A. S.; KOZULIN, I. A.; KOZLOV, S. P. Correlation of the flow pattern and flow boiling heat transfer in microchannels. Heat Transfer Engineering, v. 34, n. 2-3, p. 235-245, 2013.

LAW, M.; LEE, P.-S. A comparative study of experimental flow boiling heat transfer and pressure characteristics in straight- and oblique-finned microchannels. International Journal of Heat and Mass Transfer, v. 85, p. 797 - 810, 2015. ISSN 0017-9310.

LAW, M.; LEE, P.-S. Comparative study of temperature and pressure instabilities during flow boiling in straight- and $10 \hat{\mathrm{A}}^{\circ}$ oblique-finned microchannels. Energy Procedia, v. 75, p. 3105 3112, 2015. ISSN 1876-6102. Clean, Efficient and Affordable Energy for a Sustainable Future: The 7th International Conference on Applied Energy (ICAE2015).

LAZAREK, G.; BLACK, S. Evaporative heat transfer, pressure drop and critical heat flux in a small vertical tube with r-113. International Journal of Heat and Mass Transfer, v. 25, n. 7, p. $945-960,1982$.

LEÃO, H. L. S. L. Análise experimental dos efeitos do fluido e da orientação do escoamento no desempnho de dissipadores de calor baseados na ebulição convectiva em microcanais. Dissertação (Mestrado) - Escola de Engenharia de Sao Carlos, Universidade de São Paulo, November 3-7. 2014.

LEÃO, H. L. S. L.; CHÁVEZ, C. A.; JASINEVICIUS, R.; RIBATSKI, G. A comparative analyses of the thermal performance of the refrigerants r134a, r245fa, r407c and r600a during flow boiling in a microchannels heat sink. p. in review, 2016.

LEÃO, H. L. S. L.; CHÁVEZ, C. A.; NASCIMENTO, F. J. do; RIBATSKI, G. An analysis of the effect of the footprint orientation on the thermal-hydraulic performance of a microchannels heat sink during flow boiling of r245fa. Applied Thermal Engineering, v. 90, p. 907 - 926, 2015. ISSN 1359-4311. 
LEÃO, H. L. S. L.; CHÁVEZ, C. A.; RIBATSKI, G. The effect of footprint orientation on the performance of a heat spreader based on flow boiling inside micro-scale channels. In: 22nd International Congress of Mechanical Engineering (COBEM 2013). RibeirãoPreto, SP, Brazil. [S.1.: s.n.], 2013.

LEÃO, H. L. S. L.; NASCIMENTO, F. J. do; RIBATSKI, G. Flow boiling heat transfer of r407c in a microchannels based heat spreader. Experimental Thermal and Fluid Science, v. 59, p. 140 - 151, 2014. ISSN 0894-1777.

LEE, H.; PARK, I.; MUDAWAR, I.; HASAN, M. M. Micro-channel evaporator for space applications - 1. experimental pressure drop and heat transfer results for different orientations in earth gravity. International Journal of Heat and Mass Transfer, v. 77, n. 0, p. 1213-1230, 2014a.

LEE, H.; PARK, I.; MUDAWAR, I.; HASAN, M. M. Micro-channel evaporator for space applications - 2. assessment of predictive tools. International Journal of Heat and Mass Transfer, v. 77, n. 0, p. 1231-1249, 2014b.

LEE, H. J.; LEE, S. Y. Heat transfer correlation for boiling flows in small rectangular horizontal channels with low aspect ratios. International Journal of Multiphase Flow, v. 27, n. 12, p. 2043 $-2062,2001$.

LEE, H. J.; LEE, S. Y. Pressure drop correlations for two-phase flow within horizontal rectangular channels with small heights. International Journal of Multiphase Flow, v. 27, n. 5, p. $783-796,2001$.

LEE, H. J.; LIU, D. Y.; YAO, S. chune. Flow instability of evaporative micro-channels. International Journal of Heat and Mass Transfer, v. 53, n. 9-10, p. 1740 - 1749, 2010.

LEE, J.; MUDAWAR, I. Two-phase flow in high-heat-flux micro-channel heat sink for refrigeration cooling applications: Part i - pressure drop characteristics. International Journal of Heat and Mass Transfer, v. 48, n. 5, p. 928 - 940, 2005a.

LEE, J.; MUDAWAR, I. Two-phase flow in high-heat-flux micro-channel heat sink for refrigeration cooling applications: Part ii-heat transfer characteristics. International Journal of Heat and Mass Transfer, v. 48, n. 5, p. 941 - 955, $2005 \mathrm{~b}$.

LEE, J.; MUDAWAR, I. Critical heat flux for subcooled flow boiling in micro-channel heat sinks. International Journal of Heat and Mass Transfer, v. 52, n. 13-14, p. 3341 - 3352, 2009.

LEE, P.-S.; GARIMELLA, S. V. Saturated flow boiling heat transfer and pressure drop in silicon microchannel arrays. International Journal of Heat and Mass Transfer, v. 51, n. 3-4, p. 789 806, 2008.

LEE, P.-S.; GARIMELLA, S. V.; LIU, D. Investigation of heat transfer in rectangular microchannels. International Journal of Heat and Mass Transfer, v. 48, n. 9, p. 1688 - 1704, 2005 .

LI, W.; WU, Z. A general criterion for evaporative heat transfer in micro/mini-channels. International Journal of Heat and Mass Transfer, v. 53, n. 9-10, p. 1967 - 1976, 2010. ISSN 0017-9310.

LI, W.; WU, Z. Generalized adiabatic pressure drop correlations in evaporative micro/minichannels. Experimental Thermal and Fluid Science, v. 35, n. 6, p. 866 - 872, 2011. 
LIN, S.; KWOK, C.; LI, R.-Y.; CHEN, Z.-H.; CHEN, Z.-Y. Local frictional pressure drop during vaporization of r-12 through capillary tubes. International Journal of Multiphase Flow, v. 17, n. 1, p. $95-102,1991$.

LIU, D.; GARIMELLA, S. V. Flow boiling heat transfer in microchannels. Journal of Heat Transfer, v. 129, p. 1321-1332, 2007.

LIU, D.; LEE, P.-S.; GARIMELLA, S. V. Prediction of the onset of nucleate boiling in microchannel flow. International Journal of Heat and Mass Transfer, v. 48, n. 25-26, p. 5134 $5149,2005 b$.

LIU, Z.; WINTERTON, R. A general correlation for saturated and subcooled flow boiling in tubes and annuli, based on a nucleate pool boiling equation. International Journal of Heat and Mass Transfer, v. 34, n. 11, p. 2759 - 2766, 1991.

LOCKHART, R.; MARTINELLI, R. Proposed correlation of data for isothermal two-phase, two component flow in pipes. Chem. Eng. Progr., v. 45, p. 39-48, 1949.

LU, C. T.; PAN, C. Stabilization of flow boiling in microchannel heat sinks with a diverging cross-section design. Journal of Micromechanics and Microengineering, v. 18, n. 7, p. 075035, 2008.

LU, C. T.; PAN, C. A highly stable microchannel heat sink for convective boiling. Journal of Micromechanics and Microengineering, v. 19, n. 5, p. 055013, 2009.

LU, C. T.; PAN, C. Convective boiling in a parallel microchannel heat sink with a diverging cross section and artificial nucleation sites. Experimental Thermal and Fluid Science, v. 35, n. 5, p. $810-815,2011$. <ce:title>7th ECI-International Conference on Boiling Heat Transfer ICBHT-2009</ce:title>.

MADHOUR, Y.; OLIVIER, J.; COSTA-PATRY, E.; PAREDES, S.; MICHEL, B.; THOME, J. Flow boiling of r134a in a multi-microchannel heat sink with hotspot heaters for energyefficient microelectronic cpu cooling applications. Components, Packaging and Manufacturing Technology, IEEE Transactions on, v. 1, n. 6, p. 873-883, 2011.

MAHALINGAM, M. Thermal management in semiconductor device packaging. Proceedings of the IEEE, v. 73, n. 9, p. 1396-1404, 1985.

MAQBOOL, M. H.; PALM, B.; KHODABANDEH, R. Experimental investigation of dryout of propane in uniformly heated single vertical mini-channels. Experimental Thermal and Fluid Science, v. 37, p. 121 - 129, 2012. ISSN 0894-1777.

MAQBOOL, M. H.; PALM, B.; KHODABANDEH, R. Investigation of two phase heat transfer and pressure drop of propane in a vertical circular minichannel. Experimental Thermal and Fluid Science, v. 46, p. 120 - 130, 2013. ISSN 0894-1777.

MARKAL, B.; AYDIN, O.; AVCI, M. Effect of aspect ratio on saturated flow boiling in microchannels. International Journal of Heat and Mass Transfer, v. 93, p. 130 - 143, 2016. ISSN 0017-9310.

MARKAL, B.; AYDIN, O.; AVCI, M. An experimental investigation of saturated flow boiling heat transfer and pressure drop in square microchannels. International Journal of Refrigeration, In Press, p. -, 2016. ISSN 0140-7007. 
MAURO, A.; THOME, J.; TOTO, D.; VANOLI, G. Saturated critical heat flux in a multimicrochannel heat sink fed by a split flow system. Experimental Thermal and Fluid Science, v. 34 , n. 1 , p. $81-92,2010$.

MCADAMS, W.; WOODS, W.; BRYAN, R. Vaporization inside horizontal tubes-ii-benzene-oil mixtures. J. Heat Transfer., v. 64, p. 193-200, 1942.

MCGEE, J. Two-Phase Flow through Abrupt Expansions and Contractions. Tese (Doutorado), 1966.

MEGAHED, A. Experimental investigation of flow boiling characteristics in a cross-linked microchannel heat sink. International Journal of Multiphase Flow, v. 37, n. 4, p. 380 - 393, 2011.

MEGAHED, A.; HASSAN, I. Two-phase pressure drop and flow visualization of fc-72 in a silicon microchannel heat sink. International Journal of Heat and Fluid Flow, v. 30, n. 6, p. $1171-1182,2009$.

MENDLER, O. Sudden Expansion Losses in Single and Two-Phase Flow. Tese (Doutorado), 1963.

MISHIMA, K.; HIBIKI, T. Some characteristics of air-water two-phase flow in small diameter vertical tubes. International Journal of Multiphase Flow, v. 22, n. 4, p. 703 - 712, 1996.

MORINI, G. L. Single-phase convective heat transfer in microchannels: a review of experimental results. International Journal of Thermal Sciences, v. 43, n. 7, p. 631 - 651, 2004. ISSN 1290-0729.

MOTA-BABILONI, A.; NAVARRO-ESBRÍÂ, J.; BARRAGÁN-CERVERA, Á.; MOLÉS, F.; PERIS, B. Analysis based on eu regulation no 517/2014 of new hfc/hfo mixtures as alternatives of high gwp refrigerants in refrigeration and hvac systems. International Journal of Refrigeration, v. 52, p. 21 - 31, 2015. ISSN 0140-7007.

MÜLLER-STEINHAGEN, H.; HECK, K. A simple friction pressure drop correlation for twophase flow in pipes. Chemical Engineering and Processing: Process Intensification, v. 20, n. 6, p. $297-308,1986$.

MUWANGA, R.; MACDONALD, R.; I.I., H. Characteristics of flow boiling oscillations in silicon microchannel heat sinks. J. Heat Transfer., v. 129, n. 10, p. 1341-1351, 2007.

NAYAK, D.; HWANG, L.-T.; TURLIK, I.; REISMAN, A. A high-performance thermal module for computer packaging. Journal of Electronic Materials, Springer-Verlag, v. 16, n. 5, p. 357364, 1987.

NICENO, B. A Two-Dimensional Quality Mesh Generator. Version 1.4. [s.n.], 1995. Disponível em: $\langle$ http://web.mit.edu/easymesh_v1.4/www/easymesh.html $\rangle$.

NIÑO, V. G.; HRNJAK, P. S.; NEWELL, T. A. Two-phase flow visualization of r134a in a multiport microchannel tube. Heat Transfer Engineering, v. 24, n. 1, p. 41-52, 2003.

OLIEMANS, R.; POTS, B.; TROMPE, N. Modelling of annular dispersed two-phase flow in vertical pipes. International Journal of Multiphase Flow, v. 12, n. 5, p. 711 - 732, 1986. ISSN 0301-9322. 
ONG, C.; THOME, J. Macro-to-microchannel transition in two-phase flow: Part 1 - two-phase flow patterns and film thickness measurements. Experimental Thermal and Fluid Science, v. 35, n. 1 , p. $37-47,2011$ a.

ONG, C. L.; THOME, J. R. Flow boiling heat transfer of r134a, r236fa and r245fa in a horizontal $1.030 \mathrm{~mm}$ circular channel. Experimental Thermal and Fluid Science, v. 33, n. 4, p. $651-663,2009$.

OWENS, W. Two-phase pressure gradient. Int. Dev. in Heat Transfer, Pt. II, ASME., 1961.

PAMITRAN, A.; CHOI, K.-I.; OH, J.-T.; HRNJAK, P. Characteristics of two-phase flow pattern transitions and pressure drop of five refrigerants in horizontal circular small tubes. International Journal of Refrigeration, v. 33, n. 3, p. 578 - 588, 2010. ISSN 0140-7007.

PAMITRAN, A.; CHOI, K.-I.; OH, J.-T.; NASRUDDIN. Evaporation heat transfer coefficient in single circular small tubes for flow natural refrigerants of c3h8, nh3, and co2. International Journal of Multiphase Flow, v. 37, n. 7, p. 794 - 801, 2011. ISSN 0301-9322.

PARK, J. E.; THOME, J. R. Critical heat flux in multi-microchannel copper elements with low pressure refrigerants. International Journal of Heat and Mass Transfer, v. 53, n. 1-3, p. 110 $122,2010$.

PENG, X.; PETERSON, G.; WANG, B. Flow boiling of binary mixtures in microchanneled plates. International Journal of Heat and Mass Transfer, v. 39, n. 6, p. 1257 - 1264, 1996.

PENG, X.; WANG, B.-X. Forced convection and flow boiling heat transfer for liquid flowing through microchannels. International Journal of Heat and Mass Transfer, v. 36, n. 14, p. 3421 $-3427,1993$.

PETERS, J.; KANDLIKAR, S. G. Further evaluation of a flow boiling correlation for microchannels and minichannels. In: In: 5th Int. Conf. on Nanochannels, Microchannels and Minichannels, Puebla, Mexico. [S.1.: s.n.], 2007.

PHILLIPS, R. J. Microchannel heat sinks. Advances in thermal modeling of electronic components and systems, v. 2, p. 109-184, 1990.

PHILLIPS, W. A. Experimental and Numerical Investigation of Fluid Flow and Heat Transfer in Microchannels. Dissertação (Mestrado) - Department of Mechanical Engineering, Louisiana State University, 2008.

QU, W.; MALA, G.; LI, D. Heat transfer for water flow in trapezoidal silicon microchannels. International Journal of Heat and Mass Transfer, v. 43, n. 21, p. 3925 - 3936, 2000.

QU, W.; MUDAWAR, I. Measurement and prediction of pressure drop in two-phase microchannel heat sinks. International Journal of Heat and Mass Transfer, v. 46, n. 15, p. 2737 2753, 2003a.

QU, W.; MUDAWAR, I. Flow boiling heat transfer in two-phase micro-channel heat sinks. part i. experimental investigation and assessment of correlation methods. International Journal of Heat and Mass Transfer, v. 46, n. 15, p. 2755 - 2771, 2003b.

QU, W.; MUDAWAR, I. Flow boiling heat transfer in two-phase micro-channel heat sinks. part ii. annular two-phase flow model. International Journal of Heat and Mass Transfer, v. 46, n. 15, p. $2773-2784,2003 \mathrm{c}$. 
QU, W.; MUDAWAR, I. Measurement and correlation of critical heat flux in two-phase microchannel heat sinks. International Journal of Heat and Mass Transfer, v. 47, n. 10-11, p. 2045 2059, 2004.

QU, W.; SIU-HO, A. Experimental study of saturated flow boiling heat transfer in an array of staggered micro-pin-fins. International Journal of Heat and Mass Transfer, v. 52, n. 7-8, p. $1853-1863,2009$.

RAHMAN, M. M. Measurements of heat transfer in microchannel heat sinks. International Communications in Heat and Mass Transfer, v. 27, n. 4, p. 495 - 506, 2000.

RAVIGURURAJAN., T. Impact of channel geometry on two-phase flow heat transfer characteristics of refrigerants in microchannel heat exchangers. J. Heat Transfer., v. 120, n. 2, p. 485-491, 1998.

REVELLIN, R.; THOME, J. A new type of diabatic flow pattern map for boiling heat transfer in microchannels. J. Micromech. Microeng., v. 17, p. 788-796, 2007.

RIBATSKI, G. A critical overview on the recent literature concerning flow boiling and twophase flows inside micro-scale channels. Experimental Heat Transfer, v. 26, n. 2-3, p. 198-246, 2013.

RIBATSKI, G.; WOJTAN, L.; THOME, J. R. An analysis of experimental data and prediction methods for two-phase frictional pressure drop and flow boiling heat transfer in micro-scale channels. Experimental Thermal and Fluid Science, v. 31, n. 1, p. 1-19, 2006.

SAITOH, S.; DAIGUJI, H.; HIHARA, E. Correlation for boiling heat transfer of r-134a in horizontal tubes including effect of tube diameter. International Journal of Heat and Mass Transfer, v. 50, n. 25-26, p. 5215 - 5225, 2007.

SASAKI, S.; KISHIMOTO, T. Optimal structure for microgrooved cooling fin for high-power lsi devices. Electronics Letters, v. 22, n. 25, p. 1332-1334, 1986.

SCHMIDT, J.; FRIEDEL, L. Two-phase flow pressure change across sudden expansions in duct areas. Chemical Engineering Communications, v. 141-142, n. 1, p. 175-190, 1996.

SCHNEIDER, B.; KOSAR, A.; KUO, C.-J.; MISHRA, C.; COLE, G. S.; SCARINGE, R. P.; PELES, Y. Cavitation enhanced heat transfer in microchannels. Journal of Heat Transfer, v. 128, p. 1293-1601, 2006.

SCHNEIDER, B.; KOSAR, A.; PELES, Y. Hydrodynamic cavitation in flow boiling of refrigerant (r-123) inside microchannels. International Journal of Heat and Mass Transfer, v. 50, n. 13-14, p. 2838-2854, 2007.

SEMPÉRTEGUI-TAPIA, D.; ALVES, J. D. O.; RIBATSKI, G. Two-phase flow characteristics during convective boiling of halocarbon refrigerants inside horizontal small-diameter tubes. Heat Transfer Engineering, v. 34, n. 13, p. 1073-1087, 2013.

SEMPÉRTEGUI-TAPIA, D.; RIBATSKI, G. An analysis of experimental data and prediction methods for heat transfer coefficient during convective boiling in non-circular micro-scale channels. In: 8th International Conference on Multiphase Flow. ICMF 2013, Jeju, Korea. [S.1.: s.n.], 2013.

SEMPÉRTEGUI-TAPIA, D. F.; RIBATSKI, G. Two-phase frictional pressure drop in horizontal micro-scale channels: experimental data analysis and prediction method development. International Journal of Multiphase Flow, p. in review, 2016. 
SHAH, M. A new correlation for heat transfer during boiling flow through pipes. ASHRAE Trans., v. 82, p. 66-86, 1976.

SHAH, R.; LONDON, A. Chapter vii - rectangular ducts. In: LONDON, R. S. (Ed.). Laminar Flow Forced Convection in Ducts. [S.1.]: Academic Press, 1978. p. 196 - 222. ISBN 978-0-12020051-1.

SHAH, R.; SEKULIC, D. Fundamentals of Heat Exchanger Design. [S.1.]: Wiley, 2003. ISBN 9780471321712.

SIEDER, E. N.; TATE, G. E. Heat transfer and pressure drop of liquids in tubes. Industrial \& Engineering Chemistry, v. 28, n. 12, p. 1429-1435, 1936.

SILVÉRIO, V.; CARDOSO, S.; GASPAR, J.; FREITAS, P. P.; MOREIRA, A. Design, fabrication and test of an integrated multi-microchannel heat sink for electronics cooling. Sensors and Actuators A: Physical, v. 235, p. 14 - 27, 2015. ISSN 0924-4247.

SINGH, S.; BHIDE, R. R.; DUTTAGUPTA, S.; PURANIK, B.; AGRAWAL, A. Twophase flow pressure drop characteristics in trapezoidal silicon microchannels. Components and Packaging Technologies, IEEE Transactions on, v. 32, n. 4, p. 887-900, 2009.

STEINER, D.; TABOREK, J. Flow boiling heat transfer in vertical tubes correlated by an asymptotic model. Heat Transfer Engineering, v. 13, n. 2, p. 43-69, 1992.

STEINKE, M.; KANDLIKAR, S. An experimental investigation of flow boiling characteristics of water in parallel microchannels. J. Heat Transfer., v. 126, n. 4, p. 518-526, 2004.

STEPHAN, K.; ABDELSALAM, M. Heat-transfer correlations for natural convection boiling. International Journal of Heat and Mass Transfer, v. 23, n. 1, p. 73 - 87, 1980. ISSN 0017-9310.

STEPHAN, K.; PREUBER, P. Wärmeübergang und maximale wärmestromdichte beim behältersieden binärer und ternärer flüssigkeitsgemische. Chemie Ingenieur Technik, v. 51, n. 1, p. 37-37, 1979.

SUN, L.; MISHIMA, K. Evaluation analysis of prediction methods for two-phase flow pressure drop in mini-channels. International Journal of Multiphase Flow, v. 35, n. 1, p. 47 - 54, 2009.

SZCZUKIEWICZ, S. Thermal and Visual Operational Characteristics of Multi-Microchannel Evaporators using Refrigerants. Tese (Doutorado) — ÉCOLE POLYTECHNIQUE FÉDÉRALE DE LAUSANNE, 2012.

SZCZUKIEWICZ, S.; BORHANI, N.; THOME, J. Two-phase flow boiling in a single layer of future high-performance 3d stacked computer chips. In: Thermal and Thermomechanical Phenomena in Electronic Systems (ITherm), 2012 13th IEEE Intersociety Conference on. [S.1.: s.n.], 2012. p. 597-605.

SZCZUKIEWICZ, S.; BORHANI, N.; THOME, J. R. Two-phase flow operational maps for multi-microchannel evaporators. International Journal of Heat and Fluid Flow, v. 42, n. 0, p. $176-189,2013 a$.

SZCZUKIEWICZ, S.; BORHANI, N.; THOME, J. R. Two-phase heat transfer and highspeed visualization of $\hat{A}$ refrigerant flows in $100 \times 100 \hat{A} \hat{I} 1 / 4 \mathrm{~m} 2$ silicon multi-microchannels. International Journal of Refrigeration, v. 36, n. 2, p. 402 - 413, 2013b. <ce:title>SI: New Developments in Boiling and Condensation</ce:title $>$. 
SZCZUKIEWICZ, S.; BORHANI, N.; THOME, J. R. Fine-resolution two-phase flow heat transfer coefficient measurements of refrigerants in multi-microchannel evaporators. International Journal of Heat and Mass Transfer, v. 67, n. 0, p. 913 - 929, 2013c.

TAITEL, Y.; DUKLER, A. E. A model for predicting flow regime transitions in horizontal and near horizontal gas-liquid flow. AIChE Journal, American Institute of Chemical Engineers, v. 22 , n. 1 , p. $47-55,1976$.

TAMANNA, A.; LEE, P. S. Flow boiling heat transfer and pressure drop characteristics in expanding silicon microgap heat sink. International Journal of Heat and Mass Transfer, v. 82, p. 1 - 15, 2015. ISSN 0017-9310.

TAYLOR, B.; KUYATT, C. Guidelines for evaluating and expressing the uncertainty of nist measurement results. nist technical note 1297. National Institute of Standards and Technology, 1994.

THOME, J.; DUPONT, V.; JACOBI, A. Heat transfer model for evaporation in microchannels. part i: presentation of the model. International Journal of Heat and Mass Transfer, v. 47, n. 14-16, p. 3375 - 3385, 2004.

THOME, J. R. Engineering Data Book III. [S.1.], 2008.

THOME, J. R.; CHENG, L.; RIBATSKI, G.; VALES, L. F. Flow boiling of ammonia and hydrocarbons: A state-of-the-art review. International Journal of Refrigeration, v. 31, n. 4, p. 603 - 620, 2008. ISSN 0140-7007. Refrigeration with Ammonia and Hydrocarbons.

TIBIRIÇÁ, C. Estudo teorico experimental da transferencia de calor e do fluxo critico durante a ebulicao convectiva no interior de microcanais. Tese (Doutorado) - Escola de Engenharia de Sao Carlos, Universidade de Sao Paulo, 2011.

TIBIRIÇÁ, C. B.; CZELUSNIAK, L. E.; RIBATSKI, G. Critical heat flux in a $0.38 \mathrm{~mm}$ microchannel and actions for suppression of flow boiling instabilities. Experimental Thermal and Fluid Science, v. 67, p. 48 - 56, 2015. ISSN 0894-1777. Heat Transfer and Fluid Flow in Microscale.

TIBIRIÇÁ, C. B.; RIBATSKI, G. Flow boiling in micro-scale channels - synthesized literature review. International Journal of Refrigeration, v. 36, n. 2, p. 301 - 324, 2013. ISSN 0140-7007. SI: New Developments in Boiling and Condensation.

TIBIRIÇÁ, C. B.; RIBATSKI, G. Flow patterns and bubble departure fundamental characteristics during flow boiling in microscale channels. Experimental Thermal and Fluid Science, v. 59, p. 152 - 165, 2014. ISSN 0894-1777.

TOMCZYK, J.; SILBERSTEIN, E.; WHITMAN, B.; JOHNSON, B. Refrigeration and Air Conditioning Technology. [S.1.]: Cengage Learning, 2016. ISBN 9781305578296.

TRAN, T.; CHYU, M.-C.; WAMBSGANSS, M.; FRANCE, D. Two-phase pressure drop of refrigerants during flow boiling in small channels: an experimental investigation and correlation development. International Journal of Multiphase Flow, v. 26, n. 11, p. 1739 - 1754, 2000.

TRAN, T.; WAMBSGANSS, M.; FRANCE, D. Small circular- and rectangular-channel boiling with two refrigerants. International Journal of Multiphase Flow, v. 22, n. 3, p. 485 - 498, 1996.

TUCKERMAN, D.; PEASE, R. F. W. High-performance heat sinking for vlsi. Electron Device Letters, IEEE, v. 2, n. 5, p. 126-129, 1981. 
WANG, C.-C.; CHANG, W.-J.; DAI, C.-H.; LIN, Y.-T.; YANG, K.-S. Effect of inclination on the convective boiling performance of a microchannel heat sink using hfe-7100. Experimental Thermal and Fluid Science, v. 36, n. 0, p. 143 - 148, 2012.

WANG, C.-C.; TSENG, C.-Y.; CHEN, I. Y. A new correlation and the review of two-phase flow pressure change across sudden expansion in small channels. International Journal of Heat and Mass Transfer, v. 53, n. 19-20, p. 4287 - 4295, 2010. ISSN 0017-9310.

WANG, G.; CHENG, P.; BERGLES, A. Effects of inlet/outlet configurations on flow boiling instability in parallel microchannels. International Journal of Heat and Mass Transfer, v. 51, n. 9-10, p. $2267-2281,2008$.

WANG, G.; CHENG, P.; WU, H. Unstable and stable flow boiling in parallel microchannels and in a single microchannel. International Journal of Heat and Mass Transfer, v. 50, n. 21-22, p. $4297-4310,2007$.

WARRIER, G.; DHIR, V.; MOMODA, L. Heat transfer and pressure drop in narrow rectangular channel. Exp. Therm. Fluid Science., v. 26, p. 53-64, 2002.

WEN, M.-Y.; HO, C.-Y. Evaporation heat transfer and pressure drop characteristics of r-290 (propane), r-600 (butane), and a mixture of r-290 with r-600 in the three-lines serpentine smalltube. Applied Thermal Engineering, v. 25, n. 17-18, p. 2921 - 2936, 2005. ISSN 1359-4311.

WEXLER, E.; ORTEGA, A.; WALLINGER, D.; PRINDIVILLE, T. Novel boiling-enhanced multi-channel heat sinks. In: The 6th ASME-JSME Thermal Engineering Joint Conference. [S.l.: s.n.], 2003.

WHITE, F. M. Fluid Mechanics. Fourth edition. [S.1.]: McGraw-Hill Companies, 1998. 230 p.

WOODCOCK, C.; YU, X.; PLAWSKY, J.; PELES, Y. Piranha pin fin (ppf) - advanced flow boiling microstructures with low surface tension dielectric fluids. International Journal of Heat and Mass Transfer, v. 90, p. 591 - 604, 2015. ISSN 0017-9310.

WU, H.; CHENG, P. Boiling instability in parallel silicon microchannels at different heat flux. International Journal of Heat and Mass Transfer, v. 47, n. 17-18, p. 3631 - 3641, 2004.

XU, J.; GAN, Y.; ZHANG, D.; LI, X. Microscale boiling heat transfer in a micro-timescale at high heat fluxes. Journal of Micromechanics and Microengineering, v. 15, n. 2, p. 362, 2005 b.

XU, J.; LIU, G.; ZHANG, W.; LI, Q.; WANG, B. Seed bubbles stabilize flow and heat transfer in parallel microchannels. International Journal of Multiphase Flow, v. 35, n. 8, p. 773 - 790, 2009.

XU, J.; SHEN, S.; GAN, Y.; LI, Y.; ZHANG, W.; SU, Q. Transient flow pattern based microscale boiling heat transfer mechanisms. Journal of Micromechanics and Microengineering, v. 15 , n. 6, p. 1344, 2005a.

XU, J.; ZHOU, J.; GAN, Y. Static and dynamic flow instability of a parallel microchannel heat sink at high heat fluxes. Energy Conversion and Management, v. 46, n. 2, p. 313 - 334, 2005 c.

XU, S.; LI, Y.; HU, X.; YANG, L. Characteristics of heat transfer and fluid flow in a fractal multilayer silicon microchannel. International Communications in Heat and Mass Transfer, v. 71, p. $86-95,2016$. ISSN 0735-1933. 
XU, Y.; FANG, X. A new correlation of two-phase frictional pressure drop for evaporating flow in pipes. International Journal of Refrigeration, v. 35, n. 7, p. $2039-2050$, 2012. ISSN 0140-7007.

YAN, Y.-Y.; LIN, T.-F. Evaporation heat transfer and pressure drop of refrigerant r-134a in a small pipe. International Journal of Heat and Mass Transfer, v. 41, n. 24, p. 4183 - 4194, 1998.

YIN, L.; JIA, L.; GUAN, P.; LIU, D. Experimental investigation on bubble confinement and elongation in microchannel flow boiling. Experimental Thermal and Fluid Science, v. 54, p. 290 - 296, 2014. ISSN 0894-1777.

YU, S.; XIN, M. An approximate model of microchannel cooling. Journal of Thermal Science, Science Press, v. 3, n. 4, p. 243-249, 1994.

YU, W.; FRANCE, D.; WAMBSGANSS, M.; HULL, J. Two-phase pressure drop, boiling heat transfer, and critical heat flux to water in a small-diameter horizontal tube. International Journal of Multiphase Flow, v. 28, n. 6, p. 927 - 941, 2002.

YUN, R.; HEO, J. H.; KIM, Y. Evaporative heat transfer and pressure drop of r410a in microchannels. International Journal of Refrigeration, v. 29, n. 1, p. 92 - 100, 2006.

YUN, R.; HEO, J. H.; KIM, Y.; CHUNG, J. T. Convective boiling heat transfer characteristics of r410a in microchannels. In: International Refrigeration and Air Conditioning Conference at Purdue. [S.1.: s.n.], 2004.

ZHANG, H.; PINJALA, D.; WONG, T.; TOH, K.; JOSHI, Y. Single-phase liquid cooled microchannel heat sink for electronic packages. Applied Thermal Engineering, v. 25, n. 10, p. $1472-1487,2005$.

ZHANG, M.; WEBB, R. L. Correlation of two-phase friction for refrigerants in small-diameter tubes. Experimental Thermal and Fluid Science, v. 25, n. 3-4, p. 131-139, 2001.

ZHANG, W.; HIBIKI, T.; MISHIMA, K. Correlation for flow boiling heat transfer in minichannels. International Journal of Heat and Mass Transfer, v. 47, n. 26, p. 5749 - 5763, 2004.

ZHANG, W.; HIBIKI, T.; MISHIMA, K. Correlations of two-phase frictional pressure drop and void fraction in mini-channel. International Journal of Heat and Mass Transfer, v. 53, n. 1-3, p. $453-465,2010$.

ZHUAN, R.; WANG, W. Boiling heat transfer characteristics in a microchannel array heat sink with low mass flow rate. Applied Thermal Engineering, v. 51, n. 1-2, p. 65 - 74, 2013. 